\title{
THE EFFECT OF CLAY, CEMENT AND FIBERS ON THE STRENGTH AND DURABILITY OF COMPRESSED EARTH BLOCKS
}

\author{
A Thesis \\ presented to \\ the Faculty of California Polytechnic State University, \\ San Luis Obispo
}

In Partial Fulfillment
of the Requirements for the Degree
Master of Science in Civil and Environmental Engineering

by

Wyatt Adair Banker-Hix

June 2014 
C2014

Wyatt Adair Banker-Hix

ALL RIGHTS RESERVED 
TITLE:

AUTHOR:

DATE SUBMITTED:

COMMITTEE CHAIR:

COMMITTEE MEMBER:

COMMITTEE MEMBER:
The Effect of Clay, Cement and Fibers on the Strength and Durability of Compressed Earth Blocks

Wyatt Adair Banker-Hix

June 2014

Daniel C. Jansen, PhD, PE

Professor and Department Chair, CEEN

Bing Qu, PhD, PE

Assistant Professor, CEEN

James Mwangi, PhD, SE

Associate Professor, ARCE 


\begin{abstract}
The Effect of Clay, Cement and Fibers on the Strength and Durability of Compressed Earth Blocks

Wyatt Adair Banker-Hix
\end{abstract}

This Thesis examines the effect of soil characteristics, cement content and fibers on the strength and durability of compressed earth blocks (CEBs). This work expands on the available information regarding the constituent properties which affect the compressive and tensile strengths and durability of CEBs. Additionally, little research on the subject of synthetic fibers and their effect on strength and durability of CEBs is available and this work provides an initial study in this area.

To study the effects of fibers, as well as confirm the trends of previous research regarding the effects of clay and cement, 27 unique batches of CEBs were pressed and tested using a Vermeer BP 714 block press. Three different soil types and two fiber types were utilized. The compressive strength, modulus of rupture (MOR), absorption, and durability were measured on over 185 specimens. The strength and absorption tests were adapted from common ASTM International test methods for similar materials, while the durability test was a uniquely developed method to quantify durability by measuring mass loss during drying and wetting cycles.

After the testing regimen was completed, a trend between clay content and strength could not be determined. Durability testing suggested that as clay content decreases, durability increases. A linear relationship was found between cement content and strength, which was confirmed during durability testing. The addition of different fibers did not have an effect on the peak strength of CEBs, although it appears they may decrease the durability. The gross versus net unit strengths of CEBs were examined due to the unique shape of the CEBs utilized. Additionally, a mathematical expression relating the MOR to the compressive strength was developed.

Keywords: Compressed Earth Blocks, Synthetic Fibers, Clay Content, Cement Content, Fiber Content, Sand Content, Modulus of Rupture 


\section{ACKNOWLEDGMENTS}

This project was immense effort made possible thanks to efforts of many people:

Vermeer Corporation and Dwell Earth lent the block press used in this project and provided training and literature on its use. Their generosity and helpfulness is greatly appreciated.

Thanks to Ron Faria for taking the time to show me the Prado and Mind Body soil sites, as well as assisting me in collecting samples. Ron made finding and gathering the ideal soil simple and convenient. Thank you.

Many students from my CE 259 - Civil Engineering Materials classes helped me prepare and move soil samples. I am so thankful I was able to spend time teaching and working with so many of you.

I would like to thank both Angel Ventura and Emilio Rossi. Their help during soil collection, material preparation and CEB pressing was invaluable. I am truly thankful for your cheerfulness and hard work.

My father David and brother William also helped me prepare soil and press CEBs on multiple occasions. My education has always been a family effort, and I am blessed to have such a supportive and caring family.

Much thanks to my committee members Bing Qu and James Mwangi for the thoughtful insight into my paper and their supportive attitude throughout the project.

Nephi Derbidge assisted me with soil testing and analysis, for which I am absolutely grateful. Thank you for patiently sharing your soil expertise.

Finally, I would like to thank Daniel Jansen, whose energy and dedication to success kept me motivated and focused. Thank you for introducing me to compressed earth blocks and guiding me throughout my Cal Poly career. Your commitment to others was truly inspiring to me, both as a graduate student and teacher. It was truly my honor to work with you.

"Non nobis solum nati sumus. (Not for ourselves alone are we born.)"

-Cicero 


\section{TABLE OF CONTENTS}

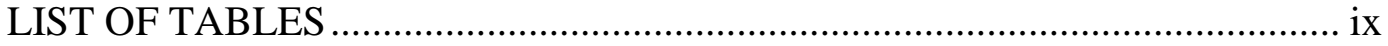

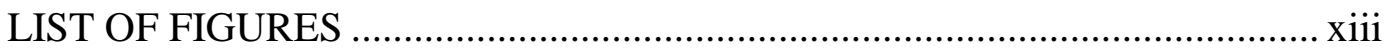

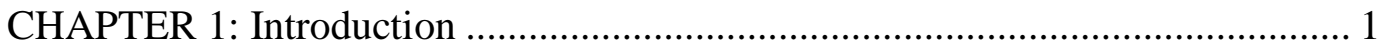

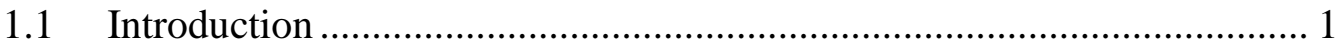

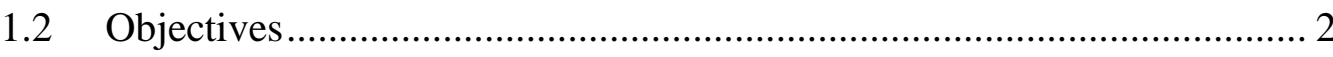

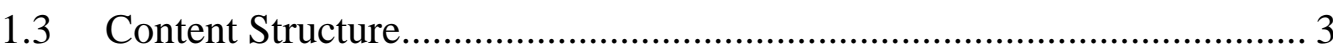

CHAPTER 2: Literature Review ………………………......................... 5

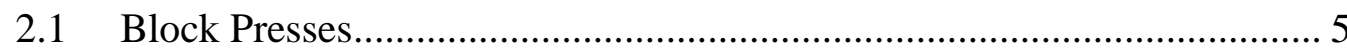

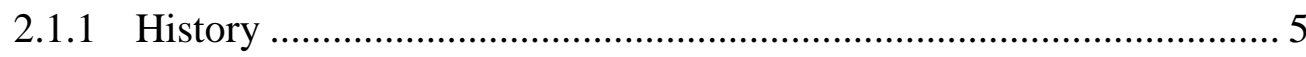

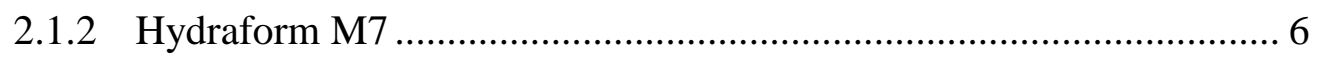

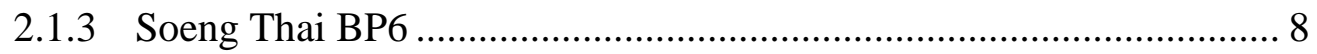

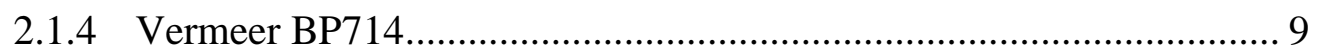

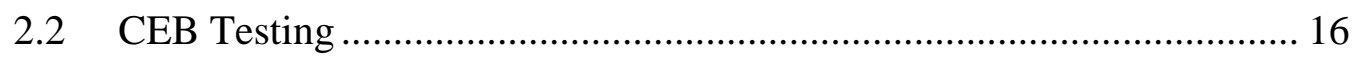

2.2.1 Soil Selection and Stabilization ....................................................... 16

2.2.2 Sand, Clay and Cement Content Testing in CEBs............................. 22

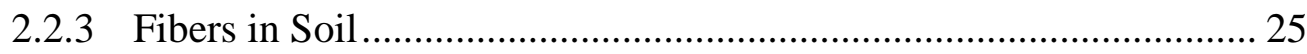

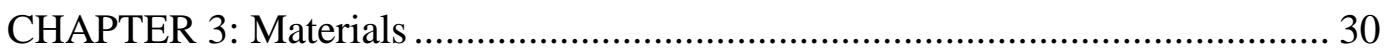

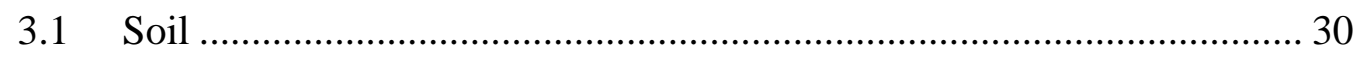

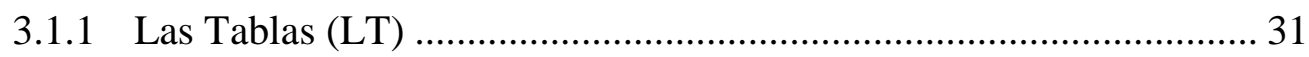

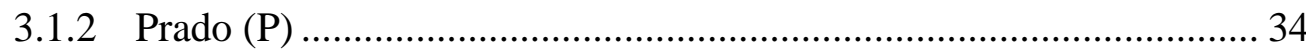

3.1.3 Mind Body Soil (MB) .................................................................. 36

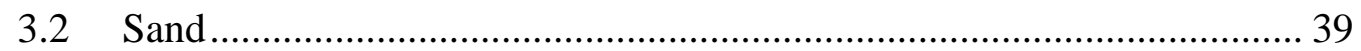

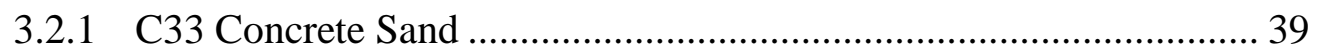

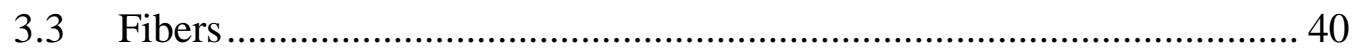

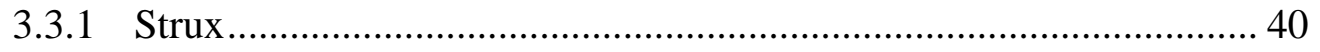

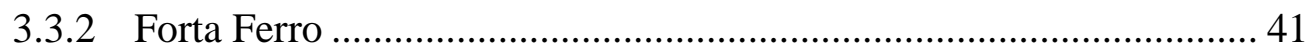

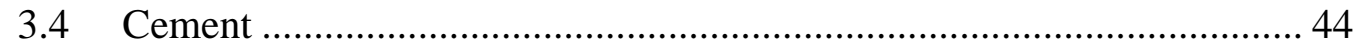

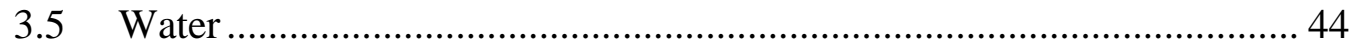

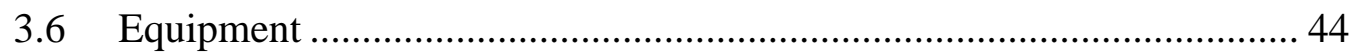

3.6.1 Soeng Thai SP3 Soil Pulverizer.................................................... 44

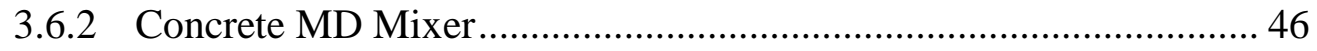

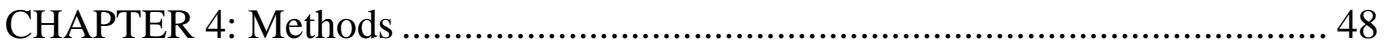




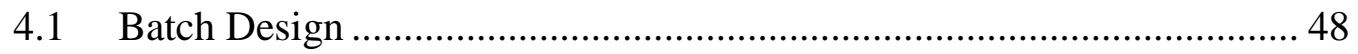

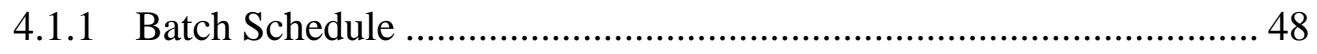

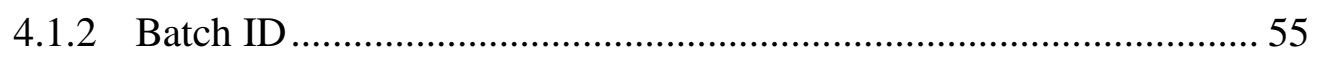

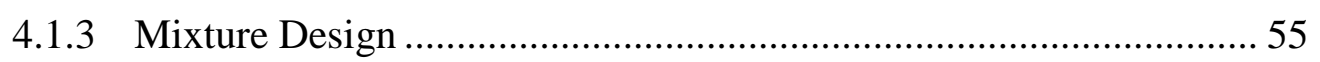

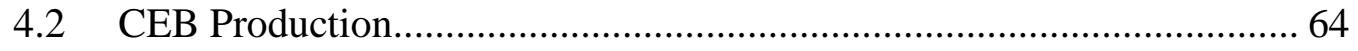

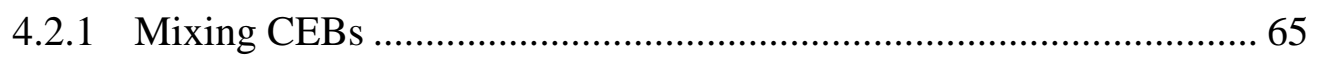

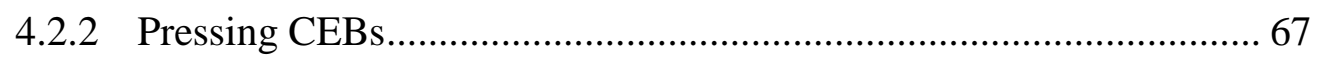

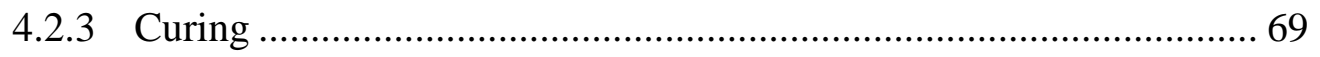

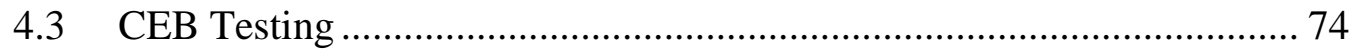

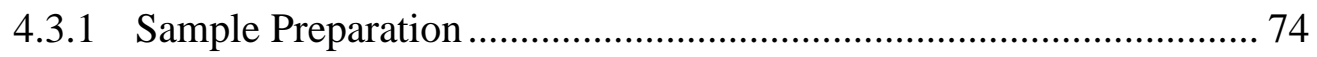

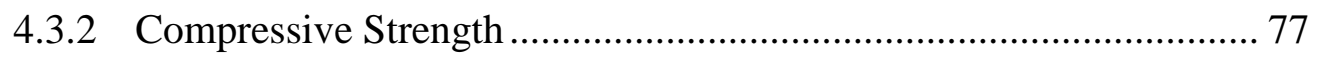

4.3.3 Modulus of Rupture Testing ......................................................... 79

4.3.4 Absorption and Specific Gravity Testing ……………....................... 82

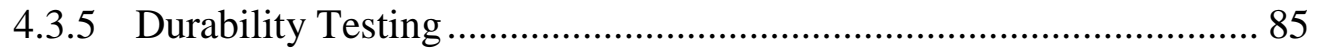

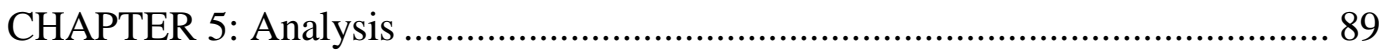

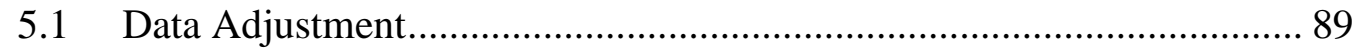

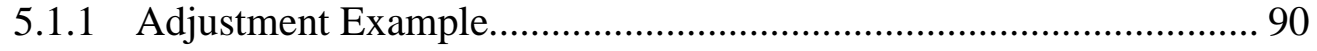

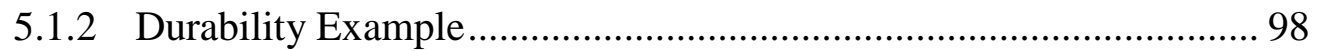

5.2 Gross Strength to Net Strength Calculation .......................................... 100

5.2.1 Compressive Strength ..................................................................... 100

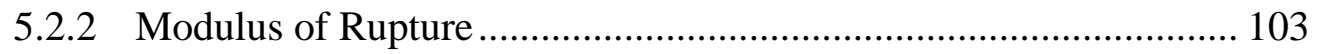

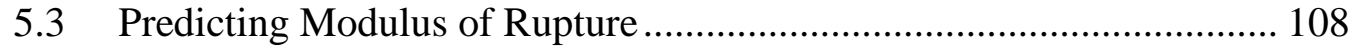

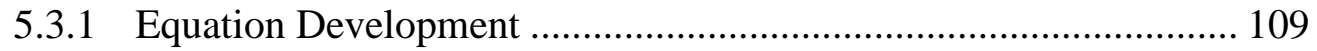

5.3.2 Normally Distributed Data.................................................................. 111

5.3.3 Confidence Intervals ................................................................... 115

5.3.4 Las Tablas Soil....................................................................... 121

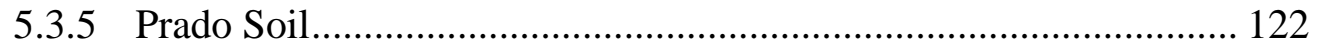

5.3.6 Mind Body Soil........................................................................... 123

5.4 Effect of Clay Content...................................................................... 124

5.4.1 Mixture Moisture ........................................................................ 124

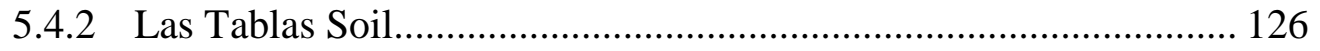

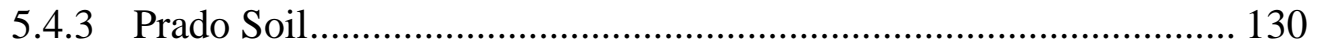

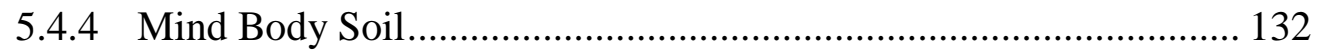

5.4.5 Combined Results ........................................................................ 133 
5.5 Effect of Cement Content (CC)...................................................... 137

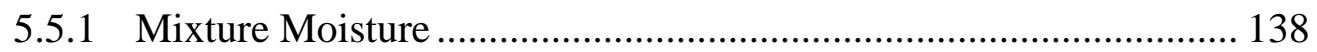

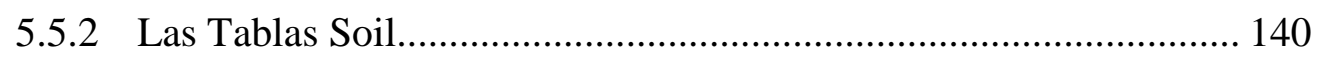

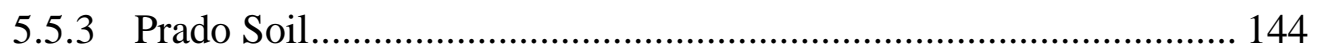

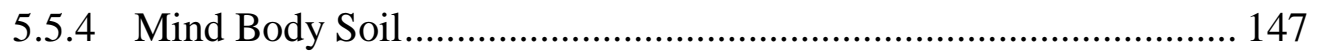

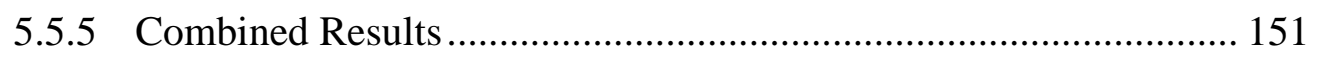

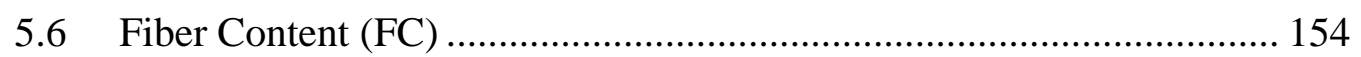

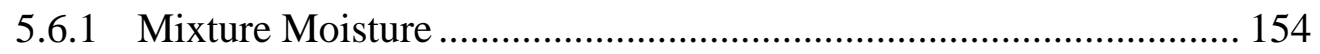

5.6.2 Las Tablas Soil - Forta Ferro Fiber (FF) ....................................... 156

5.6.3 Las Tablas Fiber - Strux 90/40 Fiber (FS) ……………………...... 161

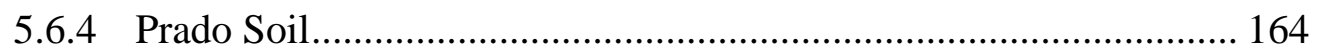

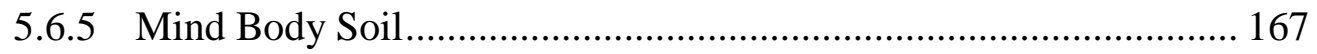

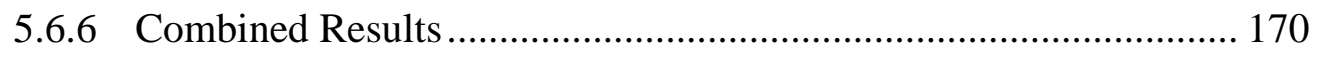

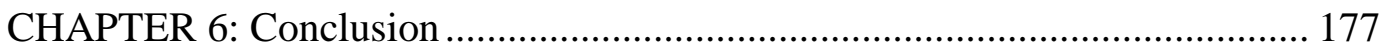

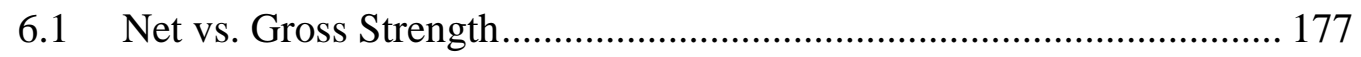

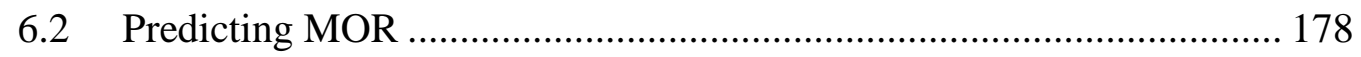

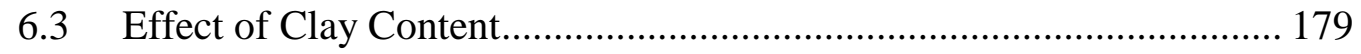

6.4 Effect of Cement Content................................................................... 179

6.5 Effect of Fiber Content................................................................... 180

6.6 Recommendations for Future Work ................................................... 180

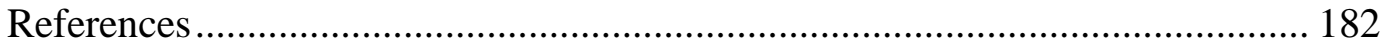

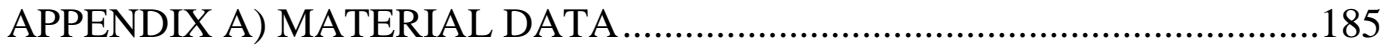

A-1) Las Tablas Soil Testing ....................................................................186

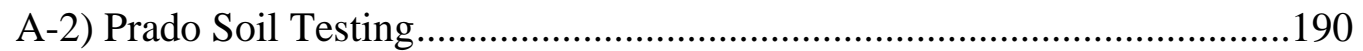

A-3) Mind Body Soil Testing.......................................................................194

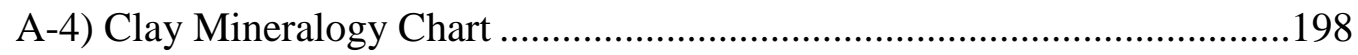

A-5) Sand Testing ……............................................................................199

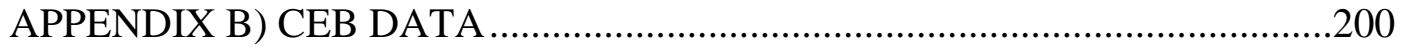

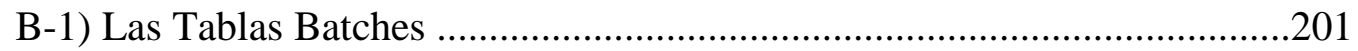

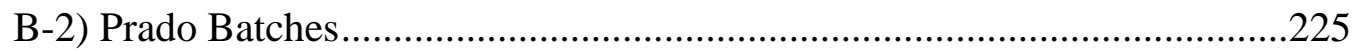

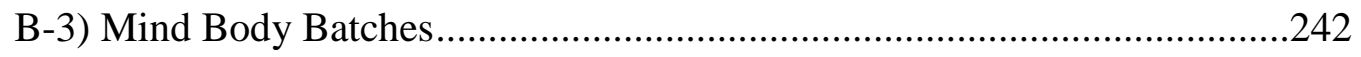




\section{LIST OF TABLES}

Table 3.1.1-1 Las Tablas Soil Properties ............................................................. 33

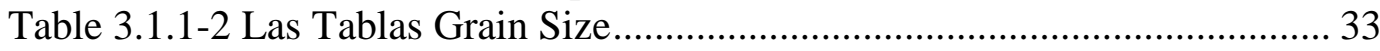

Table 3.1.2-1 Prado Soil Properties ............................................................... 35

Table 3.1.2-2 Prado Grain Size ......................................................................... 36

Table 3.1.3-1 Mind Body Soil Properties ............................................................ 38

Table 3.1.3-2 Mind Body Grain Size ................................................................ 38

Table 3.3.1-1 Strux Properties (Grace Construction 2007) ..................................... 41

Table 3.3.2-1 Forta Properties (Forta Corporation n.d.) ……............................... 43

Table 4.1.1-1 Theoretical Batch Schedule ......................................................... 49

Table 4.1.1-2 Actual Batch Schedule ………………...................................... 54

Table 4.1.3-1 Basic Mix Design Procedure .......................................................... 56

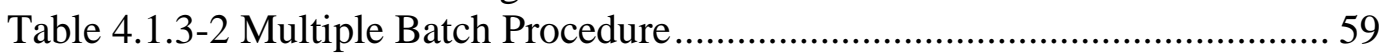

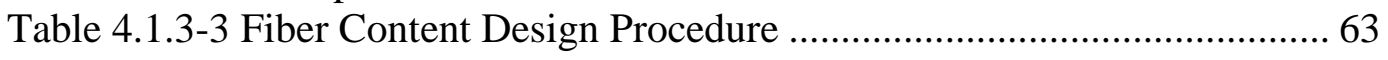

Table 4.2.3-1 Moisture Content Comparisons ........................................................ 72

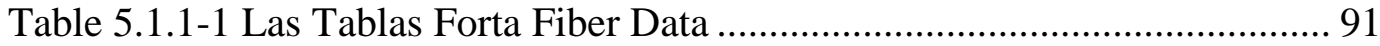

Table 5.1.1-2 Las Tablas Forta Fiber Batch Trendlines ....................................... 93

Table 5.1.1-3 Piston Pressure Adjusted Data......................................................... 94

Table 5.1.1-4 Trendline Slopes by Variable ........................................................... 96

Table 5.2.2-1 Simulated Gross vs. Net MOR Comparison.................................. 107

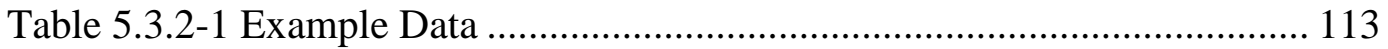

Table 5.3.3-1 Standard Error Example Data..................................................... 117

Table 5.4.1-1 Sand Batch Mixture Moisture ..................................................... 125

Table 5.5.1-1 Cement Content Mixture Moistures ............................................... 138

Table 5.6.1-1 Fiber Content Mixture Moisture.................................................. 155

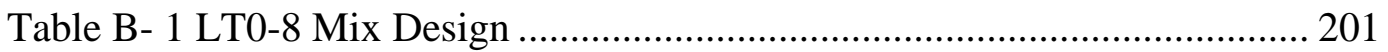

Table B- 2 LT0-8 Compression Results ........................................................... 201

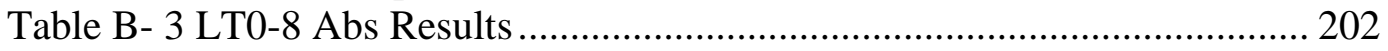

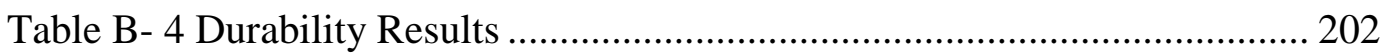

Table B- 5 LT20-8 Mix Design ................................................................... 203

Table B- 6 LT20-8 Compression Results .......................................................... 203

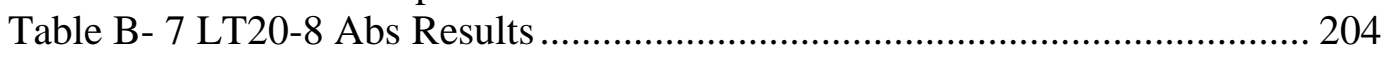

Table B- 8 LT20-8 Durability Results .............................................................. 204

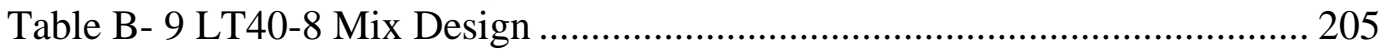

Table B- 10 LT40-8 Compression Results ………….................................... 205

Table B- 11 LT40-8 Abs Results ................................................................ 205

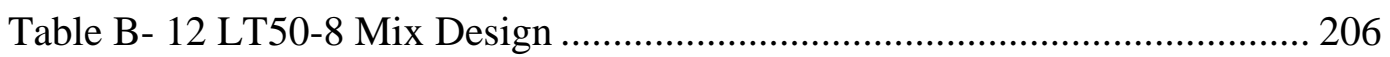

Table B- 13 Compression Results............................................................... 206

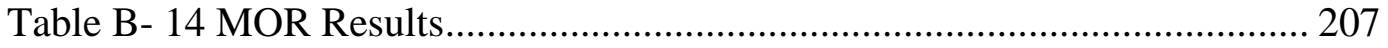

Table B- 15 Abs Results ............................................................................... 207

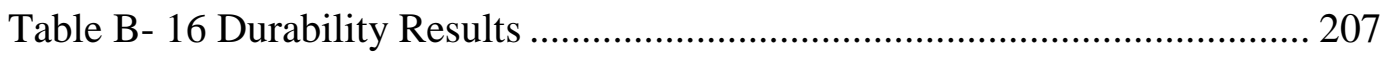

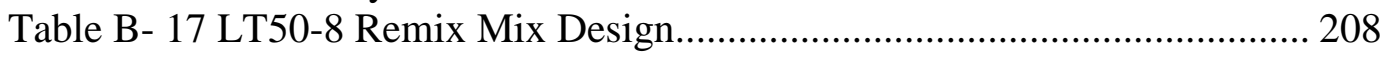

Table B- 18 LT50-8 Remix Compression Results............................................. 208

Table B- 19 LT50-8 Remix MOR Results.................................................... 208

Table B- 20 LT50-8 Remix Abs Results ........................................................ 209 
Table B- 21 LT55-8 Mix Design ............................................................... 210

Table B- 22 LT55-8 Compression Results ……………................................... 210

Table B- 23 LT55-8 Abs Results ................................................................ 210

Table B- 24 LT70-8 Mix Design .................................................................... 211

Table B- 25 LT70-8 Compression Results ………….................................... 211

Table B- 26 LT70-8 MOR Results ............................................................... 212

Table B- 27 LT70-8 Durability Results ......................................................... 212

Table B- 28 LT50-4 Mix Design ................................................................ 213

Table B- 29 LT50-4 Compression Results ......................................................... 213

Table B- 30 LT50-4 MOR Results ……………......................................... 213

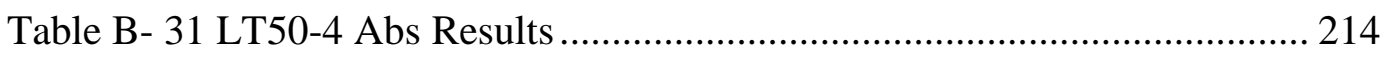

Table B- 32 LT50-4 Durability Results ........................................................... 214

Table B- 33 LT50-12 Mix Design ............................................................. 215

Table B- 34 LT50-12 Compression Results …………................................ 215

Table B- 35 LT50-12 MOR Results ........................................................... 216

Table B- 36 LT50-12 Abs Results ............................................................... 216

Table B- 37 LT50-12 Durability Results ....................................................... 216

Table B- 38 LT50-FF2-8 Mix Design ......................................................... 217

Table B- 39 LT50-FF2-8 Compression Results.................................................. 217

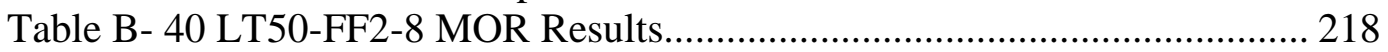

Table B- 41 LT50-FF2-8 Abs Results ...................................................... 218

Table B- 42 LT50-FF2-8 Durability Results ................................................... 218

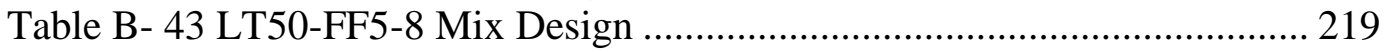

Table B- 44 LT50-FF5-8 Compression Results.............................................. 219

Table B- 45 LT50-FF5-8 MOR Results.......................................................... 220

Table B- 46 LT50-FF5-8 Abs Results ........................................................ 220

Table B- 47 LT50-FF5-8 Durability Results ................................................... 220

Table B- 48 LT50-FS2-8 Mix Design ............................................................ 221

Table B- 49 LT50-FS2-8 Compression Results................................................... 221

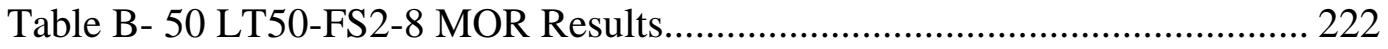

Table B- 51 LT50-FS2-8 Abs Results .......................................................... 222

Table B- 52 LT50-FS2-8 Durability Results ...................................................... 222

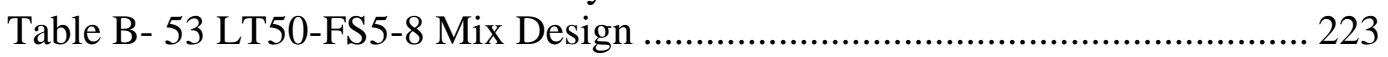

Table B- 54 LT50-FS5-8 Compression Results................................................... 223

Table B- 55 LT50-FS5-8 MOR Results........................................................ 224

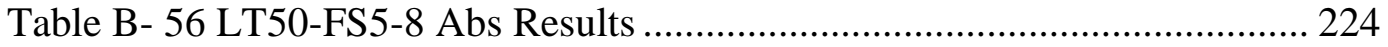

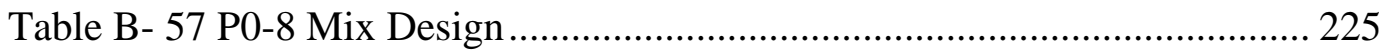

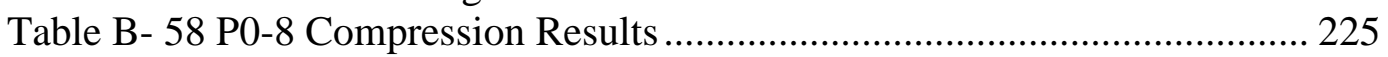

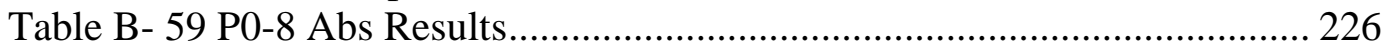

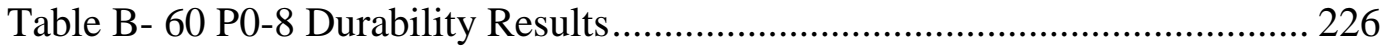

Table B- 61 P50-8 Mix Design ..................................................................... 227

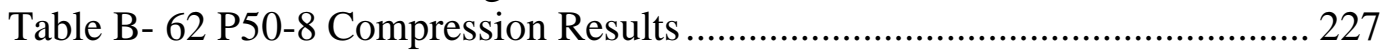

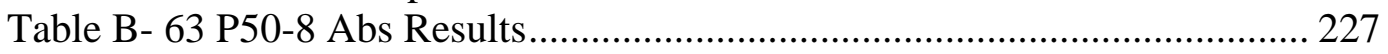

Table B- 64 P60-8 Mix Design .................................................................... 228

Table B- 65 P60-8 Compression Results ........................................................ 228

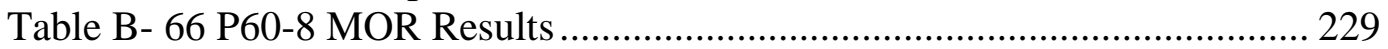


Table B- 67 P60-8 Abs Results...................................................................... 229

Table B- 68 P66-8 Mix Design ....................................................................... 230

Table B- 69 P66-8 Compression Results ....................................................... 230

Table B- 70 P66-8 MOR Results ............................................................... 231

Table B- 71 P66-8 Abs Results....................................................................... 231

Table B- 72 P66-8 Durability Results........................................................ 231

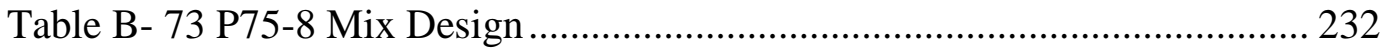

Table B- 74 P75-8 Compression Results .......................................................... 232

Table B- 75 P75-8 Abs Results................................................................... 232

Table B- 76 P75-8 Durability Results......................................................... 233

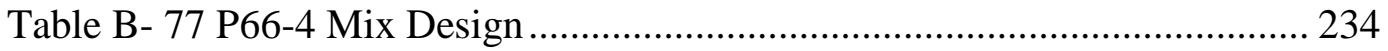

Table B- 78 P66-4 Compression Results ....................................................... 234

Table B- 79 P66-4 MOR Results ................................................................ 234

Table B- 80 P66-4 Abs Results...................................................................... 235

Table B- 81 P66-4 Durability Results.......................................................... 235

Table B- 82 P66-12 Mix Design ................................................................... 236

Table B- 83 P66-12 Compression Results ................................................... 236

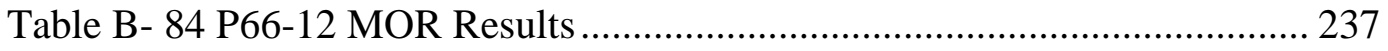

Table B- 85 P66-12 Abs Results.................................................................. 237

Table B- 86 P66-12 Durability Results........................................................ 237

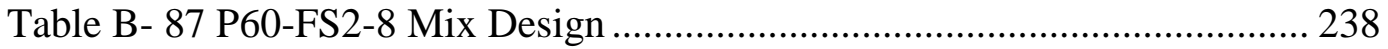

Table B- 88 P60-FS2-8 Compression Results ............................................... 238

Table B- 89 P60-FS2-8 MOR Results ........................................................ 239

Table B- 90 P60-FS2-8 Abs Results ................................................................ 239

Table B- 91 P60-FS5-8 Mix Design .............................................................. 240

Table B- 92 P60-FS5-8 Compression Results .............................................. 240

Table B- 93 P60-FS5-8 MOR Results ............................................................ 241

Table B- 94 P60-FS5-8 Abs Results .............................................................. 241

Table B- 95 MB25-8 Mix Design................................................................ 242

Table B- 96 MB25-8 Compression Results …................................................. 242

Table B- 97 MB25-8 MOR Results .............................................................. 243

Table B- 98 MB25-8 Abs Results................................................................ 243

Table B- 99 MB40-8 Mix Design.................................................................. 244

Table B- 100 MB40-8 Compression Results .................................................... 244

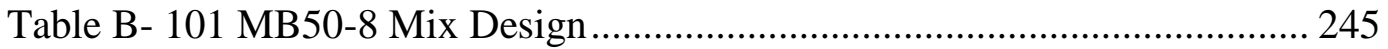

Table B- 102 MB50-8 Compression Results …................................................ 245

Table B- 103 MB 50-8 MOR Results ............................................................ 246

Table B- 104 MB50-8 Abs Results.................................................................. 246

Table B- 105 MB50-8 Durability Results..................................................... 246

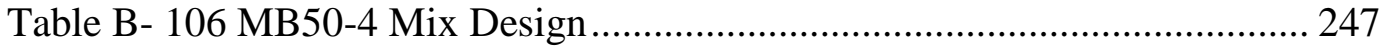

Table B- 107 MB50-4 Compression Results .................................................... 247

Table B- 108 MB50-4 MOR Results ......................................................... 248

Table B- 109 MB50-12 Mix Design................................................................. 249

Table B- 110 MB50-12 Compression Results ............................................... 249

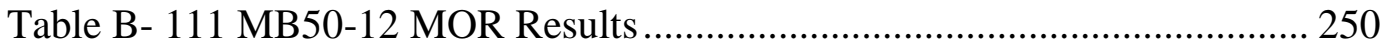

Table B- 112 MB50-12 Abs Results................................................................ 250 
Table B- 113 MB50-12 Durability Results..................................................... 250

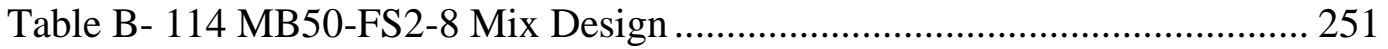

Table B- 115 MB50-FS2-8 Compression Results ............................................ 251

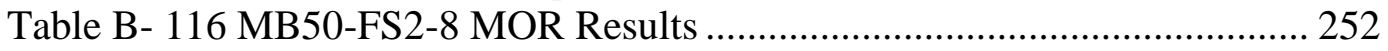

Table B- 117 MB50-FS2-8 Abs Results..................................................... 252 


\section{LIST OF FIGURES}

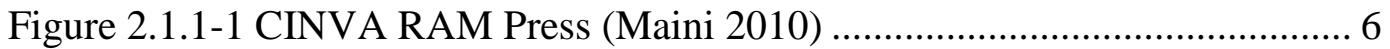

Figure 2.1.2-1 Hydraform M7 Press (Hydraform 2014)..................................... 7

Figure 2.1.2-2 Dry Stack Hydraform Project (Pave 2007) .................................. 8

Figure 2.1.3-1 Soeng Thai Press and Rhino Blocks ............................................ 9

Figure 2.1.4-1 V- Lock Block Dimensions................................................. 10

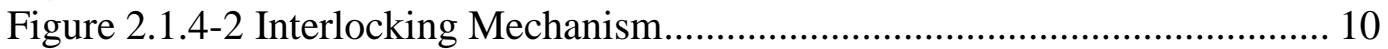

Figure 2.1.4-3 BP714 Block Pressing Process (Chu 2013) ................................. 12

Figure 2.1.4-4 Determining Moisture Based on Pressure Readings .................... 14

Figure 2.1.4-5 Block Height Reading ............................................................. 15

Figure 2.2.1-1 Identifying Clay Content using a Bottle (Rigassi 1985) ............... 17

Figure 2.2.1-2 Improvised Cone Test to Determine Soil Type (Rigassi 1985) .... 18

Figure 2.2.1-3 Drop Test................................................................................ 19

Figure 2.2.1-4 Shake Test ...................................................................... 20

Figure 2.2.3-1 Photo (a) of a fiber in soil and (b) sketch (Hejazi et al. 2011) ...... 27

Figure 3.1.1-1 Las Tablas Site Location ........................................................ 31

Figure 3.1.1-2 Las Tablas Soil Harvest Site .................................................. 32

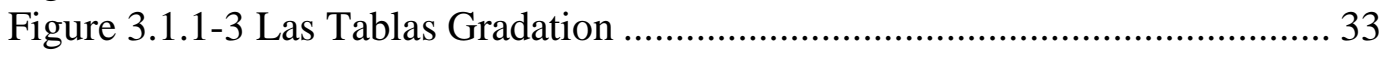

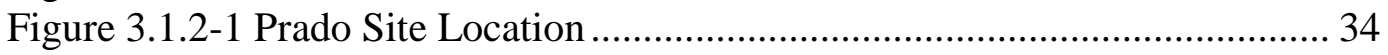

Figure 3.1.2-2 Prado Harvest Site .............................................................. 35

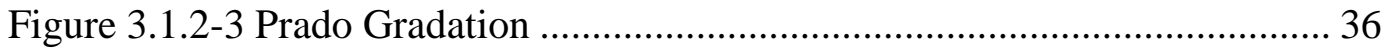

Figure 3.1.3-1 Mind Body Soil Location ...................................................... 37

Figure 3.1.3-2 Mind Body Harvest Site ...................................................... 37

Figure 3.1.3-3 Mind Body Gradation ........................................................ 38

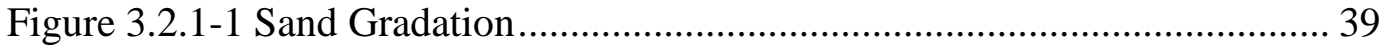

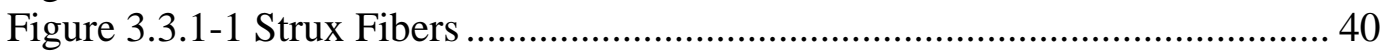

Figure 3.3.2-1 Bundled Macro Fibers ........................................................... 42

Figure 3.3.2-2 Mats of Micro Fibers .............................................................. 42

Figure 3.6.1-1 Soeng Thai SP3 Pulverizer (CVBT 2010) ................................ 45

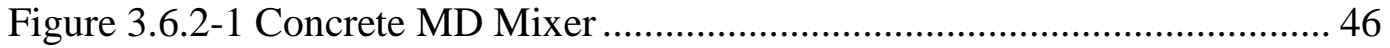

Figure 3.6.2-2 View Inside Mixer................................................................ 47

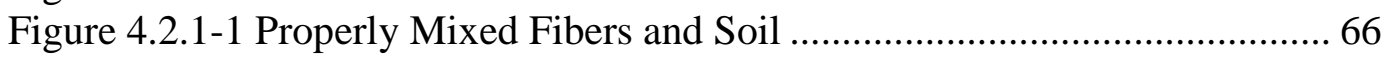

Figure 4.2.3-1 Curing Area ........................................................................... 70

Figure 4.2.3-2 Curing Area Temperature Setup .............................................. 71

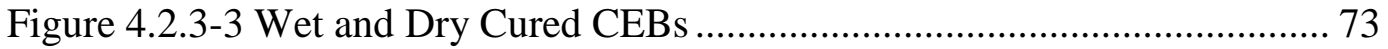

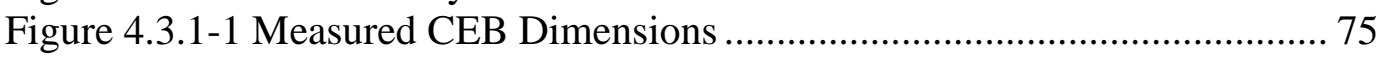

Figure 4.3.1-2 Poorly Consolidated CEB ...................................................... 76

Figure 4.3.2-1 Compression Test Set Up ...................................................... 77

Figure 4.3.2-2 Succesfully Tested Specimen................................................ 78

Figure 4.3.2-3 Fiber-Reinforced Specimen ................................................... 79

Figure 4.3.3-1 MOR Sample Preparation ....................................................... 80

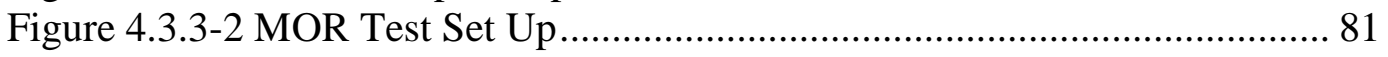

Figure 4.3.3-3 Succesfully Tested MOR Specimen....................................... 81

Figure 4.3.3-4 Fiber Reinforced MOR Specimen........................................ 82

Figure 4.3.4-1 Temperature Contolled CEB Bath .......................................... 83 


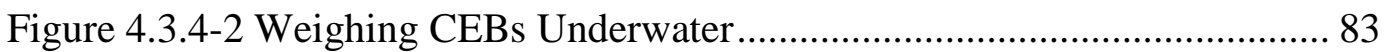

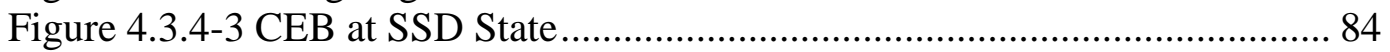

Figure 4.3.5-1 Durability Example - Rating 0 ……………………………..... 87

Figure 4.3.5-2 Durability Example - Rating 1 ................................................... 87

Figure 4.3.5-3 Durability Example - Rating 2 ………...................................... 87

Figure 4.3.5-4 Durability Example - Rating 3 ................................................ 88

Figure 4.3.5-5 Durability Example - Rating 4 ................................................ 88

Figure 5.1.1-1 Las Tablas Forta Fiber Content Raw Data ................................... 90

Figure 5.1.1-2 Piston Pressure vs. Strength ........................................................... 92

Figure 5.1.1-3 Fully Adjusted Las Tablas Forta Fiber Data ................................ 95

Figure 5.1.1-4 Adjusted Las Tablas SC Average Data ........................................ 97

Figure 5.1.2-1 Las Tablas SC Durability Results ............................................. 98

Figure 5.1.2-2 Normalized Durability Results................................................. 99

Figure 5.2.1-1 Block Height vs. Area Factor................................................... 102

Figure 5.2.2-1 MOR Test Setup...................................................................... 103

Figure 5.2.2-2 Dividing MOR Net Cross Sectional Area.................................. 105

Figure 5.2.2-3 Block Height vs. MOR Factor ................................................... 106

Figure 5.3.1-1 Combined Data vs. Kenyan Equation ......................................... 110

Figure 5.3.1-2 Combined Data vs. AAC and PCC Equation............................... 110

Figure 5.3.2-1 Compressive Strength Data Distribution ................................... 114

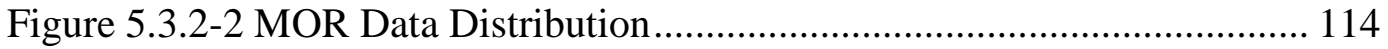

Figure 5.3.3-1 Data Best Fit Line and Equation ................................................ 116

Figure 5.3.3-2 Data with Confidence Intervals ……….................................... 120

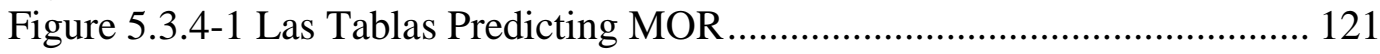

Figure 5.3.5-1 Prado Predicting MOR .......................................................... 122

Figure 5.3.6-1 Mind Body Predicting MOR …………..................................... 123

Figure 5.4.1-1 Clay Content vs. Moisture Content ............................................. 126

Figure 5.4.2-1 Las Tablas SC Results............................................................. 127

Figure 5.4.2-2 Average Las Tablas SC Results .............................................. 128

Figure 5.4.2-3 Las Tablas SC Durability Results ............................................ 129

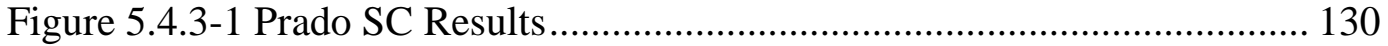

Figure 5.4.3-2 Average Prado Results ............................................................. 130

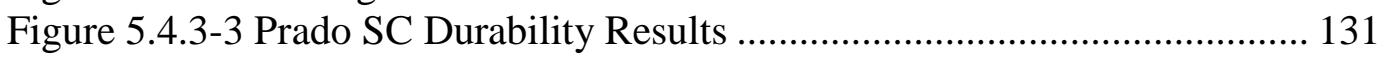

Figure 5.4.4-1 Mind Body SC Results............................................................. 132

Figure 5.4.4-2 Average Mind Body Results ...................................................... 132

Figure 5.4.4-3 Mind Body SC Durability Results ........................................... 133

Figure 5.4.5-1 Combined Strength Data .......................................................... 134

Figure 5.4.5-2 Combined Durability Results ................................................ 135

Figure 5.4.5-3 Soil Durability Comparison .................................................... 136

Figure 5.5.1-1 Cement Content vs. Moisture Content ........................................ 139

Figure 5.5.2-1 Las Tablas CC Compressive Strengths ....................................... 140

Figure 5.5.2-2 Las Tablas CC Average Compressive Strengths ........................ 141

Figure 5.5.2-3 Las Tablas CC MOR ................................................................ 142

Figure 5.5.2-4 Las Tablas CC MOR Ave Strengths .......................................... 142

Figure 5.5.2-5 Las Tablas CC Durability Results............................................... 143

Figure 5.5.3-1 Prado CC Compressive Strengths ............................................. 144 
Figure 5.5.3-2 Prado CC Average Compressive Strengths.............................. 144

Figure 5.5.3-3 Prado CC MOR ....................................................................... 145

Figure 5.5.3-4 Prado CC Average MOR ........................................................ 146

Figure 5.5.3-5 Prado CC Durability Results ..................................................... 147

Figure 5.5.4-1 Mind Body CC Compression Strengths ................................... 148

Figure 5.5.4-2 Mind Body CC Average Strengths ......................................... 148

Figure 5.5.4-3 Mind Body CC MOR ............................................................. 149

Figure 5.5.4-4 Mind Body CC Average MOR ................................................ 149

Figure 5.5.4-5 Mind Body CC Durability Results ............................................ 150

Figure 5.5.5-1 Combined CC Compressive Strengths .................................... 151

Figure 5.5.5-2 Combined MOR Compressive Strengths ................................. 152

Figure 5.5.5-3 Combined Durability Results .................................................. 153

Figure 5.6.1-1 Fiber Content vs. Moisture Content ......................................... 155

Figure 5.6.2-1 Las Tablas FF Compressive Strengths ..................................... 156

Figure 5.6.2-2 Las Tablas FF Average Compressive Strengths ........................ 157

Figure 5.6.2-3 Las Tablas FF MOR............................................................... 158

Figure 5.6.2-4 Las Tablas FF Average MOR ............................................... 159

Figure 5.6.2-5 Las Tablas FF Durability Results............................................ 160

Figure 5.6.3-1 Las Tablas FS Compressive Strengths .................................... 161

Figure 5.6.3-2 Las Tablas FS Average Compressive Strengths ....................... 162

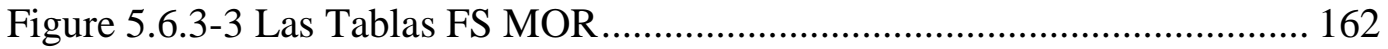

Figure 5.6.3-4 Las Tablas FS Average MOR ............................................... 163

Figure 5.6.3-5 Las Tablas FS Durability Results.......................................... 164

Figure 5.6.4-1 Prado FS Compressive Strengths ............................................. 165

Figure 5.6.4-2 Prado FS Average Compressive Strengths ............................... 166

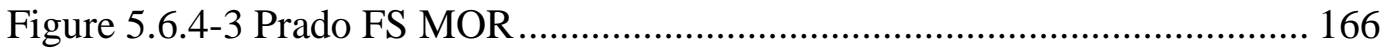

Figure 5.6.4-4 Prado FS Average MOR .......................................................... 167

Figure 5.6.5-1 Mind Body FS Compressive Strengths ..................................... 168

Figure 5.6.5-2 Mind Body FS Average Compressive Strengths ...................... 168

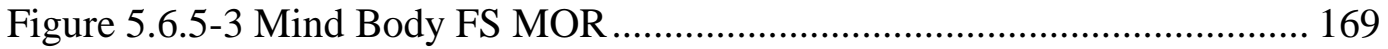

Figure 5.6.5-4 Mind Body FS Average MOR ................................................. 169

Figure 5.6.6-1 Combined FC Compressive Strengths .................................... 171

Figure 5.6.6-2 Combined FC MOR .............................................................. 171

Figure 5.6.6-3 Combined FC Durability Results ............................................ 172

Figure 5.6.6-4 Combined FC Average Wet/Dry Compressive Strengths........... 173

Figure 5.6.6-5 Combined FC Average Wet/Dry MOR.................................... 174

Figure 5.6.6-6 Las Tablas Fiber Comparison Compressive Strengths ................ 175

Figure 5.6.6-7 Las Tablas Fiber Comparison MOR ........................................ 176 


\section{CHAPTER 1: INTRODUCTION}

\subsection{Introduction}

More than one billion people lack access to adequate shelter worldwide (UN 2009). This shortage of housing promotes poverty, insecurity and unsanitary living conditions. Compressed earth blocks (CEBs) are an emerging technology that holds great promise in relieving this shortage.

Earthen construction in general is one of the oldest and most reliable building systems known, with large construction projects dated to 2500 BC (Jagadish 2007). The advantages of earthen construction are numerous: local and available materials, simple construction methods, durability and comfort. Most ancient earthen construction utilized mud bricks cured by the sun, often with straw or horse hair intermingled to create a stronger product. Modern earthen construction focuses both on stabilizing the soil with a cementitious material like cement or lime and then compacting it to create a building material more suited to modern needs.

Compressed earth blocks are a relatively new earthen construction system in which the soil is stabilized and then pressed into a shape that resembles a cinder block or 
brick. These blocks combine the reliability and strength of modern masonry with the availability and ease of traditional earthen construction.

One of the most distinct advantages compressed earth blocks hold over kiln fired bricks is their energy usage. Compressed earth blocks need only a stabilizer and water to cure, which constitutes a significant energy savings when compared to constructing and operating traditional brick kilns. Additionally, CEBs do not require mortared joints or the experienced labor that accompanies traditional masonry construction. All of these factors lower the barrier to community engagement and have allowed compressed earth block systems to rise to the forefront of local, sustainable construction.

Compressed earth block construction is already common in some parts of the world, but research efforts lag behind international demand. There are many gaps in research with CEBs, such as the effects of different soils or the effect of manufacturing processes on CEB's strength and durability.

There are few experiments where multiple soils and a single CEB manufacturing method are utilized and then compared, particularly with the effects of synthetic fibers. These fibers are often used in concrete construction, and can provide tremendous benefits in post cracking strength and crack reduction. They may provide additional advantages to CEBs like increased flexural strength.

\subsection{Objectives}

This project involved creating 26 batches of CEBs from three different soil types, then testing individual blocks for compressive strength, flexural strength and absorption. Additionally, the mass loss resulting from a five cycle soaking and drying regimen was 
performed as a measure of their durability. The wide variety of batches and testing methods sought to answer the following questions:

- How does the manufacturing process effect the strength of CEBs?

- Is there a conservative equation relating MOR using compressive strength?

- What effect does clay content have on the strength and durability of CEBs?

- What effect does cement content have on the strength and durability of CEBs?

- How does the addition of fibers into CEBs effect their strength and durability?

- How are the factors above influenced by differences in soil like clay plasticity?

\subsection{Content Structure}

This paper is divided into six chapters:

- Chapter 1 is the Introduction, which defines the need for compressed earth blocks and details the objectives of this paper.

- Chapter 2 is a review of CEB presses used today, as well as previous research conducted on soil stabilization. The use of fibers in CEBs, as well as the effect of clay and cement on the strength and durability of CEBs was also considered. 
- Chapter 3 details the materials and equipment utilized over the course of this experiment. Soil, sand and fiber properties are reviewed, and the equipment used to prepare, mix and press the CEBs is covered.

- Chapter 4 describes the methods used in material preparation, block production, and CEB testing. Batch design and the calculation of fiber content are also reviewed.

- Chapter 5 provides a review on how the data that was collected and adjusted for piston pressure. Net and gross strengths are then reviewed, with the intent of creating a simple equation between the two strengths. An equation to predict the MOR using compressive strength is developed. Finally, the effect of clay content, cement content, and fiber content is described.

- Chapter 6 details the conclusions gleaned from analysis as well as recommendations for future research. 


\section{CHAPTER 2: LITERATURE REVIEW}

\subsection{Block Presses}

The geometry and strength of a CEB is most affected by the machine used to shape and compact the block. There are no standard sizes of CEB unlike concrete masonry, which warrants describing several modern presses as well chronicling their evolution.

\subsubsection{History}

The idea of compressing soil into a standard size and shape is not new. The first notable effort was made by French architect Francois Cointereaux, who created a wooden mold that was compacted by standing atop it (Maini 2010). The modern block press originated in 1956 when Columbian engineer Raul Rameriz developed a manual block press made out of steel, called the CINVA RAM. This press steadily gained popularity in the 1960 's and other countries began to produce their own block presses, most notably Southeast Asia, South Africa and India. 


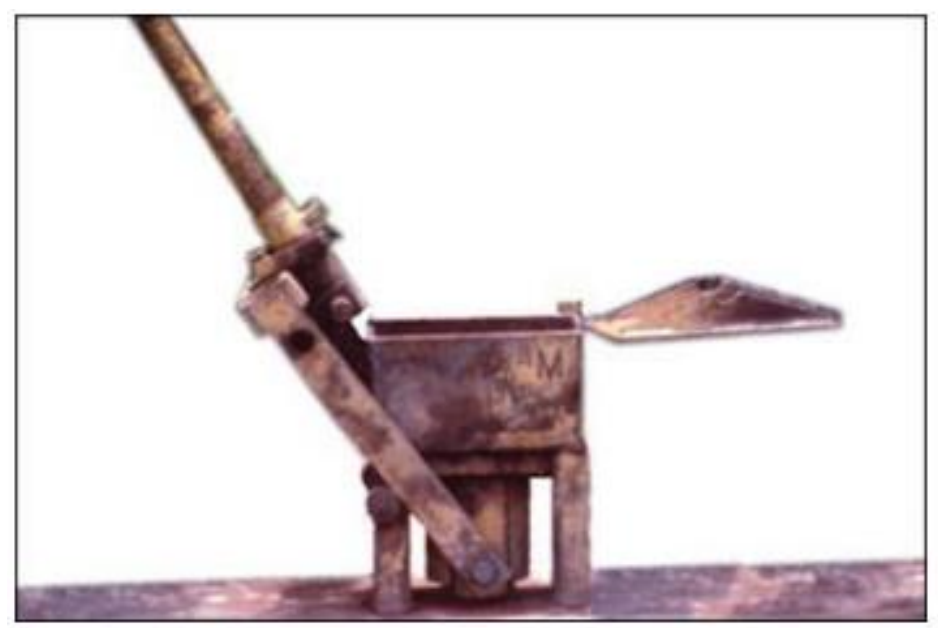

Figure 2.1.1-1 CINVA RAM Press (Maini 2010)

As CEBs gained popularity, so did the variety of presses and blocks. Many block presses require the user to manually compact the soil chamber, and are common for small scale projects and in rural areas. Other modern block presses use hydraulic pressure to compact the soil chamber, and often utilize concrete mixers and conveyor belts to maximize production. Each block press creates its own style block with specific purposes and advantages.

In order to highlight these differences, it is necessary to review three CEB presses: the Hydraform M7, Soeng Thai BP6, and Vermeer BP714.

\subsubsection{Hydraform $M 7$}

The Hydraform M7 is one of many hydraulic block presses manufactured by Hydraform, a materials company located in Johannesburg, South Africa. Hydraform produces a variety of blocks and presses for different situations, including plain and interlocking CEBs, although none feature reinforcement chambers. 
The Hydraform press volumetrically controls the amount of soil entering the compression chamber, then uses a hydraulic wedge to compress the block vertically. Different block presses come with dual compression chambers, trailer attachments and integrated mixers. As seen below, the M7 is a large CEB press attached to a trailer with a loading bucket and soil mixer.

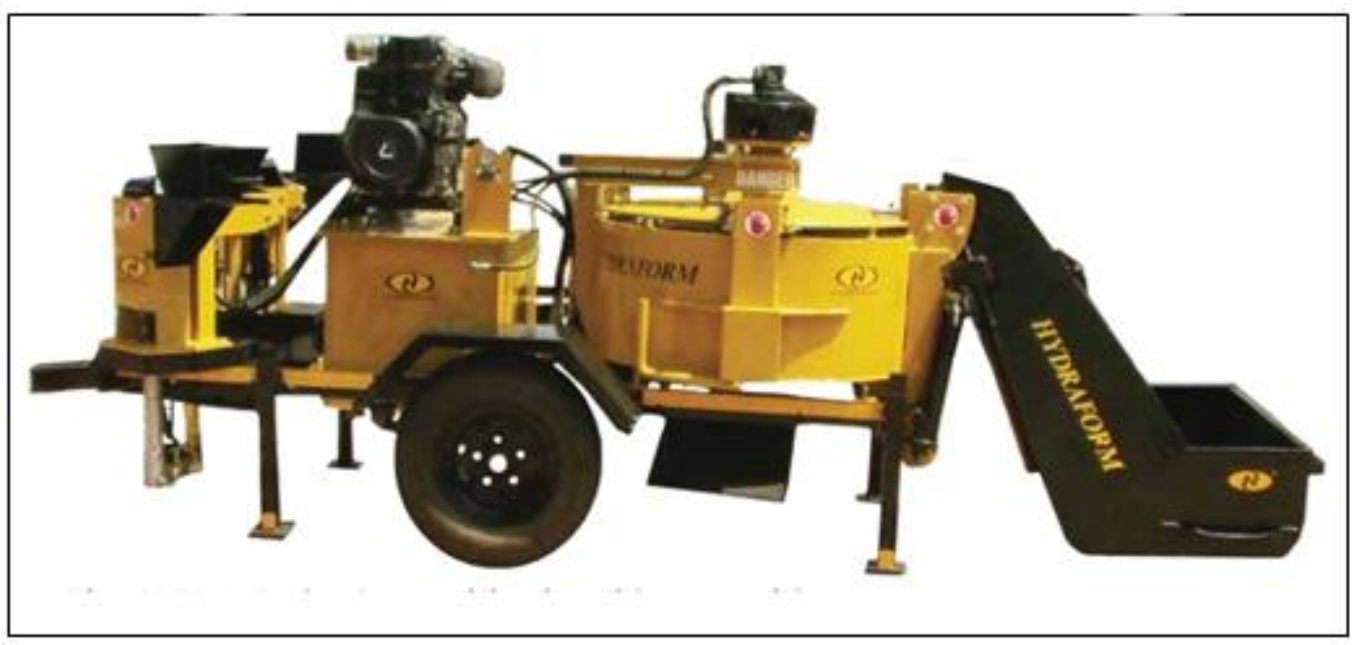

Figure 2.1.2-1 Hydraform M7 Press (Hydraform 2014)

Since they cannot be reinforced with rebar, Hydraform blocks are often used as confined or in-filled masonry in seismically prone regions. In areas without seismic activity, like South Africa, they are used for a wide variety of projects like retaining walls and residential construction. Hydraform blocks are relatively small compared to other CEBs, and are meant to be dry stacked without the use of mortar. 


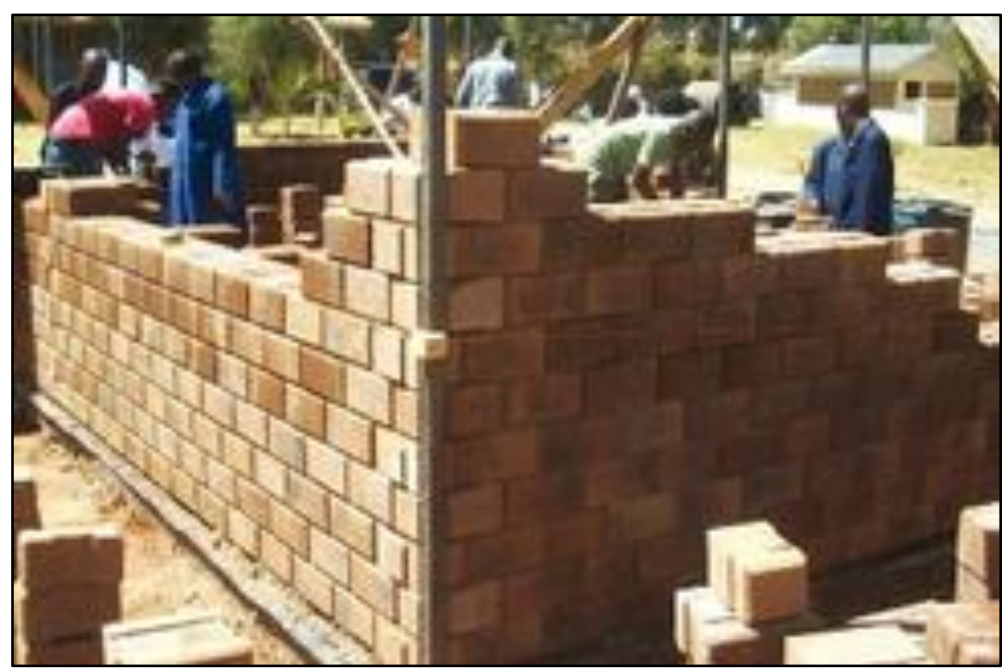

Figure 2.1.2-2 Dry Stack Hydraform Project (Pave 2007)

\subsubsection{Soeng Thai BP6}

The Soeng Thai block press was developed in 1983 by the Asian Institute of Technology and the Soil Block Development Company. The press bears strong similarities to the original CINVA press: they are both manually powered presses conceived for rural development, and utilize the same lever action to compress the soil.

The Soeng press possesses a unique block geometry, called the "Rhino Block" that features recessed reinforcement channels. This allows for simple dry stack construction, making it popular in rural Southeast Asia. The Rhino Block also accepts vertical and horizontal reinforcement, facilitating construction in seismic zones. 


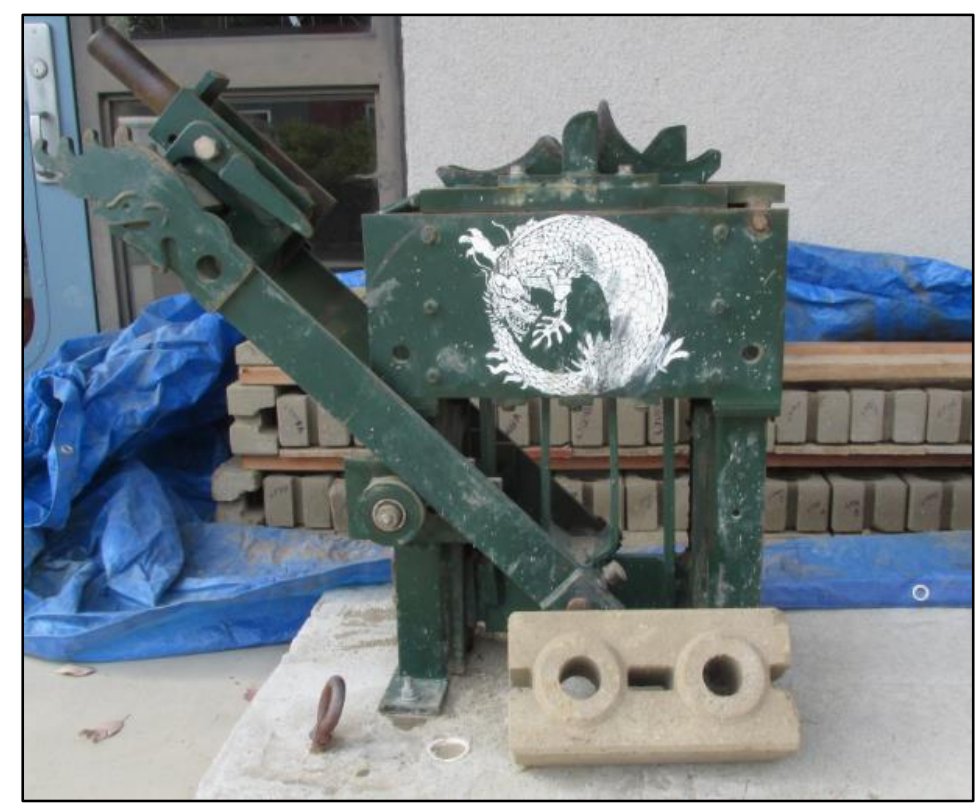

Figure 2.1.3-1 Soeng Thai Press and Rhino Blocks

\subsubsection{Vermeer BP714}

The Vermeer hydraulic block press is one of newest CEB presses to be introduced into the market. Optimized for mass production and easy construction, the BP714 combines the capacity of the Hydraform press with the interlocking shape of Rhino blocks.

The BP714 creates relatively large blocks that feature reinforcement chambers, a $5 / 8$ " deep grout channel on the bottom, and a corresponding $3 / 8$ " tall "ridge" on the top of each block to facilitate interlocking construction without the use of mortared joints. Called the "V-Lock" CEB, typical dimensions and an example of the interlocking mechanism are shown below. It should be noted that horizontal reinforcement may be placed in the cavity between the grout channel and interlocking ridge. Shown is $1 / 4$ " un- 
deformed ladder reinforcement, which is about the maximum size of horizontal reinforcement permissible.

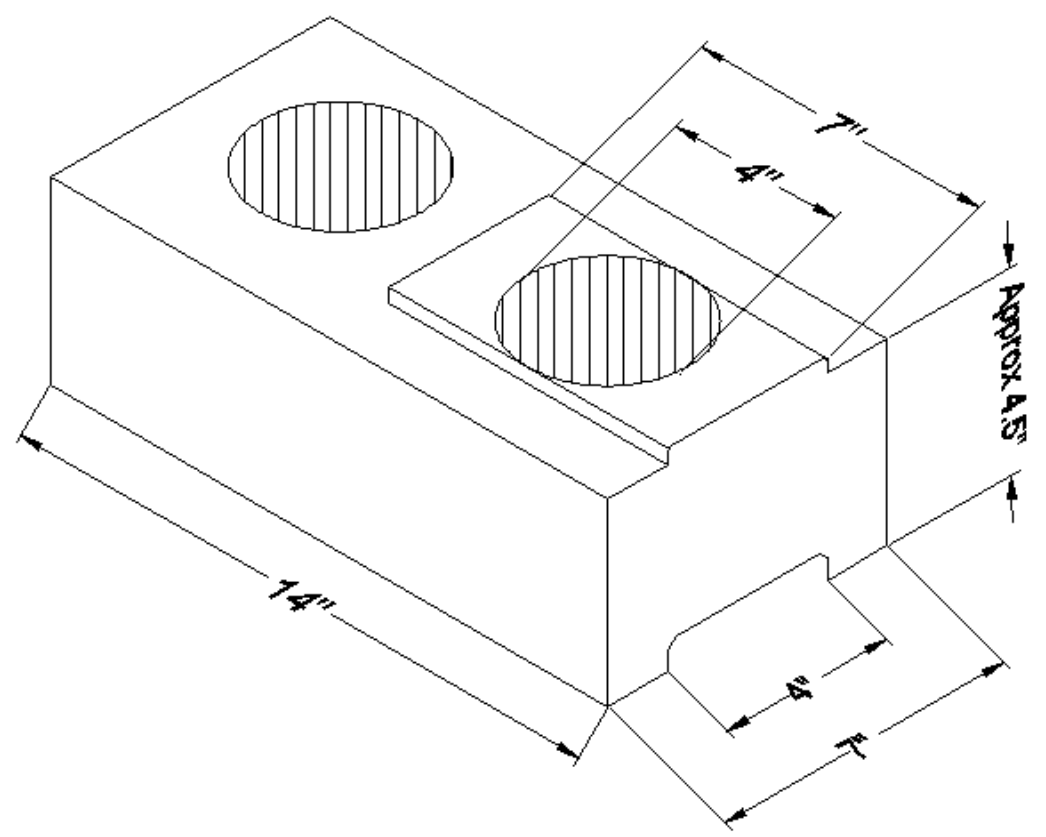

Figure 2.1.4-1 V- Lock Block Dimensions

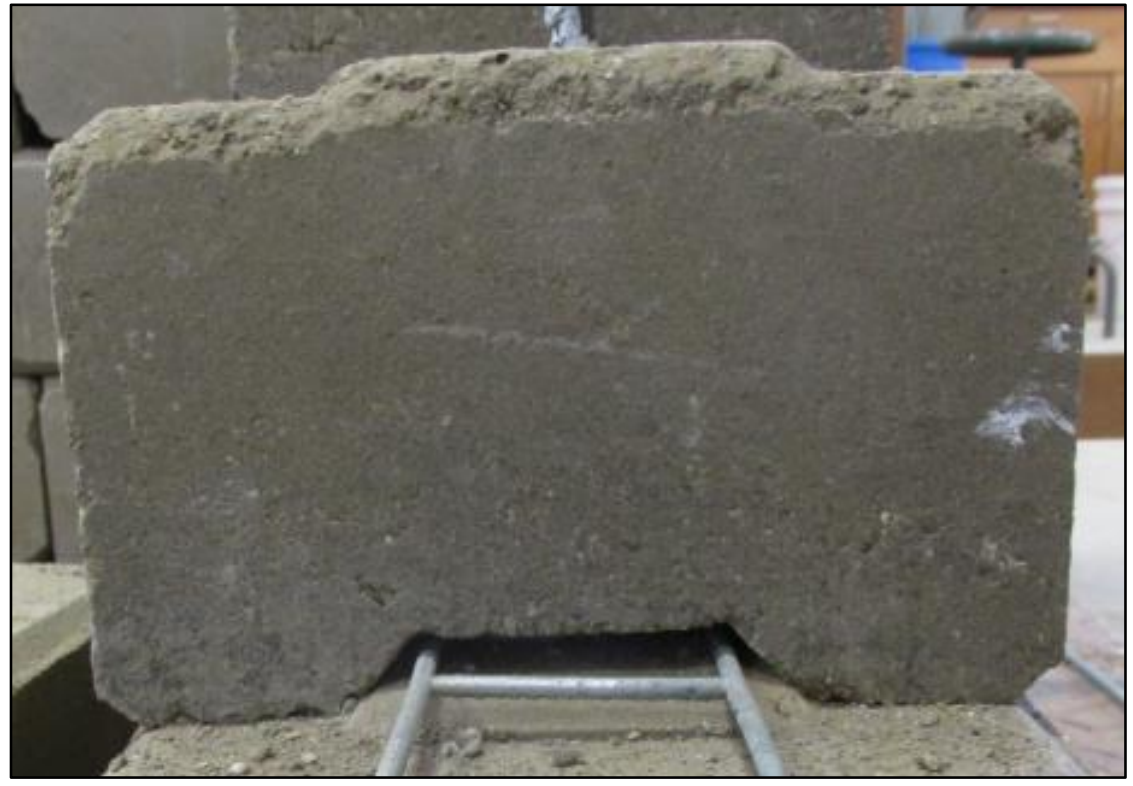

Figure 2.1.4-2 Interlocking Mechanism 
The process of creating these blocks is best illustrated in Figure 2.1.4-2. Local soil is either sieved or pulverized, then mixed with a stabilizer and occasionally sand. The mixture is moistened with water until it reaches its desired consistency, then placed into the hopper. A bucket located at the bottom of the hopper measures out a portion of the mixture volumetrically, then is moved over the compression chamber. The soil falls into the bucket, which continues to move forward until it is past the compression chamber.

Beyond the bucket, but located on the same piston, is the top plate of the compression chamber. Once the compression chamber is sealed, the operator raises the bottom platen, compacting the block. While compaction is occurring, the piston pressure exerted on the bottom platen will be displayed. The ideal range of piston pressures is between $1100 \mathrm{psi}-2000 \mathrm{psi}$. The piston attached to the bottom platen has a diameter of 6", and the bottom platen itself has dimensions of 7'x14", creating 300psi - 570psi of pressure on the CEB itself.

Then two additional tapered plates rise from the bottom platen cylinders and further compact the block. The tapered plates compact the area of the CEB within the reinforcement chambers, pushing and shearing the soil in a complicated action. The end result is further compacting of the soil and further strengthening of the CEB. 


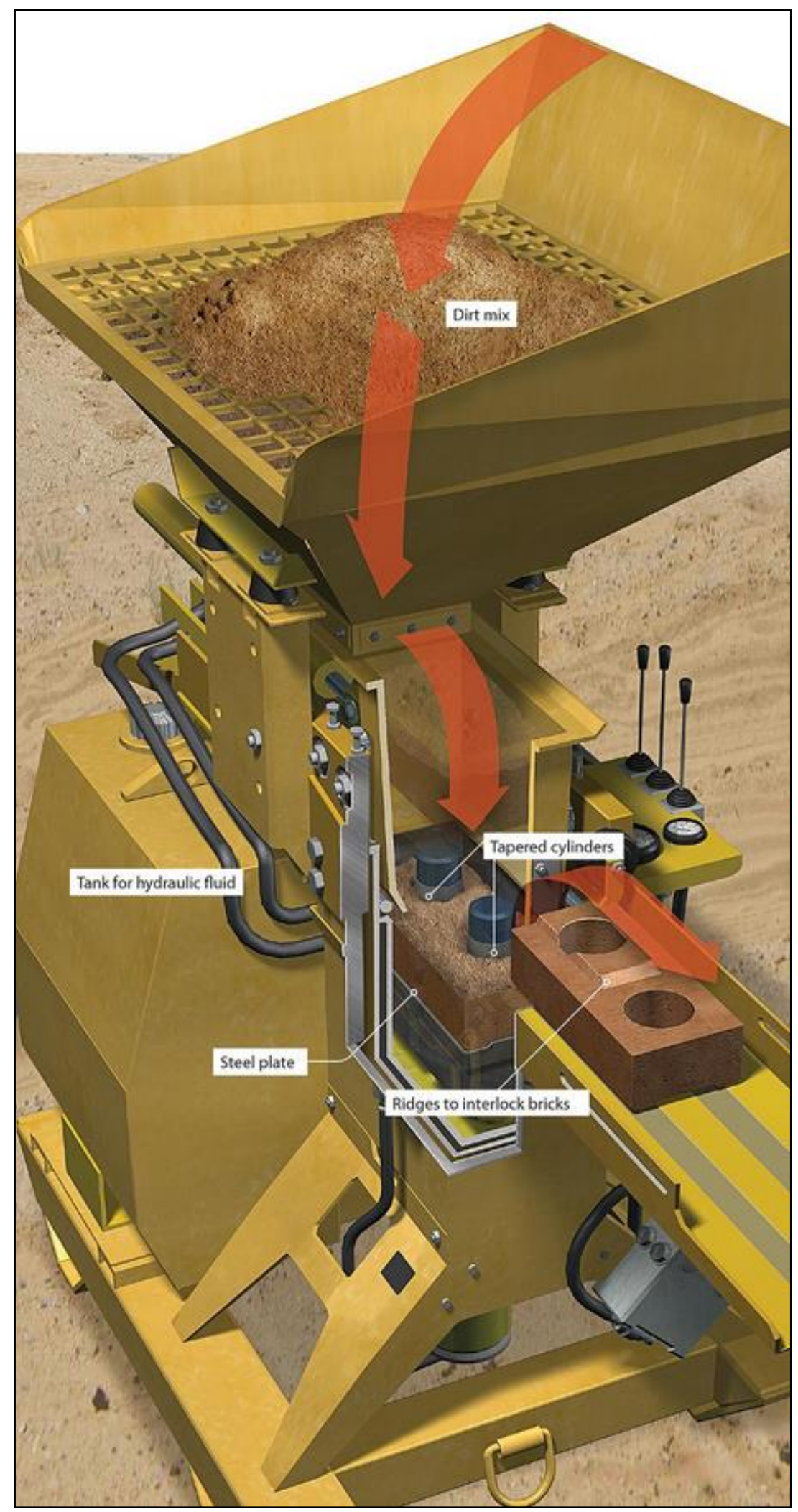

Figure 2.1.4-3 BP714 Block Pressing Process (Chu 2013) 
After compression, the bucket is completely retracted into the hopper, where it fills again with soil. Next, the bottom platen is completely raised, and the newly compacted CEB is lifted out of the compression chamber and stored for curing. The platen and cylinders are lowered to their original position and the process is repeated.

One of the most unique aspects of the BP714 is the pressure gauge, which allows an operator to observe the pressure exerted by the piston onto the bottom platen. This can be used to determine whether the mixture entering the press is too dry or wet. If the mix is too dry, the cylinder will reach its maximum permissible compression before totally compacting the block, resulting in inconsistent block heights and poorly consolidated blocks. If the mix is too wet, the cylinder will reach its maximum stroke before sufficiently compacting the block, resulting in weaker blocks that will be difficult to handle. The piston pressures and their effect are visually represented in the figure below: 
The pressure exerted by the piston onto the blocks is affected by the moisture content of the mixture. This should be used only after a successful Drop Test or Shake Test

If the pressure is below II00 psi, the mixture is Too Wet

If the pressure is between II 00 psi to 2000 psi, the mixture is Adequate
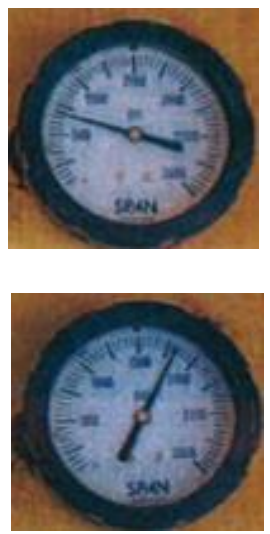

If the pressure is above $2000 \mathrm{psi}$, the

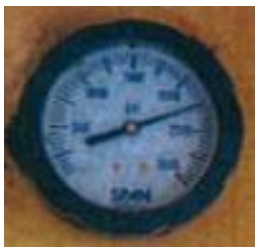

Figure 2.1.4-4 Determining Moisture Based on Pressure Readings

Due to the variability of soils and moisture contents, adjustment to the block press may be necessary. This is accomplished by adjusting the amount of soil allowed to fall into the compression chamber. As the amount of soil in the compression chamber increases, the piston is forced to compress more and more soil, which increases the pressure reading. Additionally, the height of each block can be adjusted through a similar mechanism. This raises or lowers the position of the compression chamber relative to the piston, which dictates how much stroke the piston will have to exert on the compression chamber. An example adjustment is shown in the figure below. Both these adjustments can be used to manipulate the pressure into its ideal range, and were utilized throughout this experiment. 


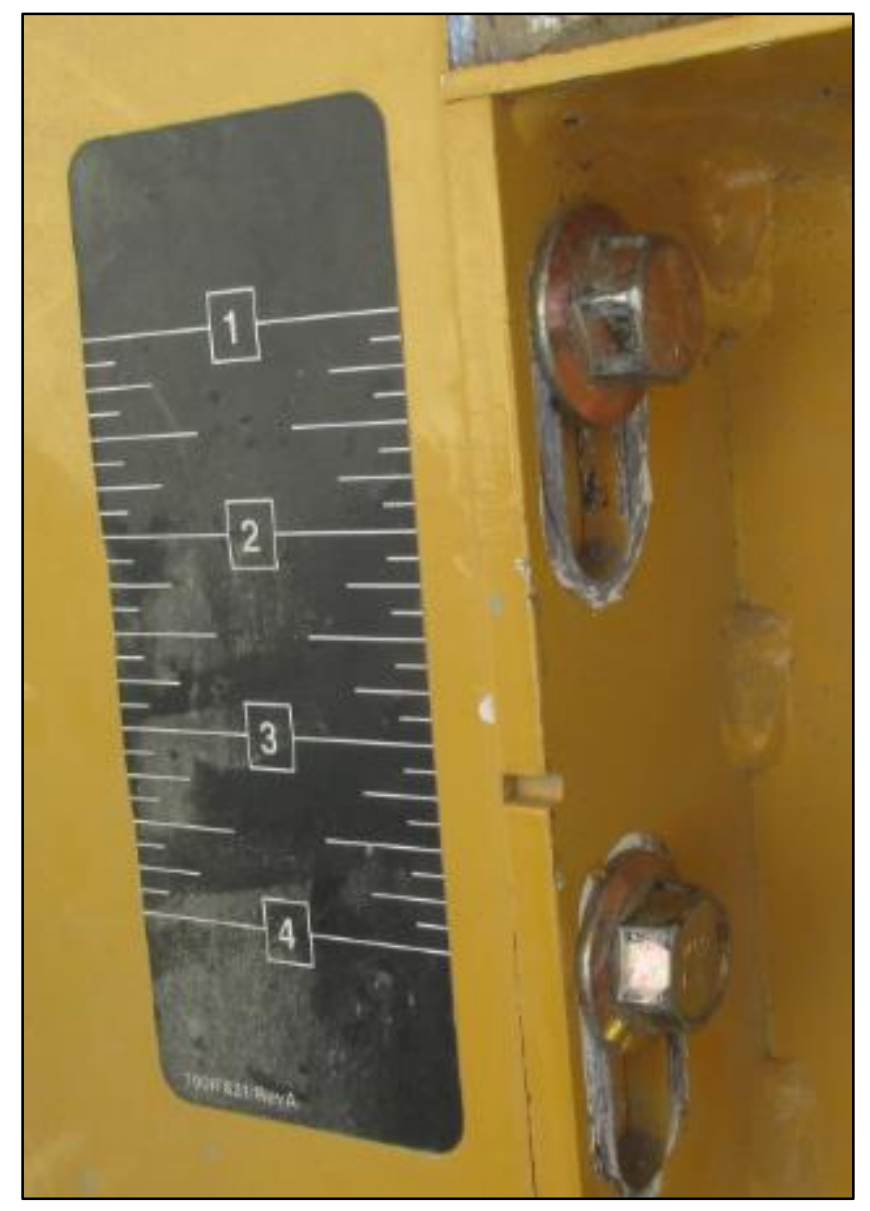

Figure 2.1.4-5 Block Height Reading

Performing adjustments to the compression chamber should be minimized as much as possible. Moisture content should be the primary way of adjusting compression pressure, as this is faster and more precise. There were multiple instances throughout this project where adjusting the compression chamber had little effect, or an exaggerated effect on the compression pressure. For mass production, these settings should be optimized and left alone, while the mixture's moisture content is adjusted.

The bucket, bottom platen and cylinders are each controlled with a seperate lever, and a skilled operator can create four blocks a minute. Additional personnel are needed to 
stack and moisten the blocks, as well as prepare the soil-cement mixture and place it into the hopper. This process can be simplified considerably with a concrete mixer and conveyor belt, which can greatly reduce manpower requirements. A well trained crew can easily create 2000 blocks in a single eight hour workday, dwarfing the capacity of manual block presses while creating a final product that is both consistent and safe for use in seismic regions.

\subsection{CEB Testing}

There has been considerable effort over the past twenty years to quantify and standardize CEB production in an effort to transform it into a modern building material.

\subsubsection{Soil Selection and Stabilization}

Before creating CEBs, it is imperative to understand soil mechanics and the process of stabilizing soil with cement.

Rigassi (1985) created a manual that deals with every aspect of CEBs, from finding the ideal soil to financing operations in rural Africa or Southeast Asia. This manual details theoretical output of presses, describes the types of mixers most effective for the soil type and suggests labor teams based on output goals.

Rigassi also suggests an ideal clay content of $8 \%-20 \%$ and describes a few experiments to determine the type of soil present on site with minimal equipment, which are seen in the figures below and were utilized when deciding which soil to use for this project. When more equipment is available, it is suggested that Atterburg limit tests, Particle size analysis and a Proctor test be performed. 
In terms of preparation and mixing, the author proposes a blade type pulverizer for clayey soils, and recommends that a mechanical mixer with hammers or blades be used to mix the soil. These suggestions were a major reason for choosing the equipment used in this experiment.

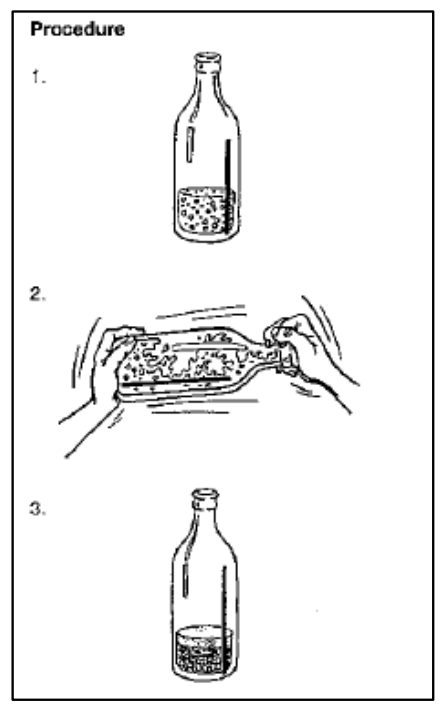

I. Fill I/3 of the bottle with a representative sample of soil then fill with water

2. Shake the bottle vigorously until the soil is suspended within the bottle

3. Allow the bottle to rest undisturbed until the soil is settled and the water is clear. The gravel, sand, silt and clay should settle in separate layers, with gravel on the bottom and clay on top

Figure 2.2.1-1 Identifying Clay Content using a Bottle (Rigassi 1985) 


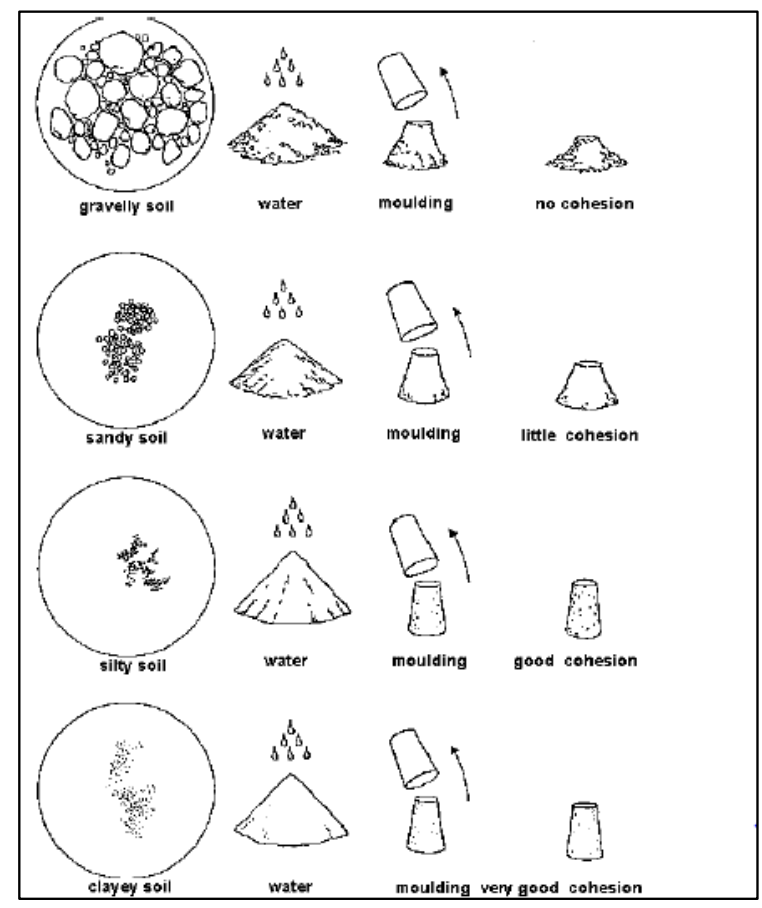

I. Obtain a bucket or cylinder

2. Take the soil sample and mix with water. Fill the bucket with the sample, making sure not to press the soil in.

3. Flip the container upside down and observe how the sample slumps. The greater the slump, the higher the gravel and sand content.

Figure 2.2.1-2 Improvised Cone Test to Determine Soil Type (Rigassi 1985)

In terms of stabilizers, Rigassi recommends $6 \%$ cement in most soils, but because of the undesirable reaction between clay and cement, Rigassi recommends using lime instead of cement in high clay soils. The experiment focused on reducing clay content using sand, not utilizing high clay stabilizers, so this comment was ignored. No physical stabilizers like fibers are recommended due to natural fibers weakness and propensity to swell when wetted.

The Dwell Earth Training Manual (De Jong 2012) covers similar topics of soil selection and material preparation, but is specific to the Vermeer BP714. Dwell Earth is a company separate from Vermeer that designed the V - Lock CEB and assisted in the design of the BP714 press. The company now provides awareness and training for the BP714, which produces the V-Lock CEB. 
The Manual suggests an ideal clay content of $10 \%$ but recommends stabilization methods similar to Rigassi. Also included are ways to determine the moisture content of the soil-cement mix before it is moved into the BP714 and pressed. These methods were utilized extensively, since proper moisture content tests could not be performed quickly enough prior to pressing. The two methods utilized in this experiment are shown below:

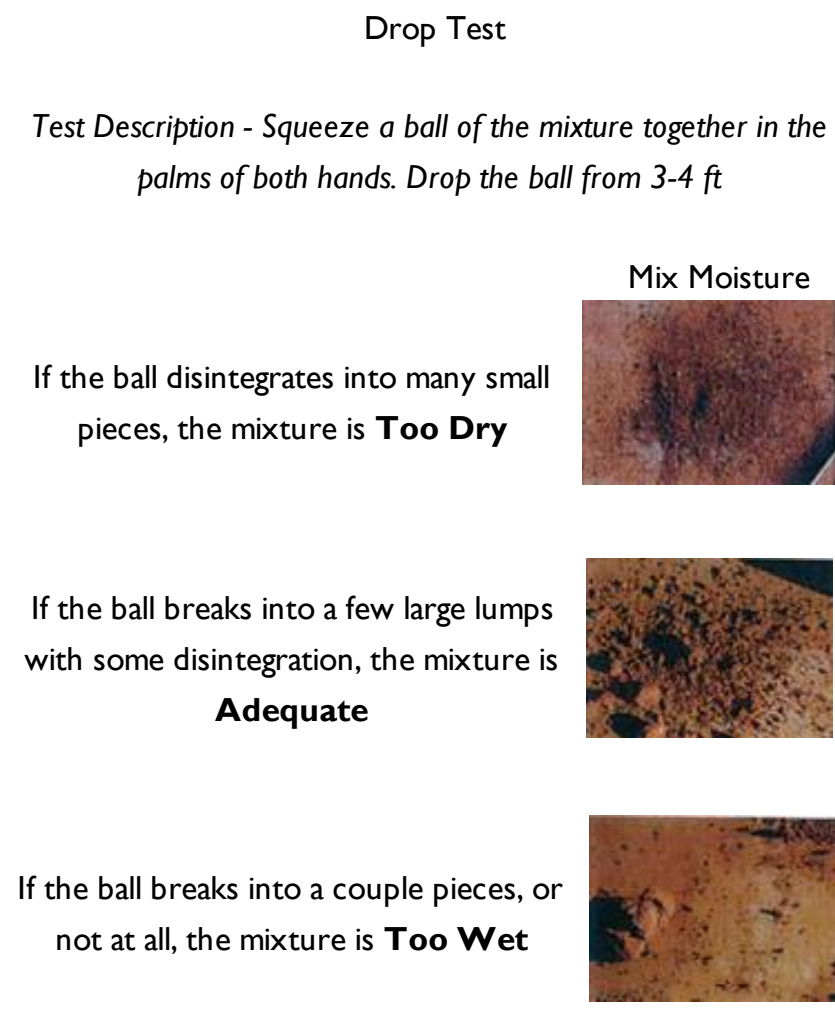

Figure 2.2.1-3 Drop Test 

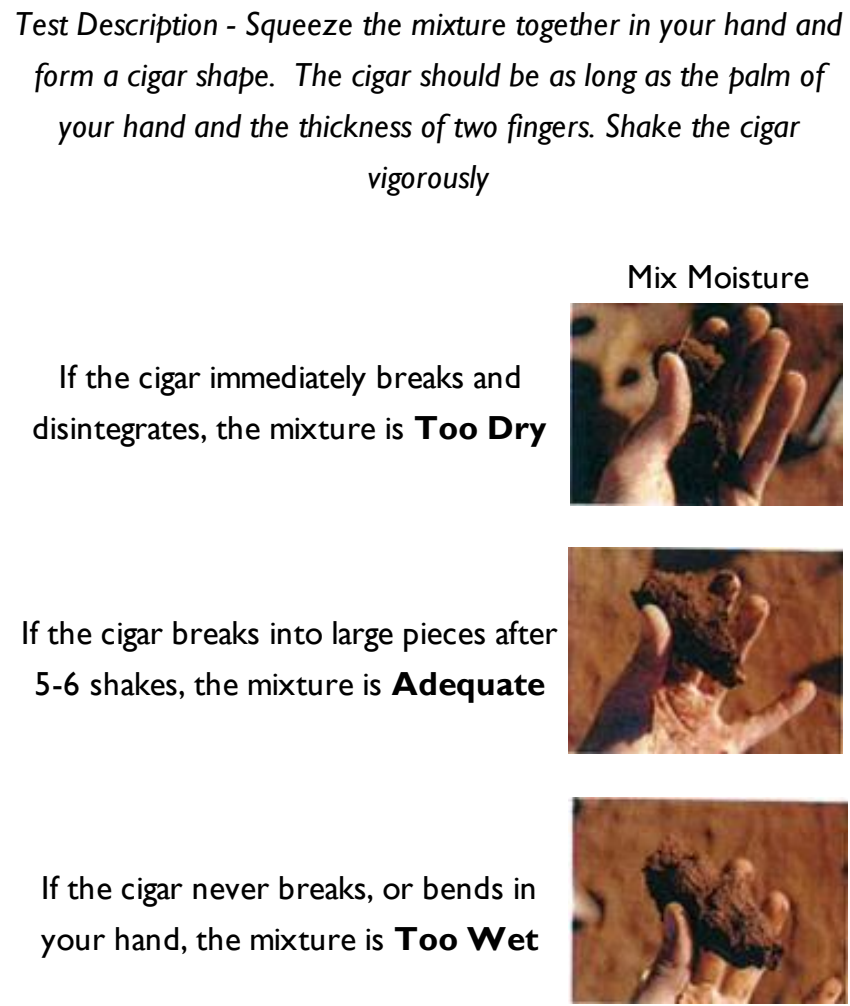

Figure 2.2.1-4 Shake Test

The bulletin Suitability of Local Soil for Cost Saving Construction Technique (Schildkamp 2009) provides additional information on soil selection and testing. It covers many of the aforementioned techniques to determine the amount of clay and sand in soil, but also recommends how to collect soil for use in CEBs. The bulletin recommends finding an embankment and harvesting soil three feet below the surface, an important consideration when choosing soils for this experiment.

Methods of stabilization are also covered, again with the recommendation that fibers not be used in compressed earth, although no reason is stated. This bulletin also gives an starting cement content of $6 \%$, but actually recommends less cement as clay 
content increases, which is in conflict with several of the papers investigated and was subsequently ignored.

Purnel, et al. (2007) investigated the reaction between cement, sand and clay with the hopes of utilizing sands contaminated with clay in concrete production. They described the interaction between sand and cement to be minimal, with cement creating a matrix of Calcium Hydroxide $(\mathrm{CH})$ and Calcium Silicate Hydroxide $(\mathrm{CSH})$ around the inert sand. However, when clay is added into the mix, there is a significant reduction in strength attributed to the clay surrounding sand particles and interfering with the cement matrix bonding to the sand.

When the clay is evenly distributed with the cement and sand, then a separate reaction takes place between the cement and clay. The cement and clay combine in a series of secondary reactions not completely understood, to create a matrix of reaction products around the inert sand and unreacted clay. The unreacted clay particles "fill" in the surrounding matrix of cement and clay to create the structure present in soil cement and CEBs.

In their experiment, the authors created concrete blocks using both normal and contaminated sands, then tested the workability of the fresh concrete, as well as the strengths of the blocks over a range of water to cement ratios. They found little decrease in strength from using contaminated sands, but a significant drop in workability based on clay type. The authors were concerned about durability, but recommended that clayey sands be used in third world construction for low rise residential purposes. 


\subsubsection{Sand, Clay and Cement Content Testing in CEBs}

This section summarizes researchers who investigated the effects of sand content, clay content, and cement content in CEBs.

Lima et al. (2012) mixed sugarcane bagasse ash, a common agricultural byproduct in Brazil, with CEBs in an attempt to create stronger and more sustainable blocks. This paper is unique in that the soils they used were so sandy they could not press blocks, so were forced to add kaolin clay to improve the workability of the mixture, although they did not report the strengths of their ultra-sandy blocks. This is one of the few papers to reach such high sand content that the strength and workability of their blocks actually decreased.

The block press used was a TERSTARAM manual press that creates CEBs without reinforcement chambers. Next the researchers tested CEB prisms in compression, as well as small walls, or "wallettes" in diagonal compression, modifying the cement content as well as the bagasse ash content. The results indicated a linear increase in mechanical properties with higher cement content, as well as the addition of bagasse ash.

Morel et al. (2007) researched and outlined the most common methods of testing the compressive strength of CEBs. No experimental testing was performed, but looking at a wealth of data from other projects, the researchers were able to observe the most significant factors that affect the compressive strength of CEBs. They began by investigating the two most common ways to investigate compressive strength: individual unit strength, and the RILEM prism testing. There are only a few basic international 
standards for unit strength due to the unique size and shape of each CEB produced, so the researchers recommended manipulating and adjusting the data on a per case basis.

After reviewing methods of measuring compressive strength, the researchers looked at factors which affected compressive strength. One of the key factors was aspect ratio, or how tall a CEB is compared to its other dimensions. The taller a block became, the less effect friction between the block and testing platen mattered. This reduced the confinement of the block and lowered its potential strength. Confinement was also considered, and as expected, the more confined a specimen the stronger it became. There was considerable discussion given to capping materials and procedures, but this is rendered moot by the testing plates Dwell Earth manufactures for testing specimens in compressive strength.

Additional factors that affected compressive strength included density and moisture content. It was found that lower density is related to lower compaction effort, and that lower density typically results in lower strength. The researchers also found that blocks with higher moisture content possessed lower strengths, again as a result of the clay bonding mechanisms and its tendency to expand in the presence of moisture. It was also observed that cement contents between $4 \%$ and $10 \%$ contributed to a linear increase in strength.

Muntohar (2011) investigated the effects of rice hull ash and lime in CEBs. Using a local soil and a mix of $70 \%$ soil with $30 \%$ Sand, Muntohar created a series of blocks with varying amounts of rice hull ash in an unnamed, manual block press that 
created homogenous bricks without reinforcement holes. He then tested the blocks in compression, modulus of rupture and absorption, with both dry and saturated blocks.

Muntohar found that during submersion, the stabilized CEBs without sand experienced significant degradation and were thus weaker than the soil-sand mix when tested. In every case, the submerged blocks were approximately $20 \%$ weaker when tested compared to the dry blocks, both in compression and modulus of rupture. There was also a diminishing return in the amount of stabilizer utilized, and some blocks actually decreased in strength as the stabilizer content increased beyond $15 \%$.

Additionally, the author found that as sand content and stabilizer content increased, the absorption of the CEB decreased. This corresponded to an increase in CEB density, as well as strength.

Pave (2007) performed a variety of tests on the hydraform CEBs with the intent of developing a design code specific to hydraform masonry systems. Pave performed wet and dry full faced compression tests and compression bearing tests on small portions of the hydraform block with a variety of different cement contents.

Pave found that wet specimens in compression were $20 \%$ to $30 \%$ weaker than air dry specimens. He also discovered that cement contents experience a bilinear relationship in strength gain: when the cement content is below $10 \%$, increasing the cement content slightly leads to a significant gain in compressive strength. Beyond $10 \%$, there are only moderate gains in strength from increasing cement content. Another significant factor in strength was the moisture content. Pave recognized that an increase in block moisture content lead to a decrease in strength. 
Walker (1995) performed testing on CEBs with varying sand contents and cement contents, testing both wet and dry compressive strength and modulus of rupture. Additionally, a discontinued durability test that involved wetting, drying and scraping the CEB with a wire brush was performed. Walker utilized sand contents that varied from $0 \%$ to $85 \%$, as well as two virgin soils with ideal clay contents. All blocks were created with an unknown manual press.

Walker found as clay content increased, the compressive strength of the CEBs decreased in a parabolic manner. This trend existed in both dry and wet blocks. In addition to compressive strength, Walker performed many modulus of rupture tests and was able to observe a linear relationship between compressive strength and modulus of rupture, which is unlike concrete and concrete masonry construction. Walker also discovered that drying shrinkage and mass loss from durability testing increased exponentially with an increase in clay content, although this effect could be defrayed by increasing cement content. Finally, Walker recommended that cement content be increased as clay content increases, since clay interferes with the creation of reaction products and results in a CEB with inferior strength.

\subsubsection{Fibers in Soil}

This section summarizes the effects of fibers in soil, soil cement and CEBs.

Hejazi et al. (2011) reported on the effects of chemical, physical and mechanical stabilization of soils. They also reviewed the most common projects involving stabilized soil and proposed the best system for each. This article focuses primarily on discrete 
fibers interspersed randomly in three dimensions. These fibers can be broadly classified as natural and synthetic, with synthetic fibers covering plastic, glass and metal fibers.

The paper focused primarily on polypropylene (PP) fibers, which are the most common synthetic fiber. The majority of research focused on the stabilization of sands and sandy soils, but some research focused on clayey soils. Research indicated that the primary benefit of PP fibers was the restraint of the soil matrix. This restraint translated into reduced shrinkage cracking, higher deformations and post cracking stress, and an increase in energy absorbed by the soil system. These effects were reversed as the fiber content began to increase above $3 \%$, since the soil could no longer sufficiently bond with the fibers.

This paper also described the bond between the fibers and soil. The strength of fiber-reinforced soil comes from the bond between the soil and fiber. This bond is typically how fiber-reinforced soil fails, instead of mechanical failure from fiber itself. The bond between the soil and fiber is dependent upon the length of the fiber, diameter of the fiber, the soil type, moisture content and compaction. Soils with high potential for shrinkage and expansion may separate themselves from the fiber, requiring some sand or cement within the material. 


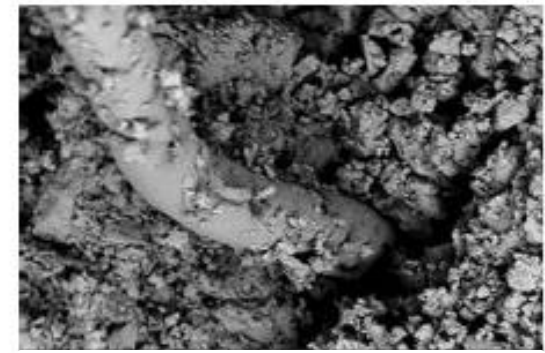

(a)

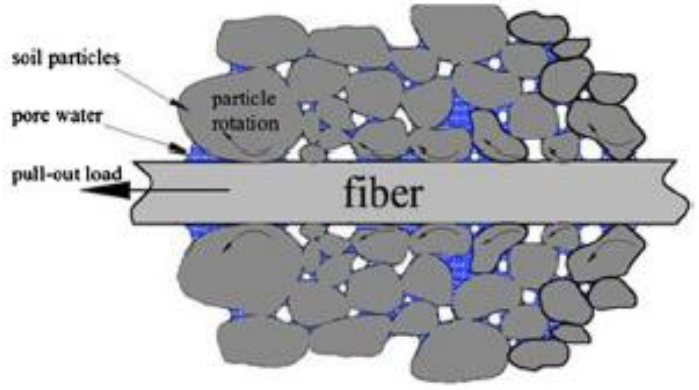

(b)

Figure 2.2.3-1 Photo (a) of a fiber in soil and (b) sketch (Hejazi et al. 2011)

The authors also discuss adequate mixing techniques, which is essential to maximizing the strength of fiber-reinforced soil. The difficulty in most projects is sufficiently mixing the soil so that the fibers are not only evenly distributed, but also "unwound" from their bundled state. Also important is to avoid over mixing the fibers until they become damaged. Some crimping is considered ideal, but fraying and splitting should be avoided.

Ghavami et al. (1999) investigated the effects of coconut and sisal fibers in rammed earth. Their experiment did not use any stabilizers, since their objective was to create an ultra-affordable earth block that minimized cracking, a major issue in rural Brazil. The majority of their testing involved the fibers themselves, but they did create compressed blocks with different fiber types and test the compressive strength over time.

The researchers found that the moisture content of the block directly affected the bond between the soil and fiber. The block experienced an increase in compressive strength as water left the clay matrix, and gained more and more ductility as the clay and 
fibers bonded more effectively. The paper suggests air drying the blocks as long as possible to maximize their strength and coating highly absorptive fibers like sisal with bitumen to decrease their tendency to absorb water from the soil mixture.

Mesbah et al. (2004) developed a direct tensile test for CEBs reinforced with natural fibers. They created several CEBs that were unreinforced and some that were reinforced with sisal fibers. Next, the researchers tested blocks in direct tensile, some with notches to define an ideal failure plane.

As was expected, soil reinforced with sisal fibers displayed superior post crack deformation and strength. However, there was little effect on pre-cracked strength, and the authors suspect that this is because of the low stiffness of natural fibers, which make no contribution to strength or ductility until cracking occurred and the block deformed significantly. The authors also suggest a fiber length around 50mm (1.96in), as the $20 \mathrm{~mm}$ (.787in) fibers they tested were insufficient to create a strong bond between fiber and soil.

Taallah et al. (2014) investigated CEBs reinforced with date palm fibers. They created blocks with different cement contents and fiber contents, and tested them in wet and dry compression, tensile strength as well as an absorption test.

The researchers discovered that date palm fibers were unsuitable for use in soil because of their high absorption and propensity for swelling. While they experienced a linear rise in strength as cement content increases, the blocks became weaker as fiber content increased. This was especially true in wet testing, when the fibers were allowed to absorb more water. However, the authors did observe that absorption decreases linearly with increasing cement content, and that compaction effort has a significant 
effect on the bond between the fiber and soil. The authors suggested that compactive effort should increase as fiber content increases, as fibers will attempt to "bounce" back to their original shape, reducing the density of the block.

Eko et al. (2012) utilized the steel from old tires to create fibers and then mixed the fibers into CEBs. The researchers used a CINVA RAM press to create blocks with varying cement contents and fiber contents, then tested the blocks for compressive strength, modulus of rupture and pure tensile. Additionally, different fiber lengths were tested.

The researchers found that the critical length of fibers in CEBs to be about $35 \mathrm{~mm}$ (1.38in), and maximum fiber content to be $2 \%$. Beyond that fiber content, there was not enough soil between each fiber to properly bond and activate the fiber during loading. Using steel fibers, the researchers observed an increase in tensile and flexural strength, as well as significant post cracking strength and ductility. However, the soil matrix was never strong enough to completely utilize the strength of the fibers, resulting in pull out failures instead of mechanical failure of the fiber.

The authors also confirmed the linear relationship between cement content and strength, but found that at higher cement contents, the subsequent strength gain began to plateau. This suggests a bi linear relationship between cement content and strength, likely a dependent upon clay content within the soil. 


\section{CHAPTER 3: MATERIALS}

This chapter summarizes the materials and equipment used to produce the CEBs that were tested.

\subsection{Soil}

Three types of soil were utilized in this project. Each soil was pulverized and then underwent testing using the following ASTM Standards:

- ASTM D2487 - Standard Practice for Classification of Soils for Engineering Purposes

- $\quad$ ASTM D4318 - Standard Test Methods for Liquid Limit, Plastic Limit, and Plasticity Index of Soils

- $\quad$ ASTM D4829 - Standard Test Method for Expansion Index of Soils

- $\quad$ ASTM D422 - Standard Test Method for Particle Size Analysis of Soils

Expansion Index (EI) tests were performed after preliminary CEB batches exhibited excessive cracking, and it was thought that expansive clays may be to blame. 
After soil testing was complete, a Casagrande chart identifying predominant clay

minerals based on Atterburg Limits was utilized. No soil possessed an easily identifiable clay mineral, and no further analysis of the clays was attempted.

All soils were collected locally between December 2013 and March 2014, and were named according to their location:

\subsubsection{Las Tablas (LT)}

The primary soil for this project was collected from a residential construction project adjacent to Las Tablas Road in Templeton, CA. After some field testing, the soil was collected with a front end loader and approximately 8 cubic yards was delivered in December 2013.

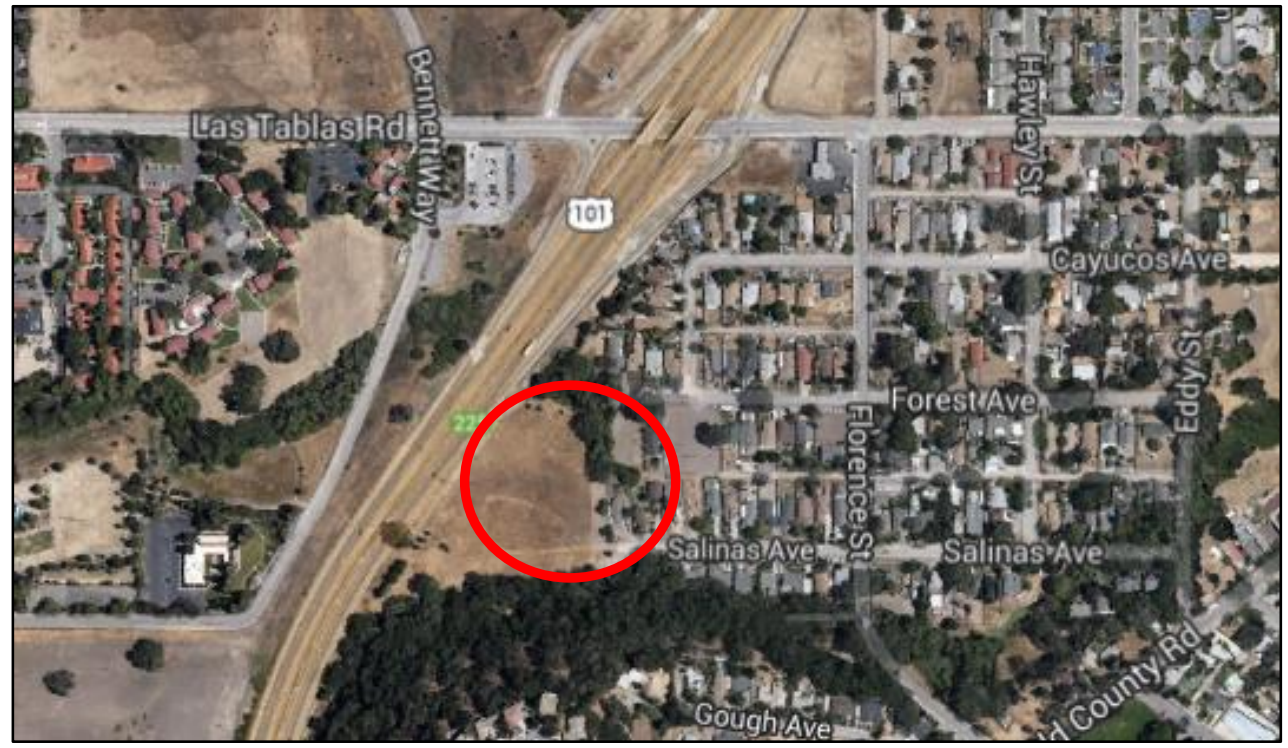

Figure 3.1.1-1 Las Tablas Site Location 


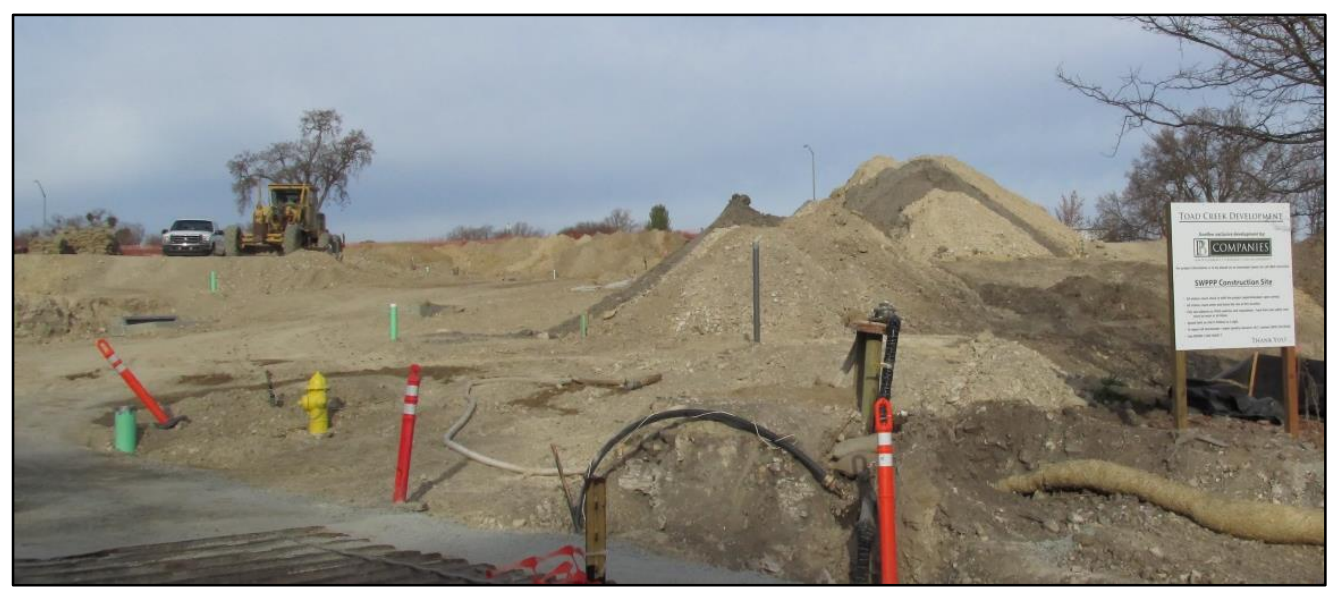

Figure 3.1.1-2 Las Tablas Soil Harvest Site

After testing, the soil was determined to be a Yellowish Brown Lean Clay with no easily identified clay mineral. The Atterburg Liquid Limit (LL), Plastic Limit (PL), Plasticity Index (PI) and gradation is shown in the table below. Using the United Soil Classification System, clay, silt, sand and gravel content were also determined.

During preliminary block production, it was discovered that LT soil exhibits shrinkage cracking to such an extent as to reduce CEB strength. For this reason, EI tests were performed on all soils. However, the clay within LT soil did not exhibit high expansion potential, so an absorption (Abs) test following ASTM C128 - Standard Test Method for Density, Relative Density and Absorption of Fine Aggregate was performed on washed material retained on the \#20 sieve. The properties are listed below: 
Table 3.1.1-1 Las Tablas Soil Properties

\begin{tabular}{|c|c|c|c|c|c|}
\hline \multicolumn{3}{|c|}{ Atterburg Limits } & \multirow{2}{*}{$\begin{array}{c}\text { Expansion } \\
\text { Index }\end{array}$} & \multirow{2}{*}{$\begin{array}{l}\text { Expansion } \\
\text { Potential }\end{array}$} & \multirow{2}{*}{$\begin{array}{c}\text { Ave Abs } \\
(\%)\end{array}$} \\
\hline LL (\%) & PL (\%) & PI (\%) & & & \\
\hline 44 & 12 & 32 & 32 & Low & 27 \\
\hline
\end{tabular}

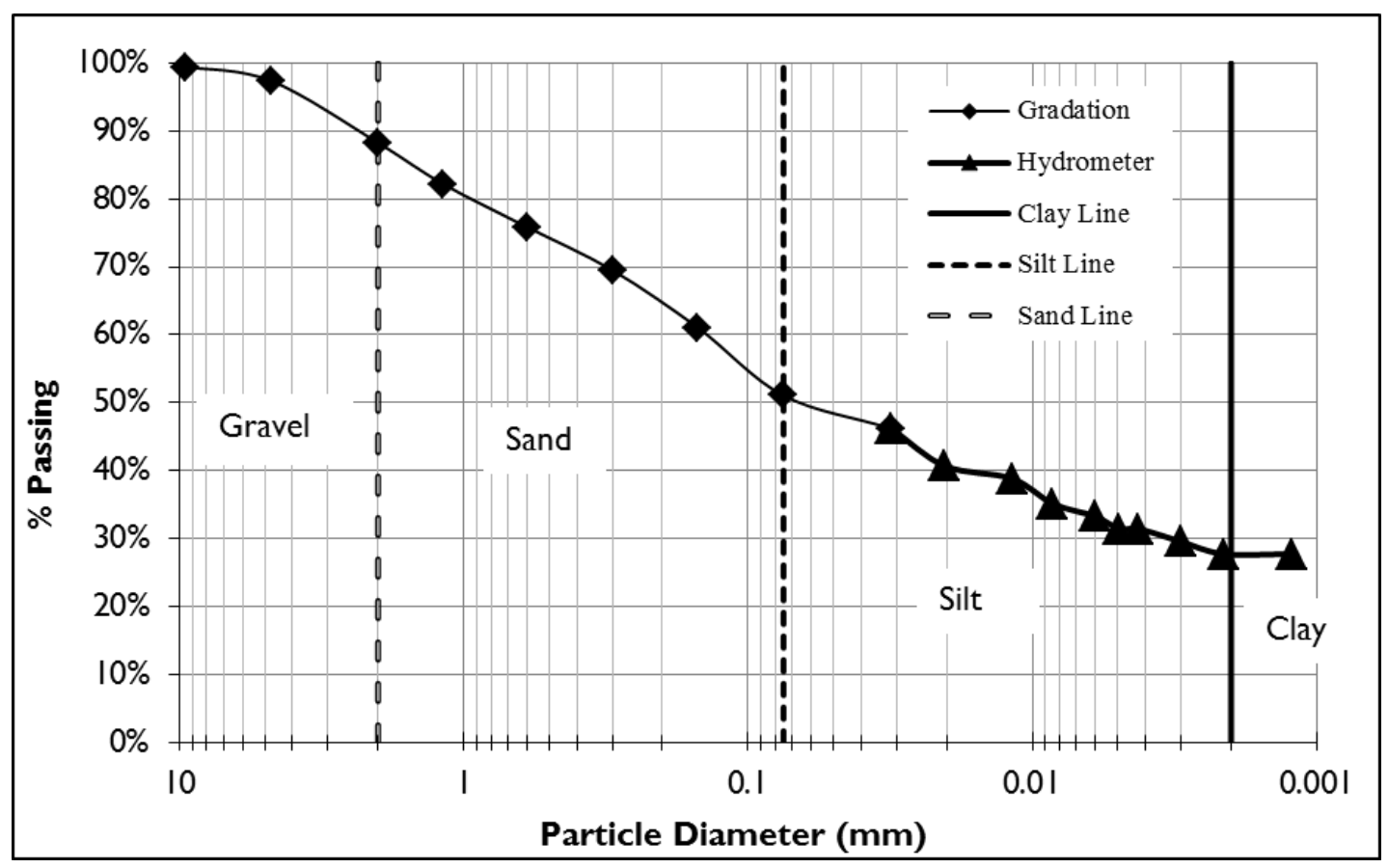

Figure 3.1.1-3 Las Tablas Gradation

Table 3.1.1-2 Las Tablas Grain Size

\begin{tabular}{|c|c|c|c|}
\hline Clay (\%) & Silt (\%) & Sand (\%) & Gravel (\%) \\
\hline 27.8 & 23.3 & 37.1 & $\mathrm{I} 1.8$ \\
\hline
\end{tabular}

As seen in the Table 3.1.1-1, LT soil possesses a low potential for expansion, but has a large percentage of highly absorptive sand and gravel. It is possible that these 
coarse particles leach water from the LT clay during drying, resulting in the large shrinkage cracks seen in blocks with pure LT soil. These absorptive coarse particles are unique to the LT soil, and may also be responsible for the rapid drying the mixture experienced during pressing. To reduce clay content, and by extension cracking, sand was mixed with the soil prior to creating blocks, a method utilized throughout this experiment.

\subsubsection{Prado $(P)$}

This soil was collected using a front end loader from a residential development at the end of Prado Road in San Luis Obispo in February 2014.

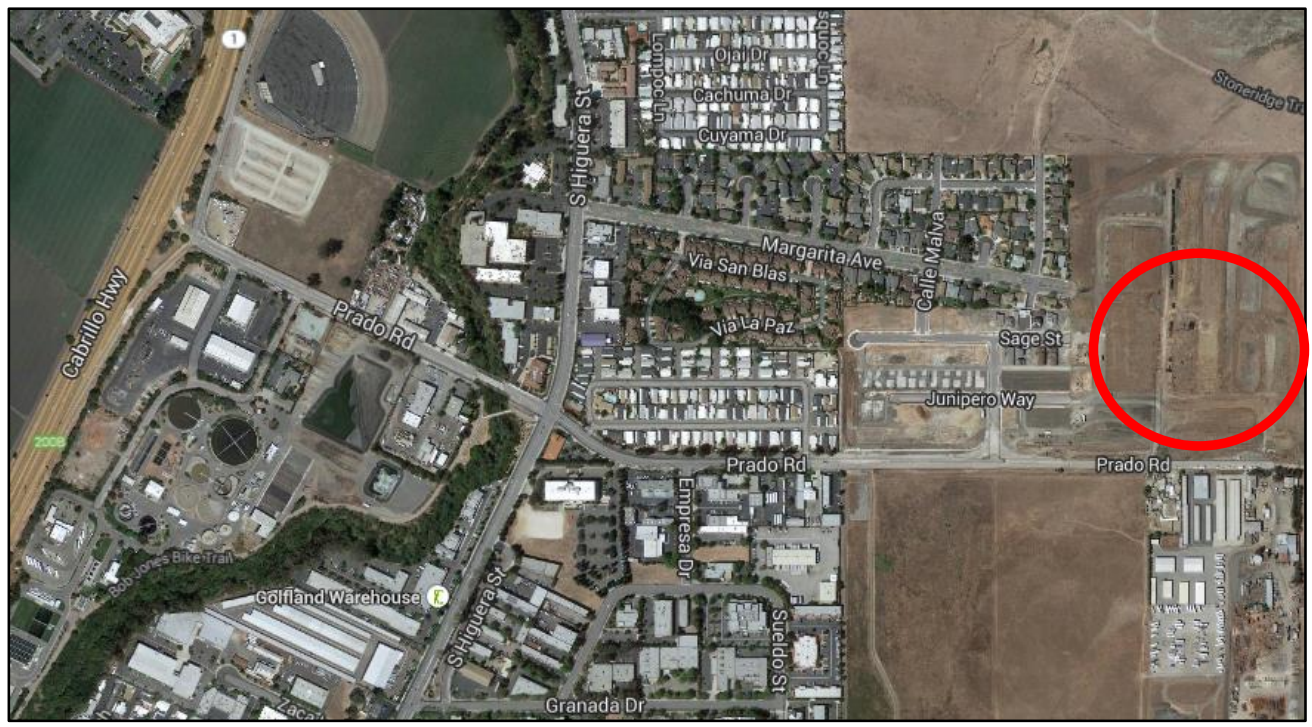

Figure 3.1.2-1 Prado Site Location 


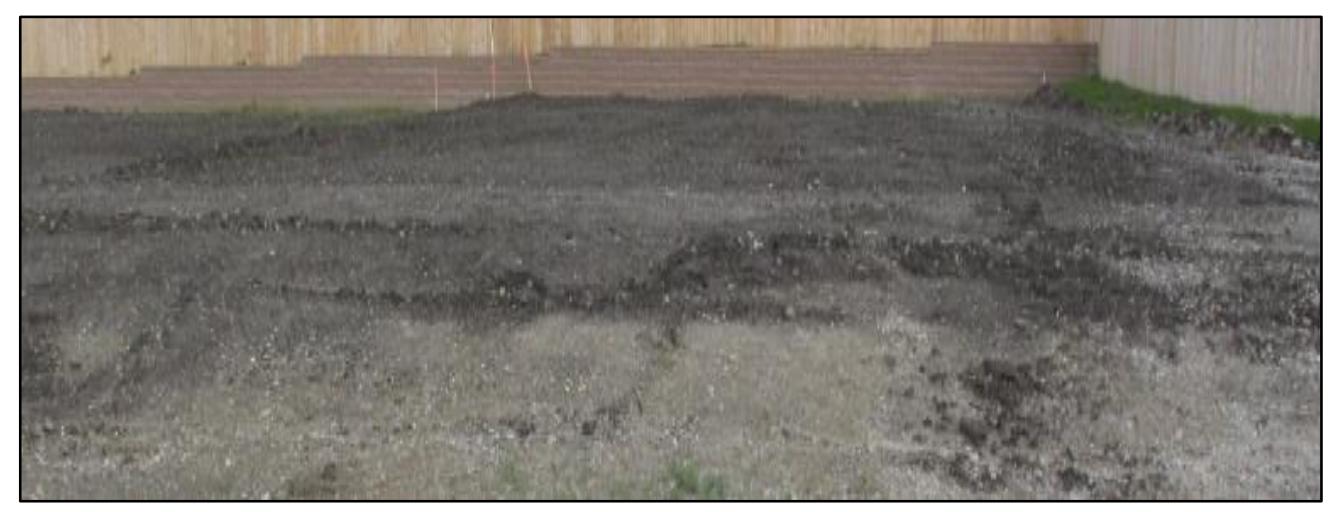

Figure 3.1.2-2 Prado Harvest Site

After testing, the Prado soil was classified as a Dark Brown Fat Clay with no easily identifiable clay minerals. The Atterburg Limits, gradation, particle distribution and EI are shown below.

Table 3.1.2-1 Prado Soil Properties

\begin{tabular}{|c|c|c|c|c|}
\hline \multicolumn{3}{|c|}{ Atterburg Limits } & Expansion & Expansion \\
\hline LL (\%) & PL (\%) & $\mathrm{PI}(\%)$ & Index & Potential \\
\hline 64 & 16 & 48 & 76 & Med \\
\hline
\end{tabular}




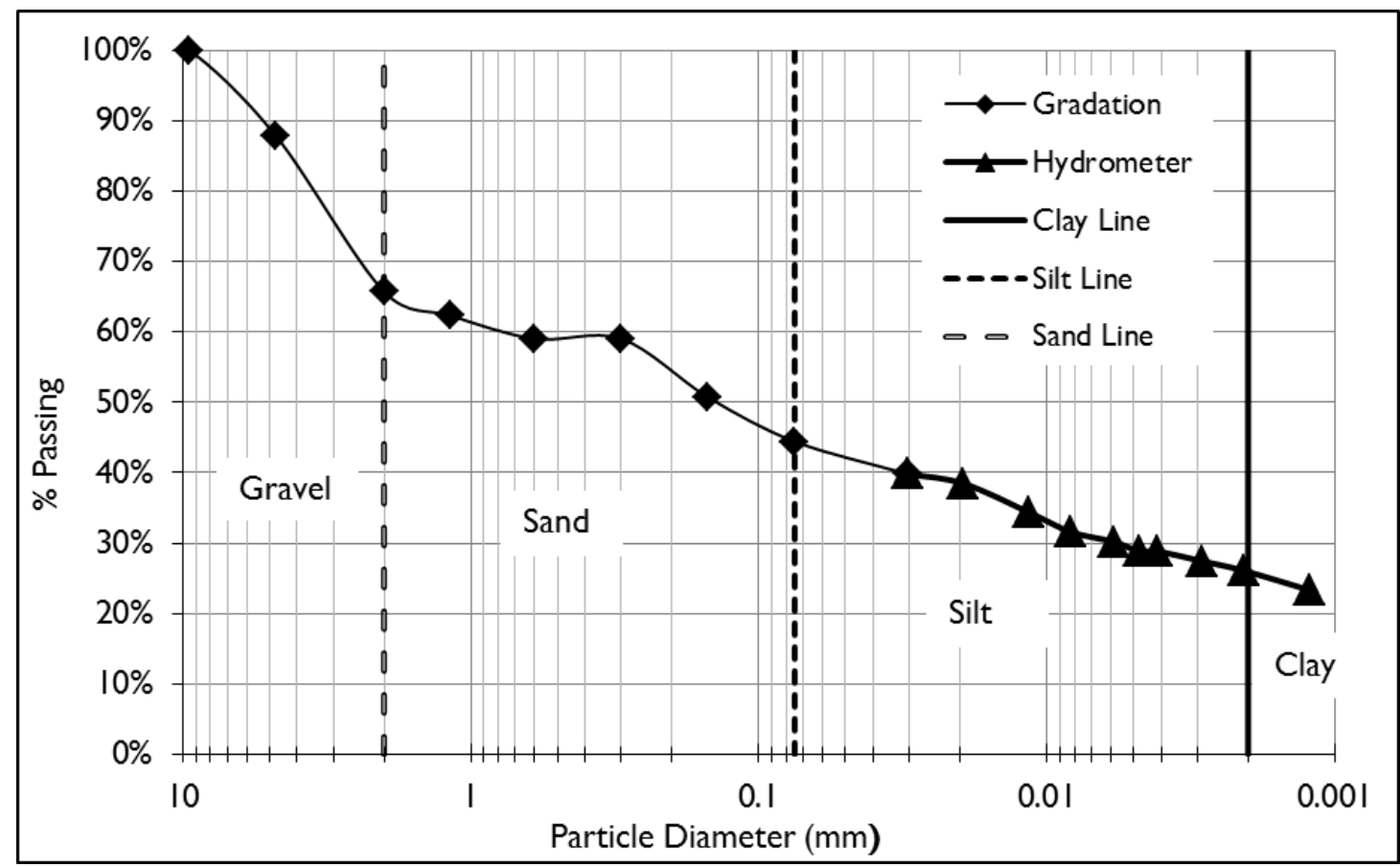

Figure 3.1.2-3 Prado Gradation

Table 3.1.2-2 Prado Grain Size

\begin{tabular}{|c|c|c|c|}
\hline Clay (\%) & Silt (\%) & Sand (\%) & Gravel (\%) \\
\hline 26.1 & 18.3 & 21.3 & 34.3 \\
\hline
\end{tabular}

As can be seen, the Prado soil possesses a high clay content with a highly expansive clay. This was confirmed in preliminary block batches, where significant shrinkage cracking occurred. Like the LT soil, all Prado blocks utilized sand.

\subsubsection{Mind Body Soil (MB)}

This soil was collected in March 2014 near the intersection of Tank Farm Road and Broad Street in San Luis Obispo. A company called MindBody was expanding into an adjacent lot, earning the soil its name. 


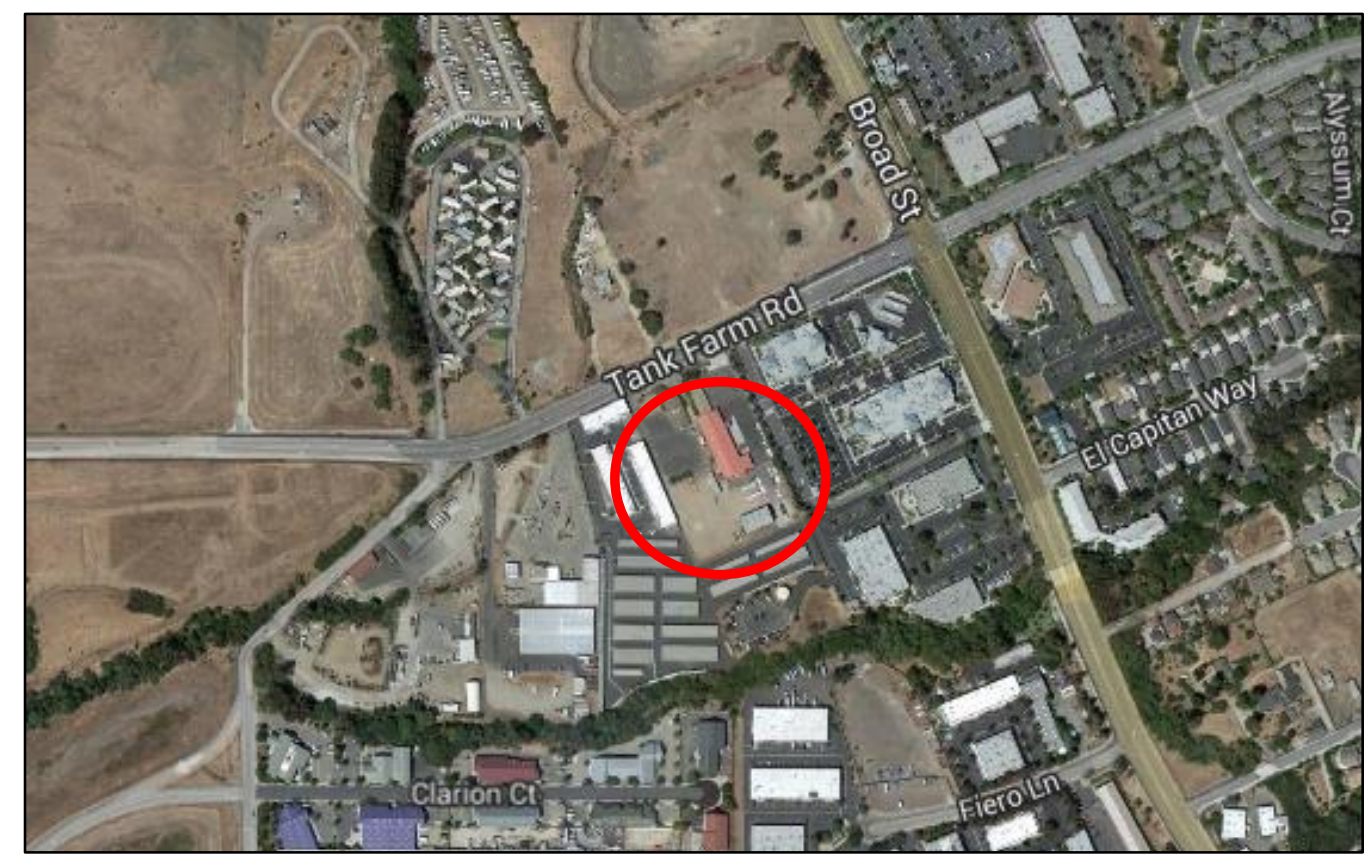

Figure 3.1.3-1 Mind Body Soil Location

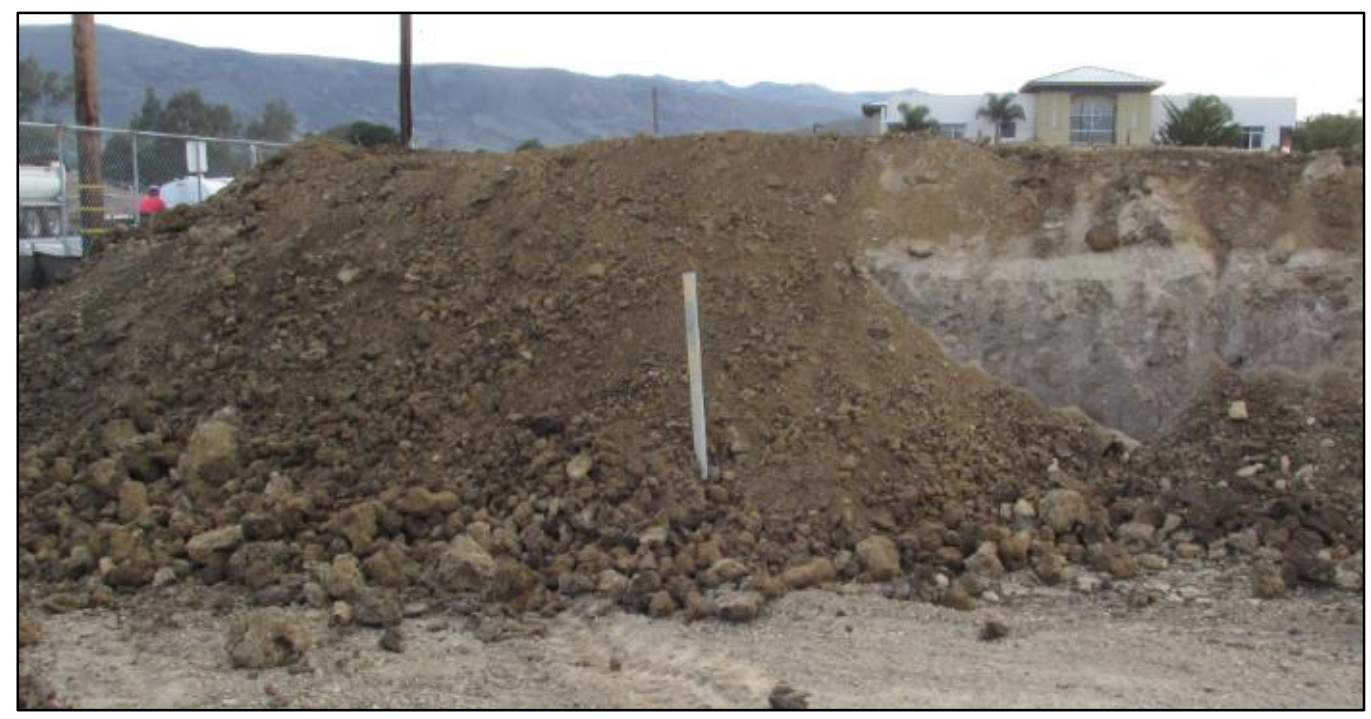

Figure 3.1.3-2 Mind Body Harvest Site 
After testing, the MB soil was classified as a Dark Yellowish Brown Fat Clay with no easily identifiable clay minerals. The Atterburg Limits, gradation, particle distribution and EI are shown below.

Table 3.1.3-1 Mind Body Soil Properties

\begin{tabular}{|c|c|c|c|c|}
\hline \multicolumn{3}{|c|}{ Atterburg Limits } & \multirow{2}{*}{$\begin{array}{c}\text { Expansion } \\
\text { Index }\end{array}$} & $\begin{array}{c}\text { Expansion } \\
\text { Potential }\end{array}$ \\
\hline LL (\%) & PL (\%) & PI (\%) & Ind \\
\hline 57 & 21 & 36 & 59 & Med \\
\hline
\end{tabular}

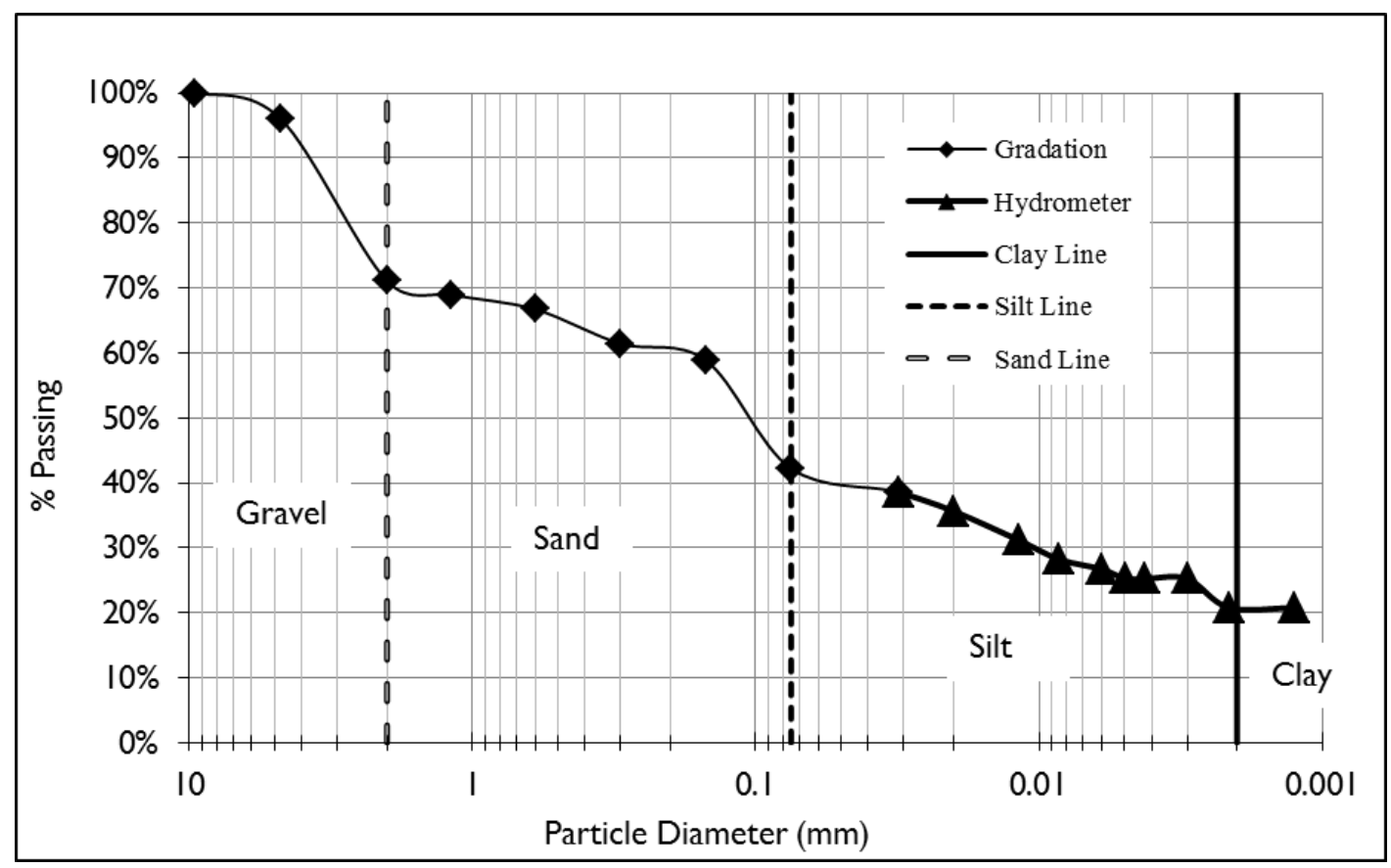

Figure 3.1.3-3 Mind Body Gradation

Table 3.1.3-2 Mind Body Grain Size

\begin{tabular}{|c|c|c|c|}
\hline Clay (\%) & Silt (\%) & Sand (\%) & Gravel (\%) \\
\hline 20.8 & 21.4 & 28.9 & 23.0 \\
\hline
\end{tabular}


The MB soil was collected by hand late into the batching process, so relatively little soil was stockpiled. For these reasons, MB soil was the least utilized for CEB production.

\subsection{Sand}

\subsubsection{C33 Concrete Sand}

Nearly all CEBs utilized some amount of sand in their design. This was harvested from the Civil Engineering stockpile of C33 sand for use in concrete. The sand was chosen for convenience and literature that suggested a coarser sand when creating CEBs (Dwell 2012, Rigassi 1985). Gradation for the sand passed according to ASTM C136 Standard Test Method for Sieve Analysis of Fine and Coarse Aggregate. The gradation is shown below:

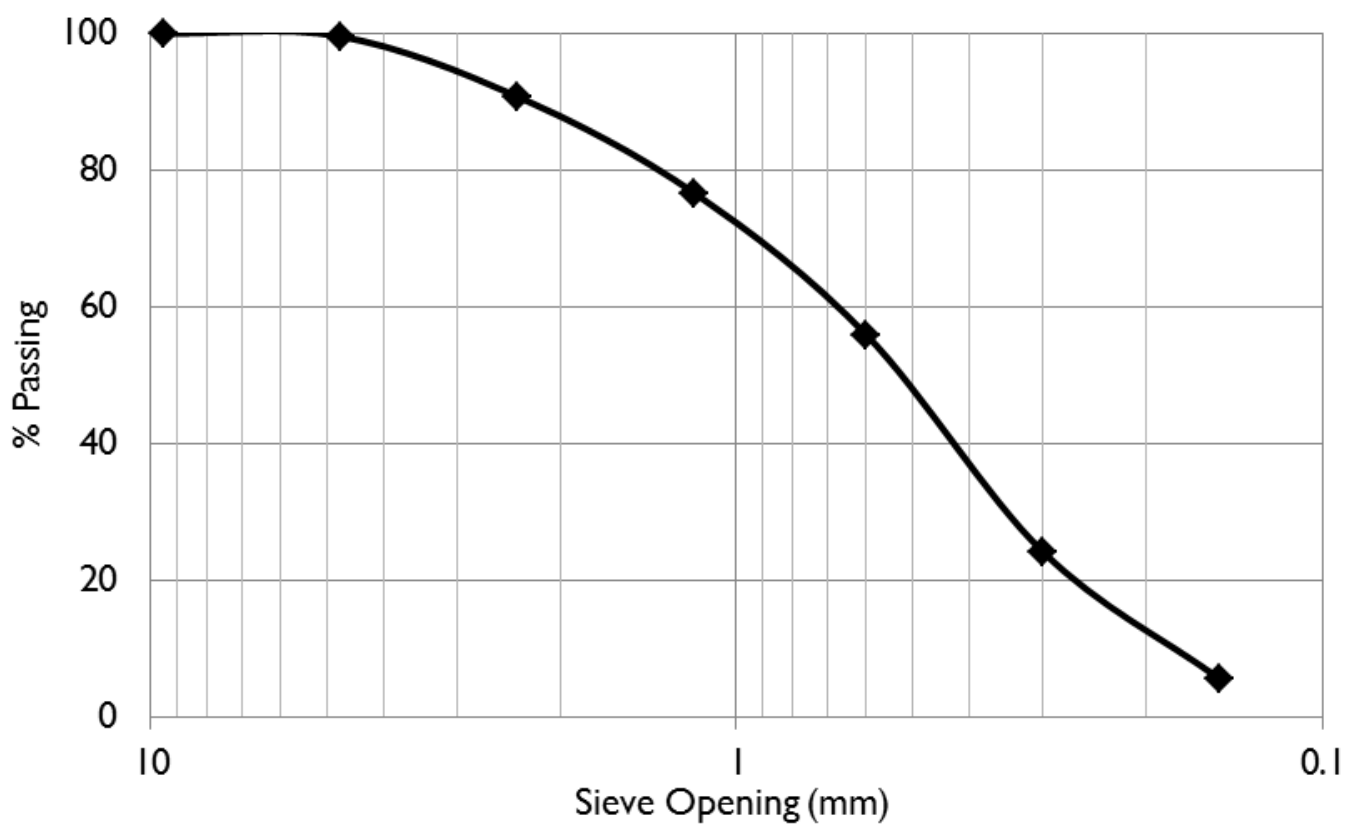

Figure 3.2.1-1 Sand Gradation 


\subsection{Fibers}

There were two types of fibers used in this paper: the Strux 90/40 and Forta Ferro fibers. Both fibers are common to the concrete industry where they are typically used for crack control and flatwork reinforcement.

\subsubsection{Strux}

The Strux 90/40 is a polypropylene fiber manufactured by W.R. Grace and Company. The fiber is $40 \mathrm{~mm}\left(1.57^{\prime \prime}\right)$ long and has an aspect ratio of 90 , meaning that the length is ninety times larger than the width.

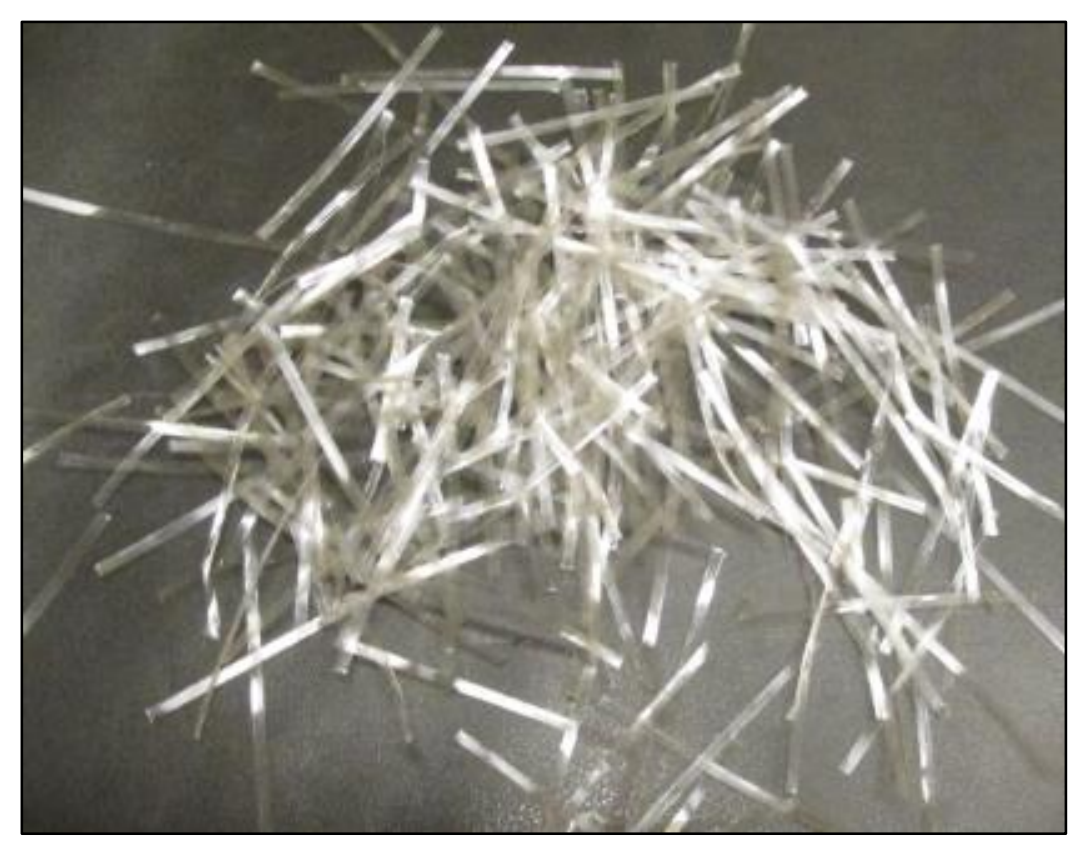

Figure 3.3.1-1 Strux Fibers

The Stux was chosen as the primary fiber because of its popularity in industry, ease of use, and toughness during mixing. The high tensile strength and modulus of 
elasticity were also sought with the intention of increasing the ultimate strength of the $\mathrm{CEB}$, since post cracking stress was not measured. Important properties are listed below:

Table 3.3.1-1 Strux Properties (Grace Construction 2007)

\begin{tabular}{|l|r|}
\hline Length (in) & $\mathrm{I} .57$ \\
\hline Specific Gravity & 0.92 \\
\hline Absorption (\%) & None \\
\hline Modulus of Elasticity (ksi) & 1378 \\
\hline Tensile Strength (ksi) & 90 \\
\hline
\end{tabular}

Grace recommends a fiber content in concrete between $.2 \%$ to $.5 \%$ by volume, which became the two fiber contents tested. Strux fibers come in $1 \mathrm{lb}$ or $5 \mathrm{lb}$ bags that are intended to be placed directly into the mixer. However, fibers were instead measured and added by hand during material mixing.

\subsubsection{Forta Ferro}

Forta Corporation manufactures a polypropylene fiber with similar applications to the Strux. However, they manufacture both a macro and micro fiber, then blend them together to create a product intended to increase toughness and impact resistance, as well as reduce cracking. 


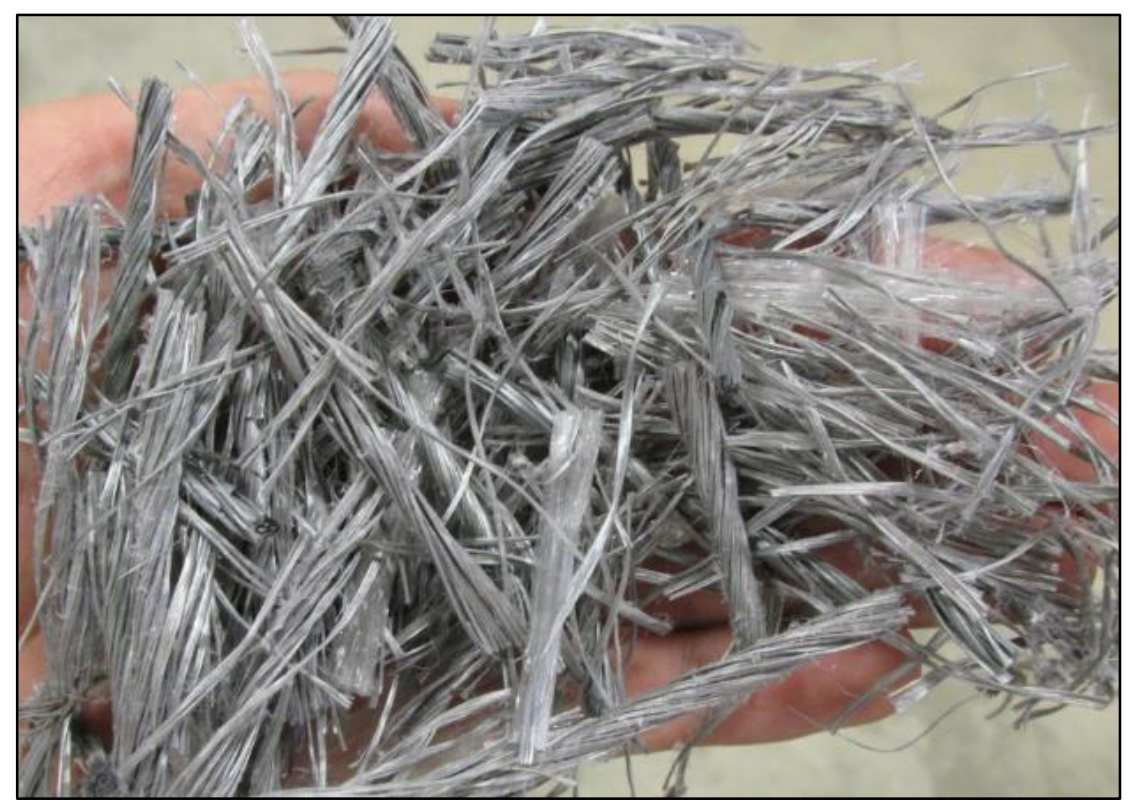

Figure 3.3.2-1 Bundled Macro Fibers

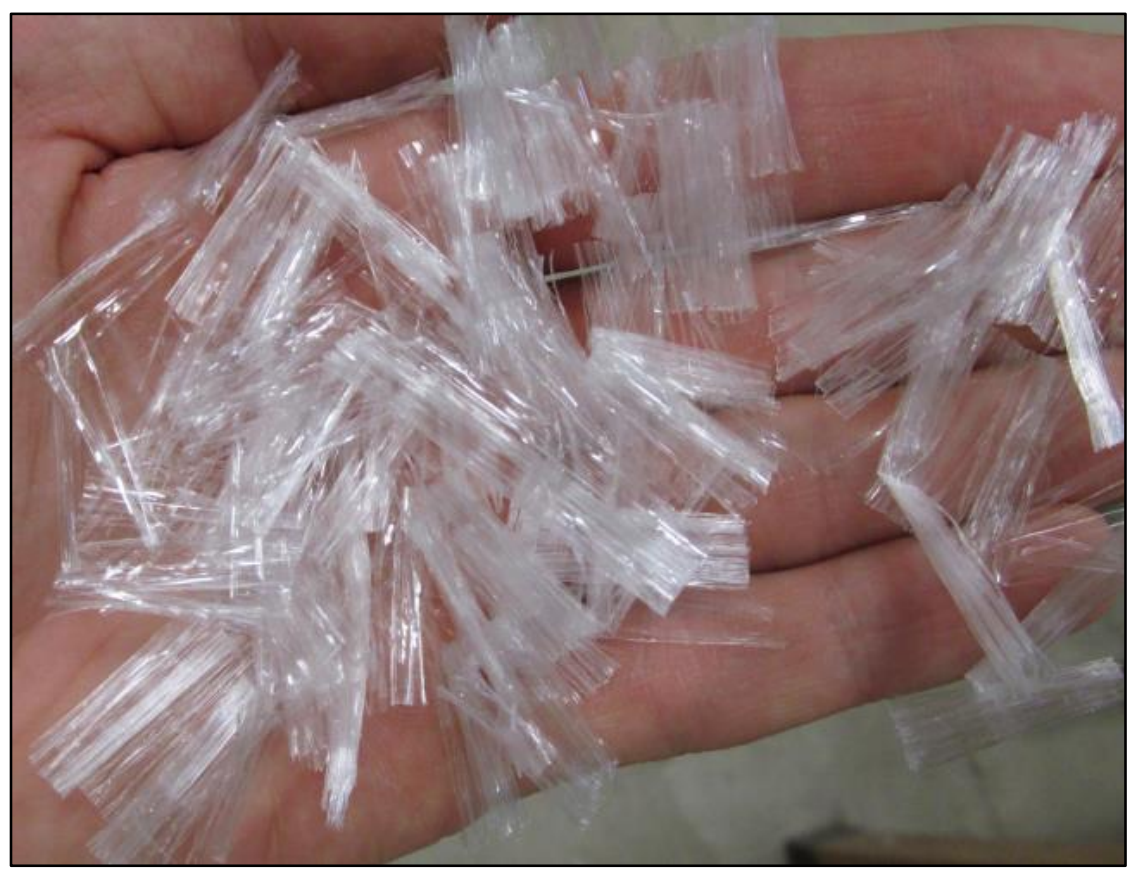

Figure 3.3.2-2 Mats of Micro Fibers 
The macro fibers are relatively long bundles of monofilaments that unwind during mixing, providing the increased toughness and impact strength. The micro fibers are shorter and formed into mats that break apart during mixing. Their purpose is to reduce shrinkage and temperature cracking. The two types of fibers work in tandem to create the Forta Ferro fiber product. Important properties are listed below:

Table 3.3.2-1 Forta Properties (Forta Corporation n.d.)

\begin{tabular}{|c|c|r|}
\hline \multirow{2}{*}{$\begin{array}{c}\text { Macro } \\
\text { fiber }\end{array}$} & Mass \% & 66 \\
\cline { 2 - 3 } $\begin{array}{c}\text { Micro } \\
\text { fiber }\end{array}$ & Length (in) & 2.13 \\
\cline { 2 - 3 } & Mass \% & 33 \\
\hline \multicolumn{2}{|c|}{ Length (in) } & 1.50 \\
\hline Combined Properties \\
\hline Specific Gravity & 0.91 \\
\hline Absorption (\%) & None \\
\hline Tensile Strength (ksi) & $83-96$ \\
\hline
\end{tabular}

The Forta Ferro fibers differ significantly from the Strux fiber in terms of fiber lengths and compositions as well as delivery and mixing requirements. However, the two fibers have similar applications and intended purposes, making them ideal for this experiment.

Like the Strux fiber, the Forta Ferro fiber comes in ready mix bags pre-blended. For the CEBs tested, the fibers were mixed and added by hand during the material mixing, although no attempt was made to unwind or otherwise disturb the fibers. Forta recommends a fiber content of $.2 \%$ to $2 \%$ by volume. Like the Strux fibers, a fiber content of $.2 \%$ and $.5 \%$ by volume was utilized. 


\subsection{Cement}

Type II/V Portland cement manufactured by CalPortland Company was used due to its local availability. The cement was kept in its moisture proof bag until use.

\subsection{Water}

Laboratory tap water was used for all aspects of block production and soil testing.

\subsection{Equipment}

In addition to the raw materials used to produce the CEBs, some basic equipment was utilized during the preparation and batching stages to ensure consistency and reduce labor requirements.

\subsubsection{Soeng Thai SP3 Soil Pulverizer}

Most of the soil utilized in this experiment was harvested using a front end loader, which allowed large chunks of soil to form and dry. Once these large chunks were broken down by hand, the soil was pulverized to ensure consistency and maximize its potential for compaction.

The pulverizer used was manufactured in Thailand by the Center for Vocational Building Technology (CVBT), the same group that manufactures the Soeng Thai manual Block Press. The Civil Engineering department was already familiar with its use and operation, so it was used for this project. 


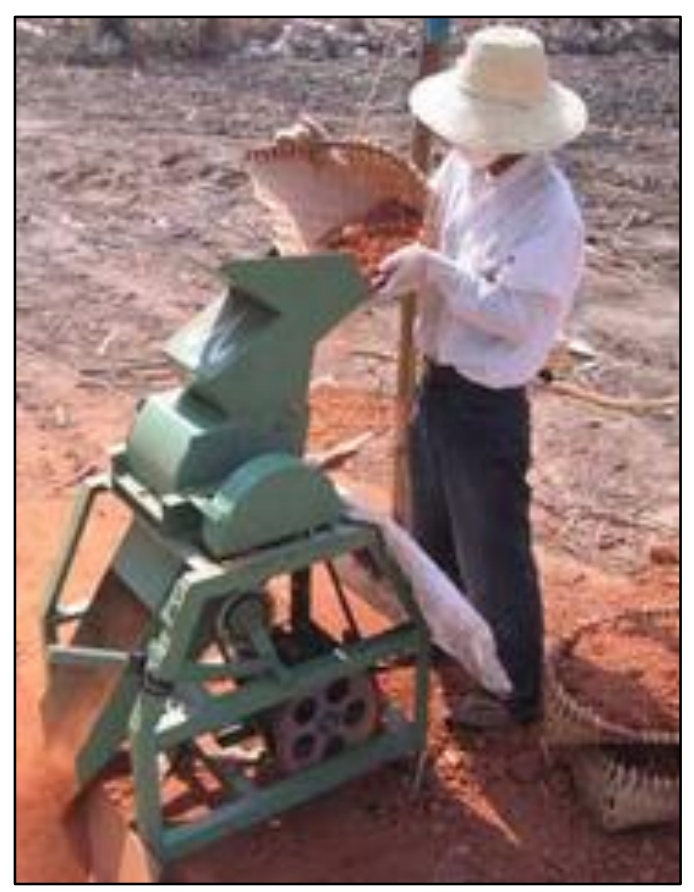

Figure 3.6.1-1 Soeng Thai SP3 Pulverizer (CVBT 2010)

The pulverizer uses a series of rotating steel blades to break up soft minerals and clay agglomerations. The soil must be friable for this to occur, and must be loaded slowly to prevent blinding the material screen. Once pulverized, the majority of the soil was able to pass through the \#4 sieve. 


\subsubsection{Concrete MD Mixer}

When the CEBs were ready to be manufactured, the soil, sand, cement, fibers and water were added to a Concrete MD $.5 \mathrm{~m}^{3}$ mixer.

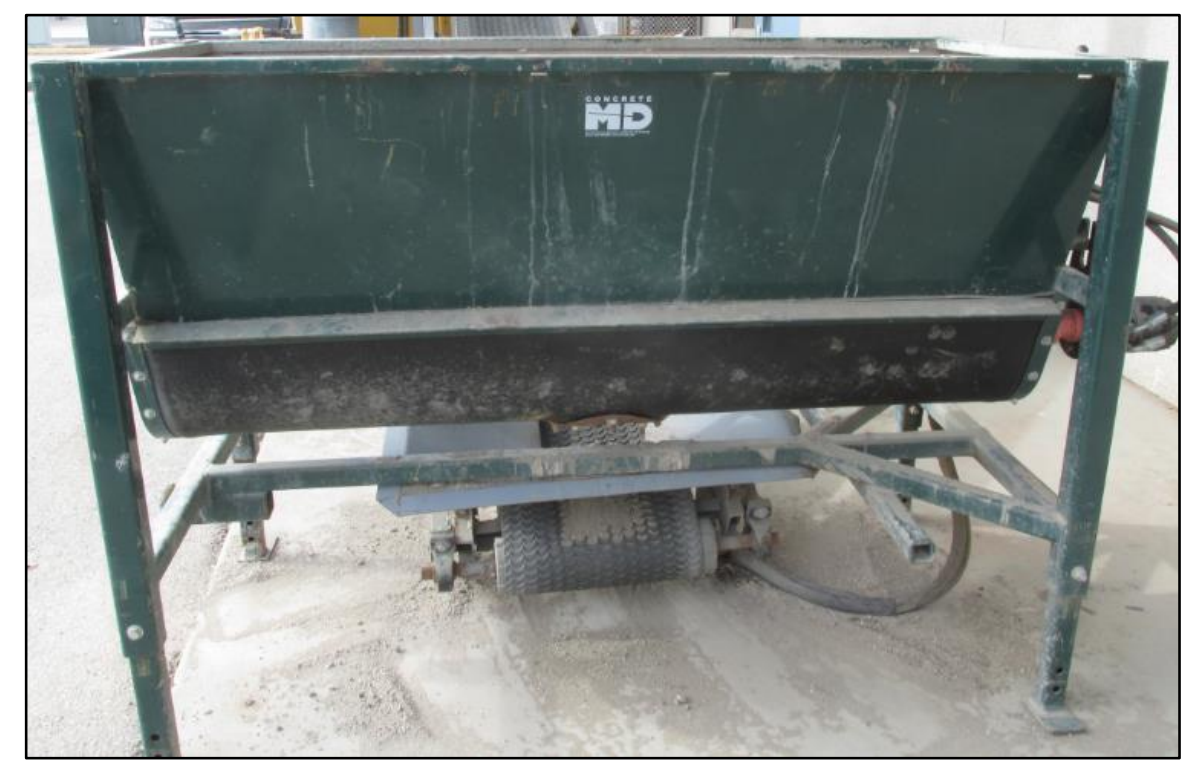

Figure 3.6.2-1 Concrete MD Mixer

The Concrete MD mixer is meant for use in third world environments where mixing concrete is difficult and labor intensive. Concrete MD is different from a rotational mixer commonly used for concrete, and utilizes a stationery mixing platform with a hydraulic auger. There are various types of augers for different applications, but the one utilized in this experiment possessed a "sheep's foot" configuration design to shear clayey soils and mix them with sand. This auger proved ideal not only for distributing water throughout the soil-sand-cement mixture, but also for incorporating fibers into the mixture without damaging them. As can be seen below, some fibers were crimped during mixing, which should be viewed as ideal (Hejazi el at. 2011). 


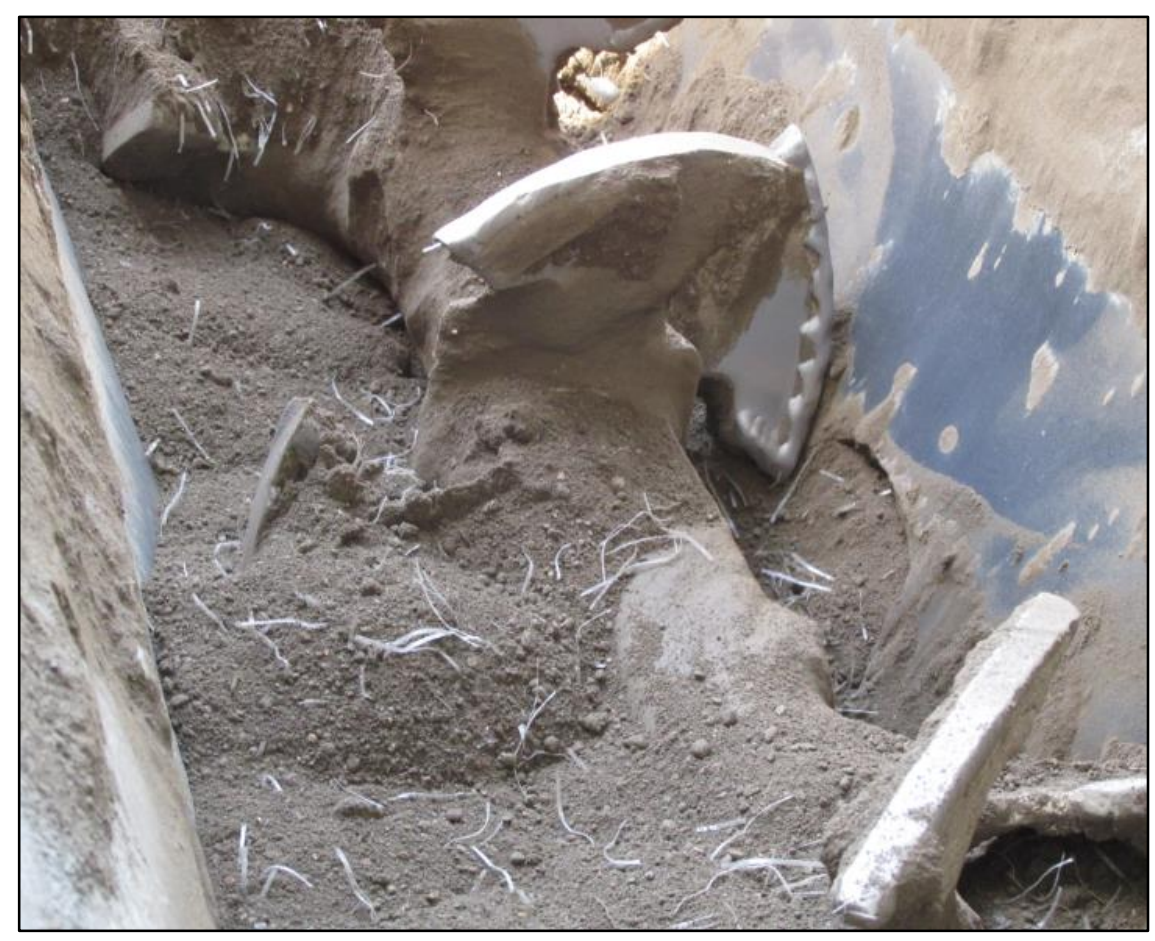

Figure 3.6.2-2 View Inside Mixer 


\section{CHAPTER 4: METHODS}

This chapter describes the process of designing the mixture proportions of each batch of CEBs, how they were created and how they were tested to achieve the results seen in this paper.

\subsection{Batch Design}

This paper sought to analyze the effects of clay content, cement content and the addition of fibers in CEBs. This required that a variety of batches with different mixture proportions be created. How the batches used in this experiment were chosen and designed is detailed below.

\subsubsection{Batch Schedule}

Once the material properties and quantities were collected, a schedule detailing the critical variables and CEB amounts of each batch could be created. The initial schedule is shown below.

Due to the limited research on synthetic fibers, it was decided that the majority of testing would focus on the strength and durability of fibers. The largest batches created 
would thus incorporate the two fiber contents discussed in the Materials section. Some of these blocks would also be tested when wet, whereas the majority of the CEBs would be tested air dry.

Table 4.1.1-1 Theoretical Batch Schedule

\begin{tabular}{|c|c|c|c|c|c|c|c|c|c|c|}
\hline \multicolumn{5}{|c|}{ Material } & \multicolumn{6}{|c|}{ Testing Method } \\
\hline \multirow[b]{2}{*}{ Soil Type } & \multirow{2}{*}{$\begin{array}{c}\text { Sand } \\
\text { Content } \\
(\%)\end{array}$} & \multirow{2}{*}{$\begin{array}{c}\text { Cement } \\
\text { Content } \\
(\%)\end{array}$} & \multirow[b]{2}{*}{$\begin{array}{l}\text { Fiber } \\
\text { Type }\end{array}$} & \multirow{2}{*}{$\begin{array}{c}\text { Fiber } \\
\text { Content } \\
(\%)\end{array}$} & \multicolumn{2}{|c|}{ Compression } & \multicolumn{2}{|c|}{ Modulus of Rupture } & \multirow[b]{2}{*}{ Abs/SG } & \multirow[b]{2}{*}{ Durability } \\
\hline & & & & & $\begin{array}{c}\text { Dry } \\
\text { Cured }\end{array}$ & $\begin{array}{c}\text { Wet } \\
\text { Cured }\end{array}$ & $\begin{array}{c}\text { Dry } \\
\text { Cured }\end{array}$ & $\begin{array}{l}\text { Wet } \\
\text { Cured }\end{array}$ & & \\
\hline Las Tablas & 0 & 8 & & & 3 & & & & 1 & 1 \\
\hline Las Tablas & 20 & 8 & & & 3 & & & & 1 & 1 \\
\hline Las Tablas & 40 & 8 & & & 3 & & & & 1 & \\
\hline Las Tablas & 55 & 8 & & & 3 & & & & 1 & \\
\hline Las Tablas & 70 & 8 & & & 3 & & & & 1 & 1 \\
\hline Las Tablas & 50 & 4 & & & 3 & & 3 & & 1 & 1 \\
\hline Las Tablas & 50 & 12 & & & 3 & & 3 & & 1 & 1 \\
\hline Las Tablas & 50 & 8 & & & 3 & 3 & 3 & 3 & 1 & 1 \\
\hline Las Tablas & 50 & 8 & Forta & 0.2 & 3 & 3 & 3 & 3 & 1 & \\
\hline Las Tablas & 50 & 8 & Forta & 0.5 & 3 & & 3 & & 1 & \\
\hline Las Tablas & 50 & 8 & Strux & 0.2 & 3 & 3 & 3 & 3 & 1 & \\
\hline Las Tablas & 50 & 8 & Strux & 0.5 & 3 & & 3 & & 1 & \\
\hline Prado & 0 & 8 & & & 3 & & & & 1 & 1 \\
\hline Prado & 50 & 8 & & & 3 & & & & 1 & \\
\hline Prado & 75 & 8 & & & 3 & & & & 1 & 1 \\
\hline Prado & 66 & 4 & & & 3 & & 3 & & 1 & 1 \\
\hline Prado & 66 & 12 & & & 3 & & 3 & & 1 & 1 \\
\hline Prado & 66 & 8 & & & 3 & 3 & 3 & 3 & 1 & 1 \\
\hline Prado & 60 & 8 & & & 3 & & 3 & & 1 & \\
\hline Prado & 60 & 8 & Strux & 0.2 & 3 & & 3 & & 1 & \\
\hline Prado & 60 & 8 & Strux & 0.5 & 3 & & 3 & & 1 & \\
\hline Mind/Body & 50 & 4 & & & 3 & & 3 & & 1 & \\
\hline Mind/Body & 50 & 12 & & & 3 & & 3 & & 1 & 1 \\
\hline Mind/Body & 50 & 8 & & & 3 & 3 & 3 & & 1 & 1 \\
\hline Mind/Body & 25 & 8 & & & 3 & & 3 & & 1 & \\
\hline Mind/Body & 0 & 8 & & & 3 & & & & 1 & \\
\hline Mind/Body & 50 & 8 & Strux & 0.2 & 3 & & 3 & & 1 & \\
\hline & & & Bloc & Totals & 81 & 15 & 54 & 12 & 27 & 13 \\
\hline
\end{tabular}

These "Fiber Content (FC)" batches were meant to highlight the gain in mechanical properties realized by using synthetic fibers. It was thought that the fibers would be strong enough to contribute to the peak MOR, and a correlation between fiber content and MOR could be seen. The blocks would also be tested wet to highlight the 
importance of the bond between the soil and fiber, and how that bond affects the peak MOR. The wet blocks would see less gain in MOR due to the weaker bond between the fiber and wet clay soil.

Further, two different fiber types would be utilized, with the hope of identifying a superior fiber reinforcement scheme and ideal fiber length. The majority of this testing would be done using the LT soil, although the Prado and MB soils would also utilize fiber content batches to further reinforce this trend.

Whenever fibers were added to the CEB batch, the standard cement content of $8 \%$ and standard sand content unique to each soil would be utilized. In this way, only the fiber content and type would affect the CEB properties.

Also of interest was the effect of clay content on the strength and durability of CEBs. In order to manipulate the clay content of each soil, a fraction of the soil was replaced with sand. Since each batch possessed a high initial clay content, it was decided that almost every batch would replace some amount of soil with sand.

Each soil type would undergo a series of "Sand Content (SC)" batches, where the soil to sand ratio would start at $0 \%$ sand and then increase to the standard sand content all non SC batches would be utilize. The sand content would then increase beyond that standard value to the point where pressing and handling CEBs would become difficult. The strategy was to highlight the ideal clay content of each soil by observing a low strength with low sand content, then a high strength with the standard sand content. Finally, as more and more of the soil was replaced with sand, the CEBs would again dip in strength. 
As stated above, when the blocks were being tested for variables other than clay content, a standard sand content was chosen for each soil based on preliminary testing to minimize cracking and maximize the strength of each batch tested. For the LT and MB soils, the default ratio of 50\% Soil: 50\% Sand was chosen. For the Prado soil, 33\% Soil: $66 \%$ Sand was chosen, due to clayey nature of the soil. Whenever fibers or a nonstandard cement content were utilized, this standard sand content would be used. If the sand contents were outside the standard values above, a standard cement content would be used, and there would be no fibers in the CEB.

Since LT was the primary soil utilized for this experiment, it would undergo the greatest change in sand content, from $0 \%$ SC to $70 \%$ SC. The Prado soil would undergo fewer changes in sand content since it was perceived to have the highest initial clay content, and utilizing sand contents of $<50 \%$ was thought to have little effect on the strength of the Prado CEBs. The MB soil was collected during block production, so there was no time for initial batching. The MB sand content batches contained only two different sand contents, which would be evaluated during production. The batch that was perceived to be strongest and easiest to handle would form the standard sand content for the remaining $\mathrm{MB}$ CEBs.

When testing the effects of clay content, only compressive strength was tested. Since fiber content and cement content blocks incorporated MOR testing, it was decided to correlate compressive strength to MOR instead of testing MOR for each of the different sand contents. 
There was also an interest in developing a relationship between strength and cement content. Most research utilized cement contents between $4 \%$ and $10 \%$, with $6 \%$ cement by weight a common choice. Due to the expansive nature of the soils used in this experiment, it was decided that a standard cement content of $8 \%$ be used. Preliminary testing with lower cement contents resulted in poor quality CEBs, so a relatively high cement content was chosen.

The relationship between strength and cement content is well documented (Morel 2007) as being linear in nature. However, most research utilized maximum cement contents of $10 \%$. It was a possibility that beyond $10 \%$, the benefit of adding additional cement would decrease. For that reason, the high cement content of $12 \%$ was chosen for additional testing.

A low cement content of $4 \%$ was also chosen. At lower cement contents, the strength of the CEBs was projected to decrease, as there would be less $\mathrm{CH}$ and $\mathrm{CSH}$ within the soil matrix to form a strong block. It was also thought that the difference in clay content and plasticity would become more apparent at a lower cement content.

For each soil, the three cement contents were tested with the hope of creating a linear relationship between block strengths and cement content. It was also hoped that the strength and durability of the CEBs would decrease as the clay contents increased, confirming prior research.

After all of the batches were cast, there were some extra and missing CEBs that slightly changed the batch schedule. The actual number of CEBs cast and how they were tested is listed below. 
As can be seen, in some instances there were fewer CEBs available than planned for, so the decision was made to focus on Absorption, Durability and MOR testing over compressive strength testing. Initial testing suggested that MOR testing experienced greater variability than compression testing, and too few Absorption or Durability samples would make it extremely difficult to identify any trends within the data.

In a few instances there were extra blocks cast, which were used primarily for Absorption testing. Some extra compression and MOR samples were also tested. 
Table 4.1.1-2 Actual Batch Schedule

\begin{tabular}{|c|c|c|c|c|c|c|c|c|c|c|}
\hline \multicolumn{5}{|c|}{ Material } & \multicolumn{6}{|c|}{ Testing Method } \\
\hline \multirow[b]{2}{*}{ Soil Type } & \multirow{2}{*}{$\begin{array}{c}\text { Sand } \\
\text { Content } \\
(\%)\end{array}$} & \multirow{2}{*}{$\begin{array}{c}\text { Cement } \\
\text { Content } \\
(\%)\end{array}$} & \multirow[b]{2}{*}{$\begin{array}{l}\text { Fiber } \\
\text { Type }\end{array}$} & \multirow{2}{*}{$\begin{array}{c}\text { Fiber } \\
\text { Content } \\
(\%)\end{array}$} & \multicolumn{2}{|c|}{ Compression } & \multicolumn{2}{|c|}{ Modulus of Rupture } & \multirow[b]{2}{*}{ Abs/SG } & \multirow[b]{2}{*}{ Durability } \\
\hline & & & & & $\begin{array}{c}\text { Dry } \\
\text { Cured }\end{array}$ & $\begin{array}{c}\text { Wet } \\
\text { Cured }\end{array}$ & $\begin{array}{c}\text { Dry } \\
\text { Cured }\end{array}$ & $\begin{array}{c}\text { Wet } \\
\text { Cured }\end{array}$ & & \\
\hline Las Tablas & 0 & 8 & & & 3 & & & & 2 & 1 \\
\hline Las Tablas & 20 & 8 & & & 3 & & & & 2 & 1 \\
\hline Las Tablas & 40 & 8 & & & 3 & & & & 1 & \\
\hline Las Tablas & 55 & 8 & & & 3 & & & & 1 & \\
\hline Las Tablas & 70 & 8 & & & 3 & & & & 1 & 1 \\
\hline Las Tablas & 50 & 4 & & & 3 & & 3 & & 1 & 1 \\
\hline Las Tablas & 50 & 12 & & & 4 & & 3 & & 2 & 1 \\
\hline Las Tablas & 50 & 8 & & & 3 & 3 & 4 & 3 & 2 & 1 \\
\hline Las Tablas & 50 & 8 & Forta & 0.2 & 3 & 3 & 3 & 3 & 2 & 1 \\
\hline Las Tablas & 50 & 8 & Forta & 0.5 & 4 & & 3 & & 2 & 1 \\
\hline Las Tablas & 50 & 8 & Strux & 0.2 & 2 & 3 & 3 & 3 & 1 & 1 \\
\hline Las Tablas & 50 & 8 & Strux & 0.5 & 3 & & 3 & & 2 & \\
\hline Prado & 0 & 8 & & & 2 & & & & 1 & 1 \\
\hline Prado & 50 & 8 & & & 2 & & & & 1 & \\
\hline Prado & 75 & 8 & & & 2 & & & & 1 & 1 \\
\hline Prado & 66 & 4 & & & 2 & & 3 & & 1 & 1 \\
\hline Prado & 66 & 12 & & & 2 & & 3 & & 1 & 1 \\
\hline Prado & 66 & 8 & & & 3 & 2 & 3 & 2 & 1 & 1 \\
\hline Prado & 60 & 8 & & & 2 & & 3 & & 1 & \\
\hline Prado & 60 & 8 & Strux & 0.2 & 2 & & 3 & & 1 & \\
\hline Prado & 60 & 8 & Strux & 0.5 & 2 & & 3 & & 1 & \\
\hline Mind/Body & 50 & 4 & & & 2 & & 2 & & & \\
\hline Mind/Body & 50 & 12 & & & 3 & & 3 & & 1 & 1 \\
\hline Mind/Body & 50 & 8 & & & 2 & 3 & 3 & & 1 & 1 \\
\hline Mind/Body & 25 & 8 & & & 2 & & 3 & & 1 & \\
\hline Mind/Body & 40 & 5.1 & & & 3 & & 3 & & 2 & \\
\hline Mind/Body & 40 & 5.1 & Strux & 0.2 & 3 & & & & 0 & \\
\hline & & & Bloc & Totals & 71 & 14 & 54 & 11 & 33 & 16 \\
\hline
\end{tabular}

The last MB batch created possesses a non-standard cement content and sand content. The original intent was to create a batch of CEBs with $0 \%$ SC, then a batch of CEBs with the Strux fibers. Unfortunately, all of the sand was added during the 0\% SC phase, resulting in non-standard cement contents and sand contents for this batch. 


\subsubsection{Batch ID}

As the CEBs were pressed, each one needed a unique and descriptive label.

Calling CEBs "Sand Content Block-1" was impractical and confusing, so a standard was developed and adhered to, which is seen below:

\section{Batch ID LT50-FS2-8A}

Description: Las Tablas soil: 50\% Sand, 8\% Cement, .2\% Strux Fiber

\begin{tabular}{|c|c|c|}
\hline LT50-FS2-8A & Soil Type & $\begin{array}{l}L T=\text { Las Tablas } \\
P=\text { Prado } \\
\text { MB = Mind Body }\end{array}$ \\
\hline LT50-FS2-8A & $\begin{array}{l}\text { Sand } \\
\text { Content }\end{array}$ & $\begin{array}{c}50 \% \text { Soil replaced } \\
\text { with sand }\end{array}$ \\
\hline LT50-FS2-8A & $\begin{array}{c}\text { Fiber } \\
\text { Content } \\
\text { (Optional) }\end{array}$ & $\begin{array}{l}F S=\text { Strux Fiber } \\
F F=\text { Forta Fiber } \\
2=.2 \% \text { Fiber Volume } \\
5=.5 \% \text { Fiber Volume }\end{array}$ \\
\hline LT50-FS2-8A & $\begin{array}{l}\text { Cement } \\
\text { Content }\end{array}$ & $\begin{array}{c}8 \% \text { Cement by } \\
\text { weight }\end{array}$ \\
\hline LT50-FS2-8A & Sample ID & \\
\hline
\end{tabular}

A complete list of each CEB pressed and tested can be found in Appendix B.

Throughout the paper, CEB batches will be referred to using their Batch ID.

\subsubsection{Mixture Design}

The batch schedule lists each batch size and mixture proportions, but provides no guidance on the amount of each material needed. For this reason, a mix design of each 
batch had to be created. This would ensure the theoretical proportions of the batch schedule could be met, and enough blocks would be created for later testing. The basic mix design procedure, complete with an example, is shown below.

\section{Table 4.1.3-1 Basic Mix Design Procedure}

\begin{tabular}{|l|c|}
\hline \multicolumn{1}{|c|}{ Design Step } & Comments \\
\hline I) Assume 25 lbs of soil per block* & This is a conservative assumption. Most blocks weigh 22 lbs \\
\hline 2) Substitute weight of soil from $(\mathrm{I})$ with sand depending on SC** & $\begin{array}{c}\text { Sand replaces soil, it does not increase the amount of mix } \\
S C=\frac{W t_{\text {Sand }}}{\left(W t_{\text {Sand }}+W t_{\text {Soil }}\right)} * 100 \%\end{array}$ \\
\hline 3) Determine the weight of cement & $\quad C C=\frac{W t_{\text {Cem }}}{\left(W t_{\text {cem }}+W t_{\text {Sand }}+W t_{\text {Soil }}\right)} * 100 \%$ \\
\hline
\end{tabular}

* During later Mix designs, an additional $50 \mathrm{lbs}$ of soil was added to step I. Some batch designs were not producing enough blocks, so a more conservative assumption was made

**All weights are assumed Oven Dry, which simplifies calculations and makes the design more conservative. Amount of water is not calculated, but determined by qualitative methods listed in Literature Review and measured during production 
Batch ID: $\quad$ LT50

Batch Description: Las Tablas Soil, 50\% Sand, 8\% Cement

\# Blocks to Press: 14

\section{Procedure}

I)

$$
\begin{aligned}
& \text { Soil } W t=(\# \text { Blocks }) *\left(25 \text { lbs } \frac{\text { soil }}{\text { block }}\right) \\
& \text { Soil Wt }=(14 \text { Blocks }) *\left(25 \text { lbs } \frac{\text { soil }}{\text { block }}\right)=350 \text { lbs soil } \\
& \text { Soil } W t=350 \text { lbs soil }+50 \text { lbs Extra }=400 \text { lbs soil }
\end{aligned}
$$

2)

$$
\begin{aligned}
& S C=\frac{W t_{\text {Sand }}}{\left(W t_{\text {Sand }}+W t_{\text {Soil }}\right)} * 100 \% \\
& 50 \%=\frac{W t_{\text {Sand }}}{400 \mathrm{lbs}} * 100 \% \\
& W t_{\text {Sand }}=200 \mathrm{lbs} \\
& W t_{\text {Soil }}=200 \mathrm{lbs}
\end{aligned}
$$

3)

$$
\begin{aligned}
& C C=\frac{W t_{\text {cem }}}{\left(W t_{\text {cem }}+W t_{\text {Sand }}+W t_{\text {Soil }}\right)} * 100 \% \\
& 8 \%=\frac{W t_{\text {Cem }}}{\left(W t_{\text {cem }}+400 \mathrm{lbs}\right)} * 100 \%
\end{aligned}
$$

Using an iterative method,

$$
W t_{\text {Cem }}=35 \mathrm{lbs}
$$

\section{Weights of Ingredients}

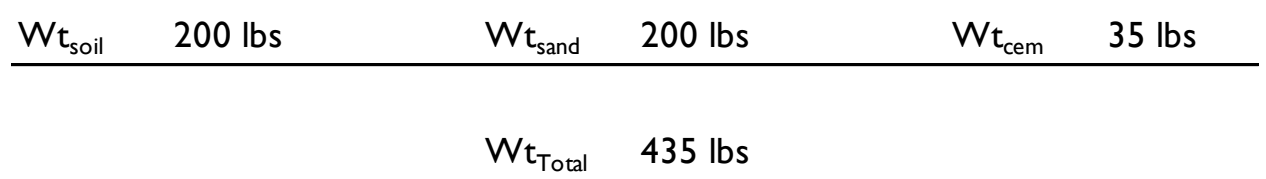


As can be seen above, the procedure for designing a batch of CEBs is relatively simple. However, this design method would force each batch of blocks to be created separately. For example, after pressing the LT0 batch, the block press and mixer would be cleaned out, then the ingredients for the LT20 batch would be added and the procedure repeated. A more efficient method would be to press all of the LT SC batches from a single reserve of soil, adding sand and cement between each batch to maintain the design sand content and cement content.

This method was used extensively to reduce the time spent cleaning and recalibrating between batches. The only issue this posed was creating a mix design that had enough extra mixture to account for wastage and loss between batches, while still being a reasonable size. Starting with an excessive amount of soil at the beginning of the mixing procedure would result in the use of a large amount of extra sand and cement, slowing down the entire process and producing extra CEBs that would have to be cured and tested.

As expected, this design method was more complicated than the previous method. The amount of mixture would have to be weighed as it left the mixer, and a moisture content would have to be assumed to better estimate the correct amount of mixture to remove and press. Whenever sand was added to the mixer, cement would also have to be added to maintain a consistent cement content. When additional cement or fibers were added to the mixer, no other materials like sand had to be added. Additional soil was never added, but after more material was added the consistency of the mixture would be reevaluated. This often resulted in additional water added to the mixture. The design procedure and an example are listed below: 


\section{Table 4.1.3-2 Multiple Batch Procedure}

\begin{tabular}{|l|r|}
\hline \multicolumn{1}{|c|}{ Design Step } & \multicolumn{1}{|c|}{ Comments } \\
\hline I) Assume 25 lbs of soil per block* & $\begin{array}{r}\text { Every block pressed must be considered. If the sand content } \\
\text { changes batch to batch, the fraction of soil in each block must } \\
\text { also be considered }\end{array}$ \\
\hline 2) Follow steps 2-3 from the basic procedure & Find SC and CC for this large initial batch \\
\hline $\begin{array}{l}\text { 3) Calculate the amount of blocks needed. Assume 25 lbs oven dry } \\
\text { mixture for each block** }\end{array}$ & $\begin{array}{r}\text { This is the amount of mixture that needs to be removed from } \\
\text { the mixer to press the first batch }\end{array}$ \\
\hline $\begin{array}{l}\text { 4) Assume a moisture content for the mixture of 10\% to I5\%. Calculate } \\
\text { the weight of mixture to be removed }\end{array}$ & $\begin{array}{r}\text { A wet weight is also required, or there will not be enough } \\
\text { mixture removed to create the desired number of blocks. }\end{array}$ \\
\hline $\begin{array}{l}\text { 5) Recalculate the weight of soil, sand, cement and fibers within the } \\
\text { batch by using the mixture proportion of the initial batch }\end{array}$ & $\begin{array}{l}\text { Using the initial total mixture weight and new mixture weight, } \\
\text { the remaining weight of each material can be recalculated. The } \\
\text { proportion of sand, cement and fibers have not changed, only } \\
\text { the amount of each within the batch }\end{array}$ \\
\hline $\begin{array}{l}\text { 6) Calculate how much additional sand, cement or fibers must be added } \\
\text { to achieve the new mixture proportions desired }\end{array}$ & $\begin{array}{l}\text { Use the equations from the basic procedure. The new SC, } \\
\text { CC and FC are in the batch schedule }\end{array}$ \\
\hline 7) Repeat steps I-6, & $\begin{array}{r}\text { This procedure can be repeated multiple times } \\
\hline\end{array}$
\end{tabular}

* During later Mix designs, an additional $50 \mathrm{lbs}$ of soil was added to step I. Some batch designs were not producing enough blocks, so a more conservative assumption was made

**This assumption is not always sufficiently conservative. Consider 26 or $27 \mathrm{lbs}$ of mix to be removed, or assume a higher MC 
Batch ID: LTO, LT20,LT40,LT55,LT70

Batch Description: Las Tablas Soil Sand Content Batches. 8\% CC, SC varies per batch \# Blocks to Press:

$\begin{array}{cl}\text { LTO } & 5 \\ \text { LT20 } & 5 \\ \text { LT40 } & 4 \\ \text { LT55 } & 4 \\ \text { L70 } & 5 \\ \text { Total } & 25\end{array}$

Procedure

I)

$$
\begin{aligned}
& \text { Soil Wt }=(\# \text { Blocks }) *\left(25 \text { lbs } \frac{\text { soil }}{\text { block }}\right) \\
& \text { Soil Wt }(\text { LT0 })=(5 \text { Blocks }) *\left(25 \text { lbs } \frac{\text { soil }}{\text { block }}\right)=125 \text { lbs soil } \\
& \text { Soil Wt }(\text { LT20 })=\left((5 \text { Blocks }) *\left(25 \text { lbs } \frac{\text { soil }}{\text { block }}\right)\right) * .80 \% \text { soil }=100 \text { lbs soil } \\
& \text { Soil Wt }(\text { LT } 40)=\left((4 \text { Blocks }) *\left(25 \text { lbs } \frac{\text { soil }}{\text { block }}\right)\right) * 60 \% \text { soil }=60 \text { lbs soil } \\
& \text { Soil Wt }(\text { LT55 })=\left((4 \text { Blocks }) *\left(25 \text { lbs } \frac{\text { soil }}{\text { block }}\right)\right) * 45 \% \text { soil }=45 \text { lbs soil } \\
& \text { Soil Wt }(\text { LT70 })=\left((5 \text { Blocks }) *\left(25 \text { lbs } \frac{\text { soil }}{\text { block }}\right)\right) * 30 \% \text { soil }=37.5 \text { lbs soil } \\
& \text { Soil Wt }=125 \text { lbs }+100 \text { lbs }+60 \text { lbs }+45 \text { lbs }+37.5 \text { lbs }=367.5 \text { lbs soil }
\end{aligned}
$$

2) Sand Content for LTO is $0 \%$, which is the initial batch

$$
\begin{aligned}
& S C=\frac{W t_{\text {Sand }}}{\left(W_{\text {tSand }}+W t_{\text {Soil }}\right)} * 100 \% \\
& 0 \%=\frac{W_{\text {tSand }}}{400 \mathrm{lbs}} * 100 \% \\
& W t_{\text {Sand }}=0 \mathrm{lbs} \\
& W t_{\text {Soil }}=360 \mathrm{lbs}
\end{aligned}
$$




$$
\begin{aligned}
& C C=\frac{W t_{\text {cem }}}{\left(W t_{\text {cem }}+W t_{\text {Sand }}+W t_{\text {Soil }}\right)} * 100 \% \\
& 8 \%=\frac{W t_{\text {cem }}}{\left(W t_{\text {cem }}+360 \mathrm{lbs}\right)} * 100 \%
\end{aligned}
$$

Using an iterative method,

$$
W t_{\text {Cem }}=31.6 \mathrm{lbs}
$$

Weights of Ingredients (Initial Batch)

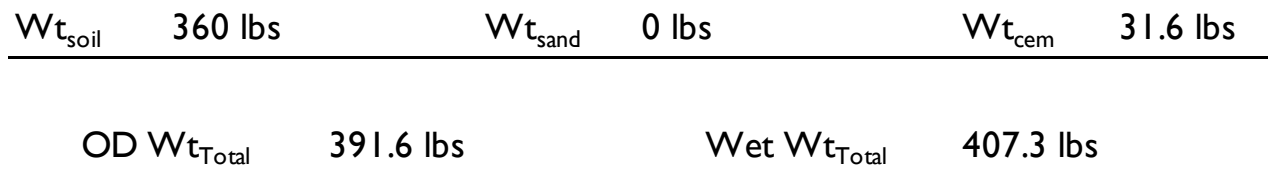

3)

$$
\begin{aligned}
& \text { Mix to Remove }=(\# \text { Blocks to Press }) *\left(25 \text { lbs } \frac{\text { mix }}{b l o c k}\right) \\
& \text { Mix to Remove }=(5 \text { Blocks }) *\left(25 \text { lbs } \frac{\text { mix }}{b l o c k}\right)=125 \text { lbs mix }
\end{aligned}
$$

4)

$$
\begin{aligned}
& \text { Wet Mix to Remove }=(\text { Mix to Remove }) *(M C) \\
& \text { Wet Mix to Remove }=(125 \text { lbs mix }) *(4 \%)=130 \text { lbs mix }
\end{aligned}
$$

This MC used above to calculated Wet Total Wt

5)

$$
\begin{aligned}
& \text { New Mix Wt }=\text { Wet Total Mix Wt }- \text { Wet Mix to Remove } \\
& \text { New Mix Wt }=391.6 \mathrm{lbs}-130 \mathrm{lbs}=261.6 \mathrm{lbs} \text { mix }
\end{aligned}
$$




\begin{tabular}{|c|c|c|c|c|}
\hline & $\begin{array}{l}\text { Initial } \\
\text { Batch }\end{array}$ & $\begin{array}{l}\text { Initial } \\
\text { Batch }\end{array}$ & $\begin{array}{c}\text { Remaining } \\
\text { Batch }\end{array}$ & $\begin{array}{l}\text { New } \\
\text { Batch }\end{array}$ \\
\hline & Fractions & Weights & Weights & Fraction \\
\hline Material & (\%) & (lbs) & (lbs) & (\%) \\
\hline Soil & 88 & 360 & 230.2 & 70.4 \\
\hline Sand & 0 & 0 & 0 & 18.8 \\
\hline Cement & 8 & 31.6 & 20.9 & 8 \\
\hline Water & 4 & 15.7 & 10.5 & 4 \\
\hline Total & 100 & 407.3 & 261.6 & 100 \\
\hline
\end{tabular}

6) Now that the LTO mix material has been removed, add additional sand and cement until the batch fractions for LT20 are met

$$
\begin{aligned}
& S C=\frac{W t_{\text {Sand }}}{\left(W t_{\text {Sand }}+W t_{\text {Soil }}\right)} * 100 \% \\
& 20 \%=\frac{W t_{\text {Sand }}}{\left(W t_{\text {Sand }}+230.2 \mathrm{lbs}\right)} * 100 \% \\
& W t_{\text {Sand }}=57.5 \mathrm{lbs}
\end{aligned}
$$

Because sand was added, cement must be added to maintain an $8 \% \mathrm{CC}$

$$
\begin{aligned}
& C C=\frac{W t_{\text {Cem added }}}{\left(W t_{\text {cemadded }}+W t_{\text {Sand added }}\right)} * 100 \% \\
& 8 \%=\frac{W t_{\text {Cemadded }}}{\left(W t_{\text {cem added }}+57.5 \mathrm{lbs}\right)} * 100 \% \\
& W t_{\text {cemadded }}=4.6 \mathrm{lbs}
\end{aligned}
$$

Weights of Ingredients

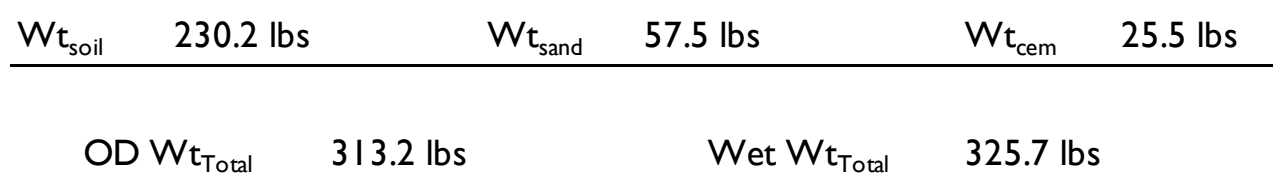

This procedure can be repeated for the LT40, LT55 and LT70 batches 
Using this procedure, the majority of the batches were created. This procedure was also used when fibers were added to the mixture.

The fiber content used in this experiment was a volumetric proportion recommended by the manufacturers. This made calculating the fiber content more difficult than the sand or cement content. The procedure is explained below with an example.

\section{Table 4.1.3-3 Fiber Content Design Procedure}

\begin{tabular}{|c|c|}
\hline Design Step & Comments \\
\hline I) Find the average net volume of a CEB & $\begin{array}{c}\text { This was completed before Absorption testing, so the } \\
\text { dimensions of multiple blocks were used to approximate this } \\
\text { value }\end{array}$ \\
\hline $\begin{array}{l}\text { 2) Acquire the average Wt of a CEB and the Specific Gravity of the } \\
\text { fibers used. Calculate the average CEB Unit Weight }\end{array}$ & $\begin{array}{l}\text { A conservative weight of } 25 \text { lbs was utilized. The Specific } \\
\text { Gravity for the primary fiber was } .92\end{array}$ \\
\hline $\begin{array}{l}\text { 3) Use the definition of volume percent to find the weight of fibers } \\
\text { required per block }\end{array}$ & $\%$ Volume $=\left(\frac{W t_{\text {fiber }}}{W t_{C E B}}\right) *\left(\frac{\text { Unit Weight }_{C E B}}{S G_{\text {Fibers }} * \text { Unit Weight }_{\text {Water }}}\right)$ \\
\hline
\end{tabular}


Batch ID: $\quad$ LT50-8-FS.02

Batch Description: Las Tablas Soil, 50\% Sand, 8\% Cement, .2\% Strux Fiber

\section{Procedure}

I)

$$
\text { Volume }_{\text {CEB Net }}=343 \frac{\text { in }^{3}}{\text { block }}=.198 \frac{f^{3}}{\text { block }}
$$

2)

$$
\begin{aligned}
& \text { Assumed CEB Wt } 25 \mathrm{lbs} \\
& \qquad \begin{array}{l}
\text { Unit Weight } \\
C E B
\end{array}=\frac{\text { Weight }_{C E B}}{\text { Volume }_{C E B ~ N e t}} \\
& \text { Unit Weight }_{C E B}=\frac{25 \mathrm{lbs}}{.198 \frac{f t^{3}}{\text { block }}}=126 \frac{\mathrm{lbs}}{f t^{3}}
\end{aligned}
$$

3)

$$
\begin{aligned}
& \% \text { Volume }=\left(\frac{W t_{\text {fiber }}}{W t_{\text {CEB }}}\right) *\left(\frac{\text { Unit Weight }_{\text {CEB }}}{S G_{\text {Fibers }} * \text { Unit Weight }_{\text {Water }}}\right) \\
& .2 \%=\left(\frac{W t_{\text {fiber }}}{25 \text { lbs }}\right) *\left(\frac{126 \frac{l b s}{f t^{3}}}{.92 * 62.4 \frac{l b s}{f t^{3}}}\right) \\
& W t_{\text {fiber }}=.0228 \frac{\text { lbs }}{\text { block }}
\end{aligned}
$$

This procedure is the same for all .2 fiber content batches. There was no major difference between the Strux and Forta fiber contents

\subsection{CEB Production}

After designing each CEB batch, they were mixed, pressed and cured. This process can vary considerably depending on the equipment and labor available, so it was imperative a process be created and adhered to as much as possible. 


\subsubsection{Mixing CEBs}

Once the soil was pulverized and proportions of each batch were known, the soil and sand were weighed and stored in bins. A significant portion of the soil and sand was oven dried, and the rest was dried until no moisture could be detected. The cement was also stored either in their original packaging, or within sealed buckets. The fibers were not vulnerable to moisture, so were stored in open pans.

On production day, a moisture content sample would be taken from both the soil and sand. Moisture content was calculated in the following manner throughout this experiment:

$$
M C=\frac{W t-W t_{O D}}{W t_{O D}}
$$

Where MC is the moisture content, Wt is the stock weight of the material and $\mathrm{Wt}_{\mathrm{OD}}$ is the oven dry weight of the material.

The sand and soil were then placed into the Concrete MD mixer and mixed with water for approximately five minutes. Since the soil and sand were near the oven dry state, they were mixed together and given time to absorb water and achieve a saturated surface dry state.

After the soils and sands appeared saturated, the cement was added along with additional water. A watering can allowed even distribution of moisture. If fibers were a part of the batch, they would be added at this time. Care was taken to avoid over-mixing and damaging the fibers, as the mixer utilized a sheep's foot auger meant to shear clay. 
When the mixer was stopped, the operator would use a shovel to manually agitate the mixture and reintroduce any pockets of dry soil or unhydrated cement. This occurred until the entire sample appeared homogeneous. The areas near the ends of the mixer and near the bottom of auger were of greatest concern, so they would be mixed by hand multiple times.

After another five minutes of mixing, the moisture content of the mixture would be assessed using the methods described in the Literature Review. A sample of the mixture would be taken and formed into a cigar. The cigar would be shaken and crushed to determine the moisture content. For the drop test, a sample of the mixture would be formed into a ball and dropped. If both tests passed visual inspection, the mixture was near its ideal moisture content.

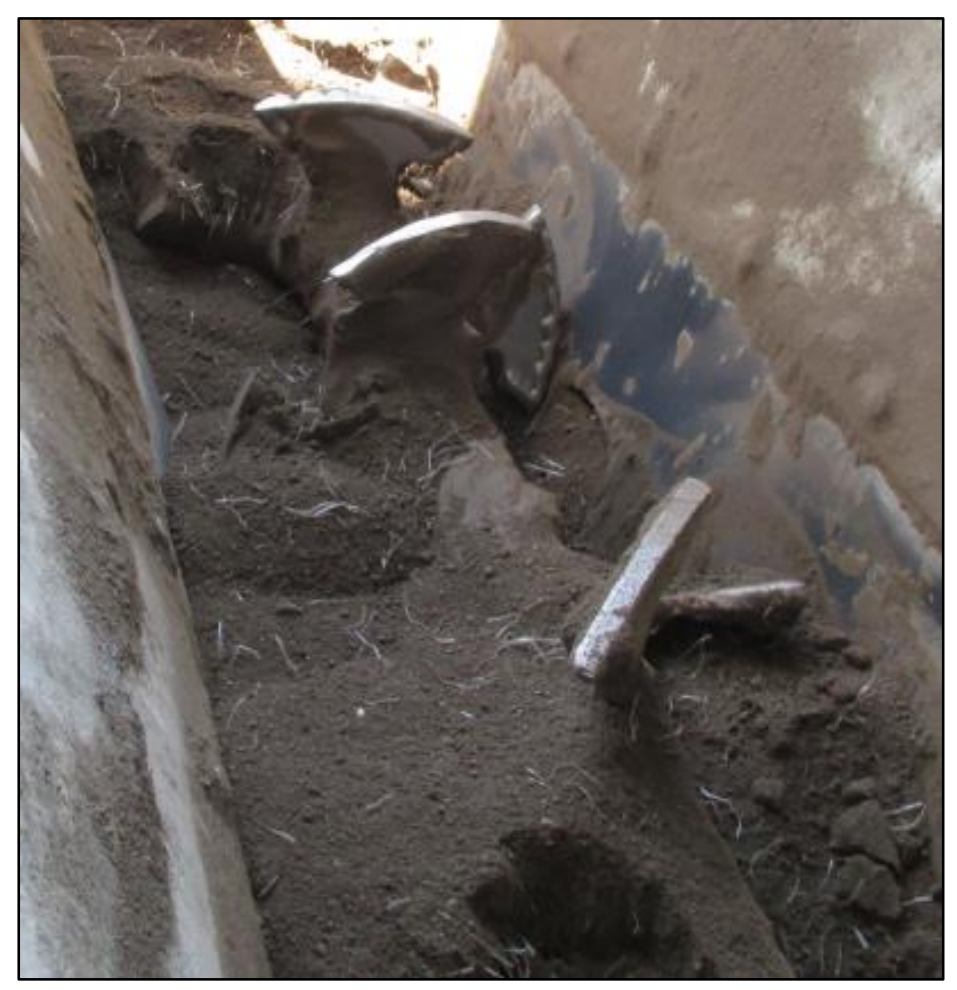

Figure 4.2.1-1 Properly Mixed Fibers and Soil 
At this point the mixer door was opened and a small amount of the mixture would be collected and reintroduced into the mixer. Near the mixer door there was often dry sand and soil that had not been properly mixed. This material was reintroduced and allowed to mix, often with a small amount of water, for one or two minutes.

Once the mixture was at the proper consistency, the mixer door was again opened and the mixture was allowed to exit the mixer. If multiple batches were being mixed at the same time, the mixture would be weighed to ensure the proper amount was removed. A moisture content sample was taken, and the mixture was placed on a conveyor belt that fed the block press. When the mixture was not being weighed, it was allowed to fall directly onto the conveyor belt.

If additional batches remained in the mixer, the mixer would be covered to prevent loss of moisture and allow the operators to focus on CEB pressing. The mixture was never allowed to linger in the mixer for more than an hour. When a new batch was ready to be pressed, the process would repeat.

\subsubsection{Pressing CEBs}

Once the soil entered the block press hopper, the mixture could be pressed and form the V - Lock CEBs. Pressing blocks with the Vermeer BP714 can be completed very quickly, with an ideal rate of 15 seconds/block.

For this experiment, the objective was not to mass produce CEBs, but create a variety of small batches. As explained in the Literature Review, the BP714 possesses a pressure gauge that measures the pressure exerted onto the bottom platens by the piston. It was decided to make every attempt to keep the piston pressure between 1100psi and 
2000psi, the ideal pressures stated in the Dwell Earth Manual. This became difficult due to the number of soils, sand and fiber contents utilized throughout this experiment.

In order to achieve this ideal pressure, the volumetric setting and block height setting were adjusted as often as needed. Whenever two blocks were pressed that had an unacceptable pressure, the volumetric setting would be adjusted. If the volumetric setting could no longer be adjusted, the block height setting was used. The block height setting adjusted the pressure exerted on the block as well as the height of the block, so this adjustment was only used when necessary.

If the CEB was pressed and it disintegrated upon handling, or possessed an excessively low pressure, it would be pulverized using a rubber mallet and placed back into the hopper to be pressed again. When this occurred, the mixture was often excessively dry, or the clay content was too low. Luckily, this was often an anomaly associated with a single block.

After the block was pressed, the reinforcement chambers were cleared and the surface brushed free of excess mixture. The block was then carefully moved to a pallet and the CEBs were closely stacked to minimize moisture loss. Any excess mixture left on the press was returned to the compression chamber, and the process would continue until there was no soil left in the hopper. The operator would record the piston pressure, volumetric setting, and the block height setting while another person cleaned and stacked the CEBs.

Occasionally the bottom platen would be cleaned and inspected. If soil was found to be sticking to the platen and damaging the bottom of the CEB, the platen was 
lubricated with WD - 40. If the piston pressure was deficient, then the press settings would be adjusted at this time as well.

During this time, the CEBs that were recently pressed would be closely stacked onto a pallet already covered with plastic sheeting. Each block was labeled and kept moist using a spray bottle. Between batches the pallet would be covered with the plastic sheeting to minimize moisture loss.

\subsubsection{Curing}

After the CEBs were pressed, they were cured for 28 days before testing commenced. All of the CEBs pressed were covered with plastic sheeting and placed onto a pallet to prevent moisture loss and allow easy transportation to the curing room and their testing location.

In order to maintain consistent hydration between the cement and water, the CEBs needed to be stored in a temperature controlled environment. The winter weather caused

the indoor ambient temperature to swing considerably, so a temperature controlled curing room was created indoors. The area was covered with plastic sheeting and a temperature probe was inserted. A space heater was triggered whenever the temperature within the curing room dropped below 75 degrees Fahrenheit. This simple system maintained a temperature of approximately $70^{\circ} \mathrm{F}$ throughout the curing process, and prevented temperature from having a major effect on the curing rate of the CEBs. 


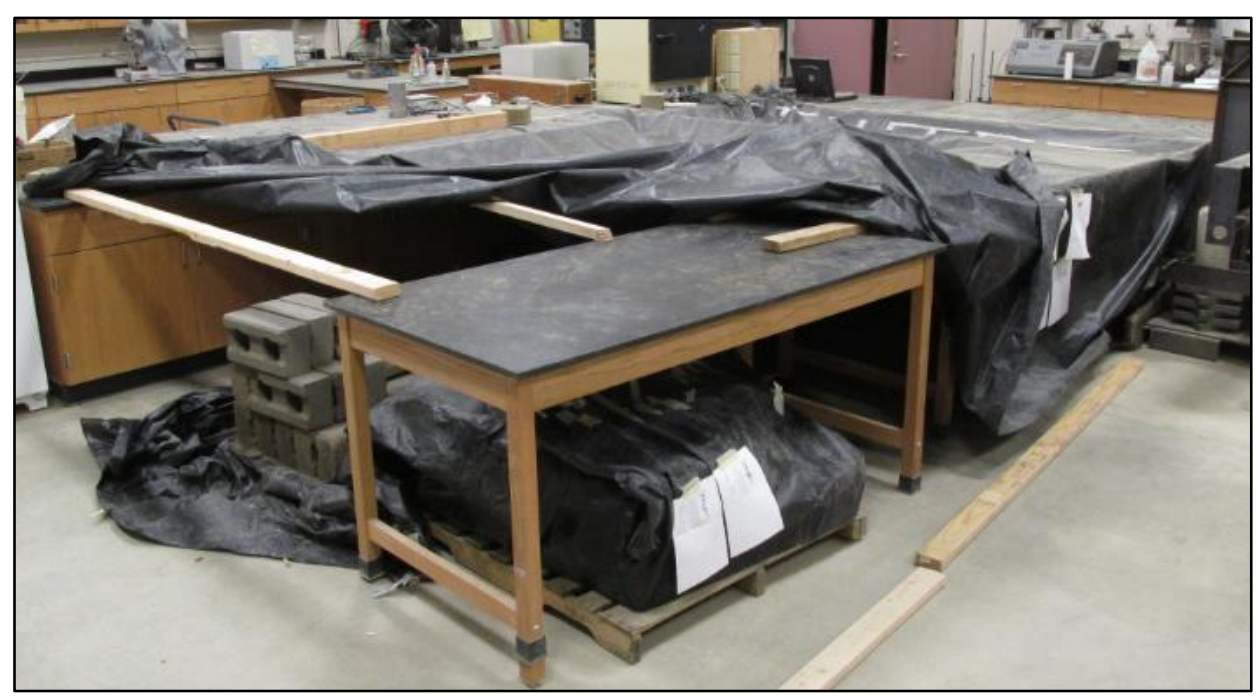

Figure 4.2.3-1 Curing Area

As seen in the photograph above, each CEB batch was wrapped in plastic and remained on their separate pallets throughout the curing process. Since the blocks were cast over a four week period, there were some batches that needed to maintain moisture and continue curing, while other batches were unwrapped to dry out. This prevented the need for multiple curing rooms and constantly disturbing the CEBs. 


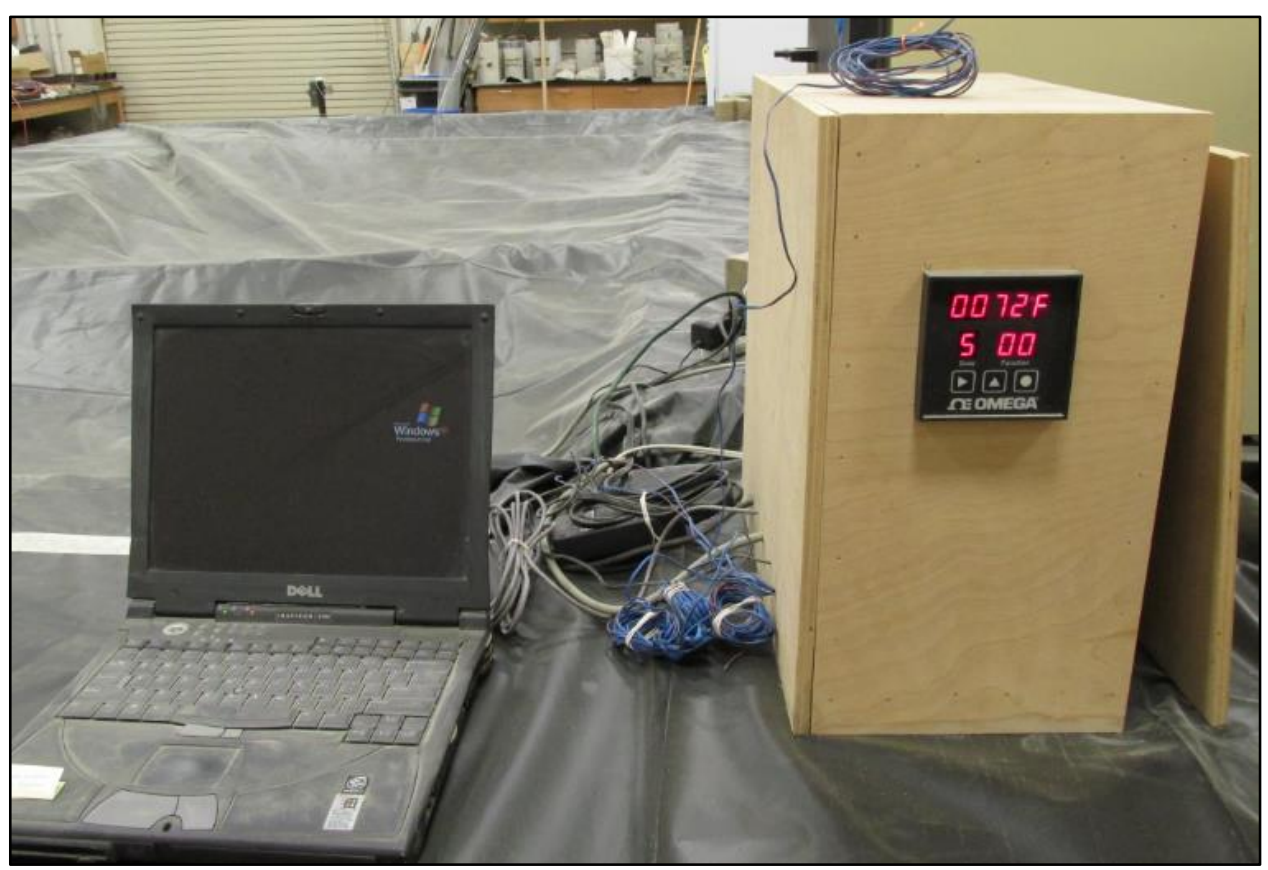

Figure 4.2.3-2 Curing Area Temperature Setup

Once the blocks were placed into the curing area, each batch was cured in the same manner for the first 21 days after the batch was pressed. The day each batch was pressed, as well as 1,3,5,10,17 and 21 days after their press day, the CEBs were uncovered and watered using a spray bottle. Every side accessible was sprayed, but the CEBs were not unstacked and sprayed separately. This would have been too labor intensive. The purpose behind the watering schedule was to introduce as much additional moisture as possible into the $\mathrm{CEB}$, assisting the cement in creating hydration products. The CEBs were sprayed until they no longer readily absorbed water, then the batch was re-wrapped in plastic sheeting until the next watering day.

The water schedule was meant to mimic the strength gain curve of cement, introducing the most water to the CEBs while the cement was most active in the 
hydration process. Once the batch reached 21 days of age, two different curing methods were employed.

The majority of CEBs cast were "Dry Cured". After the batch was watered at 21 days, the plastic sheeting was left unwrapped and the CEBs were allowed to air dry inside of the curing room for one week. At 28 days, the batch was removed from the curing area and tested.

Some CEBs were "Wet Cured". Before the batch was watered at 21 days, the CEBs selected for wet curing were separated from the remainder of the batch. These blocks were watered, along with the rest of the batch. After they were watered, the CEBs were again wrapped in plastic sheeting and not allowed to air dry. The wet cured CEBs were watered again at 25 days and finally at 28 days, about an hour before they were tested. In this way, the wet and dry strengths of the blocks could be analyzed.

Table 4.2.3-1 Moisture Content Comparisons

\begin{tabular}{|c|c|c|c|}
\hline Block ID & $\begin{array}{c}\text { Dry Cured } \\
\text { Moisture } \\
\text { Content } \\
(\%)\end{array}$ & $\begin{array}{c}\text { Wet Cured } \\
\text { Moisture } \\
\text { Content } \\
(\%)\end{array}$ & $\begin{array}{c}\text { Difference } \\
\text { in Moisture } \\
\text { Content } \\
(\%)\end{array}$ \\
\hline LT50-8 & 8.2 & 12.9 & 4.7 \\
\hline LT50-F2-8 & 7.3 & II.5 & 4.2 \\
\hline LT50-S2-8 & 8.9 & II & 2.1 \\
\hline P66-8 & 4 & 6.1 & 2.1 \\
\hline MB50-8 & 4.3 & 7.3 & 3 \\
\hline
\end{tabular}




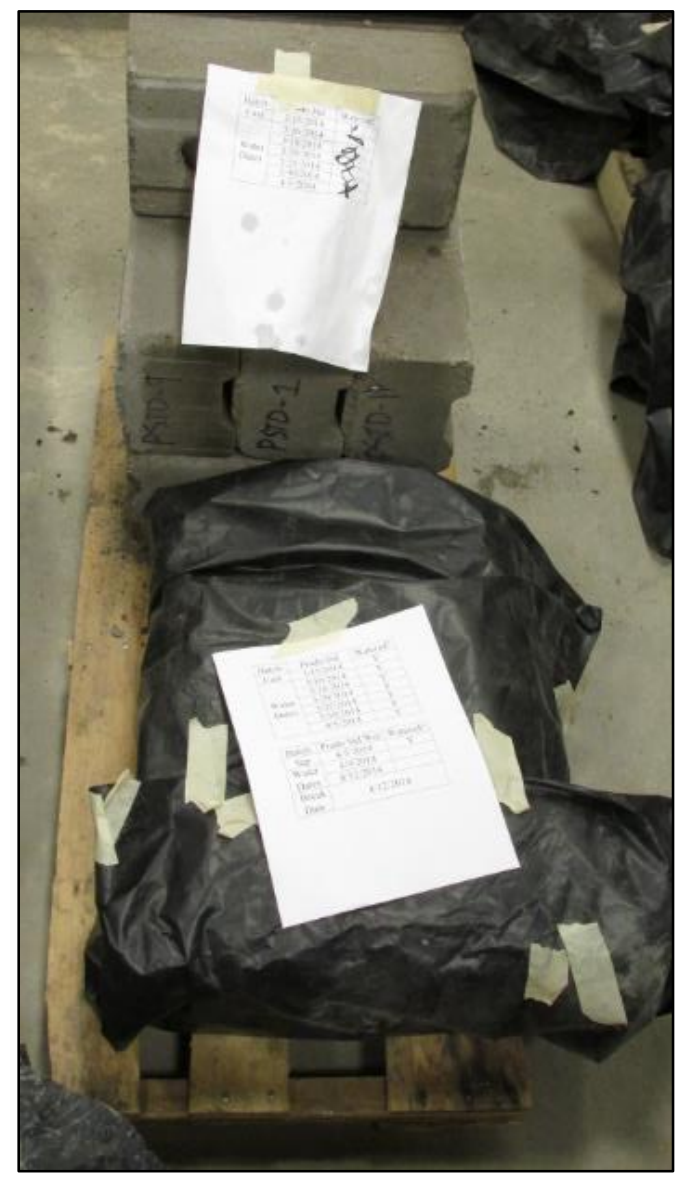

Figure 4.2.3-3 Wet and Dry Cured CEBs

As seen above, when comparing the moisture contents between the wet and dry cured batches, there is relatively little difference between the two curing methods. This suggests that either the dry cured CEBs needed more time to dry, or that the wet cured CEBs were not moistened enough when sprayed with water bottles. The table also suggests there are different absorptive capacities for different soils. Due to the highly absorptive sand and gravel, LT soil absorbed the most water, confirming the absorption tests run previously. 
Many of the dry cured CEBs remained closely stacked throughout the curing process, and when tested some of the interior blocks appeared to suffer from uneven drying. It is possible that truly air dry blocks need to be restacked and allowed sufficient time to dry, perhaps greater than a week. As seen in the results, there was not a significant difference in strength between these two curing methods.

\subsection{CEB Testing}

After the CEBs were cured for 28 days, they were removed from the curing area and tested for a variety of properties.

\subsubsection{Sample Preparation}

Once the CEBs were removed from the curing area, some basic properties were measured for each block.

Using calipers, the width of each CEB was measured in two places, as well as the height, as show below in the figure. The depth of the grout channel, interlocking ridge, and the diameter of the reinforcement chambers were ignored. These measurements would have been used strictly for the purpose of calculating net area, which was found more efficiently by using the absorption test described later. 


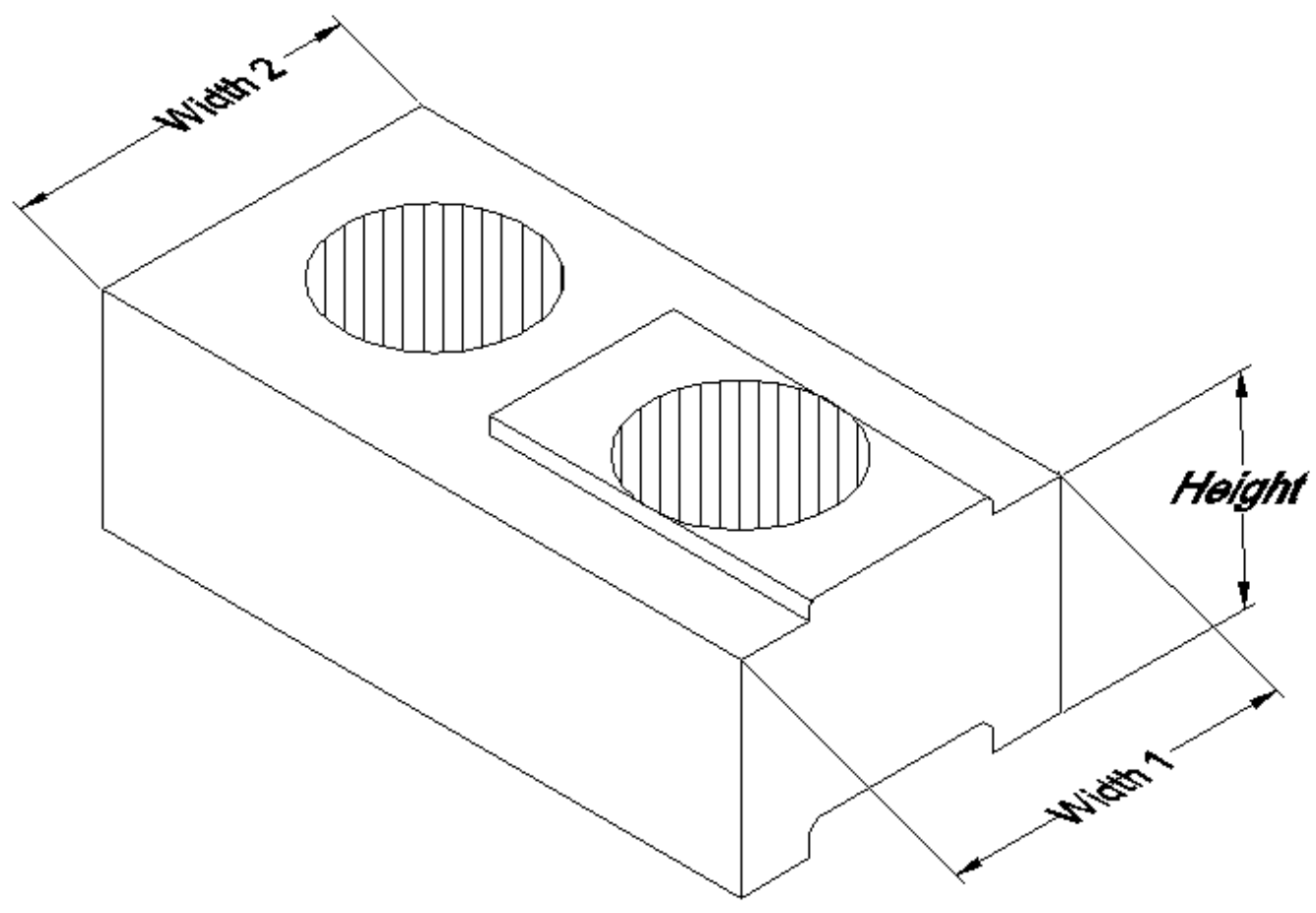

Figure 4.3.1-1 Measured CEB Dimensions

After measuring the dimensions, photographs were taken of each block to identify any reasons for poor performance, such as cracking or poor consolidation. This was also useful in identifying the most common defects the V - Lock CEBs suffered. An example of a CEB with poor consolidation is shown below.

Most of the CEBs cast suffered from negligible wearing about their corners and edges, which did not affect their strength. Some CEBs experienced more noticeable wearing about their corners. There were few blocks that experienced cracking or significant damage during the pressing process, an encouraging sign for future testing. 


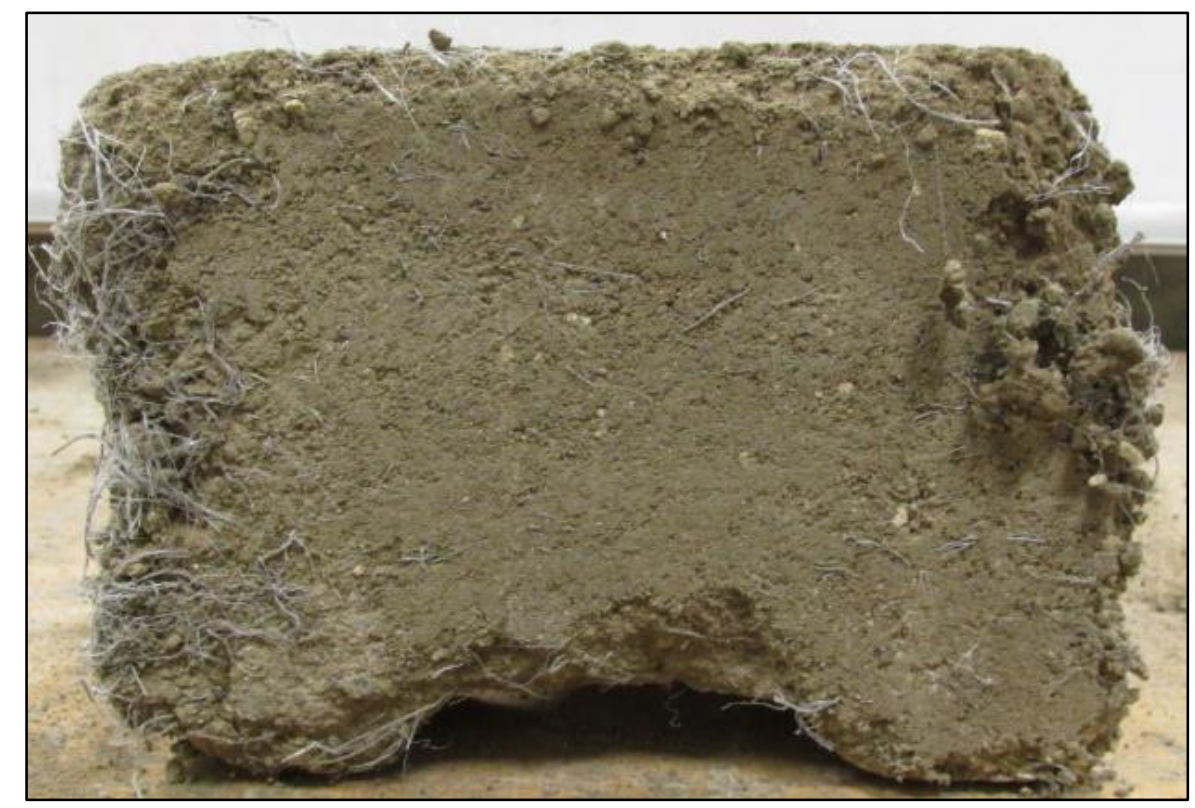

Figure 4.3.1-2 Poorly Consolidated CEB

From empirical data alone, it may not be clear why this CEB fared so poorly during testing, but a photograph reveals multiple defects present. This specimen suffers from poor consolidation, chipping along the edges and corners, as well as poorly distributed fibers.

After photographs, each CEB was weighed to help highlight the difference an adjustment in block height could make. This was also useful when designing later batches of CEBs. If the block weights were consistently near or above $25 \mathrm{lbs}$, a more conservative assumption of initial soil would have to be made.

After these properties were measured, the CEBs were then divided by test method and handled accordingly. 


\subsubsection{Compressive Strength}

The most common test performed in this experiment was the compressive strength of individual CEBs. This method is widely used for its simplicity and accuracy, and was modeled after ASTM C140 - Sampling and Testing Concrete Masonry Units and Related Units.

Each CEB was tested on a universal testing machine programmed to load the $\mathrm{CEBs}$ at a rate of $5 \mathrm{psi} / \mathrm{sec}$. Testing plates provided by Dwell Earth were used to properly confine the specimen. A large loading plate was also attached to the top platen in order to evenly distribute the stress throughout the CEB. An example test set up and a sample exhibiting a conical failure mode is shown below.

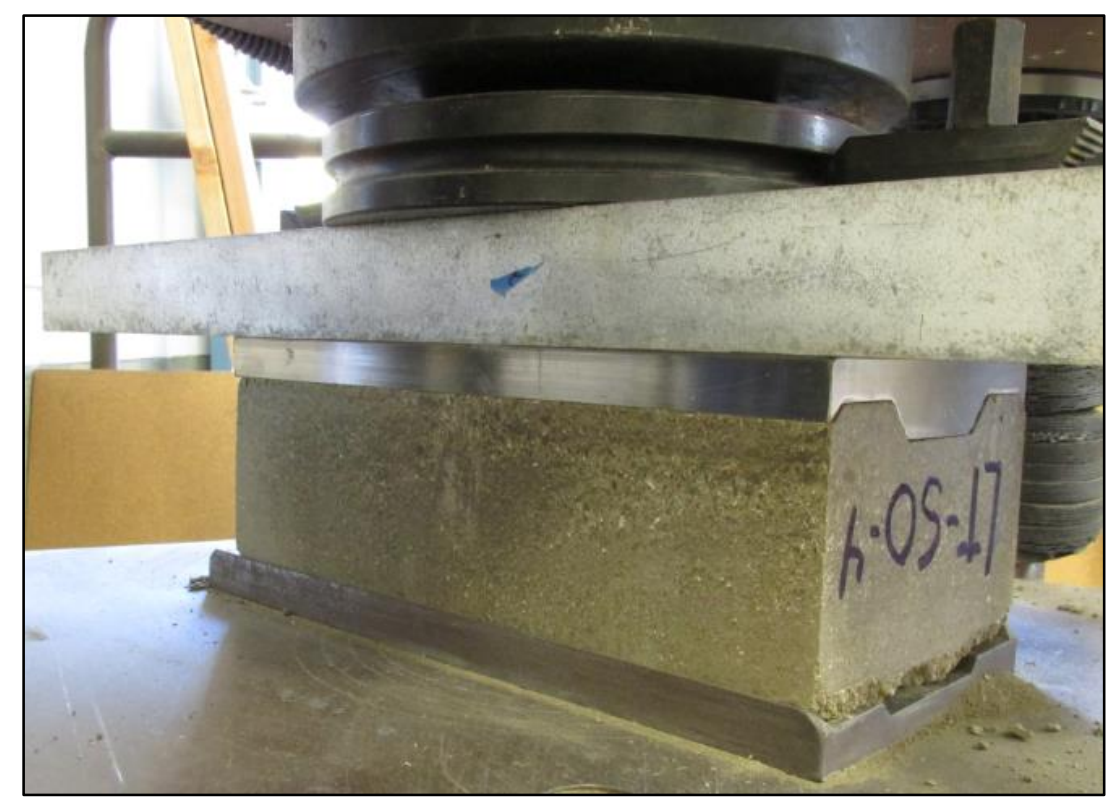

Figure 4.3.2-1 Compression Test Set Up 


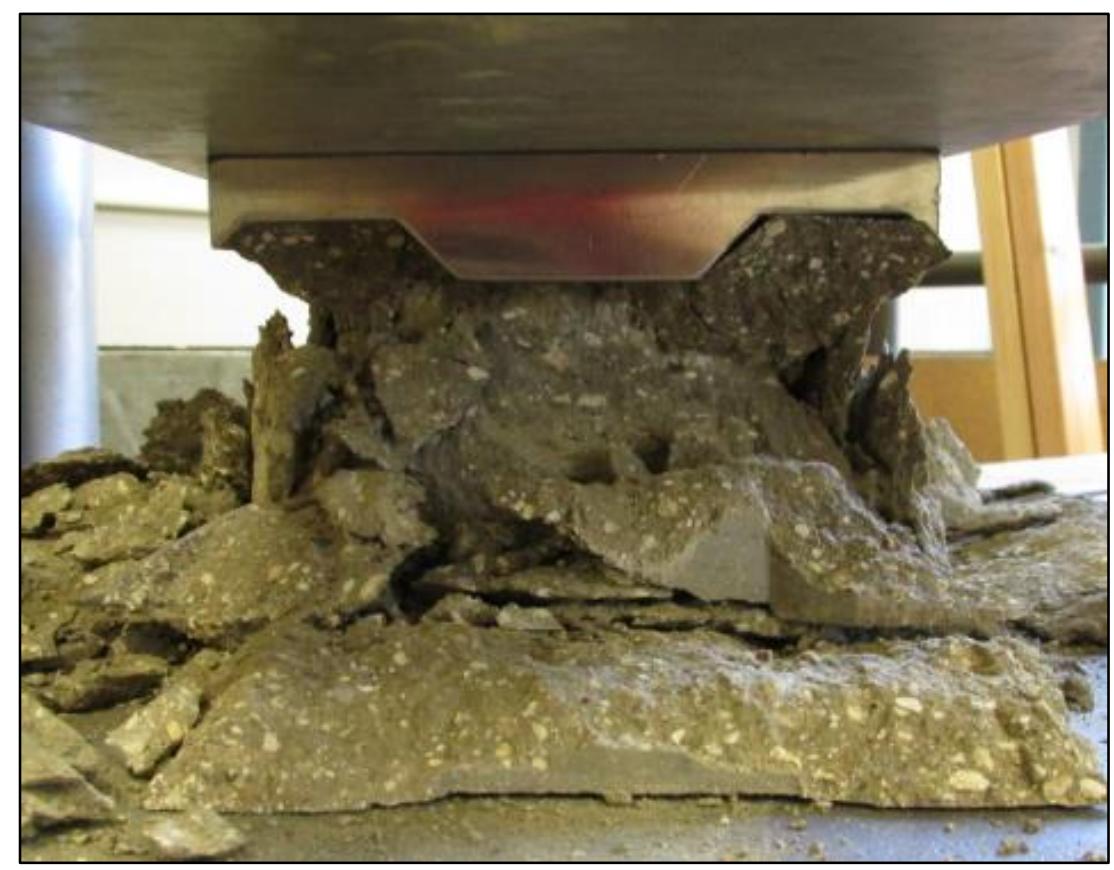

Figure 4.3.2-2 Succesfully Tested Specimen

Both wet and dry cured specimens failed in a conical manner, which is consistent with research (Morel 2007). Fiber reinforced specimens failed in a similar manner, although the addition of fibers prevented the CEB from separating in a brittle fashion. 


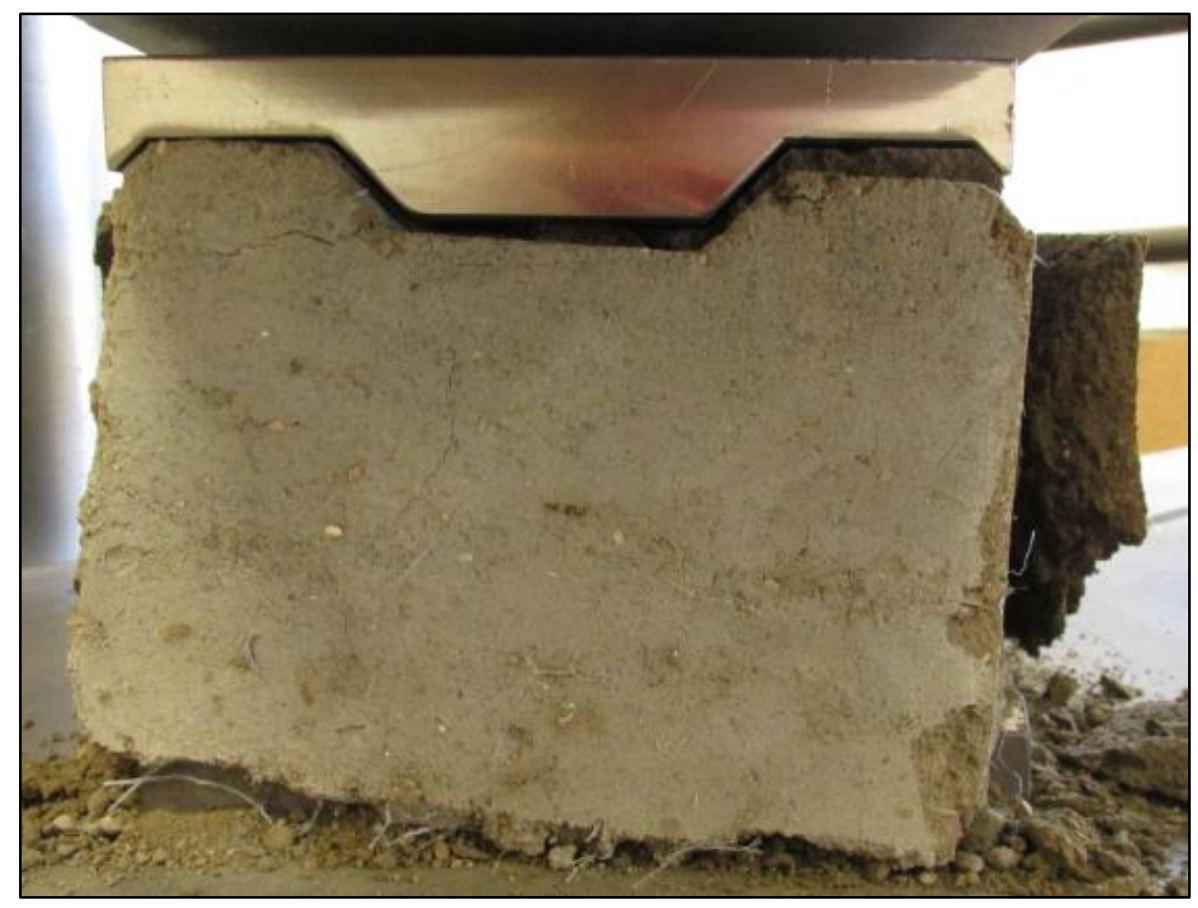

Figure 4.3.2-3 Fiber-Reinforced Specimen

For each batch of blocks, a moisture content test was performed on both wet and dry cured blocks. These samples were collected after a successful compression test, weighed, then oven dried overnight and weighed again. One moisture content test was performed per batch.

\subsubsection{Modulus of Rupture Testing}

Other samples were tested in MOR using a three point bending method modeled after ASTM C293 - Standard Test Method for Flexural Strength of Concrete (Using Simple Beam with Center-Point Loading). The specimen was simply supported at a span length of ten inches using rollers.

The test utilized a universal testing machine that loaded the CEB at a rate of 300 $\mathrm{lbs} / \mathrm{min}$ until failure. This was a strength rate test, and the deflection of the CEB over 
time was not measured, nor was the post cracking strength. The ideal method of failure is a single large crack propagating from the center third of the block. This holds true for fiber reinforced CEBs as well. Both wet and dry cured CEBs failed in the same manner.

One of the issues unique to the $\mathrm{V}$ - Lock CEBs is the length of the interlocking ridge present on the top of each block. In order to complete a single loading point test, a portion of the interlocking ridge was removed from each block. This was accomplished with a piece of threaded rod and was performed on all CEBs tested.

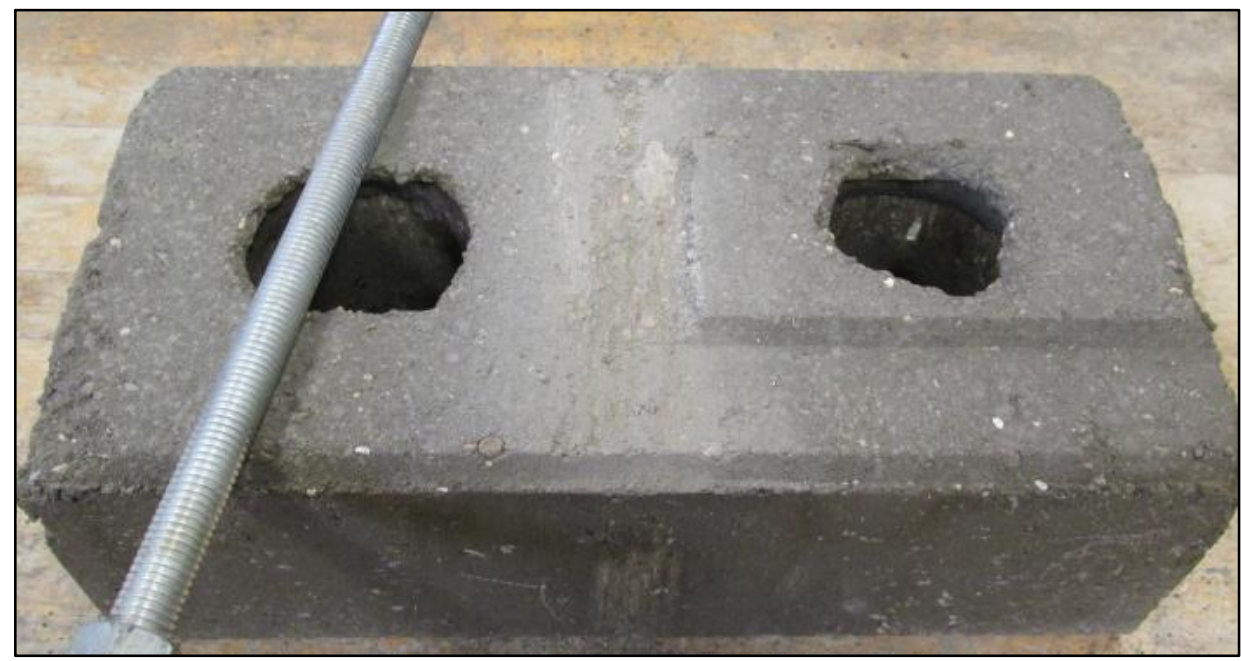

Figure 4.3.3-1 MOR Sample Preparation 


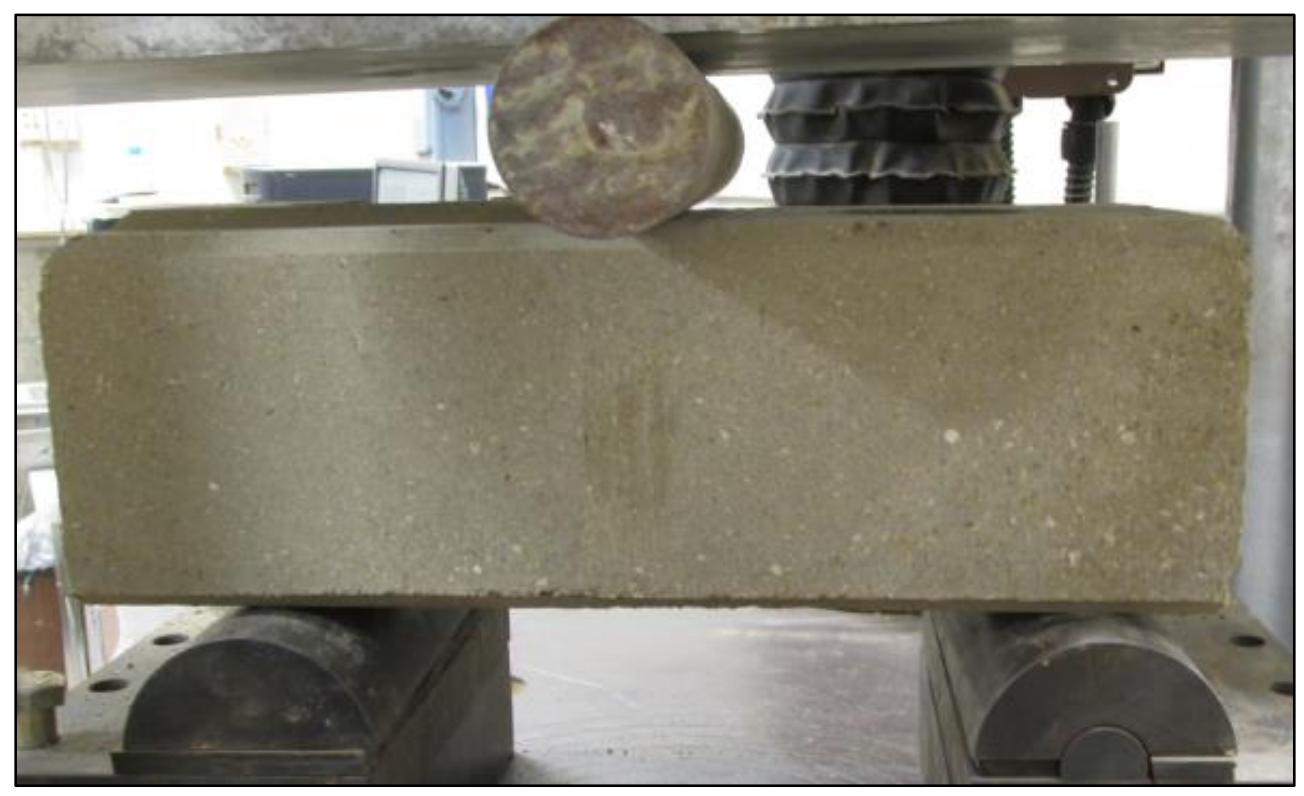

Figure 4.3.3-2 MOR Test Set Up

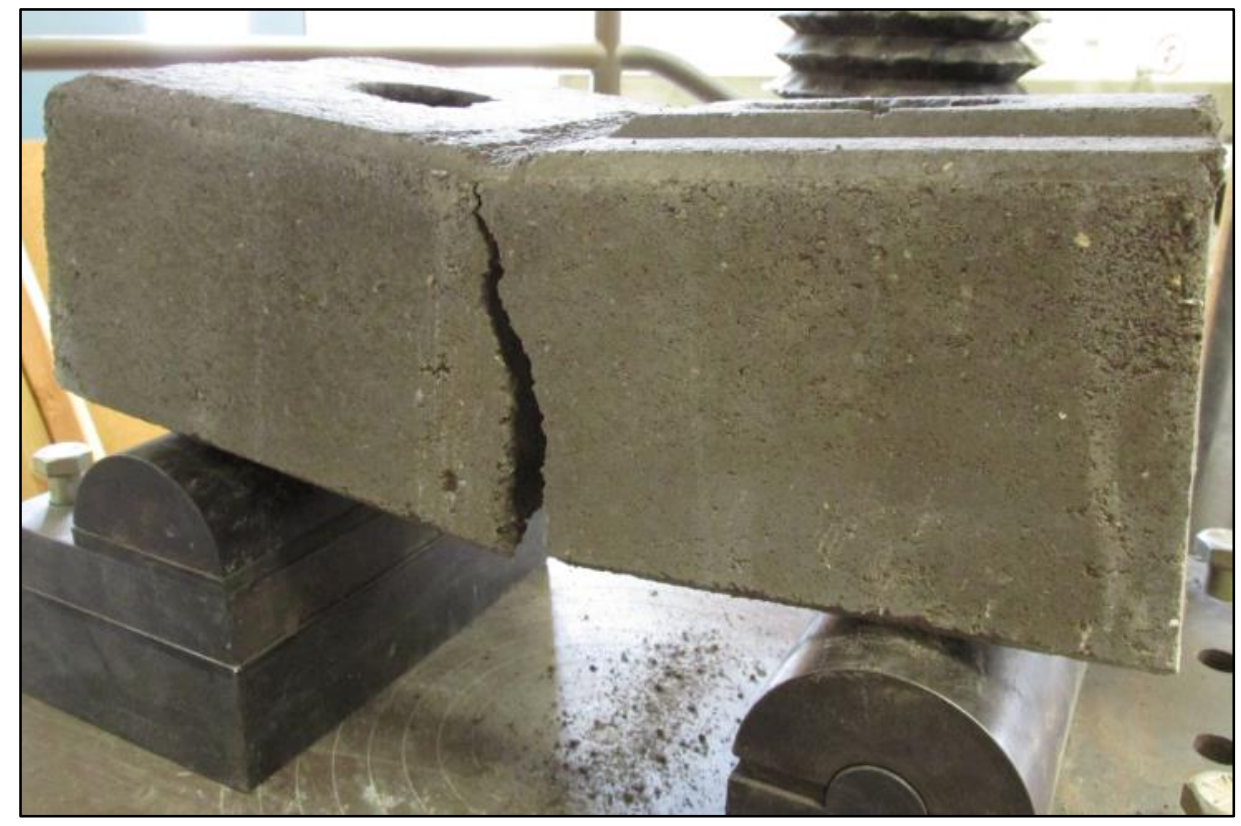

Figure 4.3.3-3 Succesfully Tested MOR Specimen 


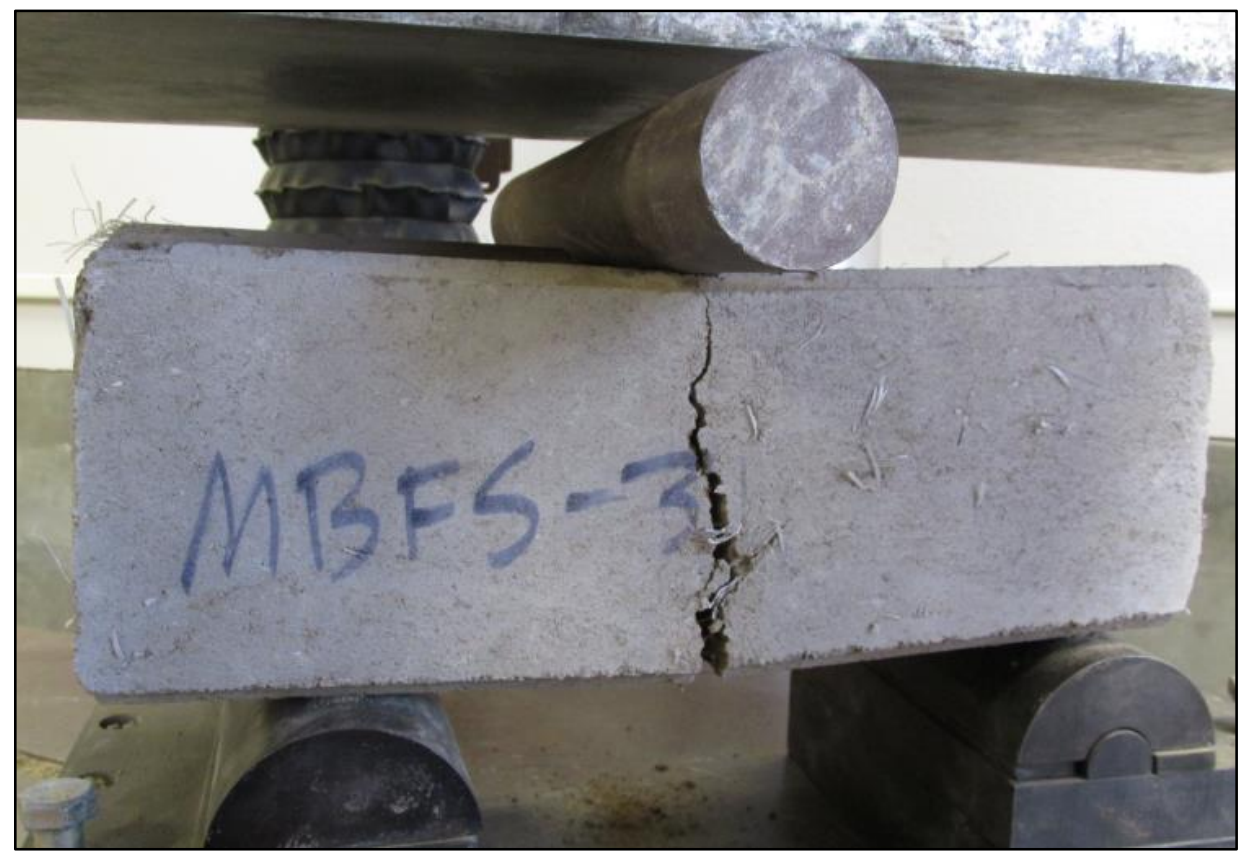

Figure 4.3.3-4 Fiber Reinforced MOR Specimen

\subsubsection{Absorption and Specific Gravity Testing}

In order to calculate the net compressive strength and MOR, the net area of each batch was required. Additionally, measuring the absorption and density of different batches of CEBs was known to be an indicator of block strength and durability (Muntohar 2011).

It was also thought that the addition of fibers to CEBs would decrease their density (Taallah et al. 2014), which may impact their durability and strength. For these reasons, absorption and density tests were performed following ASTM C140 - Sampling and Testing Concrete Masonry Units and Related Units (ASTM 2013). Each CEB tested was submerged into a temperature controlled bath for eighteen hours. An immersion 
heater and thermometer maintained a temperature above $65^{\circ} \mathrm{F}$, while a pump was utilized to circulate water.

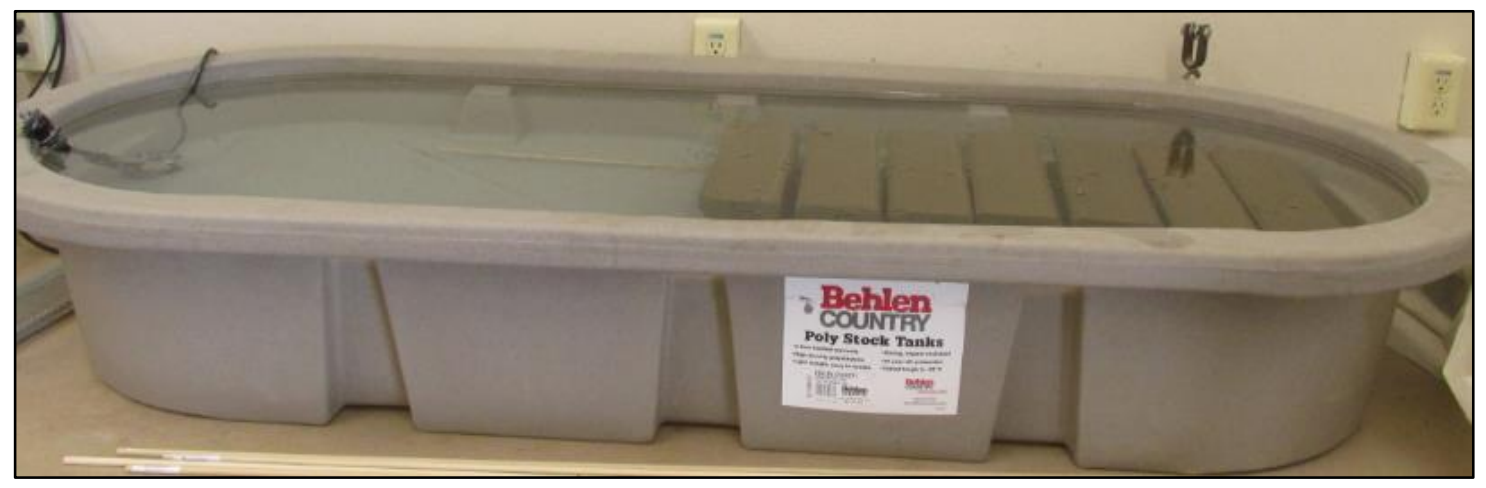

Figure 4.3.4-1 Temperature Contolled CEB Bath

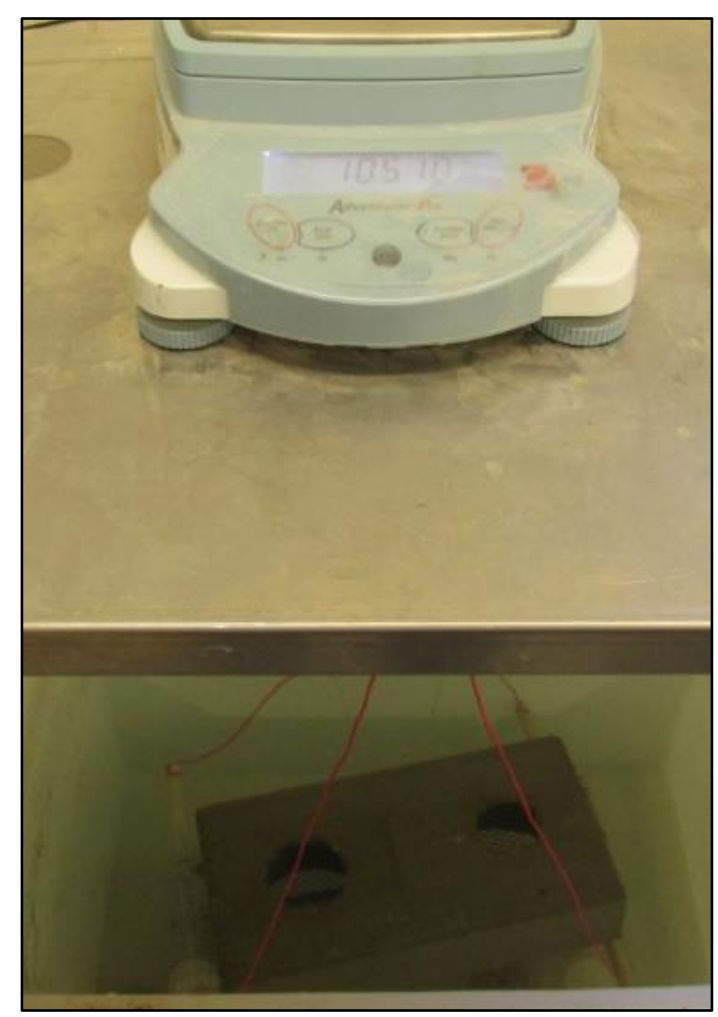

Figure 4.3.4-2 Weighing CEBs Underwater 
After soaking, the blocks were weighed underwater and then allowed to drip-dry for one minute. The CEBs were then weighed in a Saturated Surface Dry (SSD) state, and transferred to an oven and allowed to dry for eighteen hours. Each CEB would be weighed in an oven dry state, and the absorption, density and net area could be calculated for each block.

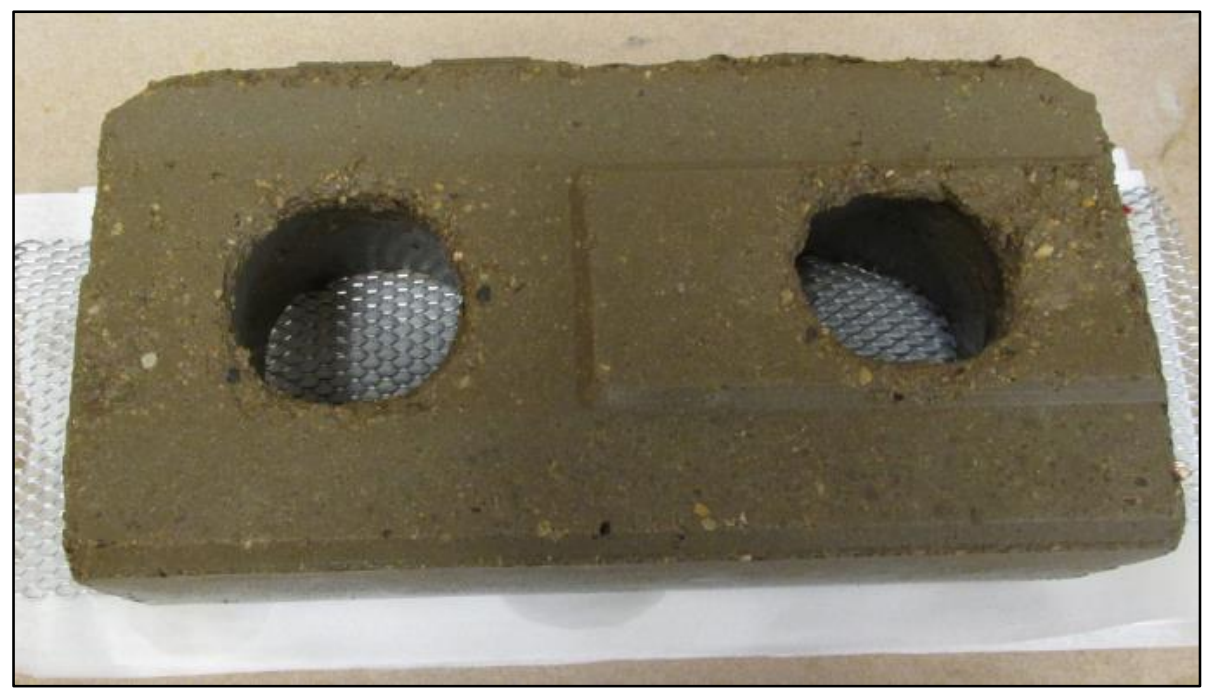

Figure 4.3.4-3 CEB at SSD State

The equations used to calculate the absorption, density and net area are shown below:

$$
\begin{gathered}
A b s=\frac{W t_{S S D}-W t_{O D}}{W t_{O D}} \\
\text { Density }=\left(\frac{W t_{O D}}{W t_{S S D}-W t_{S u b}}\right) *\left(U W_{\text {Water }}\right)
\end{gathered}
$$




$$
\text { Area }_{C E B ~ N e t}=\left(\frac{\frac{\text { Density }}{W t_{O D}}}{\text { Height }_{C E B}}\right) * 1728\left(\frac{\mathrm{in}^{3}}{f t^{3}}\right)
$$

Where Abs is the CEB absorption measured in $\%, \mathrm{Wt}_{\mathrm{SSD}}$ is the saturated surface dry weight, $\mathrm{W}_{\mathrm{OD}}$ is the oven dry weight, $\mathrm{W}_{\text {Sub }}$ is the submerged weight and $\mathrm{UW}_{\text {Water }}$ is the unit weight of water.

As discussed in section 5.2.1, this method was ultimately decided to be inaccurate for the calculation of net area, although the density data remains correct.

\subsubsection{Durability Testing}

Most of the CEBs utilized for absorption testing were also used for durability testing. Each CEB tested would undergo a wet/dry cycle, where the block was soaked in a temperature controlled bath for eighteen hours and then oven dried for eighteen hours. The CEBs were then weighed and inspected visually, with a grade assigned to each block based upon the amount of mass lost during the wet/dry cycle, and their physical appearance. A photograph was taken for each CEB at each cycle in order to illustrate the degradation many of these blocks underwent.

It was anticipated that CEBs with high clay contents or low cement contents would be less strong and durable than CEBs with an ideal clay content and high cement content. Fibers were not anticipated to have any impact on durability, due to their natural toughness and low concentration. Durability data was collected with the hope of 
reinforcing the trends seen in compressive strength and MOR, as well as provide a visual incentive for the proper selection of clay and cement content.

Rating guidelines with visual references are given below:

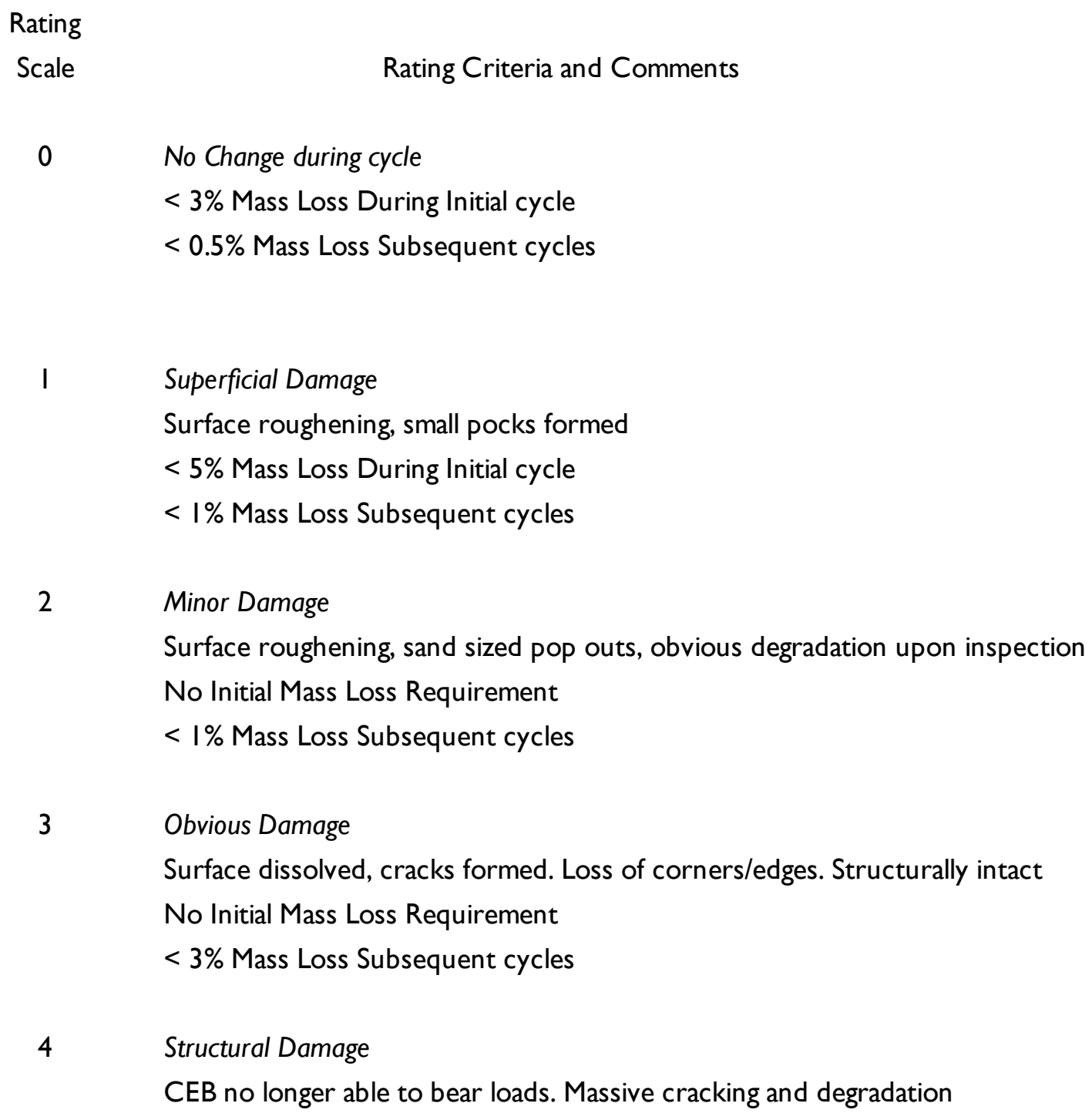




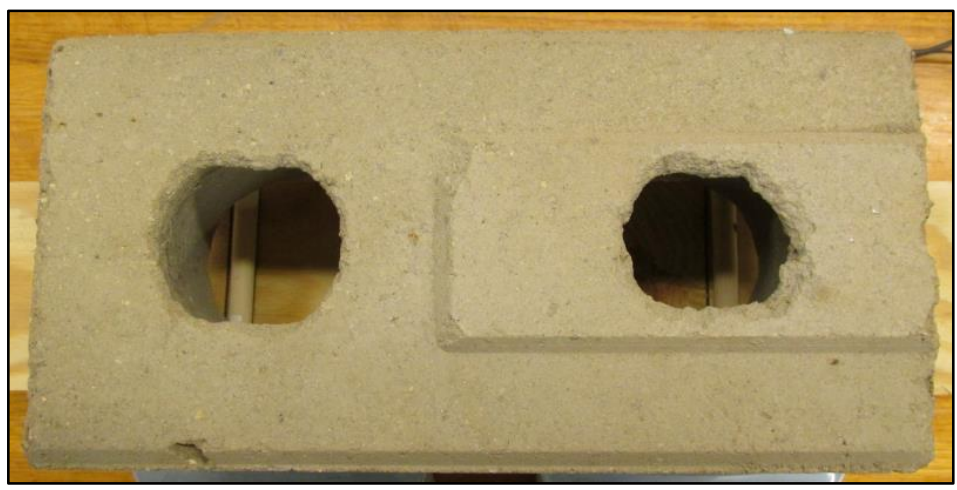

Figure 4.3.5-1 Durability Example - Rating 0

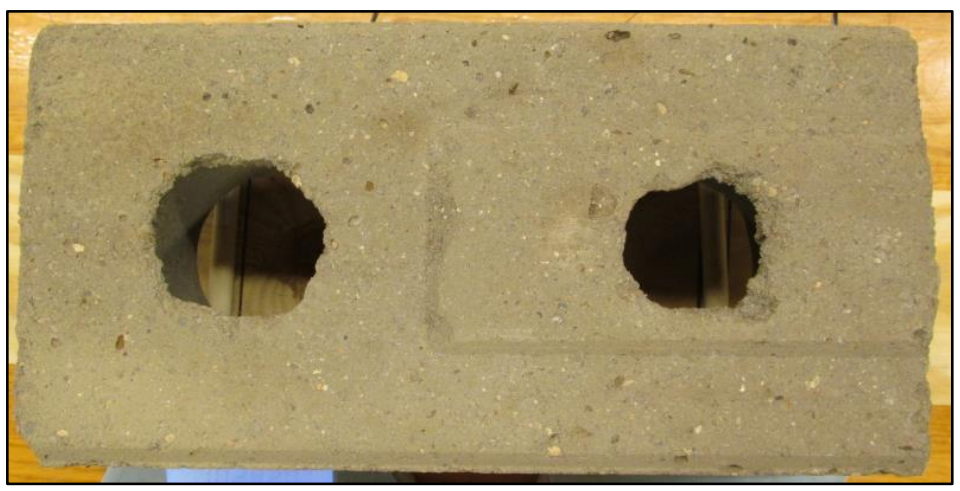

Figure 4.3.5-2 Durability Example - Rating 1

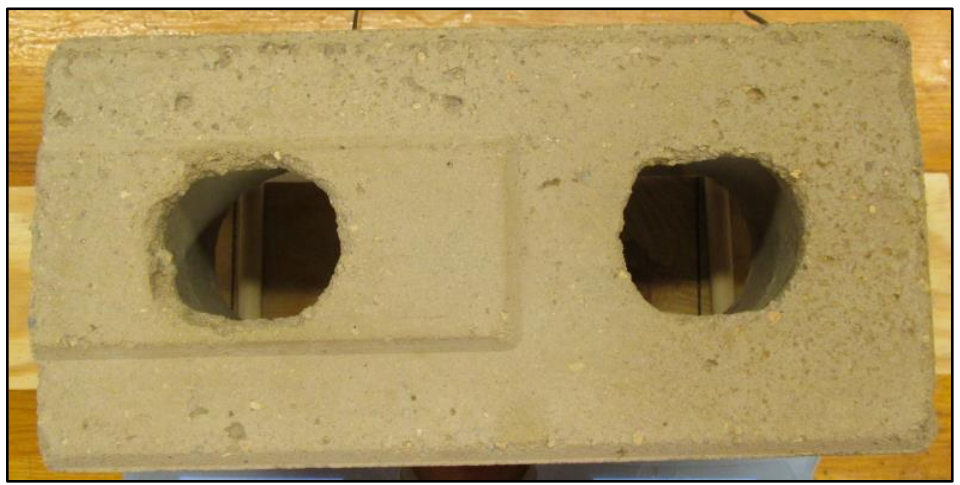

Figure 4.3.5-3 Durability Example - Rating 2 


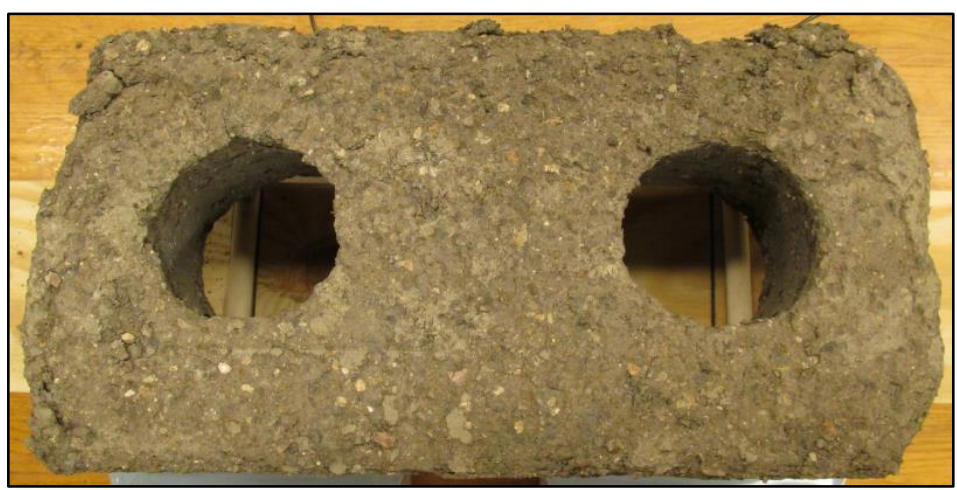

Figure 4.3.5-4 Durability Example - Rating 3

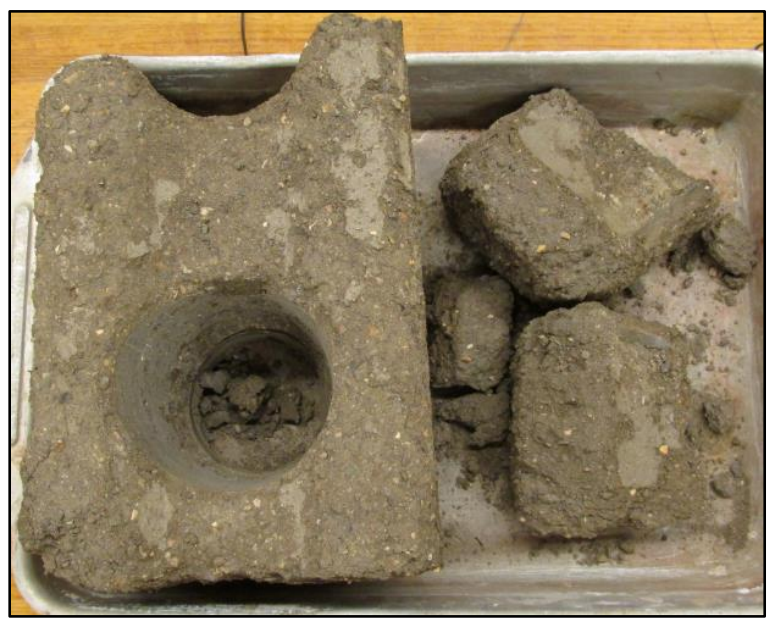

Figure 4.3.5-5 Durability Example - Rating 4 


\section{CHAPTER 5: ANALYSIS}

This chapter summarizes the process of adjusting the data collected and the unique calculation of net strength. Additionally, the effects of clay content, cement content and fiber content are investigated.

\subsection{Data Adjustment}

Once the data was collected, it became clear that some adjustment was necessary. Below is an example of how data adjustment took place, using the Forta Fiber Content LT50, LT50-FF2 and LT50-FF5 blocks. 


\subsubsection{Adjustment Example}

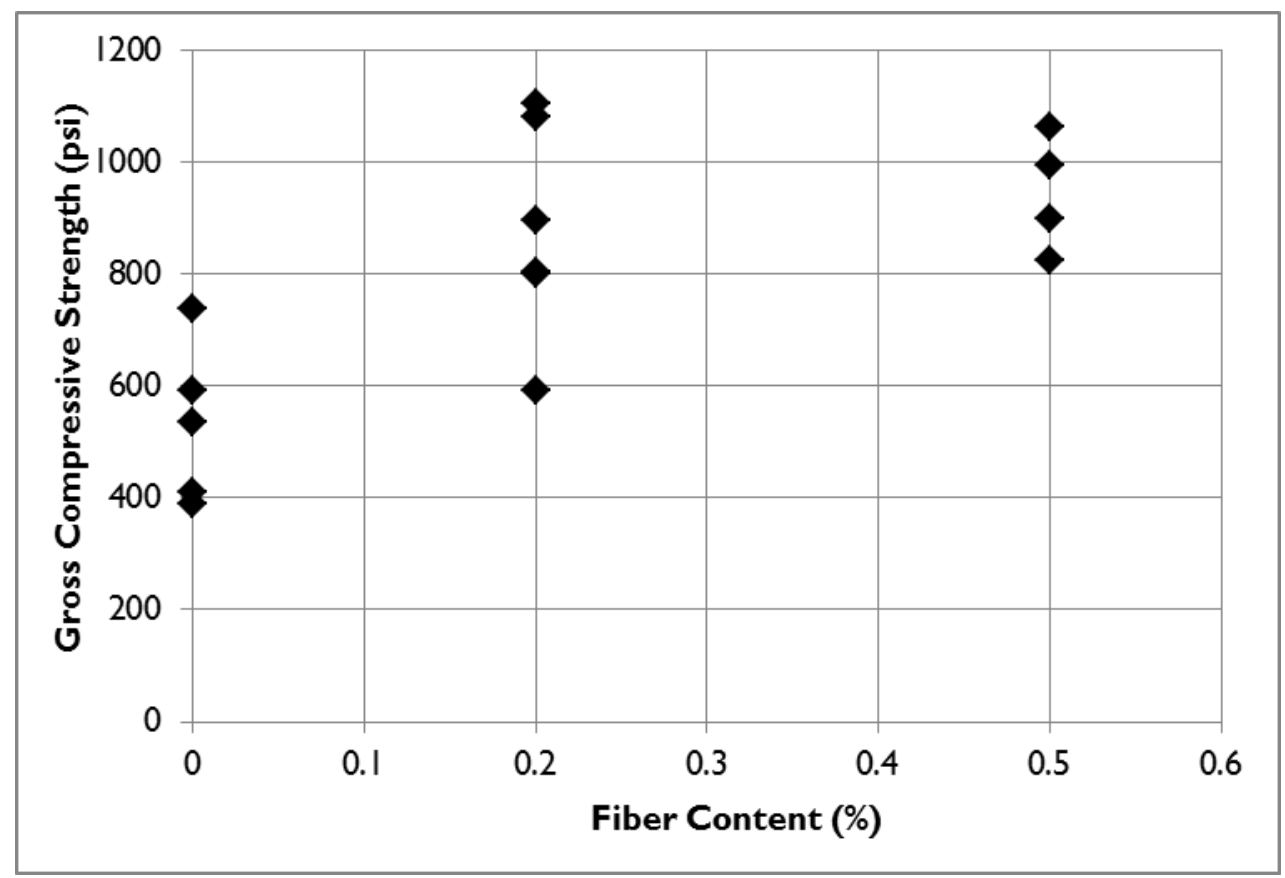

Figure 5.1.1-1 Las Tablas Forta Fiber Content Raw Data

There appears to be trend between fiber content and compressive strength. This may initially suggest that fiber content has a discernable effect on compressive strength, but looking at the data reveals that the piston pressures vary considerably, and these may affect the strength of each CEB. If there is a correlation between piston pressure and CEB strength, then the data can be adjusted to remove the effects of piston pressure and create less variable data, strengthening the final conclusions made throughout this paper. 
Table 5.1.1-1 Las Tablas Forta Fiber Data

\begin{tabular}{|c|c|c|c|}
\hline Block ID & $\begin{array}{c}\text { Fiber } \\
\text { Content } \\
(\%)\end{array}$ & $\begin{array}{c}\text { Piston } \\
\text { Pressure } \\
(\mathrm{psi})\end{array}$ & $\begin{array}{c}\text { Gross } \\
\text { Compressive } \\
\text { Strength } \\
(\mathrm{psi})\end{array}$ \\
\hline LT50-8A & 0 & 1050 & 593 \\
\hline LT50-8E & 0 & 2350 & 536 \\
\hline LT50-8G & 0 & 2350 & 737 \\
\hline LT50-8H & 0 & 2350 & $4 \mathrm{II}$ \\
\hline LT50-FF2-8B & 0.2 & 1500 & 1082 \\
\hline LT50-FF2-8I & 0.2 & 1250 & 896 \\
\hline LT50-FF2-8K & 0.2 & 2350 & 1105 \\
\hline LT50-FF5-8C & 0.5 & 1750 & 1063 \\
\hline LT50-FF5-8E & 0.5 & 1450 & 900 \\
\hline LT50-FF5-8G & 0.5 & 1400 & 824 \\
\hline LT50-FF5-8I & 0.5 & 2350 & 996 \\
\hline
\end{tabular}

Before the data can be adjusted, it must be plotted to reveal any trends that may affect strength. If there is a trend, then the data can be adjusted based upon the slope of the trendline to adjust the CEB strengths to a uniform piston pressrue. Many variables measured, such as width and batch density, do not affect the block strength in a significant manner or could not be isolated a single variable, and were not investigated further.

One issue with the presented data is its scatter, measured by standard deviation (stdev). Each batch of blocks was different from one another, due primarily to piston pressure exerted upon them. An example of piston pressure vs. strength is shown below, with each batch plotted individually. 


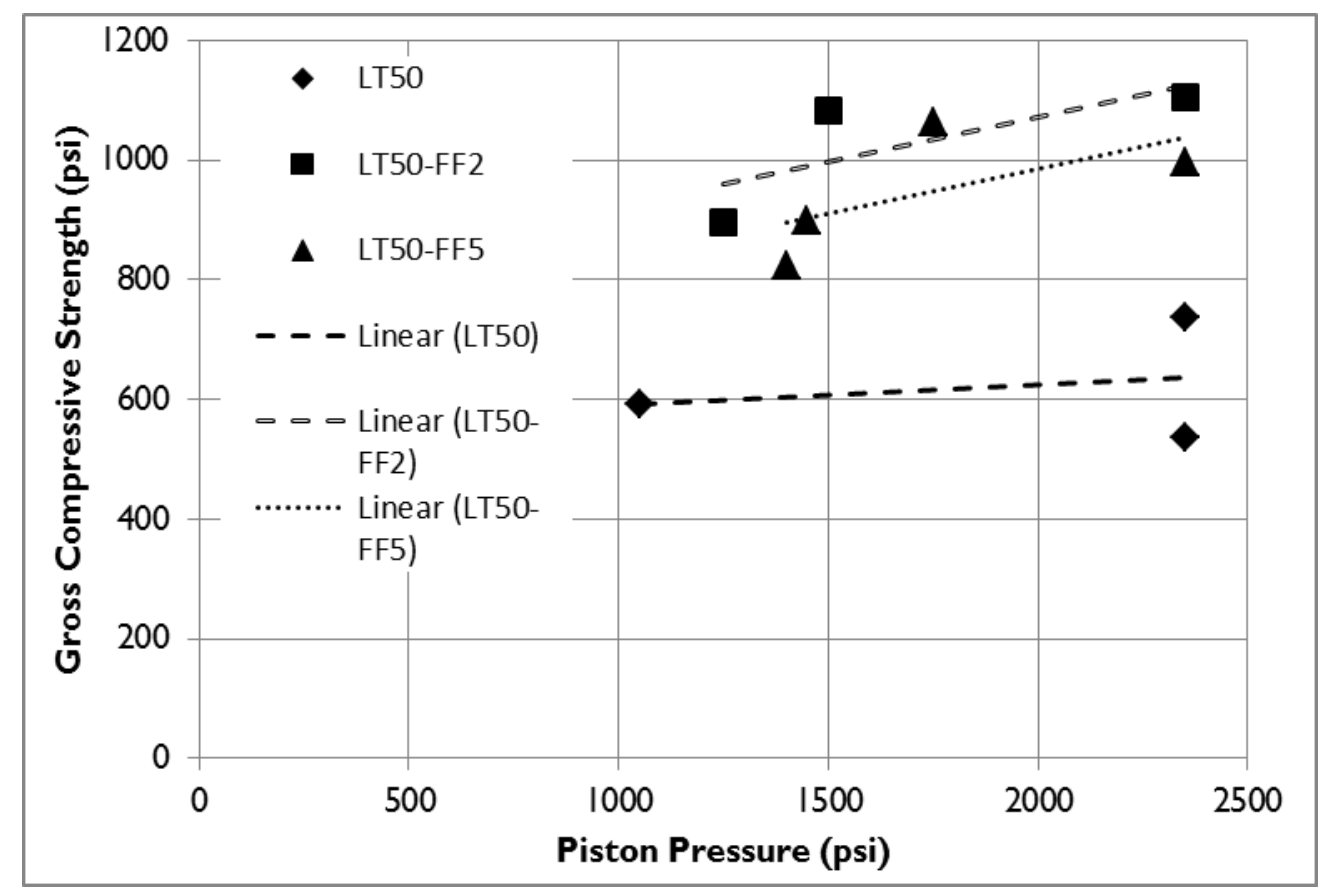

Figure 5.1.1-2 Piston Pressure vs. Strength

Once each batch is separately plotted, the effect of piston pressure can be judged on a per batch basis using the slopes of the trendlines once more. These trendlines illustrate the block strength gained from an increase in piston pressure. If the trendlines are similar, then an average value of the reasonable trendline slopes are calculated and used to adjust each block to a uniform piston pressure. This adjustment reduces the scatter between blocks in each batch, rendering the data much more useful. The trendline slopes for each batch are shown below: 
Table 5.1.1-2 Las Tablas Forta Fiber Batch Trendlines

\begin{tabular}{|c|c|c|}
\hline Batch ID & $\begin{array}{c}\text { Trendline } \\
\text { Slope } \\
\text { (psi/psi) }\end{array}$ & $\begin{array}{c}\text { Reasonable } \\
\text { Trendline } \\
\text { Slope } \\
\text { (psi/psi) }\end{array}$ \\
\hline LT50-8 & 0.033 & - \\
\hline LT50-FF2-8 & 0.149 & 0.149 \\
\hline LT50-FF5-8 & 0.152 & 0.152 \\
\hline Average & 0.111 & 0.151 \\
\hline
\end{tabular}

Most of the batches exhibit a similar trend between piston strength and block strength gained. However, the LT50 batch exhibits an unreasonable trend when compared to the other trendline slopes, so were excluded from the calculation of an average value from which to adjust the data. This will result in an increase in data scatter for the LT50 batch, while the remaining batches will see a decrease in scatter.

Despite the loss of some data precision, correlating to a single piston pressure presents an overall advantage for the data. For the sand content blocks, a piston pressure of 1500 psi was chosen. The equation used and adjusted data is shown below:

$$
f_{C E B}(1500 p s i)=\left(150 \frac{p s i}{p s i}\right) *\left(1500 p s i-\text { Pressure }_{C E B}\right)+f_{C E B}
$$


Table 5.1.1-3 Piston Pressure Adjusted Data

\begin{tabular}{|c|c|c|c|c|c|c|c|}
\hline \multirow[b]{2}{*}{ Block ID } & \multirow[b]{2}{*}{$\begin{array}{c}\text { Piston } \\
\text { Pressure } \\
\text { (psi) }\end{array}$} & \multicolumn{3}{|c|}{ Before Adjustment } & \multicolumn{3}{|c|}{ After Adjustment } \\
\hline & & $\begin{array}{c}\text { Gross } \\
\text { Compressive } \\
\text { Strength } \\
\text { (psi) }\end{array}$ & $\begin{array}{c}\text { Average } \\
\text { Compressive } \\
\text { Strength } \\
\text { (psi) }\end{array}$ & $\begin{array}{c}\text { Stdev } \\
\text { Strength } \\
\text { (psi) }\end{array}$ & \begin{tabular}{|c} 
Gross \\
Compressive \\
Strength \\
(psi)
\end{tabular} & \begin{tabular}{|} 
Average \\
Compressive \\
Strength \\
(psi)
\end{tabular} & $\begin{array}{c}\text { Stdev } \\
\text { Strength } \\
\text { (psi) }\end{array}$ \\
\hline LT50-8A & 1050 & 593 & \multirow{4}{*}{569} & \multirow{4}{*}{135} & 641 & \multirow{4}{*}{514} & \multirow{4}{*}{159} \\
\hline LT50-8E & 2350 & 536 & & & 446 & & \\
\hline LT50-8G & 2350 & 737 & & & 648 & & \\
\hline LT50-8H & 2350 & 411 & & & 322 & & \\
\hline LT50-FF2-8B & 1500 & 1082 & \multirow{3}{*}{1028} & \multirow{3}{*}{115} & 1082 & \multirow{3}{*}{1007} & \multirow{3}{*}{80} \\
\hline LT50-FF2-8I & 1250 & 896 & & & 922 & & \\
\hline LT50-FF2-8K & 2350 & 1105 & & & 1016 & & \\
\hline LT50-FF5-8C & 1750 & 1063 & \multirow{4}{*}{946} & \multirow{4}{*}{105} & 1037 & \multirow{4}{*}{921} & \multirow{4}{*}{84} \\
\hline LT50-FF5-8E & 1450 & 900 & & & 905 & & \\
\hline LT50-FF5-8G & 1400 & 824 & & & 835 & & \\
\hline LT50-FF5-8I & 2350 & 996 & & & 907 & & \\
\hline
\end{tabular}

Now that the data scatter has been reduced, the fully adjusted data can be plotted once more: 


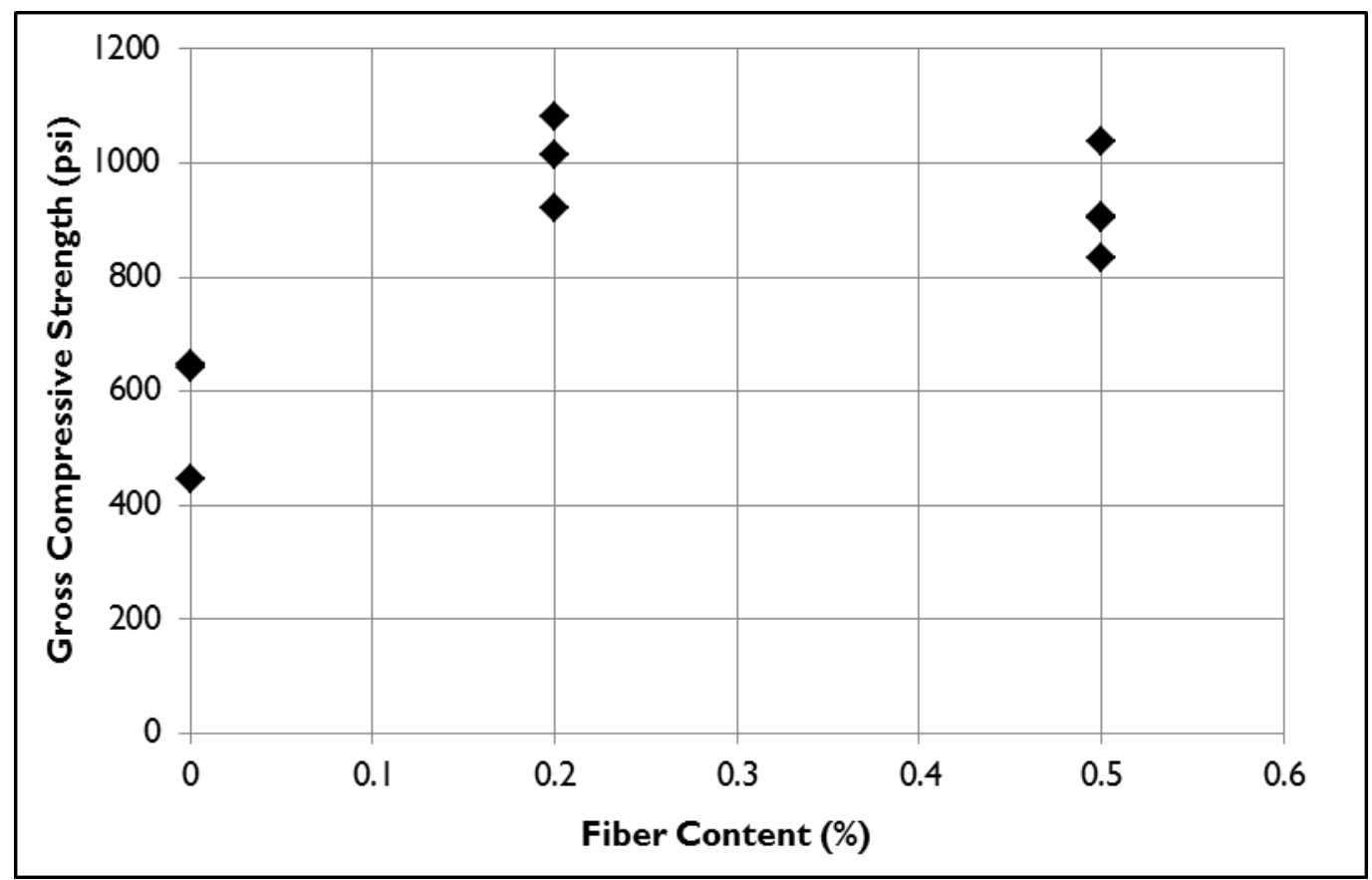

Figure 5.1.1-3 Fully Adjusted Las Tablas Forta Fiber Data

With the data adjusted for piston pressure, it appears that the addition of fibers increases compressive strength. The data is much less scattered, which strengthens the trend. However, when considering that MOR of the batches LT50 is also low, it is unlikely that the addition of fibers had an impact on compressive strength. It is more likely that the LT50 batch simply suffered from manufacturing, and that fibers do not increase the compressive strength of CEBs.

This process was performed for each set of data collected. When there was no obvious trend, then the adjustment was not attempted. The trendline slopes used for each variable is shown below: 
Table 5.1.1-4 Trendline Slopes by Variable

\begin{tabular}{|c|c|c|c|c|c|}
\hline $\begin{array}{c}\text { Batch } \\
\text { Variable }\end{array}$ & Soil & Batch ID & $\begin{array}{c}\text { Trendline } \\
\text { Slope } \\
\text { (psi/psi) }\end{array}$ & $\begin{array}{c}\text { Reasonable } \\
\text { Trendline } \\
\text { Slope } \\
\text { (psi/psi) } \\
\end{array}$ & $\begin{array}{c}\text { Reasonable } \\
\text { Average } \\
\text { Slope } \\
\text { (psi/psi) }\end{array}$ \\
\hline \multirow{14}{*}{$\begin{array}{c}\text { Clay } \\
\text { Content }\end{array}$} & \multirow{6}{*}{$\begin{array}{c}\text { Las } \\
\text { Tablas }\end{array}$} & LT0-8 & 0.436 & 0.436 & \multirow{6}{*}{$0.4 I$} \\
\hline & & LT20-8 & -0.434 & - & \\
\hline & & LT40-8 & 0.391 & 0.391 & \\
\hline & & LT50-8 & 0.033 & - & \\
\hline & & LT55-8 & 0.490 & 0.49 & \\
\hline & & LT70-8 & 0.315 & 0.315 & \\
\hline & \multirow{5}{*}{ Prado } & $\mathrm{P} 0-8$ & - & - & \multirow{5}{*}{0.18} \\
\hline & & P50-8 & - & - & \\
\hline & & P60-8 & 0.193 & 0.193 & \\
\hline & & $\mathrm{P} 66-8$ & 0.17 & 0.17 & \\
\hline & & P75-8 & - & - & \\
\hline & \multirow{3}{*}{$\begin{array}{l}\text { Mind } \\
\text { Body }\end{array}$} & MB25-8 & 1.22 & - & \multirow{3}{*}{0.21} \\
\hline & & MB40-8 & 0.226 & 0.226 & \\
\hline & & MB50-8 & 0.191 & 0.191 & \\
\hline \multirow{9}{*}{$\begin{array}{l}\text { Cement } \\
\text { Content }\end{array}$} & \multirow{3}{*}{$\begin{array}{c}\text { Las } \\
\text { Tablas }\end{array}$} & LT50-4 & - & - & \multirow{3}{*}{$\begin{array}{l}\text { None } \\
\text { Attempted }\end{array}$} \\
\hline & & LT50-8 & 0.033 & - & \\
\hline & & LT50-I 2 & 0.108 & - & \\
\hline & \multirow{3}{*}{ Prado } & P66-4 & - & - & \multirow{3}{*}{$\begin{array}{c}\text { None } \\
\text { Attempted }\end{array}$} \\
\hline & & P66-8 & 2.29 & - & \\
\hline & & P66-12 & -0.126 & - & \\
\hline & \multirow{3}{*}{$\begin{array}{l}\text { Mind } \\
\text { Body }\end{array}$} & MB50-4 & - & - & \multirow{3}{*}{$\begin{array}{c}.54 \\
\text { Compression } \\
\text { Only }\end{array}$} \\
\hline & & MB50-8 & 0.471 & $0.47 \mathrm{I}$ & \\
\hline & & MB50-I 2 & 0.609 & 0.609 & \\
\hline \multirow{5}{*}{$\begin{array}{c}\text { Forta } \\
\text { Fiber } \\
\text { Content }\end{array}$} & \multirow{5}{*}{$\begin{array}{c}\text { Las } \\
\text { Tablas }\end{array}$} & LT50-8 Dry & 0.033 & - & \multirow{5}{*}{$\begin{array}{c}.15 \\
\text { Compression } \\
\text { Only }\end{array}$} \\
\hline & & LT50-8 Wet & 0.025 & - & \\
\hline & & LT50-FF2-8 Dry & 0.149 & 0.149 & \\
\hline & & LT50-FF2-8 Wet & 0.165 & - & \\
\hline & & LT50-FF5-8 & 0.152 & 0.152 & \\
\hline \multirow{5}{*}{$\begin{array}{l}\text { Strux } \\
\text { Fiber } \\
\text { Content }\end{array}$} & \multirow{5}{*}{$\begin{array}{c}\text { Las } \\
\text { Tablas }\end{array}$} & LT50-8 Dry & 0.033 & - & \multirow{5}{*}{$\begin{array}{c}\text { None } \\
\text { Attempted }\end{array}$} \\
\hline & & LT50-8 Wet & 0.025 & - & \\
\hline & & LT50-FS2 Dry & 0.151 & - & \\
\hline & & LT50-FS2 Wet & - & - & \\
\hline & & LT50-FS5 & 0.299 & - & \\
\hline \multirow{3}{*}{$\begin{array}{c}\text { Strux } \\
\text { Fiber } \\
\text { Content }\end{array}$} & \multirow{3}{*}{ Prado } & P66-8 & 0.263 & - & \multirow{3}{*}{$\begin{array}{c}\text { None } \\
\text { Attempted }\end{array}$} \\
\hline & & P60-FS2 & -0.066 & - & \\
\hline & & P60-FS5 & - & - & \\
\hline \multirow{3}{*}{$\begin{array}{c}\text { Strux } \\
\text { Fiber } \\
\text { Content }\end{array}$} & \multirow{3}{*}{$\begin{array}{l}\text { Mind } \\
\text { Body }\end{array}$} & MB50-8 & 0.191 & 0.191 & \multirow{3}{*}{$\begin{array}{c}.32 \\
\text { Compression } \\
\text { Only }\end{array}$} \\
\hline & & MB50-FS2 & 0.442 & 0.442 & \\
\hline & & & & & \\
\hline
\end{tabular}


As seen in the previous table, there is no global trend between piston pressure and CEB strength, so the process was carried out by batch variable such as strux fiber content.

After the individual data points were adjusted, the average of each batch was taken and error bars were attached to each average. These error bars represented one standard deviation for that individual batch. Once plotted, the variability between each batch could be examined, and a baseline variability for a specific soil type or test could be established. The example is continued below:

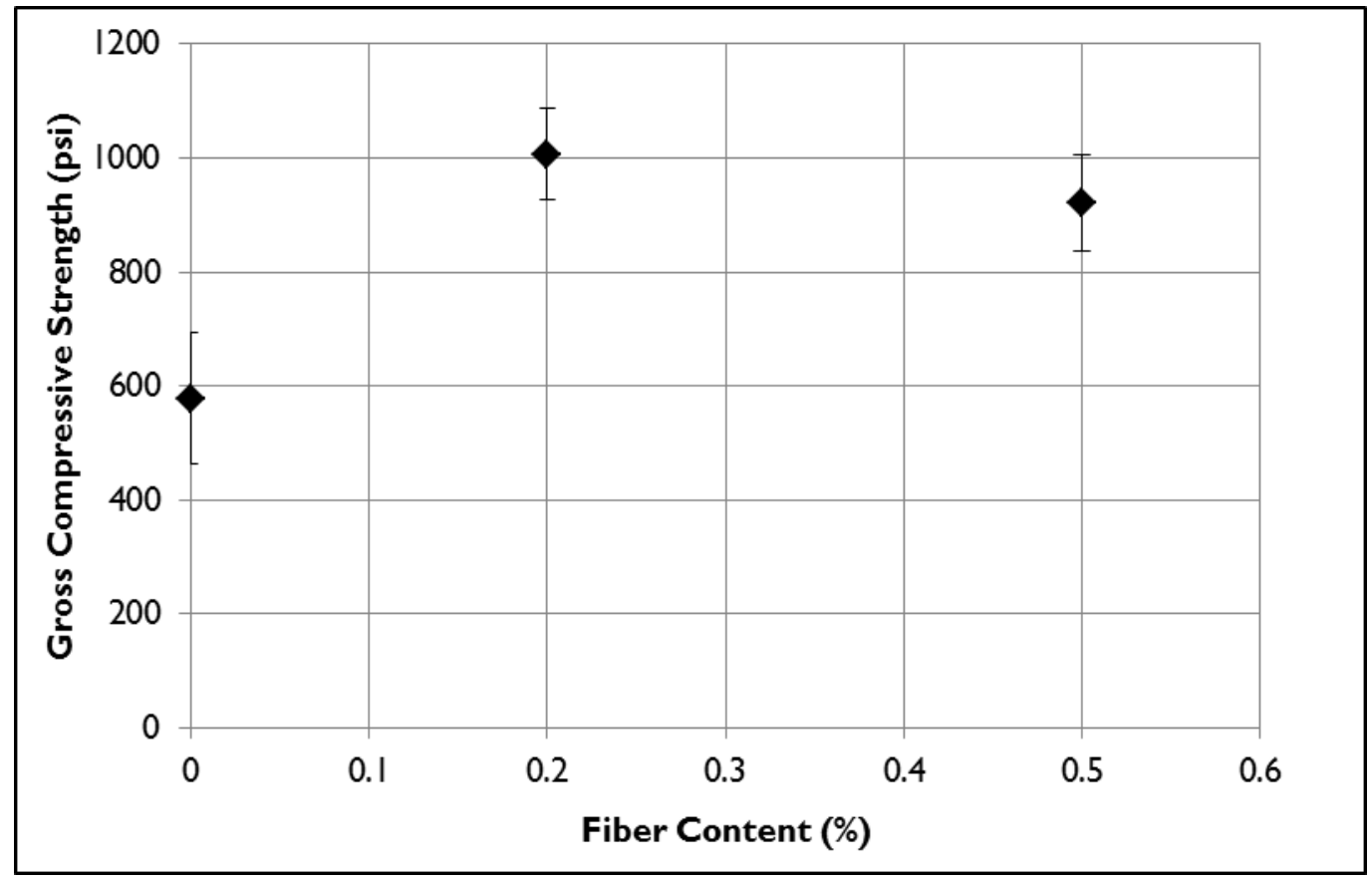

Figure 5.1.1-4 Adjusted Las Tablas SC Average Data

It can be seen that there is comparable variability between batches. This strengthens the data as a whole and makes it easier to establish a data trend. 
Adjusting data and examining the variability they experience batch to batch is an essential tool to understanding the strengths and trends that CEBs exhibit. A considerable portion of time was devoted to this effort to ensure the most accurate representation of these CEBs and their mechanical properties.

\subsubsection{Durability Example}

In addition to the mechanical properties tested, there was a durability test devised to measure the mass loss of CEBs as they were wetted and dried multiple times.

Below is an example using the LT0, LT20, LT50 and LT70 data:

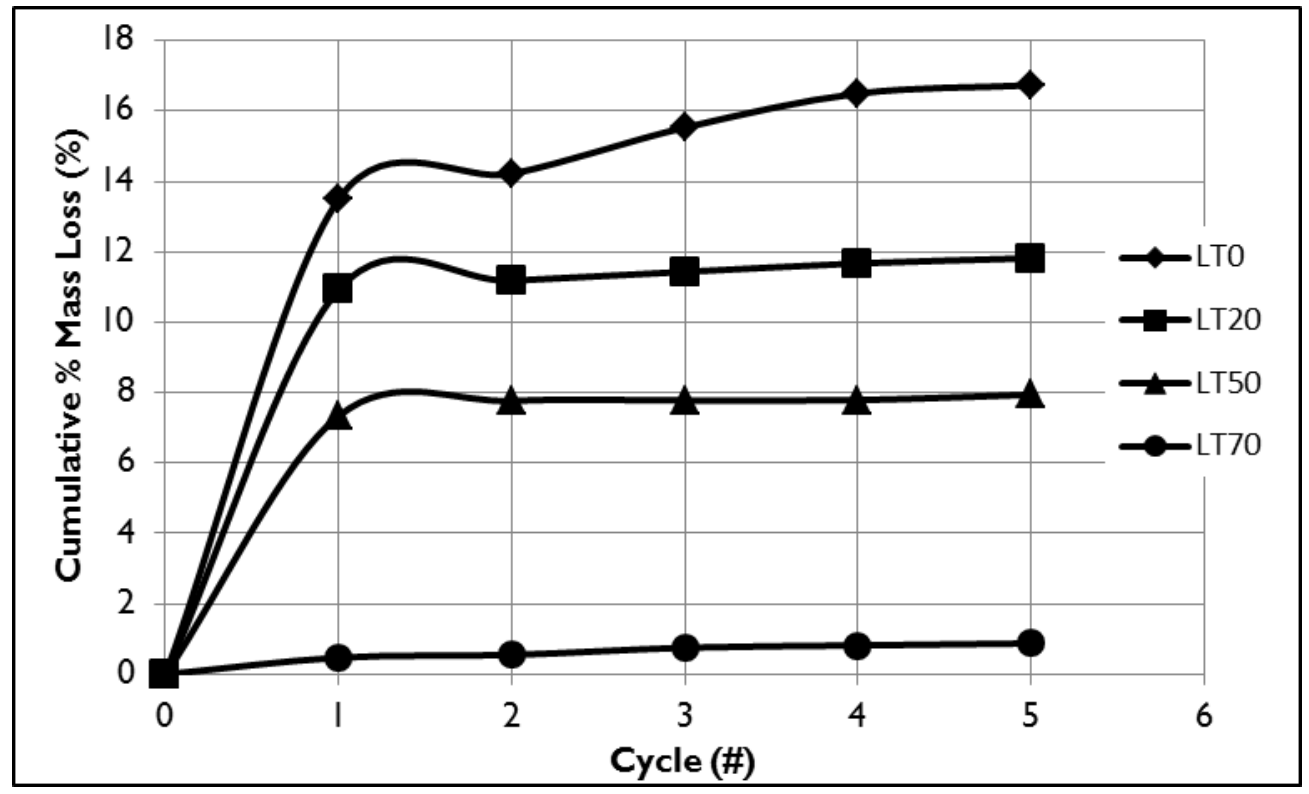

Figure 5.1.2-1 Las Tablas SC Durability Results

The results from the durability tests are clear, but each CEB experienced high mass loss during the first wet/dry cycle. During that time, the submerged weight was measured and the CEB was handled considerably more than in subsequent cycles. This 
trend is seen in every $\mathrm{CEB}$, and is not truly representative of the mass loss attempting to be measured.

For this reason, the data was normalized to the mass loss of the first cycle. The process was simply subtracting each mass loss from the initial mass loss. This net mass loss represents the cumulative CEB material lost during the second through fifth wet/dry cycles, and highlights the durability differences between batches much more easily.

The figure below presents a more easily interpreted picture of durability as a function of clay content. This method was used throughout the paper.

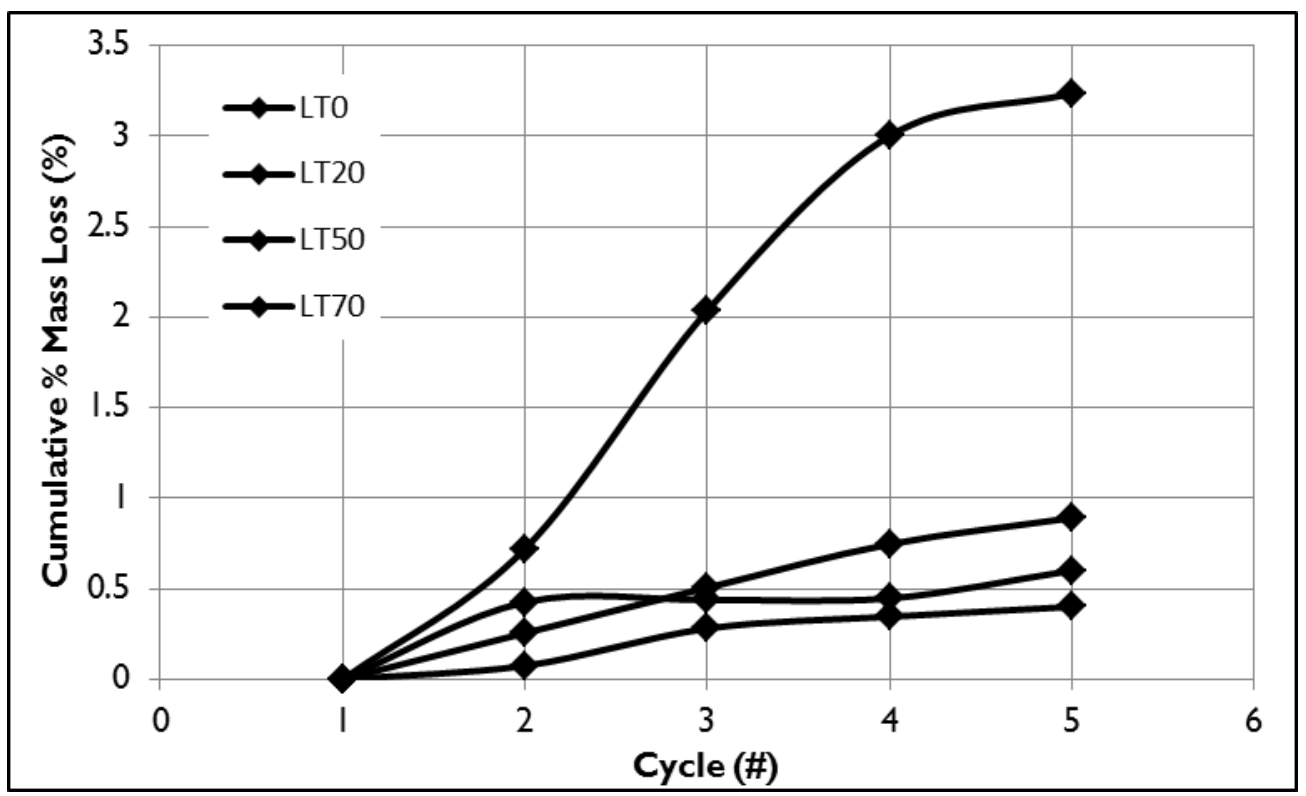

Figure 5.1.2-2 Normalized Durability Results 


\subsection{Gross Strength to Net Strength Calculation}

Concrete masonry unit strengths are often reported using net strengths instead of gross strength. Gross strength assumes any voids in the unit, such as reinforcement chambers or grout channels, contribute to the capacity of the unit. This is obviously not true, so the cross sectional area of the unit is reduced to only consider the portion of the block actually carrying load.

This practice is also commonplace with CEBs featuring voids, such as the $\mathrm{V}-$ Lock block. However, the unique features of this block made calculating the net strengths challenging. The process for both compressive strength and modulus of rupture is detailed below:

\subsubsection{Compressive Strength}

The challenge in calculating the net compressive strength is finding the net cross sectional area of the block. The equation itself is relatively simple:

$$
f_{C E B N e t}=\frac{P_{\max }}{A_{N e t}}
$$

Where $\mathrm{f}_{\mathrm{CEB} \text { Net }}$ is the net CEB compressive strength, $\mathrm{P}_{\max }$ is the maximum load applied to the block, and $\mathrm{A}_{\mathrm{Net}}$ is the net cross sectional area. There are multiple ways to calculate the net cross sectional area, but the method suggested in ASTM C140 and described in the methods section was used.

Unfortunately, ASTM C140 does not effectively calculate the net area of the VLock CEB. The final step in finding net area involves dividing the net volume by the 
block height. This is inappropriate because the cross sectional area of the V - Lock CEB changes throughout its depth. The interlocking ridge, grout channel, and conical shape of the reinforcement chambers create a cross sectional area that constantly changes. A more appropriate method may be simply subtracting the area of the reinforcement chambers from the gross area. A proposed method of calculating net area is given, assuming a mean reinforcement chamber diameter of 3.5":

$$
\text { Area }_{\text {Net }}=\text { Area }_{\text {Gross }}-2 *\left(\frac{\pi}{4}\right) *\left(3.5^{\prime 2}\right) \approx 78.8 \text { in }^{2}
$$

The strength increase between gross and net compressive strength varies primarily on the density of the CEB. The strength between gross and net compressive strength varies from $30 \%$ to $6 \%$, so all of the data was plotted against the block height. The block height plays a crucial factor in the calculation of the net area using ASTM C140, and significantly influences the block weight, so it became an obvious variable to consider. The factor between gross and net cross sectional area was calculated as follows:

$$
\text { Area Factor }=\frac{A_{C E B \text { Gross }}}{A_{C E B \text { Net }}}
$$

Using the area factor, the net compressive strength can be found as follows:

$$
f_{C E B \text { Net }}=f_{C E B \text { Gross }} * \text { Area Factor }
$$




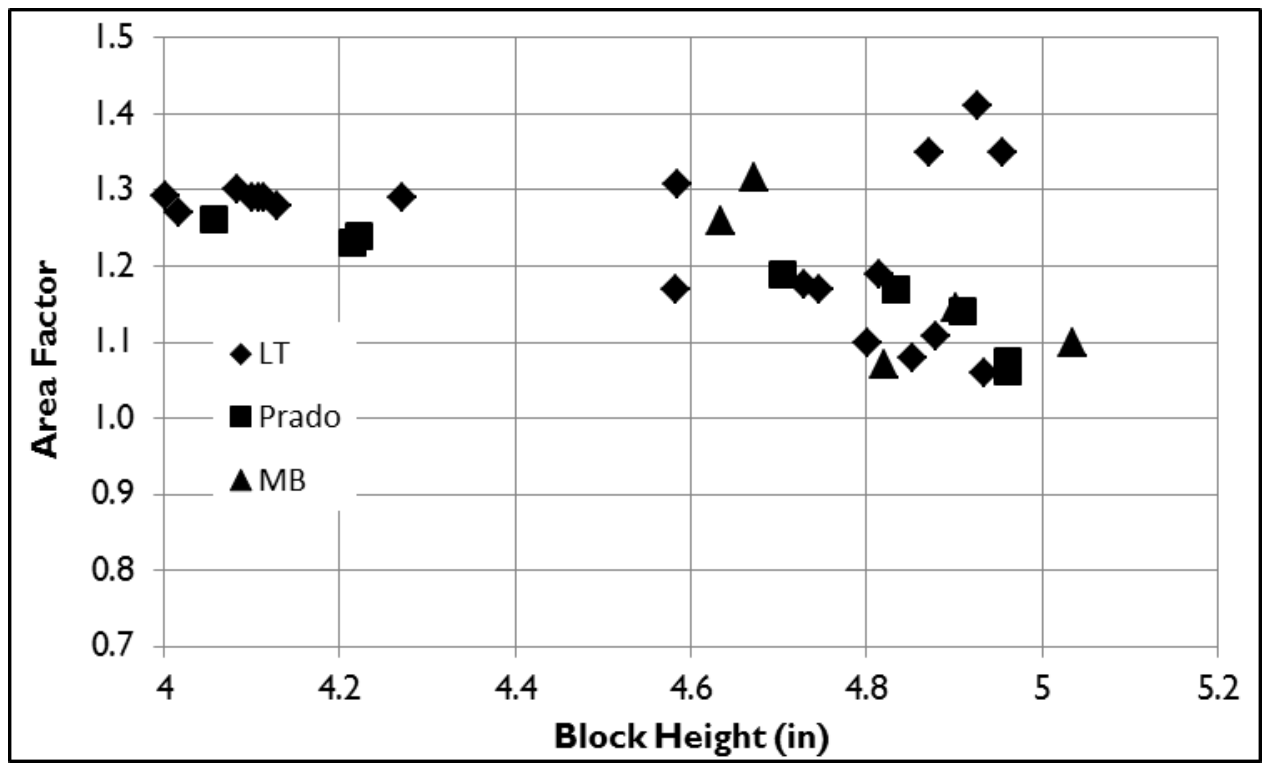

Figure 5.2.1-1 Block Height vs. Area Factor

It should be noted that Chapter 21 of the International Building Code (International Code Council 2012) suggests a minimum compressive strength for stabilized adobe: $300 p s i \mathrm{f}_{\mathrm{CEB} \text { Net }}$. This strength requirement was easily passed by all but a single CEB, whose data was discarded. This minimum strength became more important for MOR, and is discussed in further detail in Section 5.3.

There appears to be no real correlation between block height and the area factor as a whole. When soils are separately compared, there is no clear grouping of data for any soil. Strangely, as the block height increases, the variability within the data seems to increase. This precludes any recommendation of a simple equation or factor that can be used on the V-Lock CEBs. Until a more accurate method of calculating net area is used, this relationship presents no worth. 


\subsubsection{Modulus of Rupture}

The net modulus of rupture is a more challenging calculation due to the geometry of the V - Lock CEB. First consider the test method and definition of modulus of rupture:

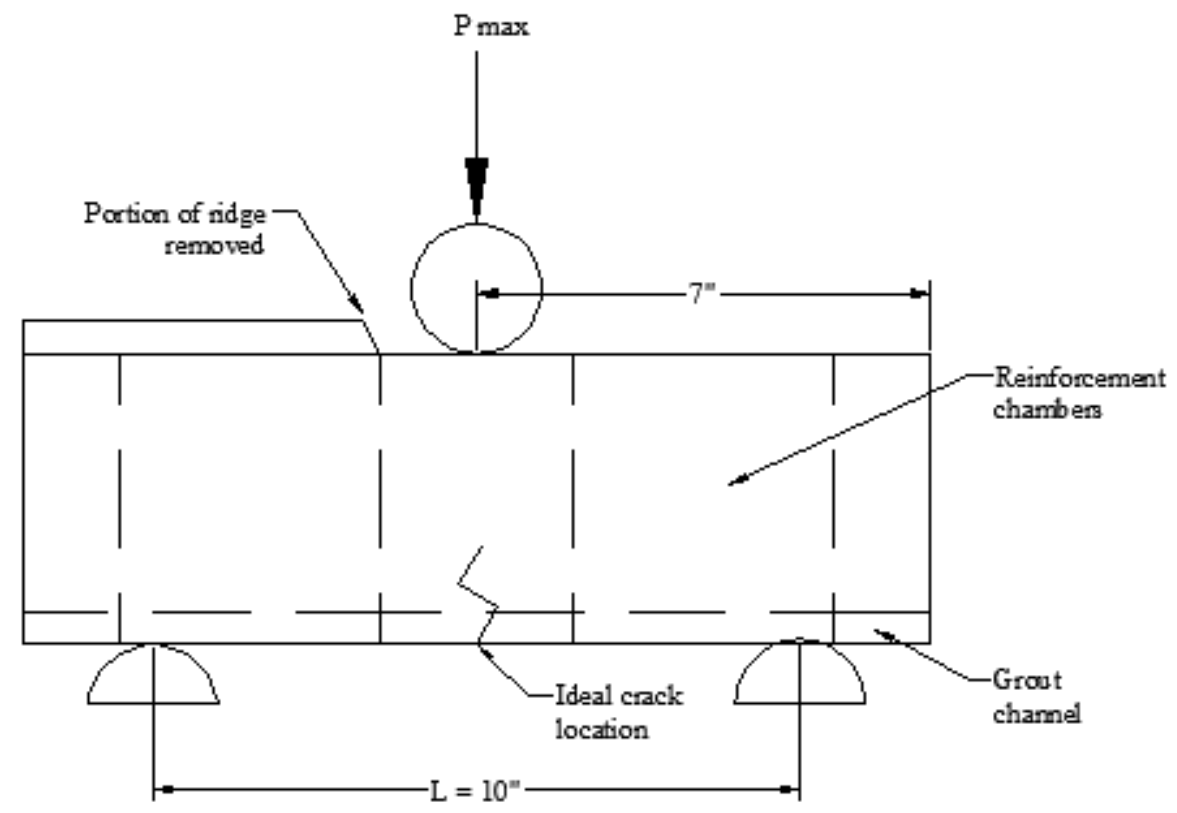

Figure 5.2.2-1 MOR Test Setup

$$
f_{r}=\frac{M y}{I}=\frac{\left(\frac{P_{\max } L}{4}\right) y}{I}
$$

Where $\mathrm{M}$ is the moment applied, $\mathrm{P}_{\max }$ is the maximum load applied to the CEB, $\mathrm{L}$ is the span length of 10 ", $\mathrm{I}$ is the second moment of inertia, and $\mathrm{y}$ is the distance from the centroid to the extreme fiber in tension. 
The CEB should fail in the middle of the block and avoid the reinforcement chambers. When the gross cross sectional area is considered, the CEB is simply a rectangle, so calculating y and I is relatively simple:

$$
\begin{gathered}
I_{\text {Gross }}=\left(\frac{1}{12}\right) * W * H^{3} \\
y_{\text {Gross }}=\frac{H}{2}
\end{gathered}
$$

However, the grout channel extends down the length of the block, so the net cross sectional area of the CEB will not be rectangular, as is shown in Figure 5.2.2-2.

When the net cross sectional area is compared to the gross cross sectional area, the second moment of inertia will decrease, increasing the net MOR. Additionally, the center of mass of the net cross sectional area will shift up, increasing the distance to the extreme fiber in tension, and further increasing the net strength. The calculation for $\mathrm{y}_{\text {net }}$ is shown below:

$$
y_{N e t}=H-c
$$

This warrants further discussion on the calculation of net MOR, especially calculating the second moment of inertia. While each CEB possesses dimensions that vary, the dimensions of the interlocking channel are constant. This information is shown below: 


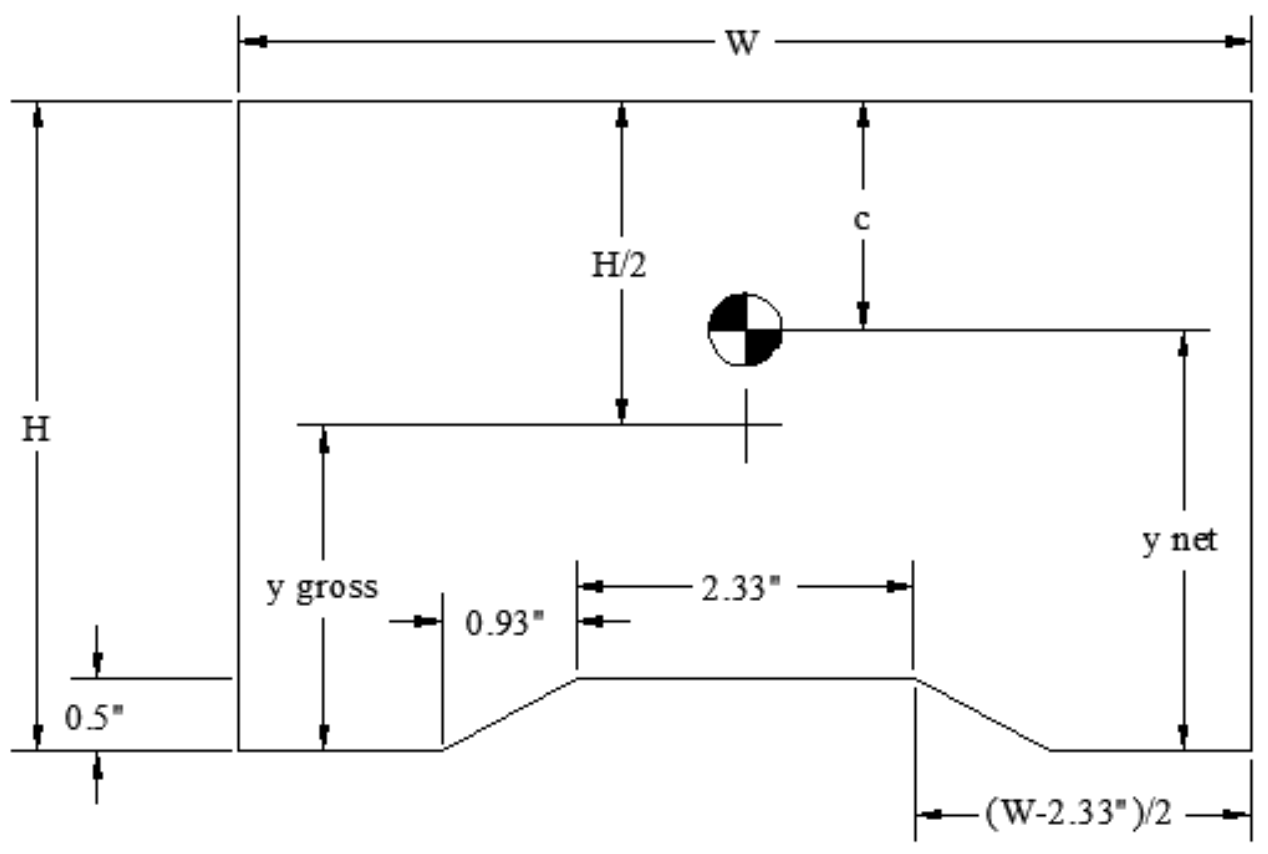

Figure 5.2.2-2 Dividing MOR Net Cross Sectional Area

Note the net center of mass is shown as above the gross center of mass

Like compressive strength, converting gross MOR to net MOR provides an increase in strength. After this procedure was performed on all of the CEBs tested, the MOR factor was calculated in a similar manner as compressive strength, using the section modulus in place of area. The equations for section modulus and MOR factor are given below:

$$
\begin{gathered}
S=\frac{I}{y} \\
\text { MOR Factor }=\frac{S_{\text {Net }}}{S_{\text {Gross }}}
\end{gathered}
$$




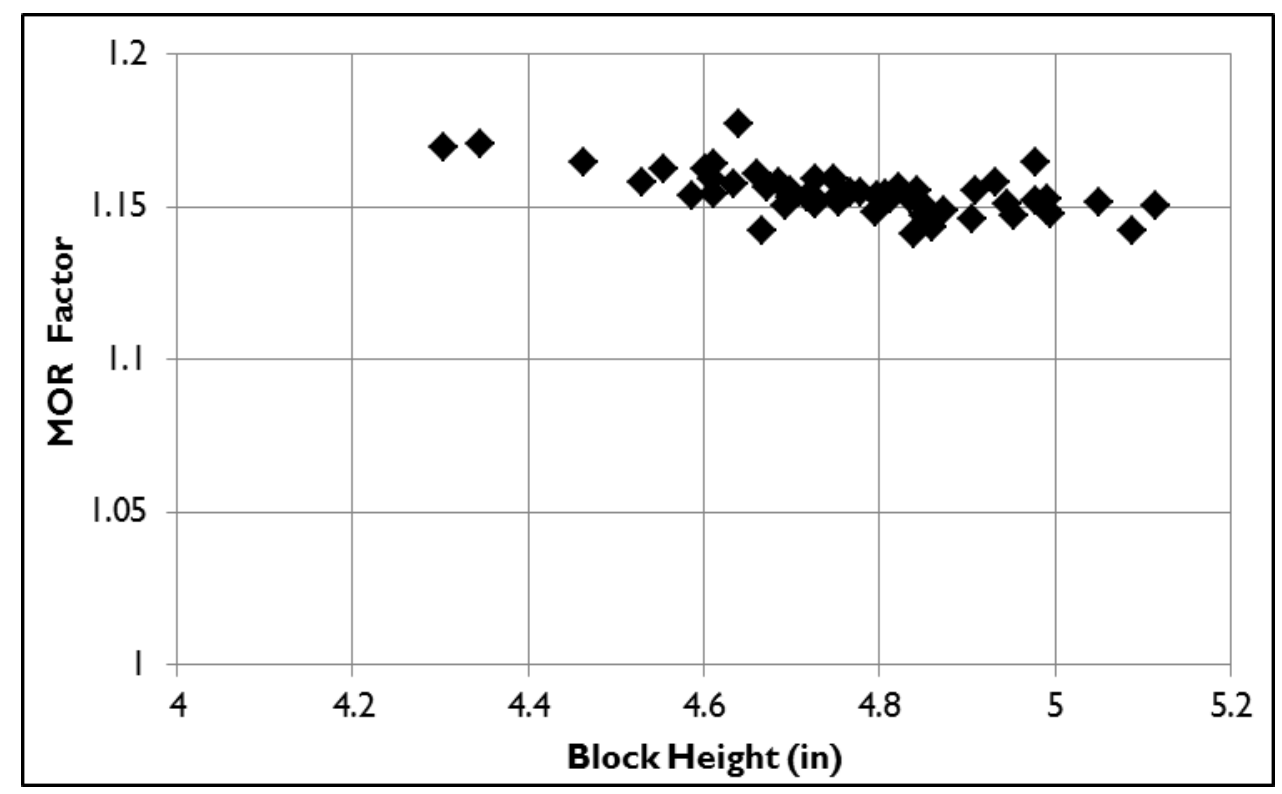

Figure 5.2.2-3 Block Height vs. MOR Factor

From the figure above, it is obvious that block height has little to any effect on the strength factor between gross and net MOR. Almost every CEB experiences an $15 \%$ gain in strength. To confirm the MOR factor, a table of simulated CEB dimensions was created. The CEB height and width were varied, and the MOR factor was calculated. 
Table 5.2.2-1 Simulated Gross vs. Net MOR Comparison

\begin{tabular}{|c|c|c|c|c|c|c|c|c|}
\hline \multicolumn{2}{|c|}{ Block Dimensions } & \multicolumn{3}{|c|}{ Gross MOR } & \multicolumn{3}{|c|}{ Net MOR } & \multirow{2}{*}{$\begin{array}{c}\text { Difference } \\
\text { in S } \\
(\%)\end{array}$} \\
\hline $\begin{array}{c}\text { Height } \\
\text { (in) }\end{array}$ & $\begin{array}{c}\text { Width } \\
\text { (in) }\end{array}$ & $\begin{array}{c}y_{t} \\
\text { (in) }\end{array}$ & $\begin{array}{c}1 \\
\left(\text { in }^{4}\right) \\
\end{array}$ & $\begin{array}{c}S \\
\left(\text { in }^{3}\right) \\
\end{array}$ & $\begin{array}{c}y_{t} \\
\text { (in) } \\
\end{array}$ & $\begin{array}{c}1 \\
\left(\text { in }^{4}\right) \\
\end{array}$ & $\begin{array}{c}S \\
\left(\mathrm{in}^{3}\right) \\
\end{array}$ & \\
\hline 4.00 & 7.00 & 2.00 & 37.3 & 18.7 & 2.11 & 33.1 & 15.7 & 16.0 \\
\hline 4.25 & 7.00 & 2.13 & 44.8 & 21.1 & 2.24 & 39.9 & 17.8 & 15.5 \\
\hline 4.50 & 7.00 & 2.25 & 53.2 & 23.6 & 2.36 & 47.5 & 20.1 & 14.8 \\
\hline 4.75 & 7.00 & 2.38 & 62.5 & 26.3 & 2.49 & 56.1 & 22.5 & 14.4 \\
\hline 5.00 & 7.00 & 2.50 & 72.9 & 29.2 & 2.61 & 65.7 & 25.2 & 13.7 \\
\hline 5.25 & 7.00 & 2.63 & 84.4 & 32.2 & 2.74 & 76.3 & 27.8 & 13.4 \\
\hline 4.50 & 6.75 & 2.25 & 51.3 & 22.8 & 2.36 & 45.8 & 19.4 & 14.8 \\
\hline 4.50 & 6.90 & 2.25 & 52.4 & 23.3 & 2.36 & 46.8 & 19.8 & 14.8 \\
\hline 4.50 & 7.00 & 2.25 & 53.2 & 23.6 & 2.36 & 47.5 & 20.1 & 14.8 \\
\hline 4.50 & 7.10 & 2.25 & 53.9 & 24.0 & 2.36 & 48.3 & 20.5 & 14.6 \\
\hline 4.50 & 7.25 & 2.25 & 55.1 & 24.5 & 2.36 & 49.4 & 20.9 & 14.5 \\
\hline
\end{tabular}

Like the experimental data, most of the simulated data experiences a $15 \%$ increase in strength. This leads to the recommendation that the net MOR always be reported, and so long as the CEB height is between 4" and 5.25", the following approximation equation can be used:

$$
f_{r N e t}(p s i)=1.15 * f_{r \text { Gross }}(p s i)
$$

The more complicated process of finding $\mathrm{S}_{\mathrm{Net}}$ can always be performed, but the equation above maintains an accuracy of $2 \%$ between CEB heights of 4 " to 5.25 " and widths of 6.75 " to 7.25 ". Considering the variability within the MOR data, this is more than accurate enough for an approximation. 


\subsection{Predicting Modulus of Rupture}

Like concrete and masonry, compression testing is the most common and simple way to determine the mechanical properties of a CEB. A relationship between compressive strength and MOR is key toward elevating CEBs to a truly modern building material.

There has been some research investigating both the compressive strength and MOR, with a few papers suggesting a relationship between the two. The most simple is proposed in the Kenyan Specification for Stabilised Soil Blocks (Walker 1995):

$$
f_{r}=\left(\frac{1}{6}\right) * f_{C E B}
$$

This equation has not yet been accepted as a design standard due to some research finding the equation non conservative (Walker 1995), but it appeared the perfect place to begin.

Since CEBs resemble other building materials like CMU and Autoclaved Aerated Concrete (AAC) blocks, there has also been an atempt to link the current masonry code with $\mathrm{CEB}$ construction. To that end, the prediction equation for AAC was also considered, along with traditional Portland Cement Concrete (PCC).

$$
\begin{aligned}
& f_{r A A C}=4.8 * \sqrt{f_{C E B}} \\
& f_{r P C C}=7.5 * \sqrt{f_{C E B}}
\end{aligned}
$$


The AAC prediction equation was found in ACI 530-13 (ACI 2013), while the PCC equation came from ACI 318-11 (ACI 2011).

Chapter 21 of the International Building Code (International Code Council 2012) also provides a minimum strength for stabilized adobe blocks, with individual MOR of 35 psi required. This was an excellent measure of CEB quality, and is used throughout this analysis.

\subsubsection{Equation Development}

The dry and wet cured CEB batch averages were combined and plotted to observe whether the data collected matched the Kenyan equation, AAC prediction equation, or PCC prediction equation. Individual data points could not be used, as there was no compressive strength corresponding to MOR, so the average of each batch was taken and used. Net compressive and MOR were utilized throughout this section to remove the effects of CEB dimensions and focus on the material strength.

The data below seems to fit within the Kenyan Specification quite well. Strangely, this equation implies a maximum strength instead of a minimum design standard. This may be useful for quality control purposes or to gauge variability within blocks, but is obviously non conservative for this data and not suited for strength prediction. 


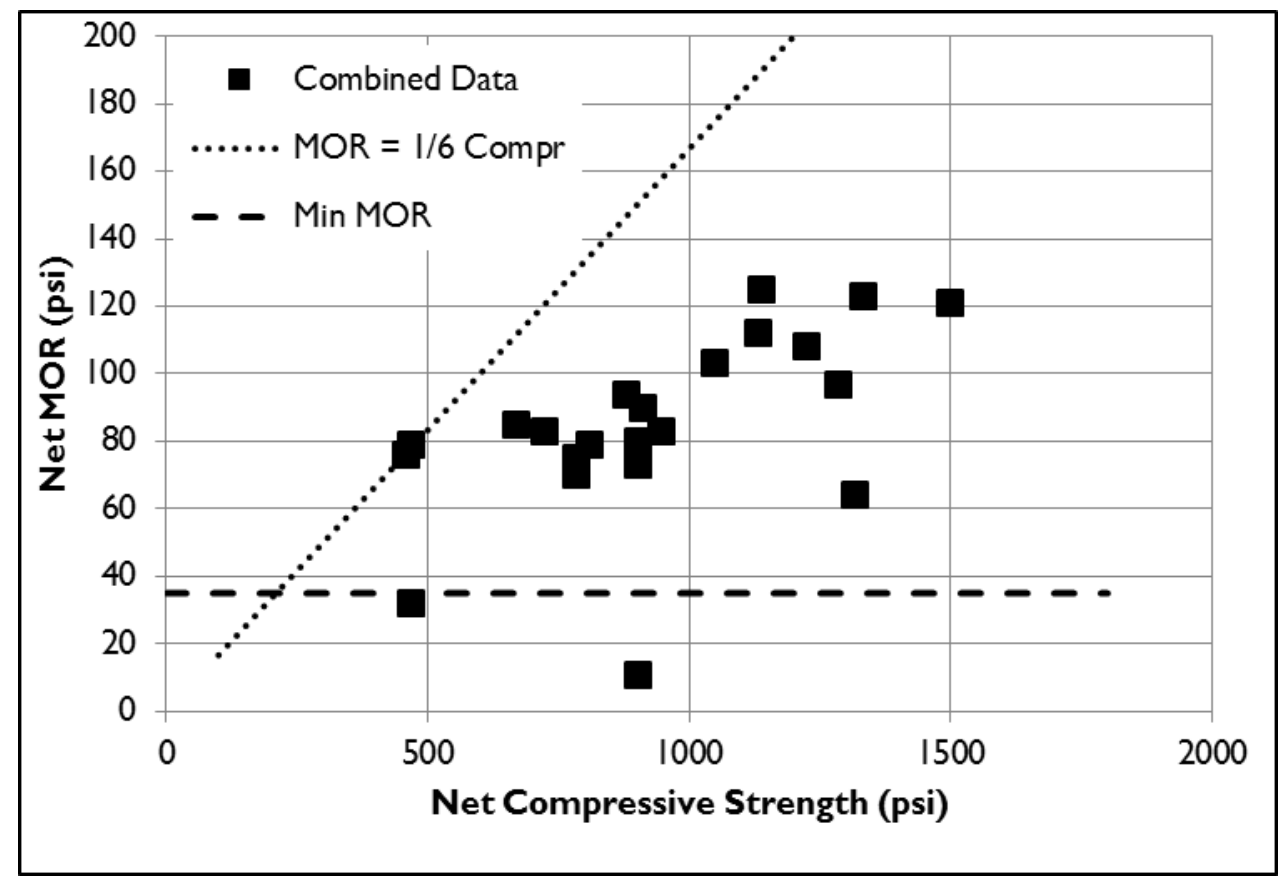

Figure 5.3.1-1 Combined Data vs. Kenyan Equation

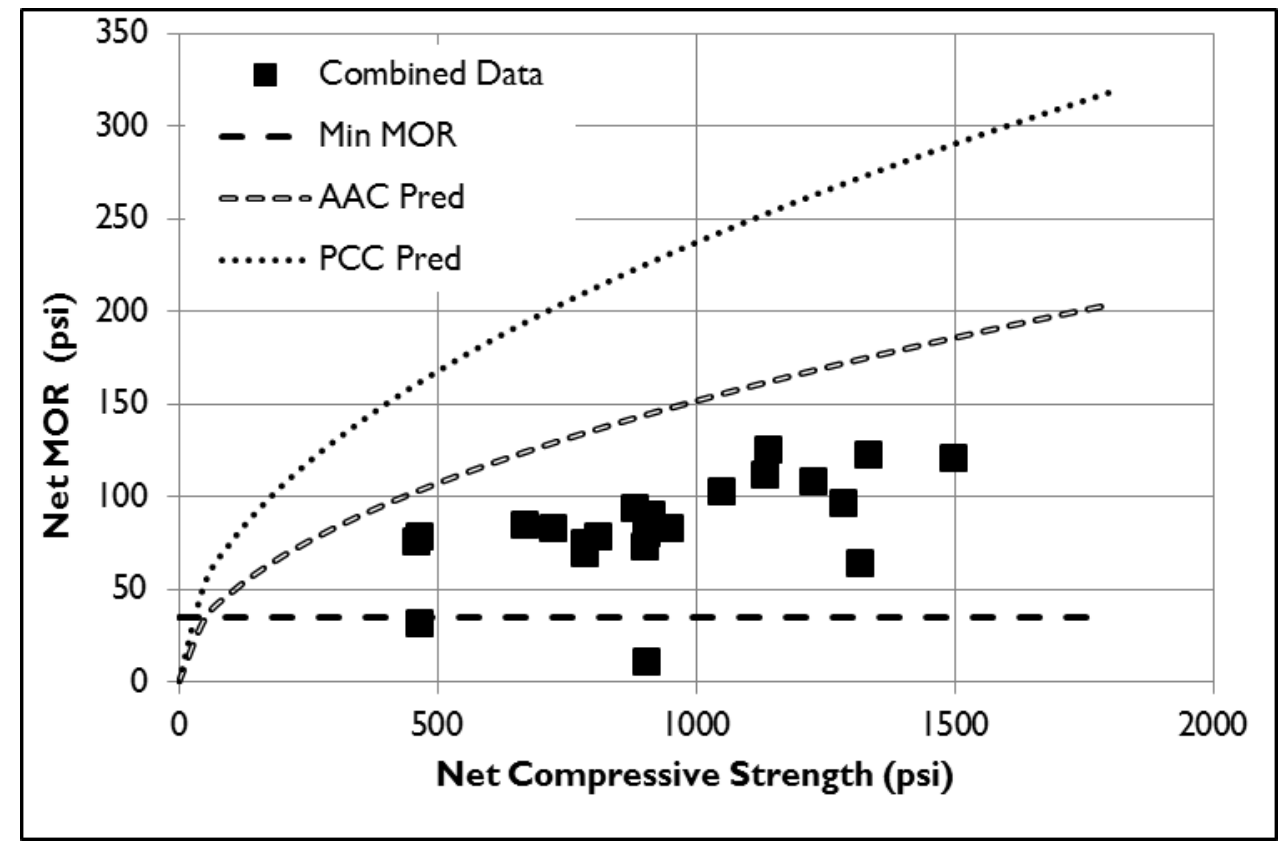

Figure 5.3.1-2 Combined Data vs. AAC and PCC Equation 
When the combined data is compared to the AAC and PCC prediction equations, it is clear that neither is conservative. The AAC equation may be used in a similar fashion to the Kenyan equation, but none of these equations are of use when predicting the MOR for these CEBs.

This required the development of an equation to conservatively predict the MOR of a CEB. While a conservative equation could simply be created below the given data, it would be far more beneficial to use statistics to create a new, conservative relationship to predict the MOR.

The first step in predicting material properties is determining whether or not the data is normally distributed. Data that is normally distributed follows a bell shaped curve, and can be easily manipulated by a variety of methods. Both the compressive strength and MOR must be confirmed as normally distributed. The process is described in the following section.

\subsubsection{Normally Distributed Data}

Once all of the raw data has been collected, it must be sorted from smallest to largest, and the mean, standard deviation, skewness and number of points were calculated. Skew measures how much data "leans" from its median, or how asymmetric it is. If the data was too skewed or asymmetric, it would not be considered normally distributed.

$$
\text { Skew Max }=2 \sqrt{\frac{6}{n}}
$$


Where $\mathrm{n}$ is the number of data points present.

Next, a cumulative distribution function (CDF) was utilized on the sorted data. The CDF determines the probability of a value less than or equal to the data point occurring. Since the equation is cumulative and the data is sorted, the probability will always increase, as seen in the example.

$$
C D F_{x}=\left\{\begin{array}{lr}
x=1, & \frac{1}{2 n} \\
x=2,3, \ldots & C D F_{x-1}+\frac{2}{2 * n}
\end{array}\right.
$$

Once the CDF was calculated, the inverse could be taken. The inverse predicts the value corresponding to the probability given by the CDF. This again assumes normally distributed data, so these values are expected data points that would be incorrect if the data is proven to be not normally distributed.

Finally, the inverse of the CDF was calculated, which showed the distance each $\mathrm{CDF}$ value was from the mean. Once these values were calculated, the table and figure below was created. 
Table 5.3.2-1 Example Data

\begin{tabular}{|c|c|c|c|}
\hline $\begin{array}{c}\text { Sorted } \\
\text { Compressive } \\
\begin{array}{c}\text { Strength } \\
(\mathrm{psi})\end{array}\end{array}$ & $\begin{array}{c}\text { Cumulative } \\
\text { Distribution } \\
\text { Probability } \\
(\%)\end{array}$ & $\begin{array}{c}\text { Normally } \\
\text { Dist } \\
\text { Expected } \\
\text { Value } \\
(\mathrm{psi})\end{array}$ & $\begin{array}{c}\text { CDF } \\
\text { Inverse } \\
\text { (\# stdev) }\end{array}$ \\
\hline 11 & 0.02 & 30 & -2.00 \\
\hline 32 & 0.07 & 44 & -1.49 \\
\hline 64 & 0.11 & 52 & -1.21 \\
\hline 70 & 0.16 & 58 & -1.00 \\
\hline. &. &. &. \\
\hline. &. &. &. \\
\hline. &. &. &. \\
\hline 108 & 0.8 & 107 & 0.8 \\
\hline 112 & 0.8 & 112 & 1.0 \\
\hline 121 & 0.9 & 118 & 1.2 \\
\hline 123 & 0.9 & 125 & 1.5 \\
\hline 125 & 1.0 & 139 & 2.0 \\
\hline
\end{tabular}

$\begin{array}{rc}\text { Mean (psi) } & 84.7 \\ \text { Stdev (psi) } & 27.2 \\ \text { Data Count (\#) } & 22 \\ \text { Skewness } & -0.91 \\ \text { Significant? } & \text { No }\end{array}$

The figure shows data that is normally distributed compared to the compressive strength data. If the data is compared, it is clear that compressive strength follows the normally distributed data fairly closely, and can be considered normal. The same is also shown for the MOR. 


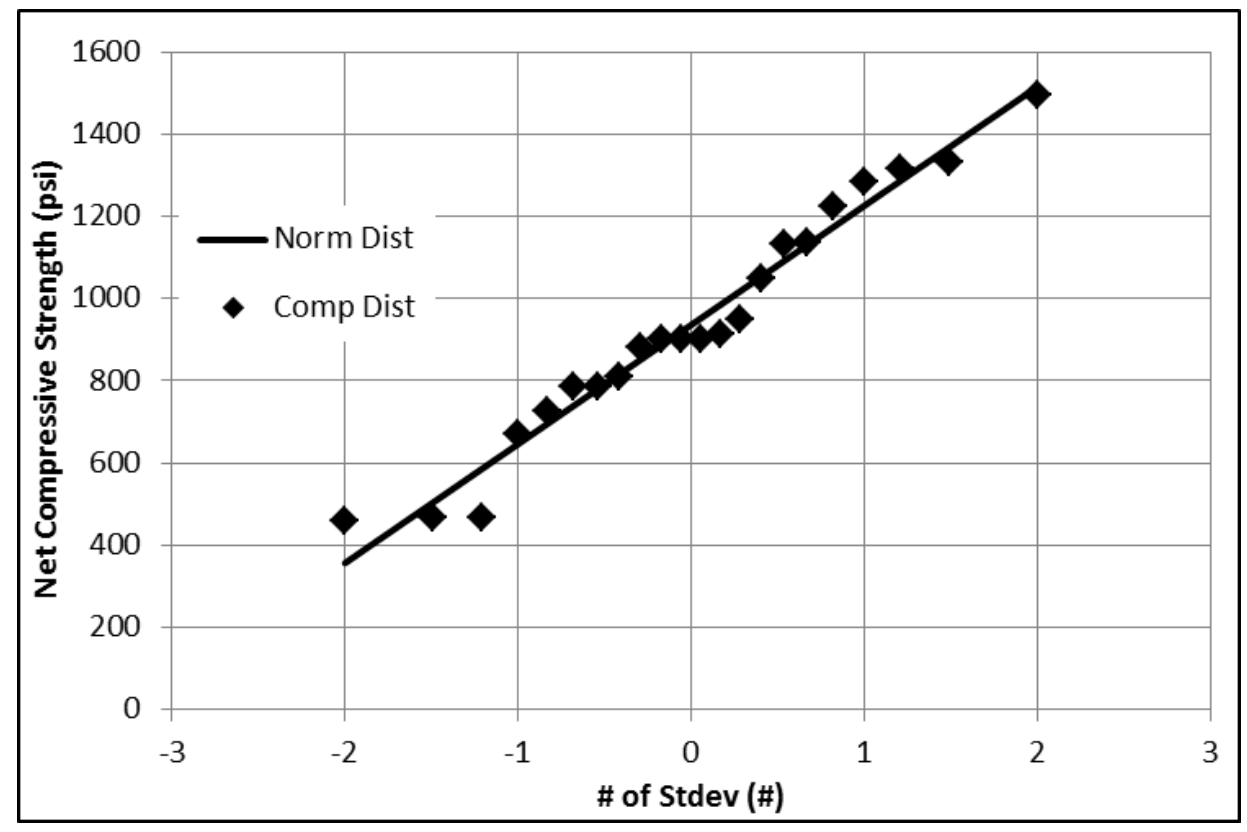

Figure 5.3.2-1 Compressive Strength Data Distribution

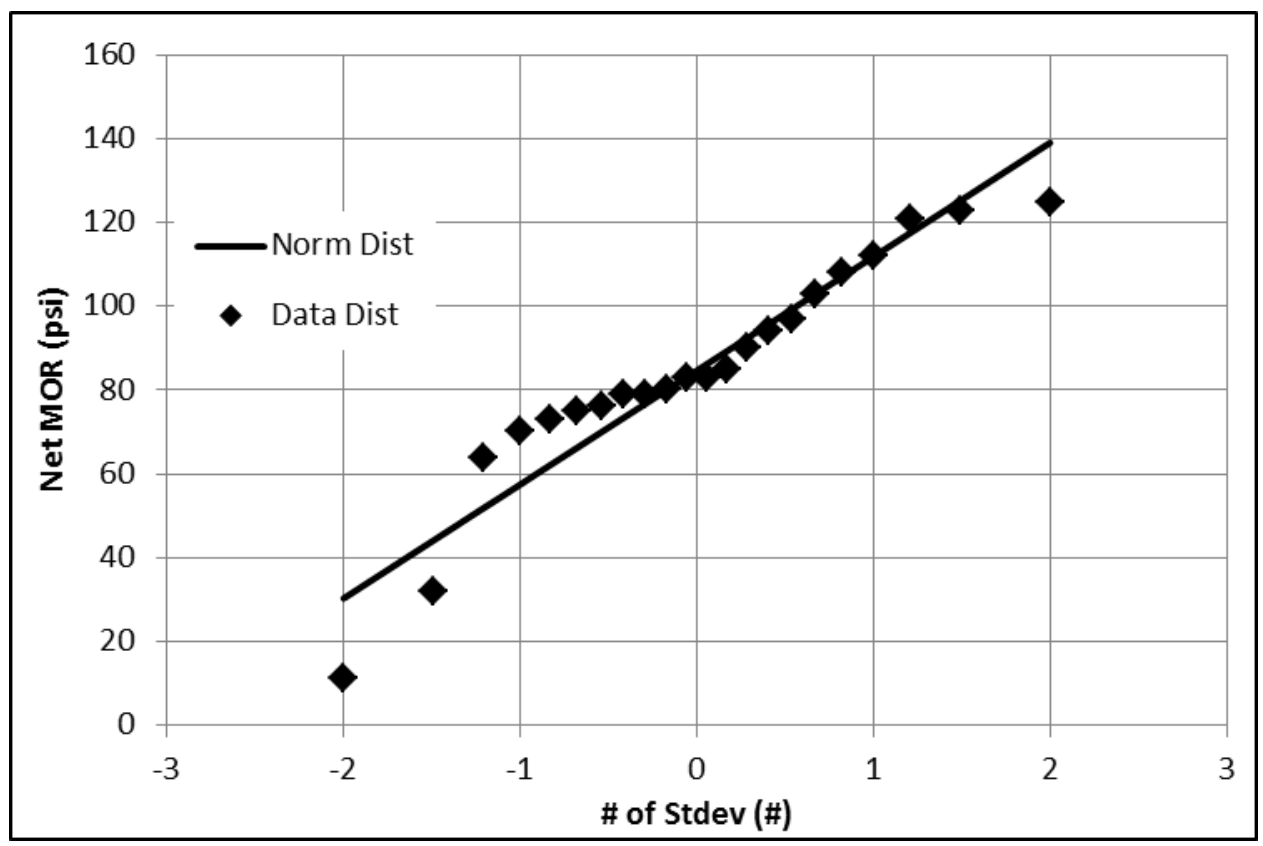

Figure 5.3.2-2 MOR Data Distribution 


\subsubsection{Confidence Intervals}

After the data was confirmed to be normally distributed, a confidence interval could be created.

In order to create a confidence interval, a Student's t distribution was assumed. The Student's t distribution is a simplification of normally distributed data: any data that is normally distributed also conforms closely to Student's t distribution. This distribution is computationally efficient and more commonly utilized in data analysis, and was used in this experiment.

The first step in creating a confidence interval was to plot the batch averages and observe a linear best fit curve. This line would form the median of the data analyzed and the confidence interval.

The boundary conditions of the equation need also be considered. Due to the limited amount of data available, the equation predicting MOR would only be valid between compressive strengths of 400psi and 1600psi.

With the batch averages and median equation, the standard error of the data could be calculated, which is a measurement of variability similar to standard deviation. From the standard error, a confidence interval could be created. 


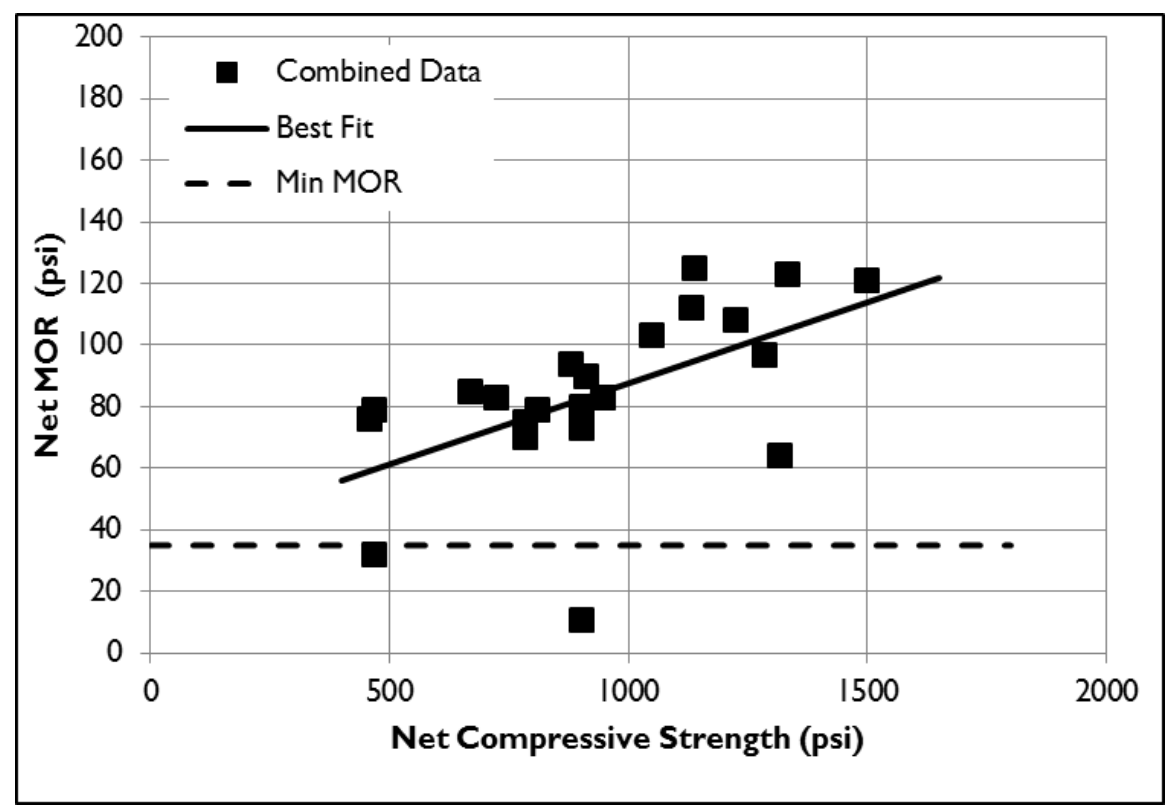

Figure 5.3.3-1 Data Best Fit Line and Equation

$$
f_{r}(p s i)=.0526 * f_{C E B}(p s i)+35 p s i
$$

The slope value from the best fit line was taken and used to predict the MOR of each compressive strength data point. The differences between the predicted and actual MORs were taken, and that error value was squared.

$$
f_{\text {Error }}=\left(f_{r \text { Adjusted }}-f_{r \text { Pred }}\right)^{2}
$$

The next step involved calculating the error between each compressive strength value and its mean. This error was also squared like MOR in order to eliminate negative values and highlight even small differences between the adjusted and ideal values.

$$
f_{C E B \text { Error }}=\left(f_{C E B \text { Adjusted }}-f_{C E B \text { Mean }}\right)^{2}
$$


Table 5.3.3-1 Standard Error Example Data

\begin{tabular}{|c|c|c|c|c|}
\hline $\begin{array}{c}\text { Comp } \\
\text { Strength } \\
(\mathrm{psi})\end{array}$ & $\begin{array}{c}\text { MOR } \\
\text { Strength } \\
(\mathrm{psi})\end{array}$ & $\begin{array}{c}\text { Predicted } \\
\text { MOR } \\
\text { Strength } \\
(\mathrm{psi})\end{array}$ & $\begin{array}{c}\text { MOR } \\
\text { Error }^{2} \\
(\mathrm{psi})^{2}\end{array}$ & $\begin{array}{c}\text { Compr }^{2} \\
\text { Error }^{2} \\
\text { (psi) }^{2}\end{array}$ \\
\hline 902 & 73 & 82 & 89 & 1165 \\
\hline 1226 & 108 & 99 & 72 & 1503076 \\
\hline 811 & 79 & 78 & 2 & 657721 \\
\hline 1138 & 125 & 95 & 908 & 1295044 \\
\hline 1048 & 103 & 90 & 166 & 1098304 \\
\hline 1285 & 97 & 103 & 31 & 1651225 \\
\hline 1498 & 121 & 114 & 52 & 2244004 \\
\hline 948 & 83 & 85 & 3 & 898704 \\
\hline 459 & 76 & 59 & 284 & 210681 \\
\hline 670 & 85 & 70 & 218 & 448900 \\
\hline 467 & 32 & 60 & 760 & 218089 \\
\hline 1334 & 123 & 105 & 318 & 1779556 \\
\hline 1132 & 112 & 95 & 305 & 1281424 \\
\hline 467 & 79 & 60 & 378 & 218089 \\
\hline 725 & 83 & 73 & 97 & 525625 \\
\hline 903 & 11 & 82 & 5112 & 815409 \\
\hline 903 & 80 & 82 & 6 & 815409 \\
\hline 881 & 94 & 81 & 160 & 776161 \\
\hline 1316 & 64 & 104 & 1618 & 1731856 \\
\hline 913 & 90 & 83 & 49 & 833569 \\
\hline 785 & 70 & 76 & 40 & 616225 \\
\hline 784 & 75 & 76 & 2 & 614656 \\
\hline
\end{tabular}

Mean (psi) 936

Data Count (\#) 22

$\Sigma$ Error (psi) $)^{2}$

$\Sigma$ Error/n-2

SQRT Error

Standard Error
$10670 \quad 20234892$

533

$23.1 \quad 4498.3$ 0.0051 
The equation for standard error is shown below:

$$
\text { Standard Error }=\frac{\sqrt{\frac{\sum f_{r \text { Error }}}{n-2}}}{\sqrt{\sum f_{\text {CEB Error }}}}
$$

Where $\mathrm{n}$ is the number of data points, and $\mathrm{f}_{\mathrm{r} \text { Error }}$ and $\mathrm{f}_{\mathrm{CEB} \text { Error }}$ are the error values given above.

With the standard error calculated, the confidence interval could now be chosen. A confidence interval of $99 \%$ was chosen, which is atypical of material testing. This large interval was chosen to best fit the CEB data, which is highly variable in nature.

With the confidence interval chosen, the margin of error could now be calculated. The margin of error manipulates the slope of the best fit line to create the upper and lower bounds of the confidence interval. The calculation process is shown below: 
Confidence Interval $(\mathrm{Cl}): \quad 99 \%$

$$
\begin{aligned}
& \alpha=1-\left(\frac{C I}{100 \%}\right) \\
& \alpha=1-\left(\frac{99}{100 \%}\right)=.01
\end{aligned}
$$

Critical Probability $=1-\left(\frac{\alpha}{2}\right)$

Critical Probability $=1-\left(\frac{.01}{2}\right)=.995$

Degrees of Freedom $=n-2$

Degrees of Freedom $=22-2=20$

Using the Degrees of Freedom and Critical Probability (cumulative) find the probability of that event occuring with a Student's $t$ distribution

Critical Value (t dist) $\quad 2.659$

$$
\begin{aligned}
& \text { Margin of Error }=\text { Standard Error } * \text { Critical Value } \\
& \text { Margin of Error }=.0051 * 2.659=.0136
\end{aligned}
$$

Now the Margin of Error is added or subtracted from the slope of the best fit line to create the upper and lower bounds of the $\mathrm{Cl}$

$$
\begin{aligned}
& \text { CI Upper Bound }=.0523+.0136=.066 f_{C E B}+35 \\
& \text { CI Lower Bound }=.0523-.0136=.039 f_{C E B}+35
\end{aligned}
$$

Now the upper and lower bounds can be plotted to observe how a $99 \%$ confidence interval fits the given data. 


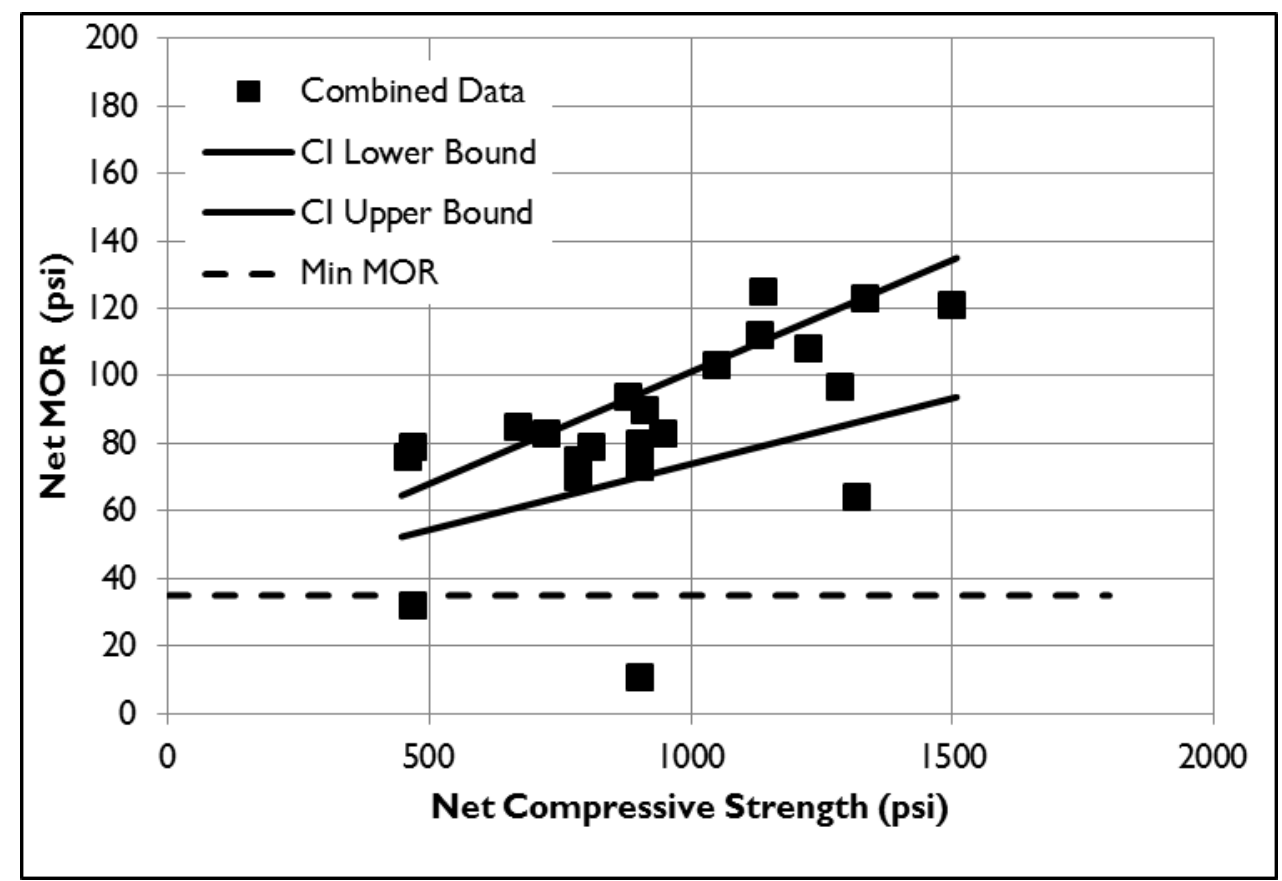

Figure 5.3.3-2 Data with Confidence Intervals

It is clear that a $99 \%$ confidence interval is not perfectly conservative, but the vast majority of data falls above the $99 \%$ lower bound. This renders the $99 \%$ lower bound a sufficiently conservative equation for the prediction of MOR.

$$
f_{r}(p s i)=\left(\frac{1}{26}\right) * f_{C E B}(p s i)+35 p s i
$$

With the new prediction equation calculated, each soil will be examined to gauge the equation's accuracy. 


\subsubsection{Las Tablas Soil}

Due to the amount of CEBs created, there was a significant amount of data to be utilized.

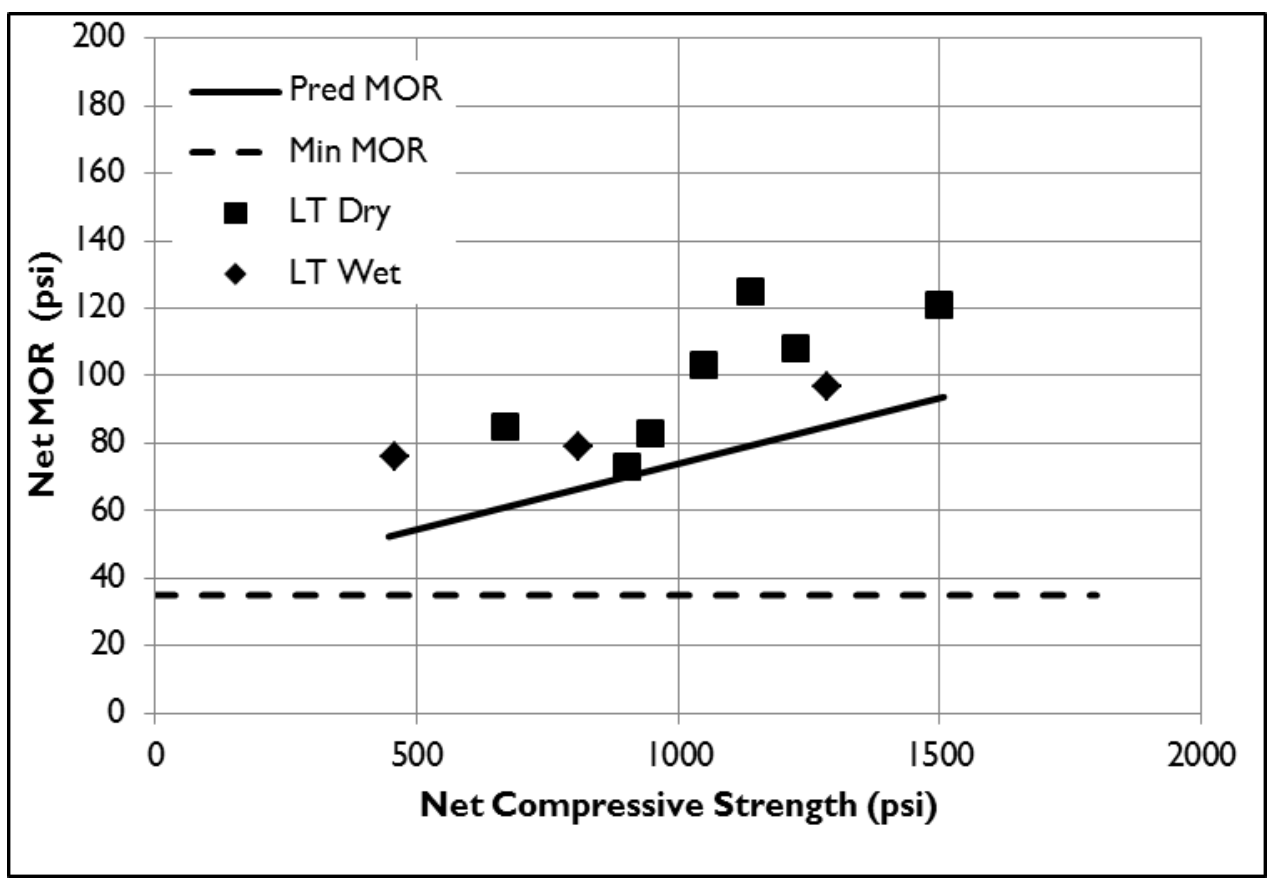

Figure 5.3.4-1 Las Tablas Predicting MOR

The predictive equation for MOR seems to be reasonably conservative and fit this data well, both wet and dry cured averages. 


\subsubsection{Prado Soil}

Next, the relationship between compressive strength and MOR was analyzed using the Prado CEBs:

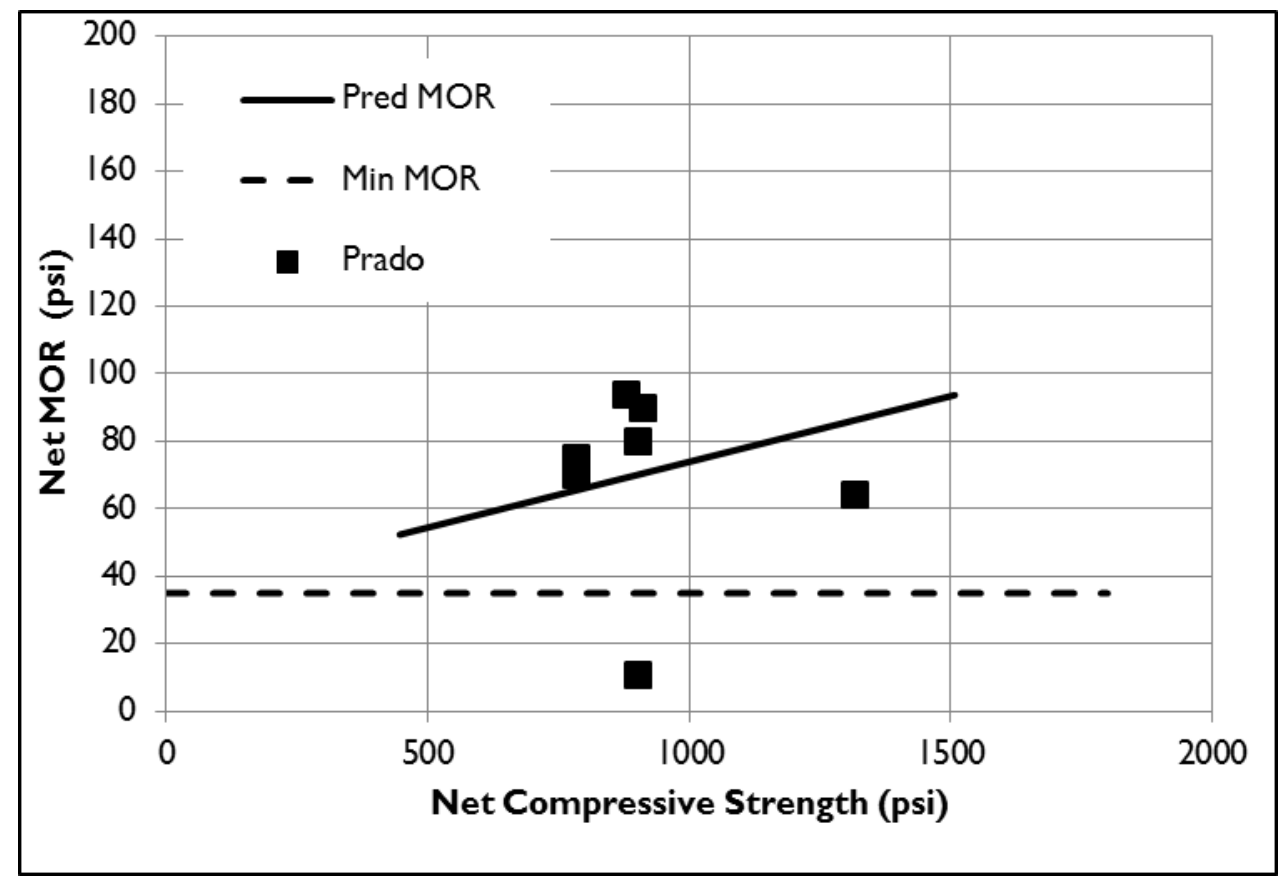

Figure 5.3.5-1 Prado Predicting MOR

While there are some CEBs that fail the minimum strength requirement, the remaining blocks fit the relationship well. There was not sufficient wet cured data to be used in analysis, making it difficult to suggest this relationship for wet or saturated blocks. 


\subsubsection{Mind Body Soil}

Like the Prado soil, there were too few blocks wet cured for the data to be used in the analysis. As seen below, the MB data fits the relationship very well, although there is one batch that fails the minimum design strength set by the IBC.

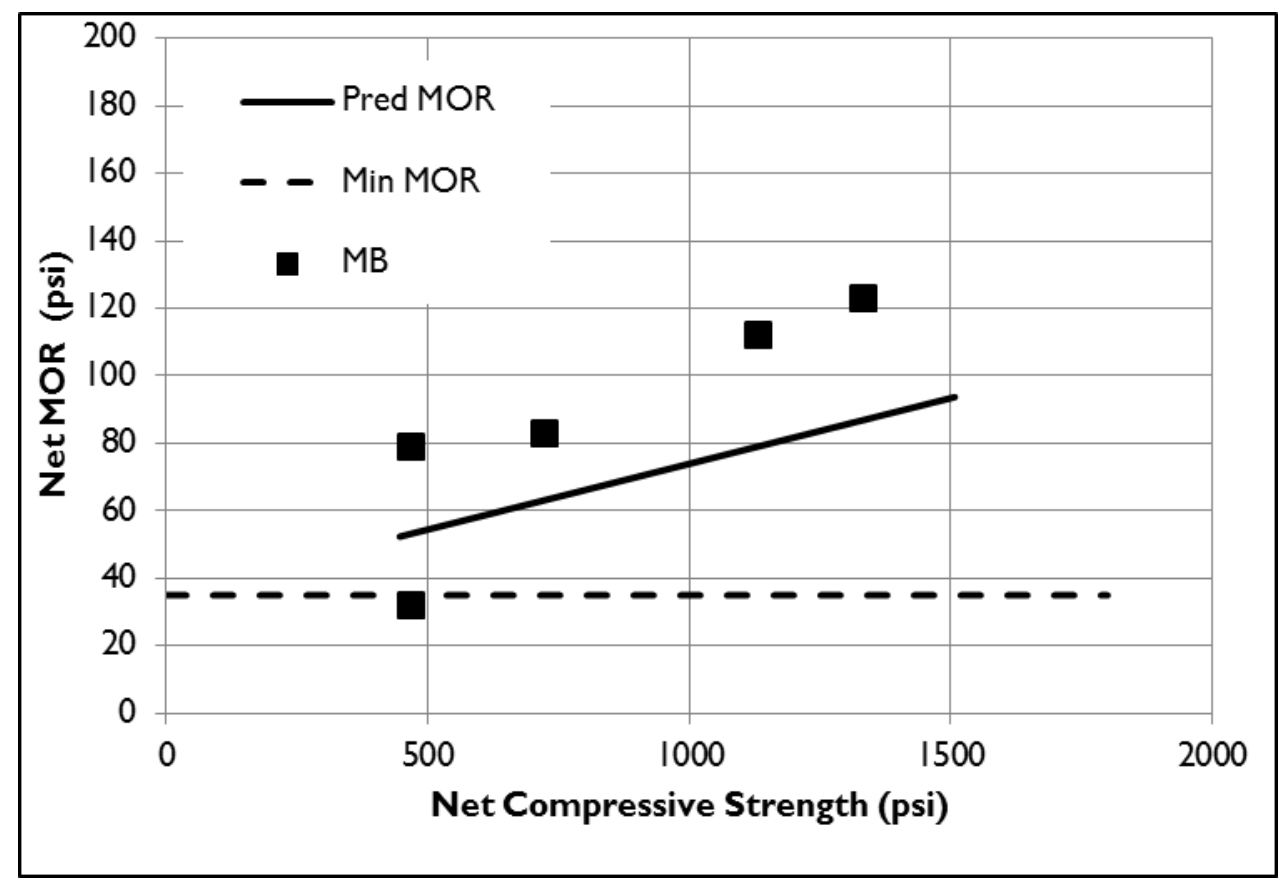

Figure 5.3.6-1 Mind Body Predicting MOR

The data would suggest that the MB CEBs can also use the prediction equation.

Overall, it can be seen that the $99 \%$ lower bound predictive equation fits the data from all soil types and curing conditions. Although it has a limited range of 400psi1600psi compressive strength, it is a useful and conservative equation. 


\subsection{Effect of Clay Content}

Some clay is needed in CEBs. When the CEB mixture is moistened and compacted, the cement provides little to no initial strength, when the block must be removed from the press and transported for curing. The cohesive nature of clay is necessary to CEB production, but too much clay interferes with the reaction between cement and water, weakening the long term strength of the block (Walker 1995). Thus, an ideal clay content was predicted, with too high of a clay content rendering the blocks unsuitable for construction, and too low of a clay content creating blocks that were difficult to press and handle, lowering their strength and consistency.

The durability of CEBs was also expected to increase linearly with decreasing clay content.

With each soil, different clay contents were designed and tested in compression only. None of the blocks were tested wet. In each case, the data was adjusted according to factors that affect CEB strength, detailed in Section 5.1.1.

Additionally, the moisture content of each sand content batch was measured to attempt to connect clay content and clay plasticity with the amount of water needed during mixing.

\subsubsection{Mixture Moisture}

The moisture content of each batch was collected and plotted. As can be seen, the Las Tablas batches possessed the highest moisture contents, while the Mind Body possessed the lowest. This is contrary to the trend in plasticity and expansion potential of each soil, which would suggest that the Prado batches would possess the highest moisture 
content. However, given the highly absorptive aggregate found within the LT soil, it becomes clear why the soil with the lowest plasticity clay absorbed so much water.

Table 5.4.1-1 Sand Batch Mixture Moisture

\begin{tabular}{|c|c|c|c|}
\hline Soil & $\begin{array}{c}\text { Clay } \\
\text { Content } \\
(\%)\end{array}$ & $\begin{array}{c}\text { Mixture } \\
\text { Moisture } \\
\text { Content } \\
(\%)\end{array}$ & $\begin{array}{c}\text { Average } \\
\text { Moisture } \\
\text { Content } \\
(\%)\end{array}$ \\
\hline Las Tablas & 27.8 & 19.6 & \multirow{6}{*}{14.4} \\
\hline Las Tablas & 22.3 & 17.3 & \\
\hline Las Tablas & 16.9 & 14.2 & \\
\hline Las Tablas & 13.5 & 12.2 & \\
\hline Las Tablas & 12.3 & 12.0 & \\
\hline Las Tablas & 8.1 & 11.0 & \\
\hline Prado & 26.1 & 11.2 & \multirow{5}{*}{9.2} \\
\hline Prado & 12.8 & 10.7 & \\
\hline Prado & 10.7 & 8.1 & \\
\hline Prado & 8.7 & 8.0 & \\
\hline Prado & 6.0 & 7.8 & \\
\hline Mind Body & 15.5 & 6.6 & \multirow{3}{*}{6.9} \\
\hline Mind Body & 13.2 & 7.7 & \\
\hline Mind Body & 10.0 & 6.4 & \\
\hline
\end{tabular}




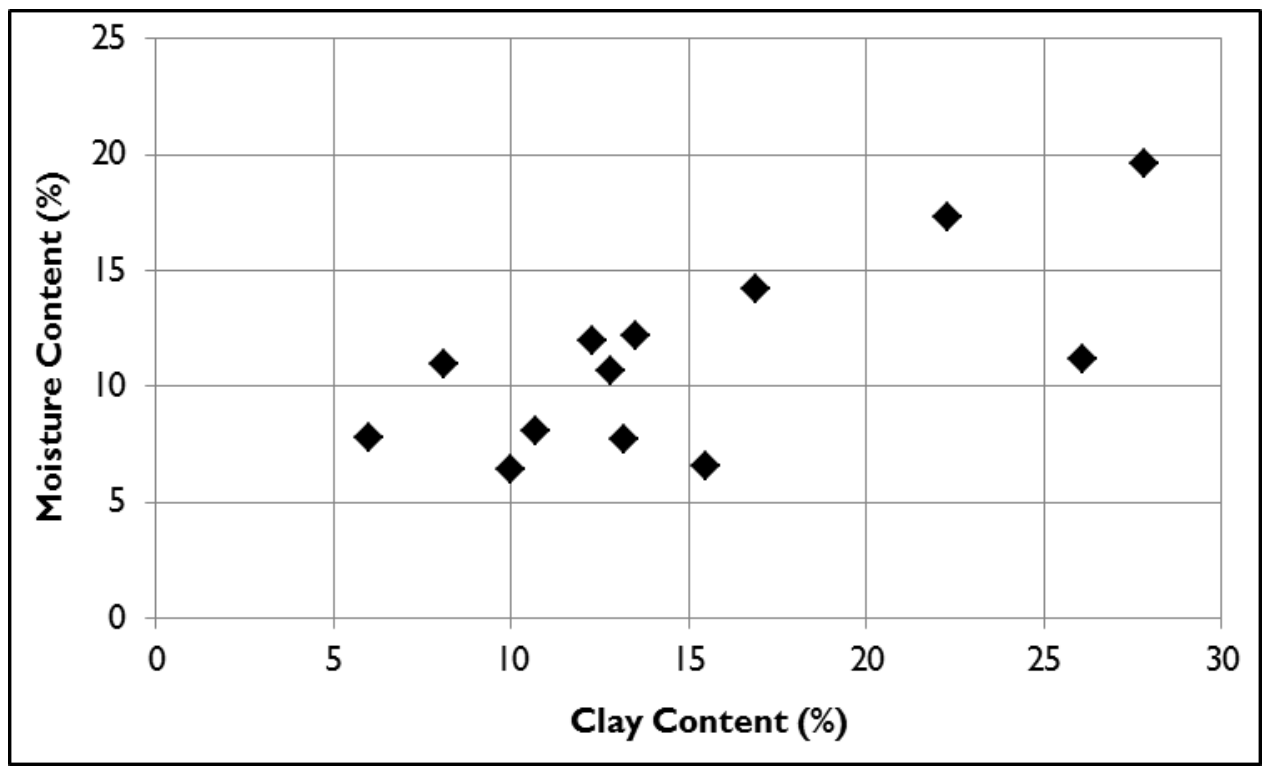

Figure 5.4.1-1 Clay Content vs. Moisture Content

The effects of clay content on the moisture content of the mixture show a linear trend: batches with more clay require more water. Considering the potential for clay to absorb water, especially when compared to the sand which was being added, this trend is unsurprising.

\subsubsection{Las Tablas Soil}

The LT soil utilized a variety of different clay contents, ranging from $27.4 \%$ to $8.3 \%$, corresponding to sand contents (SC) of $0 \%$ to $70 \%$. The data is seen below: 


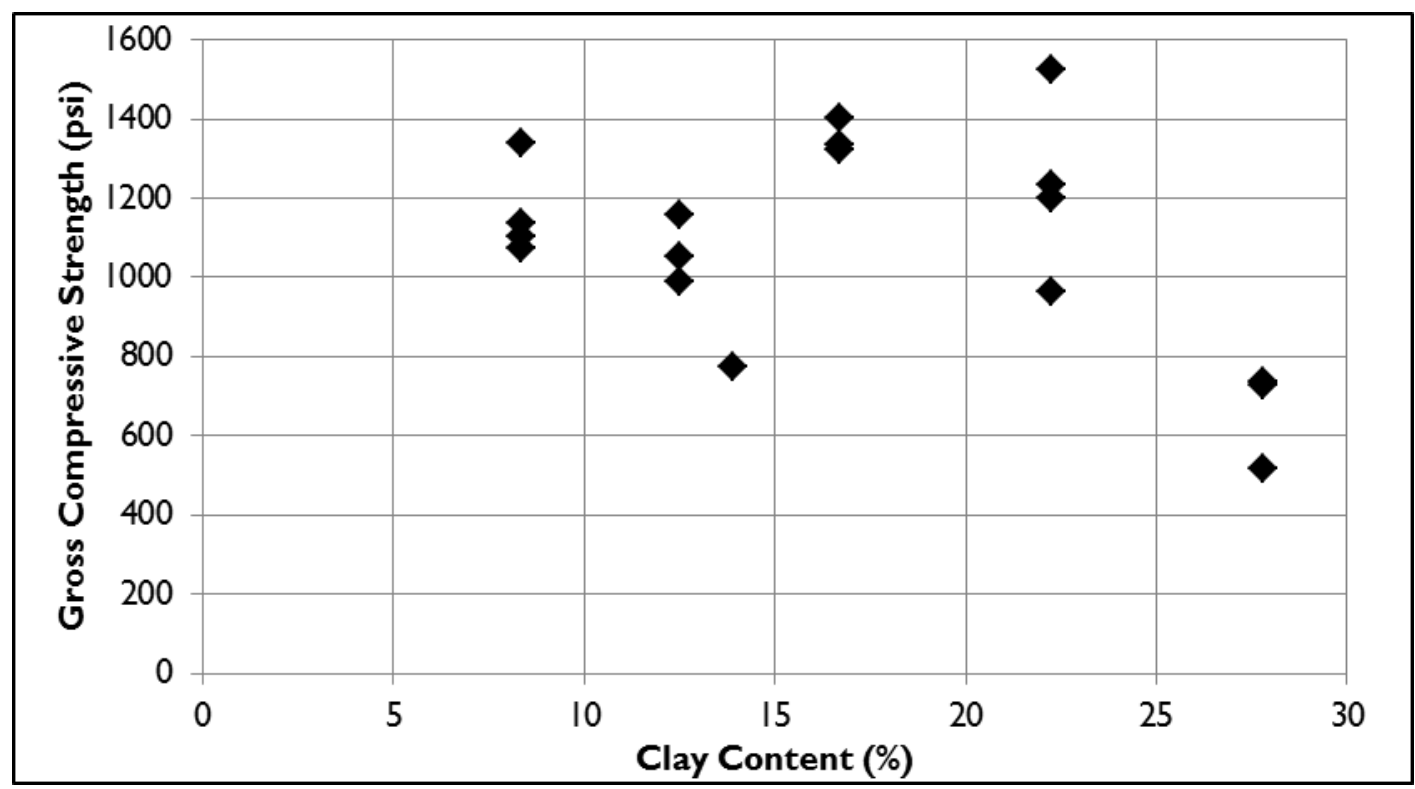

Figure 5.4.2-1 Las Tablas SC Results

The data exhibits no discernable trend, but seems to suggest that CEBs with high clay contents are weaker than those with more reasonable clay contents. The suggested clay content for V - Lock CEBs is $10 \%$ (De Jong 2012), although for the LT soil a higher clay content of $12 \%$ to $16 \%$ may be acceptable.

The average strengths are also shown, along with error bars showing one standard deviation. 


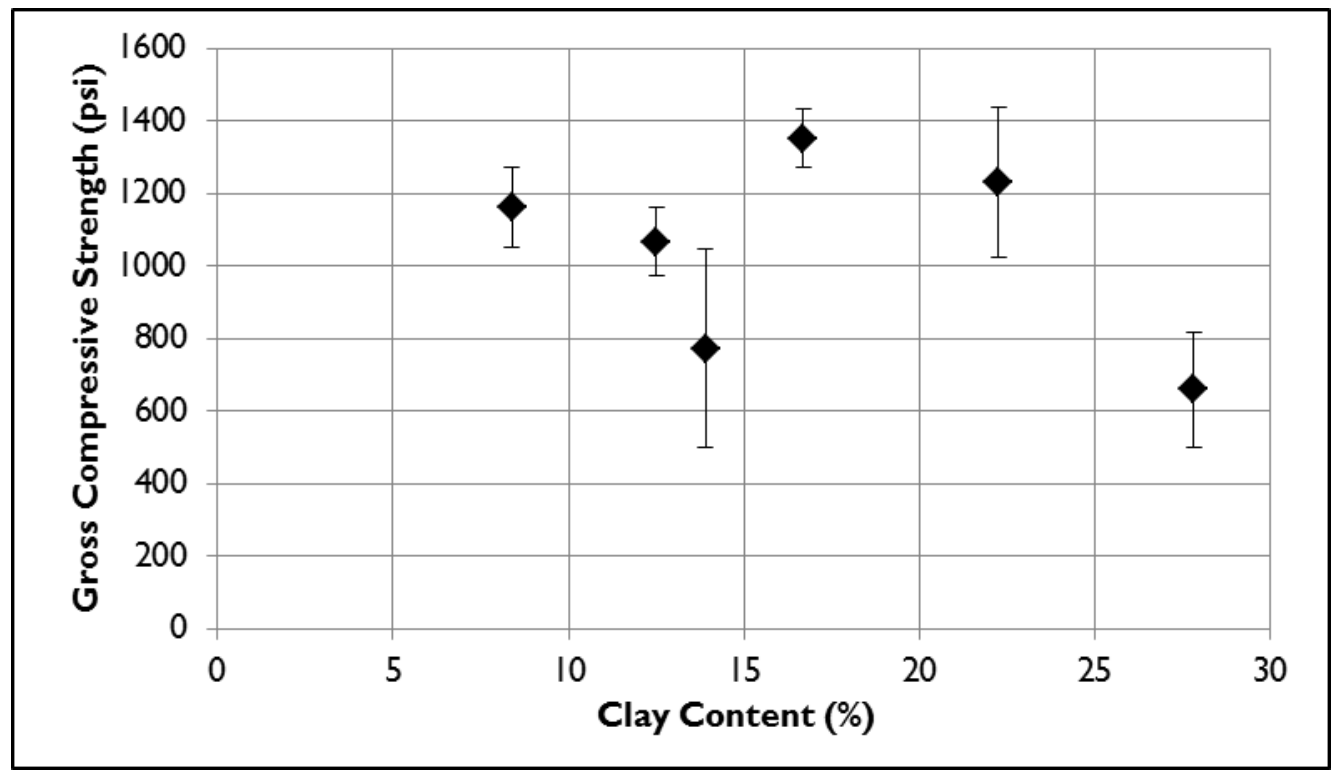

Figure 5.4.2-2 Average Las Tablas SC Results

In addition to compression tests, the durability of the LT0, LT20, LT50 and LT70 blocks were tested. As expected, CEBs with higher clay contents experienced greater mass loss from wetting and drying than those with lower clay contents. 


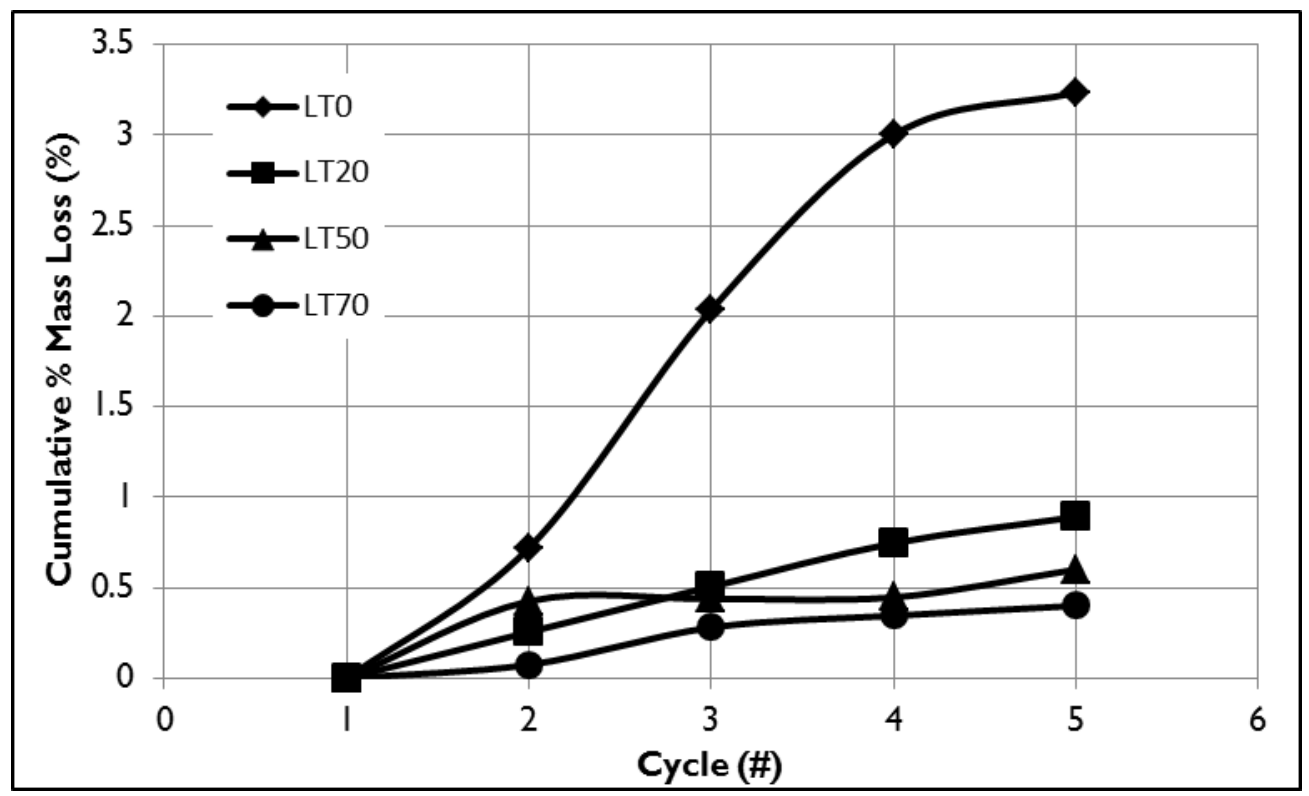

Figure 5.4.2-3 Las Tablas SC Durability Results

This confirms research (Walker 1995) that clay particles are detrimental to the durability of CEBs. While some particles bond with cement to form a matrix of reaction products, there are many unreacted clay particles that swell in contact with moisture, damaging the cement-clay matrix and causing the degradation observed.

The durability tests corroborate the strength results, and indicate that some amount of sand is necessary in the LT soil to reduce the clay content. When more than $50 \%$ of the LT soil is replaced by sand, then there seems to be little increase in durability. 


\subsubsection{Prado Soil}

Fewer sand content batches were chosen for the Prado CEBs because initial testing suggested a high clay content within the soil. The adjusted data is below:

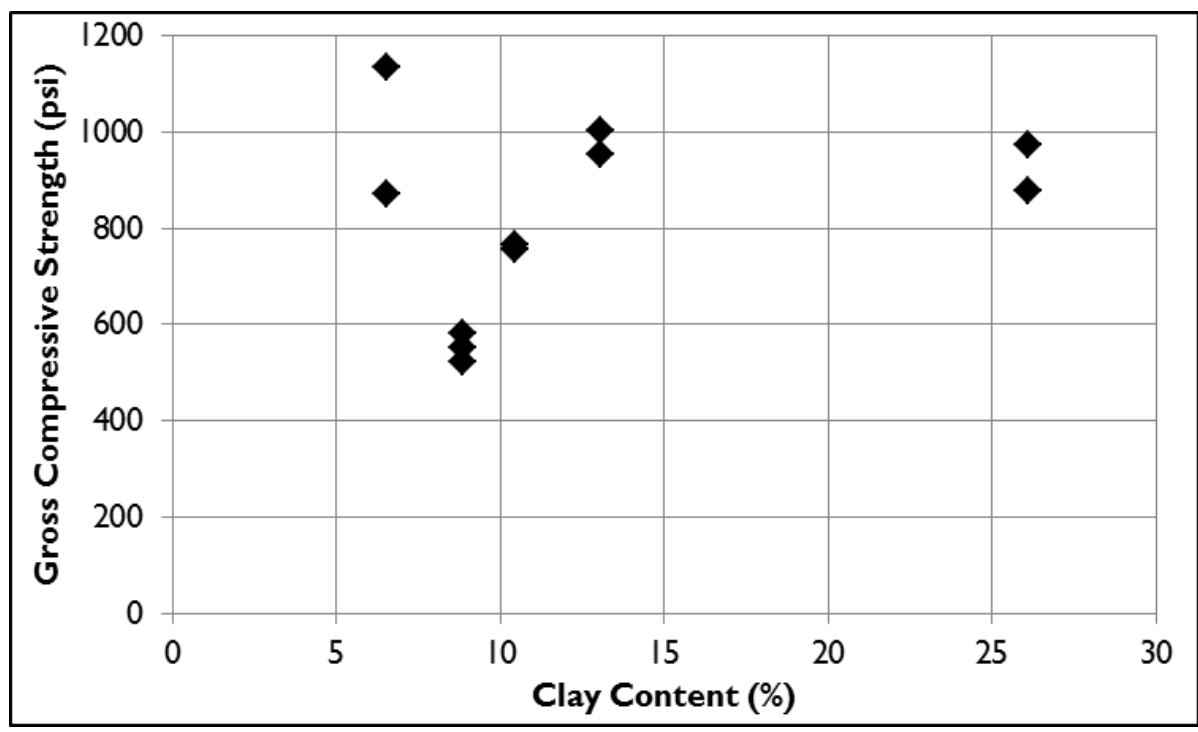

Figure 5.4.3-1 Prado SC Results

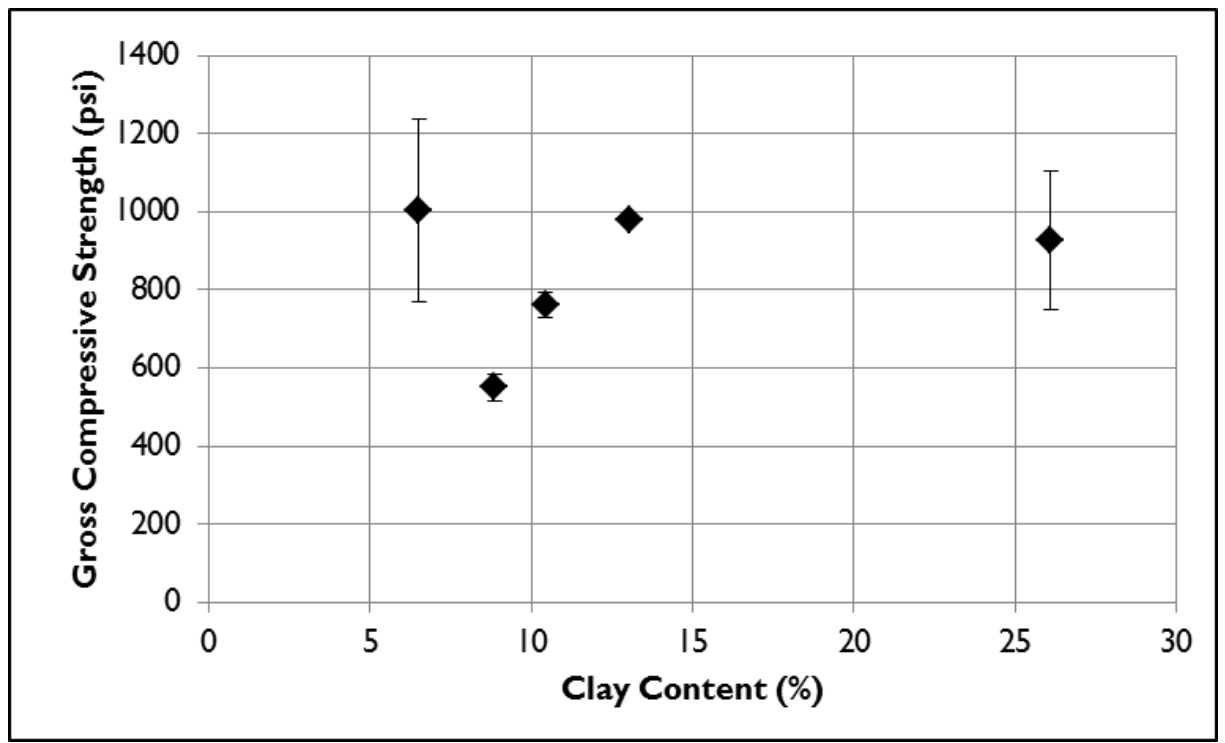

Figure 5.4.3-2 Average Prado Results 
The Prado data does not follow any obvious trend regarding strength. This could be due to the relatively few blocks broken for each different sand content batch, as well as the gap in sand content batches tested. As is evidenced by the figure above, some batches possessed very little variation block to block, while others experienced a variation more typical to the LT soil, making any conclusion based on strength suspect.

The durability testing suggests a trend between clay content and durability, with high clay content CEBs experiencing rapid, obvious degradation, while low clay CEBs fared significantly better. Without additional clay contents tested, it is difficult to suggest a correlation based upon the durability testing alone.

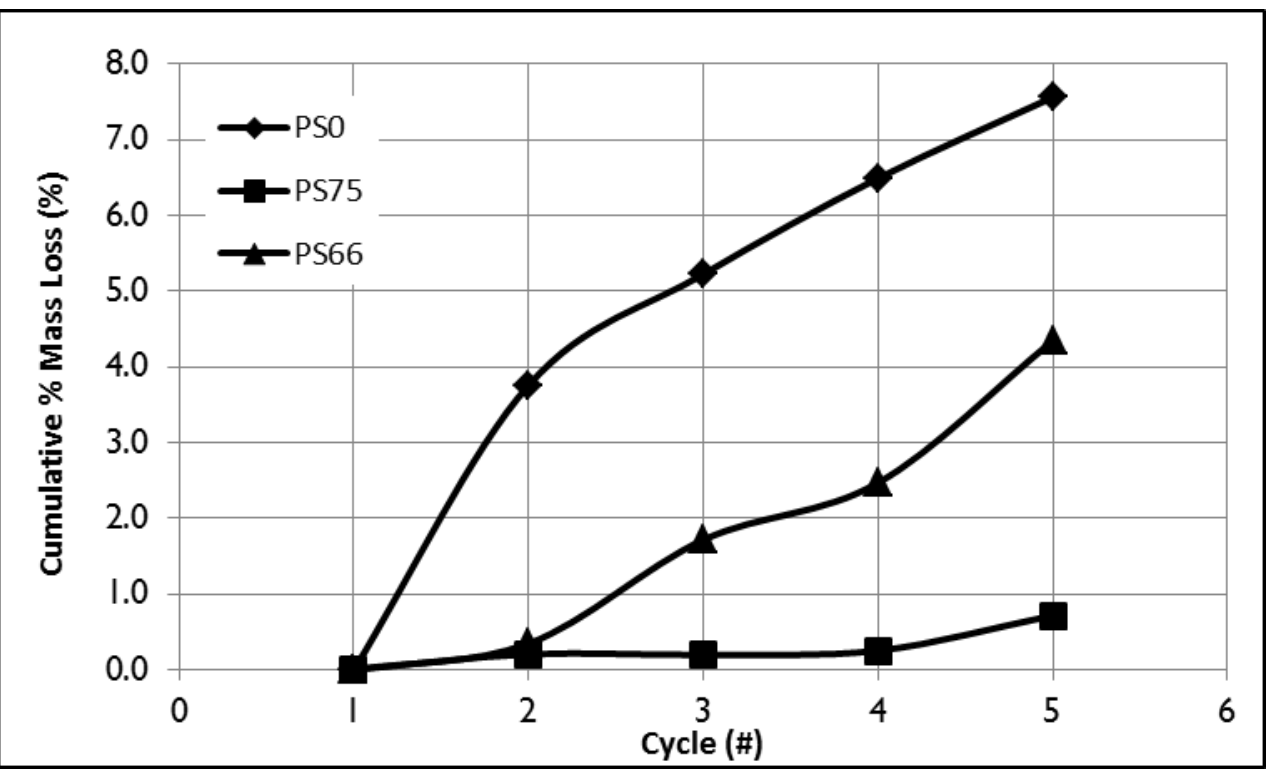

Figure 5.4.3-3 Prado SC Durability Results 


\subsubsection{Mind Body Soil}

There were only three sand content batches tested for the MB soil, and the results are shown below:

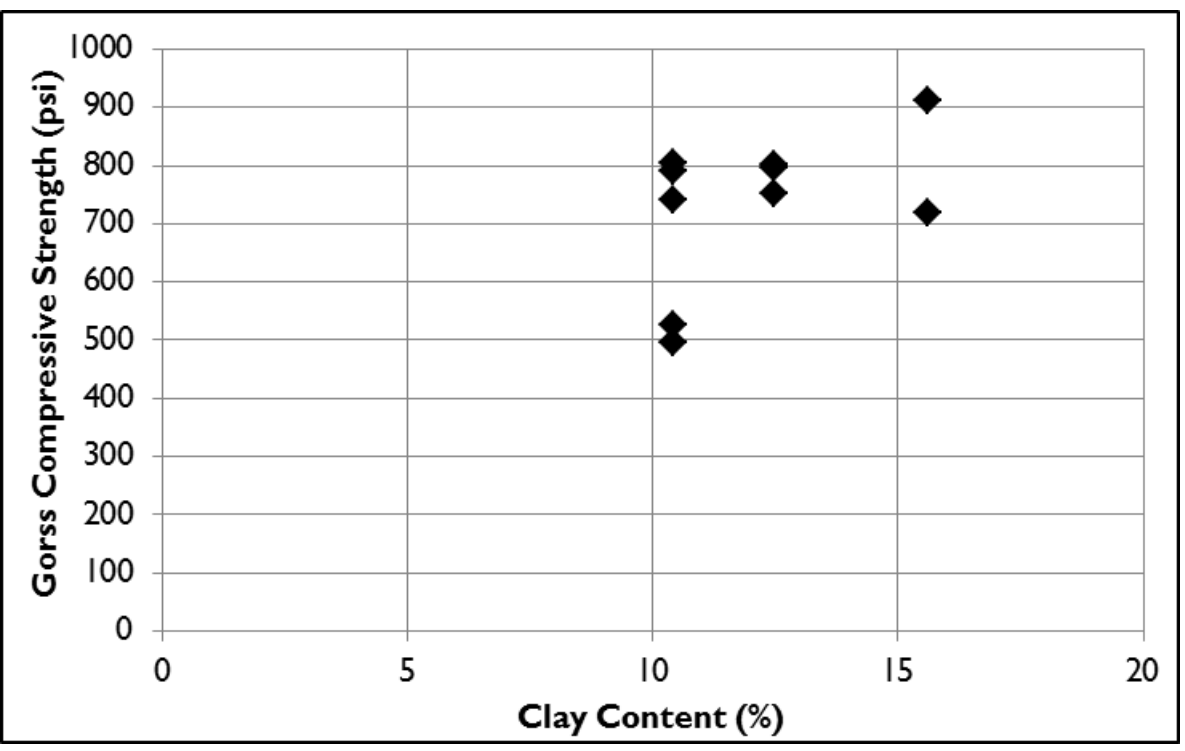

Figure 5.4.4-1 Mind Body SC Results

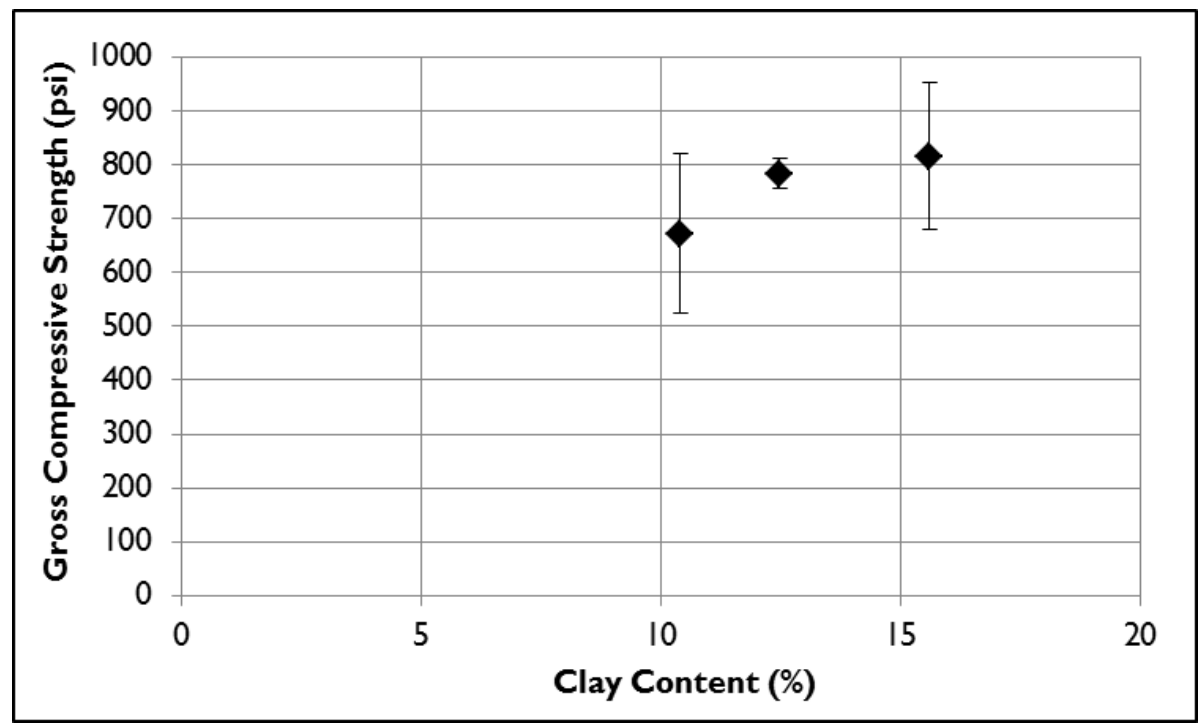

Figure 5.4.4-2 Average Mind Body Results 
Like the Prado soil, there is no clear trend between clay content and strength. Again there were relatively few sand content batches tested, and there were significant differences between batch variability. This makes it difficult to identify any trend.

Only a single sand content was tested for durability, as seen below. No comparisons can be drawn, although it is interesting to note the high mass loss sustained by the MB50 batch, which was the standard sand content chosen for the MB soil.

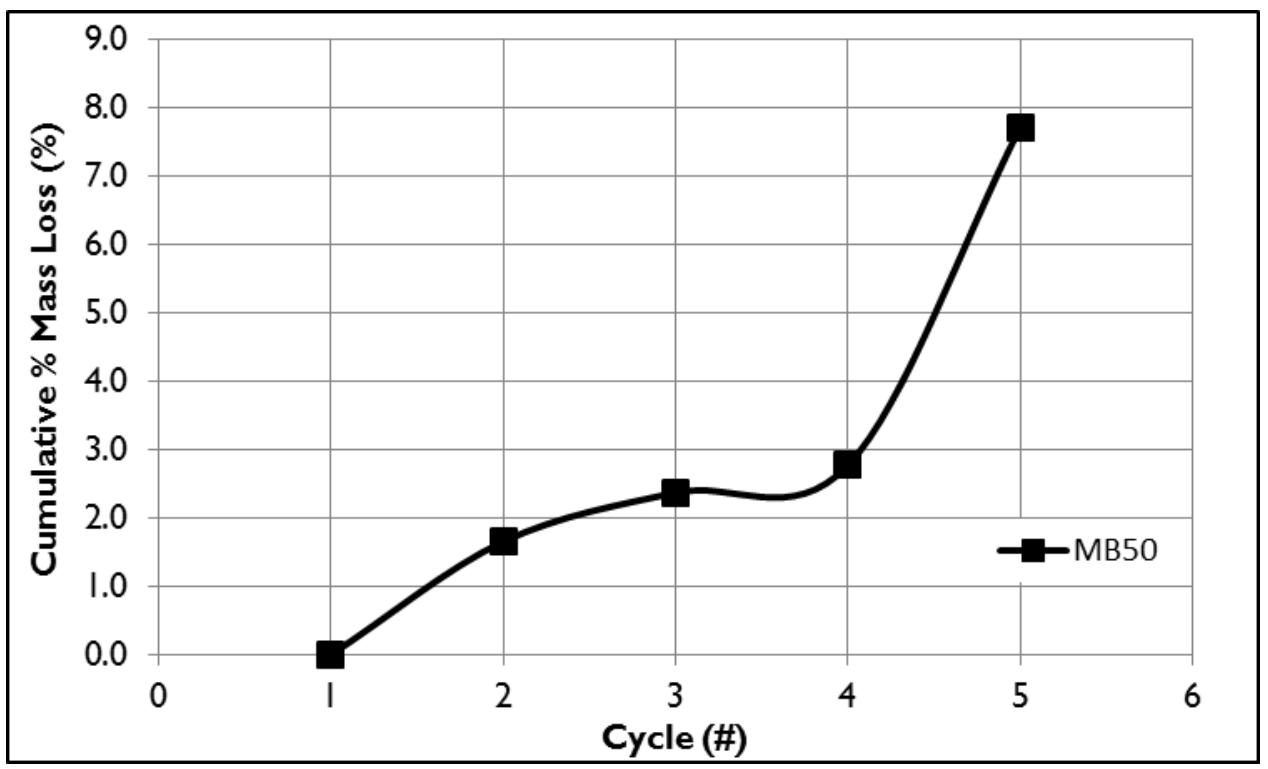

Figure 5.4.4-3 Mind Body SC Durability Results

\subsubsection{Combined Results}

After analyzing each soil individually, all of the adjusted data was combined to attempt to determine any global trends from the CEBs tested.

From the figure below, lower clay contents seem to result in stronger CEBs, and it is interesting to note that the LT and Prado blocks possessed similar strengths when their clay contents dropped below $10 \%$. At higher clay contents, it is difficult to identify any 
trend, especially considering the variability in each batch and the limited number of samples tested.

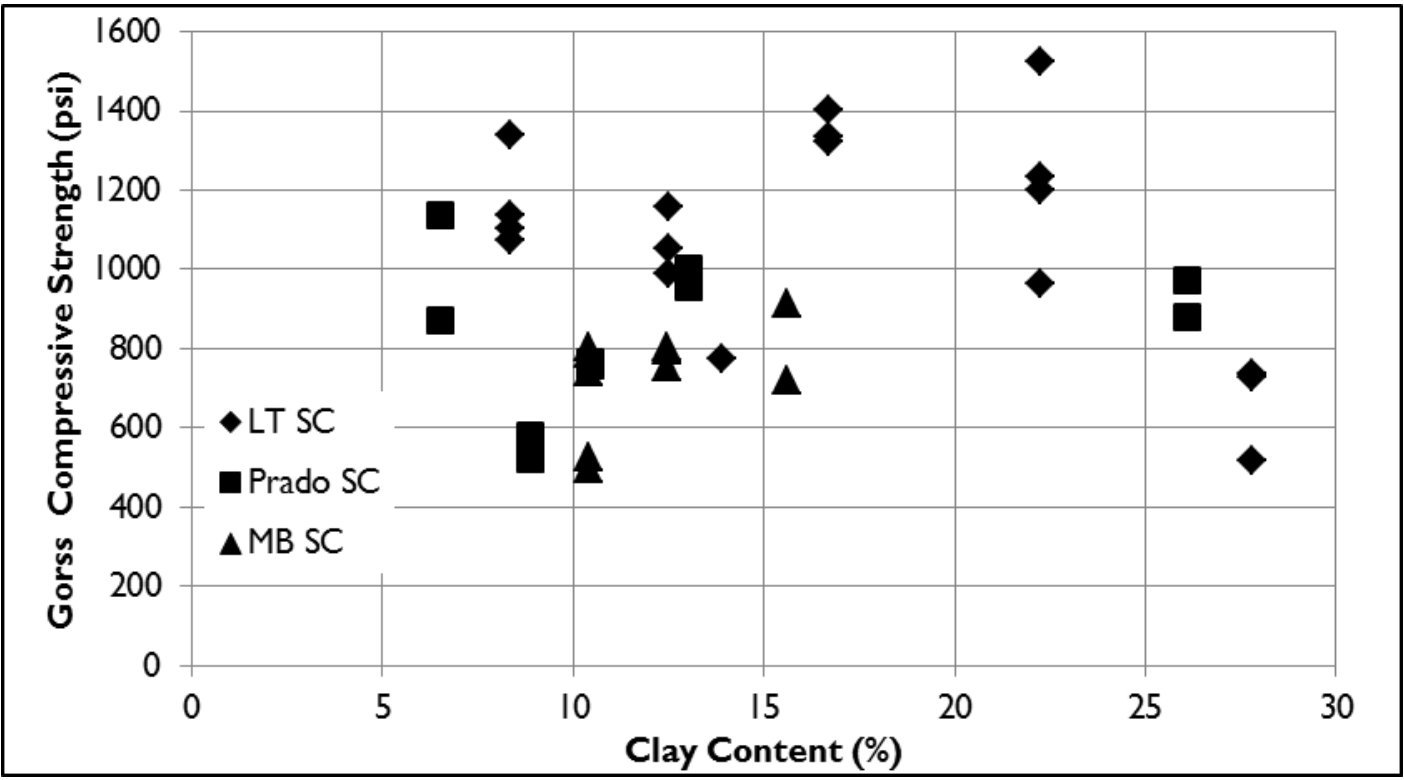

Figure 5.4.5-1 Combined Strength Data 


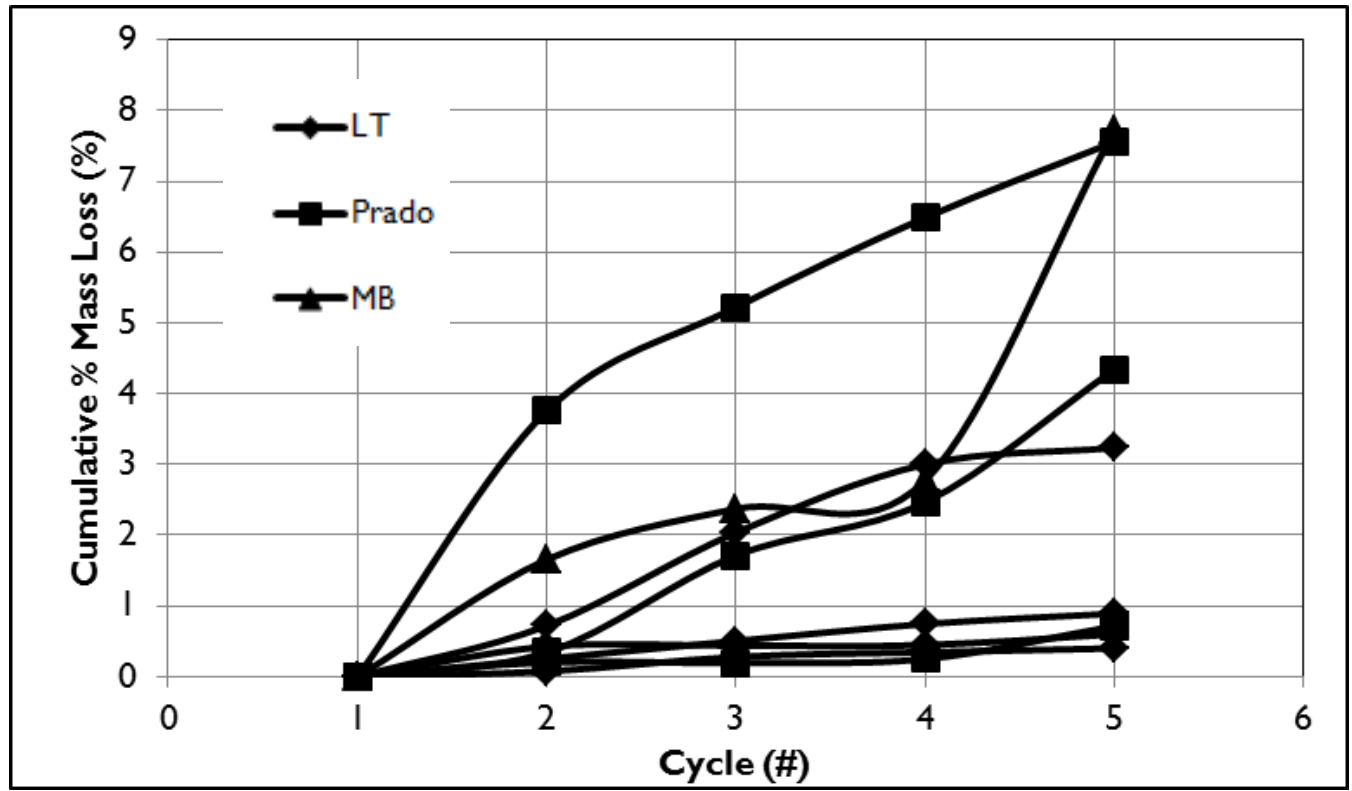

Figure 5.4.5-2 Combined Durability Results

The durability results show a strong trend. At low clay contents, both the LT and Prado soils exhibit negligible mass loss, while at higher clay contents significant deterioration is observed.

When each soil is compared at their standard sand content, or the primary sand content used throughout this project, it can be seen that the MB soil exhibits significantly higher mass loss when compared to the Prado and LT soils. 


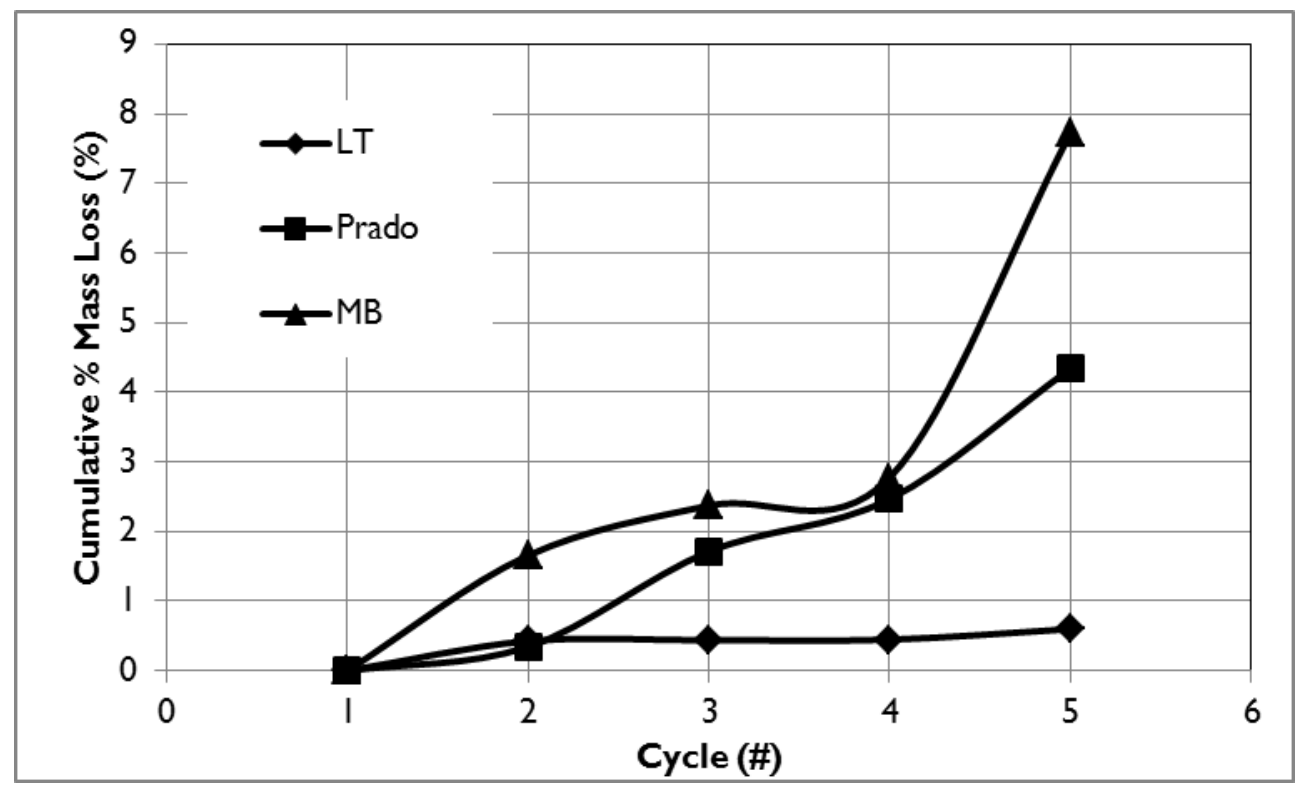

Figure 5.4.5-3 Soil Durability Comparison

This is surprising, since the standard clay content for the LT soil is $13.5 \%$, while the Prado clay content is $8.6 \%$ and the MB is $10.4 \%$. When the clay contents and their plasticity are considered, it would seem that the Prado and MB soils would see similar durability. Unfortunately, there is no batch of CEBs for each soil that possesses the same clay content so the effects of plasticity may be easily compared. This makes any conclusion or recommendation difficult.

Both the strength and durability data suggests clay content needs to be considered in CEB production. High clay contents should be avoided, as they produce blocks with poor durability and potentially lower strength. While each soil possesses its own range of acceptable clay contents, it appears that clay contents of over $20 \%$ should be avoided. Unfortunately, no broad conclusion can be drawn from this analysis. 


\subsection{Effect of Cement Content (CC)}

Most CEBs and modern earthen construction utilizes chemical stabilizers, with cement the most common choice. Using too much cement can increase material costs and diminish the environmental benefits of CEBs, so it is imperative to minimize the use of cement.

From previous experiments (Lima et al. 2012) it appeared that an increase in cement content corresponded to a linear increase in strength, although at higher contents, diminishing strength gain was reported (Pave 2007). This diminishing gain in strength seemed to occur when the cement content rose above $10 \%$ by weight, so a similar bilinear relationship was proposed and a cement content of $12 \%$ was chosen.

Durability was proposed to exponentially decrease with decreasing cement content, as suggested by previous work (Walker 1995). Unlike strength, the durability results did not seem to reach a point of diminishing returns, which made the choice of a high cement content natural.

For each soil, three cement contents were chosen and tested in both compression and modulus of rupture. The data was adjusted and the results are detailed by soil, then combined for global analysis.

The mixture moisture of each cement content batch was also measured in an attempt to illustrate a trend between increased cement content and increased moisture content. 


\subsubsection{Mixture Moisture}

The batch moisture contents are shown below:

Table 5.5.1-1 Cement Content Mixture Moistures

\begin{tabular}{|c|c|c|c|c|}
\hline Soil & $\begin{array}{c}\text { Clay } \\
\text { Content } \\
(\%)\end{array}$ & $\begin{array}{c}\text { Cement } \\
\text { Content } \\
(\%)\end{array}$ & $\begin{array}{c}\text { Mixture } \\
\text { Moisture } \\
\text { Content } \\
(\%)\end{array}$ & $\begin{array}{c}\text { Average } \\
\text { Moisture } \\
\text { Content } \\
(\%)\end{array}$ \\
\hline Las Tablas & 13.5 & 4 & 11.7 & \multirow{3}{*}{12.4} \\
\hline Las Tablas & 13.5 & 8 & 12.2 & \\
\hline Las Tablas & 13.5 & 12 & 13.3 & \\
\hline Prado & 8.7 & 4 & 5.7 & \multirow{3}{*}{6.8} \\
\hline Prado & 8.7 & 8 & 8.0 & \\
\hline Prado & 8.7 & 12 & 6.8 & \\
\hline Mind Body & 10.0 & 4 & 6.5 & \multirow{3}{*}{7.3} \\
\hline Mind Body & 10.0 & 8 & 6.4 & \\
\hline Mind Body & 10.0 & 12 & 9.1 & \\
\hline
\end{tabular}




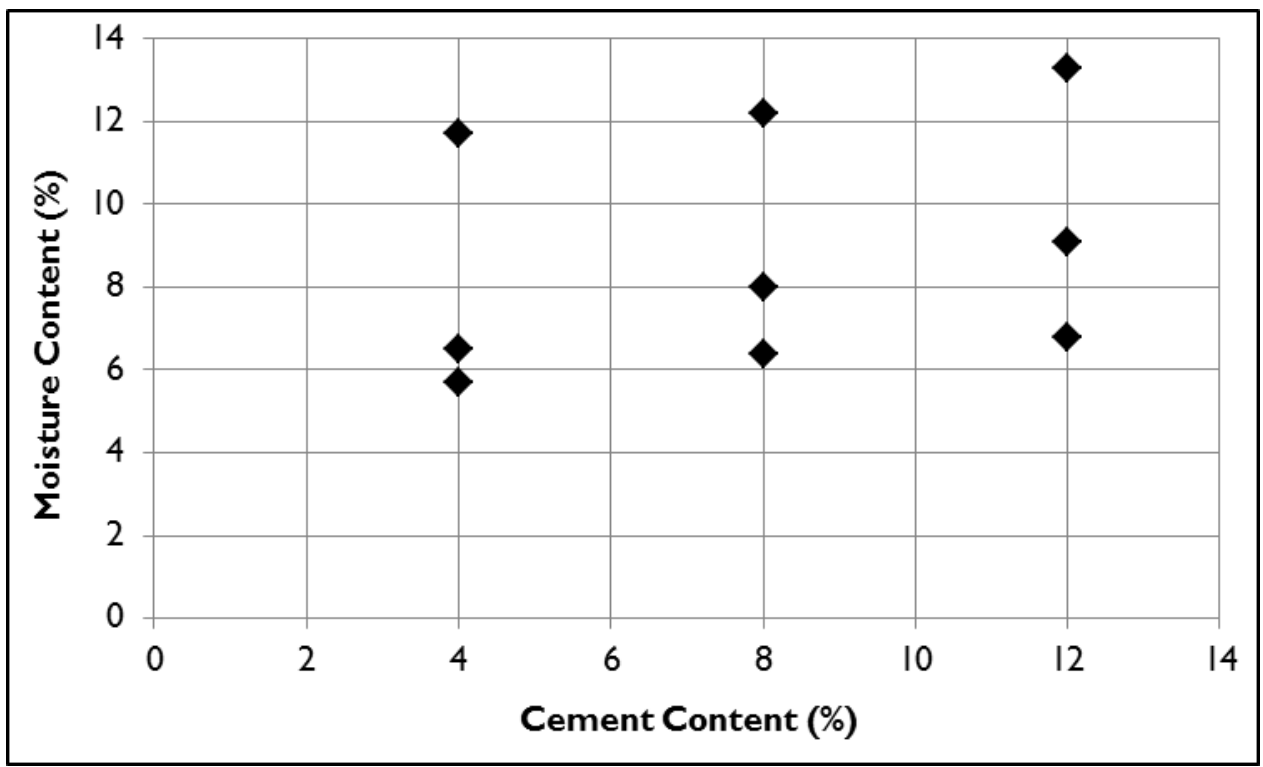

Figure 5.5.1-1 Cement Content vs. Moisture Content

As can be seen, the LT soil again has the highest moisture content, with the Prado soil possessing the smallest average moisture content. In each soil, the cement added to the mixture, the higher the water demand, as evidenced by the figure.

Since cement requires a significant amount of water to hydrate, it is clear that more cement should equate to a higher moisture content, since more water was added to the mixture. 


\subsubsection{Las Tablas Soil}

The LT cement content batch results are listed below:

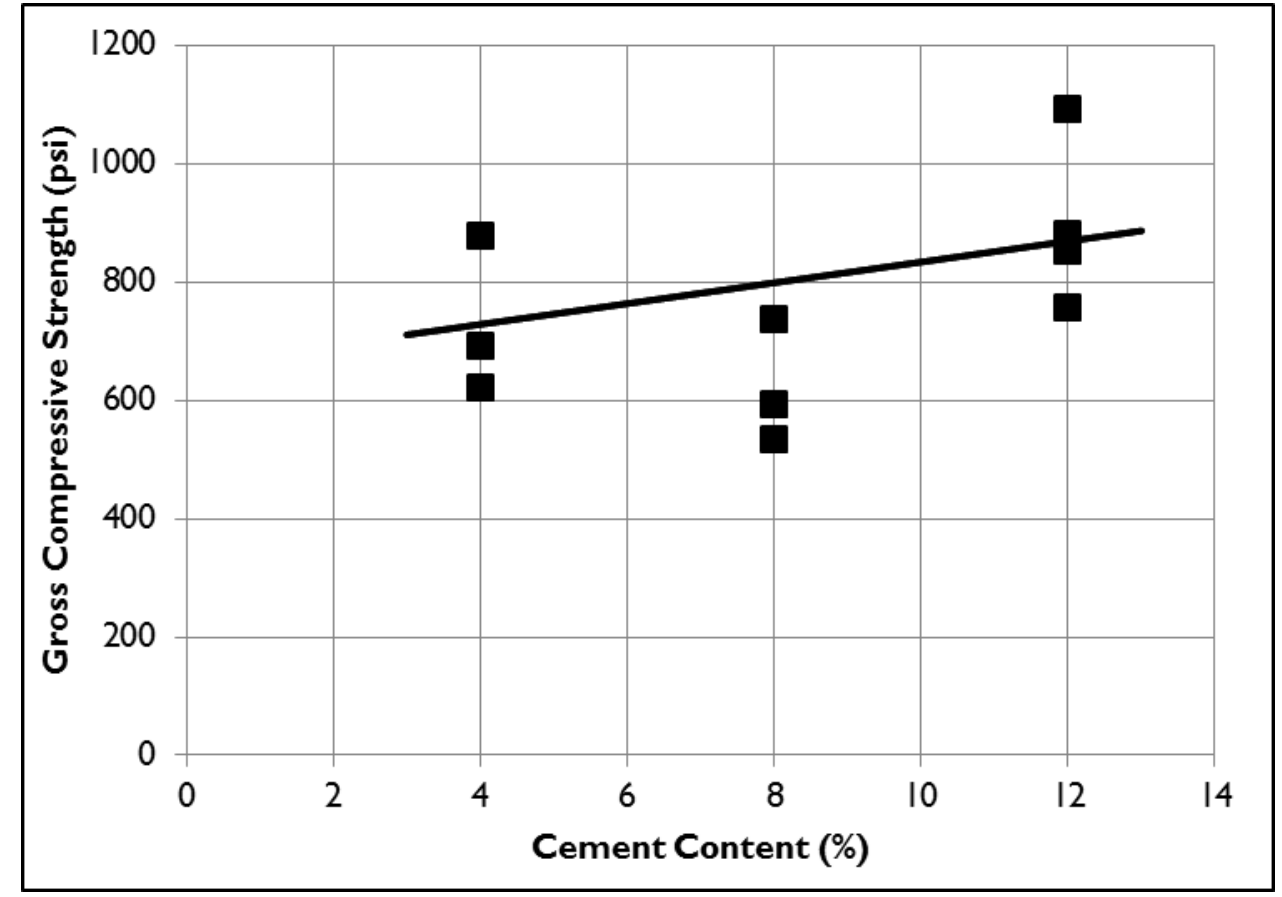

Figure 5.5.2-1 Las Tablas CC Compressive Strengths

The LT cement content batches exhibit a linear increase in strength as the cement content increases. Unfortunately, the LT50-8 samples possess unusually low compressive strengths. The LT50-8 batch cannot be further adjusted, but considering that the MOR show the same trend in strength, it seems to be an issue with the batch.

This confirms the research discussed prior, but also suggests that additional cement contents needed to be tested in order to establish a bilinear relationship. This becomes especially difficult without a $0 \%$ cement content CEB. 
The average results confirm the linear relationship between cement content and strength. The data is well adjusted and consistent, suggesting successful tests except for LT50-8.

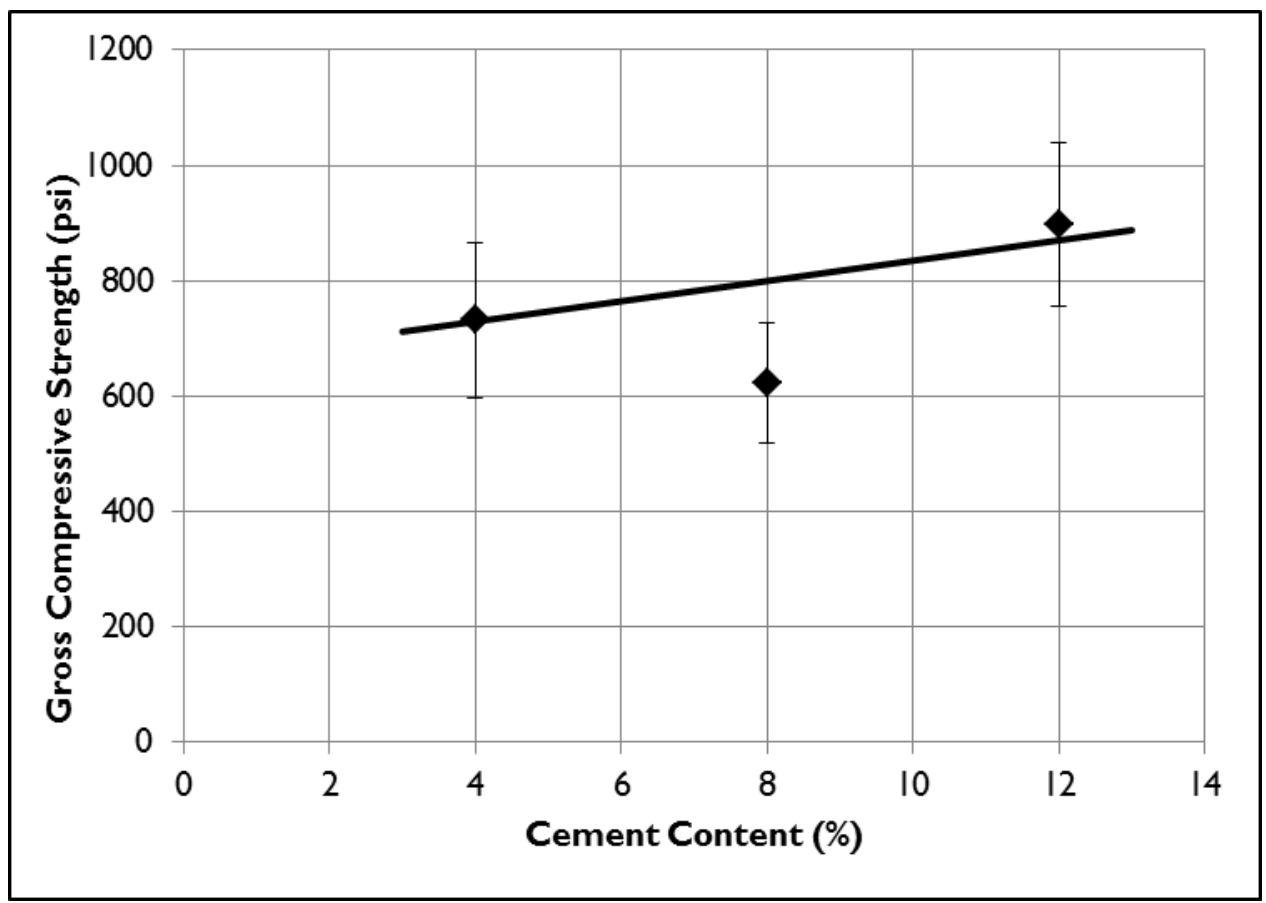

Figure 5.5.2-2 Las Tablas CC Average Compressive Strengths

The MOR results also suggest a linear relationship, as seen below. The same limitations with the choice of cement contents present themselves in the MOR results.

Like the compressive strength, variability between each batch is uniform, although an average strength of $67 \mathrm{psi}$ with a standard deviation of 21 is high, and casts the LT 4\% CC results into doubt. The LT $8 \% \mathrm{CC}$ results suffer a similar issue as seen in the figures below: 


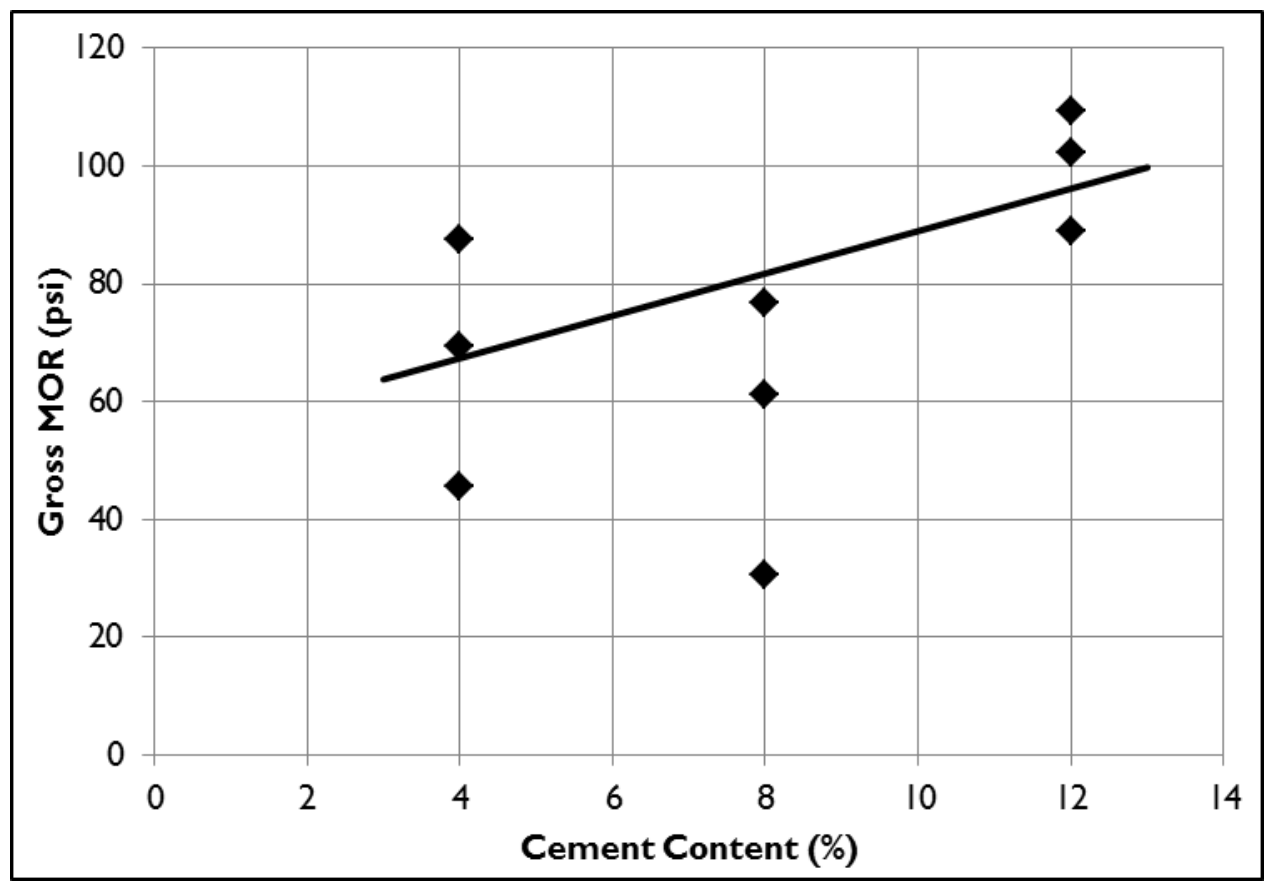

Figure 5.5.2-3 Las Tablas CC MOR

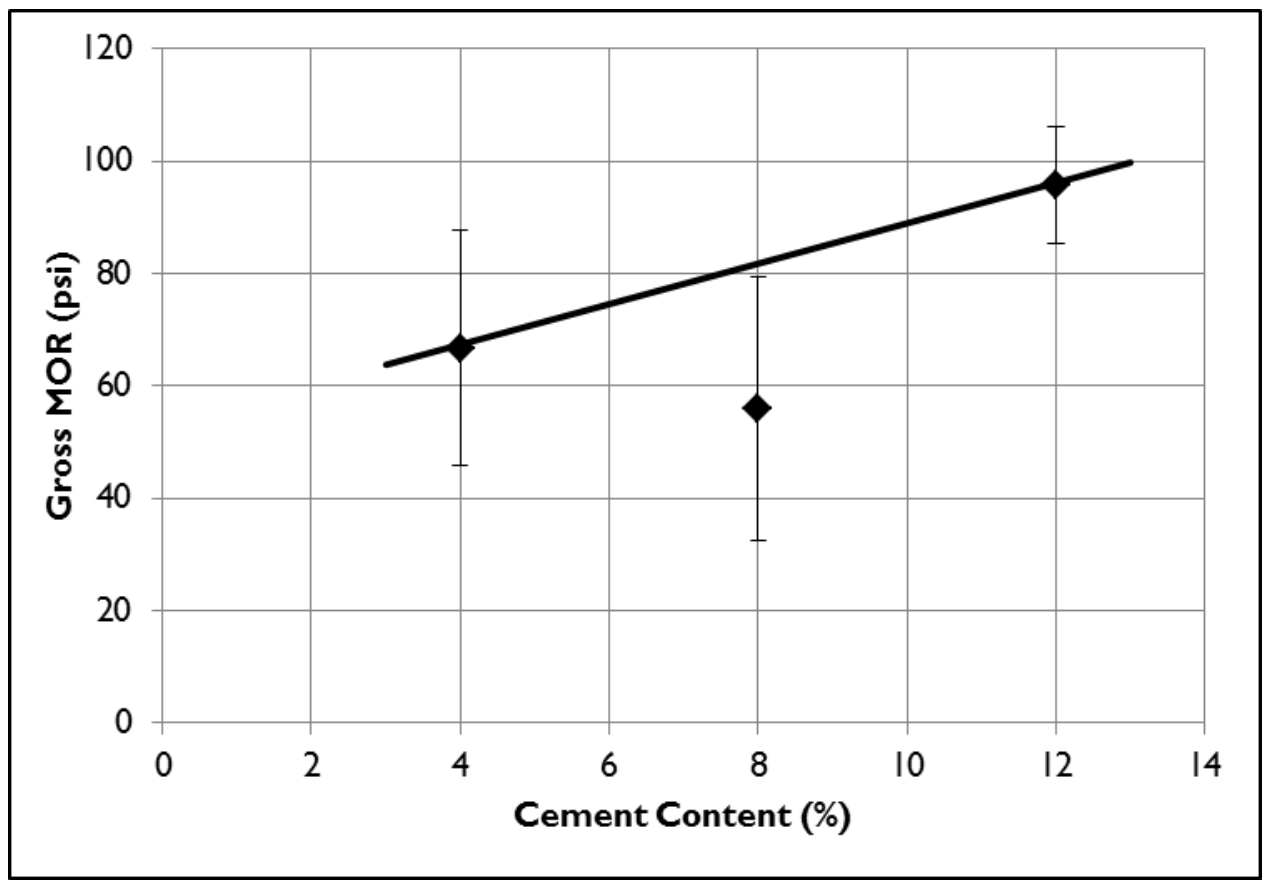

Figure 5.5.2-4 Las Tablas CC MOR Ave Strengths 


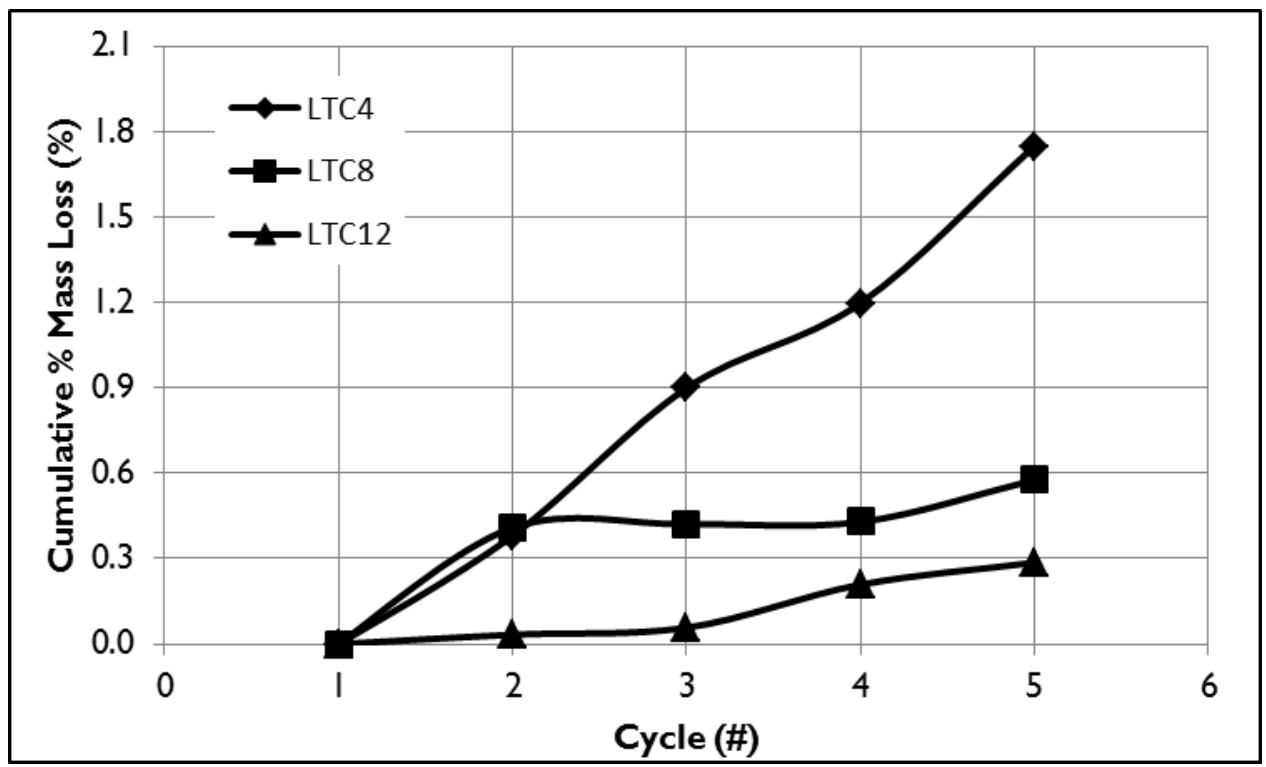

Figure 5.5.2-5 Las Tablas CC Durability Results

The durability results suggest that durability decreases rapidly as cement content decreases. This confirms research (Walker 1995) that blocks with low cement contents lack the impermeable matrix of $\mathrm{CH}$ and $\mathrm{CSH}$ that the cement provides. This results in free clay particles expanding and contracting, damaging the CEBs and inducing the mass loss measured.

The beneficial aspect of cement seems to diminish between $8 \%$ and $12 \%$, which suggests the relationship between cement content and durability is not truly linear in nature, as the strength data suggests. However, there is insufficient data to extrapolate this to the strength data.

The results overall suggest a linear relationship between cement content and strength, as well as durability. 


\subsubsection{Prado Soil}

The results for the Prado CEBs tested in compression are shown below:

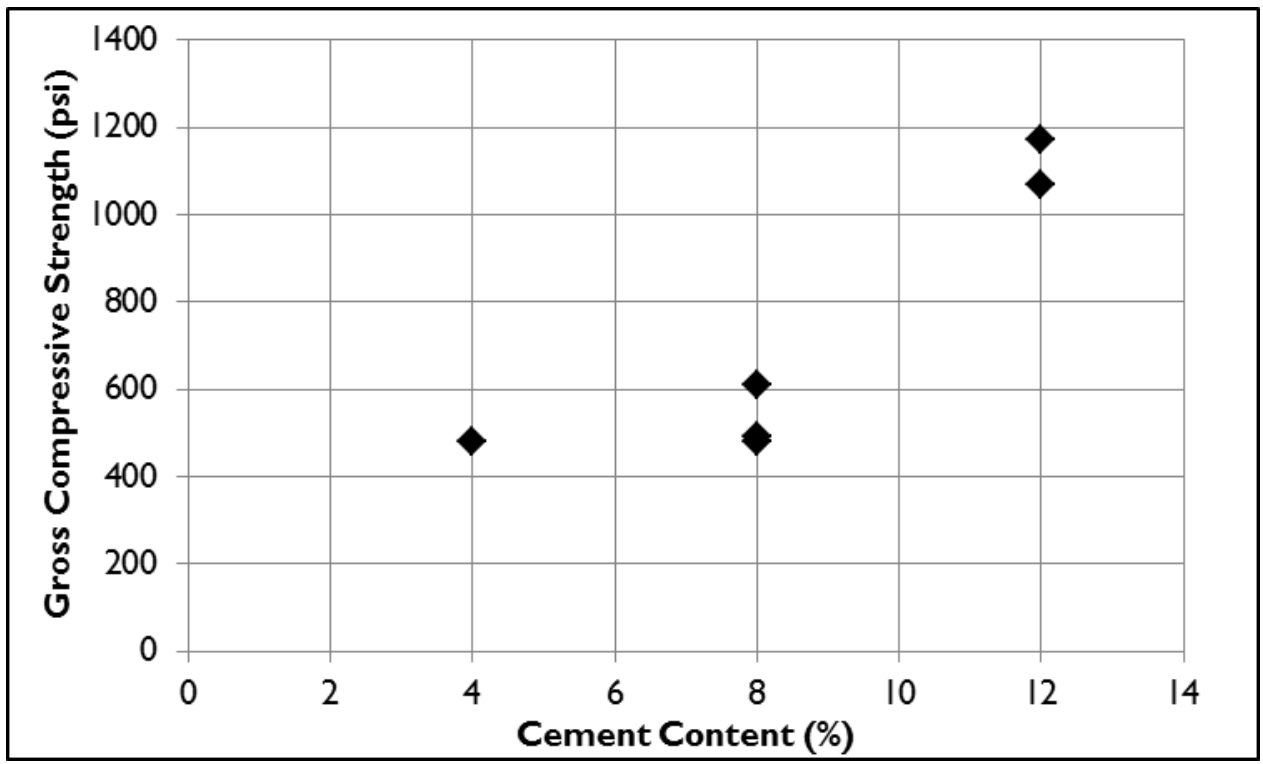

Figure 5.5.3-1 Prado CC Compressive Strengths

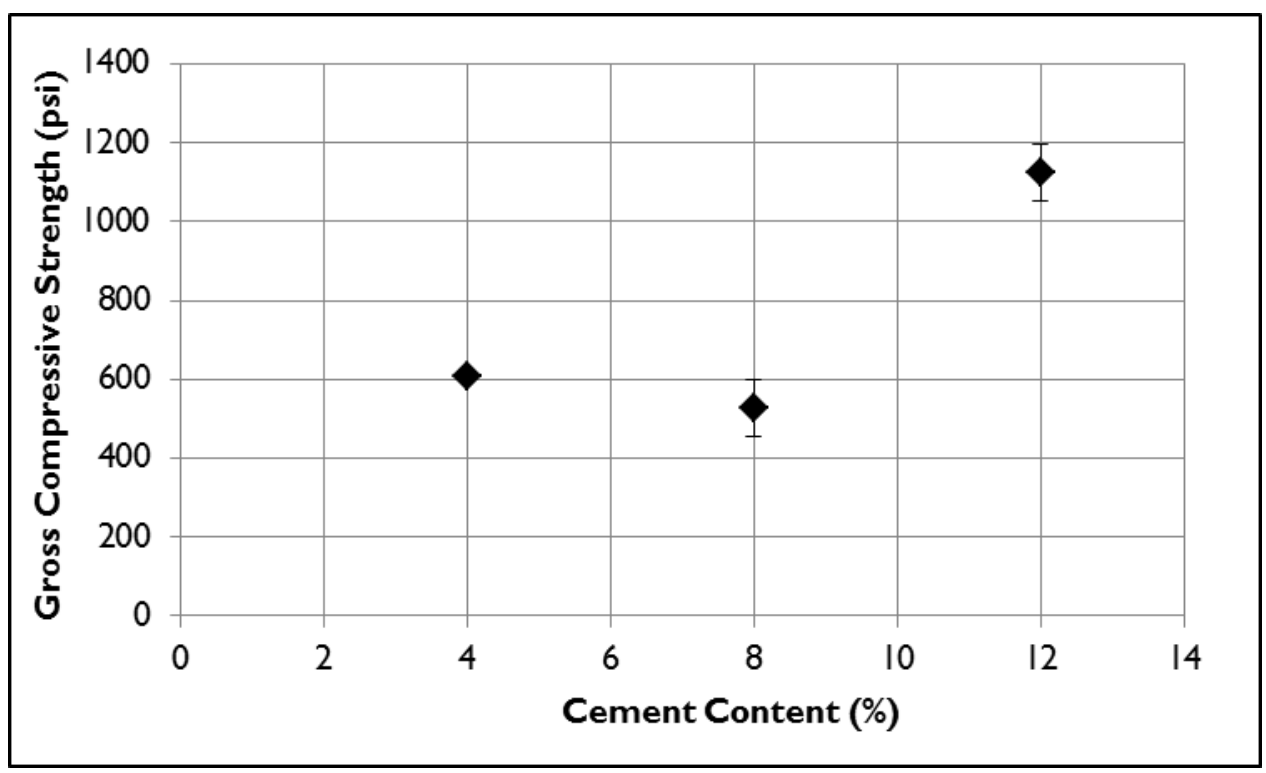

Figure 5.5.3-2 Prado CC Average Compressive Strengths 
The Prado soil exhibits a weak linear relationship between cement content and compressive strength, like the LT soil. The $8 \% \mathrm{CC}$ batch contains low strength samples, and there is only a single $4 \% \mathrm{CC}$ sample. These major issues seem to weaken the possibility of a linear relationship between compressive strength and cement content.

The MOR results are shown below. Unlike the compressive strength testing, the MOR samples exhibit a clear linear increase in strength as cement content increases. The average MOR and the batch variability reflects that of the LT soil, suggesting the MOR test is in general more variable than the compression tests performed.

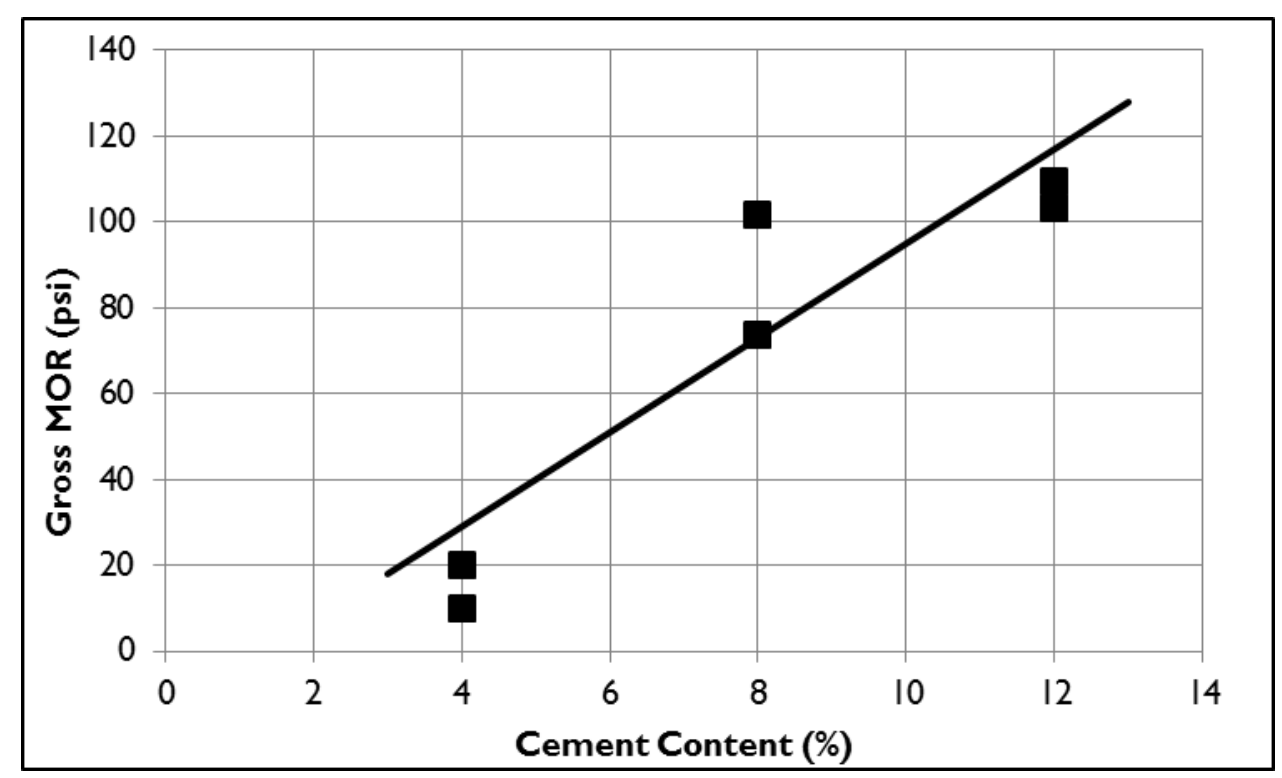

Figure 5.5.3-3 Prado CC MOR 


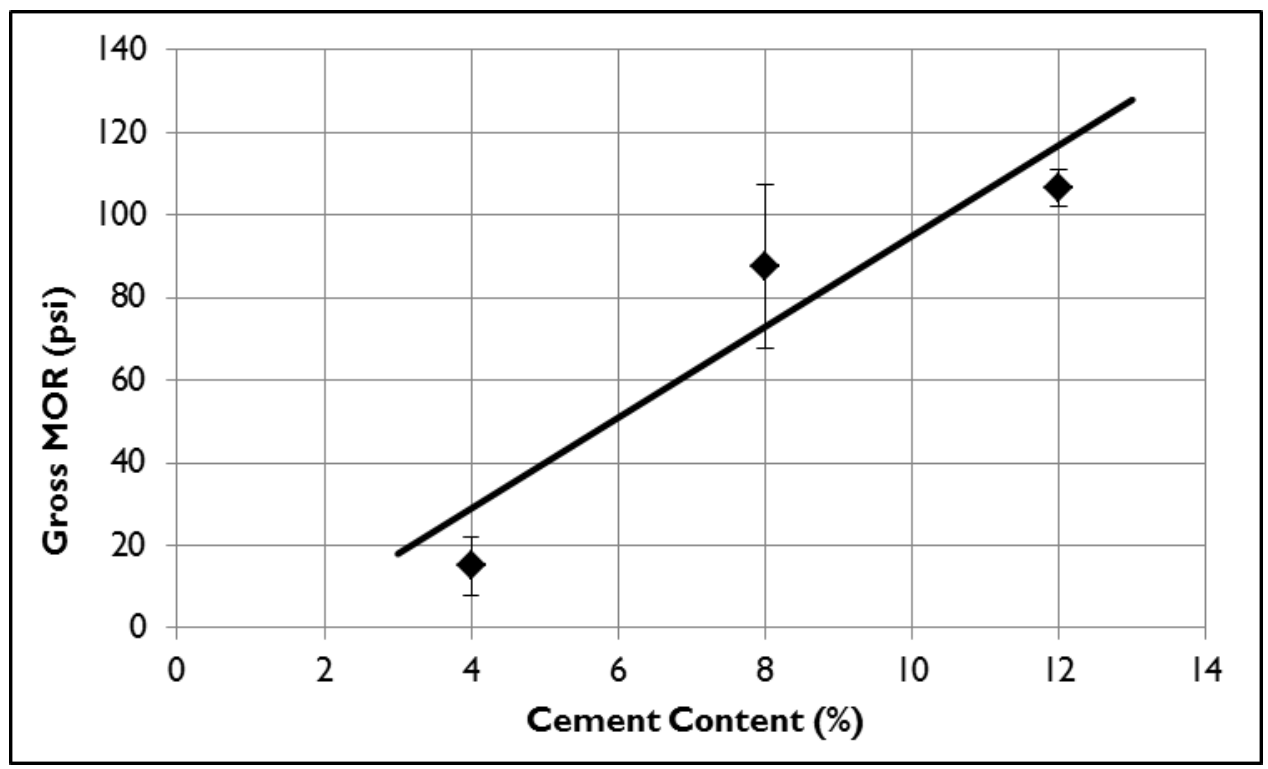

Figure 5.5.3-4 Prado CC Average MOR

The durability results from the Prado CEBs do not seem to exhibit a linear trend between cement content and durability. As seen below, there is a drastic difference between the $4 \% \mathrm{CC}$ blocks and the $8 \% \mathrm{CC}$ blocks. Between the $8 \%$ and $12 \% \mathrm{CC}$ blocks, the difference in durability is significantly less, suggesting a nonlinear or bilinear relationship.

The Prado soil possessed the most plastic and expansive clay, which significantly affected the cement as it cured within the blocks. This would suggest that a higher cement content is in general necessary as the clay content and plasticity of the clay increases. It is interesting to note that this is the only durability sample that broke apart during testing, a testament to the effect of clay content and plasticity on the durability of CEBs. 


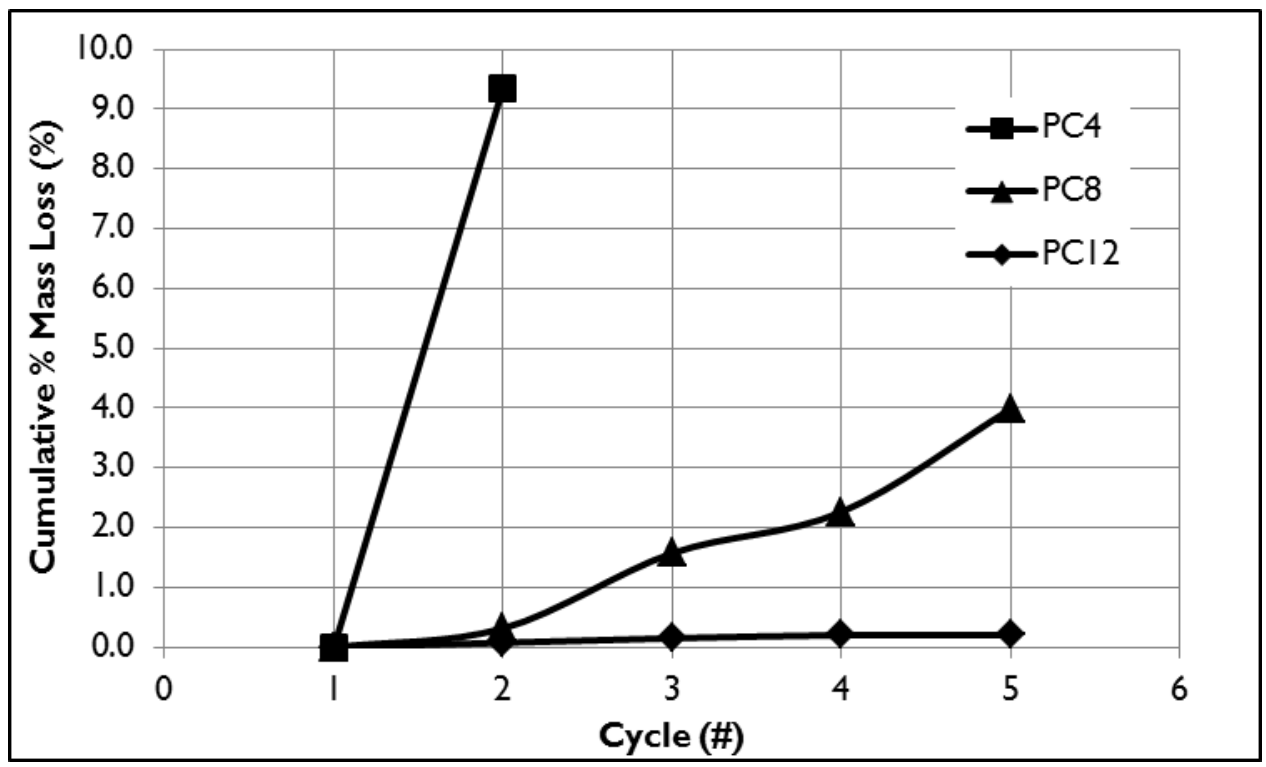

Figure 5.5.3-5 Prado CC Durability Results

The Prado soil as a whole seems to confirm the linear trend between strength gain and cement content seen in the LT CC blocks.

\subsubsection{Mind Body Soil}

The MB compression tests are shown below. Like the Prado and LT samples, the MB CEBs exhibit a linear gain in strength as cement content is increased. Unlike the Prado and LT samples, the MB 4\% CC blocks were exceptionally weak, suggesting that cement contents lower than $4 \%$ may not have an appreciable effect on strength. This is an interesting possibility, but requires significantly more testing.

Batch variability was very low for the $4 \%$ and $12 \% \mathrm{CC}$ blocks, while the $8 \% \mathrm{CC}$ blocks exhibited variability in line with the other soil types. Regardless, there is a strong linear trend between cement content and compressive strength, as well as durability. 


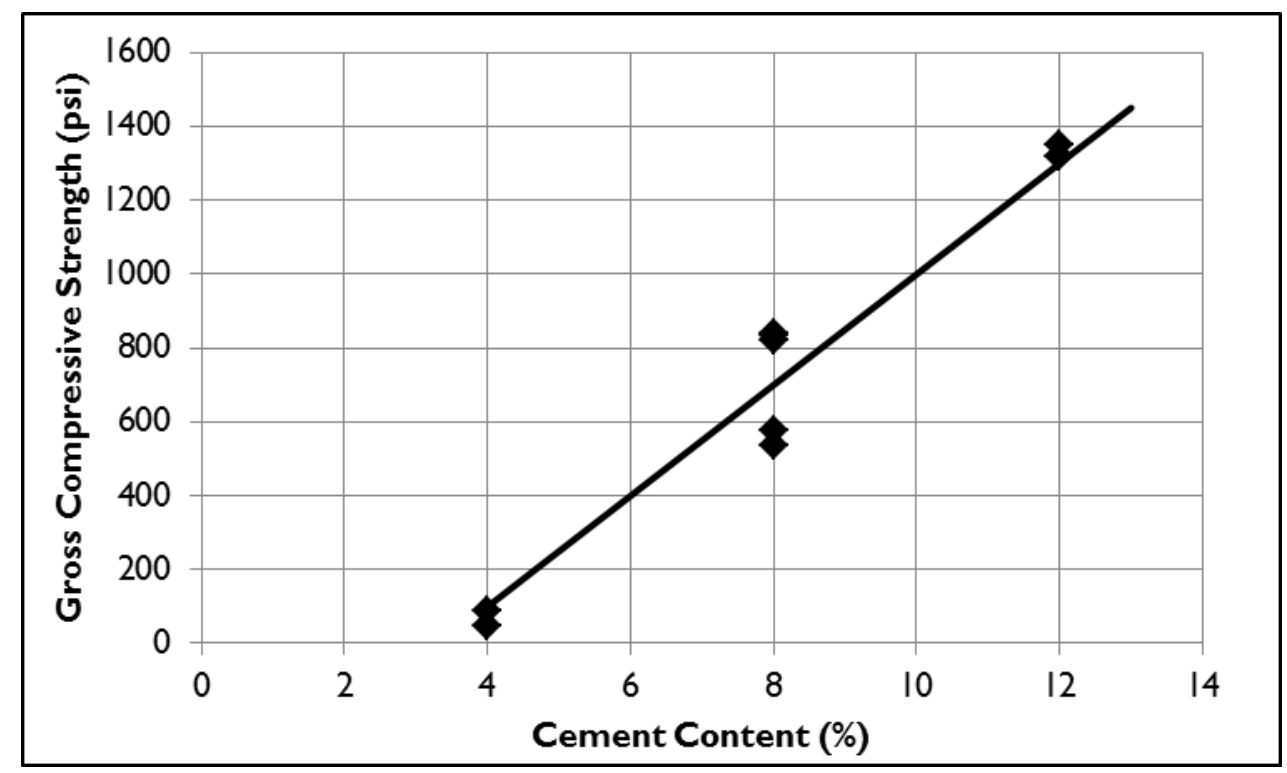

Figure 5.5.4-1 Mind Body CC Compression Strengths

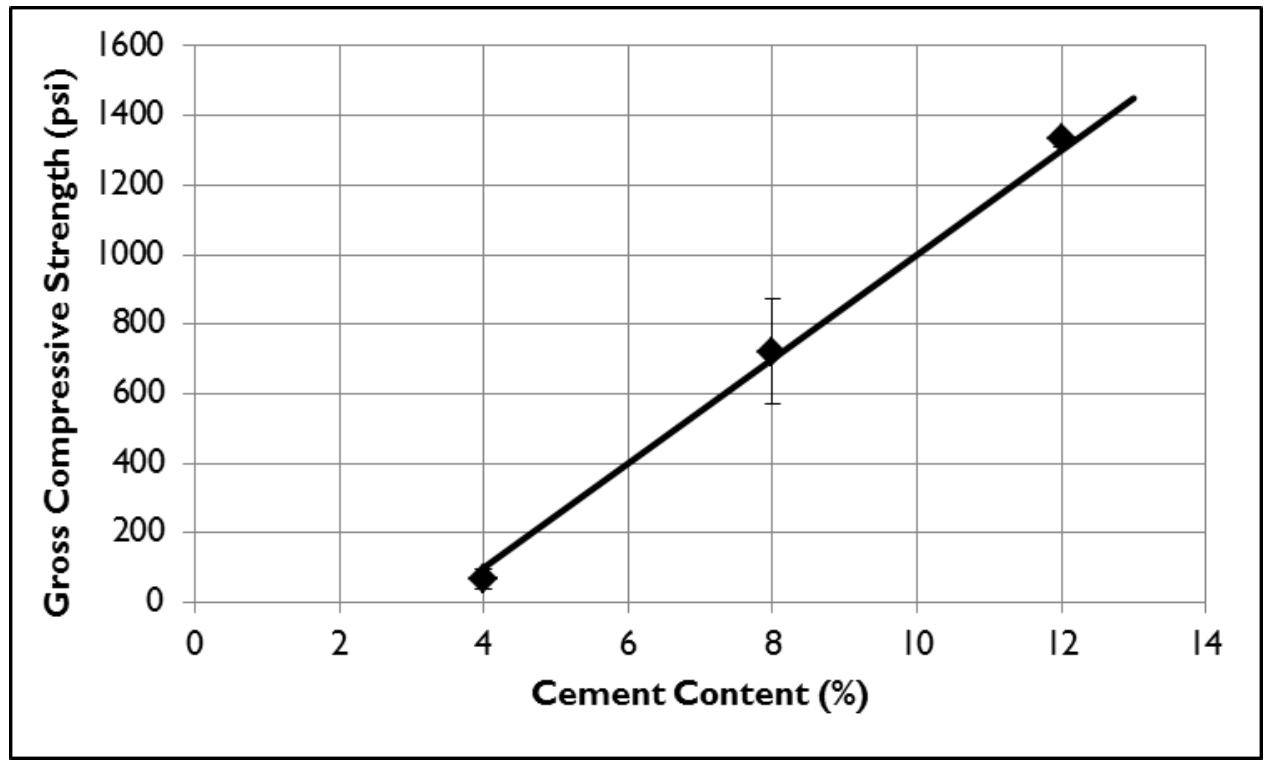

Figure 5.5.4-2 Mind Body CC Average Strengths 
The MOR results can be seen below:

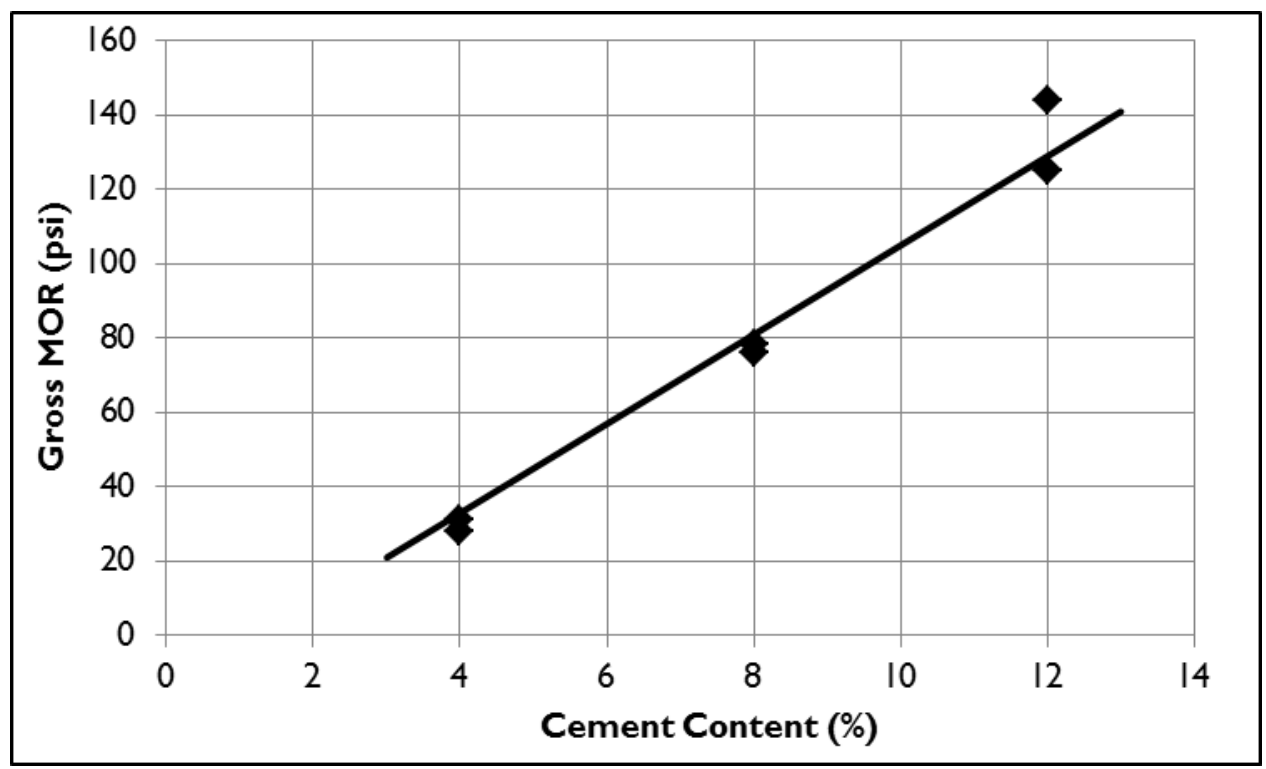

Figure 5.5.4-3 Mind Body CC MOR

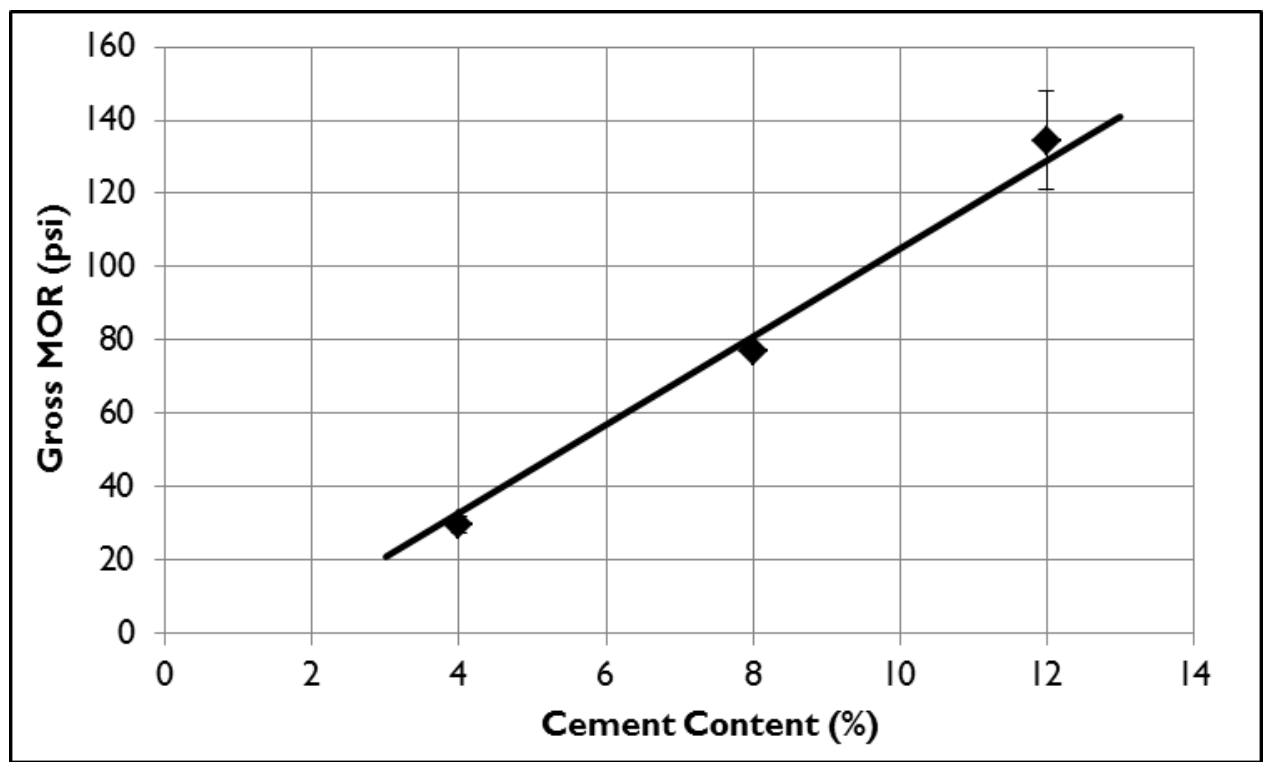

Figure 5.5.4-4 Mind Body CC Average MOR 
The MOR also exhibits a linear increase as cement content is increased. Unlike compressive strength, the $4 \% \mathrm{CC}$ MOR data is in line with the remaining data, suggesting a strong linear trend. This is unique to the MB soil, as both the LT and Prado soils did not experience such a strong trend.

The batch variability is low for the $4 \%$ and $8 \%$ CC blocks, but significantly higher for the $12 \% \mathrm{CC}$, although this pattern was also seen in the Prado soil. Regardless, the data suggests a linear trend.

Below are the durability results. A test was not performed on the $4 \% \mathrm{CC}$ blocks, but like the LT and Prado soils, there is a moderate difference in mass loss when the cement content is increased from $8 \%$ to $12 \%$. There seems to be linear trend in durability between $8 \%$ and $12 \% \mathrm{CC}$, which agrees with the strength tests.

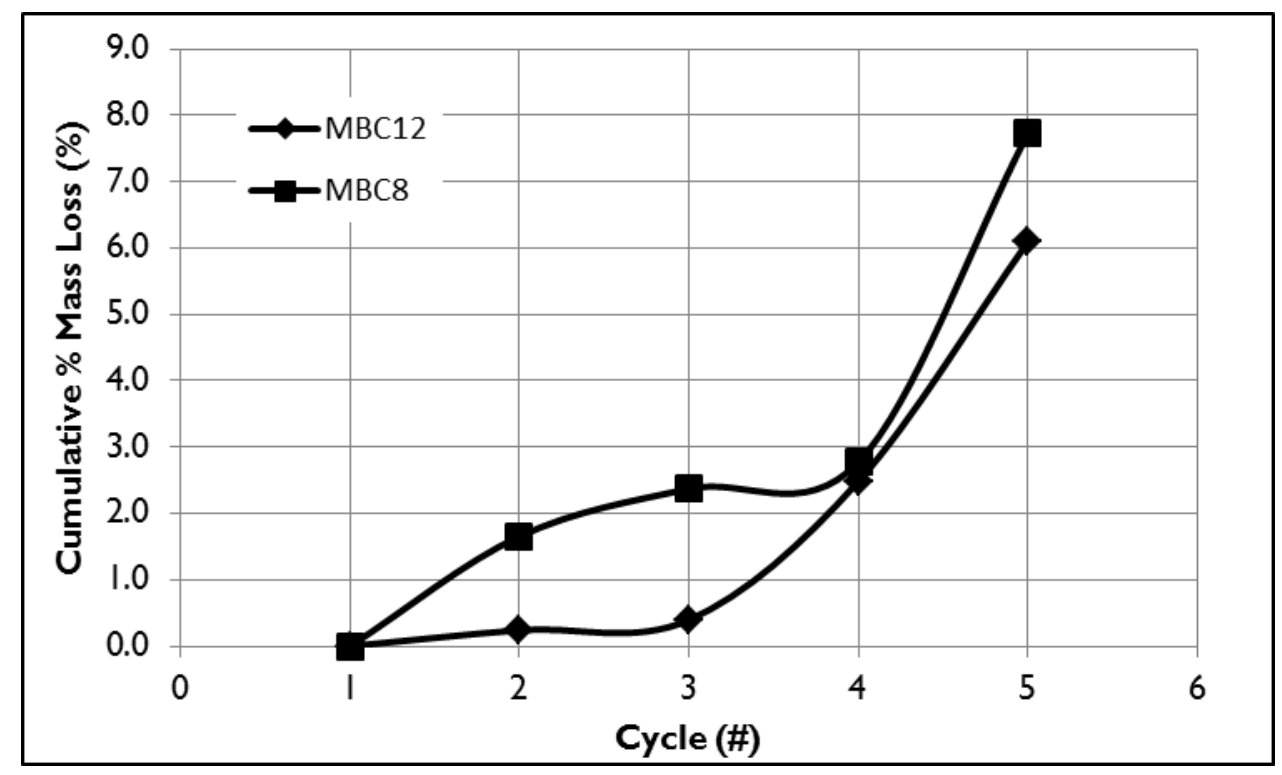

Figure 5.5.4-5 Mind Body CC Durability Results 
The MB soil as a whole suggests a linear relationship between cement content and strength, as well as durability.

\subsubsection{Combined Results}

Once each soil was analyzed individually, the results were combined to observe any global trends.

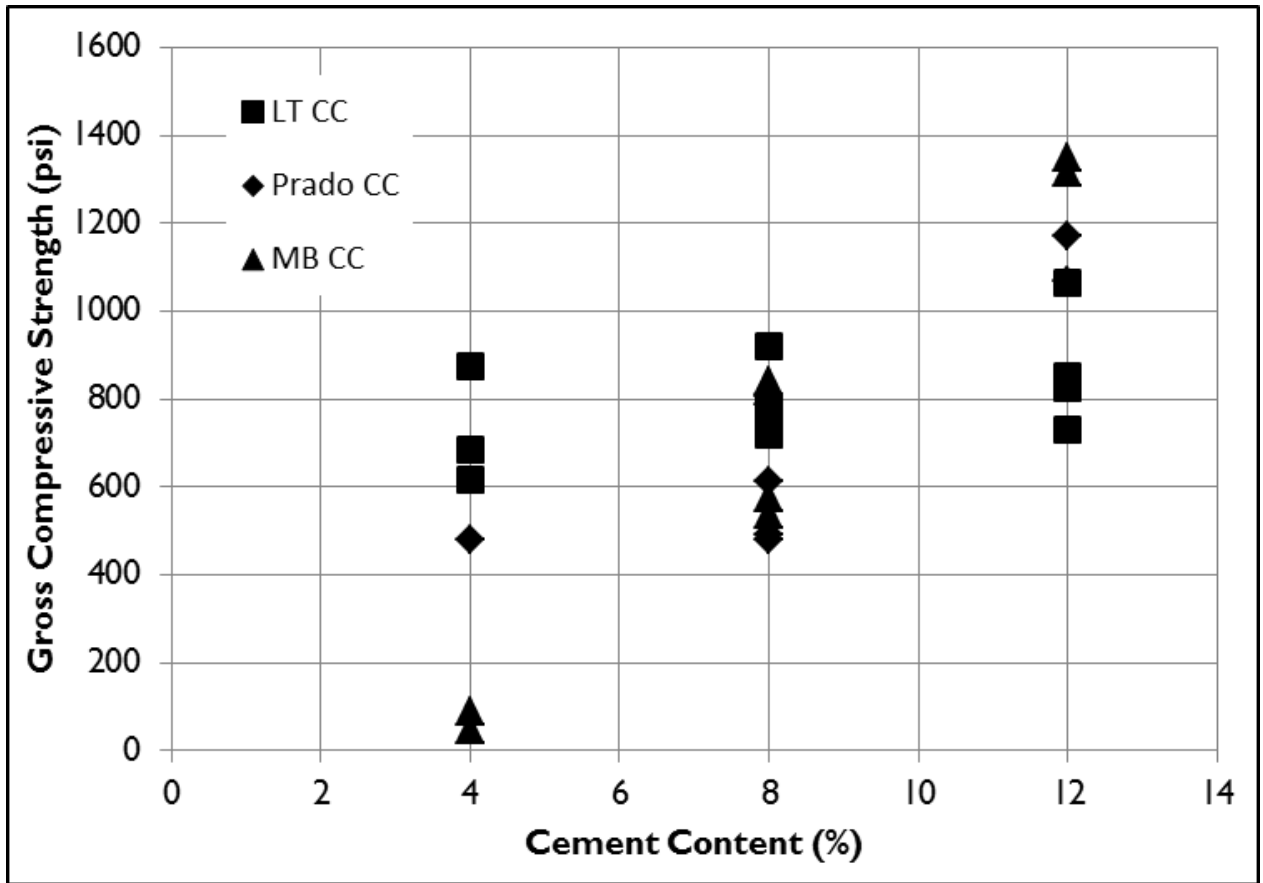

Figure 5.5.5-1 Combined CC Compressive Strengths 


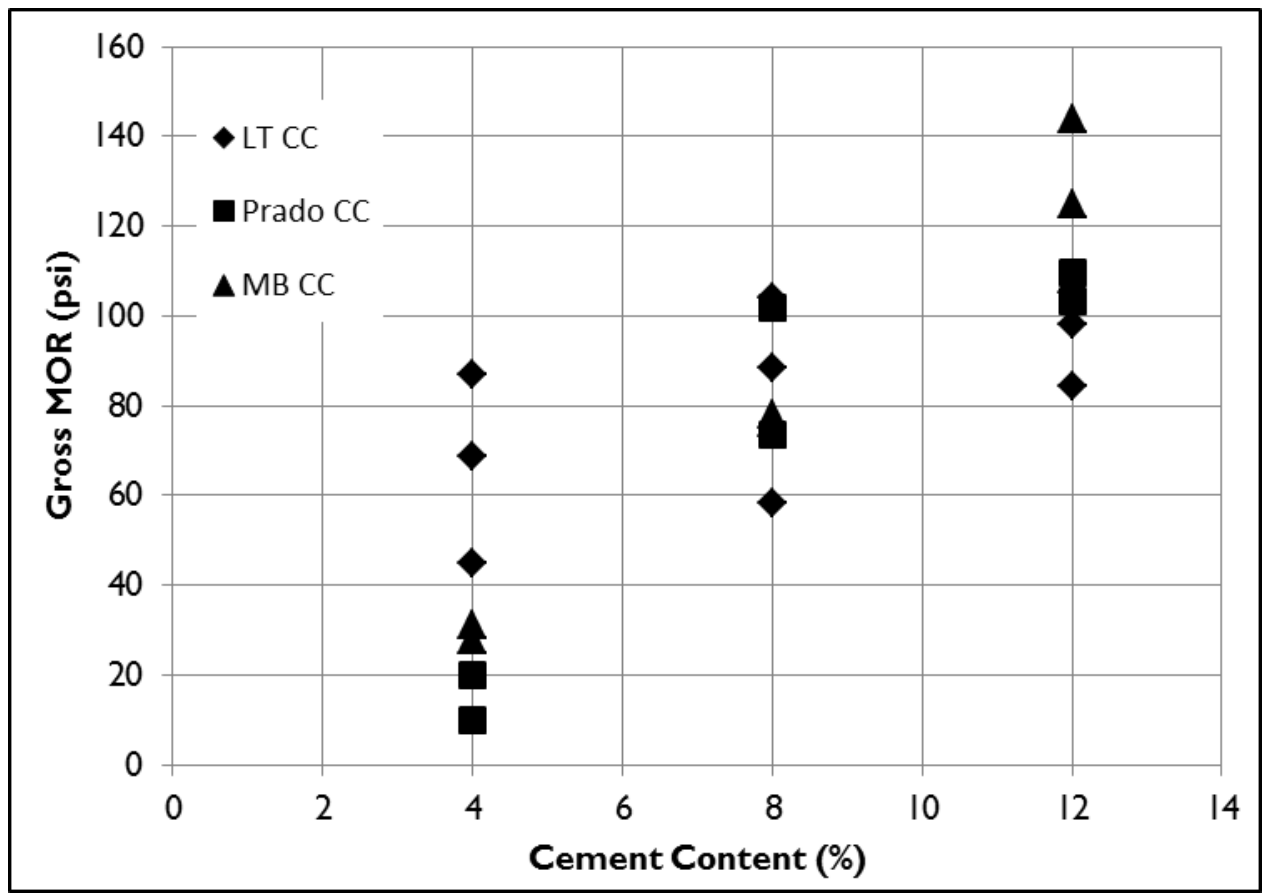

Figure 5.5.5-2 Combined MOR Compressive Strengths

The compressive strength and MOR both exhibit a linear increase as cement contents increase. It should be noted that at low cement contents, the compressive strength of the MB blocks was significantly lower than CEBs made from LT and Prado soils.

While there is considerable variability among the data as a whole, a definite linear trend can be seen, which confirms past research. 


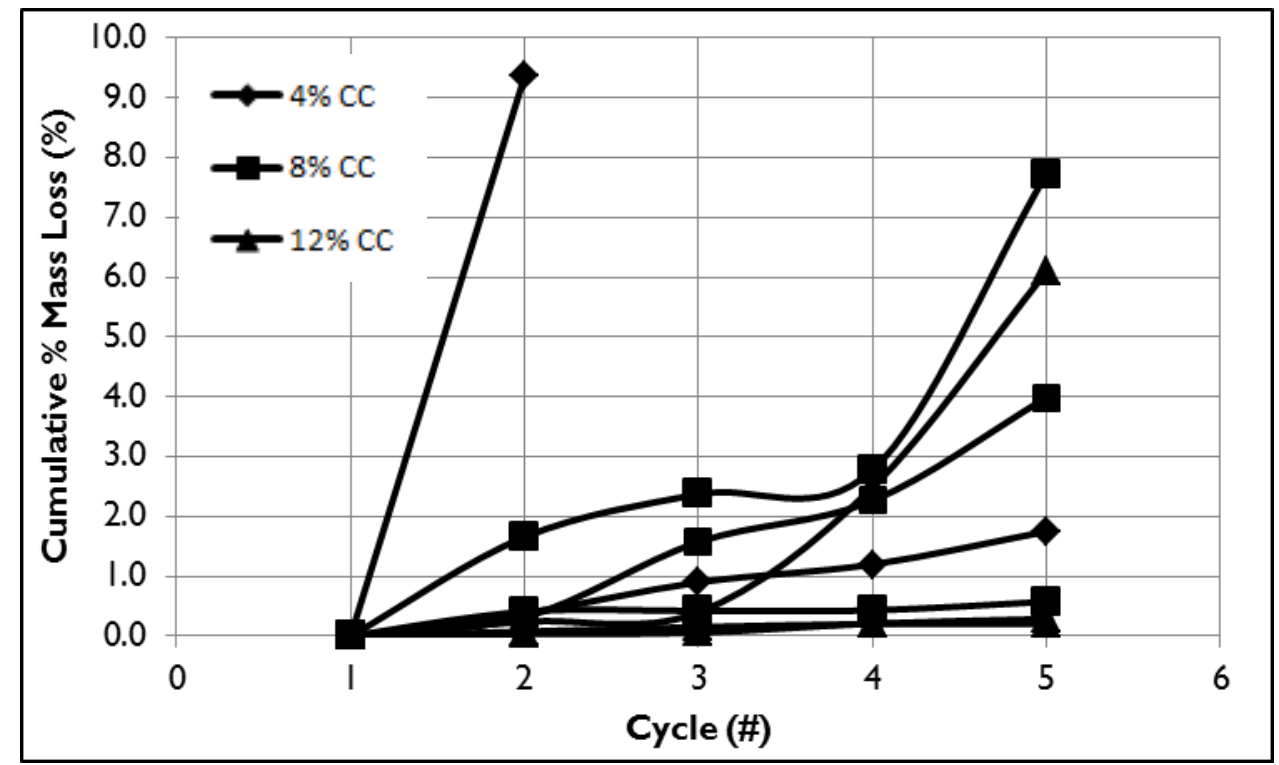

Figure 5.5.5-3 Combined Durability Results

The durability data exhibits a less clear trend, and is organized by cement content instead of soil type. This highlights that as cement content decreases, mass loss increases, although the degree of degradation also appears to be influenced by the plasticity and expansion potential of the clay.

Cement content is clearly an important aspect of CEB production. As cement content increases, strength and durability increase in a linear fashion. While blocks can be produced using low cement contents like 4\%, durability becomes a significant issue as witnessed by simply wetting and drying them. It also appears that more plastic clays require higher cement contents so that the reaction matrix of $\mathrm{CH}$ and $\mathrm{CSH}$ is strong enough to resist the swelling and shrinking of the free clay particles.

This does not appear to be strongly correlated with clay content, as the LT CEBs possessed the highest clay content among the blocks tested at $13 \%$. Trial batching and a 
simple durability test like wet dry cycles may be a key indicator of proper cement content when producing CEBs.

\subsection{Fiber Content (FC)}

The introduction of fibers into compressed earth blocks is relatively new, with older CEB production manual discouraging their use (Rigassi 1985). Adding fibers may rarely be necessary, especially when they increase the cost of the material.

Unlike natural fibers, synthetic fibers possess a high tensile strength and modulus of elasticity, and it was believed that fiber strength would increase the MOR before cracking, resulting in a higher peak stress (Mesbah et al. 2004). No change in compressive strength was predicted. There was some concern that a slight drop in durability may occur (Tallaah et al. 2014) due to the fibers pushing back upon the CEB in an attempt to return to their original position. However, the high pressures exerted on the CEB by hydraulic presses like the BP714 was thought to counteract the phenomenon, and no decrease in durability was predicted.

Like clay and cement content, the results are organized by mixture moisture content, then by soil, and finally the data is combined to observe global trends.

\subsubsection{Mixture Moisture}

The addition of polypropylene fibers to a soil - cement mixture was not anticipated to significantly affect the mixture moisture content. The fibers were added in such low volumes, and the fibers themselves do not absorb water, so there little reason to observe a change in moisture content. 
Table 5.6.1-1 Fiber Content Mixture Moisture

\begin{tabular}{|c|c|c|c|c|}
\hline Soil & $\begin{array}{c}\text { Clay } \\
\text { Content } \\
(\%)\end{array}$ & $\begin{array}{c}\text { Fiber } \\
\text { Content } \\
(\%)\end{array}$ & $\begin{array}{c}\text { Mixture } \\
\text { Moisture } \\
\text { Content } \\
(\%)\end{array}$ & $\begin{array}{c}\text { Average } \\
\text { Moisture } \\
\text { Content } \\
(\%)\end{array}$ \\
\hline Las Tablas & 13.5 & 0.0 & 12.2 & \multirow{5}{*}{11.7} \\
\hline Las Tablas & 13.5 & 0.2 & 11.7 & \\
\hline Las Tablas & 13.5 & 0.5 & 11.5 & \\
\hline Las Tablas & 13.5 & 0.2 & 11.7 & \\
\hline Las Tablas & 13.5 & 0.5 & 11.5 & \\
\hline Prado & 10.7 & 0.0 & 8.1 & \multirow{3}{*}{8.2} \\
\hline Prado & 10.7 & 0.2 & 8.1 & \\
\hline Prado & 10.7 & 0.5 & 8.5 & \\
\hline Mind Body & 10.0 & 0.0 & 6.4 & \multirow{2}{*}{7.3} \\
\hline Mind Body & 10.0 & 0.2 & 8.2 & \\
\hline
\end{tabular}

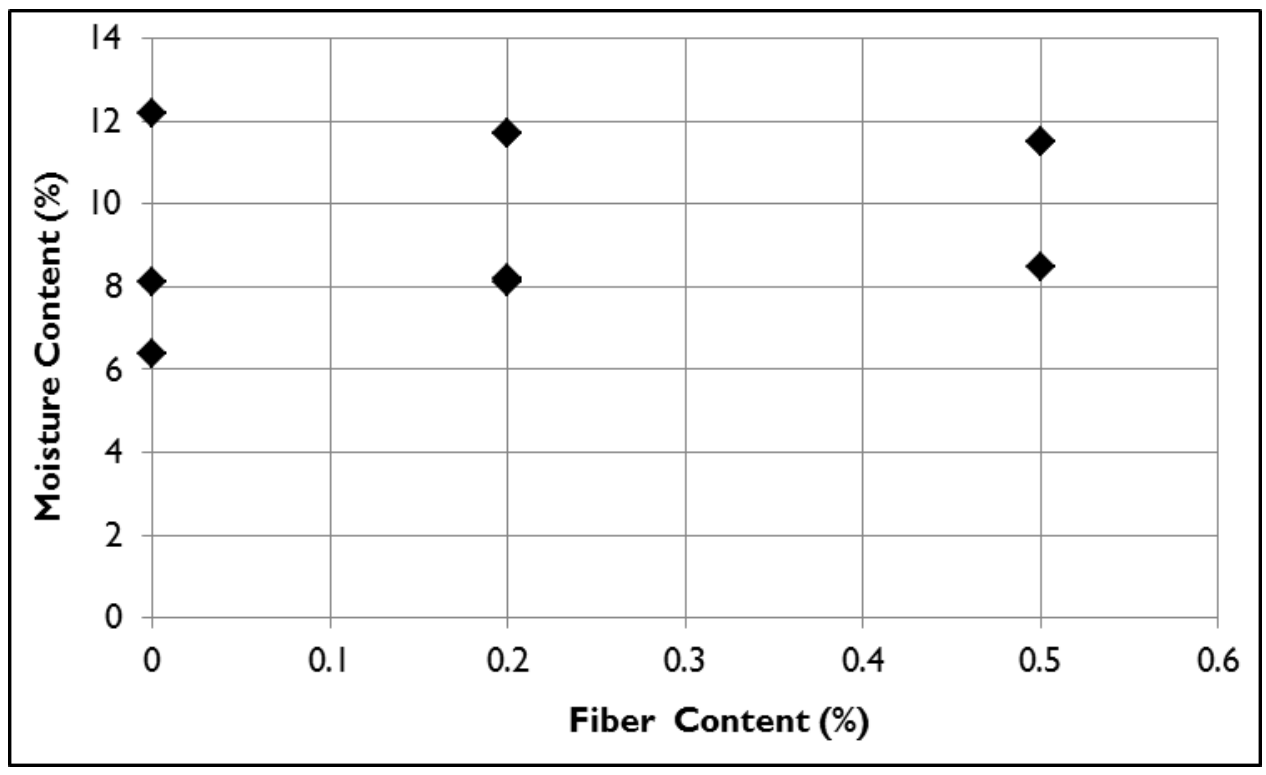

Figure 5.6.1-1 Fiber Content vs. Moisture Content

As seen before, the LT soil possess the highest moisture content, with the MB soil possessing the lowest. As expected, the addition of fibers, regardless of type or volume, does not have a significant effect on the moisture content of the mixture. 


\subsubsection{Las Tablas Soil - Forta Ferro Fiber (FF)}

The LT soil utilized two different types of fibers in separate batches. Each fiber was tested at the manufacturer's recommended amount. Some blocks were also wet cured in both compression and MOR to observe the effect of moisture content. The results from Forta Ferro fiber batches are shown below:

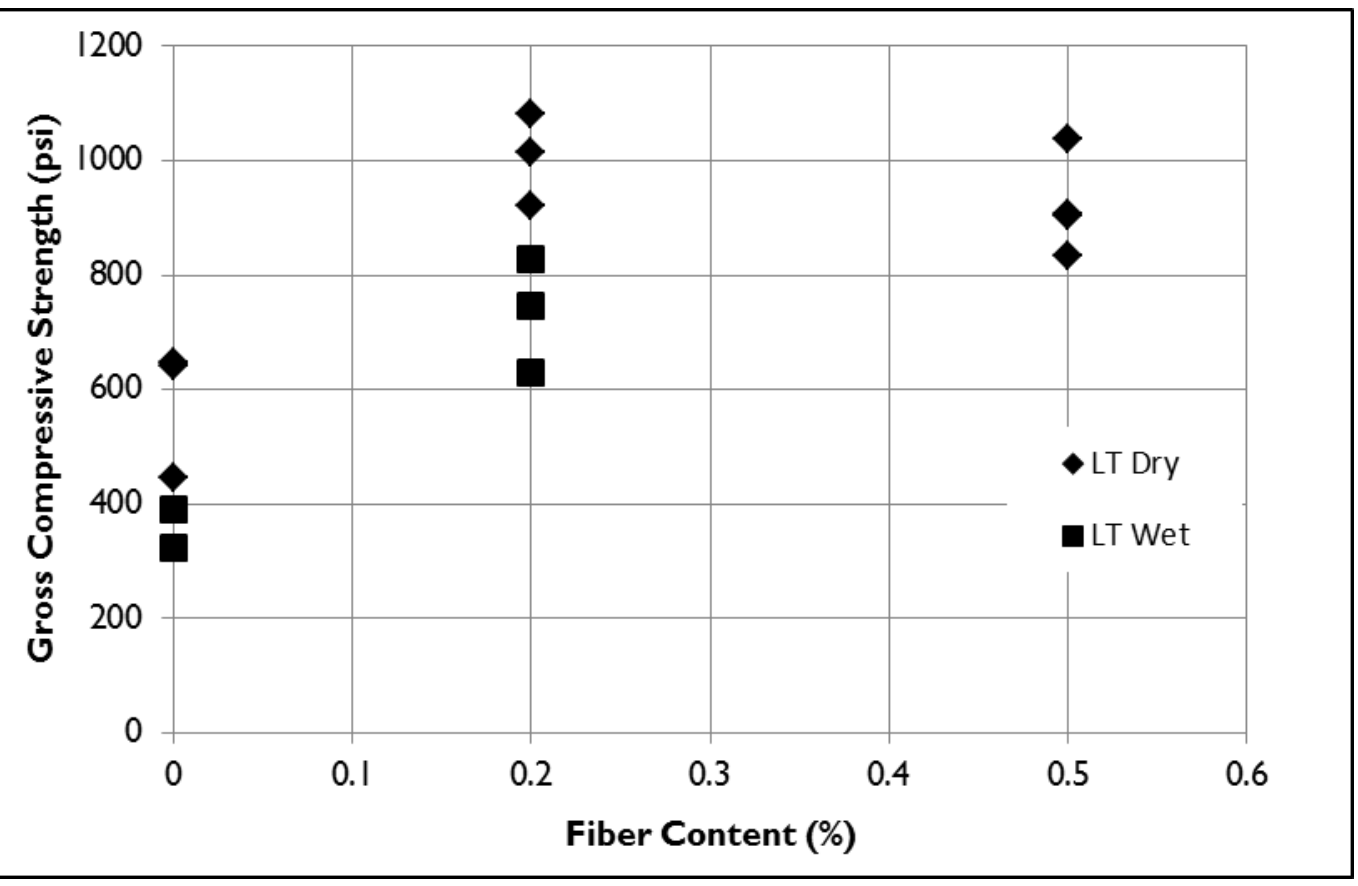

Figure 5.6.2-1 Las Tablas FF Compressive Strengths 


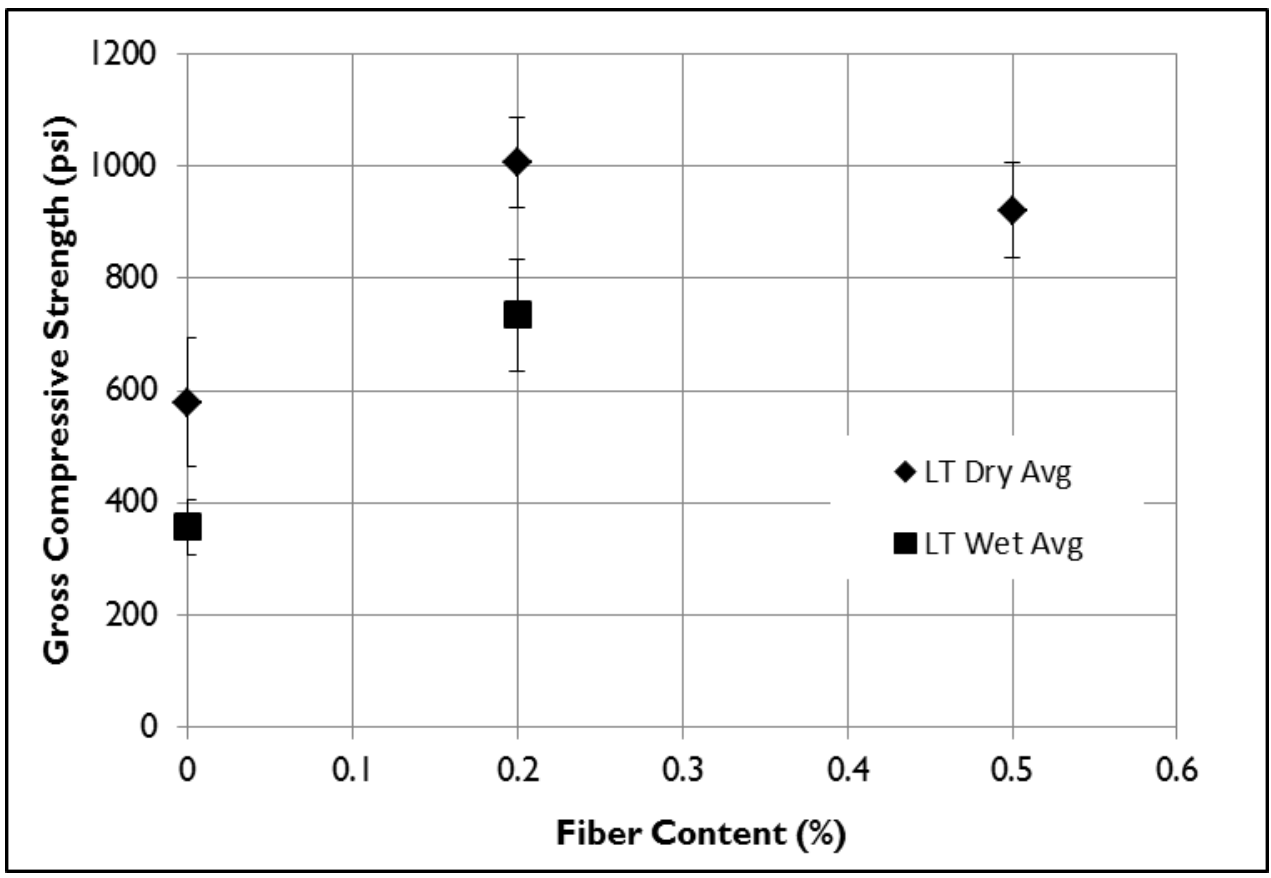

Figure 5.6.2-2 Las Tablas FF Average Compressive Strengths

There appears to be no gain in compressive strength from the addition of fibers. Once again, the LT50 batch provides weak data in compressive strength. Observing the average strengths and variability within each batch confirms this trend. Variation between batches is fairly low and consistent, suggesting quality data. These results corroborate with prior research suggesting that the addition of fibers are not useful in increasing the peak compressive strength.

As expected, wet CEBs exhibit lower compressive strengths than dry CEBs (Tallah et al. 2014). The difference in moisture content between wet and dry blocks in each separate batch was approximately $4 \%$, which explains the uniform drop in strength. The free clay particles within the cement matrix likely absorbed the additional moisture 
and swelled, decreasing the strength of the bond between one another. This mechanism is the most likely explanation for the 200 psi drop in strength.

Additionally, some of the CEBs were tested in MOR and their peak strengths were measured.

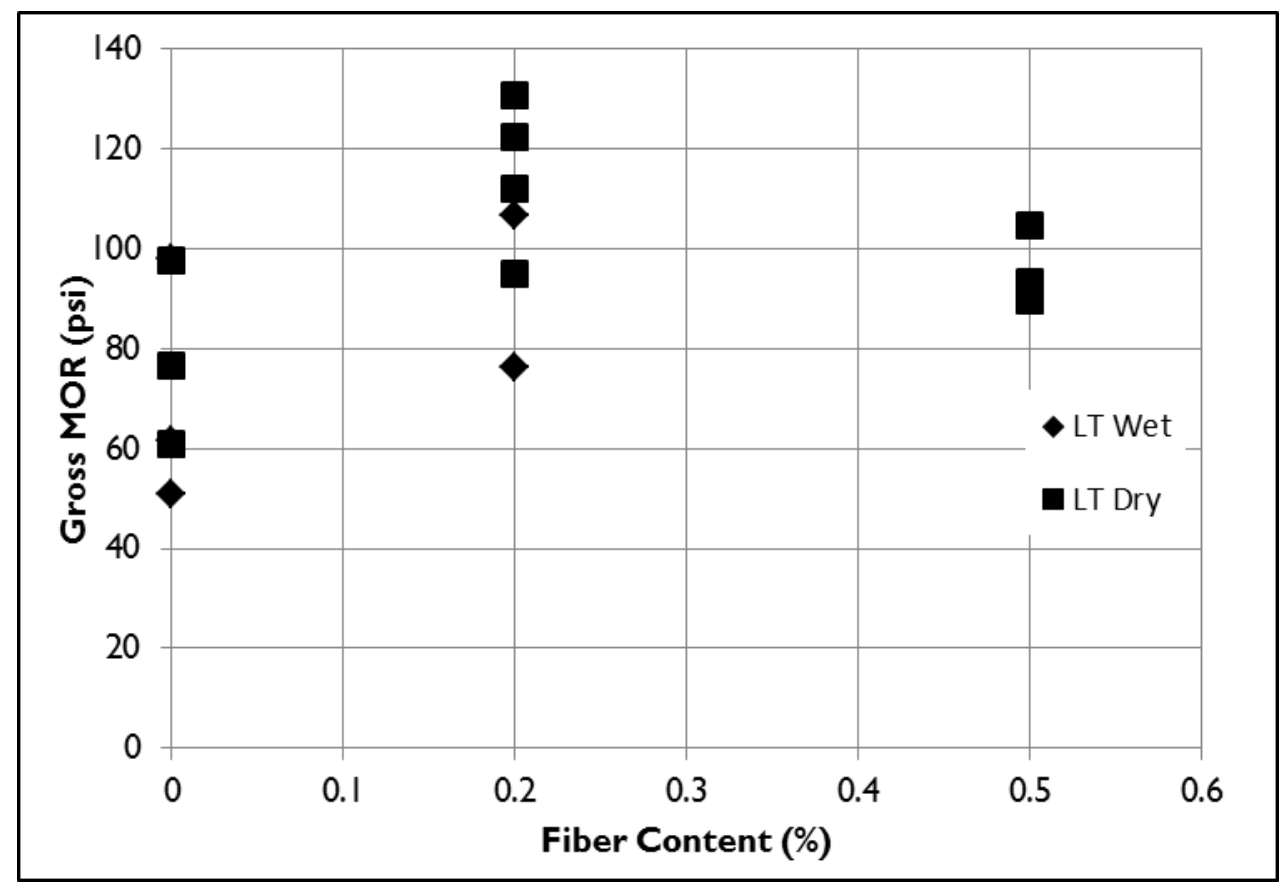

Figure 5.6.2-3 Las Tablas FF MOR 


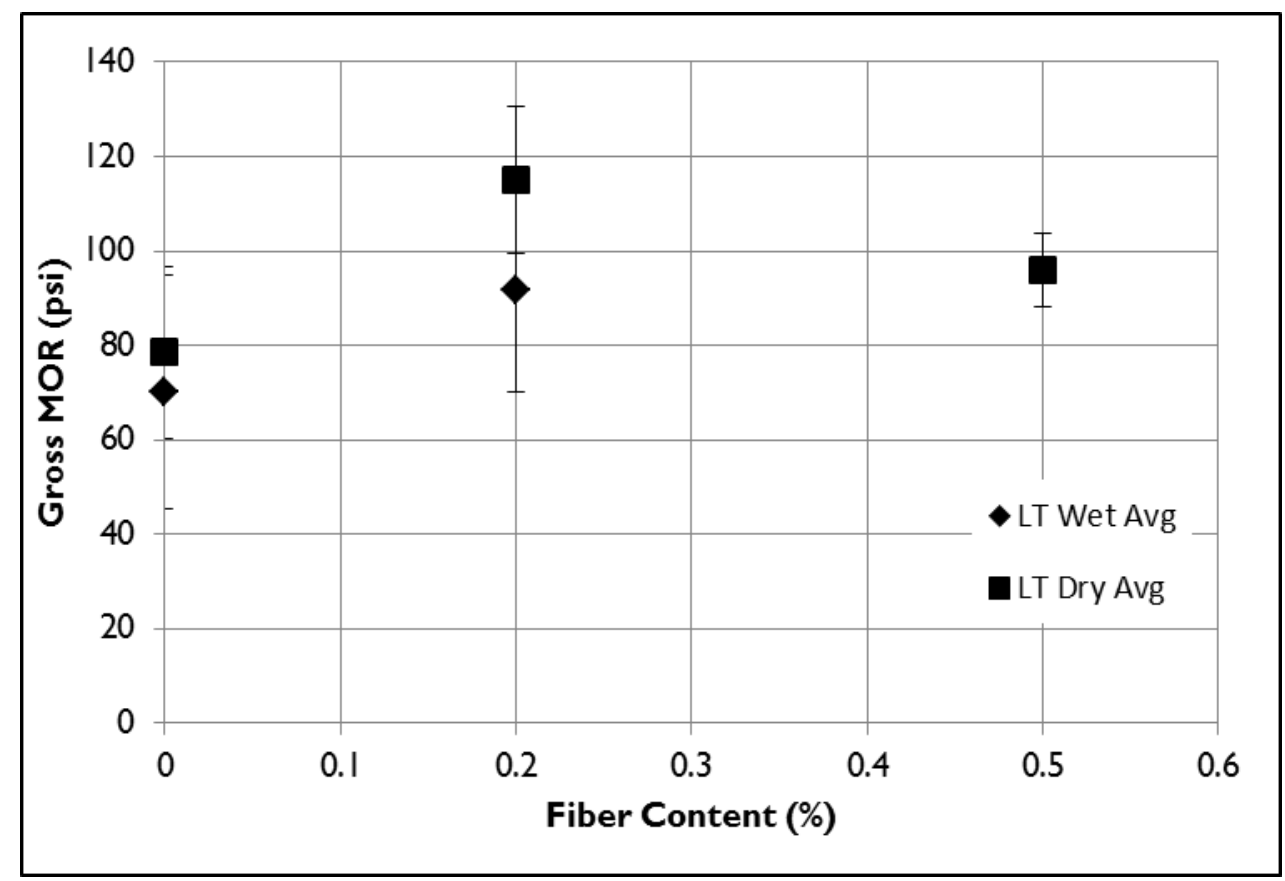

Figure 5.6.2-4 Las Tablas FF Average MOR

In MOR, there also appears to be no gain in strength from the addition of fibers. This confirms previous research with natural fibers (Mesbah et al. 2004), while the addition of steel fibers seemed to increase the peak strength as well as post cracking properties (Eko et al. 2012). Synthetic fibers may require higher fiber contents than the manufacturers recommendation in order to achieve an increase in peak MOR.

The average strengths and batch variations also suggest there is no relationship between fiber content and MOR. The variations are typical of other MOR tests, but more testing is required before a broader conclusion is drawn.

Like compressive strength, there is a drop in MOR as the moisture content of the CEB increases. The difference between the wet and dry strengths seems to increase with the addition of fibers, although the high variability between batches may be to blame. 
After the strength tests were completed, the CEBs were subjected to durability testing. The results are below.

It is seems that the addition of fibers may adversely affect the durability of CEBs. This trend only appears after a few cycles, while other trends like low cement content manifested themselves early on. This may suggest additional testing is required, especially considering the durability curve of the CEB with $.5 \%$ fiber content, which experiences less mass loss than the FF.2 sample.

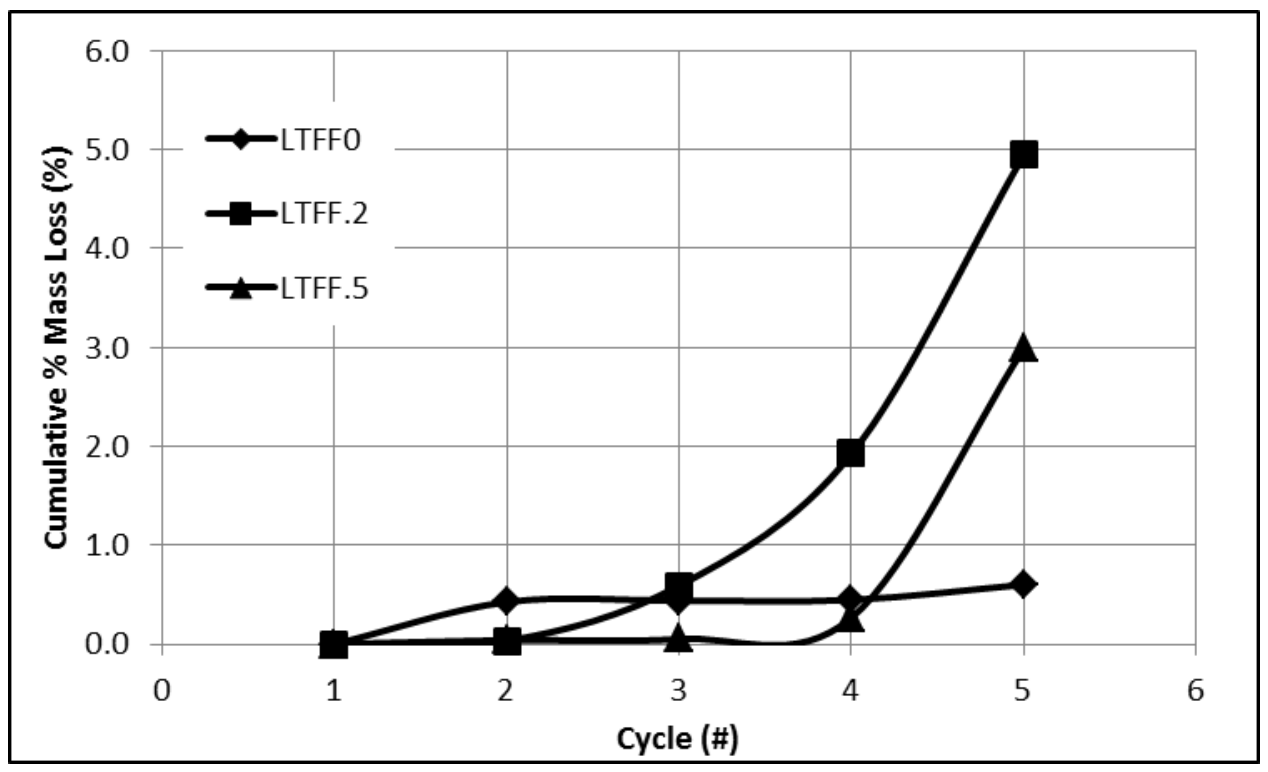

Figure 5.6.2-5 Las Tablas FF Durability Results

There is clearly no gain in peak strength with the addition of synthetic fibers in low contents, although the relationship between fiber content and durability is less clear. 


\subsubsection{Las Tablas Fiber - Strux 90/40 Fiber (FS)}

The primary fiber of this experiment was the Strux 90/40, which was utilized in all three soils. The same tests were performed as the Forta Ferro fibers, with the results below.

Like the Forta Ferro fiber CEBs, adding the Strux fiber did not produce a significant increase in compressive strength. This is confirmed when consulting the average strengths and variability between batches. The difference between the wet and dry fiber CEBs are significantly less due to the slight difference in moisture content between the wet and dry blocks (2\%).

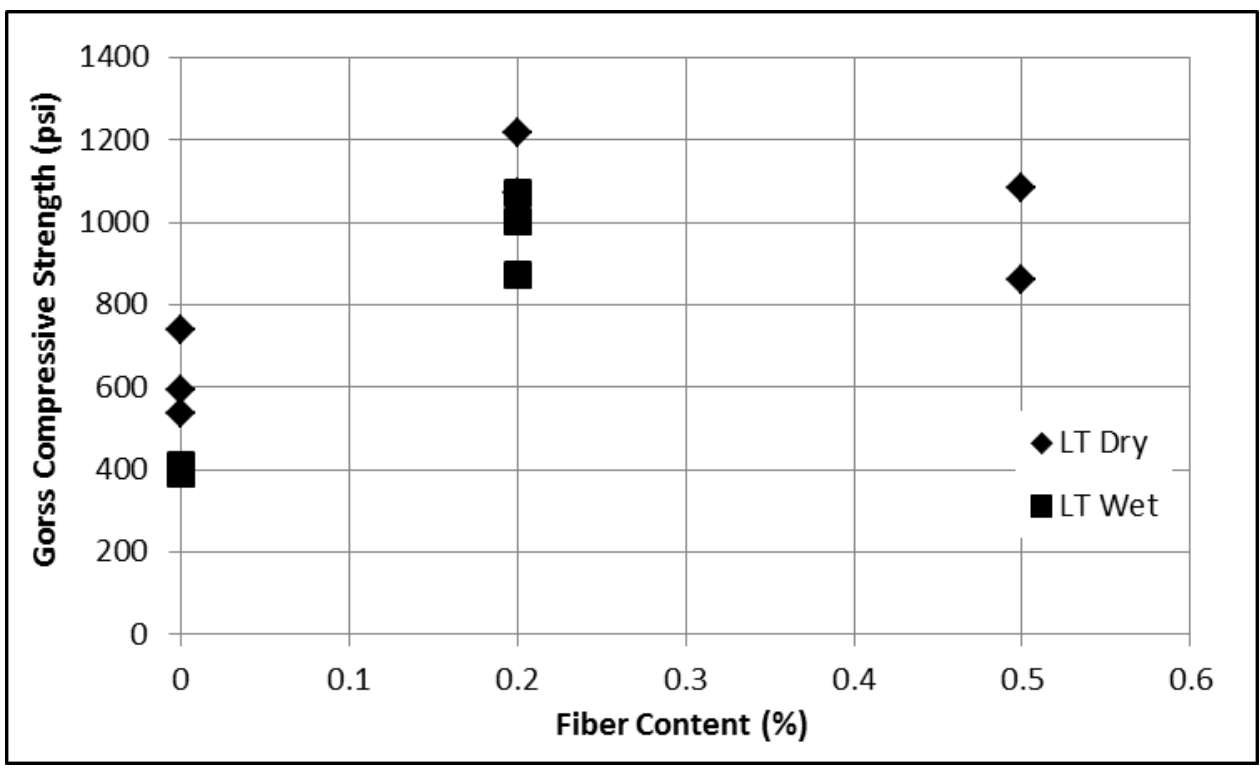

Figure 5.6.3-1 Las Tablas FS Compressive Strengths 


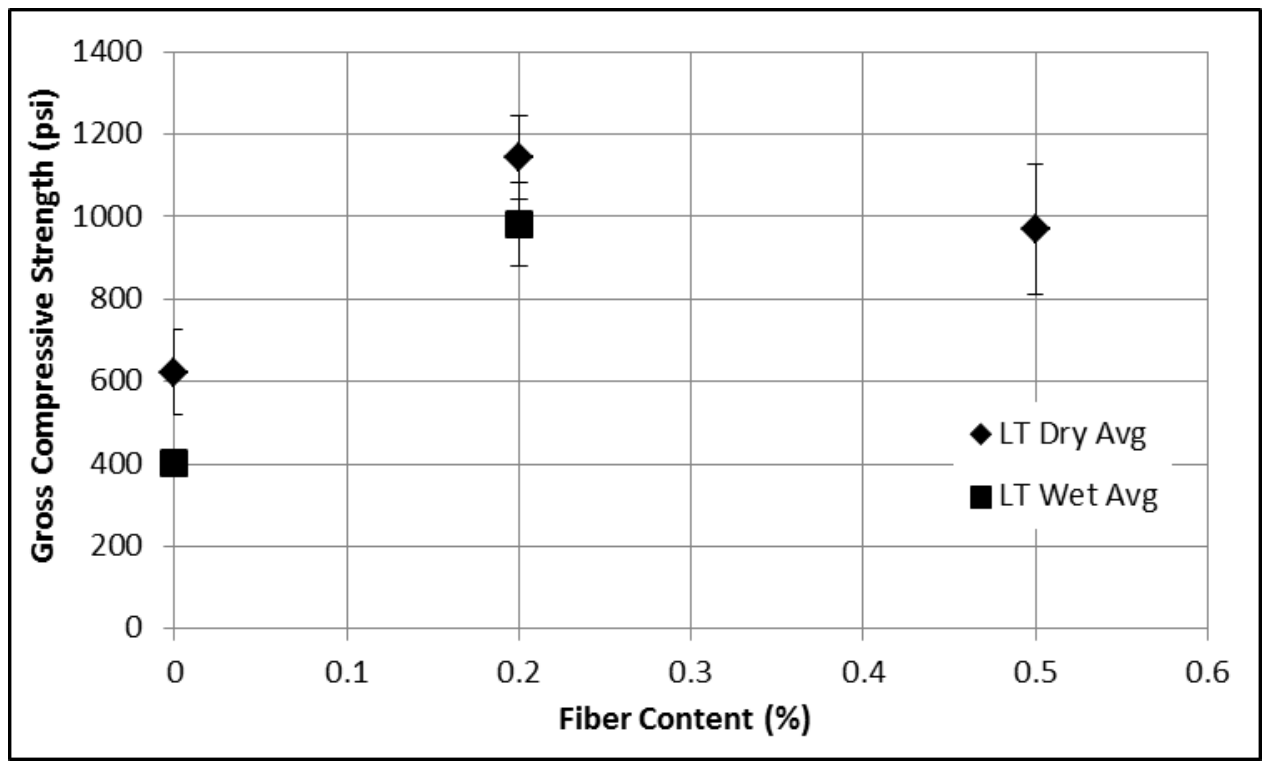

Figure 5.6.3-2 Las Tablas FS Average Compressive Strengths

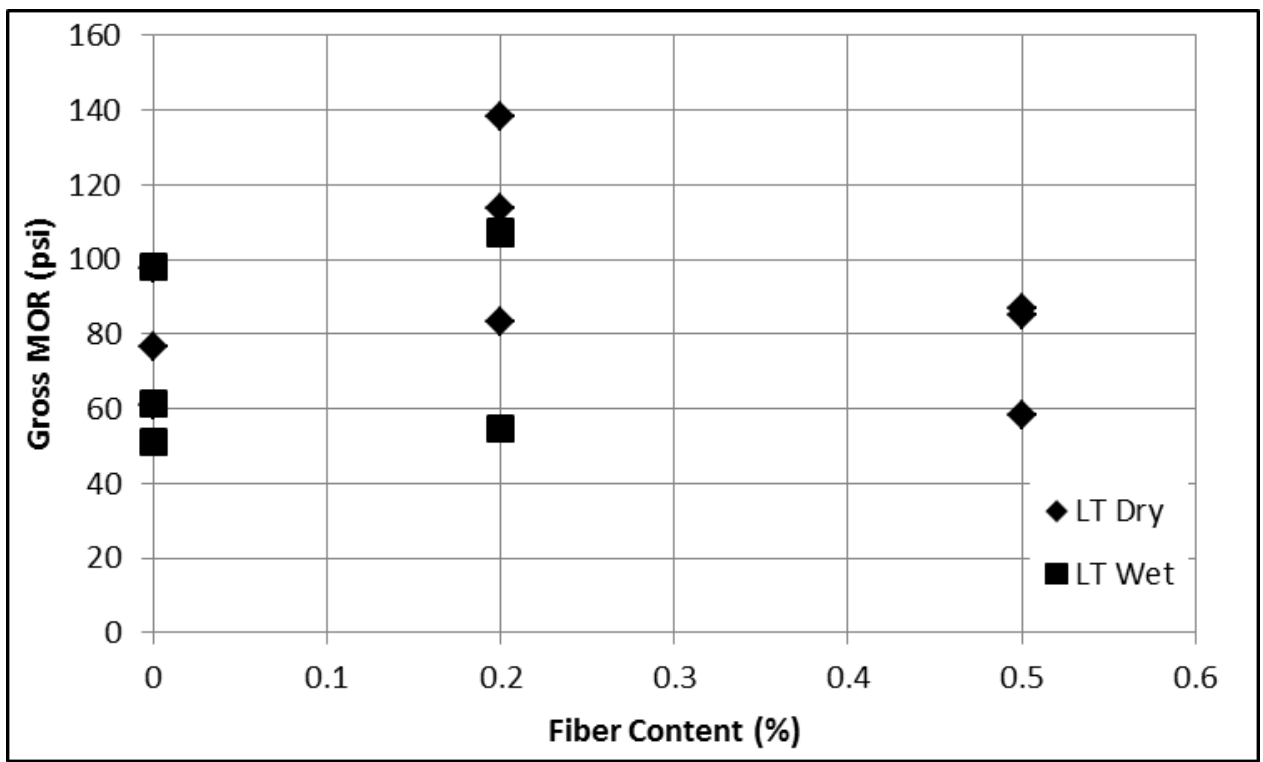

Figure 5.6.3-3 Las Tablas FS MOR 


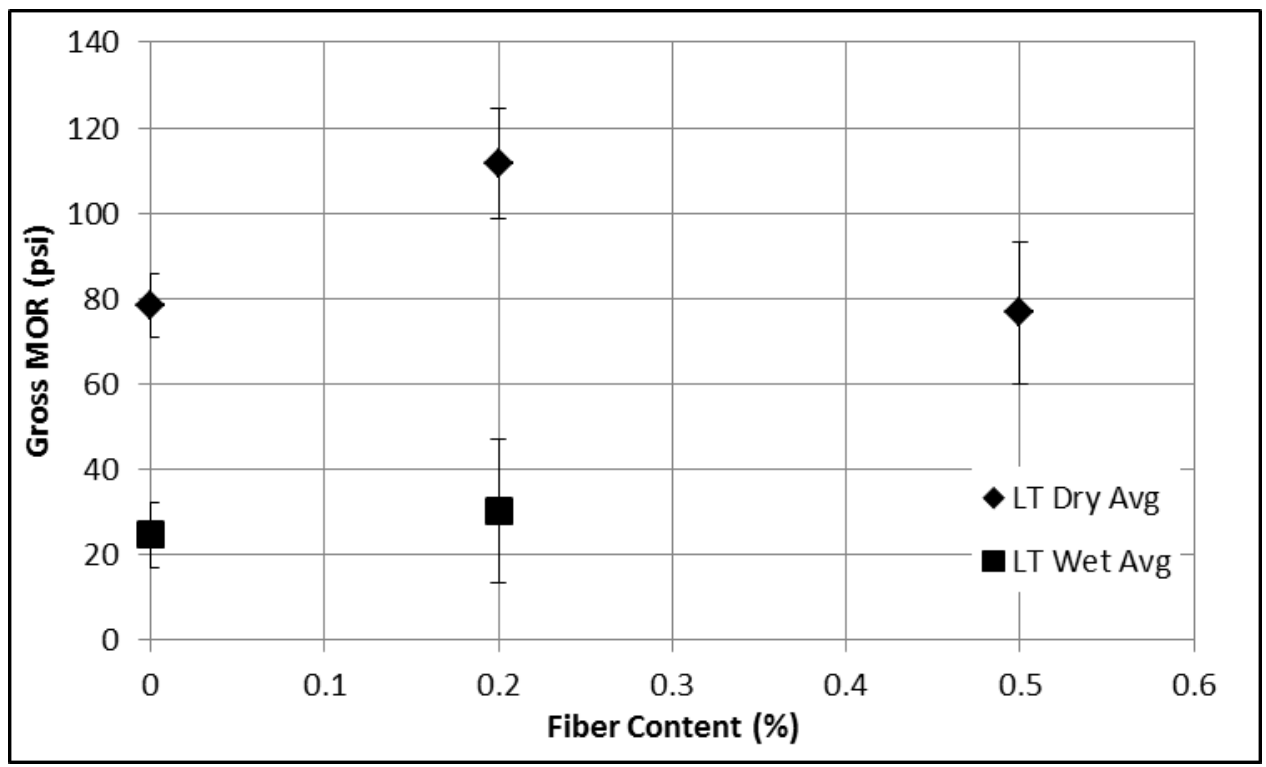

Figure 5.6.3-4 Las Tablas FS Average MOR

Like compressive strength, adding the Strux fibers to the manufacturer's specifications did not produce an appreciable increase in MOR. The slight increase in strength is within a standard deviation of the CEBs without fibers, so no concrete recommendations can be made without additional testing. The difference between wet and dry strengths is significantly less with the Strux fibers, which can once again be explained by the small difference in moisture content.

Like the Forta Ferro batch, the difference in strengths between the wet and dry CEBs increases with the addition of fibers. However, there is not enough data to draw a conclusion. 


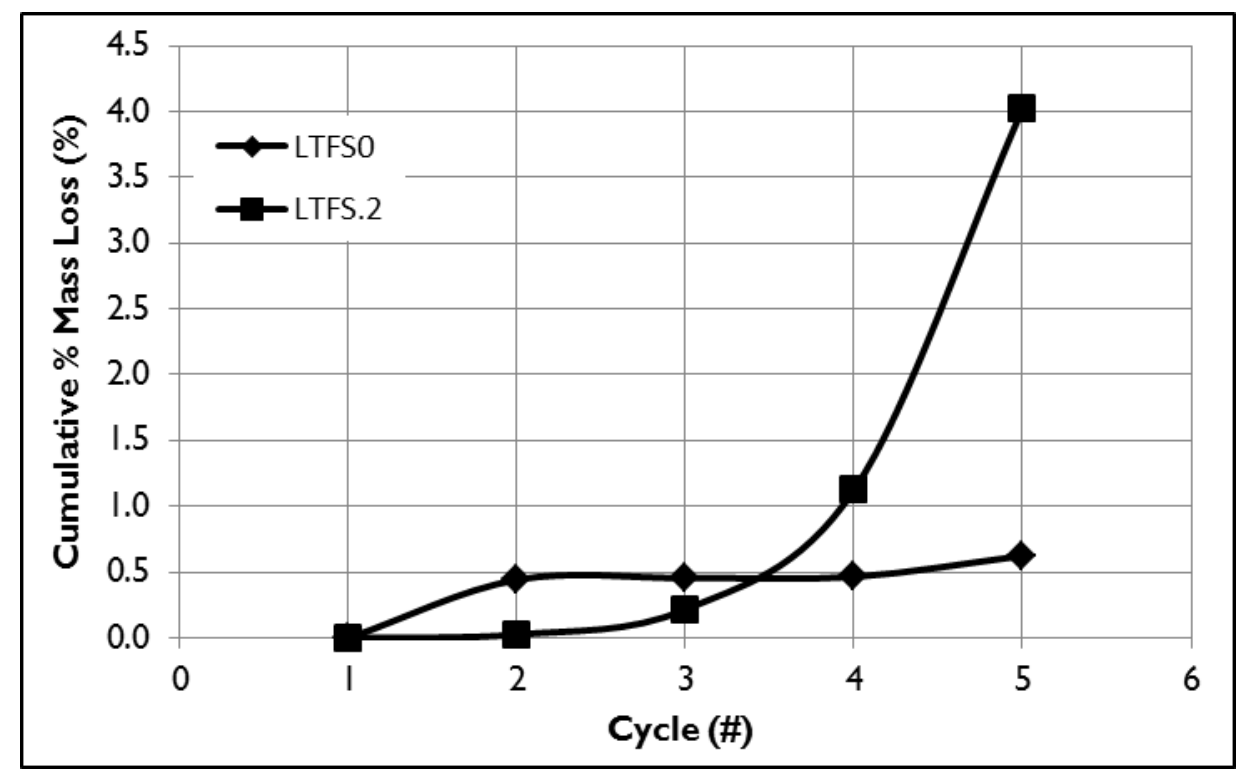

Figure 5.6.3-5 Las Tablas FS Durability Results

From the durability tests above, there is once again a decrease in durability with the addition of fibers. The same pattern of low initial mass loss followed by rapid degradation is also seen in the Forta Ferro blocks. This suggests there may be a loss in durability with the addition of fibers.

Like the Forta Ferro fibers, adding Strux fibers had no effect on the mechanical properties of the block, and seemed to decrease the durability.

\subsubsection{Prado Soil}

The Prado soil only utilized the Strux fibers, and no durability tests were performed. The compression results are discussed below.

Like the LT CEBs, the Prado blocks did not exhibit a significant change in compressive strength. Further investigation reveals the variability between each batch is considerable, which makes it difficult to declare any positive trend in strength gain from 
the addition of fibers. There were a few CEBs tested for compressive strength wet, although the difference in strengths is not significant. No wet CEBs were tested in MOR.

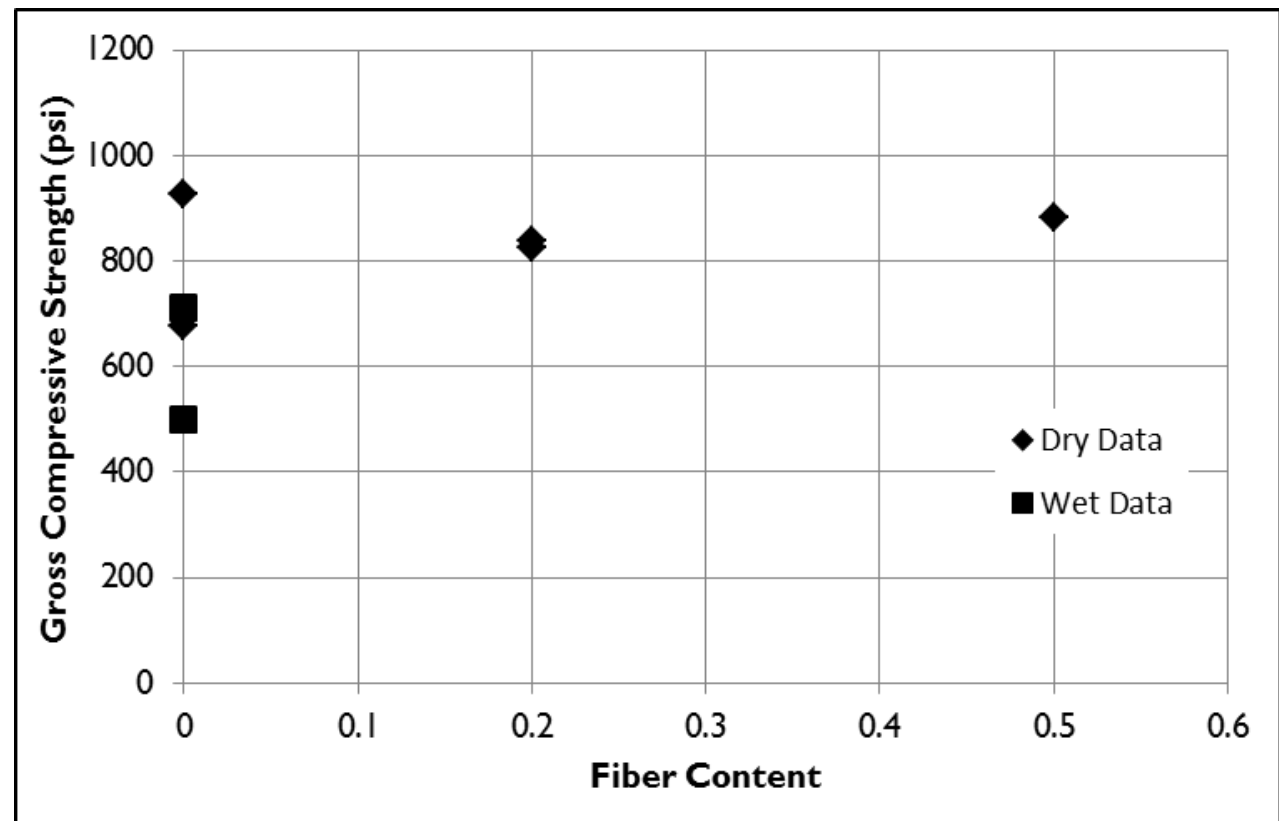

Figure 5.6.4-1 Prado FS Compressive Strengths 


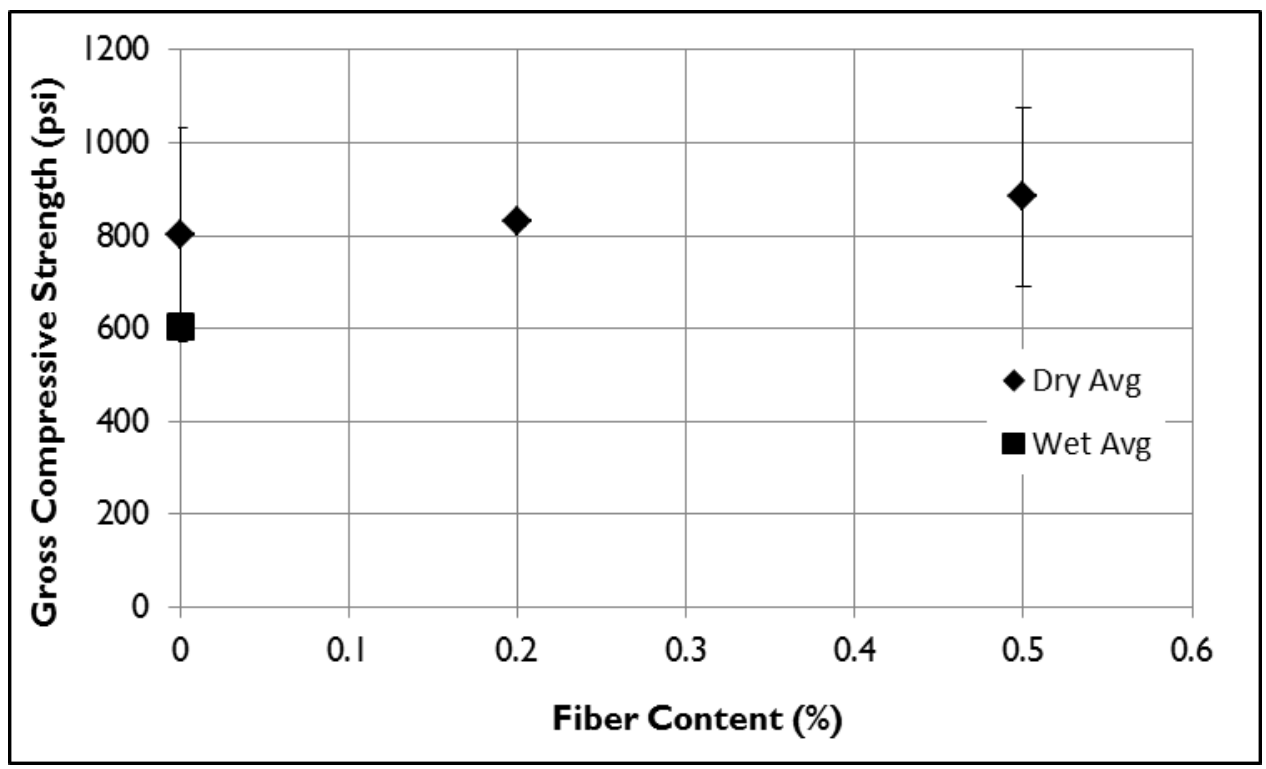

Figure 5.6.4-2 Prado FS Average Compressive Strengths

The MOR results are shown below:

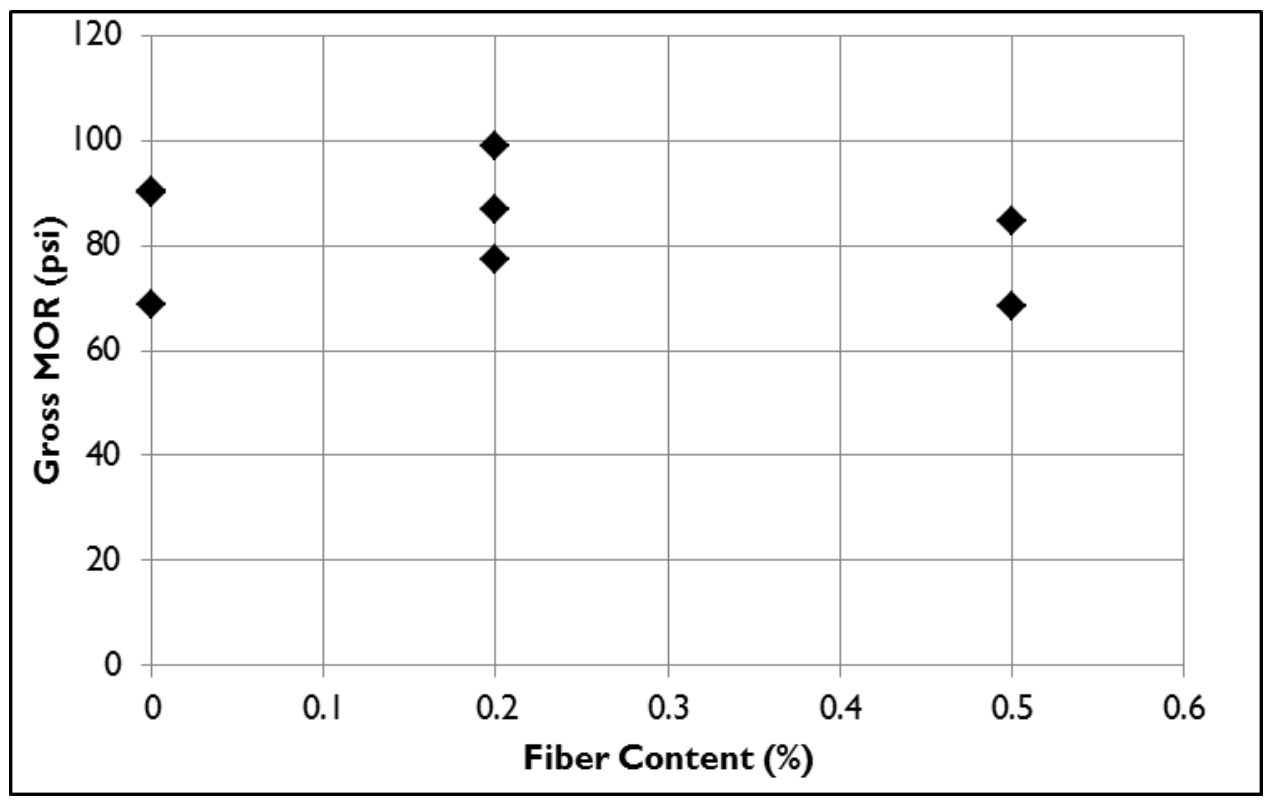

Figure 5.6.4-3 Prado FS MOR 


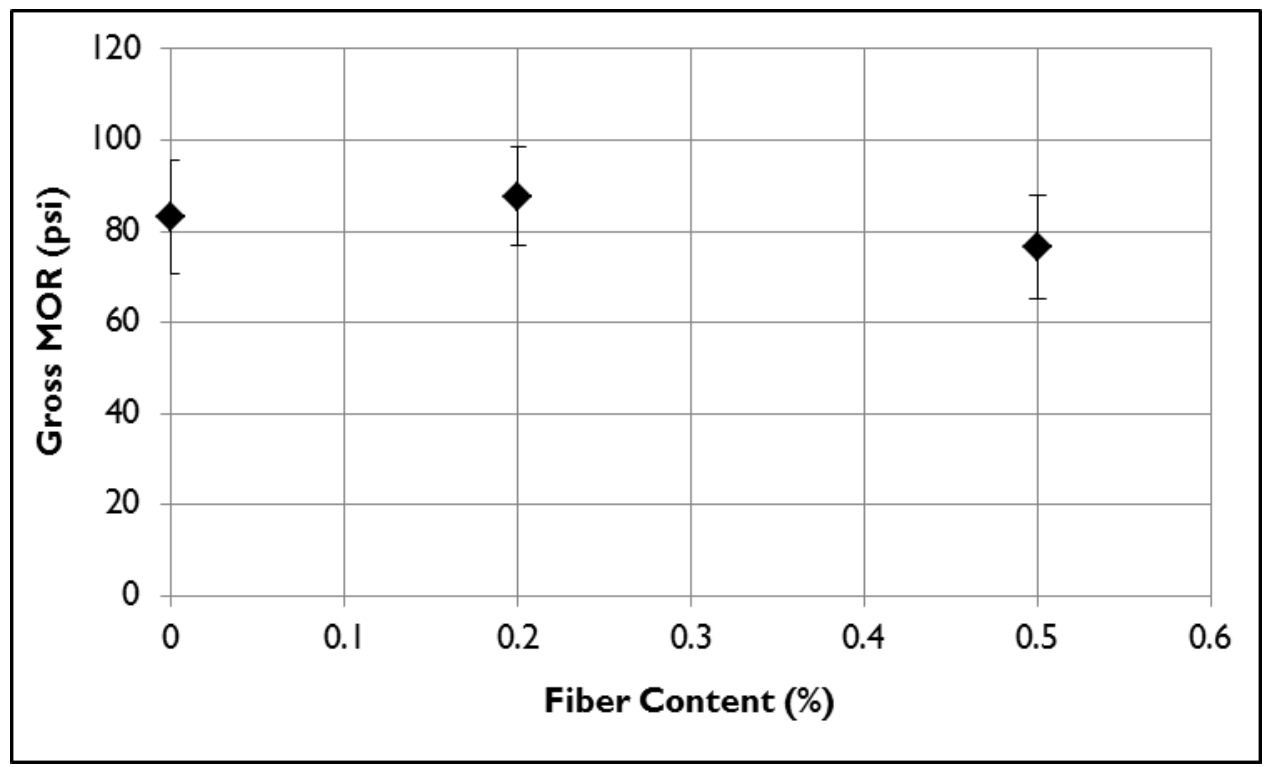

Figure 5.6.4-4 Prado FS Average MOR

Like previous data, there is no clear indication that adding fibers will increase the peak MOR. Unlike the compressive strength testing, this data appears to be much more uniform and stable, further validating the lack of correlation between fibers and peak MOR.

There was no durability testing performed for the Prado soil. From the strength data shown, it is clear that adding fibers to CEBs will not increase their peak strengths.

\subsubsection{Mind Body Soil}

Like the Prado soil, there was no durability testing performed on the MB fiber CEBs, nor was a fiber content of .5\% tested. There were some blocks that were tested wet in compression, but none in MOR. The compression data is shown below: 


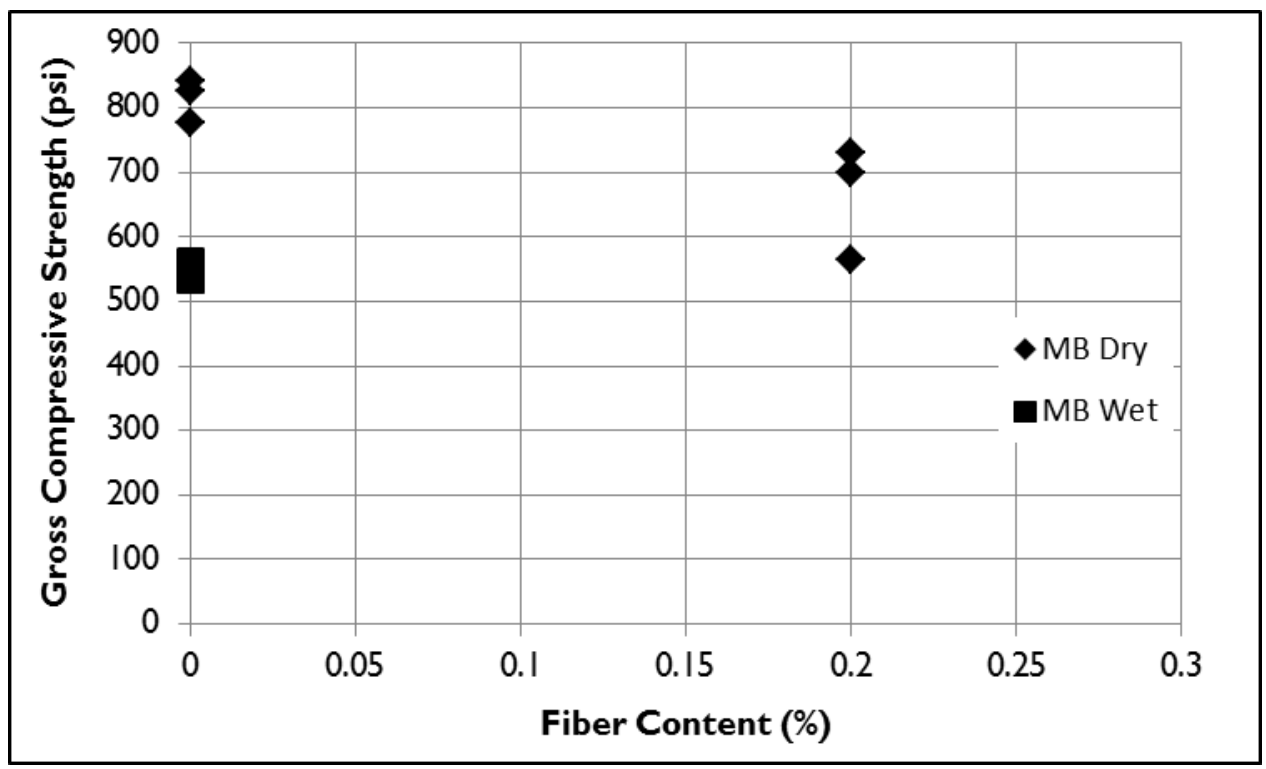

Figure 5.6.5-1 Mind Body FS Compressive Strengths

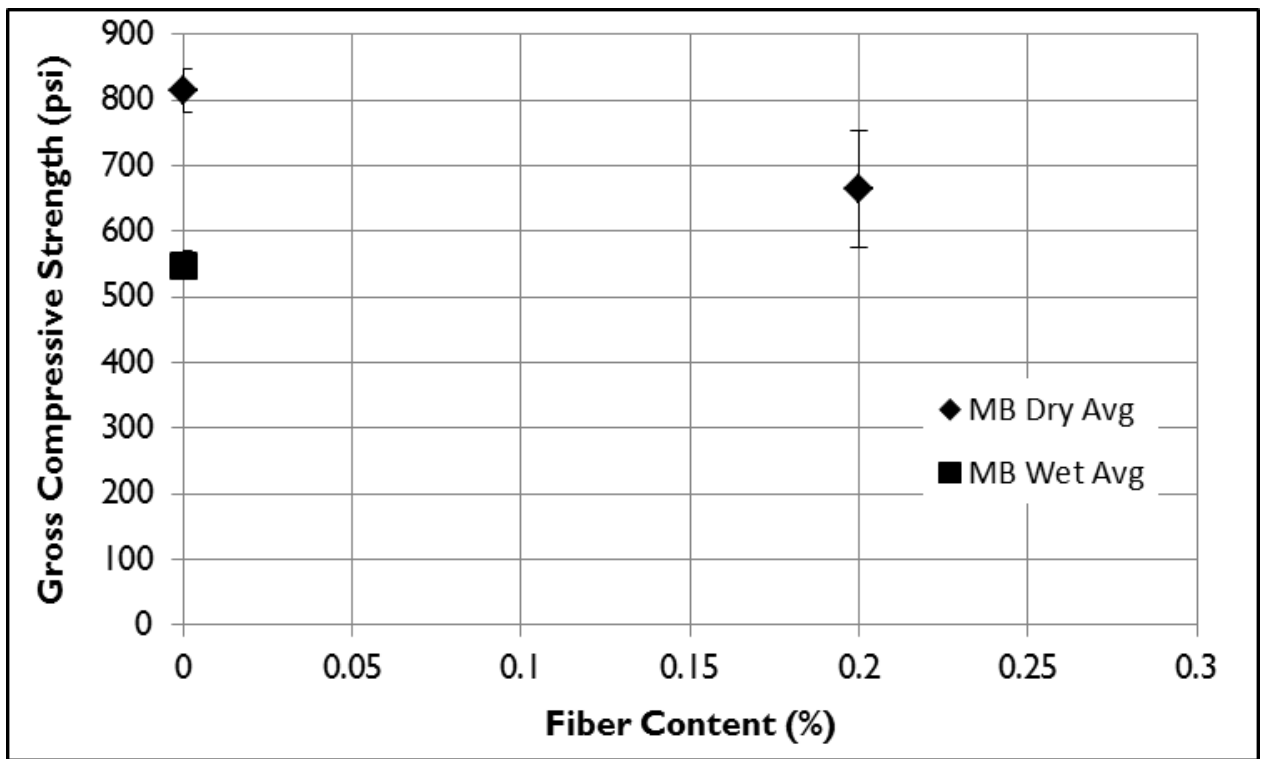

Figure 5.6.5-2 Mind Body FS Average Compressive Strengths

The addition of fibers in the MB CEBs seems to result in a slight decrease in compressive strength. This contradicts the data from other soils, and low sample size 
makes this conclusion suspect. There is also considerable variability present within the $.2 \% \mathrm{CEBs}$, so it is likely more testing is needed before a recommendation is made.

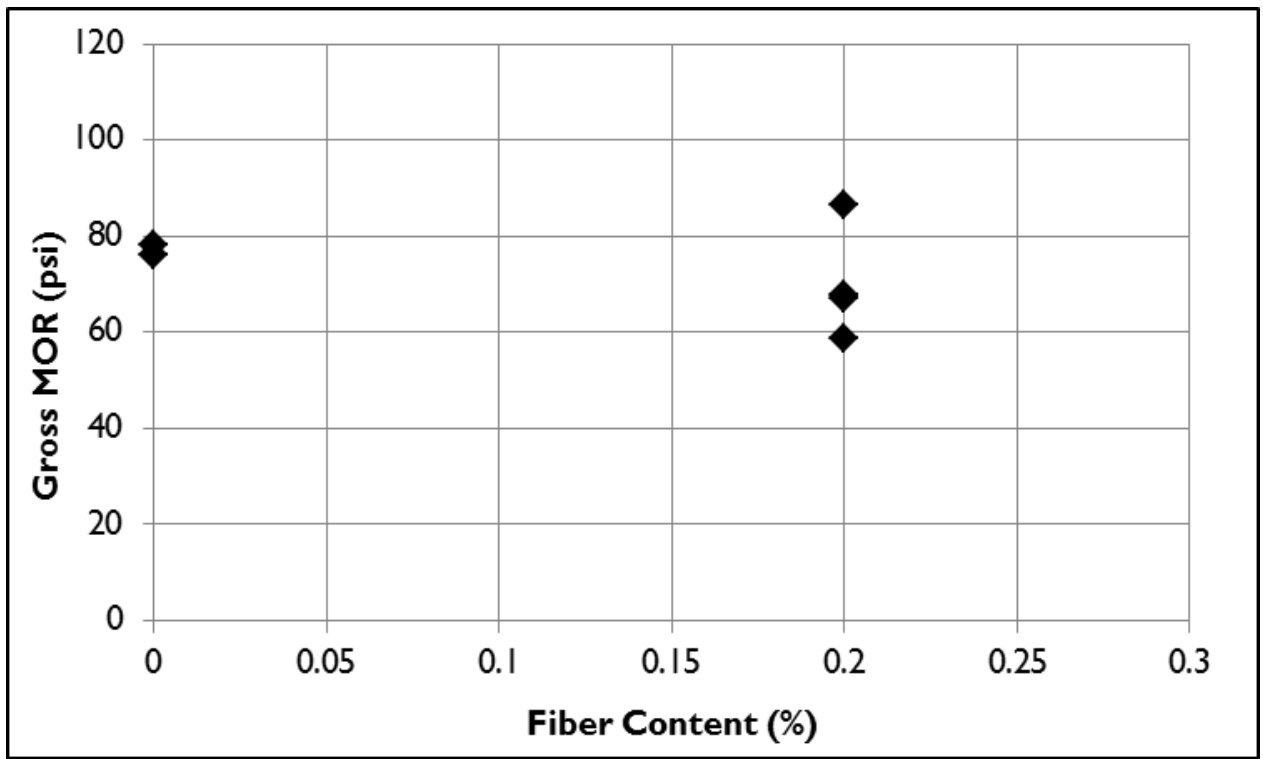

Figure 5.6.5-3 Mind Body FS MOR

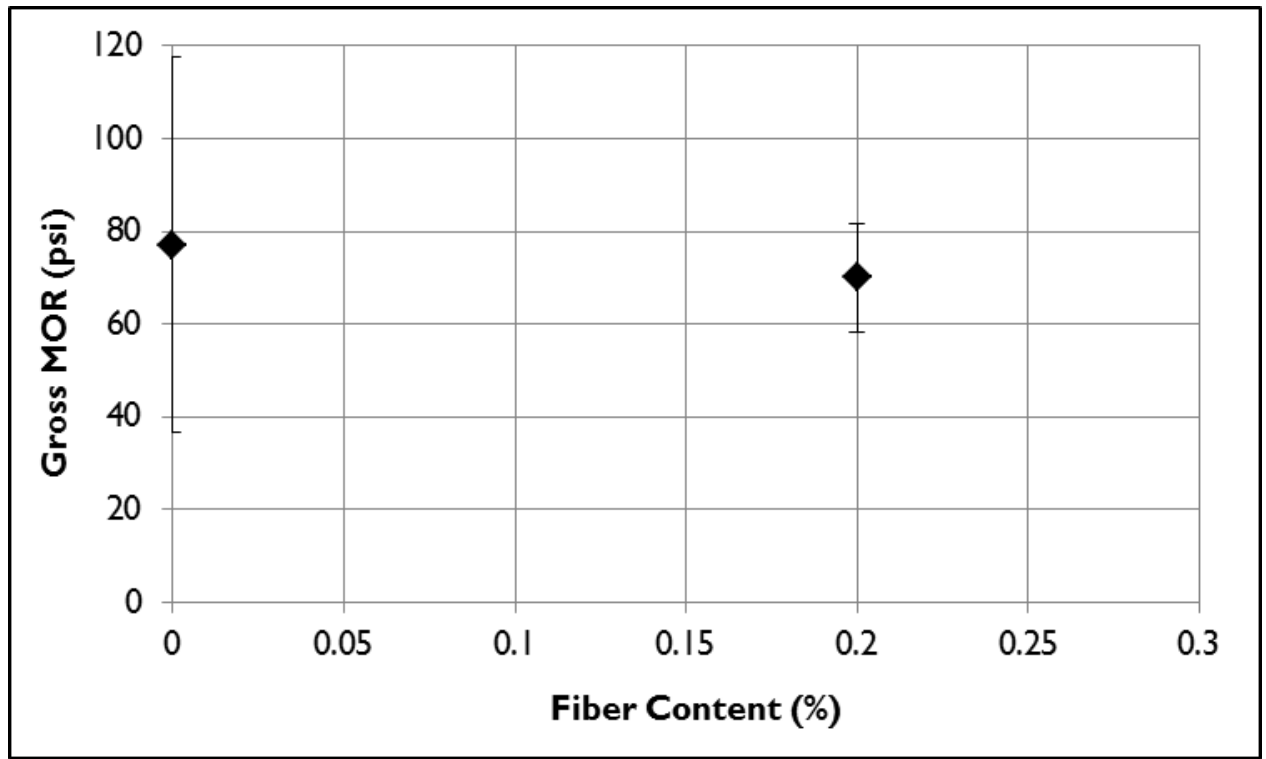

Figure 5.6.5-4 Mind Body FS Average MOR 
The MOR data is shown above, and also indicate that the addition of fibers does not increase the peak MOR. However, there is significant variability in the CEBs without fibers. While this conclusion seems natural when compared to the other sources of data, it is suggested that additional tested be done to confirm this trend within the MB soil.

There was no durability testing performed with MB blocks containing fibers, so no conclusion can be drawn. While the other batches showed a strong indication that adding fibers had no effect on the peak mechanical properties of fibers, additional testing needs to be done with the MB soil to confirm this trend.

\subsubsection{Combined Results}

After each soil was examined, the data was combined and effect of fibers and moisture were separately considered, as well as durability.

The first step in analyzing the data was to combine the dry batch data and observe the trends as fiber content increased. The compression and MOR data is shown below. Like the individual batches, the combined data indicates that the addition of fibers does not affect the peak compressive strength or MOR. This is unsurprising given the previous analysis and research.

There is considerable variability between and among the batches themselves, but it is clear that there is no global trend present. 


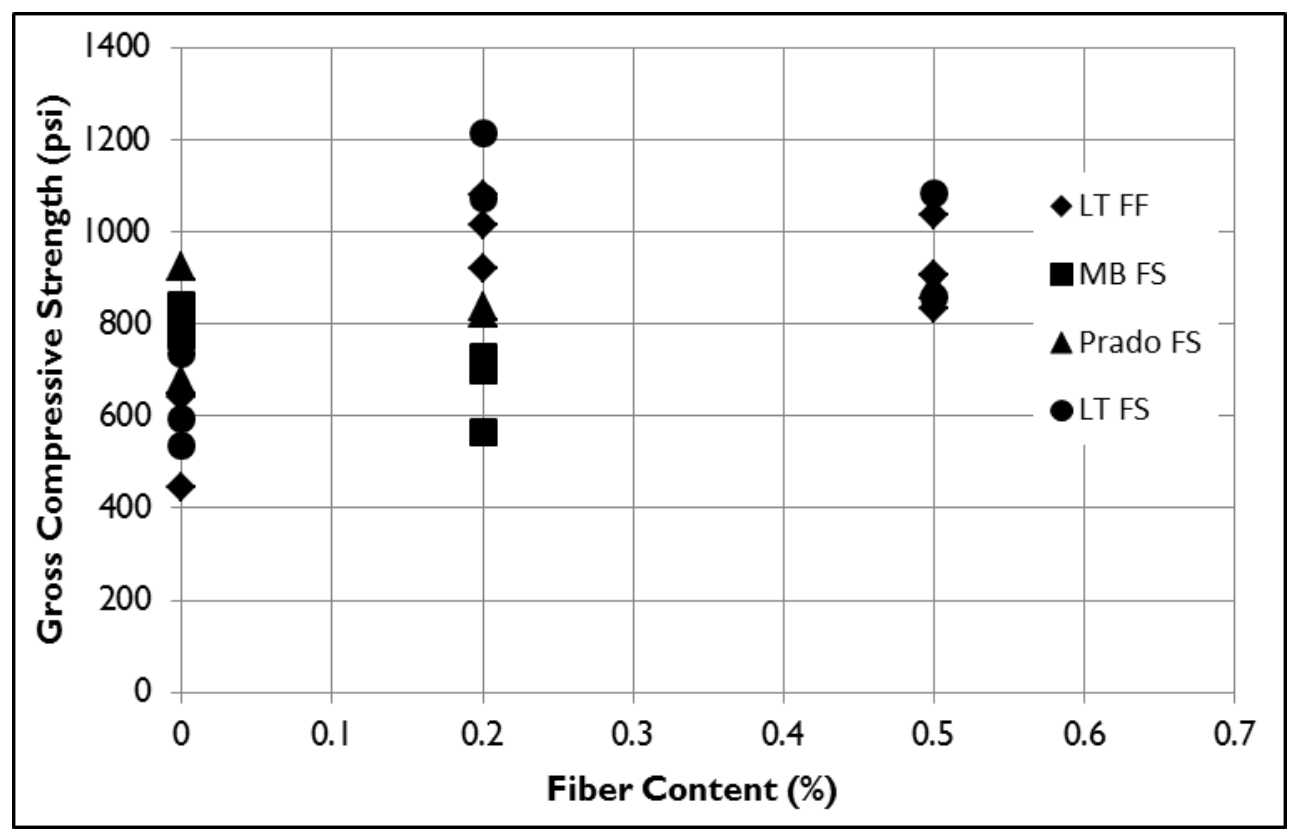

Figure 5.6.6-1 Combined FC Compressive Strengths

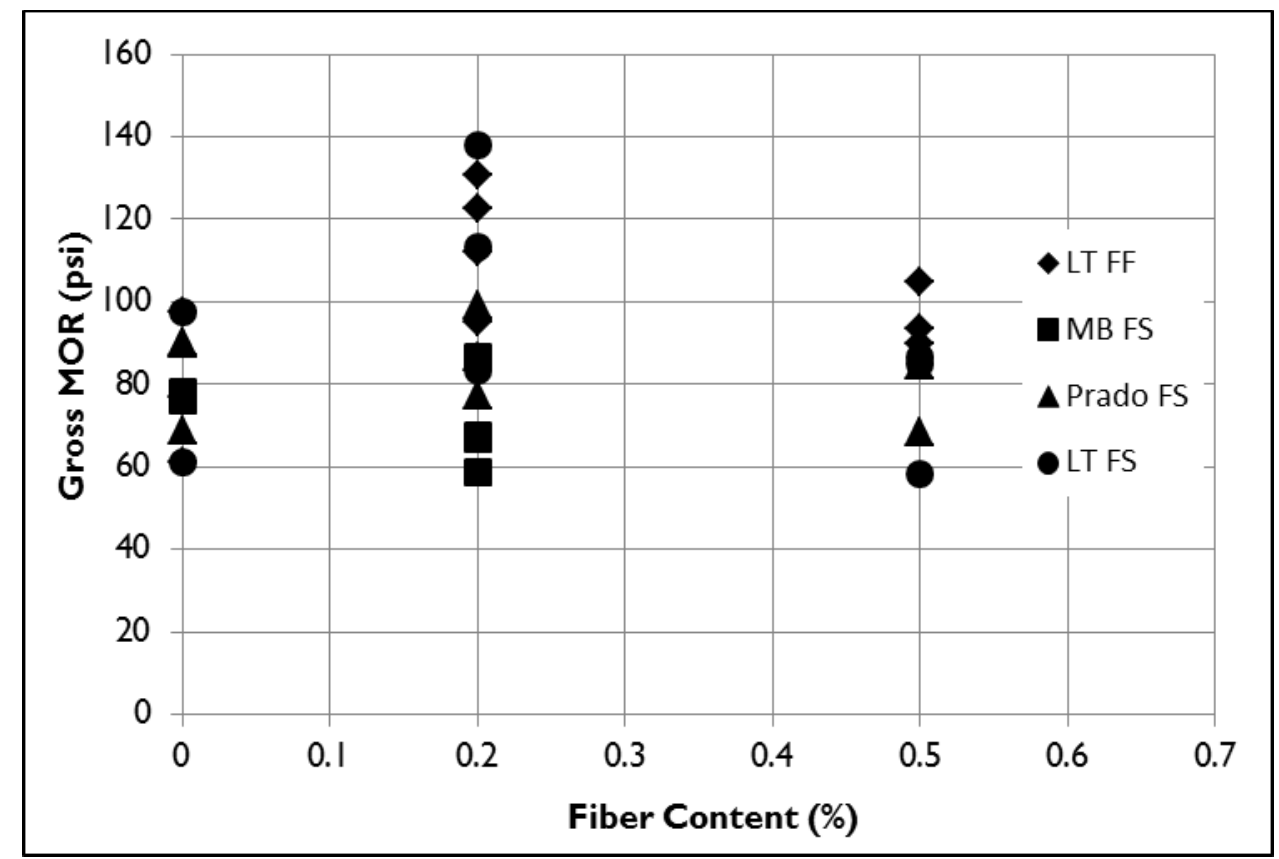

Figure 5.6.6-2 Combined FC MOR 
The durability of the LT FC batches was tested and the combined results can be seen below. In the three cases where fibers were added, there is a significant drop in durability during the last two wet/dry cycles. The fiber reinforced CEBs possess similar densities, and initial moisture content could not have played a significant role after the first cycle.

The volumes of fibers within the blocks were relatively low, especially when compared to research with natural fibers (Taallah et al. 2014). The degradation observed with the fiber reinforced CEBs was consistent across the entire block, and not focused around regions of fiber exposure. It remains unclear whether this trend is feasible, or whether more testing will observe a different pattern.

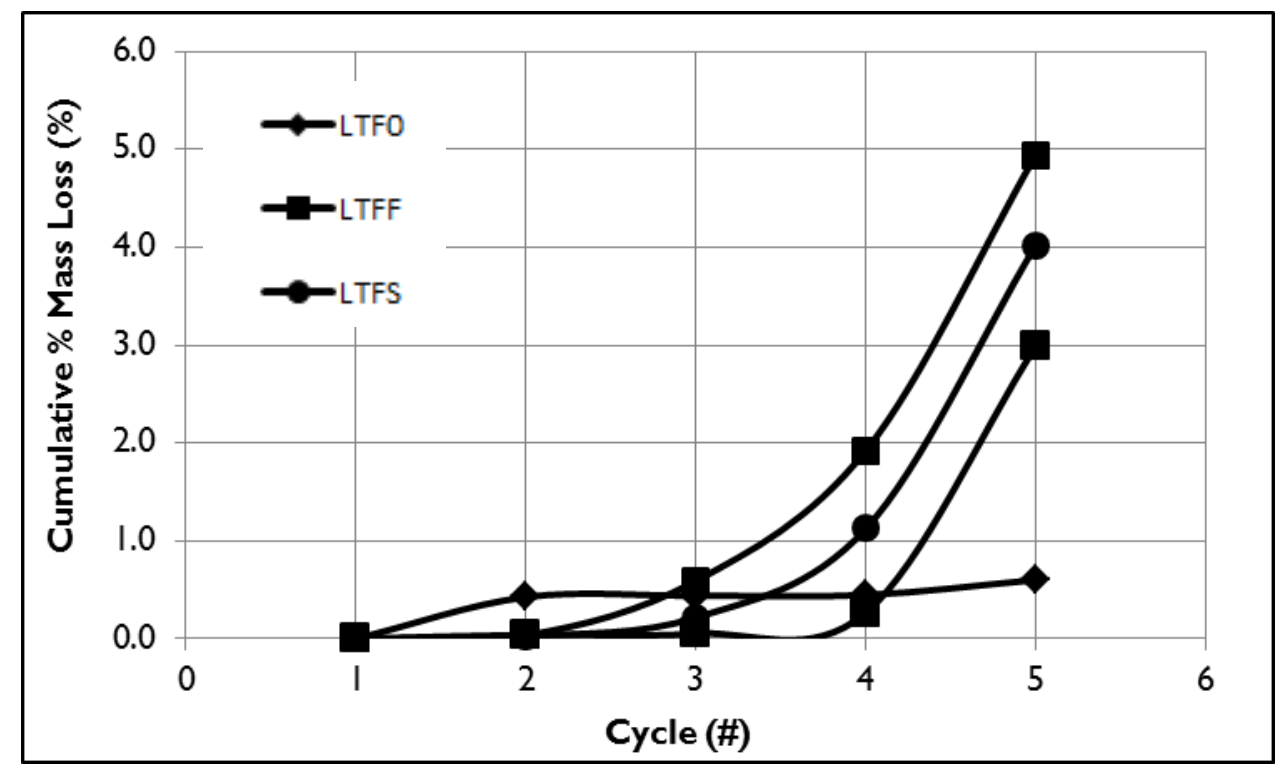

Figure 5.6.6-3 Combined FC Durability Results 
Next, the effect of moisture content in both compression and MOR was analyzed.

Due to the amount of data present, only the averages were considered, and error bars were not included.

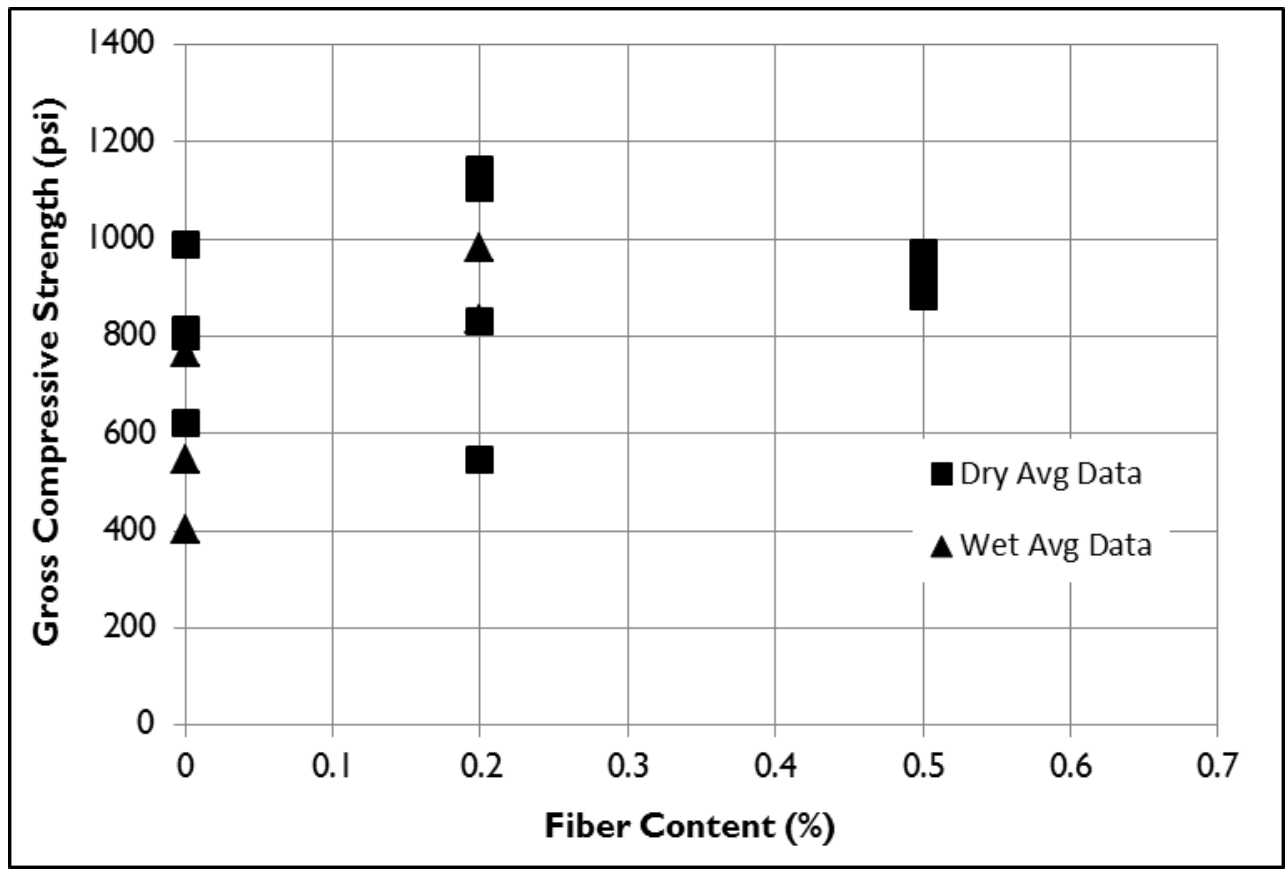

Figure 5.6.6-4 Combined FC Average Wet/Dry Compressive Strengths 


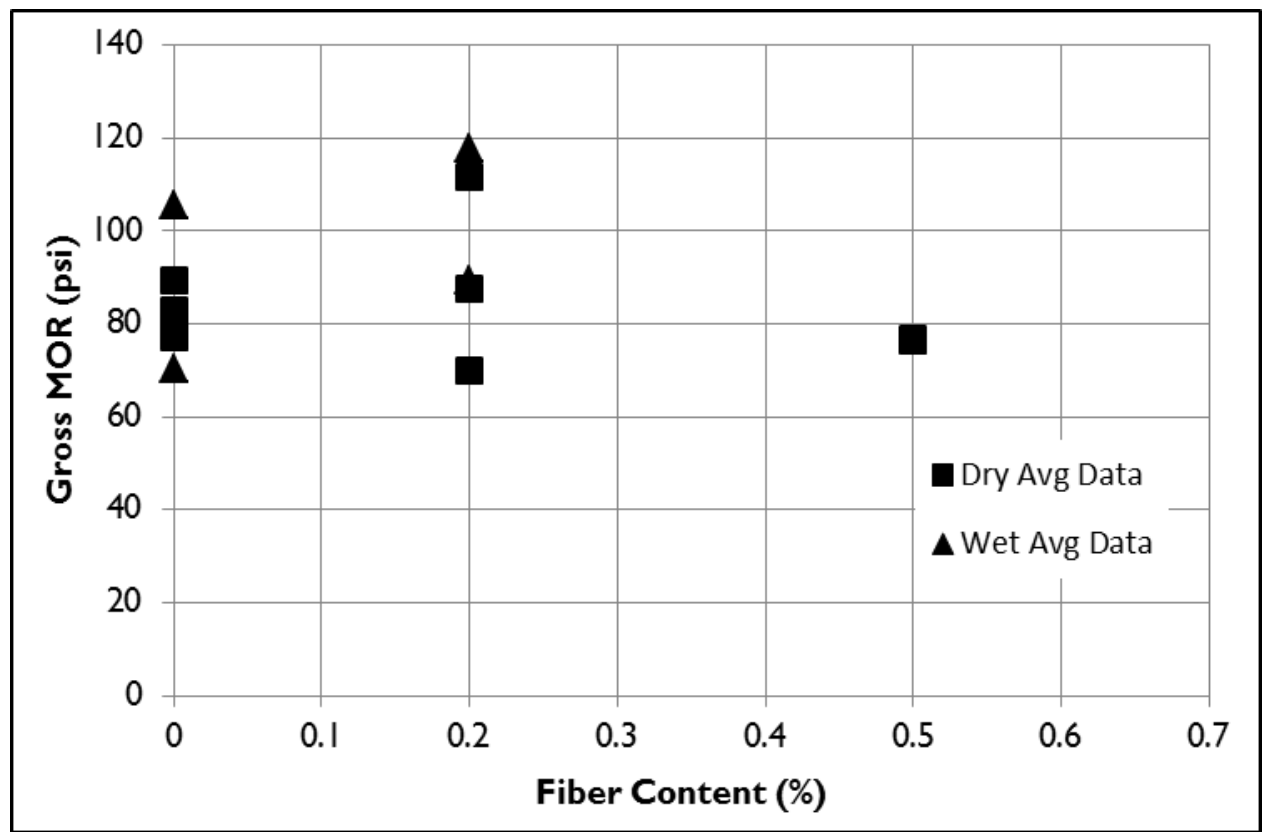

Figure 5.6.6-5 Combined FC Average Wet/Dry MOR

There is no strong trend between moisture content and strength. In both compression and MOR, there does not seem be a significant difference in moisture content, which is an issue regarding the methods of curing. There also appears to be insufficient wet cured data. Both the Prado and MB batches lacked blocks that were wet cured.

Since the Prado and MB blocks were slightly weaker than their LT counterparts, they appear to be near the same strength as the wet blocks from the LT batches. If more testing had occurred, it is likely that a global trend could be established, but the difference in strengths between the soils prevents such a conclusion using the current data. 
It was also important to compare the differences between the two fiber types and see if one fiber was more effective than the other. Only the LT soil contained two different fiber types, and only the dry strengths were considered.

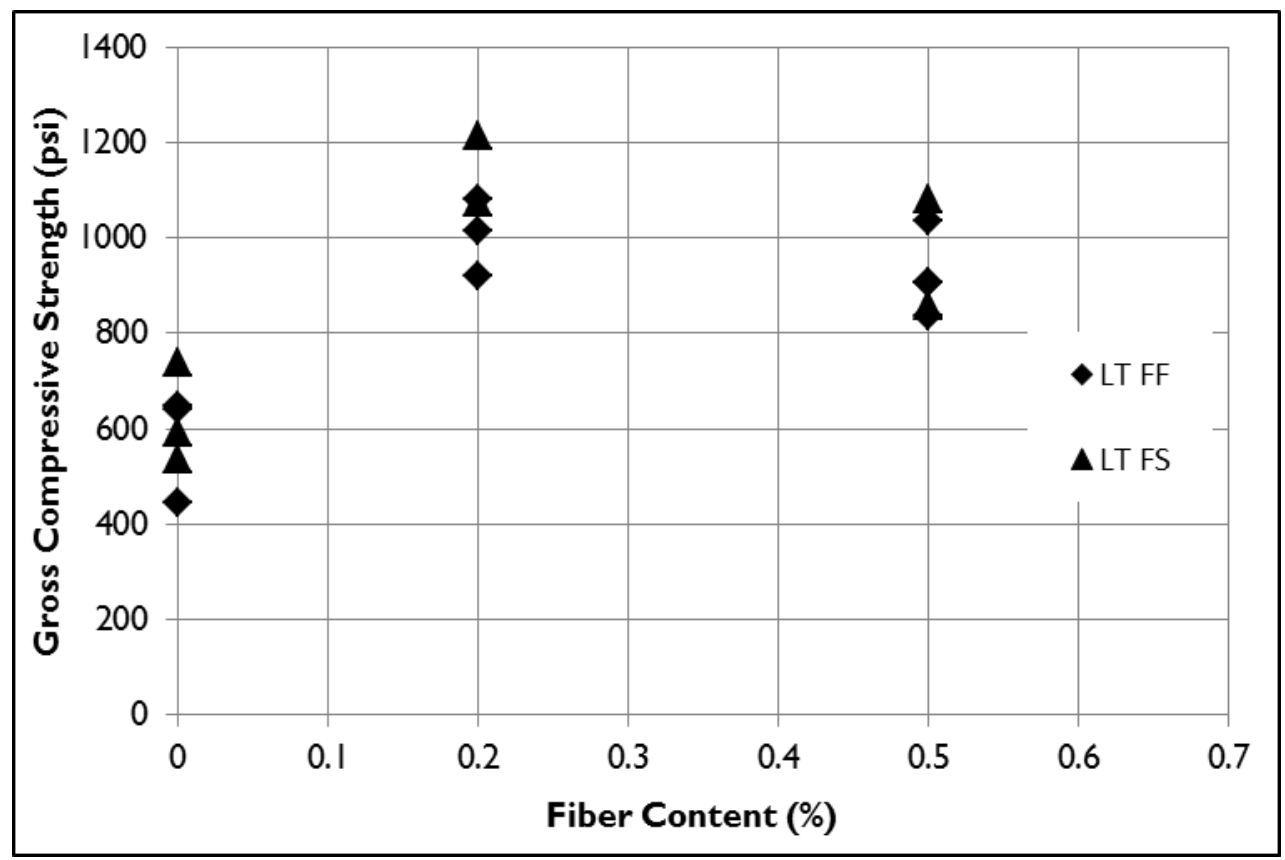

Figure 5.6.6-6 Las Tablas Fiber Comparison Compressive Strengths 


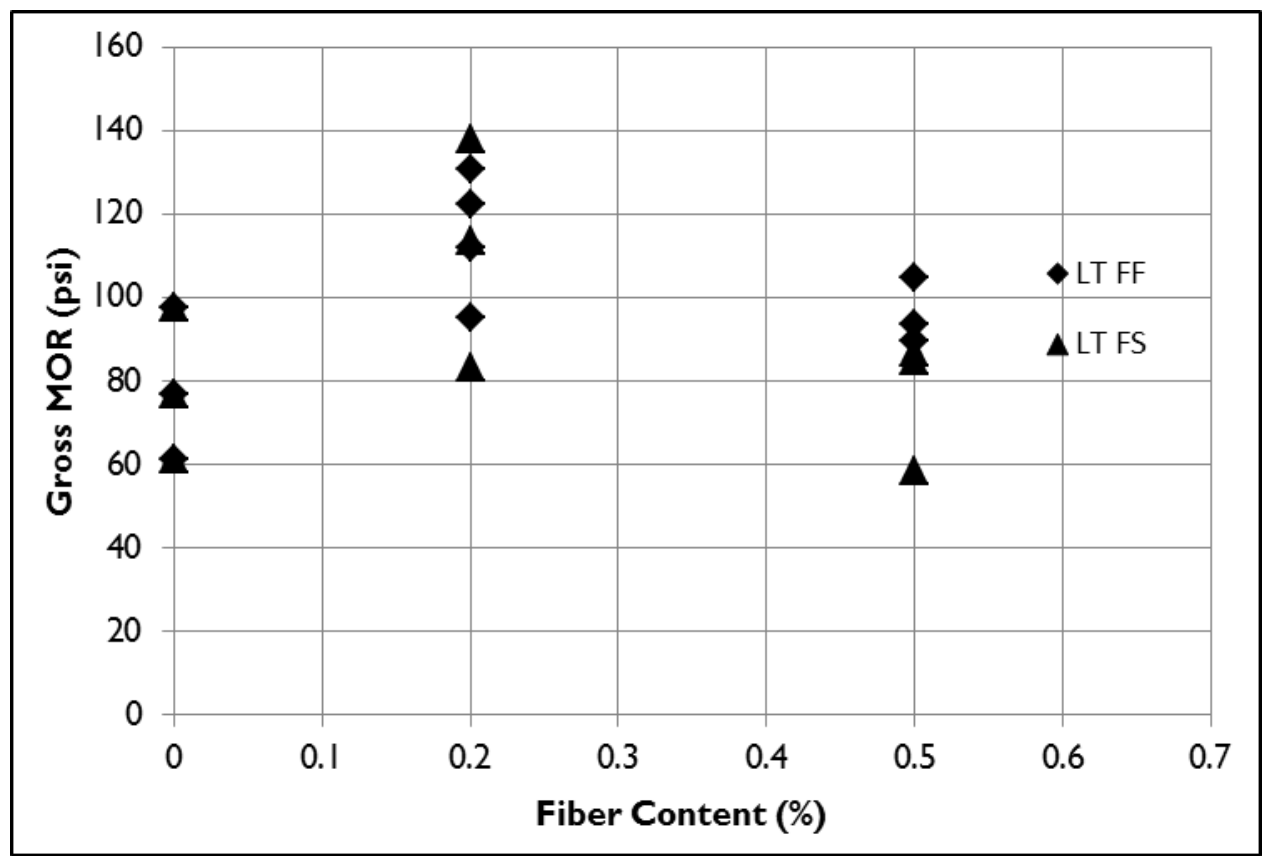

Figure 5.6.6-7 Las Tablas Fiber Comparison MOR

There is no clear difference in strengths between the Forta Ferro or Strux 90/40 fibers. Since fibers in general had no effect on the compressive strength or MOR, it is difficult to make a recommendation on fiber type.

Should additional post cracking testing and analysis be performed, then the differences in fiber lengths and reinforcement schemes may have been revealed. With the data collected, there is no advantage to using either fiber.

Using fibers to improve the peak compressive strength and MOR is ineffective, at least at low volumes. While there are obvious gains in ductility and post cracking strength, these properties were not considered, so it is impossible to recommend the use of a particular fiber type, or the use of fibers to improve the strength or durability of a CEB. 


\section{CHAPTER 6: CONCLUSION}

This project sought to quantify the mechanical and durability properties gained by CEBs through the addition of fibers and manipulation of clay and cement content. These variables were against three different soil types to ensure similar results. Additionally, net and gross strengths were discussed and an equation to predict the MOR using the compressive strength was found.

\subsection{Net vs. Gross Strength}

- The V - Lock CEB utilizes reinforcement chambers and a grout channel, which makes the calculation of Net compressive and MOR less intuitive

- ASTM C140 is an ineffective method of calculating net area. The net area should be found by simply subtracting the area of the reinforcement chambers. Since ASTM C140 was used, there was no definitive equation or factor that could be utilized to convert gross compressive strength into net. 
- The net MOR is more complicated, and involves decreasing the second moment of inertia while decreasing the distance to the extreme fiber in compression. When the net MOR calculation is performed, it is found that there is an increase in MOR, as is typical of other CEBs. Once gross MOR is calculated, the net MOR can be approximated using the following equation:

$$
f_{r \text { Net }}=1.15 * f_{r \text { Gross }}
$$

\subsection{Predicting MOR}

- A linear equation to predict MOR using compressive strength was developed using the data collected from this report

$$
f_{r}=\left(\frac{1}{35}\right) * f_{C E B}+35
$$

- The linear equation was created using the best fit line of the combined data and a $99 \%$ confidence interval

- This equation is not perfectly conservative, although the majority of samples that were not correctly predicted failed the IBC minimum requirements for MOR

- There is not a generally accepted, conservative equation in use with CEBs today. Prediction equations from the masonry and concrete design codes cannot be used for CEBs. 


\subsection{Effect of Clay Content}

- There was no identifiable trend between clay content and strength as a whole

- LT, Prado and MB soils did not show a trend between clay content and strength. This may be due to limited sampling and clay contents chosen

- In every soil, there was an increase in durability as clay content decreased, although the relationship could not be defined as linear or parabolic

\subsection{Effect of Cement Content}

- As cement content increases, CEB strength increases linearly

- This trend was seen for all three soils, although it was thought that a high cement content like $12 \%$ would result in little strength gain, creating a bilinear relationship. This never occurred.

- Durability data appeared to be nonlinear: there was a significant decrease in durability when the cement content was reduced to $4 \%$. When the cement content was raised to $12 \%$, the change in durability was less significant, suggesting the bi-linear relationship predicted

- As cement content increases, the gain in strength is blunted by higher plasticity clay and higher clay content. The higher the plasticity of the clay 
or the higher the clay content, the more cement required to achieve the same strength and durability

\subsection{Effect of Fiber Content}

- There was no trend between the use of fibers and an increase in peak compressive strength or MOR

- There was no discernable difference in strength or durability between the Strux 90/40 or Forta Ferro fibers

- CEBs tested while wet cured exhibited a decrease in strength proportional to the increase in moisture content. The difference in moisture contents was not large enough to see a considerable drop in strength

- The addition of fibers seems to decrease the durability of CEBs at later wet/dry cycles, although additional testing is necessary to confirm this trend

\subsection{Recommendations for Future Work}

- When designing batches, more blocks should be pressed to measure individual variables. With only three blocks to test the strength of a single variable, batches often lacked the sample size to create a strong conclusion. The natural variability of CEBs is such that more than three blocks need to be considered a proper sample size.

- When measuring the trend between clay content and strength, a wide variety of samples is needed to illustrate the detrimental effect clay is known to have on the hydration of cement 
- The trend between strength gain and cement content is dependent upon the natural clay content of the soil and its plasticity. The soils used in this experiment were so clayey that a higher cement content should have been chosen to test the bi-linear effect seen in other research.

- The strength of fibers does not lie in increasing peak compressive strength or MOR, but in increasing ductility and post peak strength. The benefits of fibers are not seen when the peak strengths are measured. This may change if a higher fiber content is used.

- The methods of wet and dry curing the CEBs were ineffective. The dry cured blocks needed more air flow and more time to dry, while the wet cured blocks may have benefited from increased water or submersion prior to testing. Submersion versus a wet cure method may be an interesting avenue of research.

- More testing needs to be completed to secure the equation predicting MOR. A truly conservative equation needs more samples 


\section{REFERENCES}

ACI. (2011). Building Code Requirements for Structural Concrete and Commentary. American Concrete Institute.

ACI. (2013). Building Code Requirements and Specification for Masonry Structures and Companion Commentaries. American Concrete Institute.

ASTM. (2013). Standard Test Methods for Sampling and Testing Concrete Masonry Units and Related Units. ASTM International.

Center for Vocational Building Technology. (2010). Retrieved May 14, 2014, from www.cvbt-web.org/?q=Soil-Pulverizer-SP-5M

Chu, E. (2013). How To Make Bricks Out Of Dirt. Popular Science. Retrieved May 7 , 2014, from www.popsci.com/technology/article/2013-05/building-blocks

De Jong, A. (2012). Dwell Earth Training Manual.

Eko, O. N. (2012). Potential of Salvaged Steel Fibers for Reinforcement of Unfired Earth Blocks. Construction and Building Materials, 35, 340-346.

Forta Corporation. (n.d.). Forta-Ferro Fact-Data. Retrieved 3 13, 2014, from www.fortaferro.com/products/macrofibers/forta-ferro/

Ghavami, F. B. (1999). Behaviour of Composite Soil Reinforced with Natural Fibres. Cement and Concrete Composites, 21, 39-18. 
Grace Construction. (2007). Strux 90/40 Synthetic Macro Fiber Reinforcement. Retrieved March 2014, from Grace Construction: www.aggregatemn.com/wpcontent/uploads/2012/11/Grace-Strux-90401.pdf

Hejazi, S. A. (2011). A Simple Review of Soil Reinforcement by Using Natural and Synthetic Fibers. Construction and Building Materials, 30, 100-116.

Hydraform International. (2014). Retrieved May 8, 2014, from www.hydraform.com/interlocking-blockmaking-machines.htm

International Code Council. (2012). International Building Code. International Code Council, Chapter 21: Masonry.

Jagadish. (2007). Building with Stabilized Mud. I.K. International Publishing House.

Lima, V. S. (2012). Analysis of the Mechanical Porperties of Compressed Earth Block Masonry Using the Sugarcane Bagasse Ash. Construction and Building Materials, 35, 829-837.

Maini. (2010). Earthen Architecture in the World. Retrieved May 8, 2014, from Autoville Earth Institute: www.earth-auroville.com/maintenance/uploaded_pics/7compressed-earth-block-en.pdf

Mesbah, M. W. (2004). Development of a Direct Tensile Test for Compacted Earth Blocks Reinforced with Natural Fibers. Journal of Materials in Civil Engineering, 16, 95-98.

Morel, P. W. (2007). Compressive Strength Testing of Compressed Earth Blocks. Construction and Building Materials, 21, 303-309. 
Muntohar, A. (2011). Engineering Characteristics of the Compressed-Stabilized Earth Brick. Construction and Building Materials, 25, 4215-4220.

Pave, R. (2007). Strength Evaluation of Dry-Stack Masonry. University of Witwarersrand, Johannesburg.

Purnel, S. T. (2007). The Effect of Clay Content in Sands used for Cementitious Materials in Deveoping Countries. Cement and Concrete Research, 37, 751-758.

Rigassi, V. (1985). Compressed Earth Blocks: Manuals of Production. (C. Norton, Trans.) Eschborn, Germany: German Appropriate Teachnology Exchange.

Schildkamp, M. (2009). Suitability of Local Soil for Cost Saving Construction Techniques. Smart Shelter Foundation.

Taallah, G. G. (2014). Mechanical Properties and Hygroscopicity Behavior of Compressed Earth Block Filled by Date Palm Fibers. Construction and Building Materials, 59, 161-168.

United Nations. (2009). The Right of Adequate Housing - Fact Sheet. Fact Sheet Revision 1, Office of the United Nations High Commissioner for Human Rights.

Walker, P. (1995). Strength, Durability and Shrinkage Characteristics of Cement Stabilised Soil Blocks. Cement and Concrete Composites, 19, 301-310. 


\section{APPENDIX A) MATERIAL DATA}

Attached are the data sheets for the soil and sand testing conducted for this project. For each soil, Atterburg Limits, Expansion Index and the gradation were performed. Also attached is a Casagrande clay mineralogy chart, which was used to attempt to determine the predominant clay mineral in each soil, but none could be found. A gradation was also performed for the sand, which is included here. 


\section{A-1) Las Tablas Soil Testing}

\section{DEPARTMENT OF CIVIL AND ENVIRONMENTAL ENGINEERING}

Atterberg Limits Measurements

Test Method: ASTM D43 I8, D2487

\begin{tabular}{|l|l|l|l|}
\hline Project Name & LT Thesis Testing & Project No. & -.-.-- \\
\hline Tested By & WBH & Testing Date & $4 / 12 / 2014$ \\
\hline
\end{tabular}

\begin{tabular}{|l|l|l|l|l|l|}
\hline \multicolumn{7}{|c|}{ SPECIMEN ID AND CLASSIFICATION } \\
\hline Boring No. & ---- & Sample No. & $-\cdots--$ & Depth (ft) & $-\cdots$ \\
\hline Soil Description & \multicolumn{3}{|l|}{ Lean Clay (CL): Yellowish Brown } \\
\hline
\end{tabular}

\begin{tabular}{|l|l|l|l|}
\hline \multicolumn{4}{|c|}{ LIQUID LIMIT } \\
\hline Target Range of Blows & $40-30$ & $30-25$ & $25-20$ \\
\hline Actual Number of Blows & 34 & 24 & 19 \\
\hline Dish ID & 24 & 208 & 52 \\
\hline Mass of Dish (g) & 30.70 & 30.15 & 31.09 \\
\hline Mass of Moist Soil + Dish (g) & 39.43 & 37.07 & 37.55 \\
\hline Mass of Dry Soil + Dish (g) & 36.84 & 34.97 & 35.53 \\
\hline Water Content & $42.2 \%$ & $43.6 \%$ & $45.5 \%$ \\
\hline
\end{tabular}

\begin{tabular}{|l|l|l|}
\hline \multicolumn{3}{|c|}{ PLASTIC LIMIT } \\
\hline Dish ID & 93 & 226 \\
\hline Mass of Dish (g) & 30.41 & 30.25 \\
\hline Mass of Moist Soil + Dish (g) & 37.46 & 43.14 \\
\hline Mass of Dry Soil + Dish (g) & 36.72 & 41.69 \\
\hline Water Content & $11.7 \%$ & $12.7 \%$ \\
\hline
\end{tabular}

\begin{tabular}{|l|c|}
\hline \multicolumn{2}{|c|}{ SUMMARY } \\
\hline Liquid Limt & 44 \\
\hline Plastic Limit & 12 \\
\hline Plasticity Ind. & 32 \\
\hline
\end{tabular}
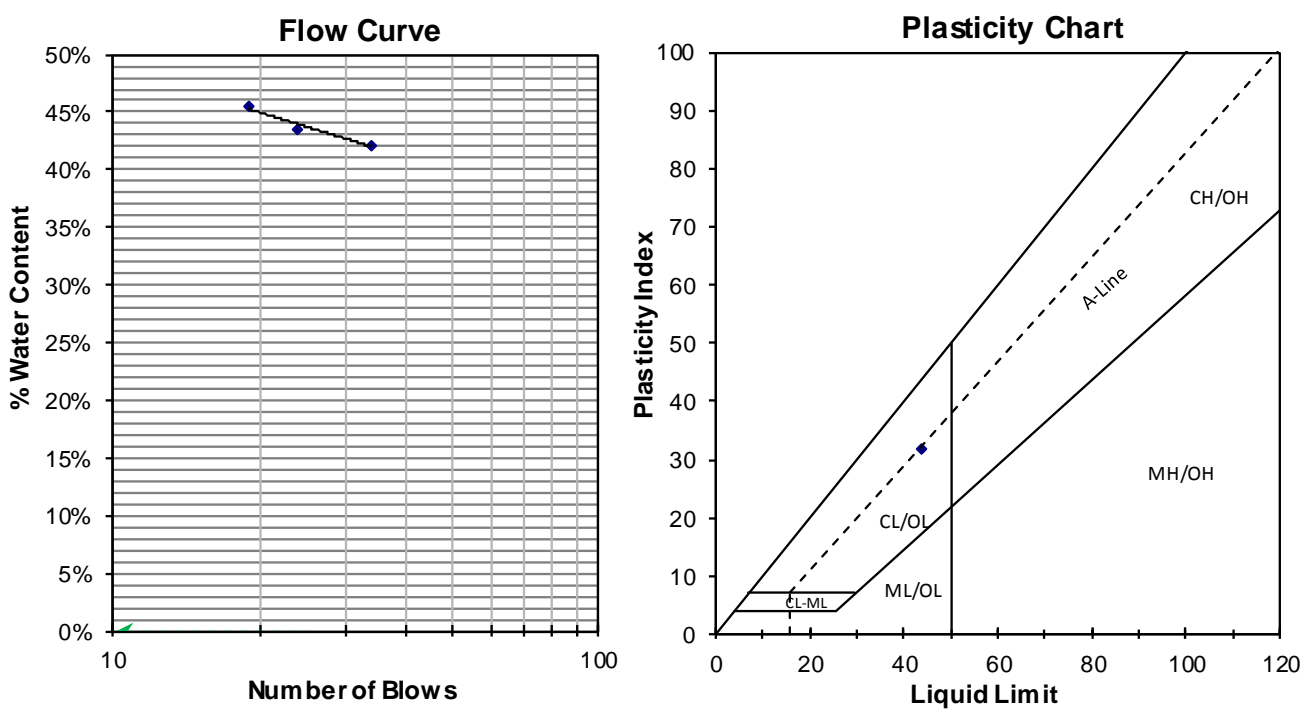


\section{DEPARTMENT OF CIVIL AND ENVIRONMENTAL ENGINEERING}

Hydrometer Analysis

Test Method: ASTM D422, D2487

\begin{tabular}{|l|l|l|l|}
\hline Project Name & \multicolumn{3}{|c|}{ LT Thesis } \\
\hline Tested By & WBH & Testing Date & $4 / 8 / 2014$ \\
\hline Soil Description & Lean Clay (CL): Yellowish Brown \\
\hline
\end{tabular}

\begin{tabular}{|l|c|l|l|l|l|}
\hline \multicolumn{7}{|c|}{ GRAVEL GRADING } \\
\hline Tray ID & $\mathrm{I}$ & Air-Dry Soil Mass $(\mathrm{g})$ & 266.07 & Corrected Dry Mass $(\mathrm{g})$ & 256.74 \\
\hline
\end{tabular}

\begin{tabular}{|c|c|c|c|c|c|}
\hline Sieve No. & Size, $\mathrm{mm}$ & Mass Retained $(\mathrm{g})$ & Cumulative Retained $(\mathrm{g})$ & $\%$ Retained & $\begin{array}{c}\text { Combineed } \% \\
\text { Passing }\end{array}$ \\
\hline 3 in & 76.2 & 0.00 & 0.00 & $0.0 \%$ & $100.0 \%$ \\
\hline 2 in * & 50.8 & 0.00 & 0.00 & $0.0 \%$ & $100.0 \%$ \\
\hline 1 in * & 25.4 & 0.00 & 0.00 & $0.0 \%$ & $100.0 \%$ \\
\hline $3 / 4$ in * & 19.1 & 0.00 & 0.00 & $0.0 \%$ & $100.0 \%$ \\
\hline $1 / 2$ in * & 12.7 & 0.00 & 0.00 & $0.0 \%$ & $100.0 \%$ \\
\hline $3 / 8$ in * & 9.50 & 1.52 & 1.52 & $0.6 \%$ & $99.4 \%$ \\
\hline No. $4 *$ & 4.75 & 5.27 & 6.79 & $2.6 \%$ & $97.4 \%$ \\
\hline \multicolumn{2}{|c|}{ Pan } & 259.28 & 266.07 & Sieve Continuity & $100.0 \%$ \\
\hline
\end{tabular}

\begin{tabular}{|l|c|l|c|l|c|}
\hline \multicolumn{2}{|c|}{ WATER CONTENT OF MINUS \#4 = } & $3.6 \%$ & \multicolumn{2}{c|}{ \#4 BY \#10 GRADING } \\
\hline Dish ID & 2 & Moist Soil + Dish (g) & 54.46 & Mass of Air-Dried Soil (g) & 120.34 \\
\hline Dish Mass (g) & 30.78 & Dry Soil + Dish (g) & 53.63 & Corrected Dry Mass (g) & $1 / 6.12$ \\
\hline
\end{tabular}

\begin{tabular}{|c|c|c|c|c|c|}
\hline Sieve No. & Size, $\mathrm{mm}$ & Mass Retained $(\mathrm{g})$ & \% Retained & \% Passing & $\begin{array}{c}\text { Combined \% } \\
\text { Passing }\end{array}$ \\
\hline No. 10 & 2.00 & 10.87 & $9.4 \%$ & $90.6 \%$ & $88.2 \%$ \\
\hline \multicolumn{2}{|c|}{ Pan } & 109.46 & \multicolumn{2}{c|}{ Split Minus \#10 for Hydrometer Test (152H) } \\
\hline
\end{tabular}

\begin{tabular}{|c|c|c|c|c|c|c|}
\hline \multirow{2}{*}{$\begin{array}{r}\text { Post Wash ID } \\
\text { Sieve No. }\end{array}$} & \multirow{2}{*}{$\begin{array}{c}\text { B-I } \\
\text { Size, mm }\end{array}$} & \multirow{2}{*}{$\begin{array}{l}\text { Dry Mass Post Wash } \\
(\mathrm{g}) \\
\text { Mass Retained (g) }\end{array}$} & \multirow{2}{*}{$\begin{array}{r}212.86 \\
\text { Cum. Ret. (g) }\end{array}$} & \multicolumn{3}{|c|}{ \#16 BY \#200 GRADING } \\
\hline & & & & $\%$ Retained & $\%$ Passing & $\begin{array}{c}\text { Combined \% } \\
\text { Passing }\end{array}$ \\
\hline No. 16 & 1.180 & 14.62 & 14.62 & $6.9 \%$ & $93.1 \%$ & $82.2 \%$ \\
\hline No. 30 & 0.600 & 15.18 & 29.80 & $14.0 \%$ & $86.0 \%$ & $75.9 \%$ \\
\hline No. 50 & 0.300 & 15.38 & 45.18 & $21.2 \%$ & $78.8 \%$ & $69.5 \%$ \\
\hline No. 100 & 0.150 & 20.42 & 65.60 & $30.8 \%$ & $69.2 \%$ & $61.0 \%$ \\
\hline No. 200 & 0.075 & 24.06 & 89.66 & $42.1 \%$ & $57.9 \%$ & $51.1 \%$ \\
\hline \multicolumn{2}{|c|}{ Pan } & 0.83 & 90.49 & \multicolumn{2}{|c|}{ Sieve Continuity } & $235.2 \%$ \\
\hline
\end{tabular}




\begin{tabular}{|l|c|l|c|l|c|}
\hline HYDROSCOPIC WATER CONTENT = & $4.1 \%$ & \multicolumn{2}{c|}{ HYDROMETER } \\
\hline Dish ID & 76 & Moist Soil + Dish (g) & 90.70 & Mass of Air-Dried Soil (g) & 49.13 \\
\hline Dish Mass (g) & 30.58 & Dry Soil + Dish (g) & 88.35 & Corrected Dry Mass (g) & 47.21 \\
\hline
\end{tabular}

\begin{tabular}{|c|c|c|c|c|c|c|}
\hline Time $(\mathrm{min})$ & $\begin{array}{c}\text { Hydro. } \\
\text { Reading }\end{array}$ & Temperature $\left({ }^{\circ} \mathrm{C}\right)$ & $\begin{array}{c}\text { Effective } \\
\text { Depth }\end{array}$ & $\begin{array}{c}\text { Diameter } \\
(\mathrm{mm})\end{array}$ & $\begin{array}{c}\text { Combined } \% \\
\text { Passing }\end{array}$ \\
\hline 2 & 31.0 & 21.0 & 11.2 & 0.0314 & $52.4 \%$ & $46.3 \%$ \\
\hline 5 & 28.0 & 21.0 & 11.7 & 0.0203 & $46.1 \%$ & $40.7 \%$ \\
\hline 15 & 27.0 & 21.0 & 11.9 & 0.0118 & $44.0 \%$ & $38.9 \%$ \\
\hline 30 & 25.0 & 21.0 & 12.2 & 0.0085 & $39.8 \%$ & $35.2 \%$ \\
\hline 60 & 24.0 & 21.0 & 12.4 & 0.0060 & $37.7 \%$ & $33.3 \%$ \\
\hline 90 & 23.0 & 21.0 & 12.5 & 0.0050 & $35.6 \%$ & $31.5 \%$ \\
\hline 120 & 23.0 & 22.0 & 12.5 & 0.0042 & $35.6 \%$ & $31.5 \%$ \\
\hline 240 & 22.0 & 22.0 & 12.7 & 0.0030 & $33.6 \%$ & $29.6 \%$ \\
\hline 480 & 21.0 & 23.0 & 12.9 & 0.0021 & $31.5 \%$ & $27.8 \%$ \\
\hline 1440 & 21.0 & 23.0 & 12.9 & 0.0012 & $31.5 \%$ & $27.8 \%$ \\
\hline
\end{tabular}

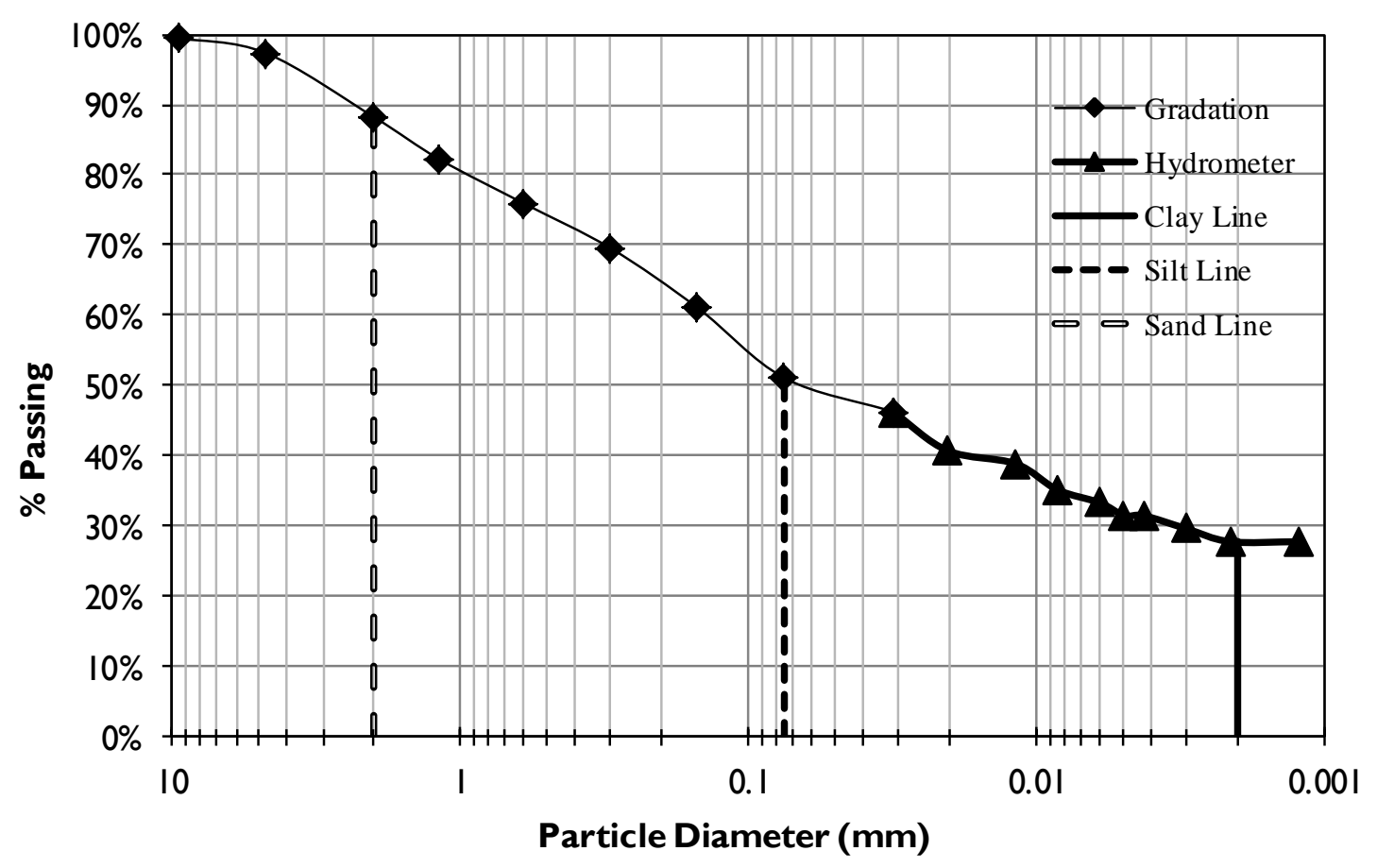


DEPARTMENT OF CIVIL AND ENVIRONMENTAL ENGINEERING

Expansion Index

Test Method: ASTM D4829

\begin{tabular}{|l|l|l|l|}
\hline Project Name & Las Tablas & Project No. & ----- \\
\hline Tested By & WBH & Testing Date & $4 / 19 / 2014$ \\
\hline
\end{tabular}

\begin{tabular}{|l|l|l|l|l|l|}
\hline \multicolumn{7}{|c|}{ SPECIMEN ID AND CLASSIFICATION } \\
\hline Boring No. & $-\cdots--$ & Sample No. & $-\cdots--$ & Depth (ft) & $-\cdots$ \\
\hline Soil Description & \multicolumn{3}{|l|}{ Lean Clay (CL): Yellowish Brown } \\
\hline
\end{tabular}

\begin{tabular}{|l|c|}
\hline \multicolumn{2}{|c|}{ Moisture Content } \\
\hline Tare No. & 15 \\
\hline Wet soil + tare, g & 685.65 \\
\hline Dry soil + tare, g & 675.96 \\
\hline Water, g & 9.69 \\
\hline Tare, g & 633.71 \\
\hline Soil, g & 42.25 \\
\hline$\%$ Water & 22.93 \\
\hline
\end{tabular}

\begin{tabular}{|l|c|}
\hline \multicolumn{2}{|c|}{ SPECIMEN MASS } \\
\hline Height, in & 0.99 \\
\hline Diameter, in & 4.01 \\
\hline Ring No. & $201 \mathrm{GM}$ \\
\hline Ring, g & 200.72 \\
\hline Ring + soil, g & 510.80 \\
\hline Wet density, pcf & 94.02 \\
\hline Dry density, pcf & 76.48 \\
\hline
\end{tabular}

\begin{tabular}{|c|c|c|c|}
\hline \multicolumn{5}{|c|}{ EXPANSION READINGS } \\
\hline DATE & TIME & DIAL READING, in. & REMARKS \\
\hline $4 / 13 / 2014$ & $10: 30$ & 0.0309 & I0 min after loading \\
\hline $4 / 14 / 2014$ & $20: 30$ & 0.0616 & FINAL READING \\
\hline
\end{tabular}

\begin{tabular}{|l|c|}
\hline SATURATION: & 51.5 \\
\hline EI MEASURED: & 31 \\
\hline EI at 50\% SAT: & 32 \\
\hline
\end{tabular}

Low Expansion Potential

\begin{tabular}{|l|c|c|}
\hline \multicolumn{3}{|c|}{ Absorption Test (Ret \#20) } \\
\hline Trial & 1 & 2 \\
\hline SSD Sand (g) & 1120.0 & 1104.5 \\
\hline Oven Dry Sand (g) & 894.6 & 855.2 \\
\hline Absorption (\%) & 25.2 & 29.2 \\
\hline
\end{tabular}




\section{A-2) Prado Soil Testing}

\section{DEPARTMENT OF CIVIL AND ENVIRONMENTAL ENGINEERING}

Atterberg Limits Measurements

Test Method: ASTM D43 I8, D2487

\begin{tabular}{|l|l|l|l|}
\hline Project Name & Prado Thesis Testing & Project No. & --.--- \\
\hline Tested By & WBH & Testing Date & $4 / 12 / 2014$ \\
\hline
\end{tabular}

\begin{tabular}{|l|l|l|l|l|l|}
\hline \multicolumn{7}{|c|}{ SPECIMEN ID AND CLASSIFICATION } \\
\hline Boring No. & $-\cdots$ & Sample No. & ---- & Depth (ft) & $-\cdots$ \\
\hline Soil Description & \multicolumn{3}{|l|}{ Fat Clay $(\mathrm{CH})$ : Dark Brown } \\
\hline
\end{tabular}

\begin{tabular}{|l|l|l|l|}
\hline \multicolumn{4}{|c|}{ LIQUID LIMIT } \\
\hline Target Range of Blows & $40-30$ & $30-25$ & $25-20$ \\
\hline Actual Number of Blows & 30 & 27 & 22 \\
\hline Dish ID & 9 & 66 & 19 \\
\hline Mass of Dish (g) & 30.73 & 30.55 & 30.74 \\
\hline Mass of Moist Soil + Dish (g) & 37.36 & 37.61 & 38.55 \\
\hline Mass of Dry Soil + Dish (g) & $34.8 I$ & 34.86 & 35.50 \\
\hline Water Content & $62.5 \%$ & $63.8 \%$ & $64.1 \%$ \\
\hline
\end{tabular}

\begin{tabular}{|l|l|l|}
\hline \multicolumn{3}{|c|}{ PLASTIC LIMIT } \\
\hline Dish ID & 96 & 87 \\
\hline Mass of Dish (g) & $30.5 \mathrm{I}$ & 30.64 \\
\hline Mass of Moist Soil + Dish (g) & 42.82 & 44.30 \\
\hline Mass of Dry Soil + Dish (g) & 41.14 & 42.46 \\
\hline Water Content & $15.8 \%$ & $15.6 \%$ \\
\hline
\end{tabular}

\begin{tabular}{|l|c|}
\hline \multicolumn{2}{|c|}{ SUMMARY } \\
\hline Liquid Limt & 64 \\
\hline Plastic Limit & 16 \\
\hline Plasticity Ind. & 48 \\
\hline
\end{tabular}
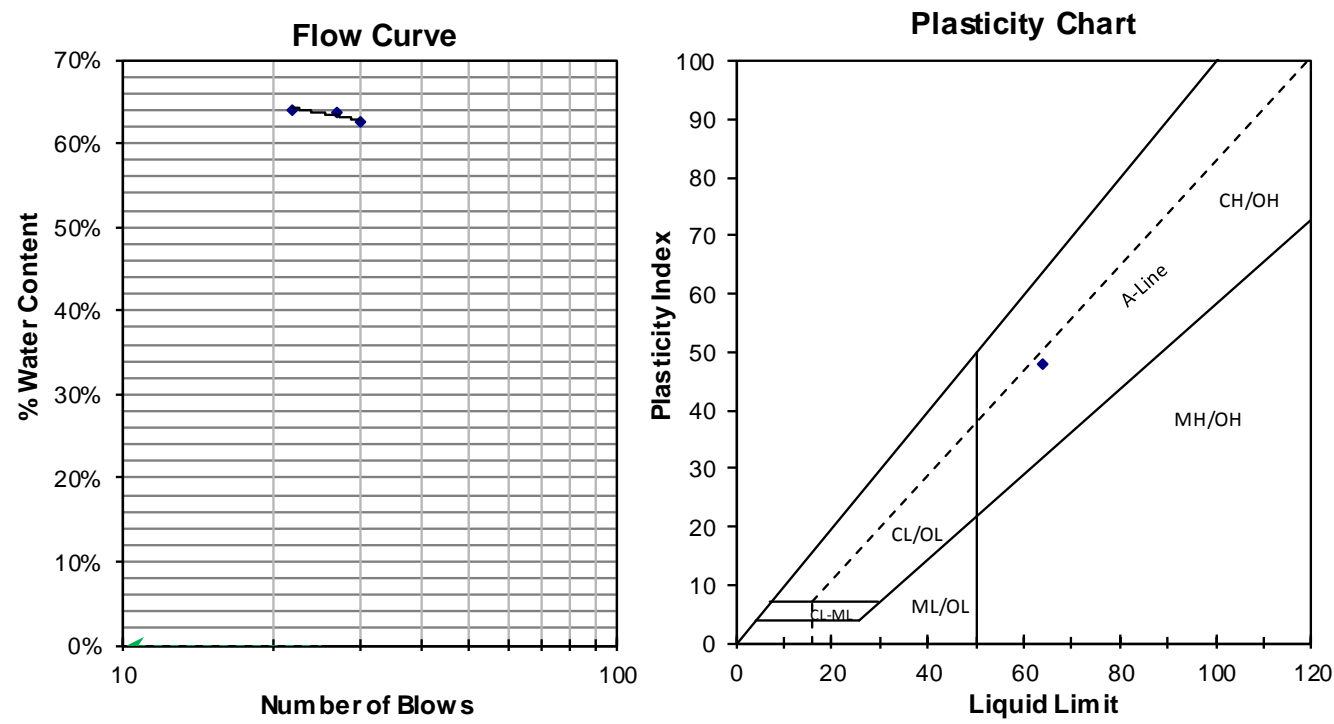


\section{DEPARTMENT OF CIVIL AND ENVIRONMENTAL ENGINEERING}

Hydrometer Analysis

Test Method: ASTM D422, D2487

\begin{tabular}{|l|l|l|l|}
\hline Project Name & \multicolumn{3}{|c|}{ Prado Thesis } \\
\hline Tested By & WBH & Testing Date & $4 / 8 / 2014$ \\
\hline Soil Description & Fat Clay $(\mathrm{CH})$ : Dark Brown & \\
\hline
\end{tabular}

\begin{tabular}{|l|c|l|l|l|l|}
\hline \multicolumn{7}{|c|}{ GRAVEL GRADING } \\
\hline Tray ID & $\mathrm{I}$ & Air-Dry Mass $(\mathrm{g})$ & 293.82 & Corrected Dry Mass $(\mathrm{g})$ & 284.44 \\
\hline
\end{tabular}

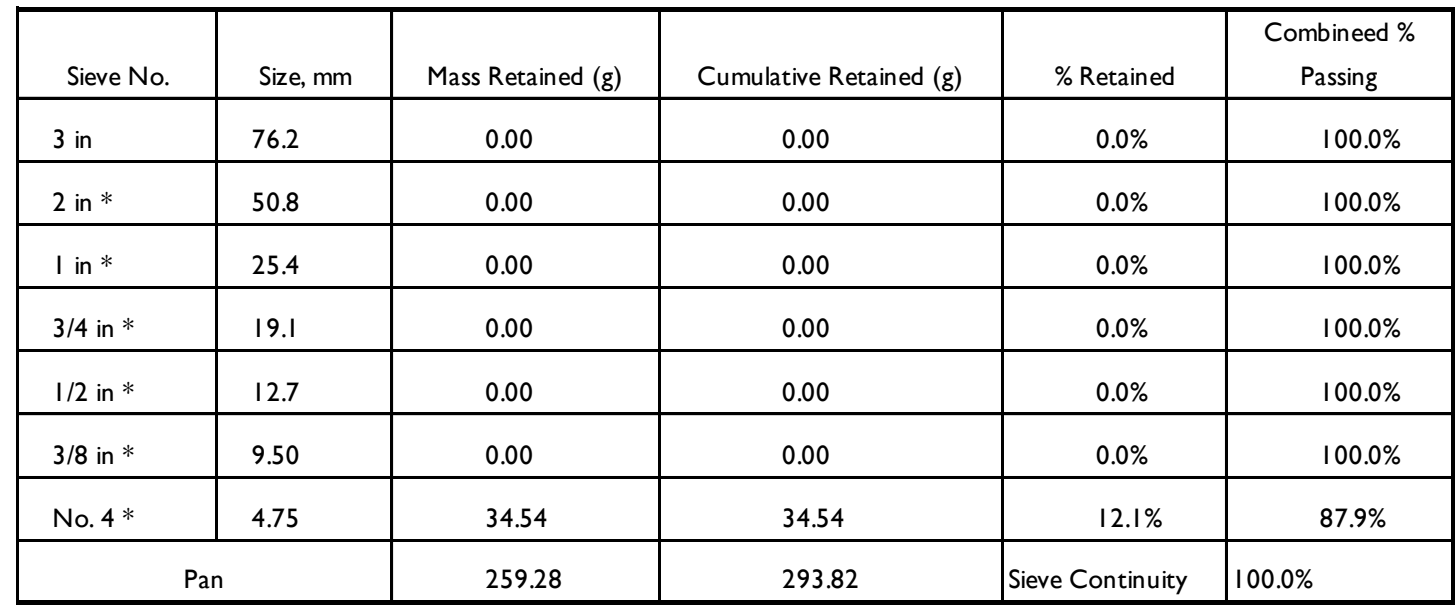

\begin{tabular}{|l|c|l|c|l|l|}
\hline \multicolumn{2}{|c|}{ WATER CONTENT OF MINUS \#4 = } & $3.3 \%$ & \multicolumn{2}{c|}{ \#4 BY \#I 0 GRADING } \\
\hline Dish ID & 228 & Wet Soil + Dish (g) & 55.04 & Mass of Air-Dried Soil (g) & I 44.54 \\
\hline Dish Mass (g) & 30.62 & Dry Soil + Dish (g) & 54.26 & Corrected Dry Mass (g) & 139.92 \\
\hline
\end{tabular}

\begin{tabular}{|c|c|c|c|c|c|}
\hline Sieve No. & Size, mm & Mass Retained $(\mathrm{g})$ & \% Retained & $\begin{array}{c}\text { Combined \% Passing } \\
\text { Passing }\end{array}$ \\
\hline No. 10 & 2.00 & 35.25 & $25.2 \%$ & $74.8 \%$ & $65.7 \%$ \\
\hline \multicolumn{2}{|c|}{ Pan } & 109.29 & Split Minus \#I O for Hydrometer Test (I52H) \\
\hline
\end{tabular}

\begin{tabular}{|c|c|c|c|c|c|c|}
\hline \multirow{2}{*}{$\begin{array}{c}\text { Post Wash ID } \\
\text { Sieve No. }\end{array}$} & \multirow{2}{*}{$\begin{array}{c}\text { B-I } \\
\text { Size, mm }\end{array}$} & \multirow{2}{*}{$\begin{array}{l}\text { Dry Mass Post Wash } \\
(\mathrm{g}) \\
\text { Mass Retained }(\mathrm{g})\end{array}$} & \multirow{2}{*}{$\begin{array}{l}133.86 \\
\text { Cum. Ret. (g) }\end{array}$} & \multicolumn{3}{|c|}{ \#16 BY \#200 GRADING } \\
\hline & & & & $\%$ Retained & $\%$ Passing & $\begin{array}{c}\text { Combined \% } \\
\text { Passing }\end{array}$ \\
\hline No. 16 & 1.180 & 6.87 & 6.87 & $5.1 \%$ & $94.9 \%$ & $62.4 \%$ \\
\hline No. 30 & 0.600 & 6.75 & 13.62 & $10.2 \%$ & $89.8 \%$ & $59.0 \%$ \\
\hline No. 50 & 0.300 & 0.03 & 13.65 & $10.2 \%$ & $89.8 \%$ & $59.0 \%$ \\
\hline No. 100 & 0.150 & 16.89 & 30.54 & $22.8 \%$ & $77.2 \%$ & $50.7 \%$ \\
\hline No. 200 & 0.075 & 12.81 & 43.35 & $32.4 \%$ & $67.6 \%$ & $44.4 \%$ \\
\hline \multicolumn{2}{|c|}{ Pan } & 0.25 & 43.60 & \multicolumn{2}{|c|}{ Sieve Continuity } & $307.0 \%$ \\
\hline
\end{tabular}




\begin{tabular}{|l|c|l|c|l|c|}
\hline HYDROSCOPIC WATER CONTENT = & $4.7 \%$ & \multicolumn{2}{c|}{ HYDROMETER } \\
\hline Dish ID & 63 & Wet Soil + Dish $(\mathrm{g})$ & 89.98 & Mass of Air-Dried Soil $(\mathrm{g})$ & 49.60 \\
\hline Dish Mass (g) & 30.54 & Dry Soil + Dish $(\mathrm{g})$ & 87.29 & Corrected Dry Mass $(\mathrm{g})$ & 47.36 \\
\hline
\end{tabular}

\begin{tabular}{|c|c|c|c|c|c|c|}
\hline Time $(\mathrm{min})$ & $\begin{array}{c}\text { Hydro. } \\
\text { Reading }\end{array}$ & Temperature $\left({ }^{\circ} \mathrm{C}\right)$ & $\begin{array}{c}\text { Effective } \\
\text { Depth }\end{array}$ & $\begin{array}{c}\text { Diameter } \\
(\mathrm{mm})\end{array}$ & $\begin{array}{c}\text { Combined } \% \\
\text { Passing }\end{array}$ \\
\hline 2 & 35.0 & 21.0 & 10.6 & 0.0305 & $60.6 \%$ & $39.8 \%$ \\
\hline 5 & 34.0 & 21.0 & 10.7 & 0.0194 & $58.5 \%$ & $38.5 \%$ \\
\hline 15 & 31.0 & 21.0 & 11.2 & 0.0115 & $52.3 \%$ & $34.4 \%$ \\
\hline 30 & 29.0 & 21.0 & 11.5 & 0.0082 & $48.1 \%$ & $31.6 \%$ \\
\hline 60 & 28.0 & 21.0 & 11.7 & 0.0059 & $46.0 \%$ & $30.2 \%$ \\
\hline 90 & 27.0 & 22.0 & 11.9 & 0.0048 & $43.9 \%$ & $28.9 \%$ \\
\hline 120 & 27.0 & 22.0 & 11.9 & 0.0041 & $43.9 \%$ & $28.9 \%$ \\
\hline 240 & 26.0 & 23.0 & 12.0 & 0.0029 & $41.8 \%$ & $27.5 \%$ \\
\hline 480 & 25.0 & 23.0 & 12.2 & 0.0021 & $39.7 \%$ & $26.1 \%$ \\
\hline 1440 & 23.0 & 22.0 & 12.5 & 0.0012 & $35.5 \%$ & $23.4 \%$ \\
\hline
\end{tabular}

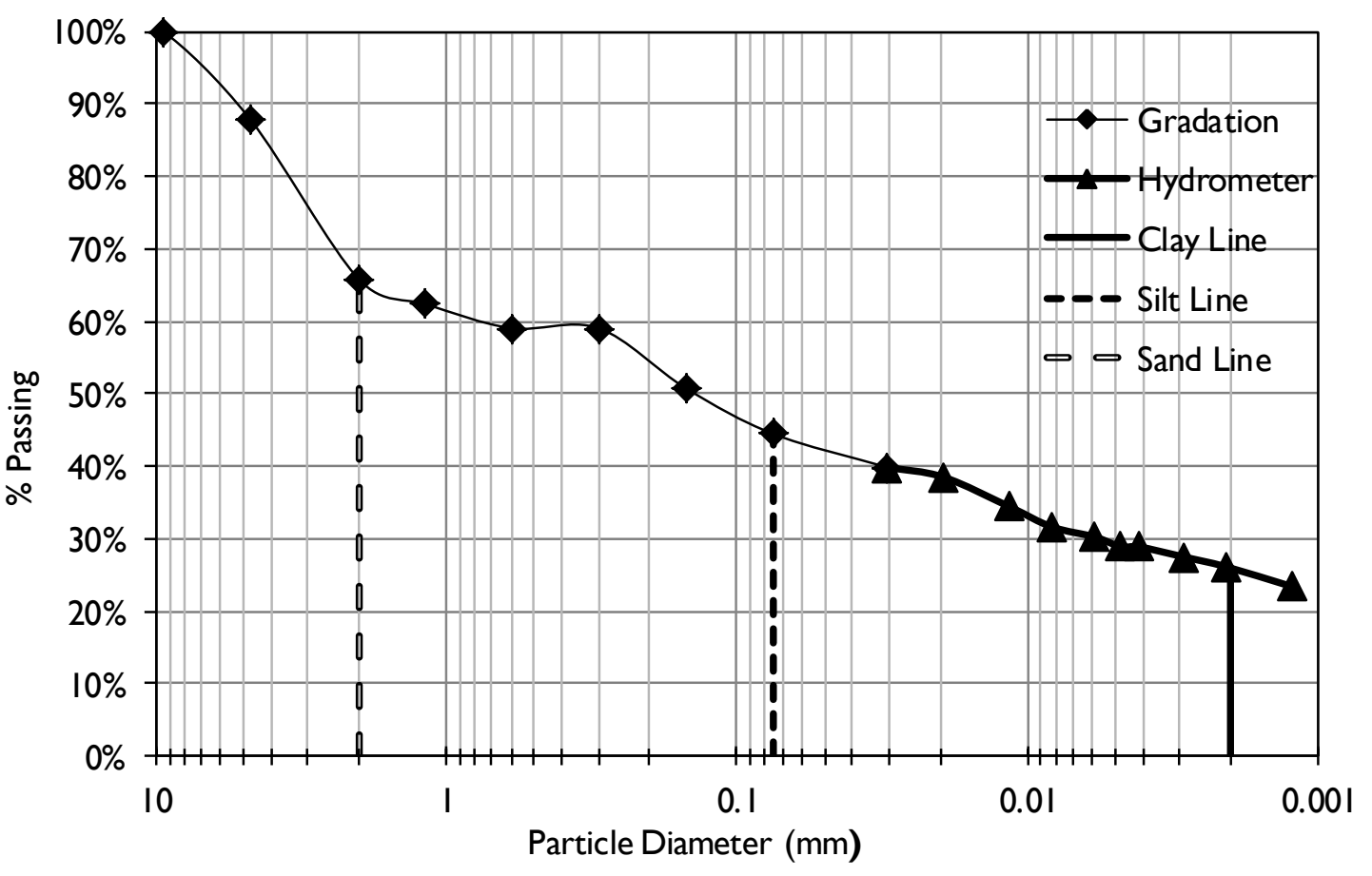


DEPARTMENT OF CIVIL AND ENVIRONMENTAL ENGINEERING

Expansion Index

Test Method: ASTM D4829

\begin{tabular}{|l|l|l|l|}
\hline Project Name & Prado Thesis & Project No. & ----- \\
\hline Tested By & WBH & Testing Date & 4/19/2014 \\
\hline
\end{tabular}

\begin{tabular}{|l|l|l|l|l|c|}
\hline \multicolumn{7}{|c|}{ SPECIMEN ID AND CLASSIFICATION } \\
\hline Boring No. & ----- & Sample No. & $-\cdots$ & Depth (ft) & $-\cdots---$ \\
\hline Soil Description & \multicolumn{2}{|l|}{ Fat Clay $(\mathrm{CH})$ : Dark Brown } \\
\hline
\end{tabular}

\begin{tabular}{|l|c|}
\hline \multicolumn{2}{|c|}{ Moisture Content } \\
\hline Tare No. & 12 \\
\hline Wet soil + tare, g & 871.98 \\
\hline Dry soil + tare, g & 851.53 \\
\hline Water, g & 20.45 \\
\hline Tare, g & 694.59 \\
\hline Soil, g & 156.94 \\
\hline$\%$ Water & 13.03 \\
\hline
\end{tabular}

\begin{tabular}{|l|c|}
\hline \multicolumn{2}{|c|}{ SPECIMEN MASS } \\
\hline Height, in & 1.00 \\
\hline Diameter, in & 3.99 \\
\hline Ring No. & 201 \\
\hline Ring, g & 200.72 \\
\hline Ring + soil, g & 556.19 \\
\hline Wet density, pcf & 107.88 \\
\hline Dry density, pcf & 95.45 \\
\hline
\end{tabular}

\begin{tabular}{|c|c|c|c|}
\hline \multicolumn{4}{|c|}{ EXPANSION READINGS } \\
\hline DATE & TIME & DIAL READING, in. & REMARKS \\
\hline $4 / 13 / 2014$ & $11: 30$ & 0.0153 & 10 min after loading \\
\hline $4 / 14 / 2014$ & $18: 30$ & 0.0954 & FINAL READING \\
\hline
\end{tabular}

\begin{tabular}{|l|c|}
\hline SATURATION: & 46.0 \\
\hline EI MEASURED: & 80 \\
\hline EI at 50\% SAT: & 76 \\
\hline
\end{tabular}

Medium Expansion Potential 


\section{A-3) Mind Body Soil Testing}

\section{DEPARTMENT OF CIVIL AND ENVIRONMENTAL ENGINEERING}

Atterberg Limits Measurements

Test Method: ASTM D43 18, D2487

\begin{tabular}{|l|l|l|l|}
\hline Project Name & MB Thesis Testing & Project No. & $--\cdot---$ \\
\hline Tested By & WBH & Testing Date & $4 / 12 / 2014$ \\
\hline
\end{tabular}

\begin{tabular}{|c|c|c|c|c|c|}
\hline \multicolumn{6}{|c|}{ SPECIMEN ID AND CLASSIFICATION } \\
\hline Boring No. & ---- & Sample No. & ----- & Depth (ft) & $---\cdot-$ \\
\hline Soil Description & \multicolumn{5}{|c|}{ Fat Clay $(\mathrm{CH})$ : Dark Yellowish Brown } \\
\hline
\end{tabular}

\begin{tabular}{|l|l|l|l|}
\hline \multicolumn{4}{|c|}{ LIQUID LIMIT } \\
\hline Target Range of Blows & $40-30$ & $30-25$ & $25-20$ \\
\hline Actual Number of Blows & 39 & 28 & 20 \\
\hline Dish ID & 21 & 8 & 75 \\
\hline Mass of Dish (g) & 30.71 & 30.56 & 30.65 \\
\hline Mass of Moist Soil + Dish (g) & 39.62 & 38.78 & 39.05 \\
\hline Mass of Dry Soil + Dish (g) & 36.51 & 35.82 & 35.97 \\
\hline Water Content & $53.6 \%$ & $56.3 \%$ & $57.9 \%$ \\
\hline
\end{tabular}

\begin{tabular}{|l|c|c|}
\hline \multicolumn{3}{|c|}{ PLASTIC LIMIT } \\
\hline Dish ID & 89 & 214 \\
\hline Mass of Dish (g) & $30.6 \mathrm{I}$ & 30.31 \\
\hline Mass of Moist Soil + Dish (g) & 37.17 & 36.72 \\
\hline Mass of Dry Soil + Dish (g) & 36.02 & 35.63 \\
\hline Water Content & $21.3 \%$ & $20.5 \%$ \\
\hline
\end{tabular}

\begin{tabular}{|l|c|}
\hline \multicolumn{2}{|c|}{ SUMMARY } \\
\hline Liquid Limt & 57 \\
\hline Plastic Limit & 21 \\
\hline Plasticity Ind. & 36 \\
\hline
\end{tabular}
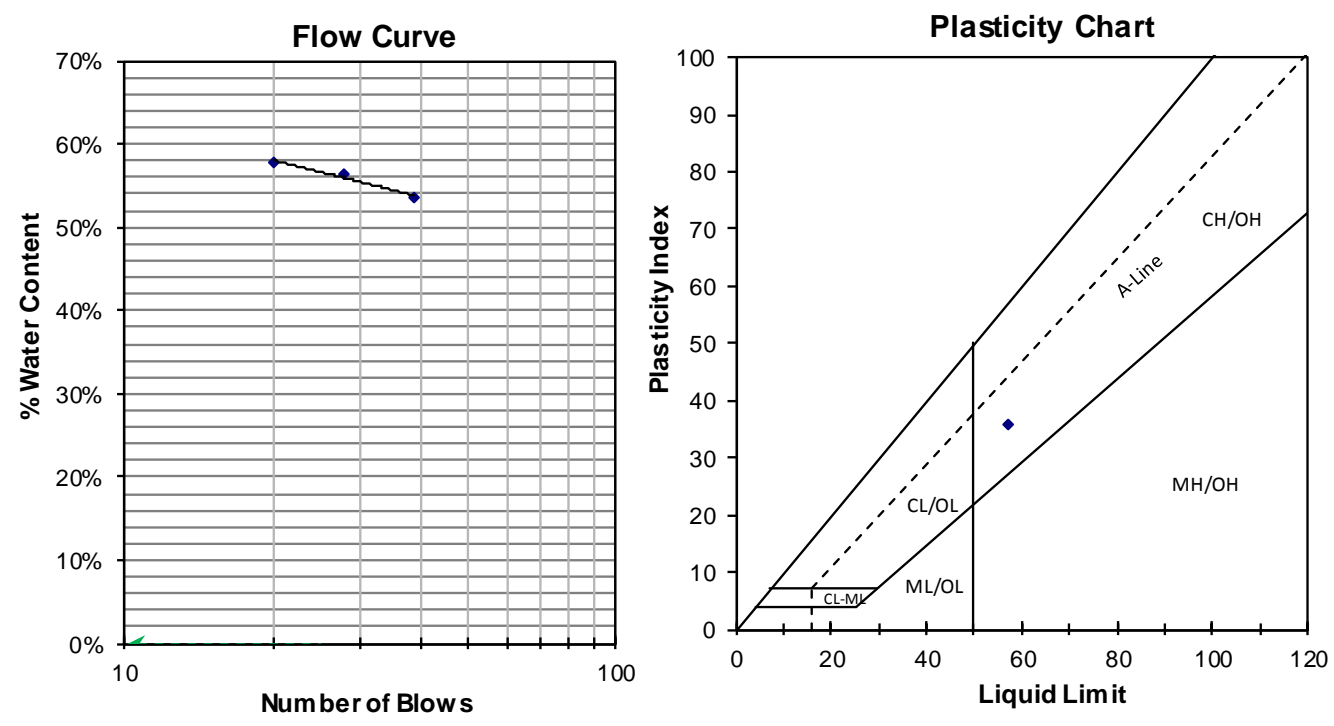


\section{DEPARTMENT OF CIVIL AND ENVIRONMENTAL ENGINEERING}

Hydrometer Analysis

Test Method: ASTM D422, D2487

\begin{tabular}{|l|l|l|l|}
\hline Project Name & \multicolumn{3}{|c|}{ Mind Body Thesis } \\
\hline Tested By & WBH & Testing Date & $4 / 8 / 2014$ \\
\hline Soil Description & Fat Clay $(\mathrm{CH})$ : Dark Yellowish Brown \\
\hline
\end{tabular}

\begin{tabular}{|l|c|l|l|l|l|}
\hline \multicolumn{7}{|c|}{ GRAVEL GRADING } \\
\hline Tray ID & $\mathrm{I}$ & Air-Dry Soil Mass $(\mathrm{g})$ & 306.70 & Corrected Dry Mass $(\mathrm{g})$ & 301.95 \\
\hline
\end{tabular}

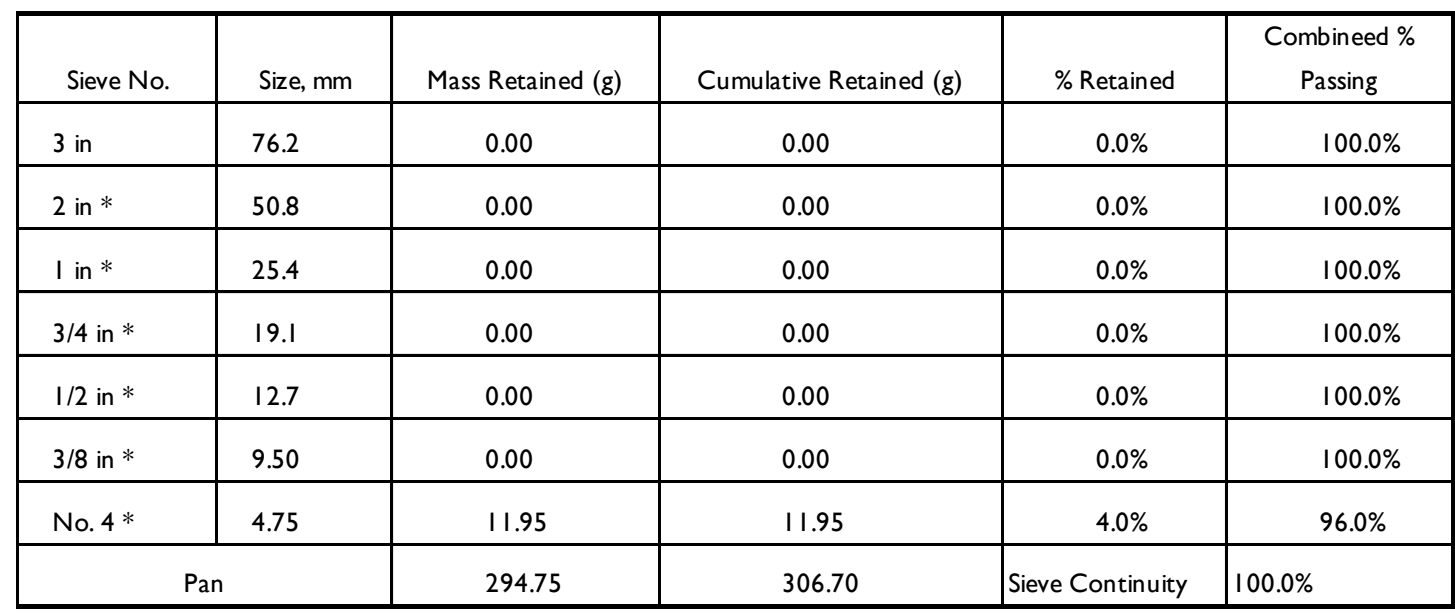

\begin{tabular}{|l|c|l|c|l|l|}
\hline \multicolumn{2}{|c|}{ WATER CONTENT OF MINUS \#4 = } & $1.6 \%$ & \multicolumn{2}{c|}{ \#4 BY \#I O GRADING } \\
\hline Dish ID & 207 & Moist Soil + Dish $(\mathrm{g})$ & 53.72 & Mass of Air-Dried Soil (g) & I66.19 \\
\hline Dish Mass (g) & 30.46 & Dry Soil + Dish $(\mathrm{g})$ & 53.36 & Corrected Dry Mass $(\mathrm{g})$ & 163.62 \\
\hline
\end{tabular}

\begin{tabular}{|c|c|c|c|c|c|}
\hline Sieve No. & Size, $\mathrm{mm}$ & Mass Retained $(\mathrm{g})$ & \% Retained & $\begin{array}{c}\text { Combined \% Passing } \\
\text { Passing }\end{array}$ \\
\hline No. 10 & 2.00 & $42.5 \mathrm{I}$ & $26.0 \%$ & $74.0 \%$ & $71.1 \%$ \\
\hline \multicolumn{2}{|c|}{ Pan } & 123.68 & Split Minus \# I 0 for Hydrometer Test (I 52H) \\
\hline
\end{tabular}

\begin{tabular}{|c|c|c|c|c|c|c|}
\hline \multirow{2}{*}{$\begin{array}{r}\text { Post Wash ID } \\
\text { Sieve No. }\end{array}$} & \multirow{2}{*}{$\begin{array}{c}\text { B-I } \\
\text { Size, mm }\end{array}$} & \multirow{2}{*}{$\begin{array}{l}\text { Dry Mass Post Wash } \\
\text { (g) } \\
\text { Mass Retained (g) }\end{array}$} & \multirow{2}{*}{$\begin{array}{l}186.12 \\
\text { Cum. Ret. (g) }\end{array}$} & \multicolumn{3}{|c|}{ \#I6 BY \#200 GRADING } \\
\hline & & & & \% Retained & $\%$ Passing & $\begin{array}{c}\text { Combined \% } \\
\text { Passing }\end{array}$ \\
\hline No. I 6 & 1.180 & 5.62 & 5.62 & $3.0 \%$ & $97.0 \%$ & $68.9 \%$ \\
\hline No. 30 & 0.600 & 5.79 & I I.4 I & $6.1 \%$ & $93.9 \%$ & $66.7 \%$ \\
\hline No. 50 & 0.300 & 13.83 & 25.24 & $13.6 \%$ & $86.4 \%$ & $61.4 \%$ \\
\hline No. 100 & 0.150 & 6.70 & 31.94 & $17.2 \%$ & $82.8 \%$ & $58.9 \%$ \\
\hline No. 200 & 0.075 & 43.60 & 75.54 & $40.6 \%$ & $59.4 \%$ & $42.2 \%$ \\
\hline \multicolumn{2}{|c|}{ Pan } & $0.4 \mathrm{I}$ & 75.95 & \multicolumn{2}{|c|}{ Sieve Continuity } & $245.1 \%$ \\
\hline
\end{tabular}




\begin{tabular}{|l|c|l|c|l|c|}
\hline \multicolumn{1}{|l|}{ HYDROSCOPIC WATER CONTENT = } & $1.4 \%$ & \multicolumn{2}{c|}{ HYDROMETER } \\
\hline Dish ID & 4 & Moist Soil + Dish (g) & 58.09 & Mass of Air-Dried Soil (g) & 48.02 \\
\hline Dish Mass (g) & 31.11 & Dry Soil + Dish (g) & 57.72 & Corrected Dry Mass (g) & 47.36 \\
\hline
\end{tabular}

\begin{tabular}{|c|c|c|c|c|c|c|}
\hline Time $(\mathrm{min})$ & $\begin{array}{c}\text { Hydro. } \\
\text { Reading }\end{array}$ & Temperature $\left({ }^{\circ} \mathrm{C}\right)$ & $\begin{array}{c}\text { Effective } \\
\text { Depth }\end{array}$ & $\begin{array}{c}\text { Diameter } \\
(\mathrm{mm})\end{array}$ & $\begin{array}{c}\text { Combined \% } \\
\text { Passing }\end{array}$ \\
\hline 2 & 32.0 & 21.0 & 11.1 & 0.0312 & $54.3 \%$ & $38.6 \%$ \\
\hline 5 & 30.0 & 21.0 & 11.4 & 0.0200 & $50.2 \%$ & $35.7 \%$ \\
\hline 15 & 27.0 & 21.0 & 11.9 & 0.0118 & $43.9 \%$ & $31.2 \%$ \\
\hline 30 & 25.0 & 21.0 & 12.2 & 0.0085 & $39.7 \%$ & $28.2 \%$ \\
\hline 60 & 24.0 & 21.0 & 12.4 & 0.0060 & $37.6 \%$ & $26.7 \%$ \\
\hline 90 & 23.0 & 21.0 & 12.5 & 0.0050 & $35.5 \%$ & $25.3 \%$ \\
\hline 120 & 23.0 & 22.0 & 12.5 & 0.0042 & $35.5 \%$ & $25.3 \%$ \\
\hline 240 & 23.0 & 22.0 & 12.5 & 0.0030 & $35.5 \%$ & $25.3 \%$ \\
\hline 480 & 20.0 & 23.0 & 13.0 & 0.0021 & $29.3 \%$ & $20.8 \%$ \\
\hline 1440 & 20.0 & 22.0 & 13.0 & 0.0012 & $29.3 \%$ & $20.8 \%$ \\
\hline
\end{tabular}

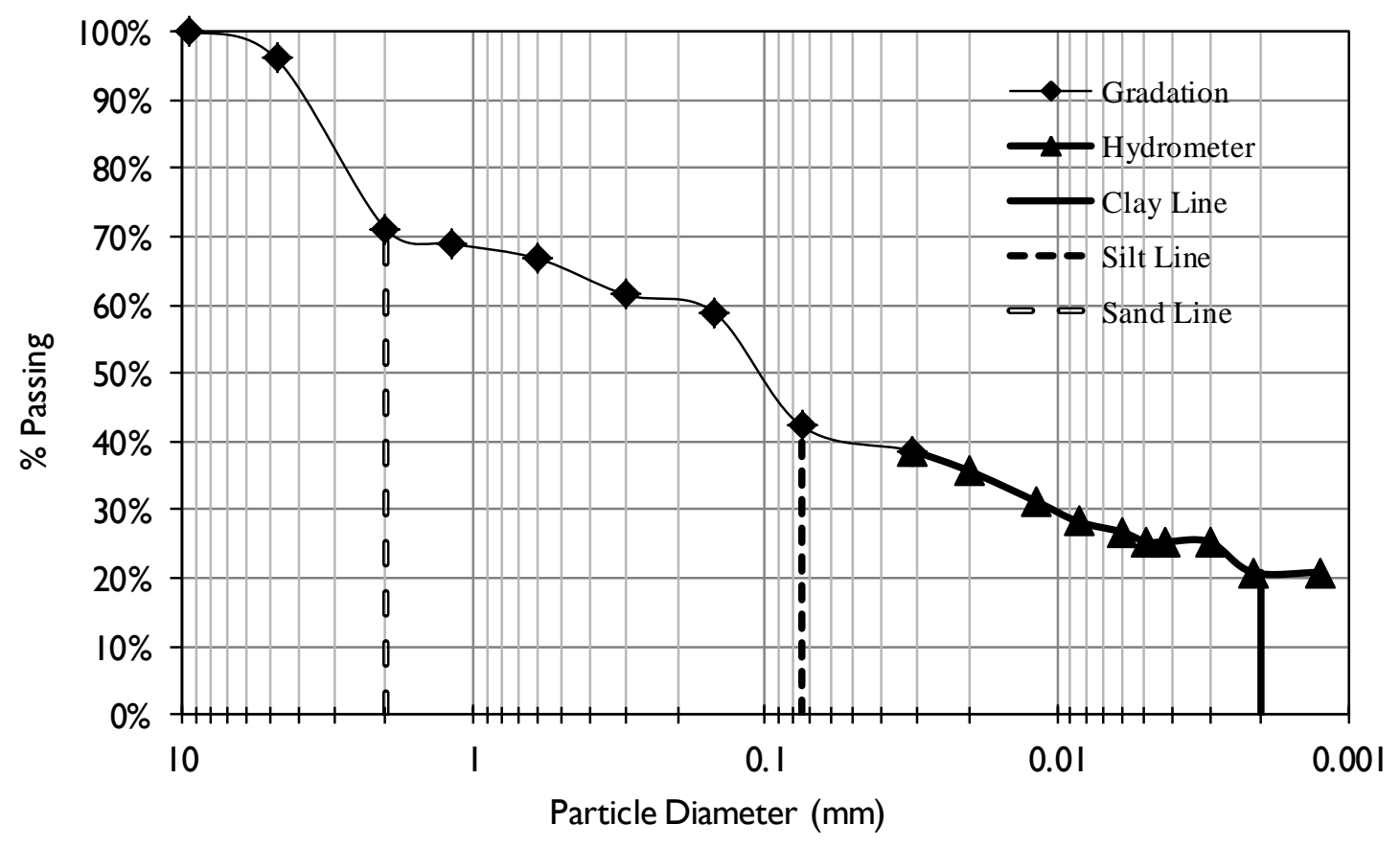


DEPARTMENT OF CIVIL AND ENVIRONMENTAL ENGINEERING

Expansion Index

Test Method: ASTM D4829

\begin{tabular}{|l|l|l|l|}
\hline Project Name & Mind Body Thesis & Project No. & ----- \\
\hline Tested By & WBH & Testing Date & $4 / 19 / 2014$ \\
\hline
\end{tabular}

\begin{tabular}{|l|l|l|l|l|l|}
\hline \multicolumn{7}{|c|}{ SPECIMEN ID AND CLASSIFICATION } \\
\hline Boring No. & $-\cdots--$ & Sample No. & $-\cdots--$ & Depth (ft) & $-\cdots$ \\
\hline Soil Description & \multicolumn{3}{|l|}{ Fat Clay $(\mathrm{CH})$ : Dark Yellowish Brown } \\
\hline
\end{tabular}

\begin{tabular}{|l|c|}
\hline \multicolumn{2}{|c|}{ Moisture Content } \\
\hline Tare No. & 4 \\
\hline Wet soil + tare, g & $1 \mathrm{I} 67.02$ \\
\hline Dry soil + tare, g & $1 \mathrm{I} 54.94$ \\
\hline Water, g & 12.08 \\
\hline Tare, g & 1048.53 \\
\hline Soil, g & $106.4 \mathrm{I}$ \\
\hline$\%$ Water & $1 \mathrm{I} .35$ \\
\hline
\end{tabular}

\begin{tabular}{|l|c|}
\hline \multicolumn{2}{|c|}{ SPECIMEN MASS } \\
\hline Height, in & 0.99 \\
\hline Diameter, in & 4.01 \\
\hline Ring No. & $201 \mathrm{GM}$ \\
\hline Ring, g & 200.72 \\
\hline Ring + soil, g & 590.86 \\
\hline Wet density, pcf & 118.29 \\
\hline Dry density, pcf & 106.23 \\
\hline
\end{tabular}

\begin{tabular}{|c|c|c|c|}
\hline \multicolumn{5}{|c|}{ EXPANSION READINGS } \\
\hline DATE & TIME & DIAL READING, in. & REMARKS \\
\hline $4 / 14 / 2014$ & $10: 30$ & 0.0250 & 10 min after loading \\
\hline $4 / 15 / 2014$ & $18: 30$ & 0.0822 & FINAL READING \\
\hline
\end{tabular}

\begin{tabular}{|l|c|}
\hline SATURATION: & 52.3 \\
\hline EI MEASURED: & 58 \\
\hline EI at 50\% SAT: & 59 \\
\hline
\end{tabular}

Medium Expansion Potential 


\section{A-4) Clay Mineralogy Chart}

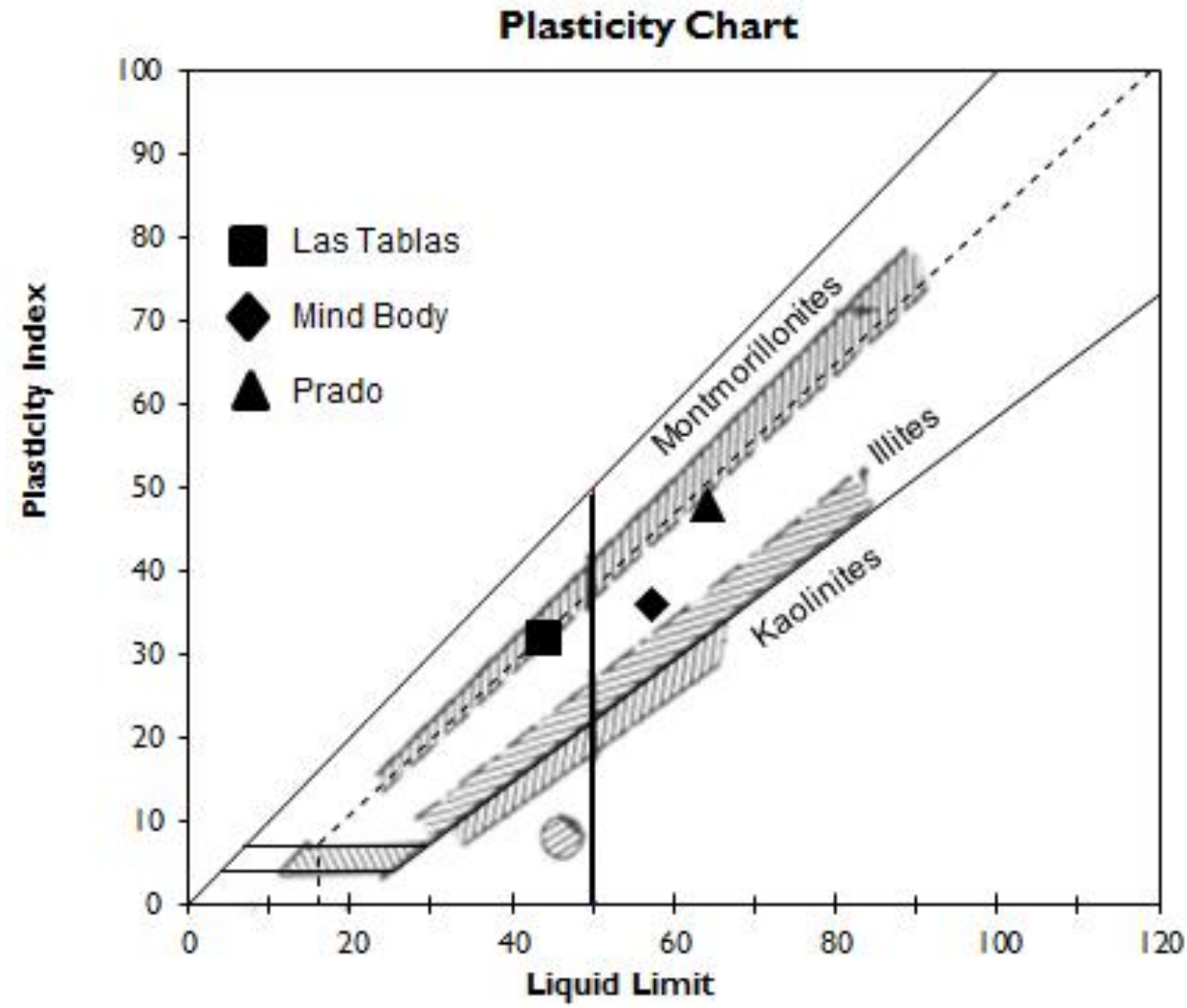

As seen above, none of the soils exhibit a clear correlation to a specific clay mineral according to the Casagrande chart. 


\section{A-5) Sand Testing}

ASTM CI 36 Fine Aggregate Gradation

Date Tested

$5 / 4 / 2014$

Tested By

WBH

\begin{tabular}{|c|c|c|c|}
\hline Sieve Size (\#) & $\begin{array}{c}\text { Cumulative Wt } \\
\text { Ret }(\mathrm{g})\end{array}$ & \% Ret & \% Pass \\
\hline $3 / 8 "$ & 0 & 0.0 & 100.0 \\
\hline 4 & 2.3 & 0.4 & 99.6 \\
\hline 8 & 48.5 & 9.3 & 90.7 \\
\hline 16 & 122.2 & 23.4 & 76.6 \\
\hline 30 & 230.7 & 44.1 & 55.9 \\
\hline 50 & 396.5 & 75.8 & 24.2 \\
\hline 100 & 493.5 & 94.4 & 5.6 \\
\hline Pan & 522.8 & \multicolumn{2}{|l}{} \\
\cline { 1 - 3 } & &
\end{tabular}

Fineness Modulus

2.47

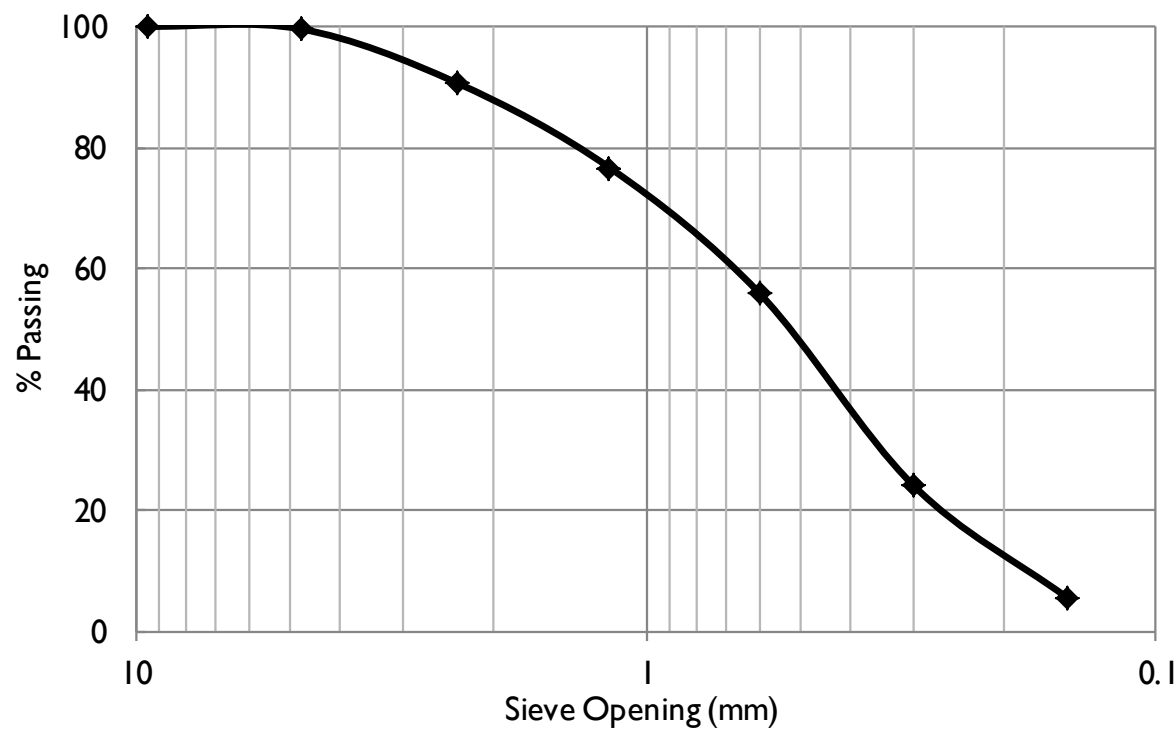




\section{APPENDIX B) CEB DATA}

Attached is an exhaustive list of each batch of CEB's. For each batch, information about the mix proportions, mechanical properties, and durability results are listed. These values are not adjusted, although the procedure for adjustment on variables that effect the strength of CEBs can be seen in the Analysis section of this paper.

Note that the net compressive strengths were calculated using the procedure from ASTM C140. The net compressive strengths should be calculated using the method proposed in section 5.2.1. 


\section{B-1) Las Tablas Batches}

\section{Batch ID: LT0-8}

Description: Las Tablas 0\% Sand Content Batch. 1:0 Ratio of Soil:Sand, 8\% Cement by weight

$\begin{array}{cccc}\text { Date Cast: } & \text { 8-Mar-l4 } & \text { \# Blocks Cast } & 5 \\ \text { Time Cast: } & 9: 30 \mathrm{am} & \text { Fiber Type } & - \\ & & \\ & & \\ \text { Calculated } & \text { Mixture Clay Fraction (\%) } & 27.8 \\ \text { Calculated } & \text { Mixture Sand Fraction (\%) } & - \\ \text { Calculated Mixture Cement Content (\%) } & 7.5 \\ \text { Measured Mixture Moisture Content (\%) } & 19.6 \\ \text { Calculated Mixture Moisture Content (\%) } & 5.8\end{array}$

Table B- 1 LT0-8 Mix Design

\begin{tabular}{|c|c|c|c|c|}
\hline Material & $\begin{array}{c}\text { Measured } \\
\text { Moisture } \\
\text { Content } \\
(\%)\end{array}$ & $\begin{array}{c}\text { Stock } \\
\text { Weight } \\
\text { (lbs) }\end{array}$ & $\begin{array}{c}\text { Oven } \\
\text { Dry } \\
\text { Weight } \\
\text { (lbs) }\end{array}$ & $\begin{array}{c}\text { Oven Dry } \\
\text { Weight } \\
\text { (lbs/100 lbs) }\end{array}$ \\
\hline Soil & 5.3 & 119.3 & 112.9 & 74.3 \\
\hline Sand & - & - & - & - \\
\hline Cement & - & 9.2 & 9.2 & 6.1 \\
\hline Water & - & 1.2 & 7.6 & 19.6 \\
\hline Fibers & - & - & - & - \\
\hline Total & 19.6 & 129.6 & 129.6 & 100.0 \\
\hline
\end{tabular}

Table B- 2 LT0-8 Compression Results

\begin{tabular}{|c|c|c|c|c|c|c|c|c|c|c|c|c|c|}
\hline \multirow[b]{2}{*}{ Block ID } & \multicolumn{3}{|c|}{ Batch Properties } & \multicolumn{3}{|c|}{ Block Properties } & \multicolumn{2}{|c|}{ Moisture Content } & \multicolumn{5}{|c|}{ Compression Testing } \\
\hline & $\begin{array}{l}\text { Chamber } \\
\text { Volume } \\
\text { Setting } \\
\text { (in) }\end{array}$ & $\begin{array}{c}\text { Block } \\
\text { Height } \\
\text { Setting } \\
\text { (in) }\end{array}$ & $\begin{array}{c}\text { Piston } \\
\text { Pressure } \\
\text { (psi) }\end{array}$ & $\begin{array}{l}\text { Height } \\
\text { (in) }\end{array}$ & $\begin{array}{c}\text { Average } \\
\text { Width } \\
\text { (in) }\end{array}$ & $\begin{array}{c}\text { Weight } \\
\text { (lbs) }\end{array}$ & $\begin{array}{c}\text { Cure } \\
\text { Method } \\
\text { (W/D) }\end{array}$ & $\begin{array}{c}\text { Testing } \\
(\%)\end{array}$ & $\begin{array}{l}\text { Max. } \\
\text { Force } \\
\text { (lbs) }\end{array}$ & $\begin{array}{c}\text { Gross } \\
\text { Strength } \\
\text { (psi) }\end{array}$ & $\begin{array}{c}\text { Average } \\
\text { Gross } \\
\text { Strength } \\
\text { (psi) }\end{array}$ & $\begin{array}{c}\text { Net } \\
\text { Strength } \\
\text { (psi) }\end{array}$ & $\begin{array}{c}\text { Average } \\
\text { Net } \\
\text { Strength } \\
\text { (psi) }\end{array}$ \\
\hline LT0-8A & 2.000 & 1.625 & 1500 & 4.244 & 6.954 & 18.369 & $\mathrm{D}$ & 13.6 & 70961 & 729 & & 946 & \\
\hline LT0-8B & 2.000 & 1.625 & 1850 & 4.184 & 6.904 & 19.788 & $\mathrm{D}$ & - & 63491 & 655 & 820 & 847 & 1060 \\
\hline LT0-8D & 1.750 & 1.625 & 2350 & 4.282 & 6.914 & 20.112 & $\mathrm{D}$ & - & 104000 & 1074 & & 1387 & \\
\hline
\end{tabular}


Table B- 3 LT0-8 Abs Results

\begin{tabular}{|c|c|c|c|c|c|c|c|c|c|c|c|c|c|}
\hline \multirow[b]{2}{*}{ Block ID } & \multicolumn{3}{|c|}{ Batch Properties } & \multicolumn{3}{|c|}{ Block Properties } & \multicolumn{7}{|c|}{ Absorption and Net Area Testing } \\
\hline & $\begin{array}{l}\text { Chamber } \\
\text { Volume } \\
\text { Setting } \\
\text { (in) }\end{array}$ & $\begin{array}{c}\text { Block } \\
\text { Height } \\
\text { Setting } \\
\text { (in) }\end{array}$ & $\begin{array}{c}\text { Piston } \\
\text { Pressure } \\
\text { (psi) }\end{array}$ & $\begin{array}{l}\text { Height } \\
\text { (in) }\end{array}$ & $\begin{array}{c}\text { Average } \\
\text { Width } \\
\text { (in) }\end{array}$ & $\begin{array}{c}\text { Weight } \\
\text { (lbs) }\end{array}$ & $\begin{array}{l}\text { Oven } \\
\text { Dry } \\
\text { Weight } \\
\text { (lbs) }\end{array}$ & $\begin{array}{c}\text { SSD } \\
\text { Weight } \\
\text { (lbs) }\end{array}$ & $\begin{array}{c}\text { Submerged } \\
\text { Weight } \\
\text { (lbs) }\end{array}$ & $\begin{array}{c}\text { Absorption } \\
(\%)\end{array}$ & $\begin{array}{l}\text { Density } \\
\left(\mathrm{lbs} / \mathrm{ft}^{3}\right)\end{array}$ & $\begin{array}{c}\text { Net Area } \\
\left(\text { in }^{3}\right)\end{array}$ & $\begin{array}{c}\text { Average } \\
\text { Net Area } \\
\left(\text { in }^{3}\right)\end{array}$ \\
\hline LT0-8C & 2.000 & 1.625 & 2350 & 4.271 & 6.904 & 19.788 & 17.092 & 21.821 & 10.270 & 27.7 & 92.3 & 74.9 & \multirow{2}{*}{75.0} \\
\hline LT0-8E & 1.750 & 1.625 & 2350 & 4.100 & 6.899 & 18.857 & 16.312 & 20.930 & 9.805 & 28.3 & 91.5 & 75.1 & \\
\hline
\end{tabular}

Table B- 4 Durability Results

\begin{tabular}{|c|c|c|c|c|c|}
\hline \multirow[b]{2}{*}{ Block ID } & \multicolumn{5}{|c|}{ Durability Testing } \\
\hline & Cycle & $\begin{array}{c}\text { Oven } \\
\text { Dry } \\
\text { Weight } \\
\text { (lbs) }\end{array}$ & \begin{tabular}{|c|} 
Mass \\
Loss Per \\
Cycle \\
$(\%)$
\end{tabular} & \begin{tabular}{|c|} 
Durability \\
Rating
\end{tabular} & Visual Observations \\
\hline \multirow{6}{*}{ LT0-8E } & 0 & 18.857 & 0.0 & - & - \\
\hline & $\mathrm{I}$ & 16.312 & 13.5 & 2 & Corner Broke off during submersion. Degradation \\
\hline & 2 & 16.176 & 0.8 & 2 & Surface degradation \\
\hline & 3 & 15.928 & 1.5 & 2 & Surface degradation \\
\hline & 4 & 15.746 & 1.1 & 3 & Degradation. Cracking along top \\
\hline & 5 & 15.702 & 0.3 & 3 & Degradation. Minor cracking throughout \\
\hline \multicolumn{3}{|c|}{ Total Mass Loss (\%) } & 17.3 & & \\
\hline
\end{tabular}




\section{Batch ID: LT20-8}

Description: Las Tablas 20\% Sand Content Batch. 5:1 Ratio of Soil:Sand, 8\% Cement by weight

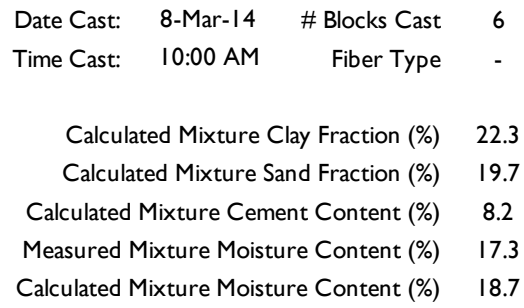

\section{Table B- 5 LT20-8 Mix Design}

\begin{tabular}{|c|c|c|c|c|}
\hline Material & $\begin{array}{c}\text { Measured } \\
\text { Coisture } \\
\text { Content }\end{array}$ & $\begin{array}{c}\text { Stock } \\
\text { Weight } \\
\text { (lbs) }\end{array}$ & $\begin{array}{c}\text { Oven } \\
\text { Dry } \\
\text { Weight } \\
\text { (lbs) }\end{array}$ & $\begin{array}{c}\text { Oven Dry } \\
\text { Weight } \\
\text { (lbs/100 lbs) }\end{array}$ \\
\hline Soil & 5.3 & 107.0 & 101.3 & 61.0 \\
\hline Sand & 0.1 & 24.8 & 24.8 & 14.9 \\
\hline Cement & - & 11.3 & 11.3 & 6.8 \\
\hline Water & - & 25.9 & 31.6 & 17.3 \\
\hline Fibers & - & - & - & - \\
\hline Total & 17.3 & 169.0 & 169.0 & 100.0 \\
\hline
\end{tabular}

\section{Table B- 6 LT20-8 Compression Results}

\begin{tabular}{|c|c|c|c|c|c|c|c|c|c|c|c|c|c|}
\hline \multirow[b]{2}{*}{ Block ID } & \multicolumn{3}{|c|}{ Batch Properties } & \multicolumn{3}{|c|}{ Block Properties } & \multicolumn{2}{|c|}{ Moisture Content } & \multicolumn{5}{|c|}{ Compression Testing } \\
\hline & $\begin{array}{c}\text { Chamber } \\
\text { Volume } \\
\text { Setting } \\
\text { (in) }\end{array}$ & $\begin{array}{c}\text { Block } \\
\text { Height } \\
\text { Setting } \\
\text { (in) }\end{array}$ & $\begin{array}{c}\text { Piston } \\
\text { Pressure } \\
\text { (psi) }\end{array}$ & $\begin{array}{l}\text { Height } \\
\text { (in) }\end{array}$ & $\begin{array}{c}\text { Average } \\
\text { Width } \\
\text { (in) }\end{array}$ & $\begin{array}{c}\text { Weight } \\
\text { (lbs) }\end{array}$ & $\begin{array}{c}\text { Cure } \\
\text { Method } \\
(\text { W/D) }\end{array}$ & $\begin{array}{c}\text { Testing } \\
(\%)\end{array}$ & $\begin{array}{l}\text { Max. } \\
\text { Force } \\
\text { (lbs) }\end{array}$ & $\begin{array}{c}\text { Gross } \\
\text { Strength } \\
\text { (psi) }\end{array}$ & $\begin{array}{c}\text { Average } \\
\text { Gross } \\
\text { Strength } \\
\text { (psi) }\end{array}$ & $\begin{array}{c}\text { Net } \\
\text { Strength } \\
\text { (psi) }\end{array}$ & $\begin{array}{l}\text { Average } \\
\text { Net } \\
\text { Strength } \\
\text { (psi) }\end{array}$ \\
\hline LT20-8B & 1.750 & 1.625 & 1250 & 4.010 & 6.909 & 19.545 & $\mathrm{D}$ & 14.6 & 137600 & 1423 & \multirow{4}{*}{$|30|$} & 1818 & \multirow{4}{*}{1663} \\
\hline LT20-8C & 1.875 & 1.625 & 1700 & 4.030 & 6.915 & 19.933 & $\mathrm{D}$ & - & 124000 & 1281 & & 1638 & \\
\hline LT20-8D & 1.875 & 1.625 & 1900 & 4.095 & 6.933 & 20.150 & $\mathrm{D}$ & - & 109000 & 1123 & & 1440 & \\
\hline LT20-8F & 1.750 & 1.625 & 1850 & 4.146 & 6.906 & 18.972 & $\mathrm{D}$ & - & 133000 & 1376 & & 1757 & \\
\hline
\end{tabular}


Table B- 7 LT20-8 Abs Results

\begin{tabular}{|c|c|c|c|c|c|c|c|c|c|c|c|c|c|}
\hline \multirow[b]{2}{*}{ Block ID } & \multicolumn{3}{|c|}{ Batch Properties } & \multicolumn{3}{|c|}{ Block Properties } & \multicolumn{7}{|c|}{ Absorption and Net Area Testing } \\
\hline & $\begin{array}{l}\text { Chamber } \\
\text { Volume } \\
\text { Setting } \\
\text { (in) }\end{array}$ & $\begin{array}{c}\text { Block } \\
\text { Height } \\
\text { Setting } \\
\text { (in) }\end{array}$ & $\begin{array}{c}\text { Piston } \\
\text { Pressure } \\
\text { (psi) }\end{array}$ & $\begin{array}{l}\text { Height } \\
\text { (in) }\end{array}$ & $\begin{array}{c}\text { Average } \\
\text { Width } \\
\text { (in) }\end{array}$ & $\begin{array}{c}\text { Weight } \\
\text { (lbs) }\end{array}$ & $\begin{array}{l}\text { Oven } \\
\text { Dry } \\
\text { Weight } \\
\text { (lbs) }\end{array}$ & $\begin{array}{c}\text { SSD } \\
\text { Weight } \\
\text { (lbs) }\end{array}$ & $\begin{array}{c}\text { Submerged } \\
\text { Weight } \\
\text { (lbs) }\end{array}$ & $\begin{array}{c}\text { Absorption } \\
(\%)\end{array}$ & $\begin{array}{l}\text { Density } \\
\left(\mathrm{lbs} / \mathrm{ft}^{3}\right)\end{array}$ & $\begin{array}{c}\text { Net Area } \\
\left(\text { in }^{3}\right)\end{array}$ & $\begin{array}{c}\text { Average } \\
\text { Net Area } \\
\left(\text { in }^{3}\right)\end{array}$ \\
\hline LT20-8A & 1.750 & 1.625 & 1850 & 4.017 & 6.920 & 19.771 & 17.494 & 21.545 & 10.515 & 23.2 & 99.0 & 76.0 & \multirow{2}{*}{75.7} \\
\hline LT20-8E & 1.875 & 1.625 & 2350 & 4.107 & 6.930 & 19.969 & 17.686 & 21.814 & 10.650 & 23.3 & 98.9 & 75.3 & \\
\hline
\end{tabular}

Table B- 8 LT20-8 Durability Results

\begin{tabular}{|c|c|c|c|c|c|}
\hline \multirow[b]{2}{*}{ Block ID } & \multicolumn{5}{|c|}{ Durability Testing } \\
\hline & Cycle & $\begin{array}{c}\text { Oven } \\
\text { Dry } \\
\text { Weight } \\
\text { (lbs) }\end{array}$ & $\begin{array}{c}\text { Mass } \\
\text { Loss Per } \\
\text { Cycle } \\
(\%)\end{array}$ & \begin{tabular}{|c|} 
Durability \\
Rating
\end{tabular} & Visual Observations \\
\hline \multirow{6}{*}{ LT20-8E } & 0 & 19.969 & 0.0 & - & - \\
\hline & I & 17.787 & 10.9 & 2 & Excellent Shape. No degradation \\
\hline & 2 & 17.736 & 0.3 & 2 & Small amounts of degradation \\
\hline & 3 & 17.686 & 0.3 & 2 & No visible change \\
\hline & 4 & 17.638 & 0.3 & 2 & Degradation. Crack along side \\
\hline & 5 & 17.609 & 0.2 & 2 & More cracking. Significant degradation along side \\
\hline \multicolumn{3}{|c|}{ Total Mass Loss (\%) } & 11.9 & & \\
\hline
\end{tabular}




\section{Batch ID: LT40-8}

Description: Las Tablas 40\% Sand Content Batch. 5:2 Ratio of Soil:Sand, 8\% Cement by weight

$\begin{array}{cccc}\text { Date Cast: } & \text { 8-Mar-I4 } & \text { \# Blocks Cast } & 4 \\ \text { Time Cast: } & \text { 10:20 AM } & \text { Fiber Type } & - \\ & & \\ & & \\ \text { Calculated Mixture Clay Fraction (\%) } & 16.9 \\ \text { Calculated Mixture Sand Fraction (\%) } & 39.4 \\ \text { Calculated Mixture Cement Content (\%) } & 8.3 \\ \text { Measured Mixture Moisture Content (\%) } & 14.2 \\ \text { Calculated Mixture Moisture Content (\%) } & 14.0\end{array}$

\section{Table B- 9 LT40-8 Mix Design}

\begin{tabular}{|c|c|c|c|c|}
\hline Material & $\begin{array}{c}\text { Measured } \\
\text { Coisture } \\
\text { Content }\end{array}$ & $\begin{array}{c}\text { Stock } \\
\text { Weight } \\
\text { (lbs) }\end{array}$ & $\begin{array}{c}\text { Oven } \\
\text { Dry } \\
\text { Weight } \\
\text { (lbs) }\end{array}$ & $\begin{array}{c}\text { Oven Dry } \\
\text { Weight } \\
\text { (lbs/100 lbs) }\end{array}$ \\
\hline Soil & 5.3 & 51.5 & 48.8 & 47.7 \\
\hline Sand & 0.1 & 31.7 & 31.6 & 31.0 \\
\hline Cement & - & 7.3 & 7.3 & 7.1 \\
\hline Water & - & 11.5 & 14.3 & 14.2 \\
\hline Fibers & - & - & - & - \\
\hline Total & 14.2 & 102.0 & 102.0 & 100.0 \\
\hline
\end{tabular}

\section{Table B- 10 LT40-8 Compression Results}

\begin{tabular}{|c|c|c|c|c|c|c|c|c|c|c|c|c|c|}
\hline \multirow[b]{2}{*}{ Block ID } & \multicolumn{3}{|c|}{ Batch Properties } & \multicolumn{3}{|c|}{ Block Properties } & \multicolumn{2}{|c|}{ Moisture Content } & \multicolumn{5}{|c|}{ Compression Testing } \\
\hline & $\begin{array}{l}\text { Chamber } \\
\text { Volume } \\
\text { Setting } \\
\text { (in) }\end{array}$ & $\begin{array}{c}\text { Block } \\
\text { Height } \\
\text { Setting } \\
\text { (in) }\end{array}$ & $\begin{array}{c}\text { Piston } \\
\text { Pressure } \\
\text { (psi) }\end{array}$ & $\begin{array}{l}\text { Height } \\
\text { (in) }\end{array}$ & $\begin{array}{l}\text { Average } \\
\text { Width } \\
\text { (in) }\end{array}$ & $\begin{array}{c}\text { Weight } \\
\text { (lbs) }\end{array}$ & $\begin{array}{c}\text { Cure } \\
\text { Method } \\
\text { (W/D) }\end{array}$ & $\begin{array}{c}\text { Testing } \\
(\%)\end{array}$ & $\begin{array}{l}\text { Max. } \\
\text { Force } \\
\text { (lbs) }\end{array}$ & $\begin{array}{c}\text { Gross } \\
\text { Strength } \\
\text { (psi) }\end{array}$ & \begin{tabular}{|} 
Average \\
Gross \\
Strength \\
(psi)
\end{tabular} & $\begin{array}{c}\text { Net } \\
\text { Strength } \\
\text { (psi) }\end{array}$ & $\begin{array}{c}\text { Average } \\
\text { Net } \\
\text { Strength } \\
\text { (psi) }\end{array}$ \\
\hline LT40-8A & 1.750 & 1.625 & 1100 & 4.001 & 6.929 & 17.748 & $\mathrm{D}$ & - & 114000 & 1175 & \multirow{3}{*}{1299} & 1518 & \multirow{3}{*}{1678} \\
\hline LT40-8B & 1.750 & 1.625 & 1400 & 4.124 & 6.923 & 19.647 & $\mathrm{D}$ & - & 132000 & 1362 & & 1758 & \\
\hline LT40-8D & 1.750 & 1.625 & 1600 & 4.086 & 6.928 & 20.444 & $\mathrm{D}$ & 11.6 & 132000 & $|36|$ & & 1758 & \\
\hline
\end{tabular}

Table B- 11 LT40-8 Abs Results

\begin{tabular}{|c|c|c|c|c|c|c|c|c|c|c|c|c|c|}
\hline \multirow[b]{2}{*}{ Block ID } & \multicolumn{3}{|c|}{ Batch Properties } & \multicolumn{3}{|c|}{ Block Properties } & \multicolumn{7}{|c|}{ Absorption and Net Area Testing } \\
\hline & $\begin{array}{l}\text { Chamber } \\
\text { Volume } \\
\text { Setting } \\
\text { (in) }\end{array}$ & $\begin{array}{c}\text { Block } \\
\text { Height } \\
\text { Setting } \\
\text { (in) }\end{array}$ & $\begin{array}{c}\text { Piston } \\
\text { Pressure } \\
\text { (psi) }\end{array}$ & $\begin{array}{l}\text { Height } \\
\text { (in) }\end{array}$ & $\begin{array}{c}\text { Average } \\
\text { Width } \\
\text { (in) }\end{array}$ & $\begin{array}{c}\text { Weight } \\
\text { (lbs) }\end{array}$ & $\begin{array}{c}\text { Oven } \\
\text { Dry } \\
\text { Weight } \\
\text { (lbs) }\end{array}$ & $\begin{array}{c}\text { SSD } \\
\text { Weight } \\
\text { (lbs) }\end{array}$ & $\begin{array}{c}\text { Submerged } \\
\text { Weight } \\
\text { (lbs) }\end{array}$ & $\begin{array}{c}\text { Absorption } \\
(\%)\end{array}$ & $\begin{array}{l}\text { Density } \\
\left(\mathrm{lbs} / \mathrm{ft}^{3}\right)\end{array}$ & $\begin{array}{c}\text { Net Area } \\
\left(\text { in }^{3}\right)\end{array}$ & $\begin{array}{c}\text { Average } \\
\text { Net Area } \\
\left(\text { in }^{3}\right)\end{array}$ \\
\hline LT40-8C & 1.750 & 1.625 & 1000 & 4.033 & 6.923 & 19.647 & 17.585 & 21.433 & 10.500 & 21.9 & 100.4 & 75.1 & 75.1 \\
\hline
\end{tabular}




\section{Batch ID: LT50-8}

Description: Las Tablas Standard Batch. 1:1 Ratio of Soil:Sand, 8\% Cement by weight

$\begin{array}{cccc}\text { Date Cast: } & \text { I3-Mar-I4 } & \text { \# Blocks Cast } & \text { I I } \\ \text { Time Cast: } & \text { 3:00 PM } & \text { Fiber Type } & - \\ & & \\ \text { Calculated Mixture Clay Fraction (\%) } & 13.5 \\ \text { Calculated Mixture Sand Fraction (\%) } & 51.3 \\ \text { Calculated Mixture Cement Content (\%) } & 8.3 \\ \text { Measured Mixture Moisture Content (\%) } & 12.2 \\ \text { Calculated Mixture Moisture Content (\%) } & 11.0\end{array}$

Table B- 12 LT50-8 Mix Design

\begin{tabular}{|c|c|c|c|c|}
\hline Material & $\begin{array}{c}\text { Measured } \\
\text { Coisture } \\
(\%)\end{array}$ & $\begin{array}{c}\text { Stock } \\
\text { Weight } \\
\text { (lbs) }\end{array}$ & $\begin{array}{c}\text { Oven } \\
\text { Dry } \\
\text { Weight } \\
\text { (lbs) }\end{array}$ & $\begin{array}{c}\text { Oven Dry } \\
\text { Weight } \\
\text { (lbs// 00 lbs) }\end{array}$ \\
\hline Soil & 6.9 & 165.0 & 153.6 & 39.2 \\
\hline Sand & 0.3 & 162.6 & 162.0 & 41.3 \\
\hline Cement & - & 28.4 & 28.4 & 7.3 \\
\hline Water & - & 30.6 & 42.6 & 12.2 \\
\hline Fibers & - & - & - & - \\
\hline Total & 12.2 & 386.6 & 386.6 & 100.0 \\
\hline
\end{tabular}

Table B- 13 Compression Results

\begin{tabular}{|c|c|c|c|c|c|c|c|c|c|c|c|c|c|}
\hline \multirow[b]{2}{*}{ Block ID } & \multicolumn{3}{|c|}{ Batch Properties } & \multicolumn{3}{|c|}{ Block Properties } & \multicolumn{2}{|c|}{ Moisture Content } & \multicolumn{5}{|c|}{ Compression Testing } \\
\hline & $\begin{array}{c}\text { Chamber } \\
\text { Volume } \\
\text { Setting } \\
\text { (in) }\end{array}$ & $\begin{array}{l}\text { Block } \\
\text { Height } \\
\text { Setting } \\
\text { (in) }\end{array}$ & \begin{tabular}{|c|} 
Piston \\
Pressure \\
(psi)
\end{tabular} & $\begin{array}{l}\text { Height } \\
\text { (in) }\end{array}$ & $\begin{array}{c}\text { Average } \\
\text { Width } \\
\text { (in) }\end{array}$ & $\begin{array}{c}\text { Weight } \\
\text { (lbs) }\end{array}$ & $\begin{array}{l}\text { Cure } \\
\text { Method } \\
\text { (W/D) }\end{array}$ & \begin{tabular}{|c} 
Testing \\
$(\%)$
\end{tabular} & $\begin{array}{l}\text { Max. } \\
\text { Force } \\
\text { (lbs) }\end{array}$ & $\begin{array}{c}\text { Gross } \\
\text { Strength } \\
\text { (psi) }\end{array}$ & $\begin{array}{l}\text { Average } \\
\text { Gross } \\
\text { Strength } \\
\text { (psi) }\end{array}$ & \begin{tabular}{|c|} 
Net \\
Strength \\
(psi)
\end{tabular} & $\begin{array}{l}\text { Average } \\
\text { Net } \\
\text { Strength } \\
\text { (psi) }\end{array}$ \\
\hline LT50-8A & 1.625 & 3.000 & 1050 & 4.684 & 6.9290 & 22.591 & $\mathrm{D}$ & 8.2 & 57553 & 593 & \multirow{5}{*}{534} & 698 & \multirow{5}{*}{628} \\
\hline LT50-8B & 1.625 & 3.000 & 1500 & 4.749 & 6.9355 & 24.096 & W & 12.9 & 37879 & 390 & & 459 & \\
\hline LT50-8E & 1.625 & 3.000 & 2350 & 4.745 & 6.9255 & 23.736 & $\mathrm{D}$ & - & 51944 & 536 & & 630 & \\
\hline LT50-8G & 1.625 & 3.125 & 2350 & 4.986 & 6.9335 & 24.952 & $\mathrm{D}$ & - & 71574 & 737 & & 868 & \\
\hline LT50-8H & 1.625 & 3.000 & 2350 & 4.911 & 6.938 & 25.264 & $\mathrm{D}$ & - & 39960 & $4 I I$ & & 484 & \\
\hline
\end{tabular}


Table B- 14 MOR Results

\begin{tabular}{|c|c|c|c|c|c|c|c|c|c|c|c|c|c|}
\hline \multirow[b]{2}{*}{ Block ID } & \multicolumn{3}{|c|}{ Batch Properties } & \multicolumn{3}{|c|}{ Block Properties } & \multicolumn{2}{|c|}{ Moisture Content } & \multicolumn{5}{|c|}{ Modulus of Rupture Testing } \\
\hline & $\begin{array}{l}\text { Chamber } \\
\text { Volume } \\
\text { Setting } \\
\text { (in) }\end{array}$ & $\begin{array}{l}\text { Block } \\
\text { Height } \\
\text { Setting } \\
\text { (in) }\end{array}$ & $\begin{array}{c}\text { Piston } \\
\text { Pressure } \\
\text { (psi) }\end{array}$ & $\begin{array}{l}\text { Height } \\
\text { (in) }\end{array}$ & $\begin{array}{c}\text { Average } \\
\text { Width } \\
\text { (in) }\end{array}$ & $\begin{array}{c}\text { Weight } \\
\text { (lbs) }\end{array}$ & $\begin{array}{c}\text { Cure } \\
\text { Method } \\
\text { (W/D) }\end{array}$ & $\begin{array}{c}\text { Testing } \\
(\%)\end{array}$ & $\begin{array}{l}\text { Max. } \\
\text { Force } \\
\text { (lbs) }\end{array}$ & $\begin{array}{c}\text { Gross } \\
\text { Strength } \\
\text { (psi) }\end{array}$ & $\begin{array}{l}\text { Average } \\
\text { Gross } \\
\text { Strength } \\
\text { (psi) }\end{array}$ & $\begin{array}{c}\text { Net } \\
\text { Strength } \\
\text { (psi) }\end{array}$ & $\begin{array}{c}\text { Average } \\
\text { Net } \\
\text { Strength } \\
\text { (psi) }\end{array}$ \\
\hline LT50-8D & 1.625 & 3.000 & 2050 & 4.767 & 6.9370 & 24.465 & W & - & 646 & 61 & \multirow{5}{*}{56} & 71 & \multirow{5}{*}{65} \\
\hline LT50-8F & 1.625 & 3.125 & 1550 & 4.932 & 6.9595 & 24.724 & W & - & 575 & 51 & & 59 & \\
\hline LT50-8I & 1.625 & 3.000 & 2350 & 4.749 & 6.9210 & 23.813 & $\mathrm{D}$ & - & 799 & 77 & & 89 & \\
\hline LT50-8J & 1.625 & 3.000 & 2350 & 4.863 & 6.9290 & 24.268 & $\mathrm{D}$ & - & 667 & 61 & & 70 & \\
\hline LT50-8K & 1.625 & 3.000 & 2350 & 4.839 & 6.9335 & 24.390 & $\mathrm{D}$ & - & 332 & 31 & & 35 & \\
\hline
\end{tabular}

Table B- 15 Abs Results

\begin{tabular}{|c|c|c|c|c|c|c|c|c|c|c|c|c|c|}
\hline \multirow[b]{2}{*}{ Block ID } & \multicolumn{3}{|c|}{ Batch Properties } & \multicolumn{3}{|c|}{ Block Properties } & \multicolumn{7}{|c|}{ Absorption and Net Area Testing } \\
\hline & $\begin{array}{l}\text { Chamber } \\
\text { Volume } \\
\text { Setting } \\
\text { (in) }\end{array}$ & $\begin{array}{c}\text { Block } \\
\text { Height } \\
\text { Setting } \\
\text { (in) }\end{array}$ & $\begin{array}{c}\text { Piston } \\
\text { Pressure } \\
\text { (psi) }\end{array}$ & $\begin{array}{l}\text { Height } \\
\text { (in) }\end{array}$ & $\begin{array}{c}\text { Average } \\
\text { Width } \\
\text { (in) }\end{array}$ & $\begin{array}{c}\text { Weight } \\
\text { (lbs) }\end{array}$ & $\begin{array}{c}\text { Oven } \\
\text { Dry } \\
\text { Weight } \\
\text { (lbs) }\end{array}$ & $\begin{array}{c}\text { SSD } \\
\text { Weight } \\
\text { (lbs) }\end{array}$ & $\begin{array}{c}\text { Submerged } \\
\text { Weight } \\
\text { (lbs) }\end{array}$ & $\begin{array}{c}\text { Absorption } \\
(\%)\end{array}$ & $\begin{array}{l}\text { Density } \\
\left(\mathrm{lbs} / \mathrm{ft}^{3}\right)\end{array}$ & $\begin{array}{c}\text { Net Area } \\
\left(\text { in }^{3}\right)\end{array}$ & $\begin{array}{c}\text { Average } \\
\text { Net Area } \\
\left(\text { in }^{3}\right)\end{array}$ \\
\hline LT50-8C & 1.625 & 3.000 & 1750 & 4.729 & 6.9215 & 23.479 & 21.655 & 25.575 & 12.910 & 18.1 & 106.69 & 82.1 & \multirow{2}{*}{82.5} \\
\hline LT50-8N & 1.625 & 2.750 & 650 & 4.583 & 6.926 & 21.537 & 19.261 & 23.506 & 11.245 & 22.0 & 98.03 & 82.8 & \\
\hline
\end{tabular}

Table B- 16 Durability Results

\begin{tabular}{|c|c|c|c|c|c|}
\hline \multirow[b]{2}{*}{ Block ID } & \multicolumn{5}{|c|}{ Durability Testing } \\
\hline & Cycle & $\begin{array}{c}\text { Oven } \\
\text { Dry } \\
\text { Weight } \\
\text { (lbs) }\end{array}$ & $\begin{array}{c}\text { Mass } \\
\text { Loss Per } \\
\text { Cycle } \\
(\%)\end{array}$ & \begin{tabular}{|c|} 
Durability \\
Rating
\end{tabular} & Visual Observations \\
\hline \multirow{6}{*}{ LT50-I2B } & 0 & 23.479 & 0.0 & - & - \\
\hline & I & 21.755 & 7.3 & 2 & Minor degradation. Pock marks formed \\
\hline & 2 & 21.655 & 0.5 & 2 & No significant change \\
\hline & 3 & 21.652 & 0.0 & 2 & Surface/edges rougher \\
\hline & 4 & 21.65 & 0.0 & 2 & No significant change \\
\hline & 5 & 21.614 & 0.2 & 2 & No significant change \\
\hline \multicolumn{3}{|c|}{ Total Mass Loss (\%) } & 8.0 & & \\
\hline
\end{tabular}




\section{Batch ID: LT50-8}

Description: Las Tablas Standard Batch. Last few blocks were too dry, so were rewetted and pressed. 1:1 Ratio of Soil:Sand, 8\% Cement by weight

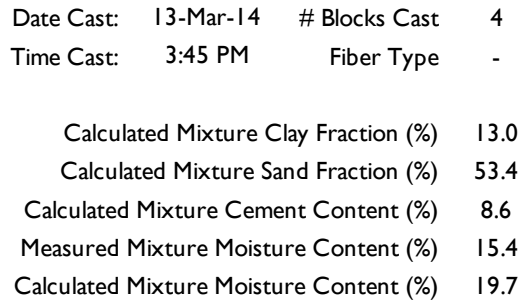

\section{Table B- 17 LT50-8 Remix Mix Design}

\begin{tabular}{|c|c|c|c|c|}
\hline Material & $\begin{array}{c}\text { Measured } \\
\text { Moisture } \\
\text { Content } \\
(\%)\end{array}$ & $\begin{array}{c}\text { Stock } \\
\text { Weight } \\
\text { (lbs) }\end{array}$ & $\begin{array}{c}\text { Oven } \\
\text { Dry } \\
\text { Weight } \\
\text { (lbs) }\end{array}$ & $\begin{array}{c}\text { Oven Dry } \\
\text { Weight } \\
\text { (lbs/I00 lbs) }\end{array}$ \\
\hline Soil & 6.9 & 35.0 & 32.6 & 36.0 \\
\hline Sand & 0.3 & 37.4 & 37.3 & 41.3 \\
\hline Cement & - & 6.6 & 6.6 & 7.3 \\
\hline Water & - & 16.2 & 18.7 & 15.4 \\
\hline Fibers & - & - & - & - \\
\hline Total & 15.4 & 95.2 & 95.2 & 100.0 \\
\hline
\end{tabular}

\section{Table B- 18 LT50-8 Remix Compression Results}

\begin{tabular}{|c|c|c|c|c|c|c|c|c|c|c|c|c|c|}
\hline & \multicolumn{3}{|c|}{ Batch Properties } & \multicolumn{3}{|c|}{ Block Properties } & \multicolumn{2}{|c|}{ Moisture Content } & \multicolumn{5}{|c|}{ Compression Testing } \\
\hline Block ID & $\begin{array}{l}\text { Chamber } \\
\text { Volume } \\
\text { Setting } \\
\text { (in) }\end{array}$ & $\begin{array}{c}\text { Block } \\
\text { Height } \\
\text { Setting } \\
\text { (in) }\end{array}$ & $\begin{array}{c}\text { Piston } \\
\text { Pressure } \\
\text { (psi) }\end{array}$ & $\begin{array}{c}\text { Height } \\
\text { (in) }\end{array}$ & $\begin{array}{c}\text { Average } \\
\text { Width } \\
\text { (in) }\end{array}$ & $\begin{array}{c}\text { Weight } \\
\text { (lbs) }\end{array}$ & $\begin{array}{c}\text { Cure } \\
\text { Method } \\
(\text { W/D) }\end{array}$ & $\begin{array}{c}\text { Testing } \\
(\%)\end{array}$ & $\begin{array}{l}\text { Max. } \\
\text { Force } \\
\text { (lbs) }\end{array}$ & $\begin{array}{c}\text { Gross } \\
\text { Strength } \\
\text { (psi) }\end{array}$ & $\begin{array}{c}\text { Average } \\
\text { Gross } \\
\text { Strength } \\
\text { (psi) }\end{array}$ & $\begin{array}{c}\text { Net } \\
\text { Strength } \\
\text { (psi) }\end{array}$ & $\begin{array}{c}\text { Average } \\
\text { Net } \\
\text { Strength } \\
\text { (psi) }\end{array}$ \\
\hline LT50-8L & 1.625 & 3 & 550 & 4.683 & 6.936 & 22.563 & W & - & 4333 & 45 & 45 & 53 & 53 \\
\hline
\end{tabular}

Table B- 19 LT50-8 Remix MOR Results

\begin{tabular}{|c|c|c|c|c|c|c|c|c|c|c|c|c|c|}
\hline \multirow[b]{2}{*}{ Block ID } & \multicolumn{3}{|c|}{ Batch Properties } & \multicolumn{3}{|c|}{ Block Properties } & \multicolumn{2}{|c|}{ Moisture Content } & \multicolumn{5}{|c|}{ Modulus of Rupture Testing } \\
\hline & $\begin{array}{l}\text { Chamber } \\
\text { Volume } \\
\text { Setting } \\
\text { (in) }\end{array}$ & $\begin{array}{c}\text { Block } \\
\text { Height } \\
\text { Setting } \\
\text { (in) }\end{array}$ & $\begin{array}{c}\text { Piston } \\
\text { Pressure } \\
\text { (psi) }\end{array}$ & $\begin{array}{l}\text { Height } \\
\text { (in) }\end{array}$ & $\begin{array}{c}\text { Average } \\
\text { Width } \\
\text { (in) }\end{array}$ & $\begin{array}{c}\text { Weight } \\
\text { (lbs) }\end{array}$ & $\begin{array}{c}\text { Cure } \\
\text { Method } \\
(\text { W/D) }\end{array}$ & $\begin{array}{c}\text { Testing } \\
(\%)\end{array}$ & $\begin{array}{l}\text { Max. } \\
\text { Force } \\
\text { (lbs) }\end{array}$ & $\begin{array}{c}\text { Gross } \\
\text { Strength } \\
\text { (psi) }\end{array}$ & \begin{tabular}{|c|} 
Average \\
Gross \\
Strength \\
(psi)
\end{tabular} & $\begin{array}{c}\text { Net } \\
\text { Strength } \\
\text { (psi) }\end{array}$ & $\begin{array}{l}\text { Average } \\
\text { Net } \\
\text { Strength } \\
\text { (psi) }\end{array}$ \\
\hline LT50-8M & 1.625 & 2.750 & 950 & 4.530 & 6.923 & 22.142 & $\mathrm{D}$ & - & 924 & 98 & \multirow{2}{*}{98} & 113 & \multirow{2}{*}{114} \\
\hline LT50-8O & 1.625 & 2.750 & 1250 & 4.601 & 6.942 & 23.496 & W & - & 961 & 98 & & 114 & \\
\hline
\end{tabular}


Table B- 20 LT50-8 Remix Abs Results

\begin{tabular}{|c|c|c|c|c|c|c|c|c|c|c|c|c|c|}
\hline \multirow[b]{2}{*}{ Block ID } & \multicolumn{3}{|c|}{ Batch Properties } & \multicolumn{3}{|c|}{ Block Properties } & \multicolumn{7}{|c|}{ Absorption and Net Area Testing } \\
\hline & $\begin{array}{c}\text { Chamber } \\
\text { Volume } \\
\text { Setting } \\
\text { (in) }\end{array}$ & $\begin{array}{c}\text { Block } \\
\text { Height } \\
\text { Setting } \\
\text { (in) }\end{array}$ & \begin{tabular}{|c} 
Piston \\
Pressure \\
(psi)
\end{tabular} & $\begin{array}{c}\text { Height } \\
\text { (in) }\end{array}$ & $\begin{array}{c}\text { Average } \\
\text { Width } \\
\text { (in) }\end{array}$ & $\begin{array}{c}\text { Weight } \\
\text { (lbs) }\end{array}$ & $\begin{array}{c}\text { Oven } \\
\text { Dry } \\
\text { Weight } \\
\text { (lbs) }\end{array}$ & $\begin{array}{l}\text { SSD } \\
\text { Weight } \\
\text { (lbs) }\end{array}$ & $\begin{array}{c}\text { Submerged } \\
\text { Weight } \\
\text { (lbs) }\end{array}$ & $\begin{array}{c}\text { Absorption } \\
\text { (\%) }\end{array}$ & $\begin{array}{l}\text { Density } \\
\left(\mathrm{lbs} / \mathrm{ft}^{3}\right)\end{array}$ & $\begin{array}{c}\text { Net Area } \\
\left(\mathrm{in}^{3}\right)\end{array}$ & $\begin{array}{c}\text { Average } \\
\text { Net Area } \\
\left(\mathrm{in}^{3}\right)\end{array}$ \\
\hline LT50-8N & 1.625 & 2.750 & 650 & 4.583 & 6.926 & 21.537 & 19.261 & 23.506 & 11.245 & 22.0 & 98.0 & 82.8 & 82.8 \\
\hline
\end{tabular}




\section{Batch ID: LT55-8}

Description: Las Tablas 55\% Sand Content Batch. 5.5:10 Ratio of Soil:Sand, 8\% Cement by weight

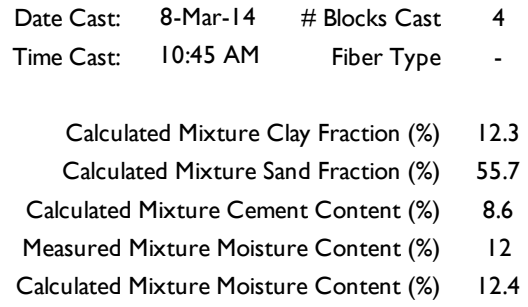

\section{Table B- 21 LT55-8 Mix Design}

\begin{tabular}{|c|c|c|c|c|}
\hline Material & $\begin{array}{c}\text { Measured } \\
\text { Moisture } \\
\text { Content } \\
(\%)\end{array}$ & $\begin{array}{c}\text { Stock } \\
\text { Weight } \\
\text { (lbs) }\end{array}$ & $\begin{array}{c}\text { Oven } \\
\text { Dry } \\
\text { Weight } \\
\text { (lbs) }\end{array}$ & $\begin{array}{c}\text { Oven Dry } \\
\text { Weight } \\
\text { (lbs/100 lbs) }\end{array}$ \\
\hline Soil & 5.3 & 41.1 & 38.9 & 35.7 \\
\hline Sand & 0.1 & 48.9 & 48.9 & 44.8 \\
\hline Cement & - & 8.2 & 8.2 & 7.5 \\
\hline Water & - & 11.4 & 13.6 & 12 \\
\hline Fibers & - & - & - & - \\
\hline Total & 12.0 & 109.7 & 109.7 & 100.0 \\
\hline
\end{tabular}

\section{Table B- 22 LT55-8 Compression Results}

\begin{tabular}{|c|c|c|c|c|c|c|c|c|c|c|c|c|c|}
\hline \multirow[b]{2}{*}{ Block ID } & \multicolumn{3}{|c|}{ Batch Properties } & \multicolumn{3}{|c|}{ Block Properties } & \multicolumn{2}{|c|}{ Moisture Content } & \multicolumn{5}{|c|}{ Compression Testing } \\
\hline & $\begin{array}{l}\text { Chamber } \\
\text { Volume } \\
\text { Setting } \\
\text { (in) }\end{array}$ & $\begin{array}{l}\text { Block } \\
\text { Height } \\
\text { Setting } \\
\text { (in) }\end{array}$ & $\begin{array}{c}\text { Piston } \\
\text { Pressure } \\
\text { (psi) }\end{array}$ & $\begin{array}{l}\text { Height } \\
\text { (in) }\end{array}$ & $\begin{array}{c}\text { Average } \\
\text { Width } \\
\text { (in) }\end{array}$ & $\begin{array}{c}\text { Weight } \\
\text { (lbs) }\end{array}$ & $\begin{array}{c}\text { Cure } \\
\text { Method } \\
\text { (W/D) }\end{array}$ & $\begin{array}{c}\text { Testing } \\
(\%)\end{array}$ & $\begin{array}{l}\text { Max. } \\
\text { Force } \\
\text { (lbs) }\end{array}$ & $\begin{array}{c}\text { Gross } \\
\text { Strength } \\
\text { (psi) }\end{array}$ & $\begin{array}{c}\text { Average } \\
\text { Gross } \\
\text { Strength } \\
\text { (psi) }\end{array}$ & $\begin{array}{c}\text { Net } \\
\text { Strength } \\
\text { (psi) }\end{array}$ & $\begin{array}{l}\text { Average } \\
\text { Net } \\
\text { Strength } \\
\text { (psi) }\end{array}$ \\
\hline LT55-8A & $\mathrm{I} .750$ & 1.625 & 2350 & 4.119 & 6.924 & 21.598 & $\mathrm{D}$ & 9.2 & 145000 & 1496 & \multirow{3}{*}{1000} & 1913 & \multirow{3}{*}{1279} \\
\hline LT55-8B & 1.500 & 1.625 & 750 & 4.09 & 6.921 & 19.205 & $\mathrm{D}$ & - & 66913 & 691 & & 883 & \\
\hline LT55-8C & 1.625 & 1.625 & 900 & 4.091 & 6.935 & 19.756 & $\mathrm{D}$ & - & 79000 & 814 & & 1042 & \\
\hline
\end{tabular}

Table B- 23 LT55-8 Abs Results

\begin{tabular}{|c|c|c|c|c|c|c|c|c|c|c|c|c|c|}
\hline \multirow[b]{2}{*}{ Block ID } & \multicolumn{3}{|c|}{ Batch Properties } & \multicolumn{3}{|c|}{ Block Properties } & \multicolumn{7}{|c|}{ Absorption and Net Area Testing } \\
\hline & $\begin{array}{l}\text { Chamber } \\
\text { Volume } \\
\text { Setting } \\
\text { (in) }\end{array}$ & $\begin{array}{c}\text { Block } \\
\text { Height } \\
\text { Setting } \\
\text { (in) }\end{array}$ & $\begin{array}{c}\text { Piston } \\
\text { Pressure } \\
\text { (psi) }\end{array}$ & $\begin{array}{l}\text { Height } \\
\text { (in) }\end{array}$ & $\begin{array}{l}\text { Average } \\
\text { Width } \\
\text { (in) }\end{array}$ & $\begin{array}{c}\text { Weight } \\
\text { (lbs) }\end{array}$ & $\begin{array}{l}\text { Oven } \\
\text { Dry } \\
\text { Weight } \\
\text { (lbs) }\end{array}$ & $\begin{array}{c}\text { SSD } \\
\text { Weight } \\
\text { (lbs) }\end{array}$ & $\begin{array}{c}\text { Submerged } \\
\text { Weight } \\
\text { (lbs) }\end{array}$ & $\begin{array}{c}\text { Absorption } \\
(\%)\end{array}$ & $\begin{array}{l}\text { Density } \\
\left(\mathrm{lbs} / \mathrm{ft}^{3}\right)\end{array}$ & $\mid \begin{array}{c}\text { Net Area } \\
\left(\text { in }^{3}\right)\end{array}$ & $\begin{array}{c}\text { Average } \\
\text { Net Area } \\
\left(\text { in }^{3}\right)\end{array}$ \\
\hline LT55-8D & 1.875 & 1.625 & 2350 & 4.128 & 6.932 & 21.499 & 19.497 & 22.952 & 11.650 & 17.7 & 107.6 & 75.8 & 75.8 \\
\hline
\end{tabular}




\section{Batch ID: LT70-8}

Description: Las Tablas 70\% Sand Content Batch. 7:10 Ratio of Soil:Sand, 8\% Cement by weight

$\begin{array}{lrrr}\text { Date Cast: } & \text { 8-Mar-I4 } & \text { \# Blocks Cast } & 6 \\ \text { Time Cast: } & \text { II:05 AM } & \text { Fiber Type } & - \\ & & \\ & & \\ \text { Calculated Mixture Clay Fraction (\%) } & 8.1 \\ \text { Calculated Mixture Sand Fraction (\%) } & 70.8 \\ \text { Calculated Mixture Cement Content (\%) } & 8.7 \\ \text { Measured Mixture Moisture Content (\%) } & \text { II } \\ \text { Calculated Mixture Moisture Content (\%) } & 9.7\end{array}$

\section{Table B- 24 LT70-8 Mix Design}

\begin{tabular}{|c|c|c|c|c|}
\hline Material & $\begin{array}{c}\text { Measured } \\
\text { Coisture } \\
\text { Content }\end{array}$ & $\begin{array}{c}\text { Stock } \\
\text { Weight } \\
\text { (lbs) }\end{array}$ & $\begin{array}{c}\text { Oven } \\
\text { Dry } \\
\text { Weight } \\
\text { (lbs) }\end{array}$ & $\begin{array}{c}\text { Oven Dry } \\
\text { Weight } \\
\text { (lbs/100 lbs) }\end{array}$ \\
\hline Soil & 5.3 & 41.1 & 38.9 & 23.7 \\
\hline Sand & 0.1 & 94.5 & 94.4 & 57.6 \\
\hline Cement & - & 12.7 & 12.7 & 7.7 \\
\hline Water & - & 13.4 & 15.7 & 11.0 \\
\hline Fibers & - & - & - & - \\
\hline Total & 11.0 & 161.6 & 161.6 & 100.0 \\
\hline
\end{tabular}

\section{Table B- 25 LT70-8 Compression Results}

\begin{tabular}{|c|c|c|c|c|c|c|c|c|c|c|c|c|c|}
\hline \multirow[b]{2}{*}{ Block ID } & \multicolumn{3}{|c|}{ Batch Properties } & \multicolumn{3}{|c|}{ Block Properties } & \multicolumn{2}{|c|}{ Moisture Content } & \multicolumn{5}{|c|}{ Compression Testing } \\
\hline & $\begin{array}{c}\text { Chamber } \\
\text { Volume } \\
\text { Setting } \\
\text { (in) }\end{array}$ & $\begin{array}{c}\text { Block } \\
\text { Height } \\
\text { Setting } \\
\text { (in) }\end{array}$ & $\begin{array}{c}\text { Piston } \\
\text { Pressure } \\
\text { (psi) }\end{array}$ & $\begin{array}{l}\text { Height } \\
\text { (in) }\end{array}$ & $\begin{array}{c}\text { Average } \\
\text { Width } \\
\text { (in) }\end{array}$ & $\begin{array}{c}\text { Weight } \\
\text { (lbs) }\end{array}$ & $\begin{array}{c}\text { Cure } \\
\text { Method } \\
(\text { W/D) }\end{array}$ & $\begin{array}{c}\text { Testing } \\
(\%)\end{array}$ & $\begin{array}{l}\text { Max. } \\
\text { Force } \\
\text { (lbs) }\end{array}$ & $\begin{array}{c}\text { Gross } \\
\text { Strength } \\
\text { (psi) }\end{array}$ & $\begin{array}{l}\text { Average } \\
\text { Gross } \\
\text { Strength } \\
\text { (psi) }\end{array}$ & $\begin{array}{c}\text { Net } \\
\text { Strength } \\
\text { (psi) }\end{array}$ & $\begin{array}{l}\text { Average } \\
\text { Net } \\
\text { Strength } \\
\text { (psi) }\end{array}$ \\
\hline LT70-8A & 1.875 & 1.625 & 1000 & 4.078 & 6.945 & 20.501 & $\mathrm{D}$ & 7.9 & 91000 & 936 & \multirow{4}{*}{1283} & 1208 & \multirow{4}{*}{1653} \\
\hline LT70-8C & 1.875 & 1.625 & 1500 & 4.096 & 6.936 & 20.961 & $\mathrm{D}$ & - & 130000 & 1339 & & 1726 & \\
\hline LT70-8D & 1.875 & 1.625 & 2350 & 4.124 & 6.930 & 21.543 & $\mathrm{D}$ & - & 137000 & 1412 & & 1819 & \\
\hline LT70-8F & 1.750 & 1.625 & 2350 & 4.204 & 6.924 & 21.930 & $\mathrm{D}$ & - & 140000 & 1444 & & 1859 & \\
\hline
\end{tabular}


Table B- 26 LT70-8 MOR Results

\begin{tabular}{|c|c|c|c|c|c|c|c|c|c|c|c|c|c|}
\hline \multirow[b]{2}{*}{ Block ID } & \multicolumn{3}{|c|}{ Batch Properties } & \multicolumn{3}{|c|}{ Block Properties } & \multicolumn{7}{|c|}{ Absorption and Net Area Testing } \\
\hline & $\begin{array}{l}\text { Chamber } \\
\text { Volume } \\
\text { Setting } \\
\text { (in) }\end{array}$ & $\begin{array}{c}\text { Block } \\
\text { Height } \\
\text { Setting } \\
\text { (in) }\end{array}$ & $\begin{array}{c}\text { Piston } \\
\text { Pressure } \\
\text { (psi) }\end{array}$ & $\begin{array}{l}\text { Height } \\
\text { (in) }\end{array}$ & $\begin{array}{l}\text { Average } \\
\text { Width } \\
\text { (in) }\end{array}$ & $\begin{array}{c}\text { Weight } \\
\text { (lbs) }\end{array}$ & $\begin{array}{l}\text { Oven } \\
\text { Dry } \\
\text { Weight } \\
\text { (lbs) }\end{array}$ & $\begin{array}{c}\text { SSD } \\
\text { Weight } \\
\text { (lbs) }\end{array}$ & $\begin{array}{c}\text { Submerged } \\
\text { Weight } \\
\text { (lbs) }\end{array}$ & \begin{tabular}{|c|} 
Absorption \\
$(\%)$
\end{tabular} & $\begin{array}{l}\text { Density } \\
\left(\mathrm{lbs} / \mathrm{ft}^{3}\right)\end{array}$ & $\begin{array}{c}\text { Net Area } \\
\left(\text { in }^{3}\right)\end{array}$ & $\begin{array}{c}\text { Average } \\
\text { Net Area } \\
\left(\text { in }^{3}\right)\end{array}$ \\
\hline LT70-8B & 1.875 & 1.625 & 1550 & 4.083 & 6.938 & 21.086 & 19.470 & 22.622 & 11.605 & 16.2 & 110.3 & 74.7 & \multirow{2}{*}{75.0} \\
\hline LT70-8E & 1.750 & 1.625 & 2350 & 4.114 & 6.930 & 21.403 & 19.794 & 23.021 & 11.835 & 16.3 & 110.4 & 75.3 & \\
\hline
\end{tabular}

Table B- 27 LT70-8 Durability Results

\begin{tabular}{|c|c|c|c|c|c|}
\hline \multirow{7}{*}{ Block ID } & \multicolumn{3}{|c|}{ Durability Testing } \\
\cline { 2 - 7 } & Cycle & $\begin{array}{c}\text { Oven } \\
\text { Dry } \\
\text { Weight } \\
\text { (lbs) }\end{array}$ & $\begin{array}{c}\text { Mass } \\
\text { Loss Per } \\
\text { Cycle } \\
(\%)\end{array}$ & $\begin{array}{c}\text { Durability } \\
\text { Rating }\end{array}$ & Visual Observations \\
\hline \multirow{5}{*}{ LT70-8E } & 0 & 21.403 & 0.0 & - & - \\
\cline { 2 - 7 } & 1 & 19.874 & 7.1 & 2 & Excellent Shape. No degradation \\
\cline { 2 - 7 } & 2 & 19.859 & 0.1 & 2 & Small amounts of degradation \\
\cline { 2 - 7 } & 3 & 19.818 & 0.2 & 2 & No visible change \\
\cline { 2 - 7 } & 4 & 19.805 & 0.1 & 2 & No visible change \\
\cline { 2 - 7 } & 5 & 19.794 & 0.1 & 2 & No visible change \\
\hline \multicolumn{2}{|c|}{ Total Mass Loss (\%) } & 7.5 & & \\
\hline
\end{tabular}




\section{Batch ID: LT50-4}

Description: Las Tablas 4\% Cement Content Batch. 1:1 Ratio of Soil:Sand, 4\% Cement by weight

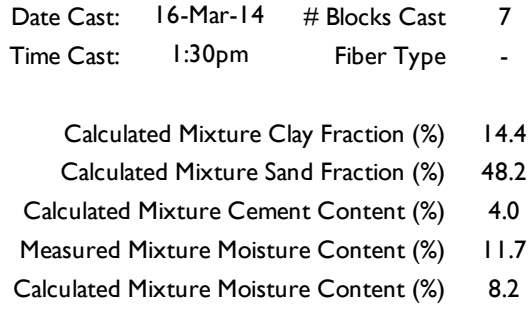

\section{Table B- 28 LT50-4 Mix Design}

\begin{tabular}{|c|c|c|c|c|}
\hline Material & $\begin{array}{c}\text { Measured } \\
\text { Moisture } \\
\text { Content } \\
(\%)\end{array}$ & $\begin{array}{c}\text { Stock } \\
\text { Weight } \\
\text { (lbs) }\end{array}$ & $\begin{array}{c}\text { Oven } \\
\text { Dry } \\
\text { Weight } \\
\text { (lbs) }\end{array}$ & $\begin{array}{c}\text { Oven Dry } \\
\text { Weight } \\
\text { (lbs/I00 lbs) }\end{array}$ \\
\hline Soil & 6.9 & 120.2 & $1 \mathrm{I} 2.4$ & 43.9 \\
\hline Sand & 0.3 & 104.8 & 104.4 & 40.8 \\
\hline Cement & - & 9.1 & 9.1 & 3.5 \\
\hline Water & - & 12.2 & 20.3 & $1 \mathrm{I} .7$ \\
\hline Fibers & - & - & - & - \\
\hline Total & $\mathrm{II} .7$ & 246.2 & 246.2 & 100.0 \\
\hline
\end{tabular}

Table B- 29 LT50-4 Compression Results

\begin{tabular}{|c|c|c|c|c|c|c|c|c|c|c|c|c|c|}
\hline & \multicolumn{3}{|c|}{ Batch Properties } & \multicolumn{3}{|c|}{ Block Properties } & \multicolumn{2}{|c|}{ Moisture Content } & \multicolumn{5}{|c|}{ Compression Testing } \\
\hline Block ID & $\begin{array}{l}\text { Chamber } \\
\text { Volume } \\
\text { Setting } \\
\text { (in) }\end{array}$ & $\begin{array}{c}\text { Block } \\
\text { Height } \\
\text { Setting } \\
\text { (in) }\end{array}$ & $\begin{array}{c}\text { Piston } \\
\text { Pressure } \\
\text { (psi) }\end{array}$ & $\begin{array}{l}\text { Height } \\
\text { (in) }\end{array}$ & $\begin{array}{l}\text { Average } \\
\text { Width } \\
\text { (in) }\end{array}$ & $\begin{array}{c}\text { Weight } \\
\text { (lbs) }\end{array}$ & $\begin{array}{l}\text { Cure } \\
\text { Method } \\
\text { (W/D) }\end{array}$ & $\begin{array}{c}\text { Testing } \\
(\%)\end{array}$ & $\begin{array}{l}\text { Max. } \\
\text { Force } \\
\text { (lbs) }\end{array}$ & $\begin{array}{c}\text { Gross } \\
\text { Strength } \\
\text { (psi) }\end{array}$ & $\begin{array}{l}\text { Average } \\
\text { Gross } \\
\text { Strength } \\
\text { (psi) }\end{array}$ & $\begin{array}{c}\text { Net } \\
\text { Strength } \\
\text { (psi) }\end{array}$ & $\begin{array}{c}\text { Average } \\
\text { Net } \\
\text { Strength } \\
\text { (psi) }\end{array}$ \\
\hline LT50-4A & 2.500 & 2.500 & 2350 & 5.147 & 6.937 & 25.694 & $\mathrm{D}$ & 3.9 & 67153 & 692 & \multirow{3}{*}{731} & 933 & \multirow{3}{*}{902} \\
\hline LT50-4B & 2.125 & 2.500 & 2350 & 4.927 & 6.932 & 24.520 & $\mathrm{D}$ & - & 60400 & 622 & & 839 & \\
\hline LT50-4D & 1.625 & 2.500 & 2350 & 4.637 & 6.930 & 23.524 & $\mathrm{D}$ & - & 67324 & 880 & & 935 & \\
\hline
\end{tabular}

Table B- 30 LT50-4 MOR Results

\begin{tabular}{|c|c|c|c|c|c|c|c|c|c|c|c|c|c|}
\hline \multirow[b]{2}{*}{ Block ID } & \multicolumn{3}{|c|}{ Batch Properties } & \multicolumn{3}{|c|}{ Block Properties } & \multicolumn{2}{|c|}{ Moisture Content } & \multicolumn{5}{|c|}{ Modulus of Rupture Testing } \\
\hline & $\begin{array}{l}\text { Chamber } \\
\text { Volume } \\
\text { Setting } \\
\text { (in) }\end{array}$ & $\begin{array}{c}\text { Block } \\
\text { Height } \\
\text { Setting } \\
\text { (in) }\end{array}$ & $\begin{array}{c}\text { Piston } \\
\text { Pressure } \\
\text { (psi) }\end{array}$ & $\begin{array}{c}\text { Height } \\
\text { (in) }\end{array}$ & $\begin{array}{c}\text { Average } \\
\text { Width } \\
\text { (in) }\end{array}$ & $\begin{array}{c}\text { Weight } \\
\text { (lbs) }\end{array}$ & $\begin{array}{c}\text { Cure } \\
\text { Method } \\
\text { (W/D) }\end{array}$ & $\begin{array}{c}\text { Testing } \\
(\%)\end{array}$ & $\begin{array}{l}\text { Max. } \\
\text { Force } \\
\text { (lbs) }\end{array}$ & $\begin{array}{c}\text { Gross } \\
\text { Strength } \\
(p s i)\end{array}$ & $\begin{array}{l}\text { Average } \\
\text { Gross } \\
\text { Strength } \\
\text { (psi) }\end{array}$ & $\begin{array}{c}\text { Net } \\
\text { Strength } \\
\text { (psi) }\end{array}$ & $\begin{array}{c}\text { Average } \\
\text { Net } \\
\text { Strength } \\
\text { (psi) }\end{array}$ \\
\hline LT50-4C & 2.000 & 2.500 & 2350 & 4.803 & 6.924 & 24.3 & $\mathrm{D}$ & - & 932 & 88 & \multirow{3}{*}{68} & 101 & \multirow{3}{*}{73} \\
\hline LT50-4F & 1.625 & 2.875 & 2350 & 4.813 & 6.928 & 24.3 & $\mathrm{D}$ & - & 742 & 69 & & 80 & \\
\hline LT50-4G & 1.625 & 3.125 & 1500 & 4.995 & 6.928 & 24.0 & $\mathrm{D}$ & - & 526 & 46 & & 52 & \\
\hline
\end{tabular}


Table B- 31 LT50-4 Abs Results

\begin{tabular}{|c|c|c|c|c|c|c|c|c|c|c|c|c|c|}
\hline \multirow[b]{2}{*}{ Block ID } & \multicolumn{3}{|c|}{ Batch Properties } & \multicolumn{3}{|c|}{ Block Properties } & \multicolumn{7}{|c|}{ Absorption and Net Area Testing } \\
\hline & $\begin{array}{l}\text { Chamber } \\
\text { Volume } \\
\text { Setting } \\
\text { (in) }\end{array}$ & $\begin{array}{c}\text { Block } \\
\text { Height } \\
\text { Setting } \\
\text { (in) }\end{array}$ & $\begin{array}{c}\text { Piston } \\
\text { Pressure } \\
\text { (psi) }\end{array}$ & $\begin{array}{l}\text { Height } \\
\text { (in) }\end{array}$ & $\begin{array}{c}\text { Average } \\
\text { Width } \\
\text { (in) }\end{array}$ & $\begin{array}{c}\text { Weight } \\
\text { (lbs) }\end{array}$ & \begin{tabular}{|c} 
Oven \\
Dry \\
Weight \\
(lbs)
\end{tabular} & $\begin{array}{c}\text { SSD } \\
\text { Weight } \\
\text { (lbs) }\end{array}$ & $\begin{array}{c}\text { Submerged } \\
\text { Weight } \\
\text { (lbs) }\end{array}$ & $\begin{array}{c}\text { Absorption } \\
(\%)\end{array}$ & $\begin{array}{l}\text { Density } \\
\left(\mathrm{lbs} / \mathrm{ft}^{3}\right)\end{array}$ & $\begin{array}{c}\text { Net Area } \\
\left(\text { in }^{3}\right)\end{array}$ & $\begin{array}{c}\text { Average } \\
\text { Net Area } \\
\left(\text { in }^{3}\right)\end{array}$ \\
\hline LT50-4E & 1.625 & 2.625 & 2350 & 4.872 & 6.927 & 24.486 & 22.327 & 24.392 & 13.290 & 9.2 & 125.5 & 72.0 & 72.0 \\
\hline
\end{tabular}

Table B- 32 LT50-4 Durability Results

\begin{tabular}{|c|c|c|c|c|c|}
\hline \multirow[b]{2}{*}{ Block ID } & \multicolumn{5}{|c|}{ Durability Testing } \\
\hline & Cycle & $\begin{array}{c}\text { Oven } \\
\text { Dry } \\
\text { Weight } \\
\text { (lbs) }\end{array}$ & $\begin{array}{c}\text { Mass } \\
\text { Loss Per } \\
\text { Cycle } \\
(\%)\end{array}$ & $\begin{array}{c}\text { Durability } \\
\text { Rating }\end{array}$ & Visual Observations \\
\hline \multirow{6}{*}{ LT50-4E } & \begin{tabular}{l|l}
0 \\
\end{tabular} & 24.486 & 0.0 & - & - \\
\hline & I & 22.327 & 8.8 & 2 & Surface degradation and roughening \\
\hline & 2 & 22.234 & 0.4 & 2 & Surface degradation and roughening \\
\hline & 3 & 22.107 & 0.6 & 3 & Surface degradation and roughening \\
\hline & 4 & 22.034 & 0.3 & 3 & Surfaced pocked/rough \\
\hline & 5 & 21.899 & 0.6 & 3 & Surfaced roughened \\
\hline \multicolumn{3}{|c|}{ Total Mass Loss (\%) } & 10.7 & & \\
\hline
\end{tabular}




\section{Batch ID: LT50-12}

Description: Las Tablas 12\% Cement Content Batch. 1:1 Ratio of Soil:Sand, 12\% Cement by weight

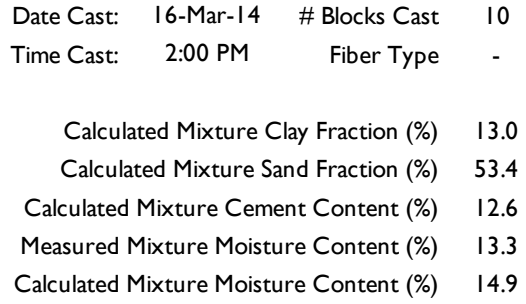

Table B- 33 LT50-12 Mix Design

\begin{tabular}{|c|c|c|c|c|}
\hline Material & $\begin{array}{c}\text { Measured } \\
\text { Moisture } \\
\text { Content } \\
(\%)\end{array}$ & $\begin{array}{c}\text { Stock } \\
\text { Weight } \\
\text { (lbs) }\end{array}$ & $\begin{array}{c}\text { Oven } \\
\text { Dry } \\
\text { Weight } \\
\text { (lbs) }\end{array}$ & $\begin{array}{c}\text { Oven Dry } \\
\text { Weight } \\
\text { (lbs/I00 lbs) }\end{array}$ \\
\hline Soil & 6.9 & 112.6 & 104.8 & 35.3 \\
\hline Sand & 0.3 & 120.6 & 120.1 & 40.4 \\
\hline Cement & - & 32.5 & 32.5 & II.0 \\
\hline Water & - & 37.0 & 45.2 & 13.3 \\
\hline Fibers & - & - & - & - \\
\hline Total & 13.3 & 302.7 & 302.7 & 100.0 \\
\hline
\end{tabular}

Table B- 34 LT50-12 Compression Results

\begin{tabular}{|c|c|c|c|c|c|c|c|c|c|c|c|c|c|}
\hline \multirow[b]{2}{*}{ Block ID } & \multicolumn{3}{|c|}{ Batch Properties } & \multicolumn{3}{|c|}{ Block Properties } & \multicolumn{2}{|c|}{ Moisture Content } & \multicolumn{5}{|c|}{ Compression Testing } \\
\hline & $\begin{array}{l}\text { Chamber } \\
\text { Volume } \\
\text { Setting } \\
\text { (in) }\end{array}$ & $\begin{array}{c}\text { Block } \\
\text { Height } \\
\text { Setting } \\
\text { (in) }\end{array}$ & $\begin{array}{c}\text { Piston } \\
\text { Pressure } \\
\text { (psi) }\end{array}$ & $\begin{array}{l}\text { Height } \\
\text { (in) }\end{array}$ & $\begin{array}{l}\text { Average } \\
\text { Width } \\
\text { (in) }\end{array}$ & $\begin{array}{c}\text { Weight } \\
\text { (lbs) }\end{array}$ & $\begin{array}{c}\text { Cure } \\
\text { Method } \\
\text { (W/D) }\end{array}$ & $\begin{array}{c}\text { Testing } \\
(\%)\end{array}$ & $\begin{array}{l}\text { Max. } \\
\text { Force } \\
\text { (lbs) }\end{array}$ & $\begin{array}{c}\text { Gross } \\
\text { Strength } \\
\text { (psi) }\end{array}$ & $\begin{array}{l}\text { Average } \\
\text { Gross } \\
\text { Strength } \\
\text { (psi) }\end{array}$ & $\begin{array}{c}\text { Net } \\
\text { Strength } \\
\text { (psi) }\end{array}$ & \begin{tabular}{|c} 
Average \\
Net \\
Strength \\
(psi)
\end{tabular} \\
\hline LT50-I2C & 1.625 & 3.000 & 1250 & 4.762 & 6.9185 & 23.738 & $\mathrm{D}$ & - & 85364 & 881 & \multirow{4}{*}{897} & 1204 & \multirow{4}{*}{1226} \\
\hline LT50-I2E & 1.625 & 3.000 & 1000 & 4.714 & 6.9320 & 23.192 & $\mathrm{D}$ & 9.3 & 73601 & 758 & & 1038 & \\
\hline LT50-I2G & 1.625 & 3.000 & 1950 & 4.754 & 6.9255 & 24.417 & $\mathrm{D}$ & - & 106000 & 1093 & & 1495 & \\
\hline LT50-12 J & 1.625 & 3.000 & 2350 & 4.770 & 6.9225 & 24.398 & $\mathrm{D}$ & - & 82850 & 855 & & 1169 & \\
\hline
\end{tabular}


Table B- 35 LT50-12 MOR Results

\begin{tabular}{|c|c|c|c|c|c|c|c|c|c|c|c|c|c|}
\hline \multirow[b]{2}{*}{ Block ID } & \multicolumn{3}{|c|}{ Batch Properties } & \multicolumn{3}{|c|}{ Block Properties } & \multicolumn{2}{|c|}{ Moisture Content } & \multicolumn{5}{|c|}{ Modulus of Rupture Testing } \\
\hline & $\begin{array}{l}\text { Chamber } \\
\text { Volume } \\
\text { Setting } \\
\text { (in) }\end{array}$ & $\begin{array}{l}\text { Block } \\
\text { Height } \\
\text { Setting } \\
\text { (in) }\end{array}$ & $\begin{array}{c}\text { Piston } \\
\text { Pressure } \\
\text { (psi) }\end{array}$ & $\begin{array}{c}\text { Height } \\
\text { (in) }\end{array}$ & $\begin{array}{c}\text { Average } \\
\text { Width } \\
\text { (in) }\end{array}$ & $\begin{array}{c}\text { Weight } \\
\text { (lbs) }\end{array}$ & $\begin{array}{c}\text { Cure } \\
\text { Method } \\
(\mathrm{W} / \mathrm{D})\end{array}$ & $\begin{array}{c}\text { Testing } \\
(\%)\end{array}$ & $\begin{array}{l}\text { Max. } \\
\text { Force } \\
\text { (lbs) }\end{array}$ & $\begin{array}{c}\text { Gross } \\
\text { Strength } \\
(p s i)\end{array}$ & $\begin{array}{c}\text { Average } \\
\text { Gross } \\
\text { Strength } \\
\text { (psi) }\end{array}$ & $\begin{array}{c}\text { Net } \\
\text { Strength } \\
\text { (psi) }\end{array}$ & $\begin{array}{c}\text { Average } \\
\text { Net } \\
\text { Strength } \\
\text { (psi) }\end{array}$ \\
\hline LT50-I2D & 1.625 & 3.000 & 1250 & 4.754 & 6.916 & 23.686 & $\mathrm{D}$ & - & 1140 & 109 & \multirow{3}{*}{100} & 126 & \multirow{3}{*}{108} \\
\hline LT50-I2F & 1.625 & 3.000 & 1650 & 4.729 & 6.916 & 24.230 & $\mathrm{D}$ & - & 1056 & 102 & & 118 & \\
\hline LT50-I2I & 1.625 & 3.000 & 1450 & 4.728 & 6.916 & 23.597 & $\mathrm{D}$ & - & 916 & 89 & & 103 & \\
\hline
\end{tabular}

Table B- 36 LT50-12 Abs Results

\begin{tabular}{|c|c|c|c|c|c|c|c|c|c|c|c|c|c|}
\hline \multirow[b]{2}{*}{ Block ID } & \multicolumn{3}{|c|}{ Batch Properties } & \multicolumn{3}{|c|}{ Block Properties } & \multicolumn{7}{|c|}{ Absorption and Net Area Testing } \\
\hline & $\begin{array}{l}\text { Chamber } \\
\text { Volume } \\
\text { Setting } \\
\text { (in) }\end{array}$ & $\begin{array}{c}\text { Block } \\
\text { Height } \\
\text { Setting } \\
\text { (in) }\end{array}$ & $\begin{array}{c}\text { Piston } \\
\text { Pressure } \\
\text { (psi) }\end{array}$ & $\begin{array}{l}\text { Height } \\
\text { (in) }\end{array}$ & $\begin{array}{c}\text { Average } \\
\text { Width } \\
\text { (in) }\end{array}$ & $\begin{array}{c}\text { Weight } \\
\text { (lbs) }\end{array}$ & $\begin{array}{l}\text { Oven } \\
\text { Dry } \\
\text { Weight } \\
\text { (lbs) }\end{array}$ & $\begin{array}{c}\text { SSD } \\
\text { Weight } \\
\text { (lbs) }\end{array}$ & $\begin{array}{c}\text { Submerged } \\
\text { Weight } \\
\text { (lbs) }\end{array}$ & $\begin{array}{c}\text { Absorption } \\
(\%)\end{array}$ & $\begin{array}{l}\text { Density } \\
\left(\mathrm{lbs} / \mathrm{ft}^{3}\right)\end{array}$ & $\begin{array}{c}\text { Net Area } \\
\left(\text { in }^{3}\right)\end{array}$ & $\begin{array}{c}\text { Average } \\
\text { Net Area } \\
\left(\text { in }^{3}\right)\end{array}$ \\
\hline LT50-I2A & 1.625 & 3.125 & 750 & 4.927 & 6.930 & 22.877 & 20.483 & 22.389 & 12.190 & 9.3 & 125.3 & 68.9 & \multirow{2}{*}{70.4} \\
\hline LT50-I2B & 1.625 & 3.125 & 800 & 4.955 & 6.916 & 23.896 & 21.795 & 23.315 & 12.895 & 7.0 & 130.5 & 71.8 & \\
\hline
\end{tabular}

Table B- 37 LT50-12 Durability Results

\begin{tabular}{|c|c|c|c|c|c|}
\hline \multirow[b]{2}{*}{ Block ID } & \multicolumn{5}{|c|}{ Durability Testing } \\
\hline & Cycle & $\begin{array}{c}\text { Oven } \\
\text { Dry } \\
\text { Weight } \\
\text { (lbs) }\end{array}$ & $\begin{array}{l}\text { Mass } \\
\text { Loss Per } \\
\text { Cycle } \\
(\%)\end{array}$ & $\begin{array}{c}\text { Durability } \\
\text { Rating }\end{array}$ & Visual Observations \\
\hline \multirow{6}{*}{ LT50-I 2B } & 0 & 23.896 & 0.0 & - & - \\
\hline & I & 21.803 & 8.8 & 2 & Excellent shape. No visible degradation \\
\hline & 2 & 21.795 & 0.0 & 2 & Hairline crack along top. Otherwise fine \\
\hline & 3 & 21.789 & 0.0 & 2 & No visible degradation \\
\hline & 4 & 21.752 & 0.2 & 2 & No visible degradation \\
\hline & 5 & 21.733 & 0.1 & 2 & No visible degradation \\
\hline \multicolumn{3}{|c|}{ Total Mass Loss (\%) } & 9.1 & & \\
\hline
\end{tabular}




\section{Batch ID: LT50-FF2-8}

Description: Las Tablas .02\% Forta Fiber Batch. 1:1 Ratio of Soil:Sand, 8\% Cement by weight

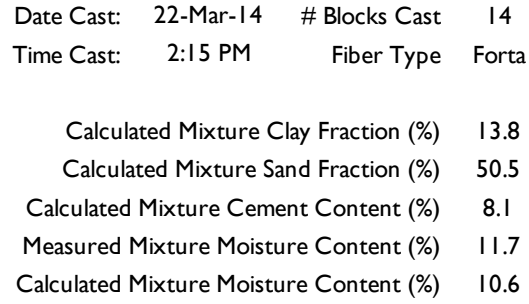

\section{Table B- 38 LT50-FF2-8 Mix Design}

\begin{tabular}{|c|c|c|c|c|}
\hline Material & $\begin{array}{c}\text { Measured } \\
\text { Moisture } \\
\text { Content } \\
(\%)\end{array}$ & $\begin{array}{c}\text { Stock } \\
\text { Weight } \\
\text { (lbs) }\end{array}$ & $\begin{array}{c}\text { Oven } \\
\text { Dry } \\
\text { Weight } \\
\text { (lbs) }\end{array}$ & $\begin{array}{c}\text { Oven Dry } \\
\text { Weight } \\
\text { (lbs/I00 lbs) }\end{array}$ \\
\hline Soil & 5.9 & 190.2 & 179.0 & 40.1 \\
\hline Sand & 0.8 & 184.3 & 182.8 & 41.0 \\
\hline Cement & - & 31.9 & 31.9 & 7.2 \\
\hline Water & - & 33.7 & 46.7 & $1 \mathrm{I} .7$ \\
\hline Fibers & - & 0.3 & 0.3 & - \\
\hline Total & $\mathrm{II} .7$ & 440.5 & 440.5 & 100.0 \\
\hline
\end{tabular}

Table B- 39 LT50-FF2-8 Compression Results

\begin{tabular}{|c|c|c|c|c|c|c|c|c|c|c|c|c|c|}
\hline \multirow[b]{2}{*}{ Block ID } & \multicolumn{3}{|c|}{ Batch Properties } & \multicolumn{3}{|c|}{ Block Properties } & \multicolumn{2}{|c|}{ Moisture Content } & \multicolumn{5}{|c|}{ Compression Testing } \\
\hline & $\begin{array}{l}\text { Chamber } \\
\text { Volume } \\
\text { Setting } \\
\text { (in) }\end{array}$ & $\begin{array}{c}\text { Block } \\
\text { Height } \\
\text { Setting } \\
\text { (in) }\end{array}$ & $\begin{array}{c}\text { Piston } \\
\text { Pressure } \\
\text { (psi) }\end{array}$ & $\begin{array}{l}\text { Height } \\
\text { (in) }\end{array}$ & $\begin{array}{c}\text { Average } \\
\text { Width } \\
\text { (in) }\end{array}$ & $\begin{array}{c}\text { Weight } \\
\text { (lbs) }\end{array}$ & $\begin{array}{c}\text { Cure } \\
\text { Method } \\
\text { (W/D) }\end{array}$ & $\begin{array}{c}\text { Testing } \\
(\%)\end{array}$ & $\begin{array}{l}\text { Max. } \\
\text { Force } \\
\text { (lbs) }\end{array}$ & $\begin{array}{c}\text { Gross } \\
\text { Strength } \\
\text { (psi) }\end{array}$ & $\begin{array}{l}\text { Average } \\
\text { Gross } \\
\text { Strength } \\
\text { (psi) }\end{array}$ & $\begin{array}{c}\text { Net } \\
\text { Strength } \\
\text { (psi) }\end{array}$ & $\begin{array}{c}\text { Average } \\
\text { Net } \\
\text { Strength } \\
\text { (psi) }\end{array}$ \\
\hline LT50-FF2-8A & 1.500 & 3.125 & 1300 & 4.760 & 6.9175 & 24.128 & W & 11.5 & 78021 & 806 & \multirow{6}{*}{880} & 892 & \multirow{6}{*}{975} \\
\hline LT50-FF2-8B & 1.500 & 3.125 & 1500 & 4.733 & 6.9325 & 24.140 & $\mathrm{D}$ & - & 105000 & 1082 & & 1200 & \\
\hline LT50-FF2-8D & 1.500 & 3.125 & 1150 & 4.722 & 6.9200 & 24.001 & W & - & 57419 & 593 & & 656 & \\
\hline LT50-FF2-8I & 1.500 & 2.875 & 1250 & 4.628 & 6.9225 & 23.052 & $\mathrm{D}$ & 7.3 & 86813 & 896 & & 992 & \\
\hline LT50-FF2-8K & 1.500 & 2.875 & 2350 & 4.807 & 6.9155 & 24.623 & $\mathrm{D}$ & - & 107000 & 1105 & & 1223 & \\
\hline LT50-FF2-8L & 1.500 & 3.000 & 2000 & 4.895 & 6.9250 & 24.575 & $\mathrm{~W}$ & - & 77555 & 800 & & 886 & \\
\hline
\end{tabular}


Table B- 40 LT50-FF2-8 MOR Results

\begin{tabular}{|c|c|c|c|c|c|c|c|c|c|c|c|c|c|}
\hline \multirow[b]{2}{*}{ Block ID } & \multicolumn{3}{|c|}{ Batch Properties } & \multicolumn{3}{|c|}{ Block Properties } & \multicolumn{2}{|c|}{ Moisture Content } & \multicolumn{5}{|c|}{ Modulus of Rupture Testing } \\
\hline & $\begin{array}{l}\text { Chamber } \\
\text { Volume } \\
\text { Setting } \\
\text { (in) }\end{array}$ & $\begin{array}{c}\text { Block } \\
\text { Height } \\
\text { Setting } \\
\text { (in) }\end{array}$ & $\begin{array}{c}\text { Piston } \\
\text { Pressure } \\
\text { (psi) }\end{array}$ & $\begin{array}{l}\text { Height } \\
\text { (in) }\end{array}$ & $\begin{array}{l}\text { Average } \\
\text { Width } \\
\text { (in) }\end{array}$ & $\begin{array}{c}\text { Weight } \\
\text { (lbs) }\end{array}$ & $\begin{array}{c}\text { Cure } \\
\text { Method } \\
\text { (W/D) }\end{array}$ & $\begin{array}{c}\text { Testing } \\
(\%)\end{array}$ & $\begin{array}{l}\text { Max. } \\
\text { Force } \\
\text { (lbs) }\end{array}$ & $\begin{array}{c}\text { Gross } \\
\text { Strength } \\
\text { (psi) }\end{array}$ & $\begin{array}{c}\text { Average } \\
\text { Gross } \\
\text { Strength } \\
\text { (psi) }\end{array}$ & $\begin{array}{c}\text { Net } \\
\text { Strength } \\
\text { (psi) }\end{array}$ & $\begin{array}{c}\text { Average } \\
\text { Net } \\
\text { Strength } \\
\text { (psi) }\end{array}$ \\
\hline LT50-FF2-8C & 1.500 & 3.125 & 1300 & 4.728 & 6.9175 & 23.903 & $\mathrm{D}$ & - & 1263 & 123 & \multirow{6}{*}{95} & $|4|$ & \multirow{6}{*}{109} \\
\hline LT50-FF2-8E & 1.500 & 3.125 & 1550 & 4.759 & 6.9200 & 24.381 & $\mathrm{D}$ & - & 1367 & 131 & & 151 & \\
\hline LT50-FF2-8F & 1.500 & 3.125 & 1250 & 4.726 & 6.9240 & 24.347 & W & - & 788 & 76 & & 88 & \\
\hline LT50-FF2-8G & 1.500 & 3.125 & 1000 & 4.694 & 6.9170 & 22.638 & W & - & 371 & 37 & & 42 & \\
\hline LT50-FF2-8J & 1.500 & 2.875 & 2350 & 4.699 & 6.9220 & 24.299 & $\mathrm{~W}$ & - & 1087 & 107 & & 123 & \\
\hline LT50-FF2-8M & 1.500 & 3.000 & 2350 & 4.851 & 6.9290 & 25.007 & D & - & 1033 & 95 & & 109 & \\
\hline
\end{tabular}

Table B- 41 LT50-FF2-8 Abs Results

\begin{tabular}{|c|c|c|c|c|c|c|c|c|c|c|c|c|c|}
\hline \multirow[b]{2}{*}{ Block ID } & \multicolumn{3}{|c|}{ Batch Properties } & \multicolumn{3}{|c|}{ Block Properties } & \multicolumn{7}{|c|}{ Absorption and Net Area Testing } \\
\hline & $\begin{array}{l}\text { Chamber } \\
\text { Volume } \\
\text { Setting } \\
\text { (in) }\end{array}$ & $\begin{array}{c}\text { Block } \\
\text { Height } \\
\text { Setting } \\
\text { (in) }\end{array}$ & $\begin{array}{c}\text { Piston } \\
\text { Pressure } \\
\text { (psi) }\end{array}$ & $\begin{array}{l}\text { Height } \\
\text { (in) }\end{array}$ & $\begin{array}{l}\text { Average } \\
\text { Width } \\
\text { (in) }\end{array}$ & $\begin{array}{l}\text { Weight } \\
\text { (lbs) }\end{array}$ & $\begin{array}{l}\text { Oven } \\
\text { Dry } \\
\text { Weight } \\
\text { (lbs) }\end{array}$ & $\begin{array}{c}\text { SSD } \\
\text { Weight } \\
\text { (lbs) }\end{array}$ & $\begin{array}{c}\text { Submerged } \\
\text { Weight } \\
\text { (lbs) }\end{array}$ & $\begin{array}{c}\text { Absorption } \\
(\%)\end{array}$ & $\begin{array}{l}\text { Density } \\
\left(\mathrm{lbs} / \mathrm{ft}^{3}\right)\end{array}$ & $\begin{array}{c}\text { Net Area } \\
\left(\text { in }^{3}\right)\end{array}$ & $\begin{array}{c}\text { Average } \\
\text { Net Area } \\
\left(\text { in }^{3}\right)\end{array}$ \\
\hline LT50-FF2-8H & 1.500 & 3.125 & 1000 & 4.747 & 6.919 & 23.191 & 21.481 & 25.564 & 12.835 & 19.0 & 105.3 & 82.5 & \\
\hline LT50-FF2-8N & 1.500 & 3.000 & 2350 & 4.802 & 6.933 & 24.288 & 22.142 & 26.325 & 13.260 & 18.9 & 105.8 & 88.1 & נ. \\
\hline
\end{tabular}

Table B- 42 LT50-FF2-8 Durability Results

\begin{tabular}{|c|c|c|c|c|c|}
\hline \multirow[b]{2}{*}{ Block ID } & \multicolumn{5}{|r|}{ Durability Testing } \\
\hline & Cycle & $\begin{array}{c}\text { Oven } \\
\text { Dry } \\
\text { Weight } \\
\text { (lbs) }\end{array}$ & $\begin{array}{c}\text { Mass } \\
\text { Loss Per } \\
\text { Cycle } \\
(\%)\end{array}$ & $\begin{array}{c}\text { Durability } \\
\text { Rating }\end{array}$ & Visual Observations \\
\hline \multirow{6}{*}{ LT50-FF2-8H } & 0 & 23.191 & 0.0 & - & - \\
\hline & I & 22.036 & 5.0 & 2 & Surface degradation. Fibers burnt off. Cracked face \\
\hline & 2 & 22.028 & 0.0 & 2 & No significant degradtion \\
\hline & 3 & 21.899 & 0.6 & 2 & No significant degradtion \\
\hline & 4 & 21.590 & 1.4 & 2 & No significant degradtion \\
\hline & 5 & 20.890 & 3.2 & 2 & Surface degradation. Fibers removed \\
\hline \multicolumn{3}{|c|}{ Total Mass Loss (\%) } & 10.3 & & \\
\hline
\end{tabular}




\section{Batch ID: LT50-FF5-8}

Description: Las Tablas .05\% Forta Fiber Batch. 1:1 Ratio of Soil:Sand, 8\% Cement by weight

\begin{tabular}{|c|c|c|c|}
\hline Date Cast: & 22-Mar-14 & \# Blocks Cast & 14 \\
\hline Time Cast: & 6:00 PM & Fiber Type & Forta \\
\hline \multicolumn{3}{|c|}{ Calculated Mixture Clay Fraction (\%) } & 13.2 \\
\hline \multicolumn{3}{|c|}{ Calculated Mixture Sand Fraction (\%) } & 52.6 \\
\hline \multicolumn{3}{|c|}{ Calculated Mixture Cement Content (\%) } & \\
\hline \multicolumn{3}{|c|}{ Measured Mixture Moisture Content (\%) } & \\
\hline \multicolumn{3}{|c|}{ Calculated Mixture Moisture Content (\%) } & \\
\hline
\end{tabular}

\section{Table B- 43 LT50-FF5-8 Mix Design}

\begin{tabular}{|c|c|c|c|c|}
\hline Material & $\begin{array}{c}\text { Measured } \\
\text { Coisture } \\
\text { Content } \\
(\%)\end{array}$ & $\begin{array}{c}\text { Stock } \\
\text { Weight } \\
\text { (lbs) }\end{array}$ & $\begin{array}{c}\text { Oven } \\
\text { Dry } \\
\text { Weight } \\
\text { (lbs) }\end{array}$ & $\begin{array}{c}\text { Oven Dry } \\
\text { Weight } \\
\text { (lbs// 00 lbs) }\end{array}$ \\
\hline Soil & 5.9 & 109.8 & 103.3 & 38.4 \\
\hline Sand & 0.8 & 115.7 & 114.8 & 42.6 \\
\hline Cement & - & 20.3 & 20.3 & 7.5 \\
\hline Water & - & 30.5 & 38.4 & 11.5 \\
\hline Fibers & - & 0.5 & 0.5 & - \\
\hline Total & 11.5 & 276.8 & 276.8 & 100.0 \\
\hline
\end{tabular}

Table B- 44 LT50-FF5-8 Compression Results

\begin{tabular}{|c|c|c|c|c|c|c|c|c|c|c|c|c|c|}
\hline \multirow[b]{2}{*}{ Block ID } & \multicolumn{3}{|c|}{ Batch Properties } & \multicolumn{3}{|c|}{ Block Properties } & \multicolumn{2}{|c|}{ Moisture Content } & \multicolumn{5}{|c|}{ Compression Testing } \\
\hline & \begin{tabular}{|c|} 
Chamber \\
Volume \\
Setting \\
(in)
\end{tabular} & $\begin{array}{c}\text { Block } \\
\text { Height } \\
\text { Setting } \\
\text { (in) }\end{array}$ & $\begin{array}{c}\text { Piston } \\
\text { Pressure } \\
\text { (psi) }\end{array}$ & $\begin{array}{l}\text { Height } \\
\text { (in) }\end{array}$ & $\begin{array}{c}\text { Average } \\
\text { Width } \\
\text { (in) }\end{array}$ & $\begin{array}{c}\text { Weight } \\
\text { (lbs) }\end{array}$ & $\begin{array}{c}\text { Cure } \\
\text { Method } \\
\text { (W/D) }\end{array}$ & $\begin{array}{l}\text { Testing } \\
\text { (\%) }\end{array}$ & $\begin{array}{c}\text { Max. } \\
\text { Force } \\
\text { (lbs) }\end{array}$ & $\begin{array}{c}\text { Gross } \\
\text { Strength } \\
(\mathrm{psi})\end{array}$ & $\begin{array}{l}\text { Average } \\
\text { Gross } \\
\text { Strength } \\
\text { (psi) }\end{array}$ & $\begin{array}{c}\text { Net } \\
\text { Strength } \\
\text { (psi) }\end{array}$ & $\begin{array}{l}\text { Average } \\
\text { Net } \\
\text { Strength } \\
\text { (psi) }\end{array}$ \\
\hline LT50-FF5-8C & 1.5 & 3.125 & 1750 & 4.887 & 6.918 & 24.726 & $\mathrm{D}$ & 7.3 & 103000 & 1063 & \multirow{4}{*}{946} & 1177 & \multirow{4}{*}{1048} \\
\hline LT50-FF5-8E & 1.5 & 3.125 & 1450 & 4.935 & 6.923 & 24.512 & D & - & 87188 & 900 & & 996 & \\
\hline LT50-FF5-8G & 1.5 & 3.125 & 1400 & 4.872 & 6.9295 & 24.111 & $\mathrm{D}$ & - & 79966 & 824 & & 914 & \\
\hline LT50-FF5-8I & 1.5 & 3.125 & 2350 & 4.98 & 6.9325 & 25.071 & $\mathrm{D}$ & - & 96702 & 996 & & 1105 & \\
\hline
\end{tabular}


Table B- 45 LT50-FF5-8 MOR Results

\begin{tabular}{|c|c|c|c|c|c|c|c|c|c|c|c|c|c|}
\hline \multirow[b]{2}{*}{ Block ID } & \multicolumn{3}{|c|}{ Batch Properties } & \multicolumn{3}{|c|}{ Block Properties } & \multicolumn{2}{|c|}{ Moisture Content } & \multicolumn{5}{|c|}{ Modulus of Rupture Testing } \\
\hline & $\begin{array}{l}\text { Chamber } \\
\text { Volume } \\
\text { Setting } \\
\text { (in) }\end{array}$ & $\begin{array}{c}\text { Block } \\
\text { Height } \\
\text { Setting } \\
\text { (in) }\end{array}$ & $\begin{array}{c}\text { Piston } \\
\text { Pressure } \\
\text { (psi) }\end{array}$ & $\begin{array}{c}\text { Height } \\
\text { (in) }\end{array}$ & $\begin{array}{c}\text { Average } \\
\text { Width } \\
\text { (in) }\end{array}$ & $\begin{array}{c}\text { Weight } \\
\text { (lbs) }\end{array}$ & $\begin{array}{c}\text { Cure } \\
\text { Method } \\
(\mathrm{W} / \mathrm{D})\end{array}$ & $\begin{array}{c}\text { Testing } \\
(\%)\end{array}$ & $\begin{array}{l}\text { Max. } \\
\text { Force } \\
\text { (lbs) }\end{array}$ & $\begin{array}{c}\text { Gross } \\
\text { Strength } \\
\text { (psi) }\end{array}$ & $\begin{array}{l}\text { Average } \\
\text { Gross } \\
\text { Strength } \\
\text { (psi) }\end{array}$ & $\begin{array}{c}\text { Net } \\
\text { Strength } \\
\text { (psi) }\end{array}$ & $\begin{array}{l}\text { Average } \\
\text { Net } \\
\text { Strength } \\
\text { (psi) }\end{array}$ \\
\hline LT50-FF5-8D & 1.500 & 3.125 & 2350 & 4.906 & 6.922 & 24.951 & $\mathrm{D}$ & - & 1163 & 105 & \multirow{3}{*}{96} & 120 & \multirow{3}{*}{110} \\
\hline LT50-FF5-8F & 1.500 & 3.125 & 2350 & 4.909 & 6.925 & 24.770 & $\mathrm{D}$ & - & 1040 & 93 & & 108 & \\
\hline LT50-FF5-8H & 1.500 & 3.125 & 2350 & 4.953 & 6.920 & 24.734 & $\mathrm{D}$ & - & 1016 & 90 & & 103 & \\
\hline
\end{tabular}

\section{Table B- 46 LT50-FF5-8 Abs Results}

\begin{tabular}{|c|c|c|c|c|c|c|c|c|c|c|c|c|c|}
\hline \multirow[b]{2}{*}{ Block ID } & \multicolumn{3}{|c|}{ Batch Properties } & \multicolumn{3}{|c|}{ Block Properties } & \multicolumn{7}{|c|}{ Absorption and Net Area Testing } \\
\hline & $\begin{array}{l}\text { Chamber } \\
\text { Volume } \\
\text { Setting } \\
\text { (in) }\end{array}$ & $\begin{array}{c}\text { Block } \\
\text { Height } \\
\text { Setting } \\
\text { (in) }\end{array}$ & $\begin{array}{c}\text { Piston } \\
\text { Pressure } \\
\text { (psi) }\end{array}$ & $\begin{array}{l}\text { Height } \\
\text { (in) }\end{array}$ & $\begin{array}{c}\text { Average } \\
\text { Width } \\
\text { (in) }\end{array}$ & $\begin{array}{c}\text { Weight } \\
\text { (lbs) }\end{array}$ & $\begin{array}{l}\text { Oven } \\
\text { Dry } \\
\text { Weight } \\
\text { (lbs) }\end{array}$ & $\begin{array}{c}\text { SSD } \\
\text { Weight } \\
\text { (lbs) }\end{array}$ & $\begin{array}{c}\text { Submerged } \\
\text { Weight } \\
\text { (lbs) }\end{array}$ & $\begin{array}{c}\text { Absorption } \\
(\%)\end{array}$ & $\begin{array}{l}\text { Density } \\
\left(\mathrm{lbs} / \mathrm{ft}^{3}\right)\end{array}$ & $\begin{array}{c}\text { Net Area } \\
\left(\text { in }^{3}\right)\end{array}$ & $\begin{array}{c}\text { Average } \\
\text { Net Area } \\
\left(\text { in }^{3}\right)\end{array}$ \\
\hline LT50-FF5-8B & 1.500 & 3.000 & 2350 & 4.880 & 6.917 & 24.759 & 21.481 & 25.564 & 12.835 & 19.0 & 105.3 & 82.5 & \multirow{2}{*}{85.3} \\
\hline LT50-FF5-8E & 1.500 & 3.125 & 1450 & 4.935 & 6.923 & 24.512 & 22.142 & 26.325 & 13.260 & 18.9 & 105.8 & 88.1 & \\
\hline
\end{tabular}

Table B- 47 LT50-FF5-8 Durability Results

\begin{tabular}{|c|c|c|c|c|c|}
\hline \multirow[b]{2}{*}{ Block ID } & \multicolumn{5}{|c|}{ Durability Testing } \\
\hline & Cycle & $\begin{array}{c}\text { Oven } \\
\text { Dry } \\
\text { Weight } \\
\text { (lbs) }\end{array}$ & $\begin{array}{c}\text { Mass } \\
\text { Loss Per } \\
\text { Cycle } \\
(\%)\end{array}$ & $\begin{array}{c}\text { Durability } \\
\text { Rating }\end{array}$ & Visual Observations \\
\hline \multirow{6}{*}{ LT50-FF5-8B } & 0 & 24.759 & 0.0 & - & - \\
\hline & 1 & 22.875 & 7.6 & 2 & Fibers burnt off. Minor roughening \\
\hline & 2 & 22.865 & 0.0 & 2 & No significant degradtion \\
\hline & 3 & 22.862 & 0.0 & 2 & No significant degradtion \\
\hline & 4 & 22.809 & 0.2 & 2 & No significant degradtion \\
\hline & 5 & 22.135 & 3.0 & 2 & Fibers removed. Corners/edges damaged \\
\hline \multicolumn{3}{|c|}{ Total Mass Loss (\%) } & 10.9 & & \\
\hline
\end{tabular}




\section{Batch ID: LT50-FS2-8}

Description: Las Tablas .02\% Strux Fiber Batch. 1:1 Ratio of Soil:Sand, 8\% Cement by weight

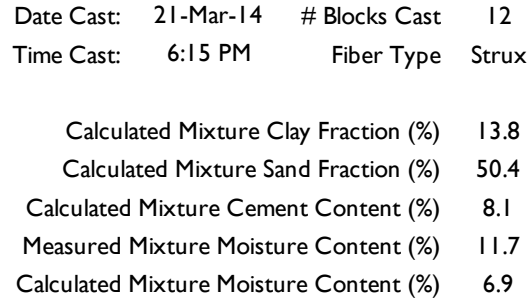

\section{Table B- 48 LT50-FS2-8 Mix Design}

\begin{tabular}{|c|c|c|c|c|}
\hline Material & $\begin{array}{c}\text { Measured } \\
\text { Moisture } \\
\text { Content } \\
(\%)\end{array}$ & $\begin{array}{c}\text { Stock } \\
\text { Weight } \\
\text { (lbs) }\end{array}$ & $\begin{array}{c}\text { Oven } \\
\text { Dry } \\
\text { Weight } \\
\text { (lbs) }\end{array}$ & $\begin{array}{c}\text { Oven Dry } \\
\text { Weight } \\
\text { (lbs/I00 lbs) }\end{array}$ \\
\hline Soil & 4.9 & 152.7 & 145.2 & 40.3 \\
\hline Sand & 0.4 & 148.1 & 147.5 & 40.9 \\
\hline Cement & - & 25.7 & 25.7 & 7.1 \\
\hline Water & - & 15.2 & 23.7 & $\mathrm{II} .7$ \\
\hline Fibers & - & 0.3 & 0.3 & - \\
\hline Total & $\mathrm{II} .7$ & 342.0 & 342.0 & 100.0 \\
\hline
\end{tabular}

Table B- 49 LT50-FS2-8 Compression Results

\begin{tabular}{|c|c|c|c|c|c|c|c|c|c|c|c|c|c|}
\hline \multirow[b]{2}{*}{ Block ID } & \multicolumn{3}{|c|}{ Batch Properties } & \multicolumn{3}{|c|}{ Block Properties } & \multicolumn{2}{|c|}{ Moisture Content } & \multicolumn{5}{|c|}{ Compression Testing } \\
\hline & $\begin{array}{l}\text { Chamber } \\
\text { Volume } \\
\text { Setting } \\
\text { (in) }\end{array}$ & $\begin{array}{l}\text { Block } \\
\text { Height } \\
\text { Setting } \\
\text { (in) }\end{array}$ & $\begin{array}{c}\text { Piston } \\
\text { Pressure } \\
\text { (psi) }\end{array}$ & $\begin{array}{l}\text { Height } \\
\text { (in) }\end{array}$ & $\begin{array}{c}\text { Average } \\
\text { Width } \\
\text { (in) }\end{array}$ & $\begin{array}{c}\text { Weight } \\
\text { (lbs) }\end{array}$ & $\begin{array}{c}\text { Cure } \\
\text { Method } \\
\text { (W/D) }\end{array}$ & $\begin{array}{c}\text { Testing } \\
(\%)\end{array}$ & $\begin{array}{l}\text { Max. } \\
\text { Force } \\
\text { (lbs) }\end{array}$ & $\begin{array}{c}\text { Gross } \\
\text { Strength } \\
(p s i)\end{array}$ & $\begin{array}{l}\text { Average } \\
\text { Gross } \\
\text { Strength } \\
\text { (psi) }\end{array}$ & $\begin{array}{c}\text { Net } \\
\text { Strength } \\
\text { (psi) }\end{array}$ & $\begin{array}{c}\text { Average } \\
\text { Net } \\
\text { Strength } \\
\text { (psi) }\end{array}$ \\
\hline LT50-FS2-8A & 1.625 & 2.875 & 2350 & 4.753 & 6.9265 & 24.795 & W & 11.0 & 104000 & 1072 & \multirow{5}{*}{1047} & 1404 & \multirow{5}{*}{1370} \\
\hline LT50-FS2-8E & 1.500 & 2.625 & 2350 & 4.695 & 6.9320 & 24.675 & W & - & 97186 & 1001 & & 1312 & \\
\hline LT50-FS2-8G & 1.500 & 2.875 & 2350 & 4.659 & 6.9325 & 24.150 & $\mathrm{D}$ & 8.9 & 118000 & 1216 & & 1592 & \\
\hline LT50-FS2-8I & 1.500 & 3.125 & 1400 & 4.730 & 6.9260 & 24.194 & $\mathrm{D}$ & - & 104000 & 1073 & & 1404 & \\
\hline LT50-FS2-8K & 1.500 & 3.125 & 2350 & 4.974 & 6.9265 & 25.053 & W & - & 84534 & 872 & & $114 \mid$ & \\
\hline
\end{tabular}


Table B- 50 LT50-FS2-8 MOR Results

\begin{tabular}{|c|c|c|c|c|c|c|c|c|c|c|c|c|c|}
\hline \multirow[b]{2}{*}{ Block ID } & \multicolumn{3}{|c|}{ Batch Properties } & \multicolumn{3}{|c|}{ Block Properties } & \multicolumn{2}{|c|}{ Moisture Content } & \multicolumn{5}{|c|}{ Modulus of Rupture Testing } \\
\hline & $\begin{array}{l}\text { Chamber } \\
\text { Volume } \\
\text { Setting } \\
\text { (in) }\end{array}$ & $\begin{array}{c}\text { Block } \\
\text { Height } \\
\text { Setting } \\
\text { (in) }\end{array}$ & $\begin{array}{c}\text { Piston } \\
\text { Pressure } \\
\text { (psi) }\end{array}$ & $\begin{array}{l}\text { Height } \\
\text { (in) }\end{array}$ & $\begin{array}{l}\text { Average } \\
\text { Width } \\
\text { (in) }\end{array}$ & $\begin{array}{c}\text { Weight } \\
\text { (lbs) }\end{array}$ & $\begin{array}{c}\text { Cure } \\
\text { Method } \\
\text { (W/D) }\end{array}$ & $\begin{array}{c}\text { Testing } \\
(\%)\end{array}$ & $\begin{array}{l}\text { Max. } \\
\text { Force } \\
\text { (lbs) }\end{array}$ & $\begin{array}{c}\text { Gross } \\
\text { Strength } \\
\text { (psi) }\end{array}$ & $\begin{array}{c}\text { Average } \\
\text { Gross } \\
\text { Strength } \\
\text { (psi) }\end{array}$ & $\begin{array}{c}\text { Net } \\
\text { Strength } \\
\text { (psi) }\end{array}$ & $\begin{array}{c}\text { Average } \\
\text { Net } \\
\text { Strength } \\
\text { (psi) }\end{array}$ \\
\hline LT50-FS2-8C & 1.625 & 2.875 & 1550 & 4.672 & 6.9285 & 23.778 & W & - & 1081 & 107 & \multirow{6}{*}{101} & 124 & \multirow{6}{*}{116} \\
\hline LT50-FS2-8D & 1.625 & 2.875 & 2350 & 4.609 & 6.9260 & 24.005 & $\mathrm{D}$ & - & 1354 & 138 & & 160 & \\
\hline LT50-FS2-8F & 1.500 & 2.875 & 1450 & 4.611 & 6.9185 & 23.446 & $\mathrm{D}$ & - & 1113 & 113 & & $13 \mid$ & \\
\hline LT50-FS2-8H & 1.500 & 3.000 & 2350 & 4.661 & 6.9360 & 24.953 & W & - & 1073 & 107 & & 124 & \\
\hline LT50-FS2-8j & 1.500 & 3.125 & 2350 & 4.823 & 6.9240 & 24.589 & $\mathrm{~W}$ & - & 585 & 54 & & 63 & \\
\hline LT50-FS2-8L & 1.500 & 3.125 & 2350 & 4.945 & 6.9205 & 24.748 & $\mathrm{D}$ & - & 941 & 83 & & 96 & \\
\hline
\end{tabular}

\section{Table B- 51 LT50-FS2-8 Abs Results}

\begin{tabular}{|c|c|c|c|c|c|c|c|c|c|c|c|c|c|}
\hline \multirow[b]{2}{*}{ Block ID } & \multicolumn{3}{|c|}{ Batch Properties } & \multicolumn{3}{|c|}{ Block Properties } & \multicolumn{7}{|c|}{ Absorption and Net Area Testing } \\
\hline & $\begin{array}{l}\text { Chamber } \\
\text { Volume } \\
\text { Setting } \\
\text { (in) }\end{array}$ & $\begin{array}{c}\text { Block } \\
\text { Height } \\
\text { Setting } \\
\text { (in) }\end{array}$ & $\begin{array}{c}\text { Piston } \\
\text { Pressure } \\
\text { (psi) }\end{array}$ & $\begin{array}{l}\text { Height } \\
\text { (in) }\end{array}$ & $\begin{array}{l}\text { Average } \\
\text { Width } \\
\text { (in) }\end{array}$ & $\begin{array}{c}\text { Weight } \\
\text { (lbs) }\end{array}$ & $\begin{array}{c}\text { Oven } \\
\text { Dry } \\
\text { Weight } \\
\text { (lbs) }\end{array}$ & $\begin{array}{c}\text { SSD } \\
\text { Weight } \\
\text { (lbs) }\end{array}$ & $\begin{array}{c}\text { Submerged } \\
\text { Weight } \\
\text { (lbs) }\end{array}$ & $\begin{array}{c}\text { Absorption } \\
(\%)\end{array}$ & $\begin{array}{l}\text { Density } \\
\left(\mathrm{lbs} / \mathrm{ft}^{3}\right)\end{array}$ & $\mid \begin{array}{c}\text { Net Area } \\
\left(\text { in }^{3}\right)\end{array}$ & $\begin{array}{c}\text { Average } \\
\text { Net Area } \\
\left(\text { in }^{3}\right)\end{array}$ \\
\hline LT50-FS2-8B & 1.500 & 2.875 & 950 & 4.584 & 6.909 & 22.582 & 20.875 & 22.722 & 11.290 & 8.8 & 113.9 & 74.1 & 74.1 \\
\hline
\end{tabular}

Table B- 52 LT50-FS2-8 Durability Results

\begin{tabular}{|c|c|c|c|c|c|}
\hline \multirow[b]{2}{*}{ Block ID } & \multicolumn{5}{|c|}{ Durability Testing } \\
\hline & Cycle & $\begin{array}{c}\text { Oven } \\
\text { Dry } \\
\text { Weight } \\
\text { (lbs) }\end{array}$ & $\begin{array}{c}\text { Mass } \\
\text { Loss Per } \\
\text { Cycle } \\
(\%)\end{array}$ & $\begin{array}{c}\text { Durability } \\
\text { Rating }\end{array}$ & Visual Observations \\
\hline \multirow{6}{*}{ LT50-FS2-8B } & 0 & 22.582 & 0.0 & - & - \\
\hline & 1 & 20.884 & 7.5 & 2 & Fibers burnt off. No significant change \\
\hline & 2 & 20.878 & 0.0 & 2 & No significant change \\
\hline & 3 & 20.835 & 0.2 & 2 & No significant change \\
\hline & 4 & 20.630 & 1.0 & 2 & No significant change \\
\hline & 5 & 19.976 & 3.2 & 3 & Portion of face chipped off \\
\hline \multicolumn{3}{|c|}{ Total Mass Loss (\%) } & 11.9 & & \\
\hline
\end{tabular}




\section{Batch ID: LT50-FS5-8}

Description: Las Tablas .05\% Strux Fiber Batch. 1:1 Ratio of Soil:Sand, 8\% Cement by weight

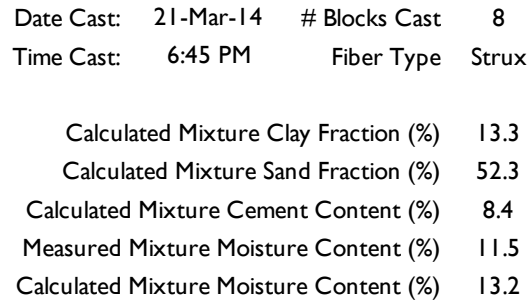

\section{Table B- 53 LT50-FS5-8 Mix Design}

\begin{tabular}{|c|c|c|c|c|}
\hline Material & $\begin{array}{c}\text { Measured } \\
\text { Moisture } \\
\text { Content } \\
(\%)\end{array}$ & $\begin{array}{c}\text { Stock } \\
\text { Weight } \\
\text { (lbs) }\end{array}$ & $\begin{array}{c}\text { Oven } \\
\text { Dry } \\
\text { Weight } \\
\text { (lbs) }\end{array}$ & $\begin{array}{c}\text { Oven Dry } \\
\text { Weight } \\
\text { (lbs/I00 lbs) }\end{array}$ \\
\hline Soil & 4.9 & 97.3 & 92.5 & 38.7 \\
\hline Sand & 0.4 & 101.9 & 101.4 & 42.4 \\
\hline Cement & - & 17.8 & 17.8 & 7.4 \\
\hline Water & - & 26.6 & 32.2 & 11.5 \\
\hline Fibers & - & 0.4 & 0.4 & - \\
\hline Total & 11.5 & 244.0 & 244.0 & 100.0 \\
\hline
\end{tabular}

Table B- 54 LT50-FS5-8 Compression Results

\begin{tabular}{|c|c|c|c|c|c|c|c|c|c|c|c|c|c|}
\hline \multirow[b]{2}{*}{ Block ID } & \multicolumn{3}{|c|}{ Batch Properties } & \multicolumn{3}{|c|}{ Block Properties } & \multicolumn{2}{|c|}{ Moisture Content } & \multicolumn{5}{|c|}{ Compression Testing } \\
\hline & $\begin{array}{l}\text { Chamber } \\
\text { Volume } \\
\text { Setting } \\
\text { (in) }\end{array}$ & $\begin{array}{c}\text { Block } \\
\text { Height } \\
\text { Setting } \\
\text { (in) }\end{array}$ & $\begin{array}{c}\text { Piston } \\
\text { Pressure } \\
\text { (psi) }\end{array}$ & $\begin{array}{c}\text { Height } \\
\text { (in) }\end{array}$ & $\begin{array}{c}\text { Average } \\
\text { Width } \\
\text { (in) }\end{array}$ & $\begin{array}{c}\text { Weight } \\
\text { (lbs) }\end{array}$ & $\begin{array}{c}\text { Cure } \\
\text { Method } \\
(\text { W/D) }\end{array}$ & $\begin{array}{c}\text { Testing } \\
(\%)\end{array}$ & $\begin{array}{l}\text { Max. } \\
\text { Force } \\
\text { (lbs) }\end{array}$ & $\begin{array}{c}\text { Gross } \\
\text { Strength } \\
\text { (psi) }\end{array}$ & $\begin{array}{l}\text { Average } \\
\text { Gross } \\
\text { Strength } \\
\text { (psi) }\end{array}$ & $\begin{array}{c}\text { Net } \\
\text { Strength } \\
\text { (psi) }\end{array}$ & $\begin{array}{c}\text { Average } \\
\text { Net } \\
\text { Strength } \\
\text { (psi) }\end{array}$ \\
\hline LT50-FS5-8A & 1.500 & 3.125 & 2000 & 4.829 & 6.9275 & 24.705 & $\mathrm{D}$ & 9.4 & 105000 & 1083 & \multirow{3}{*}{839} & 1224 & \multirow{3}{*}{948} \\
\hline LT50-FS5-8A & 1.500 & 3.125 & 1250 & 4.797 & 6.9205 & 23.982 & $\mathrm{D}$ & - & 83159 & 858 & & 969 & \\
\hline LT50-FS5-8A & 1.500 & 3.125 & 1250 & 4.795 & 6.920 & 23.378 & $\mathrm{D}$ & - & 55728 & 575 & & 650 & \\
\hline
\end{tabular}


Table B- 55 LT50-FS5-8 MOR Results

\begin{tabular}{|c|c|c|c|c|c|c|c|c|c|c|c|c|c|}
\hline \multirow[b]{2}{*}{ Block ID } & \multicolumn{3}{|c|}{ Batch Properties } & \multicolumn{3}{|c|}{ Block Properties } & \multicolumn{2}{|c|}{ Moisture Content } & \multicolumn{5}{|c|}{ Modulus of Rupture Testing } \\
\hline & \begin{tabular}{|c|} 
Chamber \\
Volume \\
Setting \\
(in)
\end{tabular} & $\begin{array}{l}\text { Block } \\
\text { Height } \\
\text { Setting } \\
\text { (in) }\end{array}$ & \begin{tabular}{|c|} 
Piston \\
Pressure \\
$(\mathrm{psi})$ \\
\end{tabular} & $\begin{array}{l}\text { Height } \\
\text { (in) }\end{array}$ & $\begin{array}{c}\text { Average } \\
\text { Width } \\
\text { (in) }\end{array}$ & $\begin{array}{c}\text { Weight } \\
\text { (lbs) }\end{array}$ & \begin{tabular}{|c} 
Cure \\
Method \\
(W/D) \\
\end{tabular} & $\begin{array}{c}\text { Testing } \\
(\%)\end{array}$ & $\begin{array}{l}\text { Max. } \\
\text { Force } \\
\text { (lbs) }\end{array}$ & $\begin{array}{c}\text { Gross } \\
\text { Strength } \\
\text { (psi) }\end{array}$ & $\begin{array}{l}\text { Average } \\
\text { Gross } \\
\text { Strength } \\
\text { (psi) }\end{array}$ & $\begin{array}{c}\text { Net } \\
\text { Strength } \\
\text { (psi) }\end{array}$ & $\begin{array}{c}\text { Average } \\
\text { Net } \\
\text { Strength } \\
\text { (psi) }\end{array}$ \\
\hline LT50-FS5-8B & 1.500 & 3.125 & 1350 & 4.797 & 6.9200 & 24.287 & $\mathrm{D}$ & - & 920 & 87 & \multirow{3}{*}{77} & 100 & \multirow{3}{*}{88} \\
\hline LT50-FS5-8D & 1.500 & 3.125 & 1350 & 4.808 & 6.9225 & 24.099 & $\mathrm{D}$ & - & 906 & 85 & & 98 & \\
\hline LT50-FS5-8G & 1.500 & 3.125 & 1900 & 4.795 & 6.9200 & 23.604 & $\mathrm{D}$ & - & 619 & 58 & & 67 & \\
\hline
\end{tabular}

Table B- 56 LT50-FS5-8 Abs Results

\begin{tabular}{|c|c|c|c|c|c|c|c|c|c|c|c|c|c|}
\hline \multirow[b]{2}{*}{ Block ID } & \multicolumn{3}{|c|}{ Batch Properties } & \multicolumn{3}{|c|}{ Block Properties } & \multicolumn{7}{|c|}{ Absorption and Net Area Testing } \\
\hline & $\begin{array}{l}\text { Chamber } \\
\text { Volume } \\
\text { Setting } \\
\text { (in) }\end{array}$ & $\begin{array}{c}\text { Block } \\
\text { Height } \\
\text { Setting } \\
\text { (in) }\end{array}$ & $\begin{array}{c}\text { Piston } \\
\text { Pressure } \\
\text { (psi) }\end{array}$ & $\begin{array}{l}\text { Height } \\
\text { (in) }\end{array}$ & $\begin{array}{l}\text { Average } \\
\text { Width } \\
\text { (in) }\end{array}$ & $\begin{array}{c}\text { Weight } \\
\text { (lbs) }\end{array}$ & $\begin{array}{c}\text { Oven } \\
\text { Dry } \\
\text { Weight } \\
\text { (lbs) }\end{array}$ & $\begin{array}{c}\text { SSD } \\
\text { Weight } \\
\text { (lbs) }\end{array}$ & $\begin{array}{c}\text { Submerged } \\
\text { Weight } \\
\text { (lbs) }\end{array}$ & $\begin{array}{c}\text { Absorption } \\
(\%)\end{array}$ & $\begin{array}{l}\text { Density } \\
\left(\mathrm{lbs} / \mathrm{ft}^{3}\right)\end{array}$ & $\begin{array}{c}\text { Net Area } \\
\left(\text { in }^{3}\right)\end{array}$ & $\begin{array}{c}\text { Average } \\
\text { Net Area } \\
\left(\text { in }^{3}\right)\end{array}$ \\
\hline LT50-FS5-8F & 1.500 & 3.125 & 2350 & 4.814 & 6.917 & 23.841 & 22.246 & 24.065 & 11.995 & 8.2 & 115.0 & 81.5 & \multirow{2}{*}{85.8} \\
\hline LT50-FS5-8H & 1.500 & 3.125 & 1500 & 4.852 & 6.919 & 22.835 & 21.363 & 24.508 & 11.435 & 14.7 & 102.0 & 90.1 & \\
\hline
\end{tabular}




\section{B-2) Prado Batches}

\section{Batch ID: P0-8}

Description: Prado 0\% Sand Content Batch. 1:0 Ratio of Soil:Sand, 8\% Cement by weight

$\begin{array}{lrrr}\text { Date Cast: } & \text { I3-Mar-14 } & \text { \# Blocks Cast } & 3 \\ \text { Time Cast: } & \text { I0:30 AM } & \text { Fiber Type } & - \\ & & \\ \text { Calculated Mixture Clay Fraction (\%) } & 26.1 \\ \text { Calculated Mixture Sand Fraction (\%) } & 0.0 \\ \text { Calculated Mixture Cement Content (\%) } & 8.1 \\ \text { Measured Mixture Moisture Content (\%) } & \text { 11.2 } \\ \text { Calculated Mixture Moisture Content (\%) } & 10.6\end{array}$

Table B- 57 P0-8 Mix Design

\begin{tabular}{|c|c|c|c|c|}
\hline Material & $\begin{array}{c}\text { Measured } \\
\text { Moisture } \\
\text { Content } \\
(\%)\end{array}$ & $\begin{array}{c}\text { Stock } \\
\text { Weight } \\
\text { (lbs) }\end{array}$ & $\begin{array}{c}\text { Oven } \\
\text { Dry } \\
\text { Weight } \\
\text { (lbs) }\end{array}$ & $\begin{array}{c}\text { Oven Dry } \\
\text { Weight } \\
\text { (lbs//00 lbs) }\end{array}$ \\
\hline Soil & 4.9 & 103.3 & 98.3 & 81.6 \\
\hline Sand & - & - & - & - \\
\hline Cement & - & 8.7 & 8.7 & 7.2 \\
\hline Water & - & 7.6 & 12.6 & 11.2 \\
\hline Fibers & - & - & - & - \\
\hline Total & 11.2 & 119.6 & 119.6 & 100.0 \\
\hline
\end{tabular}

Table B- 58 P0-8 Compression Results

\begin{tabular}{|c|c|c|c|c|c|c|c|c|c|c|c|c|c|}
\hline \multirow[b]{2}{*}{ Block ID } & \multicolumn{3}{|c|}{ Batch Properties } & \multicolumn{3}{|c|}{ Block Properties } & \multicolumn{2}{|c|}{ Moisture Content } & \multicolumn{5}{|c|}{ Compression Testing } \\
\hline & \begin{tabular}{|c|} 
Chamber \\
Volume \\
Setting \\
(in)
\end{tabular} & $\begin{array}{l}\text { Block } \\
\text { Height } \\
\text { Setting } \\
\text { (in) }\end{array}$ & \begin{tabular}{|c|} 
Piston \\
Pressure \\
$(\mathrm{psi})$ \\
\end{tabular} & $\begin{array}{c}\text { Height } \\
\text { (in) }\end{array}$ & $\begin{array}{c}\text { Average } \\
\text { Width } \\
\text { (in) }\end{array}$ & $\begin{array}{c}\text { Weight } \\
\text { (lbs) }\end{array}$ & $\begin{array}{l}\text { Cure } \\
\text { Method } \\
\text { (W/D) }\end{array}$ & $\begin{array}{c}\text { Testing } \\
(\%)\end{array}$ & $\begin{array}{l}\text { Max. } \\
\text { Force } \\
\text { (lbs) }\end{array}$ & $\begin{array}{c}\text { Gross } \\
\text { Strength } \\
\text { (psi) }\end{array}$ & $\begin{array}{l}\text { Average } \\
\text { Gross } \\
\text { Strength } \\
\text { (psi) }\end{array}$ & $\begin{array}{c}\text { Net } \\
\text { Strength } \\
\text { (psi) }\end{array}$ & $\begin{array}{l}\text { Average } \\
\text { Net } \\
\text { Strength } \\
\text { (psi) }\end{array}$ \\
\hline $\mathrm{P} 0-8 \mathrm{~A}$ & 1.750 & 2.375 & 2350 & 4.056 & 6.941 & 21.794 & $\mathrm{D}$ & 9.6 & 102000 & 1050 & & 1323 & \\
\hline $\mathrm{P} 0-8 \mathrm{C}$ & 1.625 & 2.375 & 2350 & 4.275 & 6.995 & 23.651 & $\mathrm{D}$ & - & 112000 & 1144 & 1097 & 1453 & 1388 \\
\hline
\end{tabular}




\section{Table B- 59 P0-8 Abs Results}

\begin{tabular}{|c|c|c|c|c|c|c|c|c|c|c|c|c|c|}
\hline \multirow[b]{2}{*}{ Block ID } & \multicolumn{3}{|c|}{ Batch Properties } & \multicolumn{3}{|c|}{ Block Properties } & \multicolumn{7}{|c|}{ Absorption and Net Area Testing } \\
\hline & $\begin{array}{l}\text { Chamber } \\
\text { Volume } \\
\text { Setting } \\
\text { (in) }\end{array}$ & $\begin{array}{c}\text { Block } \\
\text { Height } \\
\text { Setting } \\
\text { (in) }\end{array}$ & $\begin{array}{c}\text { Piston } \\
\text { Pressure } \\
\text { (psi) }\end{array}$ & $\begin{array}{l}\text { Height } \\
\text { (in) }\end{array}$ & $\begin{array}{c}\text { Average } \\
\text { Width } \\
\text { (in) }\end{array}$ & $\begin{array}{c}\text { Weight } \\
\text { (lbs) }\end{array}$ & $\begin{array}{c}\text { Oven } \\
\text { Dry } \\
\text { Weight } \\
\text { (lbs) }\end{array}$ & $\begin{array}{c}\text { SSD } \\
\text { Weight } \\
\text { (lbs) }\end{array}$ & $\begin{array}{c}\text { Submerged } \\
\text { Weight } \\
\text { (lbs) }\end{array}$ & $\begin{array}{c}\text { Absorption } \\
(\%)\end{array}$ & $\begin{array}{l}\text { Density } \\
\left(\mathrm{lbs} / \mathrm{ft}^{3}\right)\end{array}$ & $\begin{array}{c}\text { Net Area } \\
\left(\text { in }^{3}\right)\end{array}$ & $\begin{array}{c}\text { Average } \\
\text { Net Area } \\
\left(\text { in }^{3}\right)\end{array}$ \\
\hline $\mathrm{P} 0-8 \mathrm{~B}$ & 1.625 & 2.375 & 2350 & 4.056 & 6.941 & 21.794 & 21.362 & 25.142 & 13.250 & 17.7 & 112.1 & 77.1 & 77.1 \\
\hline
\end{tabular}

\section{Table B- 60 P0-8 Durability Results}

\begin{tabular}{|c|c|c|c|c|c|}
\hline \multirow[b]{2}{*}{ Block ID } & \multicolumn{5}{|c|}{ Durability Testing } \\
\hline & Cycle & $\begin{array}{c}\text { Oven } \\
\text { Dry } \\
\text { Weight } \\
\text { (lbs) }\end{array}$ & $\begin{array}{c}\text { Mass } \\
\text { Loss Per } \\
\text { Cycle } \\
(\%)\end{array}$ & $\begin{array}{c}\text { Durability } \\
\text { Rating }\end{array}$ & Visual Observations \\
\hline \multirow{6}{*}{ P0-8B } & 0 & 24.863 & 0.0 & - & - \\
\hline & 1 & 21.362 & 14.1 & 3 & Significant degradation. Some mass loss \\
\hline & 2 & 20.428 & 4.4 & 4 & Significant degradation. Some mass loss \\
\hline & 3 & 20.064 & 1.8 & 4 & Significant degradation. Some mass loss \\
\hline & 4 & 19.749 & 1.6 & 4 & Significant degradation. Some mass loss \\
\hline & 5 & 19.483 & 1.3 & 4 & Significant degradation. Some mass loss \\
\hline \multicolumn{3}{|c|}{ Total Mass Loss (\%) } & 23.2 & & \\
\hline
\end{tabular}




\section{Batch ID: P50-8}

Description: Prado 50\% Sand Content Batch. 1:1 Ratio of Soil:Sand, 8\% Cement by weight

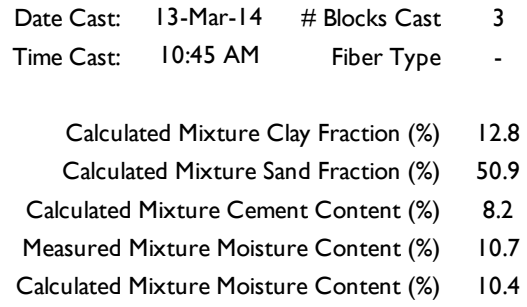

Table B- 61 P50-8 Mix Design

\begin{tabular}{|c|c|c|c|c|}
\hline Material & $\begin{array}{c}\text { Measured } \\
\text { Moisture } \\
\text { Content } \\
(\%)\end{array}$ & $\begin{array}{c}\text { Stock } \\
\text { Weight } \\
\text { (lbs) }\end{array}$ & $\begin{array}{c}\text { Oven } \\
\text { Dry } \\
\text { Weight } \\
\text { (lbs) }\end{array}$ & $\begin{array}{c}\text { Oven Dry } \\
\text { Weight } \\
\text { (lbs/I00 lbs) }\end{array}$ \\
\hline Soil & 4.9 & 45.5 & 43.3 & 40.2 \\
\hline Sand & 0.0 & 44.9 & 44.9 & 41.7 \\
\hline Cement & - & 7.9 & 7.9 & 7.3 \\
\hline Water & - & 8.9 & $1 \mathrm{I} .2$ & 10.7 \\
\hline Fibers & - & - & - & - \\
\hline Total & 10.7 & 107.3 & 107.3 & 100.0 \\
\hline
\end{tabular}

Table B- 62 P50-8 Compression Results

\begin{tabular}{|c|c|c|c|c|c|c|c|c|c|c|c|c|c|}
\hline \multirow[b]{2}{*}{ Block ID } & \multicolumn{3}{|c|}{ Batch Properties } & \multicolumn{3}{|c|}{ Block Properties } & \multicolumn{2}{|c|}{ Moisture Content } & \multicolumn{5}{|c|}{ Compression Testing } \\
\hline & $\begin{array}{l}\text { Chamber } \\
\text { Volume } \\
\text { Setting } \\
\text { (in) }\end{array}$ & $\begin{array}{l}\text { Block } \\
\text { Height } \\
\text { Setting } \\
\text { (in) }\end{array}$ & $\begin{array}{c}\text { Piston } \\
\text { Pressure } \\
\text { (psi) }\end{array}$ & $\begin{array}{c}\text { Height } \\
\text { (in) }\end{array}$ & $\begin{array}{c}\text { Average } \\
\text { Width } \\
\text { (in) }\end{array}$ & $\begin{array}{c}\text { Weight } \\
\text { (lbs) }\end{array}$ & $\begin{array}{c}\text { Cure } \\
\text { Method } \\
(\text { W/D) }\end{array}$ & $\begin{array}{c}\text { Testing } \\
(\%)\end{array}$ & $\begin{array}{l}\text { Max. } \\
\text { Force } \\
\text { (lbs) }\end{array}$ & $\begin{array}{c}\text { Gross } \\
\text { Strength } \\
\text { (psi) }\end{array}$ & $\begin{array}{l}\text { Average } \\
\text { Gross } \\
\text { Strength } \\
\text { (psi) }\end{array}$ & $\begin{array}{c}\text { Net } \\
\text { Strength } \\
\text { (psi) }\end{array}$ & $\begin{array}{l}\text { Average } \\
\text { Net } \\
\text { Strength } \\
\text { (psi) }\end{array}$ \\
\hline P50-8B & 1.625 & 2.375 & 2350 & 4.221 & 6.939 & 25.538 & $\mathrm{D}$ & 6.4 & 114000 & 1174 & \multirow{2}{*}{1149} & 1454 & \multirow{2}{*}{1422} \\
\hline P50-8C & 1.625 & 2.500 & 2350 & 4.462 & 6.937 & 24.389 & $\mathrm{D}$ & - & 109000 & 1124 & & 1390 & \\
\hline
\end{tabular}

Table B- 63 P50-8 Abs Results

\begin{tabular}{|c|c|c|c|c|c|c|c|c|c|c|c|c|c|}
\hline \multirow[b]{2}{*}{ Block ID } & \multicolumn{3}{|c|}{ Batch Properties } & \multicolumn{3}{|c|}{ Block Properties } & \multicolumn{7}{|c|}{ Absorption and Net Area Testing } \\
\hline & $\begin{array}{l}\text { Chamber } \\
\text { Volume } \\
\text { Setting } \\
\text { (in) }\end{array}$ & $\begin{array}{c}\text { Block } \\
\text { Height } \\
\text { Setting } \\
\text { (in) }\end{array}$ & $\begin{array}{c}\text { Piston } \\
\text { Pressure } \\
\text { (psi) }\end{array}$ & $\begin{array}{l}\text { Height } \\
\text { (in) }\end{array}$ & $\begin{array}{c}\text { Average } \\
\text { Width } \\
\text { (in) }\end{array}$ & $\begin{array}{c}\text { Weight } \\
\text { (lbs) }\end{array}$ & $\begin{array}{c}\text { Oven } \\
\text { Dry } \\
\text { Weight } \\
\text { (lbs) }\end{array}$ & $\begin{array}{c}\text { SSD } \\
\text { Weight } \\
\text { (lbs) }\end{array}$ & $\begin{array}{c}\text { Submerged } \\
\text { Weight } \\
\text { (lbs) }\end{array}$ & $\begin{array}{c}\text { Absorption } \\
(\%)\end{array}$ & $\begin{array}{l}\text { Density } \\
\left(\mathrm{lbs} / \mathrm{ft}^{3}\right)\end{array}$ & $\begin{array}{c}\text { Net Area } \\
\left(\text { in }^{3}\right)\end{array}$ & $\begin{array}{c}\text { Average } \\
\text { Net Area } \\
\left(\text { in }^{3}\right)\end{array}$ \\
\hline P50-8A & 1.625 & 2.375 & 2350 & 4.221 & 6.939 & 25.538 & 22.177 & 24.800 & 13.195 & 11.8 & 119.2 & 78.4 & 78.4 \\
\hline
\end{tabular}




\section{Batch ID: P60-8}

Description: Prado 60\% Sand Content Batch. 3:5 Ratio of Soil:Sand, 8\% Cement by weight

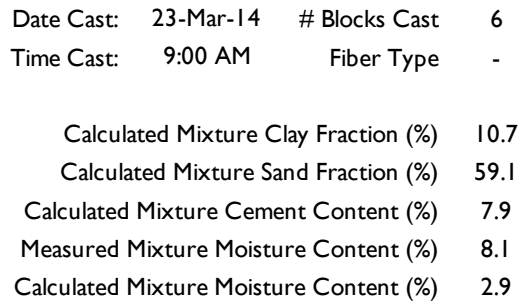

\section{Table B- 64 P60-8 Mix Design}

\begin{tabular}{|c|c|c|c|c|}
\hline Material & $\begin{array}{c}\text { Measured } \\
\text { Moisture } \\
\text { Content } \\
(\%)\end{array}$ & $\begin{array}{c}\text { Stock } \\
\text { Weight } \\
\text { (lbs) }\end{array}$ & $\begin{array}{c}\text { Oven } \\
\text { Dry } \\
\text { Weight } \\
\text { (lbs) }\end{array}$ & $\begin{array}{c}\text { Oven Dry } \\
\text { Weight } \\
\text { (lbs/I00 lbs) }\end{array}$ \\
\hline Soil & 4.9 & 81.8 & 77.8 & 34.6 \\
\hline Sand & 0.5 & $1 \mathrm{I} 3.1$ & $\mathrm{I} 12.6$ & 50.1 \\
\hline Cement & - & 16.2 & 16.2 & 7.2 \\
\hline Water & - & 1.6 & 6.1 & 8.1 \\
\hline Fibers & - & - & - & - \\
\hline Total & 8.1 & 212.7 & 212.7 & 100.0 \\
\hline
\end{tabular}

\section{Table B- 65 P60-8 Compression Results}

\begin{tabular}{|c|c|c|c|c|c|c|c|c|c|c|c|c|c|}
\hline \multirow[b]{2}{*}{ Block ID } & \multicolumn{3}{|c|}{ Batch Properties } & \multicolumn{3}{|c|}{ Block Properties } & \multicolumn{2}{|c|}{ Moisture Content } & \multicolumn{5}{|c|}{ Compression Testing } \\
\hline & $\begin{array}{l}\text { Chamber } \\
\text { Volume } \\
\text { Setting } \\
\text { (in) }\end{array}$ & $\begin{array}{l}\text { Block } \\
\text { Height } \\
\text { Setting } \\
\text { (in) }\end{array}$ & $\begin{array}{c}\text { Piston } \\
\text { Pressure } \\
\text { (psi) }\end{array}$ & $\begin{array}{l}\text { Height } \\
\text { (in) }\end{array}$ & $\begin{array}{c}\text { Average } \\
\text { Width } \\
\text { (in) }\end{array}$ & $\begin{array}{c}\text { Weight } \\
\text { (lbs) }\end{array}$ & $\begin{array}{c}\text { Cure } \\
\text { Method } \\
\text { (W/D) }\end{array}$ & $\begin{array}{c}\text { Testing } \\
(\%)\end{array}$ & $\begin{array}{l}\text { Max. } \\
\text { Force } \\
\text { (lbs) }\end{array}$ & $\begin{array}{c}\text { Gross } \\
\text { Strength } \\
\text { (psi) }\end{array}$ & $\begin{array}{l}\text { Average } \\
\text { Gross } \\
\text { Strength } \\
\text { (psi) }\end{array}$ & $\begin{array}{c}\text { Net } \\
\text { Strength } \\
\text { (psi) }\end{array}$ & $\begin{array}{l}\text { Average } \\
\text { Net } \\
\text { Strength } \\
\text { (psi) }\end{array}$ \\
\hline P60-8B & 1.500 & 3.125 & 1500 & 4.910 & 6.937 & 26.313 & $\mathrm{D}$ & 5.7 & 89954 & 926 & \multirow{2}{*}{801} & 1056 & \multirow{2}{*}{913} \\
\hline P60-8E & 1.500 & 3.125 & 1050 & 4.833 & 6.928 & 25.283 & $\mathrm{D}$ & - & 65553 & 676 & & 769 & \\
\hline
\end{tabular}


Table B- 66 P60-8 MOR Results

\begin{tabular}{|c|c|c|c|c|c|c|c|c|c|c|c|c|c|}
\hline \multirow[b]{2}{*}{ Block ID } & \multicolumn{3}{|c|}{ Batch Properties } & \multicolumn{3}{|c|}{ Block Properties } & \multicolumn{2}{|c|}{ Moisture Content } & \multicolumn{5}{|c|}{ Modulus of Rupture Testing } \\
\hline & $\begin{array}{l}\text { Chamber } \\
\text { Volume } \\
\text { Setting } \\
\text { (in) }\end{array}$ & $\begin{array}{c}\text { Block } \\
\text { Height } \\
\text { Setting } \\
\text { (in) }\end{array}$ & $\begin{array}{c}\text { Piston } \\
\text { Pressure } \\
\text { (psi) }\end{array}$ & $\begin{array}{l}\text { Height } \\
\text { (in) }\end{array}$ & $\begin{array}{l}\text { Average } \\
\text { Width } \\
\text { (in) }\end{array}$ & $\begin{array}{c}\text { Weight } \\
\text { (lbs) }\end{array}$ & $\begin{array}{c}\text { Cure } \\
\text { Method } \\
\text { (W/D) }\end{array}$ & $\begin{array}{c}\text { Testing } \\
(\%)\end{array}$ & $\begin{array}{l}\text { Max. } \\
\text { Force } \\
\text { (lbs) }\end{array}$ & $\begin{array}{c}\text { Gross } \\
\text { Strength } \\
\text { (psi) }\end{array}$ & $\begin{array}{c}\text { Average } \\
\text { Gross } \\
\text { Strength } \\
\text { (psi) }\end{array}$ & $\begin{array}{c}\text { Net } \\
\text { Strength } \\
\text { (psi) }\end{array}$ & $\begin{array}{l}\text { Average } \\
\text { Net } \\
\text { Strength } \\
\text { (psi) }\end{array}$ \\
\hline $\mathrm{P} 60-8 \mathrm{C}$ & 1.500 & 3.125 & 1500 & 4.851 & 6.945 & 25.727 & $\mathrm{D}$ & - & 985 & 90 & \multirow{3}{*}{83} & 104 & \multirow{3}{*}{96} \\
\hline$P 60-8 D$ & 1.500 & 3.125 & 1750 & 4.843 & 6.933 & 26.430 & $\mathrm{D}$ & - & 976 & 90 & & 104 & \\
\hline P60-8F & 1.500 & 3.125 & 2350 & 4.991 & 6.934 & 26.308 & $\mathrm{D}$ & - & 792 & 69 & & 79 & \\
\hline
\end{tabular}

\section{Table B- 67 P60-8 Abs Results}

\begin{tabular}{|c|c|c|c|c|c|c|c|c|c|c|c|c|c|}
\hline \multirow[b]{2}{*}{ Block ID } & \multicolumn{3}{|c|}{ Batch Properties } & \multicolumn{3}{|c|}{ Block Properties } & \multicolumn{7}{|c|}{ Absorption and Net Area Testing } \\
\hline & $\begin{array}{l}\text { Chamber } \\
\text { Volume } \\
\text { Setting } \\
\text { (in) }\end{array}$ & $\begin{array}{c}\text { Block } \\
\text { Height } \\
\text { Setting } \\
\text { (in) }\end{array}$ & $\begin{array}{c}\text { Piston } \\
\text { Pressure } \\
\text { (psi) }\end{array}$ & $\begin{array}{l}\text { Height } \\
\text { (in) }\end{array}$ & $\begin{array}{c}\text { Average } \\
\text { Width } \\
\text { (in) }\end{array}$ & $\begin{array}{c}\text { Weight } \\
\text { (lbs) }\end{array}$ & $\begin{array}{c}\text { Oven } \\
\text { Dry } \\
\text { Weight } \\
\text { (lbs) }\end{array}$ & $\begin{array}{c}\text { SSD } \\
\text { Weight } \\
\text { (lbs) }\end{array}$ & $\begin{array}{c}\text { Submerged } \\
\text { Weight } \\
\text { (lbs) }\end{array}$ & $\begin{array}{c}\text { Absorption } \\
(\%)\end{array}$ & $\begin{array}{l}\text { Density } \\
\left(\mathrm{lbs} / \mathrm{ft}^{3}\right)\end{array}$ & $\begin{array}{c}\text { Net Area } \\
\left(\text { in }^{3}\right)\end{array}$ & $\begin{array}{c}\text { Average } \\
\text { Net Area } \\
\left(\text { in }^{3}\right)\end{array}$ \\
\hline P60-8A & 1.500 & 3.125 & 1150 & 4.971 & 6.934 & 25.823 & 24.501 & 27.669 & 14.530 & 12.9 & 116.4 & 85.2 & 85.2 \\
\hline
\end{tabular}




\section{Batch ID: P66-8}

Description: Prado Standard Batch. 2:3 Ratio of Soil:Sand, 8\% Cement by weight

$\begin{array}{lrrr}\text { Date Cast: } & \text { I5-Mar-I4 } & \text { \# Blocks Cast } & \text { II } \\ \text { Time Cast: } & \text { I:00 PM } & \text { Fiber Type } & \text { - } \\ & & \\ \text { Calculated Mixture Clay Fraction (\%) } & 8.7 \\ \text { Calculated Mixture Sand Fraction (\%) } & 66.8 \\ \text { Calculated Mixture Cement Content (\%) } & 8.4 \\ \text { Measured Mixture Moisture Content (\%) } & 8.0 \\ \text { Calculated Mixture Moisture Content (\%) } & \text { I I.6 }\end{array}$

Table B- 68 P66-8 Mix Design

\begin{tabular}{|c|c|c|c|c|}
\hline Material & $\begin{array}{c}\text { Measured } \\
\text { Moisture } \\
\text { Content } \\
(\%)\end{array}$ & $\begin{array}{c}\text { Stock } \\
\text { Weight } \\
\text { (lbs) }\end{array}$ & $\begin{array}{c}\text { Oven } \\
\text { Dry } \\
\text { Weight } \\
\text { (lbs) }\end{array}$ & $\begin{array}{c}\text { Oven Dry } \\
\text { Weight } \\
\text { (lbs/I00 lbs) }\end{array}$ \\
\hline Soil & 6.6 & 108.0 & 100.9 & 28.0 \\
\hline Sand & 0.6 & 217.0 & 202.7 & 56.2 \\
\hline Cement & - & 28.0 & 28.0 & 7.8 \\
\hline Water & - & 22.3 & 43.7 & 8.0 \\
\hline Fibers & - & - & - & - \\
\hline Total & 8.0 & 375.3 & 375.3 & 100.0 \\
\hline
\end{tabular}

Table B- 69 P66-8 Compression Results

\begin{tabular}{|c|c|c|c|c|c|c|c|c|c|c|c|c|c|}
\hline \multirow[b]{2}{*}{ Block ID } & \multicolumn{3}{|c|}{ Batch Properties } & \multicolumn{3}{|c|}{ Block Properties } & \multicolumn{2}{|c|}{ Moisture Content } & \multicolumn{5}{|c|}{ Compression Testing } \\
\hline & $\begin{array}{l}\text { Chamber } \\
\text { Volume } \\
\text { Setting } \\
\text { (in) }\end{array}$ & $\begin{array}{l}\text { Block } \\
\text { Height } \\
\text { Setting } \\
\text { (in) }\end{array}$ & $\begin{array}{c}\text { Piston } \\
\text { Pressure } \\
\text { (psi) }\end{array}$ & $\begin{array}{c}\text { Height } \\
\text { (in) }\end{array}$ & $\begin{array}{c}\text { Average } \\
\text { Width } \\
\text { (in) }\end{array}$ & $\begin{array}{c}\text { Weight } \\
\text { (lbs) }\end{array}$ & $\begin{array}{c}\text { Cure } \\
\text { Method } \\
\text { (W/D) }\end{array}$ & $\begin{array}{c}\text { Testing } \\
(\%)\end{array}$ & $\begin{array}{c}\text { Max. } \\
\text { Force } \\
\text { (lbs) }\end{array}$ & $\begin{array}{c}\text { Gross } \\
\text { Strength } \\
\text { (psi) }\end{array}$ & $\begin{array}{c}\text { Average } \\
\text { Gross } \\
\text { Strength } \\
\text { (psi) }\end{array}$ & $\begin{array}{c}\text { Net } \\
\text { Strength } \\
\text { (psi) }\end{array}$ & $\begin{array}{c}\text { Average } \\
\text { Net } \\
\text { Strength } \\
\text { (psi) }\end{array}$ \\
\hline P66-8A & 1.500 & 3.000 & 1000 & 4.676 & 6.941 & 24.302 & $\mathrm{D}$ & 4.0 & 46658 & 480 & \multirow{5}{*}{559} & 622 & \multirow{5}{*}{724} \\
\hline P66-8D & 1.500 & 2.280 & 2350 & 4.417 & 6.950 & 24.918 & W & 6.1 & 69104 & 710 & & 921 & \\
\hline P66-8F & 1.500 & 3.000 & 1500 & 4.692 & 6.948 & 25.613 & W & - & 48698 & 501 & & 649 & \\
\hline P66-8I & 1.500 & 3.250 & 1800 & 4.808 & 6.933 & 25.331 & $\mathrm{D}$ & - & 59431 & 612 & & 792 & \\
\hline P66-8K & 1.500 & 3.250 & 1350 & 4.793 & 6.940 & 25.249 & $\mathrm{D}$ & - & 47738 & 491 & & 637 & \\
\hline
\end{tabular}


Table B- 70 P66-8 MOR Results

\begin{tabular}{|c|c|c|c|c|c|c|c|c|c|c|c|c|c|}
\hline \multirow[b]{2}{*}{ Block ID } & \multicolumn{3}{|c|}{ Batch Properties } & \multicolumn{3}{|c|}{ Block Properties } & \multicolumn{2}{|c|}{ Moisture Content } & \multicolumn{5}{|c|}{ Modulus of Rupture Testing } \\
\hline & $\begin{array}{l}\text { Chamber } \\
\text { Volume } \\
\text { Setting } \\
\text { (in) }\end{array}$ & $\begin{array}{l}\text { Block } \\
\text { Height } \\
\text { Setting } \\
\text { (in) }\end{array}$ & $\begin{array}{c}\text { Piston } \\
\text { Pressure } \\
\text { (psi) }\end{array}$ & $\begin{array}{l}\text { Height } \\
\text { (in) }\end{array}$ & $\begin{array}{l}\text { Average } \\
\text { Width } \\
\text { (in) }\end{array}$ & $\begin{array}{c}\text { Weight } \\
\text { (lbs) }\end{array}$ & $\begin{array}{c}\text { Cure } \\
\text { Method } \\
\text { (W/D) }\end{array}$ & $\begin{array}{c}\text { Testing } \\
(\%)\end{array}$ & $\begin{array}{l}\text { Max. } \\
\text { Force } \\
\text { (lbs) }\end{array}$ & $\begin{array}{c}\text { Gross } \\
\text { Strength } \\
(p s i)\end{array}$ & $\begin{array}{l}\text { Average } \\
\text { Gross } \\
\text { Strength } \\
\text { (psi) }\end{array}$ & $\begin{array}{c}\text { Net } \\
\text { Strength } \\
\text { (psi) }\end{array}$ & $\begin{array}{c}\text { Average } \\
\text { Net } \\
\text { Strength } \\
\text { (psi) }\end{array}$ \\
\hline P66-8C & 1.500 & 2.500 & 2350 & 4.303 & 6.944 & 23.993 & $\mathrm{D}$ & - & 872 & 102 & \multirow{4}{*}{68} & 119 & \multirow{4}{*}{79} \\
\hline P66-8E & 1.500 & 2.750 & 2350 & 4.634 & 6.952 & 25.821 & $\mathrm{~W}$ & - & 645 & 65 & & 75 & \\
\hline P66-8G & 1.500 & 3.000 & 2350 & 4.718 & 6.940 & 25.424 & $\mathrm{D}$ & - & 759 & 74 & & 85 & \\
\hline P66-8J & 1.500 & 3.250 & 950 & 4.778 & 6.933 & 24.507 & $\mathrm{D}$ & - & 329 & 31 & & 36 & \\
\hline
\end{tabular}

Table B- 71 P66-8 Abs Results

\begin{tabular}{|c|c|c|c|c|c|c|c|c|c|c|c|c|c|}
\hline \multirow[b]{2}{*}{ Block ID } & \multicolumn{3}{|c|}{ Batch Properties } & \multicolumn{3}{|c|}{ Block Properties } & \multicolumn{7}{|c|}{ Absorption and Net Area Testing } \\
\hline & $\begin{array}{c}\text { Chamber } \\
\text { Volume } \\
\text { Setting } \\
\text { (in) }\end{array}$ & $\begin{array}{c}\text { Block } \\
\text { Height } \\
\text { Setting } \\
\text { (in) }\end{array}$ & \begin{tabular}{|} 
Piston \\
Pressure \\
(psi)
\end{tabular} & $\begin{array}{l}\text { Height } \\
\text { (in) }\end{array}$ & $\begin{array}{c}\text { Average } \\
\text { Width } \\
\text { (in) }\end{array}$ & $\begin{array}{c}\text { Weight } \\
\text { (lbs) }\end{array}$ & $\begin{array}{c}\text { Oven } \\
\text { Dry } \\
\text { Weight } \\
\text { (lbs) }\end{array}$ & $\begin{array}{c}\text { SSD } \\
\text { Weight } \\
\text { (lbs) }\end{array}$ & $\begin{array}{c}\text { Submerged } \\
\text { Weight } \\
\text { (lbs) }\end{array}$ & $\begin{array}{c}\text { Absorption } \\
(\%)\end{array}$ & $\begin{array}{l}\text { Density } \\
\left(\mathrm{lbs} / \mathrm{ft}^{3}\right)\end{array}$ & $\begin{array}{c}\text { Net Area } \\
\left(\text { in }^{3}\right)\end{array}$ & $\begin{array}{c}\text { Average } \\
\text { Net Area } \\
\left(\text { in }^{3}\right)\end{array}$ \\
\hline P66-8B & 1.500 & 3.000 & 750 & 4.705 & 6.926 & 23.237 & 19.857 & 25.527 & 12.995 & 28.6 & 98.9 & 81.3 & 81.3 \\
\hline
\end{tabular}

Table B- 72 P66-8 Durability Results

\begin{tabular}{|c|c|c|c|c|c|}
\hline \multirow{7}{*}{ Block ID } & \multicolumn{3}{|c|}{ Durability Testing } \\
\cline { 2 - 7 } & Cycle & $\begin{array}{c}\text { Oven } \\
\text { Dry } \\
\text { Weight } \\
\text { (lbs) }\end{array}$ & $\begin{array}{c}\text { Mass } \\
\text { Loss Per } \\
\text { Cycle } \\
(\%)\end{array}$ & $\begin{array}{c}\text { Durability } \\
\text { Rating }\end{array}$ & Visual Observations \\
\hline \multirow{5}{*}{ P66-8B } & 0 & 23.237 & 0.0 & - & - \\
\cline { 2 - 7 } & 1 & 21.992 & 5.4 & 3 & Corner cracked. Portion of bottom missing. Pock marks \\
\cline { 2 - 7 } & 2 & 21.912 & 0.4 & 3 & Pock marks/popouts \\
\cline { 2 - 7 } & 3 & 21.594 & 1.5 & 3 & Roughening of top/edge \\
\cline { 2 - 7 } & 4 & 21.419 & 0.8 & 3 & Corner cracked. Face/edges degrading \\
\cline { 2 - 6 } & 5 & 20.983 & 2.0 & 4 & Corner fell off \\
\hline \multicolumn{2}{|c|}{ Total Mass Loss (\%) } & 10.0 & & \\
\hline
\end{tabular}




\section{Batch ID: P75-8}

Description: Prado 75\% Sand Content Batch. 1:4 Ratio of Soil:Sand, 8\% Cement by weight

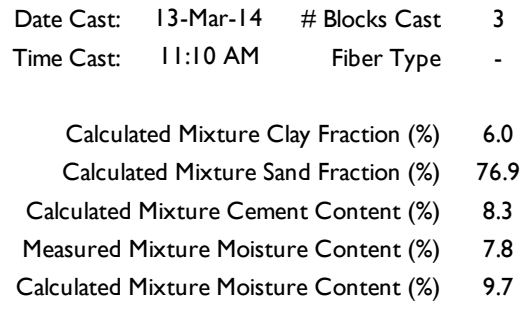

Table B- 73 P75-8 Mix Design

\begin{tabular}{|c|c|c|c|c|}
\hline Material & $\begin{array}{c}\text { Measured } \\
\text { Moisture } \\
\text { Content } \\
(\%)\end{array}$ & $\begin{array}{c}\text { Stock } \\
\text { Weight } \\
\text { (lbs) }\end{array}$ & $\begin{array}{c}\text { Oven } \\
\text { Dry } \\
\text { Weight } \\
\text { (lbs) }\end{array}$ & $\begin{array}{c}\text { Oven Dry } \\
\text { Weight } \\
\text { (lbs/I00 lbs) }\end{array}$ \\
\hline Soil & 4.9 & 26.2 & 25.0 & 19.5 \\
\hline Sand & 0.0 & 83.1 & 83.0 & 65.0 \\
\hline Cement & - & 9.7 & 9.7 & 7.6 \\
\hline Water & - & $1 \mathrm{I} .4$ & 12.7 & 7.8 \\
\hline Fibers & - & - & - & - \\
\hline Total & 7.8 & 130.4 & 130.4 & 100.0 \\
\hline
\end{tabular}

Table B- 74 P75-8 Compression Results

\begin{tabular}{|c|c|c|c|c|c|c|c|c|c|c|c|c|c|}
\hline \multirow[b]{2}{*}{ Block ID } & \multicolumn{3}{|c|}{ Batch Properties } & \multicolumn{3}{|c|}{ Block Properties } & \multicolumn{2}{|c|}{ Moisture Content } & \multicolumn{5}{|c|}{ Compression Testing } \\
\hline & $\begin{array}{l}\text { Chamber } \\
\text { Volume } \\
\text { Setting } \\
\text { (in) }\end{array}$ & $\begin{array}{c}\text { Block } \\
\text { Height } \\
\text { Setting } \\
\text { (in) }\end{array}$ & $\begin{array}{c}\text { Piston } \\
\text { Pressure } \\
\text { (psi) }\end{array}$ & $\begin{array}{c}\text { Height } \\
\text { (in) }\end{array}$ & $\begin{array}{c}\text { Average } \\
\text { Width } \\
\text { (in) }\end{array}$ & $\begin{array}{c}\text { Weight } \\
\text { (lbs) }\end{array}$ & $\begin{array}{c}\text { Cure } \\
\text { Method } \\
(\text { W/D) }\end{array}$ & $\begin{array}{c}\text { Testing } \\
(\%)\end{array}$ & $\begin{array}{l}\text { Max. } \\
\text { Force } \\
\text { (lbs) }\end{array}$ & $\begin{array}{c}\text { Gross } \\
\text { Strength } \\
\text { (psi) }\end{array}$ & $\begin{array}{c}\text { Average } \\
\text { Gross } \\
\text { Strength } \\
\text { (psi) }\end{array}$ & $\begin{array}{c}\text { Net } \\
\text { Strength } \\
\text { (psi) }\end{array}$ & $\begin{array}{l}\text { Average } \\
\text { Net } \\
\text { Strength } \\
\text { (psi) }\end{array}$ \\
\hline P75-8A & 1.625 & 2.375 & 2350 & 4.366 & 6.929 & 24.105 & $\mathrm{D}$ & - & 101000 & 1041 & \multirow{2}{*}{1174} & 1275 & \multirow{2}{*}{1439} \\
\hline P75-8B & 1.625 & 2.375 & 2350 & 4.456 & 6.946 & 24.224 & $\mathrm{D}$ & 4.5 & 127000 & 1306 & & 1604 & \\
\hline
\end{tabular}

Table B- 75 P75-8 Abs Results

\begin{tabular}{|c|c|c|c|c|c|c|c|c|c|c|c|c|c|}
\hline \multirow[b]{2}{*}{ Block ID } & \multicolumn{3}{|c|}{ Batch Properties } & \multicolumn{3}{|c|}{ Block Properties } & \multicolumn{7}{|c|}{ Absorption and Net Area Testing } \\
\hline & $\begin{array}{l}\text { Chamber } \\
\text { Volume } \\
\text { Setting } \\
\text { (in) }\end{array}$ & $\begin{array}{c}\text { Block } \\
\text { Height } \\
\text { Setting } \\
\text { (in) }\end{array}$ & $\begin{array}{c}\text { Piston } \\
\text { Pressure } \\
\text { (psi) }\end{array}$ & $\begin{array}{l}\text { Height } \\
\text { (in) }\end{array}$ & $\begin{array}{c}\text { Average } \\
\text { Width } \\
\text { (in) }\end{array}$ & $\begin{array}{c}\text { Weight } \\
\text { (lbs) }\end{array}$ & $\begin{array}{c}\text { Oven } \\
\text { Dry } \\
\text { Weight } \\
\text { (lbs) }\end{array}$ & $\begin{array}{c}\text { SSD } \\
\text { Weight } \\
\text { (lbs) }\end{array}$ & $\begin{array}{c}\text { Submerged } \\
\text { Weight } \\
\text { (lbs) }\end{array}$ & $\begin{array}{c}\text { Absorption } \\
\text { (\%) }\end{array}$ & $\begin{array}{l}\text { Density } \\
\left(\mathrm{lbs} / \mathrm{ft}^{3}\right)\end{array}$ & $\begin{array}{c}\text { Net Area } \\
\left(\text { in }^{3}\right)\end{array}$ & $\begin{array}{c}\text { Average } \\
\text { Net Area } \\
\left(\text { in }^{3}\right)\end{array}$ \\
\hline P75-8C & 1.625 & 2.375 & 2350 & 4.215 & 6.932 & 23.105 & 21.940 & 24.458 & 12.965 & 11.5 & 119.1 & 79.2 & 79.2 \\
\hline
\end{tabular}


Table B- 76 P75-8 Durability Results

\begin{tabular}{|c|c|c|c|c|c|}
\hline \multirow[b]{2}{*}{ Block ID } & \multicolumn{5}{|c|}{ Durability Testing } \\
\hline & Cycle & $\begin{array}{c}\text { Oven } \\
\text { Dry } \\
\text { Weight } \\
\text { (lbs) }\end{array}$ & $\begin{array}{c}\text { Mass } \\
\text { Loss Per } \\
\text { Cycle } \\
(\%)\end{array}$ & \begin{tabular}{|c|} 
Durability \\
Rating
\end{tabular} & Visual Observations \\
\hline \multirow{6}{*}{ P75-8C } & 0 & 23.105 & 0.0 & - & - \\
\hline & 1 & 21.940 & 5.0 & 1 & Excellent shape. No degradation \\
\hline & 2 & 21.893 & 0.2 & I & Pock marks. Otherwise intact \\
\hline & 3 & 21.895 & 0.0 & 2 & Larger pock marks \\
\hline & 4 & 21.882 & 0.1 & 2 & No significant change \\
\hline & 5 & 21.775 & 0.5 & 2 & Larger pock marks \\
\hline \multicolumn{3}{|c|}{ Total Mass Loss (\%) } & 5.8 & & \\
\hline
\end{tabular}




\section{Batch ID: P66-4}

Description: Prado 4\% Cement Content Batch. 2:3 Ratio of Soil:Sand, 4\% Cement by weight

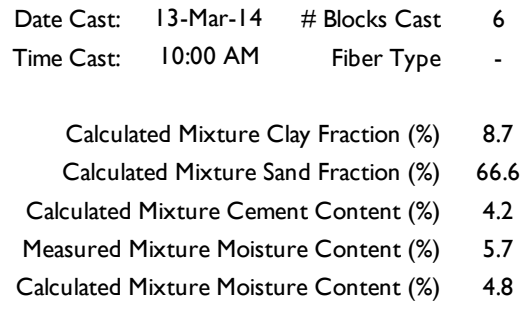

Table B- 77 P66-4 Mix Design

\begin{tabular}{|c|c|c|c|c|}
\hline Material & $\begin{array}{c}\text { Measured } \\
\text { Moisture } \\
\text { Content } \\
(\%)\end{array}$ & $\begin{array}{c}\text { Stock } \\
\text { Weight } \\
\text { (lbs) }\end{array}$ & $\begin{array}{c}\text { Oven } \\
\text { Dry } \\
\text { Weight } \\
\text { (lbs) }\end{array}$ & $\begin{array}{c}\text { Oven Dry } \\
\text { Weight } \\
\text { (lbs/100 lbs) }\end{array}$ \\
\hline Soil & 4.9 & 50.1 & 47.7 & 30.2 \\
\hline Sand & 0.0 & 95.2 & 95.2 & 60.2 \\
\hline Cement & - & 6.2 & 6.2 & 3.9 \\
\hline Water & - & 5.1 & 7.6 & 5.7 \\
\hline Fibers & - & - & - & - \\
\hline Total & 5.7 & 156.7 & 156.7 & 100.0 \\
\hline
\end{tabular}

Table B- 78 P66-4 Compression Results

\begin{tabular}{|c|c|c|c|c|c|c|c|c|c|c|c|c|c|}
\hline \multirow[b]{2}{*}{ Block ID } & \multicolumn{3}{|c|}{ Batch Properties } & \multicolumn{3}{|c|}{ Block Properties } & \multicolumn{2}{|c|}{ Moisture Content } & \multicolumn{5}{|c|}{ Compression Testing } \\
\hline & $\begin{array}{l}\text { Chamber } \\
\text { Volume } \\
\text { Setting } \\
\text { (in) }\end{array}$ & $\begin{array}{c}\text { Block } \\
\text { Height } \\
\text { Setting } \\
\text { (in) }\end{array}$ & $\begin{array}{c}\text { Piston } \\
\text { Pressure } \\
\text { (psi) }\end{array}$ & $\begin{array}{c}\text { Height } \\
\text { (in) }\end{array}$ & $\begin{array}{c}\text { Average } \\
\text { Width } \\
\text { (in) }\end{array}$ & $\begin{array}{c}\text { Weight } \\
\text { (lbs) }\end{array}$ & $\begin{array}{c}\text { Cure } \\
\text { Method } \\
\text { (W/D) }\end{array}$ & $\begin{array}{c}\text { Testing } \\
(\%)\end{array}$ & $\begin{array}{l}\text { Max. } \\
\text { Force } \\
\text { (lbs) }\end{array}$ & $\begin{array}{c}\text { Gross } \\
\text { Strength } \\
\text { (psi) }\end{array}$ & $\begin{array}{l}\text { Average } \\
\text { Gross } \\
\text { Strength } \\
\text { (psi) }\end{array}$ & $\begin{array}{c}\text { Net } \\
\text { Strength } \\
\text { (psi) }\end{array}$ & $\begin{array}{c}\text { Average } \\
\text { Net } \\
\text { Strength } \\
\text { (psi) }\end{array}$ \\
\hline P66-4A & 1.625 & 2.375 & 2350 & 4.784 & 6.939 & 24.913 & $\mathrm{D}$ & 3.5 & 46541 & 479 & \multirow{2}{*}{790} & 548 & \multirow{2}{*}{903} \\
\hline P66-4D & 1.625 & 2.750 & 2350 & 4.764 & 6.947 & 26.013 & $\mathrm{D}$ & - & 107000 & 1100 & & 1259 & \\
\hline
\end{tabular}

Table B- 79 P66-4 MOR Results

\begin{tabular}{|c|c|c|c|c|c|c|c|c|c|c|c|c|c|}
\hline & \multicolumn{3}{|c|}{ Batch Properties } & \multicolumn{3}{|c|}{ Block Properties } & \multicolumn{2}{|c|}{ Moisture Content } & \multicolumn{5}{|c|}{ Modulus of Rupture Testing } \\
\hline Block ID & $\begin{array}{l}\text { Chamber } \\
\text { Volume } \\
\text { Setting } \\
\text { (in) }\end{array}$ & $\begin{array}{c}\text { Block } \\
\text { Height } \\
\text { Setting } \\
\text { (in) }\end{array}$ & $\begin{array}{c}\text { Piston } \\
\text { Pressure } \\
\text { (psi) }\end{array}$ & $\begin{array}{l}\text { Height } \\
\text { (in) }\end{array}$ & $\begin{array}{c}\text { Average } \\
\text { Width } \\
\text { (in) }\end{array}$ & $\begin{array}{c}\text { Weight } \\
\text { (lbs) }\end{array}$ & $\begin{array}{c}\text { Cure } \\
\text { Method } \\
(\text { W/D) }\end{array}$ & $\begin{array}{c}\text { Testing } \\
(\%)\end{array}$ & $\begin{array}{l}\text { Max. } \\
\text { Force } \\
\text { (lbs) }\end{array}$ & $\begin{array}{c}\text { Gross } \\
\text { Strength } \\
(p s i)\end{array}$ & $\begin{array}{l}\text { Average } \\
\text { Gross } \\
\text { Strength } \\
\text { (psi) }\end{array}$ & $\begin{array}{c}\text { Net } \\
\text { Strength } \\
\text { (psi) }\end{array}$ & $\begin{array}{l}\text { Average } \\
\text { Net } \\
\text { Strength } \\
\text { (psi) }\end{array}$ \\
\hline $\mathrm{P} 66-4 \mathrm{C}$ & 1.625 & 2.625 & 2350 & 5.104 & 6.954 & 26.645 & $\mathrm{D}$ & - & 120 & 10 & 10 & II & II \\
\hline
\end{tabular}


Table B- 80 P66-4 Abs Results

\begin{tabular}{|c|c|c|c|c|c|c|c|c|c|c|c|c|c|}
\hline \multirow[b]{2}{*}{ Block ID } & \multicolumn{3}{|c|}{ Batch Properties } & \multicolumn{3}{|c|}{ Block Properties } & \multicolumn{7}{|c|}{ Absorption and Net Area Testing } \\
\hline & $\begin{array}{l}\text { Chamber } \\
\text { Volume } \\
\text { Setting } \\
\text { (in) }\end{array}$ & $\begin{array}{c}\text { Block } \\
\text { Height } \\
\text { Setting } \\
\text { (in) }\end{array}$ & $\begin{array}{c}\text { Piston } \\
\text { Pressure } \\
\text { (psi) }\end{array}$ & $\begin{array}{l}\text { Height } \\
\text { (in) }\end{array}$ & $\begin{array}{l}\text { Average } \\
\text { Width } \\
\text { (in) }\end{array}$ & $\begin{array}{c}\text { Weight } \\
\text { (lbs) }\end{array}$ & $\begin{array}{l}\text { Oven } \\
\text { Dry } \\
\text { Weight } \\
\text { (lbs) }\end{array}$ & $\begin{array}{c}\text { SSD } \\
\text { Weight } \\
\text { (lbs) }\end{array}$ & $\begin{array}{c}\text { Submerged } \\
\text { Weight } \\
\text { (lbs) }\end{array}$ & $\begin{array}{c}\text { Absorption } \\
(\%)\end{array}$ & $\begin{array}{l}\text { Density } \\
\left(\mathrm{lbs} / \mathrm{ft}^{3}\right)\end{array}$ & $\begin{array}{c}\text { Net Area } \\
\left(\text { in }^{3}\right)\end{array}$ & $\begin{array}{c}\text { Average } \\
\text { Net Area } \\
\left(\text { in }^{3}\right)\end{array}$ \\
\hline P66-4B & 1.625 & 2.500 & 2350 & 4.834 & 6.949 & 25.320 & 23.291 & 26.936 & 14.080 & 15.6 & 113.0 & 83.4 & 83.4 \\
\hline
\end{tabular}

Table B- 81 P66-4 Durability Results

\begin{tabular}{|c|c|c|c|c|c|}
\hline \multirow[b]{2}{*}{ Block ID } & \multicolumn{5}{|c|}{ Durability Testing } \\
\hline & Cycle & $\begin{array}{c}\text { Oven } \\
\text { Dry } \\
\text { Weight } \\
\text { (lbs) }\end{array}$ & $\begin{array}{c}\text { Mass } \\
\text { Loss Per } \\
\text { Cycle } \\
(\%)\end{array}$ & $\begin{array}{c}\text { Durability } \\
\text { Rating }\end{array}$ & Visual Observations \\
\hline \multirow{6}{*}{ P66-4B } & 0 & 25.320 & 0.0 & - & - \\
\hline & $\mathrm{I}$ & 23.291 & 8.0 & 4 & Significant degradation and some mass loss \\
\hline & 2 & 20.922 & 10.2 & - & Broke while soaking. Recorded mass of pieces \\
\hline & 3 & - & - & - & - \\
\hline & 4 & - & - & - & - \\
\hline & 5 & - & - & - & - \\
\hline \multicolumn{3}{|c|}{ Total Mass Loss (\%) } & 18.2 & & \\
\hline
\end{tabular}




\section{Batch ID: P66-12}

Description: Prado 12\% Cement Content Batch. 2:3 Ratio of Soil:Sand, 12\% Cement by weight

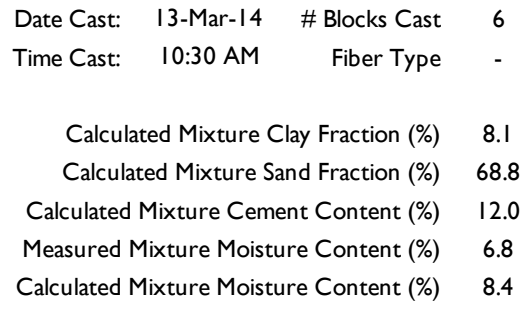

Table B- 82 P66-12 Mix Design

\begin{tabular}{|c|c|c|c|c|}
\hline Material & $\begin{array}{c}\text { Measured } \\
\text { Moisture } \\
\text { Content } \\
(\%)\end{array}$ & $\begin{array}{c}\text { Stock } \\
\text { Weight } \\
(\mathrm{lbs})\end{array}$ & $\begin{array}{c}\text { Oven } \\
\text { Dry } \\
\text { Weight } \\
\text { (lbs) }\end{array}$ & $\begin{array}{c}\text { Oven Dry } \\
\text { Weight } \\
\text { (lbs/I00 lbs) }\end{array}$ \\
\hline Soil & 4.9 & 49.9 & 47.4 & 25.6 \\
\hline Sand & 0.0 & 104.8 & 104.8 & 56.4 \\
\hline Cement & - & 20.8 & 20.8 & $1 \mathrm{I} .2$ \\
\hline Water & - & 13.5 & 15.9 & 6.8 \\
\hline Fibers & - & - & - & - \\
\hline Total & 6.8 & 188.9 & 188.9 & 100.0 \\
\hline
\end{tabular}

Table B- 83 P66-12 Compression Results

\begin{tabular}{|c|c|c|c|c|c|c|c|c|c|c|c|c|c|}
\hline \multirow[b]{2}{*}{ Block ID } & \multicolumn{3}{|c|}{ Batch Properties } & \multicolumn{3}{|c|}{ Block Properties } & \multicolumn{2}{|c|}{ Moisture Content } & \multicolumn{5}{|c|}{ Compression Testing } \\
\hline & $\begin{array}{l}\text { Chamber } \\
\text { Volume } \\
\text { Setting } \\
\text { (in) }\end{array}$ & $\begin{array}{c}\text { Block } \\
\text { Height } \\
\text { Setting } \\
\text { (in) }\end{array}$ & $\begin{array}{c}\text { Piston } \\
\text { Pressure } \\
\text { (psi) }\end{array}$ & $\begin{array}{l}\text { Height } \\
\text { (in) }\end{array}$ & $\begin{array}{c}\text { Average } \\
\text { Width } \\
\text { (in) }\end{array}$ & $\begin{array}{c}\text { Weight } \\
\text { (lbs) }\end{array}$ & $\begin{array}{c}\text { Cure } \\
\text { Method } \\
(\text { W/D) }\end{array}$ & $\begin{array}{c}\text { Testing } \\
(\%)\end{array}$ & $\begin{array}{l}\text { Max. } \\
\text { Force } \\
\text { (lbs) }\end{array}$ & $\begin{array}{c}\text { Gross } \\
\text { Strength } \\
\text { (psi) }\end{array}$ & $\begin{array}{l}\text { Average } \\
\text { Gross } \\
\text { Strength } \\
\text { (psi) }\end{array}$ & $\begin{array}{c}\text { Net } \\
\text { Strength } \\
\text { (psi) }\end{array}$ & $\begin{array}{l}\text { Average } \\
\text { Net } \\
\text { Strength } \\
\text { (psi) }\end{array}$ \\
\hline$P 66-12 B$ & 1.625 & 2.875 & 2100 & 4.834 & 38.251 & 25.320 & $\mathrm{D}$ & 4.7 & $4654 I$ & 479 & \multirow{2}{*}{790} & 548 & \multirow{2}{*}{903} \\
\hline P66-I2D & 1.625 & 3.000 & 1250 & 4.764 & 6.947 & 26.013 & $\mathrm{D}$ & - & 107000 & 1100 & & 1259 & \\
\hline
\end{tabular}


Table B- 84 P66-12 MOR Results

\begin{tabular}{|c|c|c|c|c|c|c|c|c|c|c|c|c|c|}
\hline \multirow[b]{2}{*}{ Block ID } & \multicolumn{3}{|c|}{ Batch Properties } & \multicolumn{3}{|c|}{ Block Properties } & \multicolumn{2}{|c|}{ Moisture Content } & \multicolumn{5}{|c|}{ Modulus of Rupture Testing } \\
\hline & $\begin{array}{l}\text { Chamber } \\
\text { Volume } \\
\text { Setting } \\
\text { (in) }\end{array}$ & $\begin{array}{l}\text { Block } \\
\text { Height } \\
\text { Setting } \\
\text { (in) }\end{array}$ & $\begin{array}{c}\text { Piston } \\
\text { Pressure } \\
\text { (psi) }\end{array}$ & $\begin{array}{l}\text { Height } \\
\text { (in) }\end{array}$ & $\begin{array}{c}\text { Average } \\
\text { Width } \\
\text { (in) }\end{array}$ & $\begin{array}{c}\text { Weight } \\
\text { (lbs) }\end{array}$ & $\begin{array}{c}\text { Cure } \\
\text { Method } \\
\text { (W/D) }\end{array}$ & $\begin{array}{c}\text { Testing } \\
(\%)\end{array}$ & $\begin{array}{l}\text { Max. } \\
\text { Force } \\
\text { (lbs) }\end{array}$ & $\begin{array}{c}\text { Gross } \\
\text { Strength } \\
(p s i)\end{array}$ & $\begin{array}{c}\text { Average } \\
\text { Gross } \\
\text { Strength } \\
\text { (psi) }\end{array}$ & $\begin{array}{c}\text { Net } \\
\text { Strength } \\
\text { (psi) }\end{array}$ & $\begin{array}{c}\text { Average } \\
\text { Net } \\
\text { Strength } \\
\text { (psi) }\end{array}$ \\
\hline P66-I2A & 1.625 & 2.875 & 2000 & 4.860 & 6.947 & 25.205 & $\mathrm{D}$ & - & 220 & 20 & \multirow{3}{*}{78} & 23 & \multirow{3}{*}{83} \\
\hline P66-I2E & 1.625 & 3.000 & 1450 & 4.639 & 6.944 & 25.699 & $\mathrm{D}$ & - & 1104 & 110 & & 129 & \\
\hline$P 66-12 F$ & 1.625 & 3.000 & 1350 & 4.667 & 6.938 & 25.752 & $\mathrm{D}$ & - & 1029 & 103 & & 118 & \\
\hline
\end{tabular}

Table B- 85 P66-12 Abs Results

\begin{tabular}{|c|c|c|c|c|c|c|c|c|c|c|c|c|c|}
\hline \multirow[b]{2}{*}{ Block ID } & \multicolumn{3}{|c|}{ Batch Properties } & \multicolumn{3}{|c|}{ Block Properties } & \multicolumn{7}{|c|}{ Absorption and Net Area Testing } \\
\hline & $\begin{array}{l}\text { Chamber } \\
\text { Volume } \\
\text { Setting } \\
\text { (in) }\end{array}$ & $\begin{array}{l}\text { Block } \\
\text { Height } \\
\text { Setting } \\
\text { (in) }\end{array}$ & $\begin{array}{c}\text { Piston } \\
\text { Pressure } \\
\text { (psi) }\end{array}$ & $\begin{array}{l}\text { Height } \\
\text { (in) }\end{array}$ & $\begin{array}{c}\text { Average } \\
\text { Width } \\
\text { (in) }\end{array}$ & $\begin{array}{c}\text { Weight } \\
\text { (lbs) }\end{array}$ & $\begin{array}{c}\text { Oven } \\
\text { Dry } \\
\text { Weight } \\
\text { (lbs) }\end{array}$ & $\begin{array}{c}\text { SSD } \\
\text { Weight } \\
\text { (lbs) }\end{array}$ & \begin{tabular}{|c} 
Submerged \\
Weight \\
(lbs)
\end{tabular} & $\begin{array}{c}\text { Absorption } \\
(\%)\end{array}$ & $\begin{array}{l}\text { Density } \\
\left(\mathrm{lbs} / \mathrm{ft}^{3}\right)\end{array}$ & $\begin{array}{c}\text { Net Area } \\
\left(\text { in }^{3}\right)\end{array}$ & $\begin{array}{c}\text { Average } \\
\text { Net Area } \\
\left(\mathrm{in}^{3}\right)\end{array}$ \\
\hline P66-12C & 1.625 & 2.500 & 2350 & 4.834 & 6.947 & 25.320 & 23.291 & 26.936 & 14.080 & 15.6 & 113.0 & 83.4 & 83.4 \\
\hline
\end{tabular}

Table B- 86 P66-12 Durability Results

\begin{tabular}{|c|c|c|c|c|c|}
\hline \multirow[b]{2}{*}{ Block ID } & \multicolumn{5}{|c|}{ Durability Testing } \\
\hline & Cycle & $\begin{array}{c}\text { Oven } \\
\text { Dry } \\
\text { Weight } \\
\text { (lbs) }\end{array}$ & $\begin{array}{c}\text { Mass } \\
\text { Loss Per } \\
\text { Cycle } \\
(\%)\end{array}$ & \begin{tabular}{|c|} 
Durability \\
Rating
\end{tabular} & Visual Observations \\
\hline \multirow{6}{*}{ P66-12C } & 0 & 25.32 & 0.0 & - & - \\
\hline & $\mathrm{I}$ & 24.267 & 4.2 & $\mathrm{I}$ & Excellent shape, little degradation \\
\hline & 2 & 24.248 & 0.1 & I & Surface pocking. No other change \\
\hline & 3 & 24.229 & 0.1 & $\mathrm{I}$ & No significant change \\
\hline & 4 & 24.216 & 0.1 & $\mathrm{I}$ & Worse surface pocking \\
\hline & 5 & 24.215 & 0.0 & $\mathrm{I}$ & No significant change \\
\hline \multicolumn{3}{|c|}{ Total Mass Loss (\%) } & 4.4 & & \\
\hline
\end{tabular}




\section{Batch ID: P60-FS2-8}

Description: Prado .02\% Strux Fiber Batch. 3:5 Ratio of Soil:Sand, 8\% Cement by weight

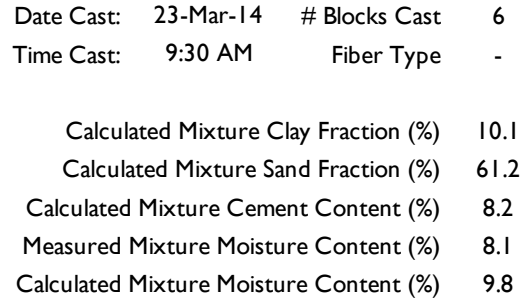

\section{Table B- 87 P60-FS2-8 Mix Design}

\begin{tabular}{|c|c|c|c|c|}
\hline Material & $\begin{array}{c}\text { Measured } \\
\text { Moisture } \\
\text { Content } \\
(\%)\end{array}$ & $\begin{array}{c}\text { Stock } \\
\text { Weight } \\
\text { (lbs) }\end{array}$ & $\begin{array}{c}\text { Oven } \\
\text { Dry } \\
\text { Weight } \\
\text { (lbs) }\end{array}$ & $\begin{array}{c}\text { Oven Dry } \\
\text { Weight } \\
\text { (lbs/I00 lbs) }\end{array}$ \\
\hline Soil & 4.9 & 76.1 & 72.4 & 32.7 \\
\hline Sand & 0.5 & $1 \mathrm{I} 4.9$ & $\mathrm{II} 4.3$ & $5 \mathrm{I} .7$ \\
\hline Cement & - & 16.6 & 16.6 & 7.5 \\
\hline Water & - & 17.8 & 22.0 & 8.1 \\
\hline Fibers & - & 0.2 & 0.2 & - \\
\hline Total & 8.1 & 225.3 & 225.3 & 100.0 \\
\hline
\end{tabular}

Table B- 88 P60-FS2-8 Compression Results

\begin{tabular}{|c|c|c|c|c|c|c|c|c|c|c|c|c|c|}
\hline \multirow[b]{2}{*}{ Block ID } & \multicolumn{3}{|c|}{ Batch Properties } & \multicolumn{3}{|c|}{ Block Properties } & \multicolumn{2}{|c|}{ Moisture Content } & \multicolumn{5}{|c|}{ Compression Testing } \\
\hline & $\begin{array}{c}\text { Chamber } \\
\text { Volume } \\
\text { Setting } \\
\text { (in) }\end{array}$ & $\begin{array}{l}\text { Block } \\
\text { Height } \\
\text { Setting } \\
\text { (in) }\end{array}$ & \begin{tabular}{|} 
Piston \\
Pressure \\
(psi)
\end{tabular} & $\begin{array}{l}\text { Height } \\
\text { (in) }\end{array}$ & $\begin{array}{c}\text { Average } \\
\text { Width } \\
\text { (in) }\end{array}$ & $\begin{array}{c}\text { Weight } \\
\text { (lbs) }\end{array}$ & $\begin{array}{l}\text { Cure } \\
\text { Method } \\
\text { (W/D) }\end{array}$ & $\begin{array}{c}\text { Testing } \\
(\%)\end{array}$ & $\begin{array}{l}\text { Max. } \\
\text { Force } \\
\text { (lbs) }\end{array}$ & $\begin{array}{c}\text { Gross } \\
\text { Strength } \\
\text { (psi) }\end{array}$ & $\begin{array}{c}\text { Average } \\
\text { Gross } \\
\text { Strength } \\
\text { (psi) }\end{array}$ & $\begin{array}{c}\text { Net } \\
\text { Strength } \\
\text { (psi) }\end{array}$ & $\begin{array}{c}\text { Average } \\
\text { Net } \\
\text { Strength } \\
\text { (psi) }\end{array}$ \\
\hline P60-FS2-8C & 1.500 & 3.250 & 1300 & 4.935 & 6.925 & 25.546 & $\mathrm{D}$ & - & 81183 & 837 & \multirow{2}{*}{831} & 888 & \multirow{2}{*}{881} \\
\hline P60-FS2-8E & 1.500 & 3.250 & 1500 & 4.964 & 6.924 & 25.985 & $\mathrm{D}$ & 5.2 & 79896 & 824 & & 874 & \\
\hline
\end{tabular}


Table B- 89 P60-FS2-8 MOR Results

\begin{tabular}{|c|c|c|c|c|c|c|c|c|c|c|c|c|c|}
\hline \multirow[b]{2}{*}{ Block ID } & \multicolumn{3}{|c|}{ Batch Properties } & \multicolumn{3}{|c|}{ Block Properties } & \multicolumn{2}{|c|}{ Moisture Content } & \multicolumn{5}{|c|}{ Modulus of Rupture Testing } \\
\hline & $\begin{array}{l}\text { Chamber } \\
\text { Volume } \\
\text { Setting } \\
\text { (in) }\end{array}$ & $\begin{array}{l}\text { Block } \\
\text { Height } \\
\text { Setting } \\
\text { (in) }\end{array}$ & $\begin{array}{c}\text { Piston } \\
\text { Pressure } \\
\text { (psi) }\end{array}$ & $\begin{array}{l}\text { Height } \\
\text { (in) }\end{array}$ & $\begin{array}{c}\text { Average } \\
\text { Width } \\
\text { (in) }\end{array}$ & $\begin{array}{c}\text { Weight } \\
\text { (lbs) }\end{array}$ & $\begin{array}{c}\text { Cure } \\
\text { Method } \\
(\mathrm{W} / \mathrm{D})\end{array}$ & $\begin{array}{c}\text { Testing } \\
(\%)\end{array}$ & $\begin{array}{l}\text { Max. } \\
\text { Force } \\
\text { (lbs) }\end{array}$ & $\begin{array}{c}\text { Gross } \\
\text { Strength } \\
(p s i)\end{array}$ & $\begin{array}{c}\text { Average } \\
\text { Gross } \\
\text { Strength } \\
\text { (psi) }\end{array}$ & $\begin{array}{c}\text { Net } \\
\text { Strength } \\
\text { (psi) }\end{array}$ & $\begin{array}{c}\text { Average } \\
\text { Net } \\
\text { Strength } \\
\text { (psi) }\end{array}$ \\
\hline P60-FS2-8B & 1.500 & 3.125 & 2350 & 4.979 & 6.927 & 26.229 & $\mathrm{D}$ & - & 1133 & 99 & \multirow{3}{*}{88} & 114 & \multirow{3}{*}{101} \\
\hline P60-FS2-8D & 1.500 & 3.250 & 2350 & 4.991 & 6.927 & 26.793 & $\mathrm{D}$ & - & 998 & 87 & & 100 & \\
\hline P60-FS2-8F & 1.500 & 3.250 & 2350 & 5.051 & 6.922 & 26.749 & $\mathrm{D}$ & - & 910 & 77 & & 89 & \\
\hline
\end{tabular}

Table B- 90 P60-FS2-8 Abs Results

\begin{tabular}{|c|c|c|c|c|c|c|c|c|c|c|c|c|c|}
\hline \multirow[b]{2}{*}{ Block ID } & \multicolumn{3}{|c|}{ Batch Properties } & \multicolumn{3}{|c|}{ Block Properties } & \multicolumn{7}{|c|}{ Absorption and Net Area Testing } \\
\hline & $\begin{array}{l}\text { Chamber } \\
\text { Volume } \\
\text { Setting } \\
\text { (in) }\end{array}$ & $\begin{array}{l}\text { Block } \\
\text { Height } \\
\text { Setting } \\
\text { (in) }\end{array}$ & $\begin{array}{c}\text { Piston } \\
\text { Pressure } \\
\text { (psi) }\end{array}$ & $\begin{array}{l}\text { Height } \\
\text { (in) }\end{array}$ & $\begin{array}{c}\text { Average } \\
\text { Width } \\
\text { (in) }\end{array}$ & $\begin{array}{c}\text { Weight } \\
\text { (lbs) }\end{array}$ & $\begin{array}{c}\text { Oven } \\
\text { Dry } \\
\text { Weight } \\
\text { (lbs) }\end{array}$ & $\begin{array}{c}\text { SSD } \\
\text { Weight } \\
\text { (lbs) }\end{array}$ & $\begin{array}{c}\text { Submerged } \\
\text { Weight } \\
\text { (lbs) }\end{array}$ & $\begin{array}{c}\text { Absorption } \\
(\%)\end{array}$ & $\begin{array}{l}\text { Density } \\
\left(\mathrm{lbs} / \mathrm{ft}^{3}\right)\end{array}$ & $\mid \begin{array}{c}\text { Net Area } \\
\left(\text { in }^{3}\right)\end{array}$ & $\begin{array}{c}\text { Average } \\
\text { Net Area } \\
\left(\text { in }^{3}\right)\end{array}$ \\
\hline P60-FS2-8A & 1.500 & 3.125 & 2350 & 4.961 & 6.928 & 25.927 & 25.821 & 29.091 & 15.552 & 12.7 & 119.0 & 91.4 & 91.4 \\
\hline
\end{tabular}




\section{Batch ID: P60-FS5-8}

Description: Prado .05\% Strux Fiber Batch. 3:5 Ratio of Soil:Sand, 8\% Cement by weight

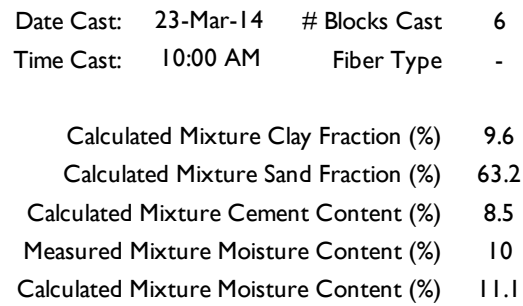

\section{Table B- 91 P60-FS5-8 Mix Design}

\begin{tabular}{|c|c|c|c|c|}
\hline Material & $\begin{array}{c}\text { Measured } \\
\text { Moisture } \\
\text { Content } \\
(\%)\end{array}$ & $\begin{array}{c}\text { Stock } \\
\text { Weight } \\
\text { (lbs) }\end{array}$ & $\begin{array}{c}\text { Oven } \\
\text { Dry } \\
\text { Weight } \\
\text { (lbs) }\end{array}$ & $\begin{array}{c}\text { Oven Dry } \\
\text { Weight } \\
\text { (lbs/I00 lbs) }\end{array}$ \\
\hline Soil & 4.9 & 62.1 & 59.1 & 30.3 \\
\hline Sand & 0.5 & 102.0 & 101.6 & 52.1 \\
\hline Cement & - & 14.9 & 14.9 & 7.6 \\
\hline Water & - & 18.3 & 21.8 & 10.0 \\
\hline Fibers & - & 0.449 & 0.449 & - \\
\hline Total & 10.0 & 197.4 & 197.4 & 100.0 \\
\hline
\end{tabular}

Table B- 92 P60-FS5-8 Compression Results

\begin{tabular}{|c|c|c|c|c|c|c|c|c|c|c|c|c|c|}
\hline \multirow[b]{2}{*}{ Block ID } & \multicolumn{3}{|c|}{ Batch Properties } & \multicolumn{3}{|c|}{ Block Properties } & \multicolumn{2}{|c|}{ Moisture Content } & \multicolumn{5}{|c|}{ Compression Testing } \\
\hline & $\begin{array}{c}\text { Chamber } \\
\text { Volume } \\
\text { Setting } \\
\text { (in) }\end{array}$ & $\begin{array}{l}\text { Block } \\
\text { Height } \\
\text { Setting } \\
\text { (in) }\end{array}$ & \begin{tabular}{|} 
Piston \\
Pressure \\
(psi)
\end{tabular} & $\begin{array}{l}\text { Height } \\
\text { (in) }\end{array}$ & $\begin{array}{c}\text { Average } \\
\text { Width } \\
\text { (in) }\end{array}$ & $\begin{array}{c}\text { Weight } \\
\text { (lbs) }\end{array}$ & $\begin{array}{l}\text { Cure } \\
\text { Method } \\
\text { (W/D) }\end{array}$ & $\begin{array}{c}\text { Testing } \\
(\%)\end{array}$ & $\begin{array}{l}\text { Max. } \\
\text { Force } \\
\text { (lbs) }\end{array}$ & $\begin{array}{c}\text { Gross } \\
\text { Strength } \\
\text { (psi) }\end{array}$ & $\begin{array}{c}\text { Average } \\
\text { Gross } \\
\text { Strength } \\
\text { (psi) }\end{array}$ & $\begin{array}{c}\text { Net } \\
\text { Strength } \\
\text { (psi) }\end{array}$ & $\begin{array}{c}\text { Average } \\
\text { Net } \\
\text { Strength } \\
\text { (psi) }\end{array}$ \\
\hline P60-FS5-8C & 1.500 & 2.875 & 950 & 4.645 & 6.928 & 22.562 & $\mathrm{D}$ & 5.9 & 85660 & 883 & \multirow{2}{*}{1224} & 949 & \multirow{2}{*}{1316} \\
\hline P60-FS5-8E & 1.500 & 2.875 & 2350 & 4.226 & 6.935 & 23.036 & $\mathrm{D}$ & - & 152000 & 1566 & & 1683 & \\
\hline
\end{tabular}


Table B- 93 P60-FS5-8 MOR Results

\begin{tabular}{|c|c|c|c|c|c|c|c|c|c|c|c|c|c|}
\hline \multirow[b]{2}{*}{ Block ID } & \multicolumn{3}{|c|}{ Batch Properties } & \multicolumn{3}{|c|}{ Block Properties } & \multicolumn{2}{|c|}{ Moisture Content } & \multicolumn{5}{|c|}{ Modulus of Rupture Testing } \\
\hline & $\begin{array}{l}\text { Chamber } \\
\text { Volume } \\
\text { Setting } \\
\text { (in) }\end{array}$ & $\begin{array}{l}\text { Block } \\
\text { Height } \\
\text { Setting } \\
\text { (in) }\end{array}$ & $\begin{array}{c}\text { Piston } \\
\text { Pressure } \\
\text { (psi) }\end{array}$ & $\begin{array}{l}\text { Height } \\
\text { (in) }\end{array}$ & $\begin{array}{c}\text { Average } \\
\text { Width } \\
\text { (in) }\end{array}$ & $\begin{array}{c}\text { Weight } \\
\text { (lbs) }\end{array}$ & $\begin{array}{c}\text { Cure } \\
\text { Method } \\
(\mathrm{W} / \mathrm{D})\end{array}$ & $\begin{array}{c}\text { Testing } \\
(\%)\end{array}$ & $\begin{array}{l}\text { Max. } \\
\text { Force } \\
\text { (lbs) }\end{array}$ & $\begin{array}{c}\text { Gross } \\
\text { Strength } \\
(p s i)\end{array}$ & $\begin{array}{c}\text { Average } \\
\text { Gross } \\
\text { Strength } \\
\text { (psi) }\end{array}$ & $\begin{array}{c}\text { Net } \\
\text { Strength } \\
\text { (psi) }\end{array}$ & $\begin{array}{c}\text { Average } \\
\text { Net } \\
\text { Strength } \\
\text { (psi) }\end{array}$ \\
\hline P60-FS2-8B & 1.500 & 3.250 & 550 & 4.979 & 6.921 & 22.040 & $\mathrm{D}$ & - & 275 & 24 & \multirow{3}{*}{59} & 28 & \multirow{3}{*}{69} \\
\hline P60-FS2-8D & 1.500 & 2.875 & 800 & 4.587 & 6.922 & 23.427 & $\mathrm{D}$ & - & 665 & 68 & & 79 & \\
\hline P60-FS2-8F & 1.500 & 2.50 & 800 & 4.346 & 6.931 & 22.608 & $\mathrm{D}$ & - & 738 & 85 & & 99 & \\
\hline
\end{tabular}

Table B- 94 P60-FS5-8 Abs Results

\begin{tabular}{|c|c|c|c|c|c|c|c|c|c|c|c|c|c|}
\hline \multirow[b]{2}{*}{ Block ID } & \multicolumn{3}{|c|}{ Batch Properties } & \multicolumn{3}{|c|}{ Block Properties } & \multicolumn{7}{|c|}{ Absorption and Net Area Testing } \\
\hline & $\begin{array}{l}\text { Chamber } \\
\text { Volume } \\
\text { Setting } \\
\text { (in) }\end{array}$ & $\begin{array}{l}\text { Block } \\
\text { Height } \\
\text { Setting } \\
\text { (in) }\end{array}$ & $\begin{array}{c}\text { Piston } \\
\text { Pressure } \\
\text { (psi) }\end{array}$ & $\begin{array}{l}\text { Height } \\
\text { (in) }\end{array}$ & $\begin{array}{c}\text { Average } \\
\text { Width } \\
\text { (in) }\end{array}$ & $\begin{array}{c}\text { Weight } \\
\text { (lbs) }\end{array}$ & $\begin{array}{c}\text { Oven } \\
\text { Dry } \\
\text { Weight } \\
\text { (lbs) }\end{array}$ & $\begin{array}{c}\text { SSD } \\
\text { Weight } \\
\text { (lbs) }\end{array}$ & $\begin{array}{c}\text { Submerged } \\
\text { Weight } \\
\text { (lbs) }\end{array}$ & $\begin{array}{c}\text { Absorption } \\
(\%)\end{array}$ & $\begin{array}{l}\text { Density } \\
\left(\mathrm{lbs} / \mathrm{ft}^{3}\right)\end{array}$ & $\mid \begin{array}{c}\text { Net Area } \\
\left(\text { in }^{3}\right)\end{array}$ & $\begin{array}{c}\text { Average } \\
\text { Net Area } \\
\left(\text { in }^{3}\right)\end{array}$ \\
\hline P60-FS5-8A & 1.500 & 3.250 & 500 & 4.961 & 6.928 & 25.927 & 22.197 & 25.614 & 12.515 & 15.4 & 105.7 & 90.3 & 90.3 \\
\hline
\end{tabular}




\section{B-3) Mind Body Batches}

\section{Batch ID: MB25-8}

Description: Mind Body 25\% Sand Content Batch. 4:1 Ratio of Soil:Sand, 8\% Cement by weight

$\begin{array}{cccc}\text { Date Cast: } & \text { 22-Mar-l4 } & \text { \# Blocks Cast } & 6 \\ \text { Time Cast: } & 9: 30 \mathrm{am} & \text { Fiber Type } & - \\ & & \\ \text { Calculated Mixture Clay Fraction (\%) } & 15.5 \\ \text { Calculated Mixture Sand Fraction (\%) } & - \\ \text { Calculated Mixture Cement Content (\%) } & 8.1 \\ \text { Measured Mixture Moisture Content (\%) } & 6.6 \\ \text { Calculated Mixture Moisture Content (\%) } & 8.6\end{array}$

Table B- 95 MB25-8 Mix Design

\begin{tabular}{|c|c|c|c|c|}
\hline Material & $\begin{array}{c}\text { Measured } \\
\text { Moisture } \\
\text { Content } \\
(\%)\end{array}$ & $\begin{array}{c}\text { Stock } \\
\text { Weight } \\
\text { (lbs) }\end{array}$ & $\begin{array}{c}\text { Oven } \\
\text { Dry } \\
\text { Weight } \\
\text { (lbs) }\end{array}$ & $\begin{array}{c}\text { Oven Dry } \\
\text { Weight } \\
\text { (lbs/I00 lbs) }\end{array}$ \\
\hline Soil & 3.9 & 162.3 & 155.9 & 64.1 \\
\hline Sand & 0.4 & 53.2 & 53.0 & 21.8 \\
\hline Cement & - & 18.3 & 18.3 & 7.5 \\
\hline Water & - & 14.7 & 21.3 & 6.6 \\
\hline Fibers & - & - & - & - \\
\hline Total & 6.6 & 248.5 & 248.5 & 100.0 \\
\hline
\end{tabular}

Table B- 96 MB25-8 Compression Results

\begin{tabular}{|c|c|c|c|c|c|c|c|c|c|c|c|c|c|}
\hline \multirow[b]{2}{*}{ Block ID } & \multicolumn{3}{|c|}{ Batch Properties } & \multicolumn{3}{|c|}{ Block Properties } & \multicolumn{2}{|c|}{ Moisture Content } & \multicolumn{5}{|c|}{ Compression Testing } \\
\hline & $\begin{array}{l}\text { Chamber } \\
\text { Volume } \\
\text { Setting } \\
\text { (in) }\end{array}$ & $\begin{array}{l}\text { Block } \\
\text { Height } \\
\text { Setting } \\
\text { (in) }\end{array}$ & $\begin{array}{c}\text { Piston } \\
\text { Pressure } \\
\text { (psi) }\end{array}$ & $\begin{array}{c}\text { Height } \\
\text { (in) }\end{array}$ & $\begin{array}{c}\text { Average } \\
\text { Width } \\
\text { (in) }\end{array}$ & $\begin{array}{c}\text { Weight } \\
\text { (lbs) }\end{array}$ & $\begin{array}{l}\text { Cure } \\
\text { Method } \\
\text { (W/D) }\end{array}$ & $\begin{array}{c}\text { Testing } \\
(\%)\end{array}$ & $\begin{array}{c}\text { Max. } \\
\text { Force } \\
\text { (lbs) }\end{array}$ & $\begin{array}{c}\text { Gross } \\
\text { Strength } \\
\text { (psi) }\end{array}$ & \begin{tabular}{|c|} 
Average \\
Gross \\
Strength \\
(psi)
\end{tabular} & $\begin{array}{c}\text { Net } \\
\text { Strength } \\
\text { (psi) }\end{array}$ & $\begin{array}{c}\text { Average } \\
\text { Net } \\
\text { Strength } \\
\text { (psi) }\end{array}$ \\
\hline MB25-8B & 2.125 & 2.375 & 1850 & 4.860 & 6.921 & 26.924 & $\mathrm{D}$ & 6.0 & 95125 & 982 & \multirow{2}{*}{886} & 1235 & \multirow{2}{*}{1115} \\
\hline MB25-8F & 1.500 & 2.875 & 1850 & 4.656 & 6.929 & 25.571 & $\mathrm{D}$ & - & 76578 & 789 & & 995 & \\
\hline
\end{tabular}


Table B- 97 MB25-8 MOR Results

\begin{tabular}{|c|c|c|c|c|c|c|c|c|c|c|c|c|c|}
\hline & \multicolumn{3}{|c|}{ Batch Properties } & \multicolumn{3}{|c|}{ Block Properties } & \multicolumn{2}{|c|}{ Moisture Content } & \multicolumn{5}{|c|}{ Modulus of Rupture Testing } \\
\hline Block ID & $\begin{array}{l}\text { Chamber } \\
\text { Volume } \\
\text { Setting } \\
\text { (in) }\end{array}$ & $\begin{array}{c}\text { Block } \\
\text { Height } \\
\text { Setting } \\
\text { (in) }\end{array}$ & $\begin{array}{c}\text { Piston } \\
\text { Pressure } \\
\text { (psi) }\end{array}$ & $\begin{array}{c}\text { Height } \\
\text { (in) }\end{array}$ & $\begin{array}{c}\text { Average } \\
\text { Width } \\
\text { (in) }\end{array}$ & $\begin{array}{c}\text { Weight } \\
\text { (lbs) }\end{array}$ & $\begin{array}{c}\text { Cure } \\
\text { Method } \\
(\mathrm{W} / \mathrm{D})\end{array}$ & $\begin{array}{c}\text { Testing } \\
(\%)\end{array}$ & $\begin{array}{l}\text { Max. } \\
\text { Force } \\
\text { (lbs) }\end{array}$ & $\begin{array}{c}\text { Gross } \\
\text { Strength } \\
\text { (psi) }\end{array}$ & \begin{tabular}{|c} 
Average \\
Gross \\
Strength \\
(psi)
\end{tabular} & $\begin{array}{c}\text { Net } \\
\text { Strength } \\
\text { (psi) }\end{array}$ & $\begin{array}{l}\text { Average } \\
\text { Net } \\
\text { Strength } \\
\text { (psi) }\end{array}$ \\
\hline MB25-8C & 2.125 & 2.375 & 2350 & 4.874 & 6.917 & 26.927 & $\mathrm{D}$ & - & 1030 & 94 & \multirow{3}{*}{102} & 108 & \multirow{3}{*}{118} \\
\hline MB25-8D & 1.500 & 2.375 & 2350 & 4.463 & 6.925 & 24.819 & $\mathrm{D}$ & - & 971 & 106 & & 123 & \\
\hline MB25-8E & 1.500 & 2.750 & 2350 & 4.554 & 6.917 & 25.303 & $\mathrm{D}$ & - & 1012 & 106 & & 123 & \\
\hline
\end{tabular}

Table B- 98 MB25-8 Abs Results

\begin{tabular}{|c|c|c|c|c|c|c|c|c|c|c|c|c|c|}
\hline \multirow[b]{2}{*}{ Block ID } & \multicolumn{3}{|c|}{ Batch Properties } & \multicolumn{3}{|c|}{ Block Properties } & \multicolumn{7}{|c|}{ Absorption and Net Area Testing } \\
\hline & $\begin{array}{l}\text { Chamber } \\
\text { Volume } \\
\text { Setting } \\
\text { (in) }\end{array}$ & $\begin{array}{c}\text { Block } \\
\text { Height } \\
\text { Setting } \\
\text { (in) }\end{array}$ & $\begin{array}{c}\text { Piston } \\
\text { Pressure } \\
\text { (psi) }\end{array}$ & $\begin{array}{c}\text { Height } \\
\text { (in) }\end{array}$ & $\begin{array}{c}\text { Average } \\
\text { Width } \\
\text { (in) }\end{array}$ & $\begin{array}{c}\text { Weight } \\
\text { (lbs) }\end{array}$ & $\begin{array}{c}\text { Oven } \\
\text { Dry } \\
\text { Weight } \\
\text { (lbs) }\end{array}$ & $\begin{array}{c}\text { SSD } \\
\text { Weight } \\
\text { (lbs) }\end{array}$ & $\begin{array}{c}\text { Submerged } \\
\text { Weight } \\
\text { (lbs) }\end{array}$ & $\begin{array}{c}\text { Absorption } \\
(\%)\end{array}$ & $\begin{array}{l}\text { Density } \\
\left(\mathrm{lbs} / \mathrm{ft}^{3}\right)\end{array}$ & $\mid \begin{array}{c}\text { Net Area } \\
\left(\text { in }^{3}\right)\end{array}$ & $\begin{array}{c}\text { Average } \\
\text { Net Area } \\
\left(\text { in }^{3}\right)\end{array}$ \\
\hline MB25-8G & 1.500 & 2.875 & 1250 & 4.634 & 6.919 & 25.356 & 23.551 & 24.585 & 12.715 & 4.4 & 123.8 & 77.0 & 77.0 \\
\hline
\end{tabular}




\section{Batch ID: MB40-8}

Description: Mind Body 40\% Sand Batch. 2:5 Ratio of Soil:Sand, $8 \%$ Cement by weight

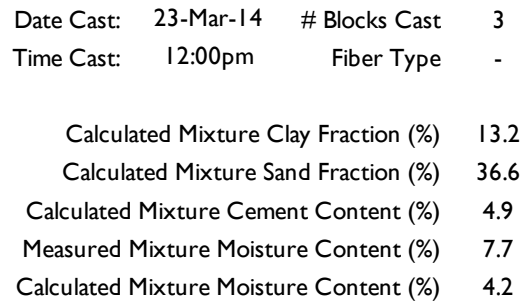

Table B- 99 MB40-8 Mix Design

\begin{tabular}{|c|c|c|c|c|}
\hline Material & $\begin{array}{c}\text { Measured } \\
\text { Moisture } \\
\text { Content } \\
(\%)\end{array}$ & $\begin{array}{c}\text { Stock } \\
\text { Weight } \\
\text { (lbs) }\end{array}$ & $\begin{array}{c}\text { Oven } \\
\text { Dry } \\
\text { Weight } \\
\text { (lbs) }\end{array}$ & $\begin{array}{c}\text { Oven Dry } \\
\text { Weight } \\
\text { (lbs/I00 lbs) }\end{array}$ \\
\hline Soil & 4.0 & 66.0 & 63.3 & 55.7 \\
\hline Sand & 0.5 & 36.7 & 36.6 & 32.1 \\
\hline Cement & - & 5.1 & 5.1 & 4.5 \\
\hline Water & - & 1.8 & 4.6 & 7.7 \\
\hline Fibers & - & - & - & - \\
\hline Total & 7.7 & 109.6 & 109.6 & 100.0 \\
\hline
\end{tabular}

Table B- 100 MB40-8 Compression Results

\begin{tabular}{|c|c|c|c|c|c|c|c|c|c|c|c|c|c|}
\hline \multirow[b]{2}{*}{ Block ID } & \multicolumn{3}{|c|}{ Batch Properties } & \multicolumn{3}{|c|}{ Block Properties } & \multicolumn{2}{|c|}{ Moisture Content } & \multicolumn{5}{|c|}{ Compression Testing } \\
\hline & $\begin{array}{l}\text { Chamber } \\
\text { Volume } \\
\text { Setting } \\
\text { (in) }\end{array}$ & $\begin{array}{l}\text { Block } \\
\text { Height } \\
\text { Setting } \\
\text { (in) }\end{array}$ & $\begin{array}{c}\text { Piston } \\
\text { Pressure } \\
\text { (psi) }\end{array}$ & $\begin{array}{l}\text { Height } \\
\text { (in) }\end{array}$ & $\begin{array}{c}\text { Average } \\
\text { Width } \\
\text { (in) }\end{array}$ & $\begin{array}{c}\text { Weight } \\
\text { (lbs) }\end{array}$ & $\begin{array}{c}\text { Cure } \\
\text { Method } \\
\text { (W/D) }\end{array}$ & $\begin{array}{c}\text { Testing } \\
(\%)\end{array}$ & $\begin{array}{l}\text { Max. } \\
\text { Force } \\
\text { (lbs) }\end{array}$ & $\begin{array}{c}\text { Gross } \\
\text { Strength } \\
\text { (psi) }\end{array}$ & $\begin{array}{l}\text { Average } \\
\text { Gross } \\
\text { Strength } \\
\text { (psi) }\end{array}$ & $\begin{array}{c}\text { Net } \\
\text { Strength } \\
\text { (psi) }\end{array}$ & $\begin{array}{c}\text { Average } \\
\text { Net } \\
\text { Strength } \\
\text { (psi) }\end{array}$ \\
\hline MB40-5A & 1.500 & 3.125 & 1150 & 4.954 & 6.934 & 24.949 & $\mathrm{D}$ & 6.4 & 37943 & 391 & \multirow{3}{*}{536} & 419 & \multirow{3}{*}{575} \\
\hline MB40-5B & 1.500 & 3.125 & 2350 & 4.965 & 6.932 & 27.190 & $\mathrm{D}$ & - & 66194 & 682 & & 731 & \\
\hline MB40-5C & 1.500 & 3.250 & 1200 & 4.976 & 6.932 & 26.275 & $\mathrm{D}$ & - & 43156 & 445 & & 476 & \\
\hline
\end{tabular}




\section{Batch ID: MB50-8}

Description: Mind Body Standard Batch. 1:1 Ratio of Soil:Sand, 8\% Cement by weight

\begin{tabular}{|c|c|c|}
\hline Date Cast: & 22-Mar-14 & \# Blocks Cast \\
\hline Time Cast: & 10:30am & Fiber Type \\
\hline \multicolumn{3}{|c|}{ Calculated Mixture Clay Fraction (\%) } \\
\hline \multicolumn{3}{|c|}{ Calculated Mixture Sand Fraction (\%) } \\
\hline \multicolumn{3}{|c|}{ Calculated Mixture Cement Content (\%) } \\
\hline \multicolumn{3}{|c|}{ Measured Mixture Moisture Content (\%) } \\
\hline \multicolumn{3}{|c|}{ Calculated Mixture Moisture Content (\%) } \\
\hline
\end{tabular}

Table B- 101 MB50-8 Mix Design

\begin{tabular}{|c|c|c|c|c|}
\hline Material & $\begin{array}{c}\text { Measured } \\
\text { Moisture } \\
\text { Content } \\
(\%)\end{array}$ & $\begin{array}{c}\text { Stock } \\
\text { Weight } \\
\text { (lbs) }\end{array}$ & $\begin{array}{c}\text { Oven } \\
\text { Dry } \\
\text { Weight } \\
\text { (lbs) }\end{array}$ & $\begin{array}{c}\text { Oven Dry } \\
\text { Weight } \\
\text { (lbs/I00 lbs) }\end{array}$ \\
\hline Soil & 3.9 & $\mathrm{I} 19.7$ & $\mathrm{I} \mathrm{I} 5.0$ & $4 \mathrm{I} . \mathrm{I}$ \\
\hline Sand & 0.4 & $\mathrm{I} 25.8$ & $\mathrm{I} 25.2$ & 44.7 \\
\hline Cement & - & $2 \mathrm{I} .8$ & $2 \mathrm{I} .8$ & 7.8 \\
\hline Water & - & $\mathrm{I} 6.5$ & $2 \mathrm{I} .8$ & 6.4 \\
\hline Fibers & - & - & - & - \\
\hline Total & 6.4 & 283.8 & 283.8 & 100.0 \\
\hline
\end{tabular}

Table B- 102 MB50-8 Compression Results

\begin{tabular}{|c|c|c|c|c|c|c|c|c|c|c|c|c|c|}
\hline \multirow[b]{2}{*}{ Block ID } & \multicolumn{3}{|c|}{ Batch Properties } & \multicolumn{3}{|c|}{ Block Properties } & \multicolumn{2}{|c|}{ Moisture Content } & \multicolumn{5}{|c|}{ Compression Testing } \\
\hline & $\begin{array}{l}\text { Chamber } \\
\text { Volume } \\
\text { Setting } \\
\text { (in) }\end{array}$ & $\begin{array}{l}\text { Block } \\
\text { Height } \\
\text { Setting } \\
\text { (in) }\end{array}$ & $\begin{array}{c}\text { Piston } \\
\text { Pressure } \\
\text { (psi) }\end{array}$ & $\begin{array}{c}\text { Height } \\
\text { (in) }\end{array}$ & $\begin{array}{c}\text { Average } \\
\text { Width } \\
\text { (in) }\end{array}$ & $\begin{array}{c}\text { Weight } \\
\text { (lbs) }\end{array}$ & $\begin{array}{c}\text { Cure } \\
\text { Method } \\
(\mathrm{W} / \mathrm{D})\end{array}$ & $\begin{array}{c}\text { Testing } \\
(\%)\end{array}$ & $\begin{array}{l}\text { Max. } \\
\text { Force } \\
\text { (lbs) }\end{array}$ & $\begin{array}{c}\text { Gross } \\
\text { Strength } \\
\text { (psi) }\end{array}$ & $\begin{array}{c}\text { Average } \\
\text { Gross } \\
\text { Strength } \\
\text { (psi) }\end{array}$ & $\begin{array}{c}\text { Net } \\
\text { Strength } \\
\text { (psi) }\end{array}$ & $\begin{array}{c}\text { Average } \\
\text { Net } \\
\text { Strength } \\
\text { (psi) }\end{array}$ \\
\hline MB50-8B & 1.625 & 2.875 & 1000 & 4.669 & 6.924 & 24.563 & $\mathrm{D}$ & 4.3 & 62060 & 640 & \multirow{5}{*}{622} & 843 & \multirow{5}{*}{819} \\
\hline MB50-8D & 1.750 & 2.875 & 1300 & 4.692 & 6.939 & 25.516 & W & 7.3 & 44312 & 456 & & 602 & \\
\hline MB50-8F & 1.750 & 2.875 & 1350 & 4.664 & 6.928 & 25.102 & $\mathrm{D}$ & - & 75219 & 776 & & 1022 & \\
\hline MB50-8G & 1.750 & 2.875 & 1250 & 4.654 & 6.933 & 25.380 & W & - & 46290 & 477 & & 629 & \\
\hline MB50-8I & 1.750 & 2.875 & 1350 & 4.627 & 6.924 & 25.056 & D & - & 73587 & 759 & & 1000 & \\
\hline
\end{tabular}


Table B- 103 MB 50-8 MOR Results

\begin{tabular}{|c|c|c|c|c|c|c|c|c|c|c|c|c|c|}
\hline & \multicolumn{3}{|c|}{ Batch Properties } & \multicolumn{3}{|c|}{ Block Properties } & \multicolumn{2}{|c|}{ Moisture Content } & \multicolumn{5}{|c|}{ Modulus of Rupture Testing } \\
\hline Block ID & $\begin{array}{l}\text { Chamber } \\
\text { Volume } \\
\text { Setting } \\
\text { (in) }\end{array}$ & $\begin{array}{c}\text { Block } \\
\text { Height } \\
\text { Setting } \\
\text { (in) }\end{array}$ & $\begin{array}{c}\text { Piston } \\
\text { Pressure } \\
\text { (psi) }\end{array}$ & $\begin{array}{c}\text { Height } \\
\text { (in) }\end{array}$ & $\begin{array}{c}\text { Average } \\
\text { Width } \\
\text { (in) }\end{array}$ & $\begin{array}{c}\text { Weight } \\
\text { (lbs) }\end{array}$ & $\begin{array}{c}\text { Cure } \\
\text { Method } \\
\text { (W/D) }\end{array}$ & $\begin{array}{c}\text { Testing } \\
(\%)\end{array}$ & $\begin{array}{l}\text { Max. } \\
\text { Force } \\
\text { (lbs) }\end{array}$ & $\begin{array}{c}\text { Gross } \\
\text { Strength } \\
\text { (psi) }\end{array}$ & \begin{tabular}{|c} 
Average \\
Gross \\
Strength \\
(psi)
\end{tabular} & $\begin{array}{c}\text { Net } \\
\text { Strength } \\
\text { (psi) }\end{array}$ & $\begin{array}{l}\text { Average } \\
\text { Net } \\
\text { Strength } \\
\text { (psi) }\end{array}$ \\
\hline MB50-8C & 1.750 & 2.875 & 1100 & 4.611 & 6.923 & 24.700 & $\mathrm{D}$ & - & 767 & 78 & \multirow{3}{*}{76} & 91 & \multirow{3}{*}{88} \\
\hline MB50-8E & 1.750 & 2.875 & 1250 & 4.685 & 6.926 & 24.995 & $\mathrm{D}$ & - & 770 & 76 & & 88 & \\
\hline MB50-8H & 1.750 & 2.875 & 2350 & 4.698 & 6.936 & 25.953 & W & - & 742 & 73 & & 84 & \\
\hline
\end{tabular}

Table B- 104 MB50-8 Abs Results

\begin{tabular}{|c|c|c|c|c|c|c|c|c|c|c|c|c|c|}
\hline \multirow[b]{2}{*}{ Block ID } & \multicolumn{3}{|c|}{ Batch Properties } & \multicolumn{3}{|c|}{ Block Properties } & \multicolumn{7}{|c|}{ Absorption and Net Area Testing } \\
\hline & $\begin{array}{l}\text { Chamber } \\
\text { Volume } \\
\text { Setting } \\
\text { (in) }\end{array}$ & $\begin{array}{c}\text { Block } \\
\text { Height } \\
\text { Setting } \\
\text { (in) }\end{array}$ & $\begin{array}{c}\text { Piston } \\
\text { Pressure } \\
\text { (psi) }\end{array}$ & $\begin{array}{c}\text { Height } \\
\text { (in) }\end{array}$ & $\begin{array}{c}\text { Average } \\
\text { Width } \\
\text { (in) }\end{array}$ & $\begin{array}{c}\text { Weight } \\
\text { (lbs) }\end{array}$ & $\begin{array}{c}\text { Oven } \\
\text { Dry } \\
\text { Weight } \\
\text { (lbs) }\end{array}$ & $\begin{array}{c}\text { SSD } \\
\text { Weight } \\
\text { (lbs) }\end{array}$ & $\begin{array}{c}\text { Submerged } \\
\text { Weight } \\
\text { (lbs) }\end{array}$ & $\begin{array}{c}\text { Absorption } \\
(\%)\end{array}$ & $\begin{array}{l}\text { Density } \\
\left(\mathrm{lbs} / \mathrm{ft}^{3}\right)\end{array}$ & $\mid \begin{array}{c}\text { Net Area } \\
\left(\text { in }^{3}\right)\end{array}$ & $\begin{array}{c}\text { Average } \\
\text { Net Area } \\
\left(\text { in }^{3}\right)\end{array}$ \\
\hline MB50-8A & 1.500 & 2.875 & 750 & 4.672 & 6.931 & 24.163 & 21.460 & 21.984 & 11.080 & 2.4 & 122.8 & 73.6 & 73.6 \\
\hline
\end{tabular}

Table B- 105 MB50-8 Durability Results

\begin{tabular}{|c|c|c|c|c|c|}
\hline \multirow[b]{2}{*}{ Block ID } & \multicolumn{5}{|c|}{ Durability Testing } \\
\hline & Cycle & $\begin{array}{c}\text { Oven } \\
\text { Dry } \\
\text { Weight } \\
\text { (lbs) }\end{array}$ & $\begin{array}{l}\text { Mass } \\
\text { Loss Per } \\
\text { Cycle } \\
(\%)\end{array}$ & $\begin{array}{c}\text { Durability } \\
\text { Rating }\end{array}$ & Visual Observations \\
\hline \multirow{6}{*}{ MB50-8A } & 0 & 24.163 & 0.0 & - & - \\
\hline & $\mathrm{I}$ & 21.385 & 11.5 & 2 & Significant loss on bottom and faces \\
\hline & 2 & 20.985 & 1.9 & 3 & No significant change \\
\hline & 3 & 20.812 & 0.8 & 3 & No significant change \\
\hline & 4 & 20.715 & 0.5 & 3 & Surface degradation \\
\hline & 5 & 19.519 & 5.8 & 4 & Portion of each face fell off \\
\hline \multicolumn{3}{|c|}{ Total Mass Loss (\%) } & 20.4 & & \\
\hline
\end{tabular}




\section{Batch ID: MB50-4}

Description: Mind Body 4\% Cement Content Batch. 1:1 Ratio of Soil:Sand, 4\% Cement by weight

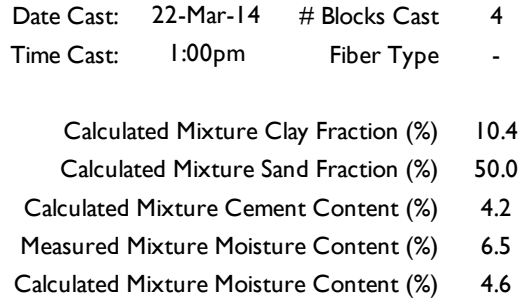

Table B- 106 MB50-4 Mix Design

\begin{tabular}{|c|c|c|c|c|}
\hline Material & $\begin{array}{c}\text { Measured } \\
\text { Moisture } \\
\text { Content } \\
(\%)\end{array}$ & $\begin{array}{c}\text { Stock } \\
\text { Weight } \\
(\mathrm{lbs})\end{array}$ & $\begin{array}{c}\text { Oven } \\
\text { Dry } \\
\text { Weight } \\
\text { (lbs) }\end{array}$ & $\begin{array}{c}\text { Oven Dry } \\
\text { Weight } \\
\text { (lbs/I00 lbs) }\end{array}$ \\
\hline Soil & 3.6 & 88.3 & 85.1 & 44.8 \\
\hline Sand & 0.8 & 85.8 & 85.1 & 44.8 \\
\hline Cement & - & 7.4 & 7.4 & 3.9 \\
\hline Water & - & 4.7 & 8.6 & 6.5 \\
\hline Fibers & - & - & - & - \\
\hline Total & 6.5 & 186.2 & 186.2 & 100.0 \\
\hline
\end{tabular}

Table B- 107 MB50-4 Compression Results

\begin{tabular}{|c|c|c|c|c|c|c|c|c|c|c|c|c|c|}
\hline \multirow[b]{2}{*}{ Block ID } & \multicolumn{3}{|c|}{ Batch Properties } & \multicolumn{3}{|c|}{ Block Properties } & \multicolumn{2}{|c|}{ Moisture Content } & \multicolumn{5}{|c|}{ Compression Testing } \\
\hline & $\begin{array}{l}\text { Chamber } \\
\text { Volume } \\
\text { Setting } \\
\text { (in) }\end{array}$ & $\begin{array}{c}\text { Block } \\
\text { Height } \\
\text { Setting } \\
\text { (in) }\end{array}$ & $\begin{array}{c}\text { Piston } \\
\text { Pressure } \\
\text { (psi) }\end{array}$ & $\begin{array}{c}\text { Height } \\
\text { (in) }\end{array}$ & $\begin{array}{c}\text { Average } \\
\text { Width } \\
\text { (in) }\end{array}$ & $\begin{array}{c}\text { Weight } \\
\text { (lbs) }\end{array}$ & $\begin{array}{c}\text { Cure } \\
\text { Method } \\
(\mathrm{W} / \mathrm{D})\end{array}$ & $\begin{array}{c}\text { Testing } \\
(\%)\end{array}$ & $\begin{array}{l}\text { Max. } \\
\text { Force } \\
\text { (lbs) }\end{array}$ & $\begin{array}{c}\text { Gross } \\
\text { Strength } \\
\text { (psi) }\end{array}$ & $\begin{array}{l}\text { Average } \\
\text { Gross } \\
\text { Strength } \\
\text { (psi) }\end{array}$ & $\begin{array}{c}\text { Net } \\
\text { Strength } \\
\text { (psi) }\end{array}$ & $\begin{array}{c}\text { Average } \\
\text { Net } \\
\text { Strength } \\
\text { (psi) }\end{array}$ \\
\hline MB50-4A & 1.500 & 3.000 & 2350 & 4.988 & 6.932 & 25.983 & $\mathrm{D}$ & 3.3 & 37656 & 388 & \multirow{2}{*}{408} & 445 & \multirow{2}{*}{467} \\
\hline MB50-4B & 1.500 & 3.000 & 2350 & 5.132 & 6.933 & 27.137 & $\mathrm{D}$ & - & 41527 & 428 & & 490 & \\
\hline
\end{tabular}


Table B- 108 MB50-4 MOR Results

\begin{tabular}{|c|c|c|c|c|c|c|c|c|c|c|c|c|c|}
\hline \multirow[b]{2}{*}{ Block ID } & \multicolumn{3}{|c|}{ Batch Properties } & \multicolumn{3}{|c|}{ Block Properties } & \multicolumn{2}{|c|}{ Moisture Content } & \multicolumn{5}{|c|}{ Modulus of Rupture Testing } \\
\hline & \begin{tabular}{|c|} 
Chamber \\
Volume \\
Setting \\
(in)
\end{tabular} & $\begin{array}{l}\text { Block } \\
\text { Height } \\
\text { Setting } \\
\text { (in) }\end{array}$ & $\begin{array}{c}\text { Piston } \\
\text { Pressure } \\
\text { (psi) }\end{array}$ & $\begin{array}{l}\text { Height } \\
\text { (in) }\end{array}$ & $\begin{array}{c}\text { Average } \\
\text { Width } \\
\text { (in) }\end{array}$ & $\begin{array}{c}\text { Weight } \\
\text { (lbs) }\end{array}$ & $\begin{array}{c}\text { Cure } \\
\text { Method } \\
\text { (W/D) }\end{array}$ & $\begin{array}{c}\text { Testing } \\
\text { (\%) }\end{array}$ & $\begin{array}{l}\text { Max. } \\
\text { Force } \\
\text { (lbs) }\end{array}$ & $\begin{array}{c}\text { Gross } \\
\text { Strength } \\
\text { (psi) }\end{array}$ & $\begin{array}{l}\text { Average } \\
\text { Gross } \\
\text { Strength } \\
\text { (psi) }\end{array}$ & $\begin{array}{c}\text { Net } \\
\text { Strength } \\
\text { (psi) }\end{array}$ & $\begin{array}{l}\text { Average } \\
\text { Net } \\
\text { Strength } \\
\text { (psi) }\end{array}$ \\
\hline MB50-4C & 1.500 & 3.250 & 2350 & 5.114 & 6.928 & 27.184 & $D$ & - & 378 & 31 & & 36 & \multirow{2}{*}{34} \\
\hline MB50-4D & 1.500 & 3.375 & 2350 & 5.272 & 6.933 & 28.461 & D & - & 359 & 28 & & 32 & \\
\hline
\end{tabular}




\section{Batch ID: MB50-12}

Description: Mind Body 12\% Cement Content Batch. 1:1 Ratio of Soil:Sand, 12\%

Cement by weight

$\begin{array}{lcrc}\text { Date Cast: } & 22-\text { Mar-l4 } & \text { \# Blocks Cast } & 7 \\ \text { Time Cast: } & \text { I:30pm } & \text { Fiber Type } & - \\ & & \\ \text { Calculated Mixture Clay Fraction (\%) } & 10.1 \\ \text { Calculated Mixture Sand Fraction (\%) } & 51.4 \\ \text { Calculated Mixture Cement Content (\%) } & 12.6 \\ \text { Measured Mixture Moisture Content (\%) } & 9.1 \\ \text { Calculated Mixture Moisture Content (\%) } & 10.6\end{array}$

Table B- 109 MB50-12 Mix Design

\begin{tabular}{|c|c|c|c|c|}
\hline Material & $\begin{array}{c}\text { Measured } \\
\text { Moisture } \\
\text { Content } \\
(\%)\end{array}$ & $\begin{array}{c}\text { Stock } \\
\text { Weight } \\
\text { (lbs) }\end{array}$ & $\begin{array}{c}\text { Oven } \\
\text { Dry } \\
\text { Weight } \\
\text { (lbs) }\end{array}$ & $\begin{array}{c}\text { Oven Dry } \\
\text { Weight } \\
\text { (lbs/ I00 lbs) }\end{array}$ \\
\hline Soil & 3.6 & 86.7 & 83.6 & 38.6 \\
\hline Sand & 0.8 & 89.2 & 88.5 & 40.9 \\
\hline Cement & - & 24.8 & 24.8 & $1 \mathrm{I} .5$ \\
\hline Water & - & 19.5 & 23.3 & 9.1 \\
\hline Fibers & - & - & - & - \\
\hline Total & 9.1 & 220.2 & 220.2 & 100.0 \\
\hline
\end{tabular}

Table B- 110 MB50-12 Compression Results

\begin{tabular}{|c|c|c|c|c|c|c|c|c|c|c|c|c|c|}
\hline \multirow[b]{2}{*}{ Block ID } & \multicolumn{3}{|c|}{ Batch Properties } & \multicolumn{3}{|c|}{ Block Properties } & \multicolumn{2}{|c|}{ Moisture Content } & \multicolumn{5}{|c|}{ Compression Testing } \\
\hline & $\begin{array}{c}\text { Chamber } \\
\text { Volume } \\
\text { Setting } \\
\text { (in) }\end{array}$ & $\begin{array}{c}\text { Block } \\
\text { Height } \\
\text { Setting } \\
\text { (in) }\end{array}$ & $\begin{array}{c}\text { Piston } \\
\text { Pressure } \\
\text { (psi) }\end{array}$ & $\begin{array}{c}\text { Height } \\
\text { (in) }\end{array}$ & $\begin{array}{c}\text { Average } \\
\text { Width } \\
\text { (in) }\end{array}$ & $\begin{array}{c}\text { Weight } \\
\text { (lbs) }\end{array}$ & $\begin{array}{c}\text { Cure } \\
\text { Method } \\
(\text { W/D) }\end{array}$ & $\begin{array}{c}\text { Testing } \\
(\%)\end{array}$ & $\begin{array}{l}\text { Max. } \\
\text { Force } \\
\text { (lbs) }\end{array}$ & $\begin{array}{c}\text { Gross } \\
\text { Strength } \\
\text { (psi) }\end{array}$ & $\begin{array}{l}\text { Average } \\
\text { Gross } \\
\text { Strength } \\
\text { (psi) }\end{array}$ & $\begin{array}{c}\text { Net } \\
\text { Strength } \\
\text { (psi) }\end{array}$ & $\begin{array}{c}\text { Average } \\
\text { Net } \\
\text { Strength } \\
\text { (psi) }\end{array}$ \\
\hline MB50-12C & 1.500 & 3.125 & 1000 & 4.839 & 6.923 & 26.253 & $\mathrm{D}$ & - & 110000 & 1135 & \multirow{3}{*}{1166} & 1299 & \multirow{3}{*}{1334} \\
\hline MB50-I2E & 1.500 & 3.00 & 1200 & 4.759 & 6.921 & 25.979 & $\mathrm{D}$ & - & 116000 & 1197 & & 1370 & \\
\hline MB50-I2G & 1.500 & 3.00 & 1350 & 4.775 & 6.930 & 26.511 & $\mathrm{D}$ & 4.5 & 125000 & 1288 & & 1476 & \\
\hline
\end{tabular}


Table B- 111 MB50-12 MOR Results

\begin{tabular}{|c|c|c|c|c|c|c|c|c|c|c|c|c|c|}
\hline \multirow[b]{2}{*}{ Block ID } & \multicolumn{3}{|c|}{ Batch Properties } & \multicolumn{3}{|c|}{ Block Properties } & \multicolumn{2}{|c|}{ Moisture Content } & \multicolumn{5}{|c|}{ Modulus of Rupture Testing } \\
\hline & $\begin{array}{l}\text { Chamber } \\
\text { Volume } \\
\text { Setting } \\
\text { (in) }\end{array}$ & $\begin{array}{l}\text { Block } \\
\text { Height } \\
\text { Setting } \\
\text { (in) }\end{array}$ & $\begin{array}{c}\text { Piston } \\
\text { Pressure } \\
\text { (psi) }\end{array}$ & $\begin{array}{l}\text { Height } \\
\text { (in) }\end{array}$ & $\begin{array}{c}\text { Average } \\
\text { Width } \\
\text { (in) }\end{array}$ & $\begin{array}{c}\text { Weight } \\
\text { (lbs) }\end{array}$ & $\begin{array}{c}\text { Cure } \\
\text { Method } \\
(\mathrm{W} / \mathrm{D})\end{array}$ & $\begin{array}{c}\text { Testing } \\
(\%)\end{array}$ & $\begin{array}{l}\text { Max. } \\
\text { Force } \\
\text { (lbs) }\end{array}$ & $\begin{array}{c}\text { Gross } \\
\text { Strength } \\
(p s i)\end{array}$ & $\begin{array}{c}\text { Average } \\
\text { Gross } \\
\text { Strength } \\
\text { (psi) }\end{array}$ & $\begin{array}{c}\text { Net } \\
\text { Strength } \\
\text { (psi) }\end{array}$ & $\begin{array}{c}\text { Average } \\
\text { Net } \\
\text { Strength } \\
\text { (psi) }\end{array}$ \\
\hline MB50-I2B & 1.500 & 3.375 & 700 & 5.089 & 6.912 & 25.529 & $\mathrm{D}$ & - & 888 & 74 & \multirow{3}{*}{114} & 85 & \multirow{3}{*}{132} \\
\hline MB50-12D & 1.500 & 3.125 & 900 & 4.835 & 6.917 & 25.723 & $\mathrm{D}$ & - & 1347 & 125 & & 144 & \\
\hline MB50-I2F & 1.500 & 3.000 & 1150 & 4.753 & 6.922 & 25.895 & $\mathrm{D}$ & - & 1500 & 144 & & 166 & \\
\hline
\end{tabular}

Table B- 112 MB50-12 Abs Results

\begin{tabular}{|c|c|c|c|c|c|c|c|c|c|c|c|c|c|}
\hline \multirow[b]{2}{*}{ Block ID } & \multicolumn{3}{|c|}{ Batch Properties } & \multicolumn{3}{|c|}{ Block Properties } & \multicolumn{7}{|c|}{ Absorption and Net Area Testing } \\
\hline & $\begin{array}{l}\text { Chamber } \\
\text { Volume } \\
\text { Setting } \\
\text { (in) }\end{array}$ & $\begin{array}{l}\text { Block } \\
\text { Height } \\
\text { Setting } \\
\text { (in) }\end{array}$ & $\begin{array}{c}\text { Piston } \\
\text { Pressure } \\
\text { (psi) }\end{array}$ & $\begin{array}{l}\text { Height } \\
\text { (in) }\end{array}$ & $\begin{array}{c}\text { Average } \\
\text { Width } \\
\text { (in) }\end{array}$ & $\begin{array}{c}\text { Weight } \\
\text { (lbs) }\end{array}$ & $\begin{array}{c}\text { Oven } \\
\text { Dry } \\
\text { Weight } \\
\text { (lbs) }\end{array}$ & $\begin{array}{c}\text { SSD } \\
\text { Weight } \\
\text { (lbs) }\end{array}$ & $\begin{array}{c}\text { Submerged } \\
\text { Weight } \\
\text { (lbs) }\end{array}$ & $\begin{array}{c}\text { Absorption } \\
(\%)\end{array}$ & $\begin{array}{l}\text { Density } \\
\left(\mathrm{lbs} / \mathrm{ft}^{3}\right)\end{array}$ & $\mid \begin{array}{c}\text { Net Area } \\
\left(\text { in }^{3}\right)\end{array}$ & $\begin{array}{c}\text { Average } \\
\text { Net Area } \\
\left(\text { in }^{3}\right)\end{array}$ \\
\hline MB50-12A & 1.500 & 3.375 & 600 & 4.902 & 6.913 & 25.289 & 23.549 & 27.207 & 14.150 & 15.5 & 112.5 & 84.7 & 84.7 \\
\hline
\end{tabular}

Table B- 113 MB50-12 Durability Results

\begin{tabular}{|c|c|c|c|c|c|}
\hline \multirow[b]{2}{*}{ Block ID } & \multicolumn{5}{|c|}{ Durability Testing } \\
\hline & Cycle & $\begin{array}{c}\text { Oven } \\
\text { Dry } \\
\text { Weight } \\
\text { (lbs) }\end{array}$ & $\begin{array}{c}\text { Mass } \\
\text { Loss Per } \\
\text { Cycle } \\
(\%)\end{array}$ & $\begin{array}{c}\text { Durability } \\
\text { Rating }\end{array}$ & Visual Observations \\
\hline \multirow{6}{*}{ MB50-I2A } & 0 & 25.289 & 0.0 & - & - \\
\hline & $\mathrm{I}$ & 23.539 & 6.9 & 2 & Significant degradation \\
\hline & 2 & 23.478 & 0.3 & 2 & Surface degradation \\
\hline & 3 & 23.439 & 0.2 & 2 & Face/corner degradation \\
\hline & 4 & 22.911 & 2.3 & 3 & Bottom degradation \\
\hline & 5 & 21.999 & 4.0 & 3 & Pock marks. Face degradation \\
\hline \multicolumn{3}{|c|}{ Total Mass Loss (\%) } & 13.6 & & \\
\hline
\end{tabular}




\section{Batch ID: MB50-FS2-8}

Description: Mind Body .02\% Strux Fiber Content Batch. 1:1 Ratio of Soil:Sand, 8\% Cement by weight

$\begin{array}{ccrc}\text { Date Cast: } & \text { 23-Mar-l4 } & \text { \# Blocks Cast } & 6 \\ \text { Time Cast: } & 9: 30 \text { AM } & \text { Fiber Type } & - \\ & & \\ \text { Calculated Mixture Clay Fraction (\%) } & 15.7 \\ \text { Calculated Mixture Sand Fraction (\%) } & 39.9 \\ \text { Calculated Mixture Cement Content (\%) } & 5.4 \\ \text { Measured Mixture Moisture Content (\%) } & 8.2 \\ \text { Calculated Mixture Moisture Content (\%) } & 9.8\end{array}$

Table B- 114 MB50-FS2-8 Mix Design

\begin{tabular}{|c|c|c|c|c|}
\hline Material & $\begin{array}{c}\text { Measured } \\
\text { Moisture } \\
\text { Content } \\
(\%)\end{array}$ & $\begin{array}{c}\text { Stock } \\
\text { Weight } \\
\text { (lbs) }\end{array}$ & $\begin{array}{c}\text { Oven } \\
\text { Dry } \\
\text { Weight } \\
\text { (lbs) }\end{array}$ & $\begin{array}{c}\text { Oven Dry } \\
\text { Weight } \\
\text { (lbs/ I00 lbs) }\end{array}$ \\
\hline Soil & 3.6 & $\mathrm{I} 74.0$ & I67.I & 52.2 \\
\hline Sand & 0.8 & $\mathrm{III} .3$ & $\mathrm{I} 10.8$ & 34.6 \\
\hline Cement & - & 15.8 & 15.8 & 4.9 \\
\hline Water & - & 24.6 & 32.0 & 8.2 \\
\hline Fibers & - & 0.3 & 0.3 & - \\
\hline Total & 8.2 & 325.7 & 325.7 & 100.0 \\
\hline
\end{tabular}

Table B- 115 MB50-FS2-8 Compression Results

\begin{tabular}{|c|c|c|c|c|c|c|c|c|c|c|c|c|c|}
\hline \multirow[b]{2}{*}{ Block ID } & \multicolumn{3}{|c|}{ Batch Properties } & \multicolumn{3}{|c|}{ Block Properties } & \multicolumn{2}{|c|}{ Moisture Content } & \multicolumn{5}{|c|}{ Compression Testing } \\
\hline & $\begin{array}{c}\text { Chamber } \\
\text { Volume } \\
\text { Setting } \\
\text { (in) }\end{array}$ & $\begin{array}{c}\text { Block } \\
\text { Height } \\
\text { Setting } \\
\text { (in) }\end{array}$ & $\begin{array}{c}\text { Piston } \\
\text { Pressure } \\
\text { (psi) }\end{array}$ & $\begin{array}{l}\text { Height } \\
\text { (in) }\end{array}$ & $\begin{array}{c}\text { Average } \\
\text { Width } \\
\text { (in) }\end{array}$ & $\begin{array}{c}\text { Weight } \\
\text { (lbs) }\end{array}$ & $\begin{array}{c}\text { Cure } \\
\text { Method } \\
(\text { W/D) }\end{array}$ & $\begin{array}{c}\text { Testing } \\
(\%)\end{array}$ & $\begin{array}{l}\text { Max. } \\
\text { Force } \\
\text { (lbs) }\end{array}$ & $\begin{array}{c}\text { Gross } \\
\text { Strength } \\
\text { (psi) }\end{array}$ & $\begin{array}{l}\text { Average } \\
\text { Gross } \\
\text { Strength } \\
\text { (psi) }\end{array}$ & $\begin{array}{c}\text { Net } \\
\text { Strength } \\
\text { (psi) }\end{array}$ & $\begin{array}{c}\text { Average } \\
\text { Net } \\
\text { Strength } \\
\text { (psi) }\end{array}$ \\
\hline MB40-FS2-5B & 1.500 & 3.250 & 1100 & 4.974 & 6.926 & 25.836 & $\mathrm{D}$ & - & 46937 & 484 & \multirow{3}{*}{637} & 518 & \multirow{3}{*}{682} \\
\hline MB40-FS2-5D & 1.500 & 3.250 & 1800 & 4.815 & 6.931 & 26.181 & $\mathrm{D}$ & - & 76657 & 790 & & 846 & \\
\hline MB40-FS2-5F & 1.500 & 3.125 & 1500 & 4.808 & 6.927 & 25.642 & $\mathrm{D}$ & 4.5 & 67723 & 698 & & 747 & \\
\hline
\end{tabular}


Table B- 116 MB50-FS2-8 MOR Results

\begin{tabular}{|c|c|c|c|c|c|c|c|c|c|c|c|c|c|}
\hline \multirow[b]{2}{*}{ Block ID } & \multicolumn{3}{|c|}{ Batch Properties } & \multicolumn{3}{|c|}{ Block Properties } & \multicolumn{2}{|c|}{ Moisture Content } & \multicolumn{5}{|c|}{ Modulus of Rupture Testing } \\
\hline & $\begin{array}{l}\text { Chamber } \\
\text { Volume } \\
\text { Setting } \\
\text { (in) }\end{array}$ & $\begin{array}{c}\text { Block } \\
\text { Height } \\
\text { Setting } \\
\text { (in) } \\
\end{array}$ & $\begin{array}{c}\text { Piston } \\
\text { Pressure } \\
\text { (psi) }\end{array}$ & $\begin{array}{c}\text { Height } \\
\text { (in) }\end{array}$ & $\begin{array}{c}\text { Average } \\
\text { Width } \\
\text { (in) }\end{array}$ & $\begin{array}{c}\text { Weight } \\
\text { (lbs) }\end{array}$ & $\begin{array}{c}\text { Cure } \\
\text { Method } \\
(\mathrm{W} / \mathrm{D})\end{array}$ & $\begin{array}{c}\text { Testing } \\
(\%)\end{array}$ & $\begin{array}{l}\text { Max. } \\
\text { Force } \\
\text { (lbs) }\end{array}$ & $\begin{array}{c}\text { Gross } \\
\text { Strength } \\
\text { (psi) }\end{array}$ & $\begin{array}{l}\text { Average } \\
\text { Gross } \\
\text { Strength } \\
\text { (psi) }\end{array}$ & $\begin{array}{c}\text { Net } \\
\text { Strength } \\
\text { (psi) }\end{array}$ & $\begin{array}{l}\text { Average } \\
\text { Net } \\
\text { Strength } \\
\text { (psi) }\end{array}$ \\
\hline MB40-FS2-5C & 1.500 & 3.250 & 1050 & 4.969 & 6.923 & 25.914 & $\mathrm{D}$ & - & 763 & 67 & \multirow{4}{*}{70} & 77 & \multirow{4}{*}{81} \\
\hline MB40-FS2-5E & 1.500 & 3.125 & 2350 & 4.868 & 6.929 & 26.722 & $\mathrm{D}$ & - & 947 & 87 & & 100 & \\
\hline MB40-FS2-5G & 1.500 & 3.125 & 1000 & 4.807 & 6.930 & 25.470 & $\mathrm{D}$ & - & 627 & 59 & & 68 & \\
\hline MB40-FS2-5I & 1.500 & 3.125 & 2350 & 4.977 & 6.939 & 27.025 & $\mathrm{D}$ & - & 777 & 68 & & 78 & \\
\hline
\end{tabular}

Table B- 117 MB50-FS2-8 Abs Results

\begin{tabular}{|c|c|c|c|c|c|c|c|c|c|c|c|c|c|}
\hline \multirow[b]{2}{*}{ Block ID } & \multicolumn{3}{|c|}{ Batch Properties } & \multicolumn{3}{|c|}{ Block Properties } & \multicolumn{7}{|c|}{ Absorption and Net Area Testing } \\
\hline & $\begin{array}{c}\text { Chamber } \\
\text { Volume } \\
\text { Setting } \\
\text { (in) } \\
\end{array}$ & $\begin{array}{c}\text { Block } \\
\text { Height } \\
\text { Setting } \\
\text { (in) }\end{array}$ & \begin{tabular}{|c|} 
Piston \\
Pressure \\
$(\mathrm{psi})$ \\
\end{tabular} & $\begin{array}{l}\text { Height } \\
\text { (in) }\end{array}$ & $\begin{array}{c}\text { Average } \\
\text { Width } \\
\text { (in) }\end{array}$ & $\begin{array}{c}\text { Weight } \\
\text { (lbs) }\end{array}$ & \begin{tabular}{|c} 
Oven \\
Dry \\
Weight \\
(lbs) \\
\end{tabular} & $\begin{array}{c}\text { SSD } \\
\text { Weight } \\
\text { (lbs) } \\
\end{array}$ & $\begin{array}{c}\text { Submerged } \\
\text { Weight } \\
\text { (lbs) }\end{array}$ & $\begin{array}{c}\text { Absorption } \\
(\%)\end{array}$ & $\begin{array}{l}\text { Density } \\
\left(\mathrm{lbs} / \mathrm{ft}^{3}\right) \\
\end{array}$ & \begin{tabular}{|c|} 
Net Area \\
$\left(\right.$ in $\left.^{3}\right)$ \\
\end{tabular} & \begin{tabular}{|c} 
Average \\
Net Area \\
$\left(\right.$ in $\left.^{3}\right)$ \\
\end{tabular} \\
\hline MB40-FS2-5A & 1.500 & 3.250 & 1300 & 5.036 & 6.926 & 26.146 & 25.613 & 29.050 & 15.400 & 13.4 & 117.1 & 88.5 & \\
\hline MB40-FS2-5H & 1.500 & 3.125 & 2350 & 4.820 & 6.935 & 27.301 & 26.184 & 29.641 & 15.910 & 13.2 & 119.0 & 92.7 & 0.0 \\
\hline
\end{tabular}

